Prepared for Ducks Unlimited, Inc.

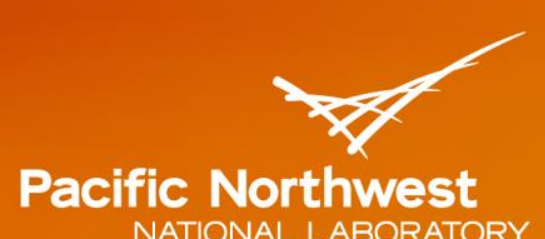

NATIONAL LABORATORY

\title{
Hydrodynamic Modeling Analysis for Leque Island and zis a ba Restoration Feasibility Study
}

\author{
JM Whiting \\ TP Khangaonkar
}

January 2015 


\title{
DISCLAIMER
}

This report was prepared as an account of work sponsored by an agency of the United States Government. Neither the United States Government nor any agency thereof, nor Battelle Memorial Institute, nor any of their employees, makes any warranty, express or implied, or assumes any legal liability or responsibility for the accuracy, completeness, or usefulness of any information, apparatus, product, or process disclosed, or represents that its use would not infringe privately owned rights. Reference herein to any specific commercial product, process, or service by trade name, trademark, manufacturer, or otherwise does not necessarily constitute or imply its endorsement, recommendation, or favoring by the United States Government or any agency thereof, or Battelle Memorial Institute. The views and opinions of authors expressed herein do not necessarily state or reflect those of the United States Government or any agency thereof.

\author{
PACIFIC NORTHWEST NATIONAL LABORATORY \\ operated by \\ BATTELLE \\ for the \\ UNITED STATES DEPARTMENT OF ENERGY
}

under Contract DE-AC05-76RL01830

Printed in the United States of America

Available to DOE and DOE contractors from the

Office of Scientific and Technical Information,

P.O. Box 62, Oak Ridge, TN 37831-0062;

ph: (865) 576-8401

fax: $(865) 576-5728$

email: reports@adonis.osti.gov

Available to the public from the National Technical Information Service

5301 Shawnee Rd., Alexandria, VA 22312

ph: (800) 553-NTIS (6847)

email: orders@ntis.gov <http://www.ntis.gov/about/form.aspx>

Online ordering: http://www.ntis.gov 


\section{Hydrodynamic Modeling Analysis for Leque Island and zis a ba Restoration Feasibility Study}

JM Whiting

TP Khangaonkar

January 2015

Prepared for

Ducks Unlimited, Inc.

through CWFO Agreement No 64274

under contract DE-AC05-76RL01830

Pacific Northwest National Laboratory

Seattle, Washington 98109 



\section{Executive Summary}

Ducks Unlimited, Inc. in collaboration with Washington State Department of Fish and Wildlife (WDFW), and the Stillaguamish Tribe of Indians have proposed the restoration of Leque Island and zis a ba (formerly Matterand) sites near the mouth of Old Stillaguamish River Channel in Port Susan Bay, Washington. The Leque Island site, which is owned by WDFW, consists of nearly 253 acres of land south of Highway 532 that is currently behind a perimeter dike. The 90 -acres zis a ba site, also shielded by dikes along the shoreline, is located just upstream of Leque Island and is owned by the Stillaguamish Tribe. The proposed actions consider the removal or modification of perimeter dikes at both locations to allow estuarine functions to be restored. The overall objective of the proposed projects is to remove the dike barriers to 1) provide connectivity and access between the tidal river channel and the restoration site for use by juvenile migrating salmon and 2) create a self-sustaining tidal marsh habitat. Ducks Unlimited engaged Pacific Northwest National Laboratory (PNNL) to develop a three-dimensional hydrodynamic model of Port Susan Bay, Skagit Bay, and the interconnecting Leque Island region for use in support of the feasibility assessment for the Leque Island and zis a ba restoration projects. The objective of this modeling-based feasibility assessment is to evaluate the performance of proposed restoration actions in terms of achieving habitat goals while assessing the potential hydraulic and sediment transport impacts to the site and surrounding parcels of land.

For this effort, PNNL developed a three-dimensional hydrodynamic model for the Leque Island and zis a ba restoration sites based on an existing model of the system including Skagit Bay and Port Susan Bay. The Finite Volume Coastal Ocean Model (FVCOM) of the region uses a combination of tides, fresh-water discharges, and surface-wind stresses as input to simulate tidal motion, circulation, and transport. As part of this work, the existing model was upgraded with latest bathymetry, river inflow data, and model grid refinement at selected locations. The predicted results were compared with fieldobserved tide, current, and salinity data for the period of October 10-26, 2005, as part of model validation. The wetting and drying process in the intertidal zone near Leque Island and the tidal exchange between Skagit Bay and Port Susan Bay through West Pass were successfully reproduced. The validated model was used to simulate tidal inundation, salinity, tidal currents, and bed shear stress in the study area for the baseline scenario (existing condition) as well as for the eight proposed restoration scenarios. These include two restoration scenarios with dike breaches at Leque Island, three scenarios with dike removal at Leque Island, and three scenarios with dike removal at zis a ba in combination with the scenarios at Leque Island.

The proposed restoration scenarios were systematically incorporated into the model configuration and subjected to three different perturbation tests with varying tidal and river flow forcing conditions. Specifically the following tests were conducted.

- Typical flow and tidal conditions (validation period of October 10-26, 2005, river flow of 2,457 cfs): The feasibility of achieving desired estuarine exchange and tidal marsh habitat benefits were tested using typical conditions experienced during the October 2005 data collection period.

- High flow (bank full) conditions (river flow of 26,508 cfs): All scenarios were subjected to a designed high flow test to confirm that the restoration actions will not lead to unstable conditions with respect to sediment erosion and morphological change. Other simulation inputs were determined from the validation period from October 10-26, 2005. 
- Year-long 2003 simulation with historic conditions: Restoration response for all scenarios was examined on a statistical basis using a year-long record from a high flow year. Potential increases in flooding and inundation impacts to neighboring lands are of interest and also were examined.

The overall conclusion based on examination of the results is that restoration of estuarine functions and marsh habitat is feasible through the proposed actions at the Leque Island and zis a ba sites. The two projects do not appear to significantly impact one another. Specific conclusions based on model simulation results are briefly described below.

- Restoration of estuarine functions to the Leque Island and zis a ba sites appears to be feasible for all scenarios based on simulation results. The predicted salinity, bottom velocities, bed shear stress, and inundation are presented for comparison with the desired ranges for preferred salmon habitat.

- Leque Island restoration response:

- Leque Island restoration scenarios involving full dike removal would result in alteration of estuarine exchange pathways with flow of Stillaguamish River water over the restoration area. High levels of bed shear stress and erosion are predicted over the interior drainage channels and at dike breach openings.

- Intertidal processes (ebb and flow of tides) would be restored to all areas. Tidal inundation would be between $20-60 \%$ of the time depending on bed elevation.

- Salinities are predicted to be in the range of $5-15 \mathrm{ppt} \approx 92 \%$ of the time at representative locations for most scenarios.

- Velocities $<0.48 \mathrm{~m} / \mathrm{s}$ and bed shear $<0.5 \mathrm{~Pa}$ are predicted to occur over $\approx 90 \%$ of the time at representative locations.

- Zia a ba restoration response:

- $\quad$ Tidal inundation would be $0-30 \%$ of the time (dry over $70 \%$ of the time).

- Low velocities $(<0.2 \mathrm{~m} / \mathrm{s})$ and low bed shear $(<0.5 \mathrm{~Pa})$ are predicted to occur $100 \%$ of the time.

- Salinities would be in the range of $0-15 \mathrm{ppt} \approx 87 \%$ of the time.

- High bed shear stress and erosion are predicted at the drainage channel connection to South Pass of Stillaguamish River for the only proposed restoration alternative at zis a ba.

- Bank-full flow conditions resulted in lower salinities, an increase in water-surface elevation of $20 \mathrm{~cm}$, higher velocities, and higher bed shear stress. Despite these changes in magnitude, all scenarios show similar gradients to those predicted during typical conditions. The highest water-surface elevations for the restoration sites were predicted for winter months

(December 25, 2003) during which Puget Sound is subjected to highest incoming tides from the Pacific Ocean. The water levels during this period overtopped the higher grounds on the western side of Leque Island and connected with Davis Slough. 


\section{Acknowledgement}

The authors would like to acknowledge the contribution and assistance provided by Dr. Wen Long who developed the post-processing routines facilitating the plotting and presentation of the results from the model simulations. Dr. Long also helped identify and debug the performance of the wetting and drying modules related to salinity diffusion in version 2.7 of the FVCOM code. We would also like to thank The Nature Conservancy and Snohomish County for providing Lidar survey, bathymetric survey and oceanographic monitoring data for use in model development and validation. 



\section{Acronyms}

\begin{tabular}{|c|c|}
\hline ADCP & Acoustic Doppler Current Profiler \\
\hline CTD & Conductivity-Temperature-Depth \\
\hline DEM & Digital Elevation Model \\
\hline DU & Ducks Unlimited, Inc. \\
\hline FVCOM & Finite Volume Coastal Ocean Model \\
\hline LIDAR & Light Detection and Ranging \\
\hline MEA & Mean Absolute Error \\
\hline ME & Mean Error \\
\hline MLLW & Mean Lower Low Water \\
\hline MSL & Mean Sea Level \\
\hline NAVD 88 & North American Vertical Datum of 1988 \\
\hline NOAA & National Oceanic and Atmospheric Administration \\
\hline PNNL & Pacific Northwest National Laboratory \\
\hline PSLC & Puget Sound Lidar Consortium \\
\hline PSNERP & Puget Sound Nearshore Ecosystem Restoration Project \\
\hline $\mathrm{RM}$ & River Mile \\
\hline RMSE & Root Mean Square Error \\
\hline SIRC & Stillaguamish Implementation Review Committee \\
\hline SRSC & Skagit River System Cooperative \\
\hline SWC & Skagit Watershed Council \\
\hline TNC & The Nature Conservancy \\
\hline USACE & United States Army Corps of Engineers \\
\hline USGS & United States Geological Survey \\
\hline UW & University of Washington \\
\hline WDFW & Washington Department of Fish and Wildlife \\
\hline
\end{tabular}





\section{Contents}

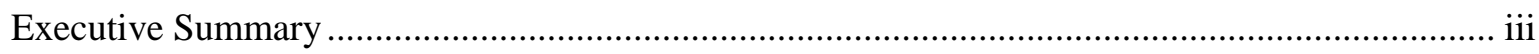

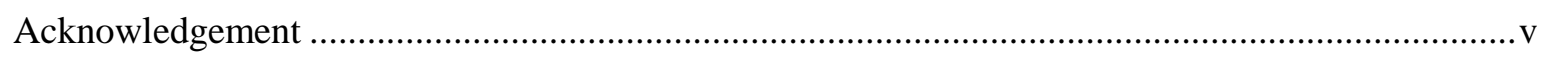

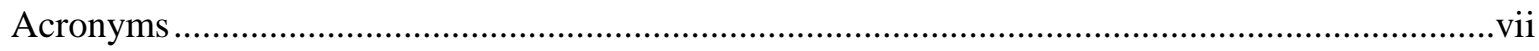

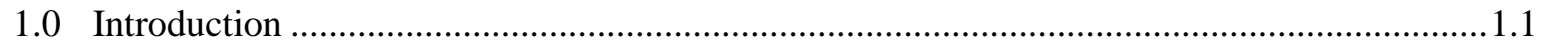

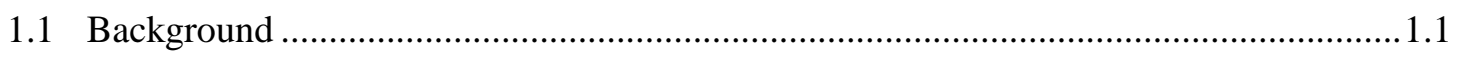

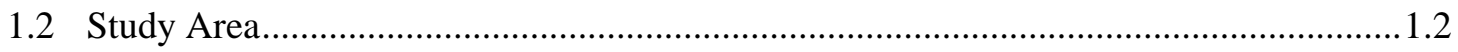

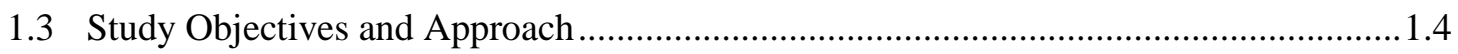

2.0 Hydrodynamic Model Setup and Validation for Stillaguamish River Estuary.......................2.1

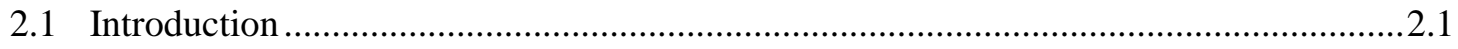

2.2 Model Setup Update............................................................................................. 2.1

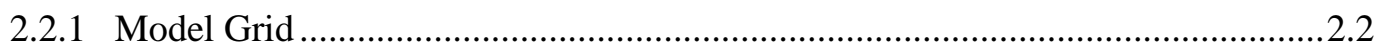

2.2.2 Model Bathymetry.................................................................................2.2

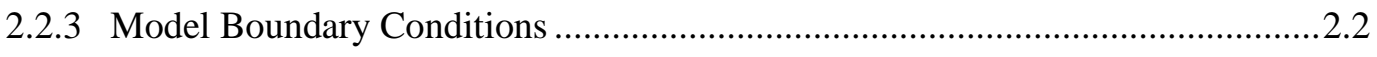

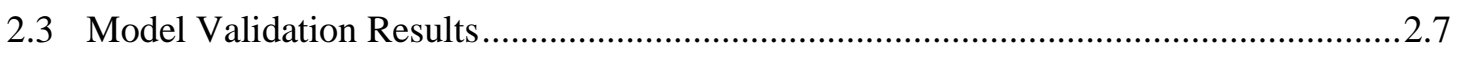

2.3.1 Field Data Collection - October 2005 ................................................................ 2.7

2.3.2 Model Validation - Tides................................................................................ 2.9

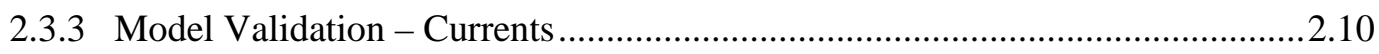

2.3.4 Model Validation - Salinity ......................................................................... 2.12

3.0 Design of Simulations for the Restoration Feasibility Assessment ......................................... 3.1

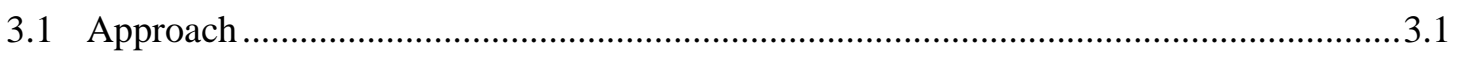

3.2 Simulation of Typical Estuarine Conditions of October 2005 ........................................2

3.3 Simulation of Stillaguamish River High Flow Conditions................................................ 3.4

3.4 Year-Long Simulation - High Flow Year 2003 ...........................................................

4.0 Results: Simulation of Restoration Scenarios...................................................................... 4.1

4.1 Baseline Scenario 0 - Existing Conditions ................................................................ 4.1

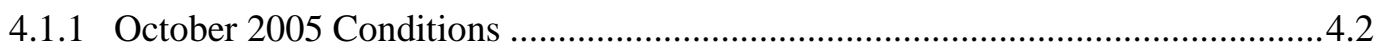

4.1.2 High Flow Conditions …............................................................................... 4.3

4.1.3 Year-Long Simulation.................................................................................. 4.5

4.2 Restoration Scenario 1 - Partial Restoration at Leque Island .......................................4.6

4.2.1 October 2005 Conditions .................................................................................. 4.7

4.2.2 High Flow Conditions …................................................................................ 4.7

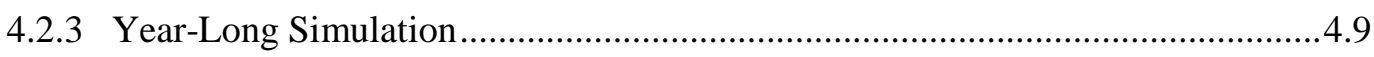

4.3 Restoration Scenario 2 - Four Levee Breaches at Leque Island ...................................4.11

4.3.1 October 2005 Conditions .................................................................................11

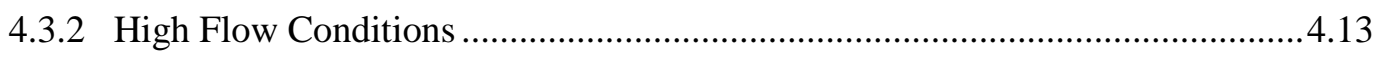

4.3.3 Year-Long Simulation ................................................................................... 4.13 
4.4 Restoration Scenario 3 - Full Removal of Dike at Leque Island (Alternative 1) .........4.15

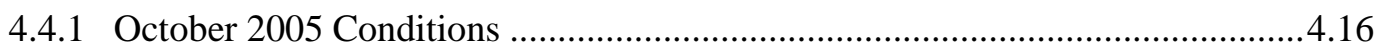

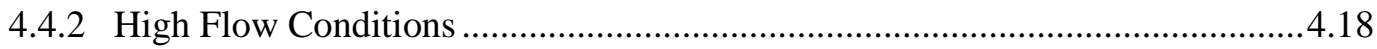

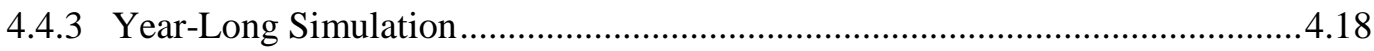

4.5 Restoration Scenario 4 - Full Removal of Lower Dike at Leque Island.......................4.21

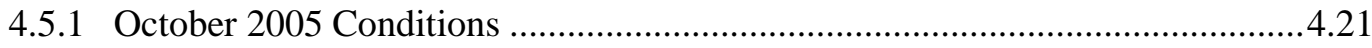

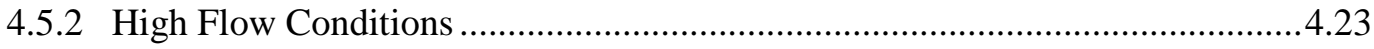

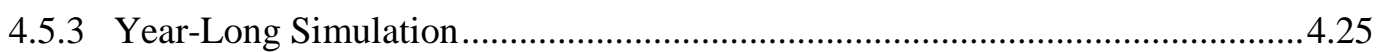

4.6 Restoration Scenario 5 - Partial Restoration at Leque Island with Full Restoration at zis

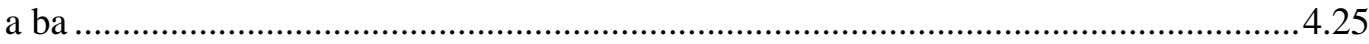

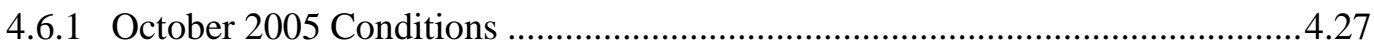

4.6.2 High Flow Conditions ....................................................................................2.29

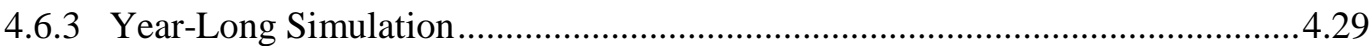

4.7 Restoration Scenario 6 - Full Removal of Lower Dike at Leque Island with Full

Restoration at zis a ba......................................................................................................32

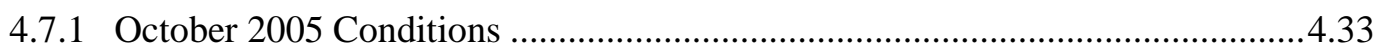

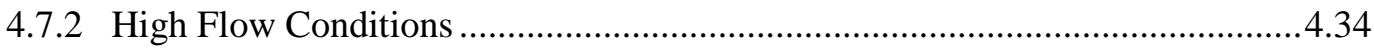

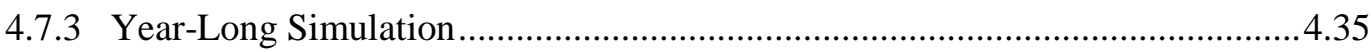

4.8 Restoration Scenario 7 - Full Removal of Dike at Leque Island with Full Restoration at

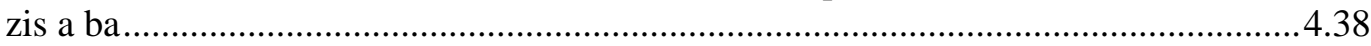

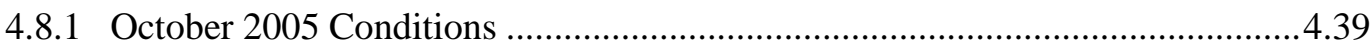

4.8.2 High Flow Conditions …...............................................................................4. 4.4

4.8.3 Year-Long Simulation........................................................................................4.4

4.9 Restoration Scenario 8 - Three Levee Breaches at Leque Island ..................................4.44

4.9.1 October 2005 Conditions .............................................................................4.45

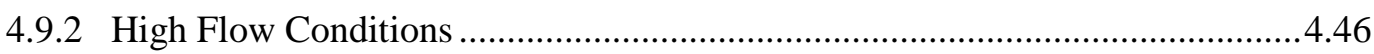

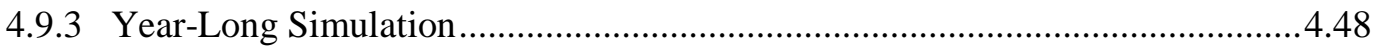

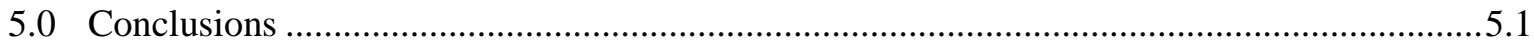

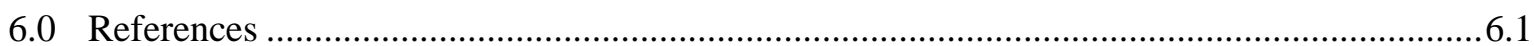

Appendix A Time Series Plots - October 2005 Conditions - WSL, Salinity, Velocity, Bed ShearA.1 Appendix B Plan View Contour Plots - October 2005 Conditions - Salinity, Velocity ............... B.1 Appendix C Time Series Plots - High-Flow (bank full) Conditions - WSL, Salinity, Velocity, Bed Shear.

Appendix D Plan View Contour Plots - High-Flow (bank-full) Conditions - Salinity, Velocity..D.1 Appendix E Plan View Contour Plots - October 2005 Conditions - Bed Shear............................ E.1 Appendix F Plan View Contour Plots - High-Flow (bank full) Conditions - Bed Shear ...............F.1 Appendix G Cumulative Frequency Plots - 2003 Year-Long Simulation - WSL, Salinity, Velocity, Bed Shear.

Appendix H Plan View Contour Plots - 2003 Year-Long Simulation - Depth, Velocity, Bed Shear..... 


\section{Figures}

Figure 1-1: Location of Leque Island in Whidbey Basin 1.3

Figure 1-2: Map showing areas of concern for Stanwood with accompanying images of the

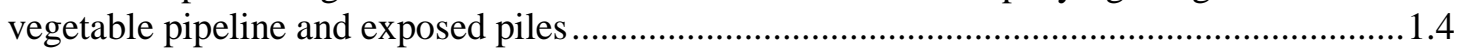

Figure 1-3: Schematic representation of the proposed restoration scenarios............................... 1.8

Figure 2-1: Model Grid for Leque Island, Including Skagit Bay and Port Susan Bay and bathymetry .....

Figure 2-2: Lidar Topography and Stillaguamish River Channel survey data used in developing Bathymetry of the Leque Island and zis a ba region of the model domain..............................2.4

Figure 2-3: Tidal elevations at the model domain boundaries for October 2005 ........................2.5

Figure 2-4: Stillaguamish River flow to Port Susan Bay, October 2005 ........................................

Figure 2-5: Skagit River flow to Skagit Bay, October 2005.......................................................2.7

Figure 2-6: Oceanographic data collection stations, Port Susan Bay, October 2005 ...................2.8

Figure 2-7: Comparison of predicted water-surface elevations and measured tides at the Kayak Point, Hatt Slough, and South Pass stations respectively .......................................................

Figure 2-8: Comparison of predicted and measured velocity components at the Hatt Slough and South Pass stations respectively. Data from mid-depth of the water column ........................2.11

Figure 2-9: Comparison of predicted and measured salinity at the Kayak Point, Hatt Slough, and South Pass stations, respectively.

Figure 3-1: Three stations locations on Leque Island and three stations locations on zis a ba.......3.3

Figure 3-2: A dike along the east side of zis a ba, approximately $3 \mathrm{~m}$ wide ................................. 3.5

Figure 3-3: Example of the transect method used to determine dike crest elevations along the banks of the lower Stillaguamish River.

Figure 3-4: Plots used to determine bank-full high flow conditions in the Old Stillaguamish

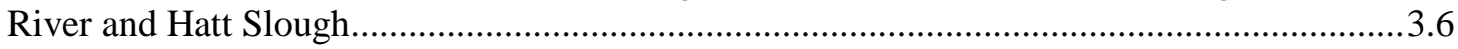

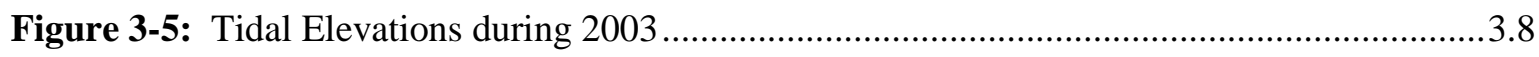

Figure 3-6: River flows during 2003 for the Stillaguamish and Skagit rivers ..............................3.8

Figure 4-1: (Scenario 0 - Baseline) Model grid overlaying the lidar elevation map .....................4.2

Figure 4-2: Salinity contours at high and low tide on October 17, 2005 ...................................4.3

Figure 4-3: A location on the southwest corner of zis a ba where the dike failed and was then repaired with a new gravel dike.....

Figure 4-4: Comparison of bed shear stress at peak ebb and peak flood during typical and high flow conditions on October 17, 2005.

Figure 4-5: (Scenario 1 - Partial Restoration Leque) Model grid overlaying the lidar elevation

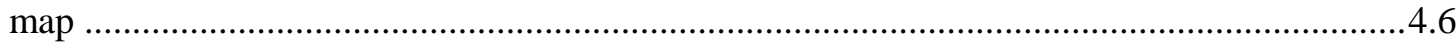

Figure 4-6: Comparison of salinity at high tide and low tide during Scenario 0 and Scenario 1 on October 17, 2005.

Figure 4-7: Comparison of bed shear stress at peak ebb and peak flood during Scenario 0 and Scenario 1 at high flow conditions.....

Figure 4-8: Cumulative frequency plots for Scenario 1 - Water-Surface Elevation, Salinity, Bottom Velocity, and Bed Shear at Station L2 on Leque Island 
Figure 4-9: (Scenario 2 - Four Breaches) Model grid overlaying the lidar elevation map .

Figure 4-10: Comparison of salinity at high tide and low tide during Scenario 0 and Scenario 2 on October 17, 2005.

Figure 4-11: Comparison of bed shear stress at peak ebb and peak flood during Scenario 0 and Scenario 2 at high flow conditions.

Figure 4-12: Cumulative frequency plots for Scenario 2 - Water-Surface Elevation, Salinity, Bottom Velocity, and Bed Shear at Station L2 on Leque Island.

Figure 4-13: (Scenario 3 - Full Restoration Leque, Alternative 1) Model grid overlaying the lidar elevation map.

Figure 4-14: Comparison of salinity at high tide and low tide during Scenario 0 and Scenario 3 on October 17, 2005.

Figure 4-15: Comparison of bed shear stress at peak ebb and peak flood during Scenario 0 and Scenario 3 at high flow conditions.

Figure 4-16: Cumulative frequency plots for Scenario 3 - Water-Surface Elevation, Salinity, Bottom Velocity, and Bed Shear at Station L2 on Leque Island

Figure 4-17: (Scenario 4 - Full Restoration Leque, Alternative 2) Model grid overlaying the lidar elevation map.

Figure 4-18: Comparison of salinity at high tide and low tide during Scenario 0 and Scenario 4 on October 17, 2005.

Figure 4-19: Comparison of bed shear stress at peak ebb and peak flood during Scenario 0 and Scenario 4 at high flow conditions.

Figure 4-20: Cumulative frequency plots for Scenario 4 - Water-Surface Elevation, Salinity, Bottom Velocity, and Bed Shear at Station L2 on Leque Island

Figure 4-21: (Scenario 5 - zis a ba Restoration + SCN1) Model grid overlaying the lidar elevation map

Figure 4-22: Comparison of salinity at high tide and low tide during Scenario 0 and Scenario 5 on October 17, 2005.

Figure 4-23: Comparison of bed shear stress at peak ebb and peak flood during Scenario 0 and Scenario 5 at high flow conditions.

Figure 4-24: Cumulative frequency plots for Scenario 5 - Water-Surface Elevation, Salinity, Bottom Velocity, and Bed Shear at Station L2 on Leque Island

Figure 4-25: Cumulative frequency plots for Scenario 5 - Water-Surface Elevation, Salinity, Bottom Velocity, and Bed Shear at Station Z2 on zis a ba.

Figure 4-26: (Scenario 6 - zis a ba Restoration + SCN4) Model grid overlaying the lidar elevation map

Figure 4-27: Comparison of salinity at high tide and low tide during Scenario 0 and Scenario 6 on October 17, 2005.

Figure 4-28: Comparison of bed shear stress at peak ebb and peak flood during Scenario 0 and Scenario 6 at high flow conditions

Figure 4-29: Cumulative frequency plots for Scenario 6 - Water-Surface Elevation, Salinity, Bottom Velocity, and Bed Shear at Station L2 on Leque Island ....

Figure 4-30: Cumulative frequency plots for Scenario 6 - Water-Surface Elevation, Salinity, Bottom Velocity, and Bed Shear at Station Z2 on zis a ba. 
Figure 4-31: (Scenario 7 - zis a ba Restoration + SCN3) Model grid overlaying the lidar elevation map

Figure 4-32: Comparison of salinity at high tide and low tide during Scenario 0 and Scenario 7 on October 17, 2005

Figure 4-33: Comparison of bed shear stress at peak ebb and peak flood during Scenario 0 and Scenario 7 at high flow conditions.

Figure 4-34: Cumulative frequency plots for Scenario 7 - Water-Surface Elevation, Salinity, Bottom Velocity, and Bed Shear at Station L2 on Leque Island.

Figure 4-35: Cumulative frequency plots for Scenario 7 - Water-Surface Elevation, Salinity, Bottom Velocity, and Bed Shear at Station Z2 on zis a ba ..................................................4.44

Figure 4-36: (Scenario 8 - Three Breaches) Model grid overlaying the lidar elevation map......4.45

Figure 4-37: Comparison of salinity at high tide and low tide during Scenario 0 and Scenario 8 on October 17, 2005.

Figure 4-38: Comparison of bed shear stress at peak ebb and peak flood during Scenario 0 and Scenario 8 at high flow conditions.

Figure 4-39: Cumulative frequency plots for Scenario 8 - Water-Surface Elevation, Salinity, Bottom Velocity, and Bed Shear at Station L2 on Leque Island

\section{Tables}

Table 1-1: Descriptions of the proposed restoration scenarios at Leque and zis a ba sites...... 1.7

Table 2-1: Model error statistics - Water-Surface Elevation. 2.10

Table 2-2: Model error statistics - Velocity 2.12

Table 2-3: Model error statistics - Salinity. 2.14

Table 3-1: Critical Shear Stress for Different Particle Sizes (from Julien 1998). 3.4

Table 5-1: Water-surface level response for year-long simulation across all scenarios .5 .3

Table 5-2: Salinity response for year-long simulation across all scenarios .5 .4

Table 5-3: Bed shear stress response for year-long simulation across all scenarios .5 .4 


\subsection{Introduction}

\subsection{Background}

Puget Sound is a complex system of estuaries, basins, deltas, and habitats occupying over 4,000 km of shoreline. Home to large populations of birds, marine mammals, and fish, this area supports an enormous industry of fishermen, hunters, nature enthusiasts, and more. However, Puget Sound has undergone significant physical changes over the last 150 years of settlement and development. Residents have built barriers and armoring along the shore to cordon off farmland and protect settlements from flooding. Compared to historical conditions, total shoreline length has decreased by $15 \%$, and embayment shore forms have declined nearly $46 \%$, while in the 16 largest river deltas, there are $56 \%$ less tidal wetlands and 27\% less shoreline length (Fresh et al. 2011). These changes have resulted in significant wildlife population declines including the loss of the largest runs of Pacific salmon in the lower 48 states. Many salmon species are now listed under the Federal Endangered Species Act. Including hatchery fish, a returning adult population of approximately 1,080 Chinook salmon has been seen in recent years, compared to an estimated 9,700-13,321 in the past (SIRC 2005). River deltas play an important role in supporting wildlife populations. Juvenile salmon must spend time in estuaries where fresh and salt water mix, to allow physiological changes to occur. This change, known as smoltification, allows them to survive in the saltwater environment. The presence of dikes has reduced connectivity between the river channels and intertidal marsh habitats historically utilized by out-migrating salmon. Because of the lack of availability of this refuge and without the required transition period, smolts become less active and more susceptible to predation, thereby decreasing populations. Therefore there is much interest and motivation to restore tidal process and access to historic tidal marsh habitat through near-shore restoration actions such as dike removal and breaching.

After nearly a century since the initial dike construction, the perimeter dikes in many Puget Sound estuaries in are in a state of disrepair. High tides combined with flood flows during storm events have resulted in breached dikes on multiple occasions, requiring expensive repairs of the dikes and associated tide gates for drainage of interior farmlands. Agencies such as U.S. Fish and Wildlife, Washington State Department of Fish and Wildlife (WDFW), and the National Oceanic and Atmospheric Administration (NOAA), along with sovereign Indian nations are actively evaluating near-shore tidal restoration as a potential long-term solution to the flooding and dike maintenance issue while also providing ecological benefits. This is also the case near the mouth of the Old Stillaguamish River Channel, where damage to the dikes in the Leque Island region have required patches and repairs as recent as 2010 by WDFW. The Puget Sound Nearshore Ecosystem Restoration Project (PSNERP) ranked the Stillaguamish Delta as the third most substantial opportunity to recover lost ecosystem service in Puget Sound, just after the Skagit and Snohomish Deltas (Cereghino et al. 2012).

Since 2007, Ducks Unlimited, Inc. (DU) in collaboration with WDFW and partners including the Stillaguamish Tribe have evaluated the feasibility of restoring historical tidal marsh habitat in the Leque Island region near the mouth of Old Stillaguamish River Channel. During Phase I of this effort, Pacific Northwest National Laboratory (PNNL) assisted DU by developing a hydrodynamic model of the site, including Skagit Bay, Port Susan Bay, and the interconnecting region of Leque Island. The model was used to simulate tidal inundation, tidal currents, and salinity intrusion in the study area for the existing condition and to evaluate potential hydrodynamic changes following future restoration in Leque Island. Hydrodynamic feasibility includes the capability of the proposed restoration to provide desirable 
restoration of tidal functions and sediment supply but without causing impacts such as flooding or excessive erosion or sedimentation requiring maintenance. Only one preferred restoration alternative was considered in the prior hydrodynamic assessment, involving restoration of nearly 50\% of the island (115 acres) by removing dikes or dike setbacks along South Pass and Davis Slough. The Phase I effort showed that the proposed restoration action would successfully restore tidal function subject to daily inundation and salinity intrusion during high tide and becoming a tidal flat during low tide. Erosion impacts were small and currents over the restored site within acceptable levels.

In Phase II of the Leque Island Restoration project, DU in collaboration with WDFW and the Stillaguamish Tribe selected eight new restoration scenarios for feasibility assessment. In addition to Leque Island, these scenarios include dike modification actions at an adjacent site named "zis a ba" (formerly Matterand). Also included in Phase II is involvement of 30 local stakeholders for feedback and selection of suitable design criteria through public meetings. PNNL was contracted by DU to participate in this Phase II effort. As in Phase I, PNNL supported DU by providing hydrodynamic modeling simulation of the proposed scenarios. All scenarios included dike modifications such as existing dike removal, removal of historic repairs to create breaches, and construction of new setback dikes. Based on Phase I results, the proposed changes would likely affect the hydrodynamic behavior in the Stillaguamish Estuary and tidal reaches of Old Stillaguamish River Channel. The effects of proposed restoration actions on physical oceanographic parameters such as water-surface elevations, currents, salinity, and bed shear stress were examined relative to existing condition as part of this assessment. The proposed restoration scenarios also were subjected to high flow conditions critical for erosion impacts and long duration run using a year-long record from 2003, which experienced the highest number of flood flow events in recent years. This report summarizes hydrodynamic modeling of the Stillaguamish River estuary as part of the restoration feasibility assessment and includes model setup and calibration information along with simulation results for various restoration alternatives.

\subsection{Study Area}

Leque Island is located in a tidal marshland between Skagit Bay and Port Susan Bay in the Whidbey Basin of Puget Sound near the mouth of Stillaguamish River estuary (Figure 1-1). Perimeter dikes surround the 294-acre island. The Old Stillaguamish River Channel splits into two tributary channels along the eastern shoreline of Leque Island. West Pass of the Stillaguamish River on the northeast side of Leque Island is the main connection between Skagit Bay and Port Susan Bay. West Pass flows northwest around Leque Island into Skagit Bay. South Pass flows into Port Susan Bay along the southeast shoreline of Leque Island. A shallow channel, Davis Slough, provides another connection between Skagit Bay and Port Susan Bay along the western shoreline of Leque Island. This connection is dry most of the time but could carry water during high-river-flow and spring tidal periods. Historically, Leque Island was a tidal marsh area that provided important habitat for a variety of fish and wildlife species, including Chinook salmon, waterfowl, and herons (WDFW 2014).

The perimeter dikes on Leque Island were originally built in the 1870s when three locals partnered to purchase the land for farming (Conroy 2004). After several generations, the land was later owned by other private farmers and eventually sold to WDFW in phases between 1974-2012. WDFW currently owns the entire land except for Highway 532 that runs across the northern end of the island. Contract farmers annually plant cereal grains as food for wintering waterfowl, providing bird watching, bird dog training, and pheasant and waterfowl hunting for the public. 
To the northeast of Leque Island, directly upstream along the Old Stillaguamish Mainstem, lies a 90-acre parcel of land known as zis a ba. The Old Stillaguamish Mainstem bends around the east and north sides of the island, separating zis a ba from the City of Stanwood to the north, while South Pass separates zis a ba from Leque Island to the west. The land is private and accessible from neighboring farmland to the south. A pipeline carries vegetable waste from a distribution center for Twin City Foods across the middle of zis a ba towards the south. The Stillaguamish Tribe recently acquired this land for restoration purposes, during which time the property was renamed.

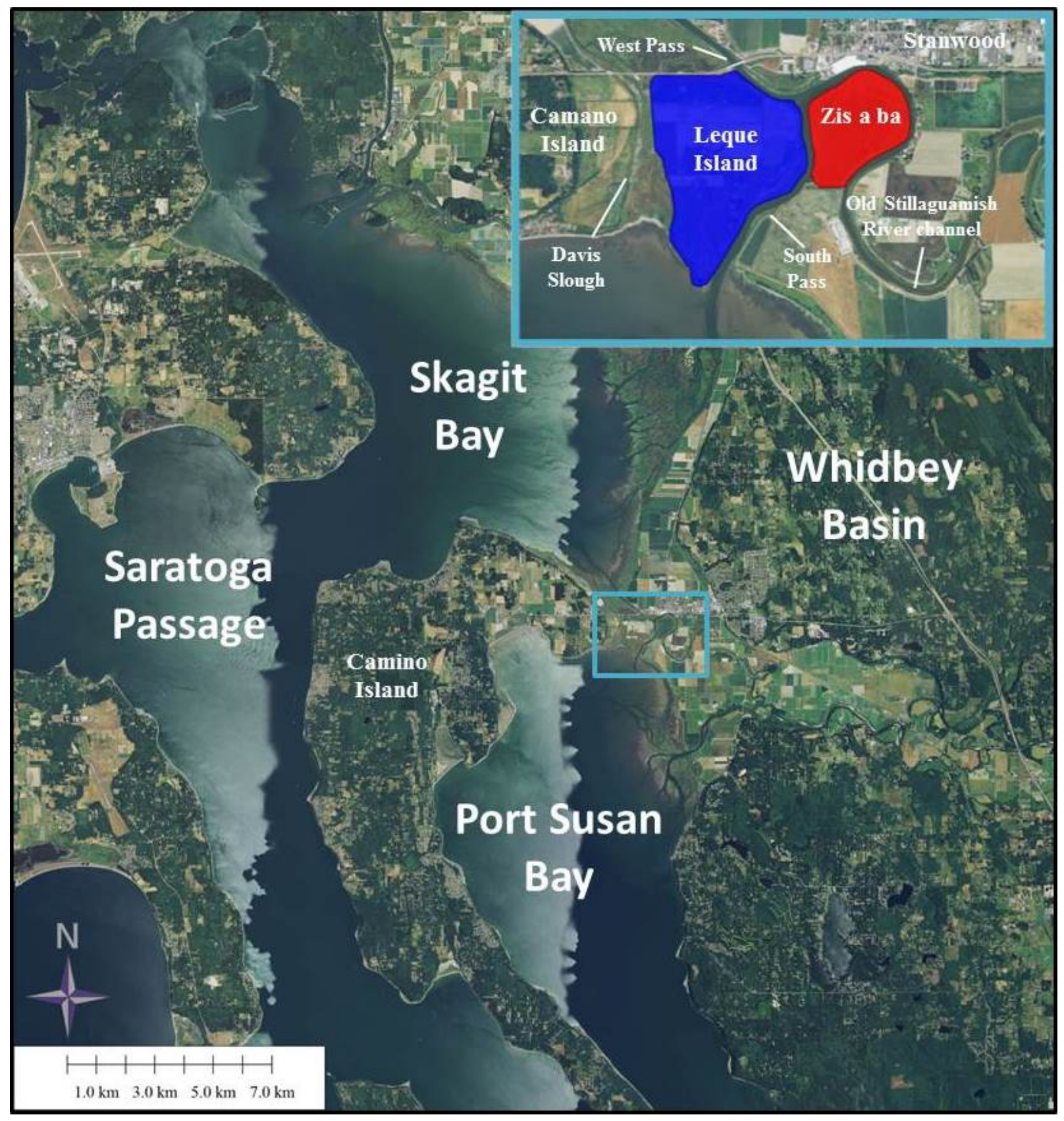

Figure 1-1: Location of Leque Island in Whidbey Basin. 


\subsection{Study Objectives and Approach}

The overall objective of the Leque Island and zis a ba Restoration Feasibility Modeling Study is to evaluate the performance of proposed restoration actions in terms of achieving habitat goals while assessing the potential hydraulic and sediment transport impacts to the site and surrounding parcels of land. PNNL previously developed a hydrodynamic model of Port Susan Bay and Skagit Bay including a high-resolution representation of the Leque Island study area (Yang et al. 2008). The approach was to utilize the previously developed model, update the model with new bathymetry information available through The Nature Conservancy (TNC) and Snohomish County, refine the grid in localized regions as needed to improve model performance, and conduct model application to simulate the proposed scenarios.

These scenarios were initially developed based on input from stakeholders and modified as new feedback was received. Figure 1-2 shows the zis a ba site and its proximity to the Stanwood wastewater plant and the Twin City Foods processing plant. A potential increase in sedimentation near the wastewater treatment plant outfall to the northeast of zis a ba is of concern although this site is already experiencing natural sedimentation at a slow rate.

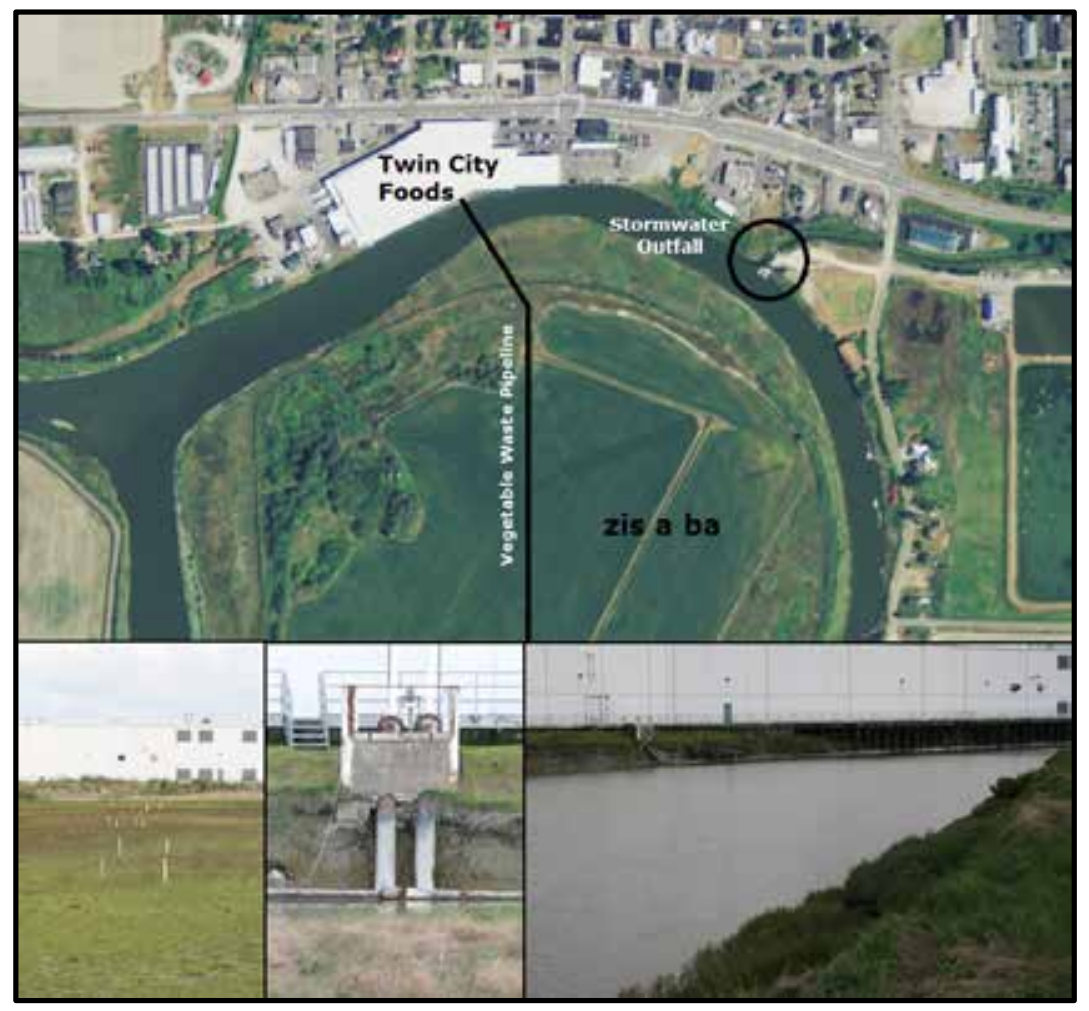

Figure 1-2: Map showing areas of concern for the City of Stanwood with accompanying images of the vegetable pipeline and exposed piles 
There is also a concern that restoration action could result in migration of the river channel south of zis a ba leading to formation of an oxbow. This would affect the mixing zone of the Stanwood wastewater treatment plant outfall to the river as well as the city's stormwater outfall. Other potential impacts of concern include any significant increase in velocity and shear near the piles supporting the Twin City Foods docks north of zis a ba or near the vegetable waste pipeline that cuts across the middle of zis a ba, which transports waste from the Twin City Foods processing plant to neighboring farmland to the south. It is important that this pipeline remains intact and not be exposed due to tidal or river flows across zis a ba.

Previously, the impacts of restoration actions at Leque on Highway 532 were a major concern for the community and WSDOT. The highway is the only way on and off Camano Island and it passes across the north end of Leque Island. However, WSDOT has secured funding and is in the process of elevating and armoring the roadway in addition to replacing the bridge over Davis Slough. The new roadway and bridge were designed to take into account tidal inundation resulting from the restoration of Leque Island.

All of these stakeholder concerns played a role in determining the alternative configurations and the associated assessment of impacts.

The scenarios evaluated in this study are listed below.

- Scenario 0 (SCN0) refers to the baseline condition, which will maintain the current river system by permanently repairing failed dikes along Leque Island.

- Scenario 1 (SCN1) involves partial restoration of Leque Island, removing all dikes on the southern side of the island, and building a setback dike across the middle. This maintains interior fresh-water wetlands while the material from the removed dike may be used to construct the new setback dike.

- Scenario 2 (SCN2) involves the full restoration of Leque Island by removing the three temporary dikes and creating another breach at a historic drainage point. With limited construction effort, it would allow Leque Island to be returned to a historic tidal marshland.

- Scenario 3 (SCN 3) involves the full removal of the Leque Island perimeter dike south of Highway 532 to accomplish the maximum restoration.

- Scenario 4 (SCN 4) removes most of the Leque dike, but allows a long stretch along the northeast of the island to remain intact to reduce the risk of the river flowing over the middle of Leque Island.

- Scenario 5 (SCN 5) examines the combined effects of partial restoration alternative (SCN1) on Leque Island with a restoration alternative on zis a ba. The only option considered for zis a ba restoration was to allow a training dike to extend to the river's point of inflection, preventing the main channel from cutting across zis a ba to alleviate concerns related about the Stanwood wastewater treatment plant outfall and the possibility of oxbow formation. 
- Scenario 6 (SCN 6) examine the combined effects of full restoration alternative with northeast section of dike intact (SCN4) on Leque Island with the restoration alternative on zis a ba as described above.

- Scenario 7 (SCN 7) examine the combined effects of full restoration alternative (SCN3) on Leque Island with the restoration alternative on zis a ba as described above.

- Scenario 8 (SCN 8) examines a modified version of Scenario 2 where only three breaches are created at the locations where the temporary dike repair patches were installed. 
The corresponding model runs are numbered SCN0 to SCN8 representing the restoration scenarios. SCN0 represents baseline existing condition. The scenarios are shown in Figure 1-3 and are described below in Table 1-1.

Table 1-1: Descriptions of the proposed restoration scenarios at Leque and zis a ba sites

\begin{tabular}{|c|c|c|c|}
\hline Number & Description & Leque Island & zis a ba \\
\hline SCN0 & $\begin{array}{l}\text { Baseline - } \\
\text { No action }\end{array}$ & Existing conditions & Existing conditions \\
\hline SCN1 & $\begin{array}{l}\text { Partial restoration at } \\
\text { Leque Island; } \\
\text { zis a ba unchanged. }\end{array}$ & $\begin{array}{l}\text { Removal of southern portion of existing Leque } \\
\text { Island levee, construction of an inner setback } \\
\text { levee and inclusion of the historic interior } \\
\text { drainage channel. }\end{array}$ & Existing conditions \\
\hline SCN2 & $\begin{array}{l}\text { Restoration at Leque } \\
\text { Island through four } \\
\text { levee breaches; } \\
\text { zis a ba unchanged. }\end{array}$ & $\begin{array}{l}\text { Four breaches of the existing Leque Island } \\
\text { levee: } \\
\text { 1. Breach } 1=30 \mathrm{~m} \\
\text { 2. Breach } 2(\text { new })=50 \mathrm{~m} \\
\text { 3. Breach } 3=90 \mathrm{~m} \\
\text { 4. Breach } 4=145 \mathrm{~m}\end{array}$ & Existing conditions \\
\hline SCN3 & $\begin{array}{l}\text { Full restoration at } \\
\text { Leque Island - } \\
\text { Alternative } 1 \text {; } \\
\text { zis a ba unchanged. }\end{array}$ & $\begin{array}{l}\text { Full removal of existing Leque Island levee } \\
\text { south of HWY } 532 .\end{array}$ & Existing conditions \\
\hline SCN4 & $\begin{array}{l}\text { Full restoration at } \\
\text { Leque Island - } \\
\text { Alternative } 2 \text {; } \\
\text { zis a ba unchanged. }\end{array}$ & $\begin{array}{l}\text { Removal of southern and western segments of } \\
\text { Leque Island levee only. Levee segments along } \\
\text { the northeast corner bordering the confluence } \\
\text { between West Pass and South Pass are to be } \\
\text { retained. }\end{array}$ & Existing conditions \\
\hline SCN5 & $\begin{array}{l}\text { Partial restoration at } \\
\text { Leque Island; } \\
\text { full restoration at zis a } \\
\text { ba. }\end{array}$ & $\begin{array}{l}\text { Removal of southern portion of existing Leque } \\
\text { Island levee, construction of an inner setback } \\
\text { levee and inclusion of the historic interior } \\
\text { drainage channel (as in SCN1). }\end{array}$ & $\begin{array}{l}\text { Partial removal of levee } \\
\text { around zis a ba and } \\
\text { construction new setback } \\
\text { levee }\end{array}$ \\
\hline SCN6 & $\begin{array}{l}\text { Full restoration at } \\
\text { Leque - } \\
\text { Alternative 2; } \\
\text { full restoration at zis a } \\
\text { ba. }\end{array}$ & $\begin{array}{l}\text { Removal of southern and western segments of } \\
\text { Leque Island levee only. Levee segments along } \\
\text { the northeast corner bordering the confluence } \\
\text { between West Pass and South Pass are to be } \\
\text { retained (as in SCN4). }\end{array}$ & $\begin{array}{l}\text { Partial removal of levee } \\
\text { around zis a ba and } \\
\text { construction new setback } \\
\text { levee }\end{array}$ \\
\hline SCN7 & $\begin{array}{l}\text { Full restoration at } \\
\text { Leque - } \\
\text { Alternative 1; } \\
\text { full restoration at zis a } \\
\text { ba. }\end{array}$ & $\begin{array}{l}\text { Full removal of existing Leque Island levee } \\
\text { south of HWY } 532 \text { (as in SCN3). }\end{array}$ & $\begin{array}{l}\text { Partial removal of levee } \\
\text { around zis a ba and } \\
\text { construction new setback } \\
\text { levee }\end{array}$ \\
\hline SCN8 & $\begin{array}{l}\text { Restoration at Leque } \\
\text { Island through three } \\
\text { levee breaches; } \\
\text { zis a ba unchanged. }\end{array}$ & $\begin{array}{l}\text { Three breaches of existing Leque Island levee: } \\
\text { 1. Breach } 1=30 \mathrm{~m} \\
\text { 2. Breach } 2=90 \mathrm{~m} \\
\text { 3. Breach } 3=145 \mathrm{~m}\end{array}$ & Existing conditions \\
\hline
\end{tabular}




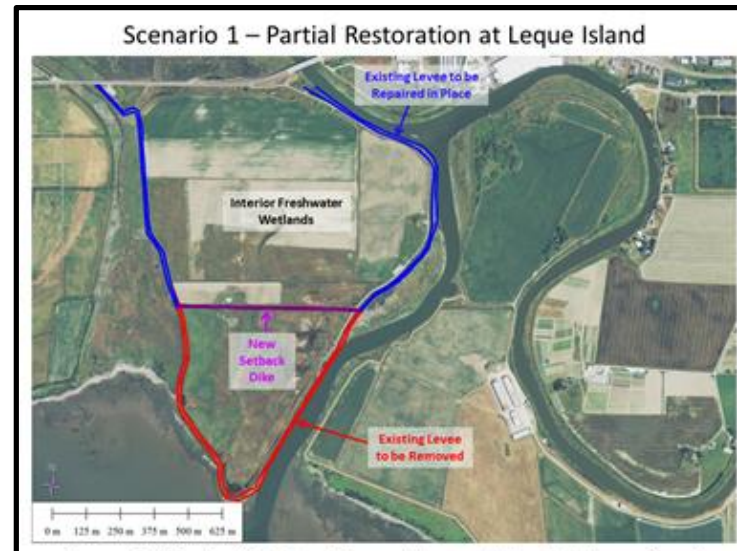

Scenario 3 - Full Restoration at Leque Island Alternative 1

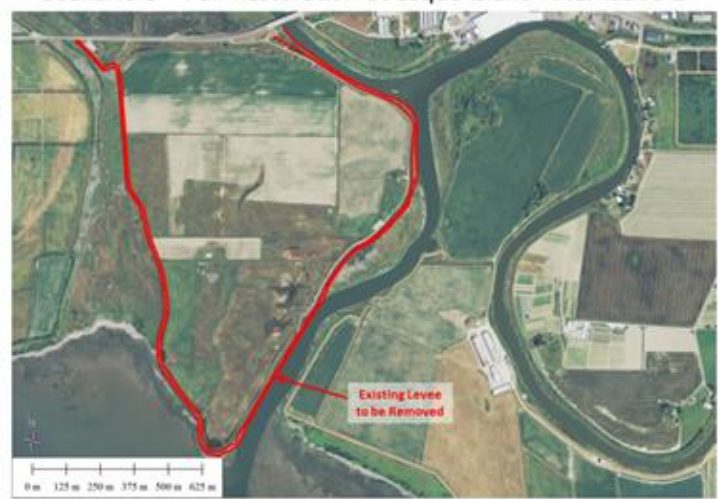

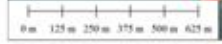

Scenario 5 - Full Restoration at zis a ba + SCNO

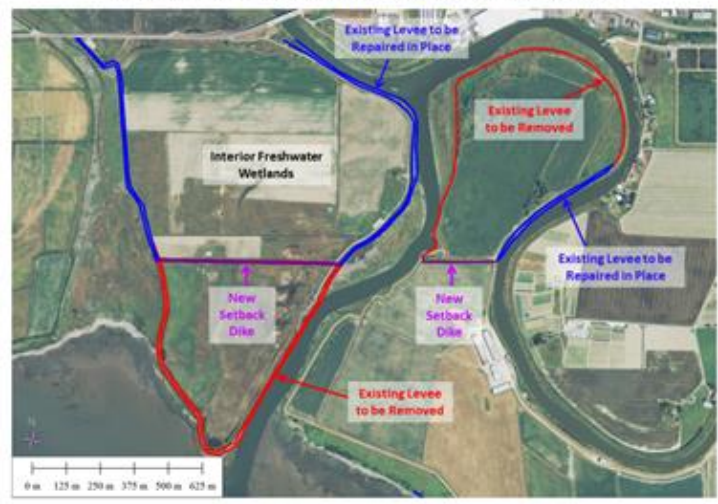

Scenario 7 - Full Restoration at zis a ba + SCN3

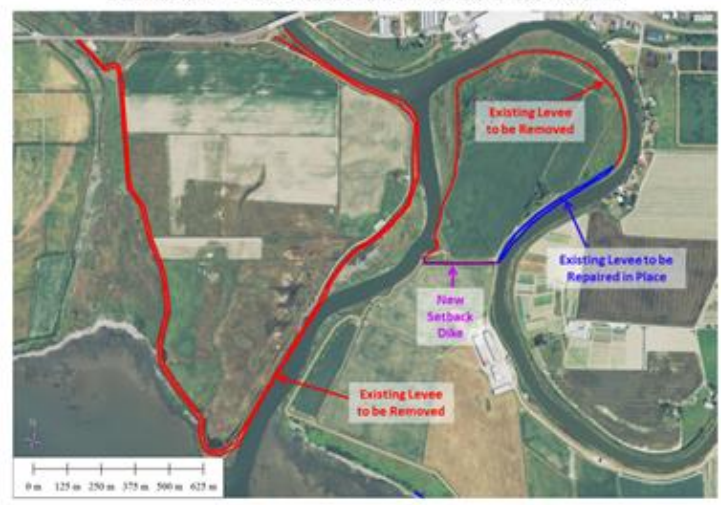

Scenario 2 - Restoration at Leque Island 4 Levee Breaches

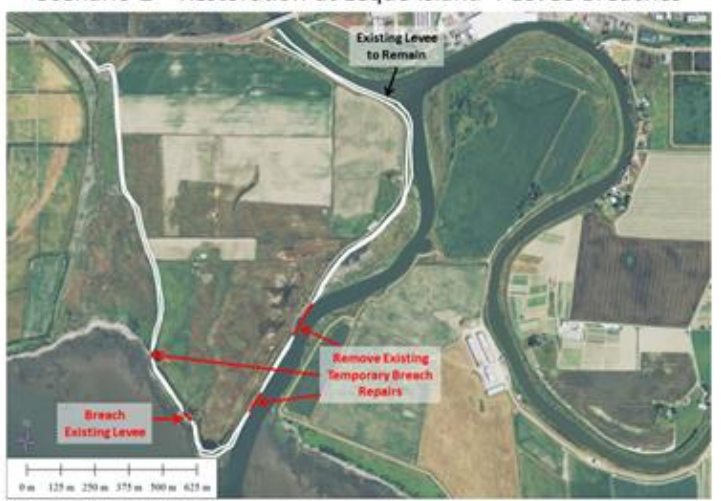

Scenario 4 - Full Restoration at Leque Island Alternative 2

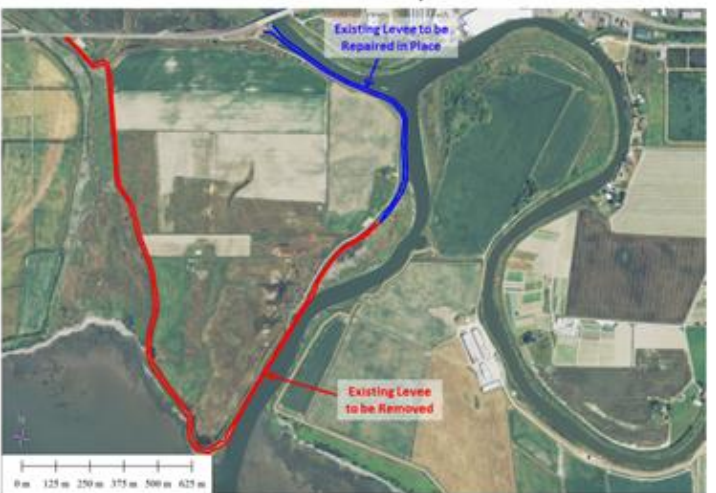

Scenario 6 - Full Restoration at zis a ba + SCN4

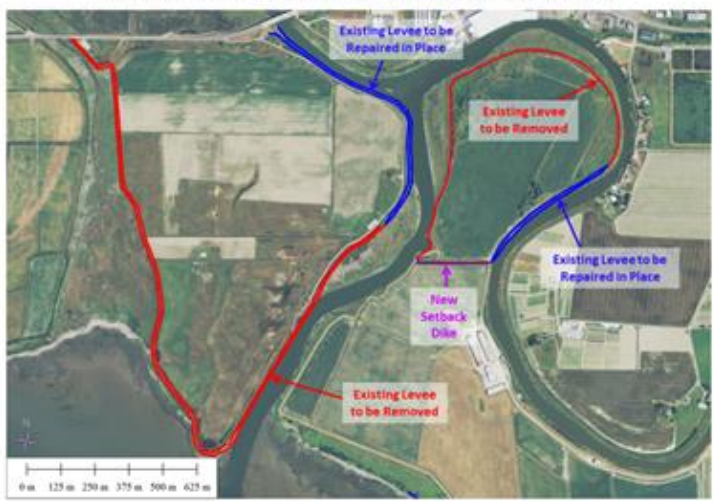

Scenario 8 - Restoration at Leque Island 3 Levee Breaches

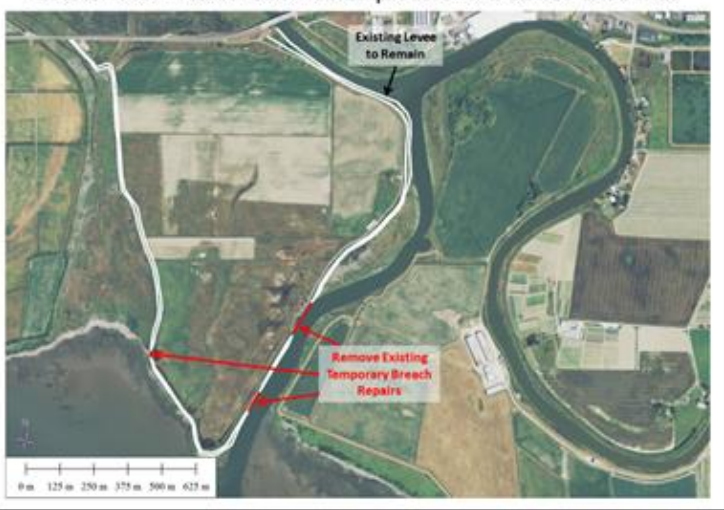

Figure 1-3: Schematic representation of the proposed restoration scenarios 


\subsection{Hydrodynamic Model Setup and Validation for Stillaguamish River Estuary}

\subsection{Introduction}

In this section, the refinement and validation of a three-dimensional hydrodynamic model for Stillaguamish River estuary are presented. A model with a detailed representation of Leque Island region was developed during Phase I of the Leque Island restoration feasibility assessment and includes the connections to Skagit Bay and Port Susan Bay. This model was constructed using the Finite Volume Coastal Ocean Model (FVCOM) developed by University of Massachusetts (Chen et al. 2003). FVCOM solves the three-dimensional momentum, continuity, temperature, salinity, and density equations in an integral form by computing fluxes between non-overlapping, horizontal, and triangular control volumes. This finite volume approach combines the advantages of finite-element methods for flexibility in handling complex shorelines and the superior ability of finite difference methods for simple discrete structures and computation efficiency. A sigma-stretched coordinate system was used in the vertical plane to better represent the irregular bathymetry. Unstructured triangular cells were used in the lateral plane. The model employs the Mellor Yamada level 2.5 turbulent closure scheme for vertical mixing and the Smagorinsky scheme for horizontal mixing. A detailed description of model setup and calibration was presented previously in the Phase I report (Yang et al. 2008)

During this Phase II effort, the model grid was refined, the bathymetry was updated, and the model calibration validated (re-checked) to ensure that model upgrades resulted in improvement and did not adversely impact previous level of calibration.

\subsection{Model Setup Update}

Data required for the hydrodynamic model setup and validation include shoreline geometry, bathymetry, tides, currents, river flow, salinity, temperature, bathymetry, and meteorological information. The shoreline geometry and bathymetry are used for construction of model grid consisting of triangular elements and nodes over which FVCOM solves the equations of continuity and momentum. Incoming tides from the domain boundaries, river inflows, and meteorological inputs are used to force the model to simulate tidal transport and circulation. The model simulates oceanographic physical properties such as water-surface elevation, currents, and salinity profiles. The original model was developed using field monitoring data collected by TNC in 2005. These data included tidal elevations, currents, salinity, and temperature time histories collected at two mooring stations near the mouths of Hatt Slough and South Pass of Stillaguamish River. These data covered a 2-week fall period from October 10-26, 2005. The approach in this Phase II effort was to update the model with new bathymetry and inflow information and re-confirm the quality of calibration model for the same October 2005 period.

Model setup information including previously developed and updated inputs is presented in the subsections below. 


\subsubsection{Model Grid}

The unstructured finite volume grid for this study covers Skagit Bay, Port Susan Bay, and includes West Pass of the Stillaguamish River which connects Port Susan Bay to Skagit Bay. The model also includes Davis Slough, the second channel between Port Susan Bay and Skagit. The Leque Island region of the domain is represented with a fine grid to represent the geometry of dikes, topography, and bathymetry. In Phase II, with the anticipated scenarios involving dike breaches and dike removal, the grid configuration near the bifurcation of the Stillaguamish River between West Pass and South Pass and surrounding intertidal region was further refined. Specifically, an intertidal flat along the east shoreline of Leque Island along South Pass previously excluded from computations is now included in the revised grid.

The model baseline grid now consists of 18,692 elements and 10,853 nodes in the horizontal plane. Five uniform vertical layers are utilized in the water column in a sigma-stretched coordinate system. The model was set up in the Universal Transverse Mercator North American Datum 83 (Zone 10) coordinates in the horizontal plane with reference to North American Vertical Datum 88 (NAVD88) in the vertical direction. This model grid also referred to as the baseline or restoration Scenario 0 (SCN0) is used for calibration simulations. It includes the area over Leque Island interior to the dikes that was is not under tidal inundation in the current existing condition but may become inundated after restoration. The baseline grid does not include zis a ba. Figure 2-1 shows the final model grid. The minimum grid size is $10 \mathrm{~m}$ in Davis Slough. The model grid was constructed in such a way that the grid lines were orientated along channels, dikes, and roads.

\subsubsection{Model Bathymetry}

Bathymetry data in the main water body of the Skagit Bay and Port Susan Bay region were obtained from the University of Washington (UW) Puget Sound Digital Elevation Model. The data have 30-ft by 30-ft spatial resolution. The UW elevation data were referenced to NAVD 88. In the study area, the mean sea level (MSL) is $1.33 \mathrm{~m}$ above the NAVD 88 datum, and the corresponding MLLW level is about $0.638 \mathrm{~m}$ below the NAVD 88 datum. Channel cross-section data from Hatt Slough and Old Stillaguamish River Channel including West Pass and South Pass reaches were provided by the Snohomish County Surface Water Management Division and were used to define the river cross. The primary source of bathymetry and topography in the intertidal regions has been lidar data from the Puget Sound Lidar Consortium (PSLC). For this effort, existing bathymetry was updated using the most recent lidar data obtained by TNC in 2012. Model bathymetry in the Leque Island area was interpolated using lidar data from PSLC, as described in Section 2. Figure 2-2 shows a close up of the topography of Leque Island study area based on available lidar data and the Snohomish County channel cross-section survey track lines.

\subsubsection{Model Boundary Conditions}

\subsubsection{Tides}

Model open-boundary conditions were tide driven water-surface elevations predicted using the X-TIDE program based on National Oceanic Service algorithms. Tidal elevations were specified at the following four open boundaries: 1) mouth of Skagit Bay - Crescent Harbor station, 2) Deception Pass Yokeko Point station, 3) Swinomish Channel - Padilla Bay station, and 4) mouth of Port Susan Bay - 
Tulalip station. Figure 2-3 shows predicted tidal elevations at Padilla Bay, Yokeko Point, Scresvent Harbor, and Tulalip stations respectively for the period of October 10-26, 2005. Tidal elevations at all stations are very similar, except for subtle differences in the tidal phase and range. The tidal range is lowest at Yokeko Point corresponding to incoming Pacific Ocean tides which amplify with propagation into Puget Sound and up Whidbey Basin through Saratoga Passage to reach the Port Susan / Skagit Bay study area. Figure 2-3 shows clear spring-neap tidal signatures and large diurnal inequalities in all the four stations.

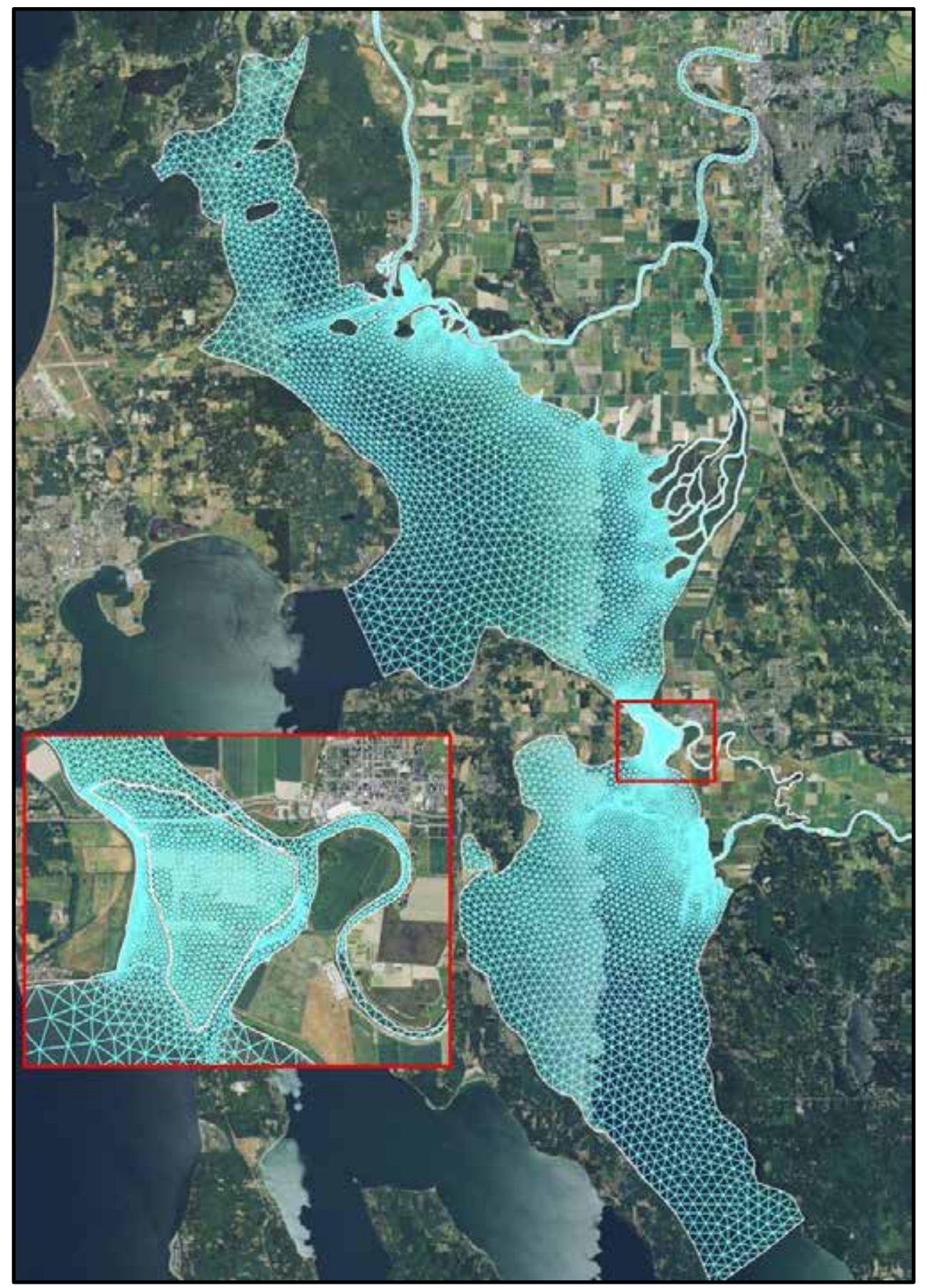

Figure 2-1: Model Grid for Leque Island, Including Skagit Bay and Port Susan Bay and bathymetry 


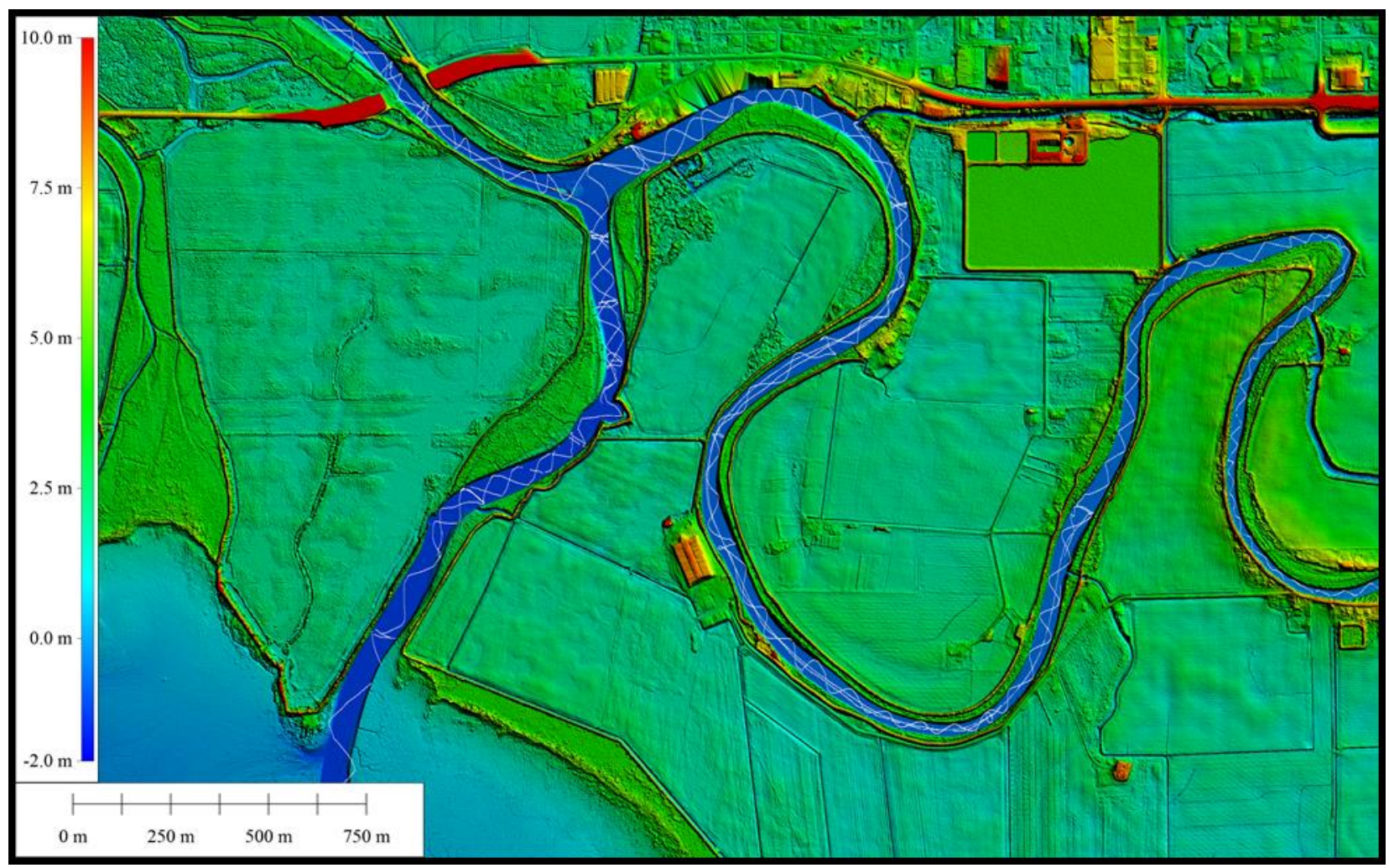

Figure 2-2: Lidar Topography and Stillaguamish River Channel survey data used in developing Bathymetry of the Leque Island and zis a ba region of the model domain

\subsubsection{Salinity and Temperature Profiles}

Salinity along the Port Susan, Yokeko Point, and Padilla Bay boundaries was specified as a nominal constant value of $30 \mathrm{ppt}$, based on field data collected at Kayak Point station. Salinity at the Skagit Bay boundary was set to $25 \mathrm{ppt}$ based on available Skagit Bay data from previous studies. Temperature at all boundaries was set to $14^{\circ} \mathrm{C}$. Field data indicated that temperature variations in the study area are less than $3^{\circ} \mathrm{C}$ most of the time, and salinity variations are more than $20 \mathrm{ppt}$. Therefore, the effect of temperature on density is not significant in affecting hydrodynamics in comparison to the effect of salinity. The temperature effect on the density-induced currents thus was not simulated in this study.

\subsubsection{Wind}

Wind data are required to correctly simulate motion induced by wind stress at the water-surface. Wind data were obtained from the NOAA's National Weather Service site at the Everett/Paine Field Station about 30 miles south of the study area. The average wind speed during the period of interest was about $3.4 \mathrm{~m} / \mathrm{s}$. The dominant wind direction is towards the north at the water-surface, wind stress was specified. Wind stress was applied uniformly to the entire model domain. 


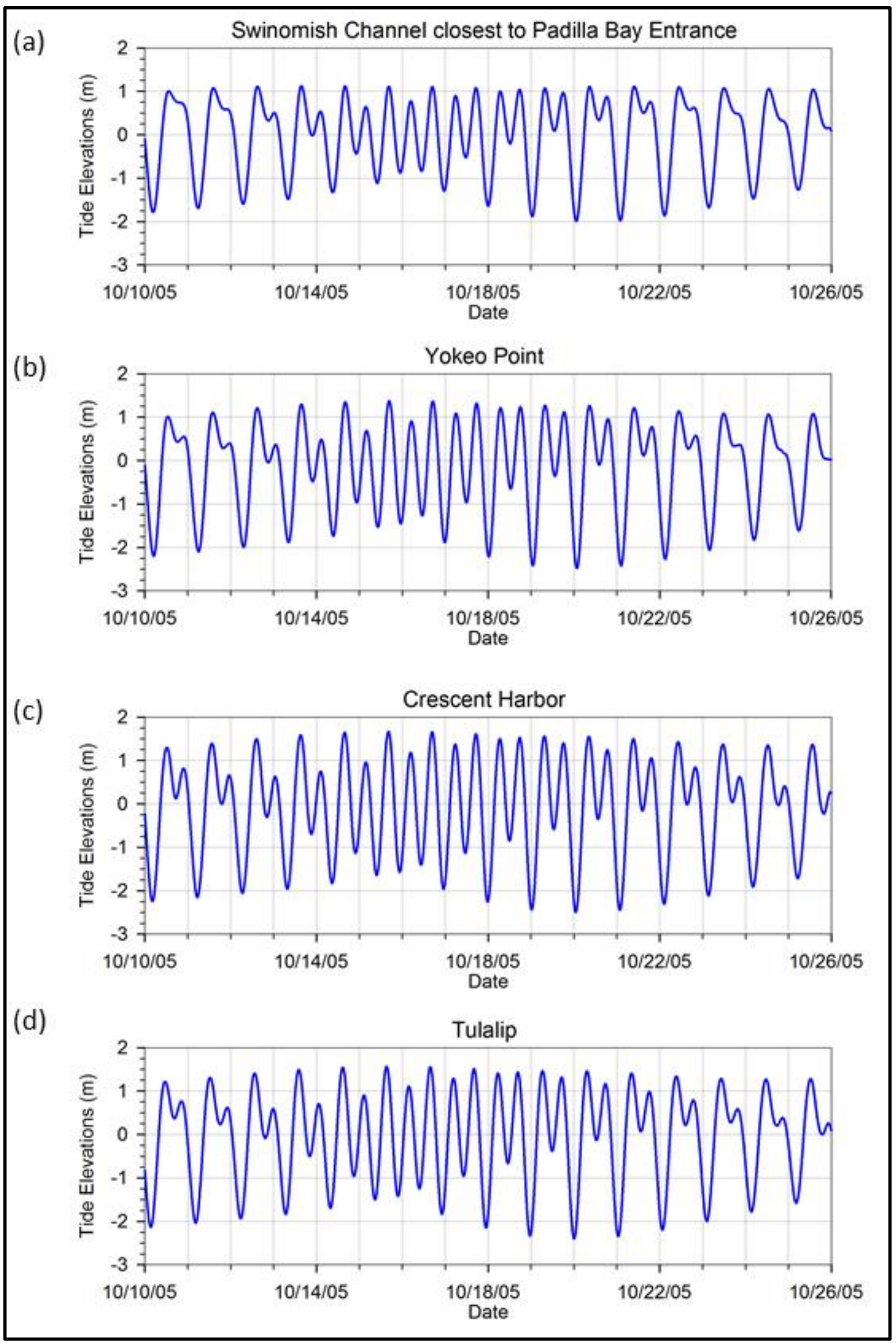

Figure 2-3: Tidal elevations at the model domain boundaries for October 2005 
The North and South Fork Stillaguamish River join at Arlington, Washington, to form the Mainstem Stillaguamish River. The Stillaguamish River flows 18 miles and discharges into Skagit Bay and Port Susan Bay through the Old Stillaguamish Channel and Hatt Slough, respectively. There were no flow records for the Mainstem Stillaguamish for the period of interest. Therefore, total Stillaguamish River flow into Port Susan Bay was estimated from the summation of Stillaguamish River flow from the North and South Fork. Flow data were obtained from USGS gauge 12167000 near Arlington at RM 6.5 on the North Fork Stillaguamish and the Washington State Department of Ecology (Ecology) gauge 05A105 at RM 33.4 on the South Fork Stillaguamish. Figure 2-4 plots inflow time history of the Stillaguamish River for October 2005. This represents the period during which field data were collected in Port Susan Bay and was selected for model calibration. The average river flow during the plotted period for October 10-26, 2005 was 2,457 cfs. It is noted that this river flow is based on reported measurements and is an improvement over Phase I work where South Fork portion of the flow was estimated using a correlation based on historic data.

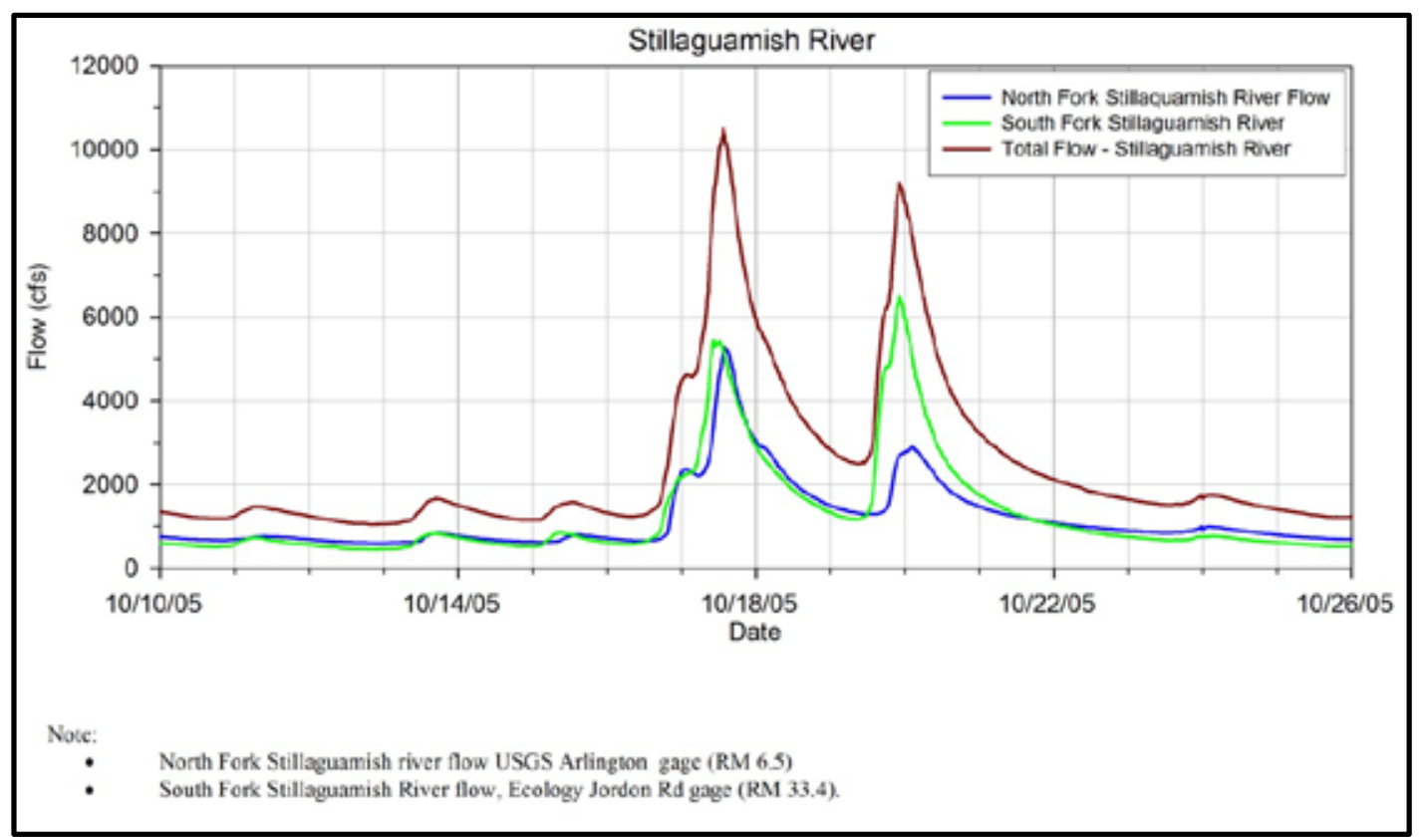

Figure 2-4: Stillaguamish River flow to Port Susan Bay, October 2005

The Skagit River brings in fresh water to Skagit Bay from the northeastern corner of the estuary through the North Fork and South Fork branches. The Skagit River flows were obtained from the USGS gauge 12200500 at Mount Vernon, Washington, at RM 15.7. Figure 2-5 shows the hydrograph of the Skagit River for the period from October 10-26, 2005. A high-flow event (about 23,000 cfs - daily average) was observed on October 18, 2005. The average river flow during the plotted period was 12,331 cfs. Daily variations in the river flow are evident during normal flow conditions because of the daily peaking-mode operation of the Skagit Hydropower Project owned and operated by Seattle City Light. 


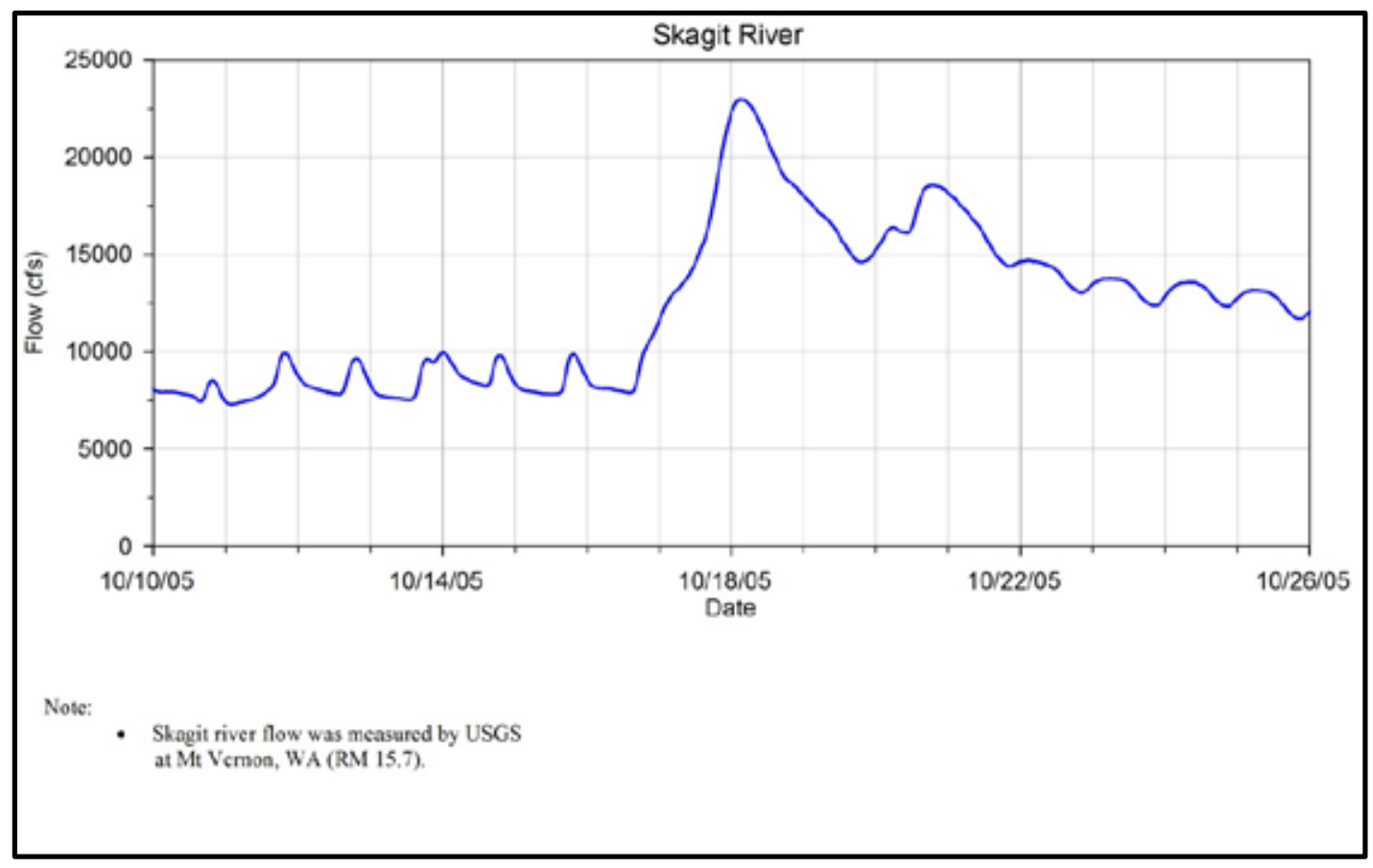

Figure 2-5: Skagit River flow to Skagit Bay, October 2005

\subsection{Model Validation Results}

Model validation is a standard procedure through which performance of the predictive tool is reconfirmed through comparison with data. Typically validation is performed using a data set independent of the one used for calibration. Calibration of the hydrodynamic model for Leque Island was conducted during Phase I (Yang et al. 2008). However, as part of this Phase II effort numerous updates were made to the model such as refinement of the model grid, update of bathymetry, and revision of river inflow inputs. Changes were also made to the model source code as the software was upgraded from FVCOM version 2.1 to 2.7. Also the wetting and drying scheme was improved to ensure that there was no diffusion of salinity between dry and wet nodes, a model limitation that was detected during the course of this study. To ensure that model calibration from Phase I was still valid, the exercise of comparing simulated variables to measured data was repeated using the same October 2005 data set and is referred to as model validation ( re-calibration). Wetting and drying was simulated using a minimum water depth of $20 \mathrm{~cm}$ as the dry cell criteria (i.e., when the depth fell below $20 \mathrm{~cm}$, the model assumed that the element was dry). All model parameters for the Phase II validation were kept the same as those developed during Phase I calibration.

\subsubsection{Field Data Collection - October 2005}

Oceanographic data collected by TNC as part of the hydrodynamic and ecological assessment for the Port Susan Bay restoration project near the mouth of the Stillaguamish River from October 10-26, 2005, were used for the model validation exercise for this study. The oceanographic data for the model validation include water-surface elevation, salinity, and velocity time series. Two mooring stations were deployed in the main channels of South Pass and Hatt Slough near the mouth of the Stillaguamish River. 
The South Pass station was equipped with an InterOcean S4 current meter and Star Oddi ConductivityTemperature-Depth (CTD) instrument for continuous measurements. The Hatt Slough station was equipped with an RD Instrument Acoustic Doppler Current Profiler (ADCP) for continuous measurements of current profiles and a Hydrolab CTD for continuous measurements of tidal elevations, salinity, and temperature. Two CTDs were deployed at the Kayak Point station for continuous measurements of tidal elevations, salinity, and temperature. Instantaneous salinity and temperature profiles were also obtained near South Pass, Hat Sough, and Kayak Point stations during the deployment and retrieval of the instruments. Figure 2-6 shows the locations of the data collection stations and a detailed description of field data collection efforts is described in the Port Susan Bay restoration study report (Yang et al. 2006) and the Leque Island Phase I calibration report (Yang et al. .2008).

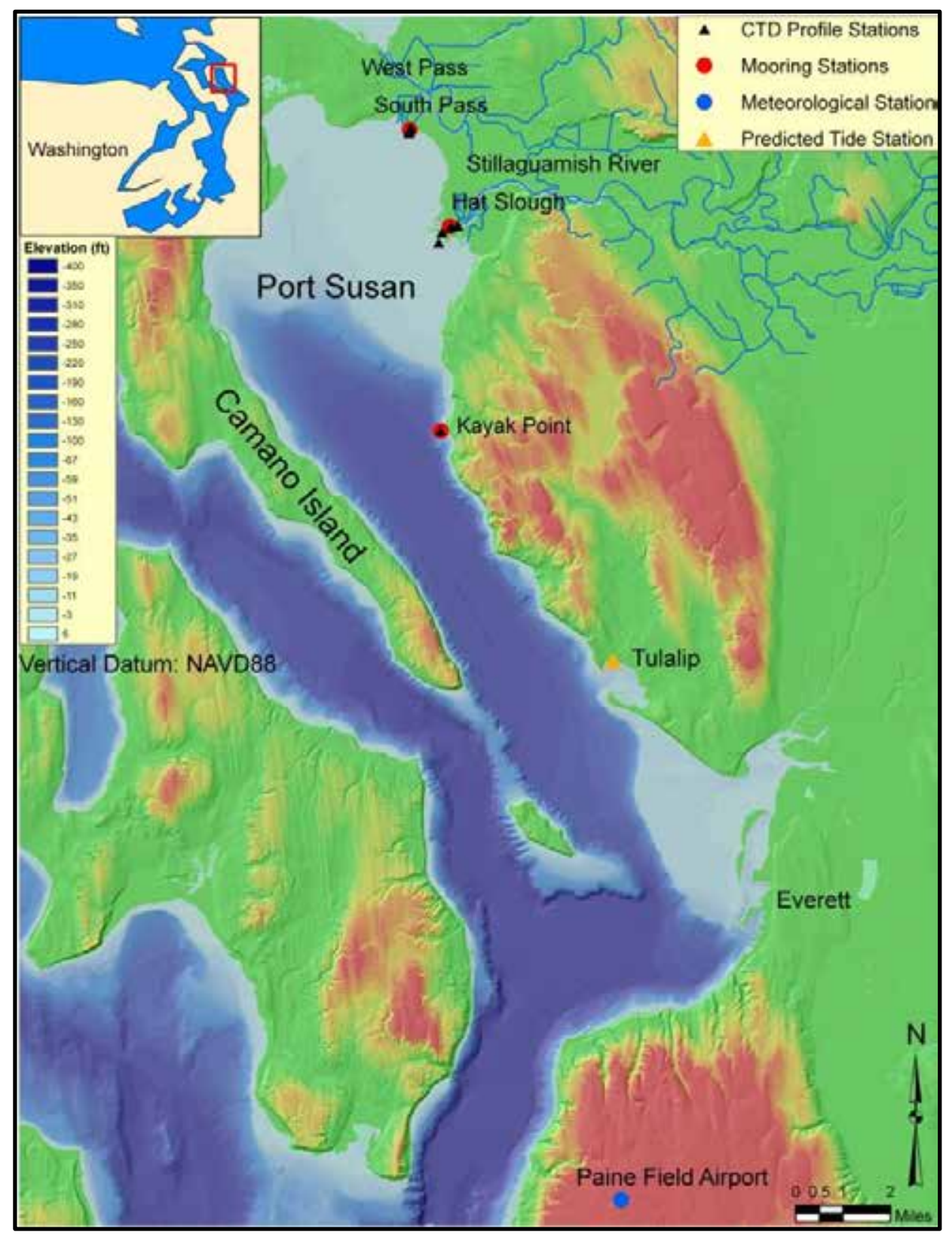

Figure 2-6: Oceanographic data collection stations, Port Susan Bay, October 2005 


\subsubsection{Model Validation - Tides}

Figure 2-7 compares predicted tidal elevations at the Kayak Point, Hatt Slough, and South Pass stations. Predicted water-surface elevations matched the observed data well. The spring-neap tidal cycle and the diurnal inequality were reproduced well in the model. Predicted high and low tidal phases were also in good agreement with observed data. The tidal elevation at the Kayak Point station shows a full tidal range of $4 \mathrm{~m}$ as observed in the Puget Sound coastal region. As the tide propagates further upstream towards the mudflat area of Port Susan Bay, tidal elevations are affected by shallow water depths and river backwater as observed at the South Pass and Hatt Slough stations. Tidal elevations during low tides at South Pass and Hatt Slough were elevated because of the shallow mudflat area near the river mouth. Tidal elevations were further elevated at Hatt Slough and South Pass during the high-flow event October 17,2005 , to October 21, 2005, because of the river backwater effect.

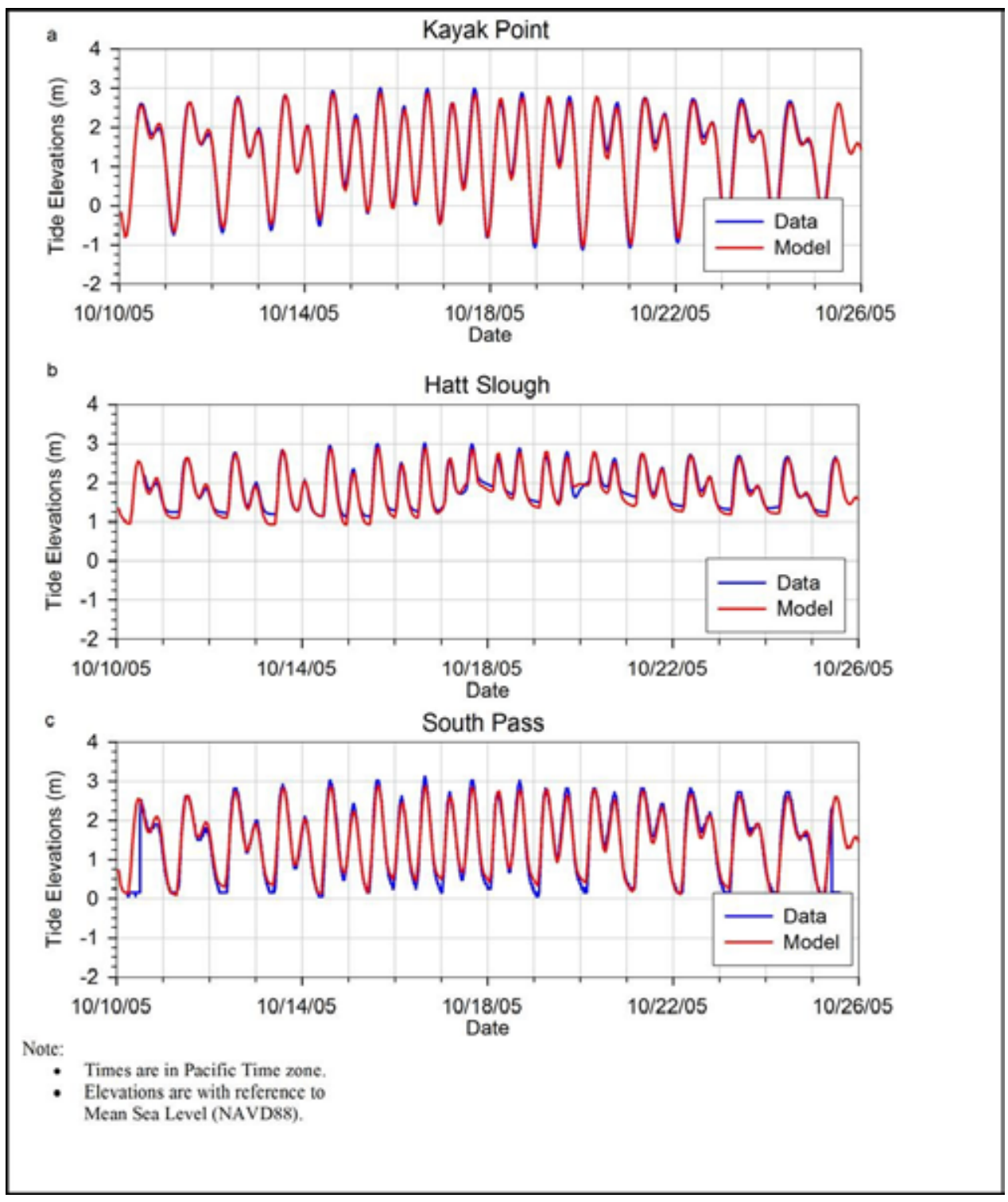

Figure 2-7: Comparison of predicted water-surface elevations and measured tides at the Kayak Point, Hatt Slough, and South Pass stations respectively 
The minimum water-surface elevation at the South Pass station was about $0.33 \mathrm{~m}$ above NAVD88. At the Hatt Slough station, water-surface elevations were also elevated because of the shallow mudflat area near the mouth of Hatt Slough, and the minimum water-surface elevation was about $1.3 \mathrm{~m}$ above NAVD88, which is about the same as MSL.

Table 2-1 below provides validation error statistics comparing measured water-surface elevation data to simulated results. Overall root mean square error (RMSE) relative to tidal range is $<10 \%$ with a negative bias of $4 \mathrm{~cm}$ and average RMSE of $24 \mathrm{~cm}$.

Table 2-1: Model error statistics - Water-Surface Elevation

\begin{tabular}{|c|c|c|c|}
\hline Station & ME (m) & RMSE (m) & RME (\%) \\
\hline \multicolumn{4}{|c|}{ Tide - Water-surface elevation, $\mathrm{m}$} \\
\hline Kayak Point & -0.05 & 0.26 & 6.33 \\
\hline Hatt Slough & -0.07 & 0.23 & 12.20 \\
\hline South Pass & 0.00 & 0.24 & 7.32 \\
\hline Mean & -0.04 & 0.24 & 8.62 \\
\hline \multicolumn{4}{|c|}{$\begin{array}{l}\text { RMSE = root mean square error, } \mathrm{ME}=\text { mean error } \\
\mathrm{RME}=\text { mean error relative to tidal range (magnitude of change } \\
\text { in tidal elevation) at each site }\end{array}$} \\
\hline
\end{tabular}

\subsubsection{Model Validation - Currents}

Predicted velocities in general matched the observed data at both the South Pass and Hatt Slough stations (Figure 2-8). Model predictions match the field data well at a level of accuracy similar to Phase I calibration effort. Unlike water-surface elevations, the signature of the neap-spring tidal cycle and diurnal inequality was not strong in velocity distributions because of the damping effects of river inflow and the presence of a shallow tide flat area. Velocities are dominant in the north component of the South Pass station and in the east component of the Hatt Slough station because of the orientations of the river channels. Dominant seaward (westward) flow was observed at the Hatt Slough station during the highriver-flow period (October 17, 2005 to October 21, 2005). 


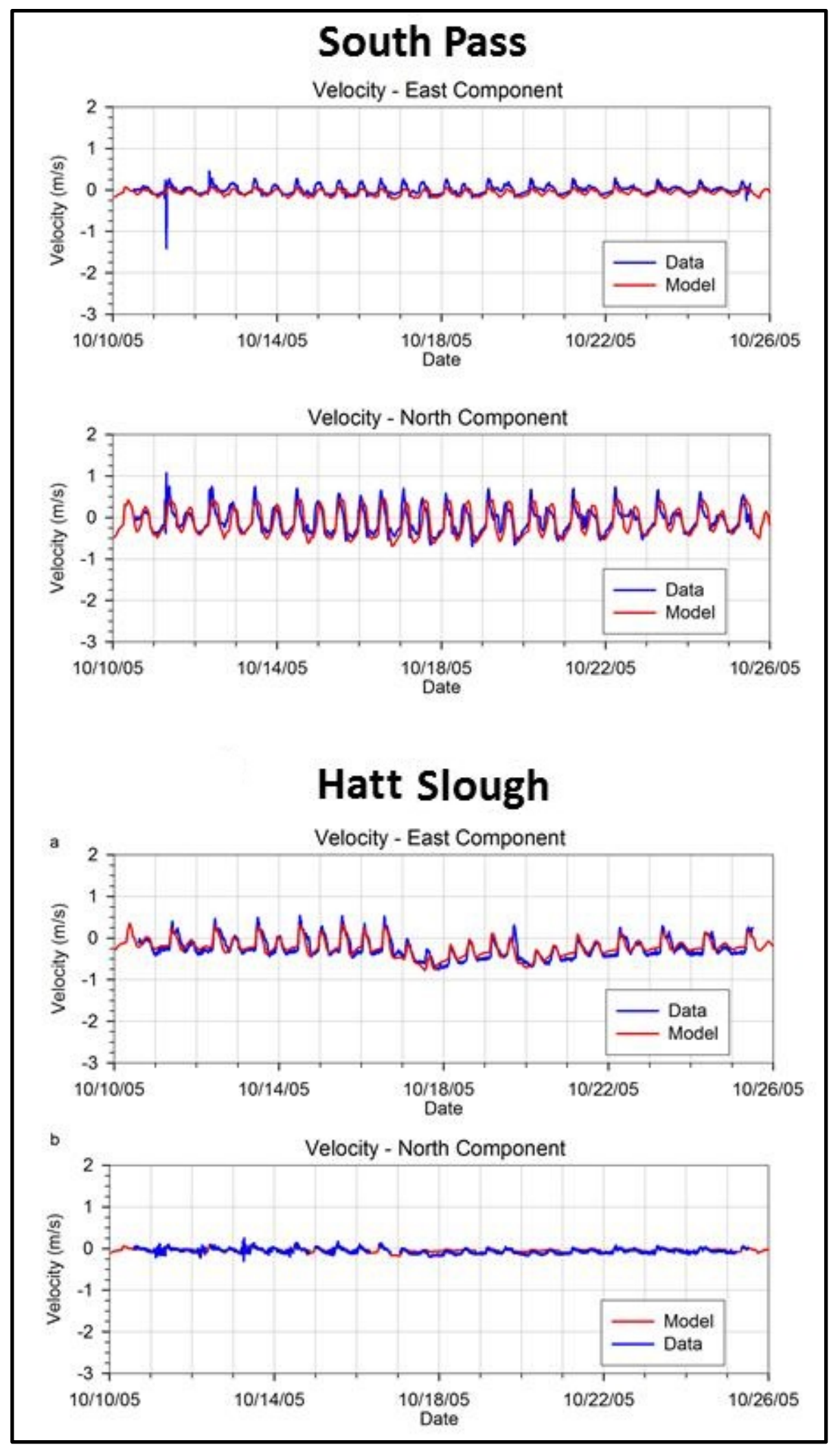

Figure 2-8: Comparison of predicted and measured velocity components at the Hatt Slough and South Pass stations respectively. Data from mid-depth of the water column 
Table 2-2 below provides validation error statistics comparing measured velocity data to simulated results. The velocity data collected at the Hatt Slough and South Pass stations was decomposed into north and south components for direct comparison to simulated results. Comparison was done for mid-depth layer at both sites. Overall RMSE in north and south directions is less than $15 \mathrm{~cm} / \mathrm{s}$ and mean absolute error is $11 \mathrm{~cm} / \mathrm{s}$. This represents $<10 \%$ error relative to the range of current magnitudes in the Stillaguamish River estuary.

Table 2-2: Model error statistics - Velocity

\begin{tabular}{|l|l|l|l|}
\hline Station & ME $(\mathbf{m} / \mathbf{s})$ & MAE $(\mathbf{m} / \mathbf{s})$ & RMSE $(\mathbf{m} / \mathbf{s})$ \\
\hline U - m/s (East Component) \\
\hline Hatt Slough & -0.07 & 0.08 & 0.11 \\
\hline South Pass & 0.01 & 0.13 & 0.17 \\
\hline Mean & -0.03 & 0.11 & 0.14 \\
\hline V - m/s (North Component \\
\hline Hatt Slough & -0.04 & 0.19 & 0.24 \\
\hline South Pass & 0.01 & 0.03 & 0.04 \\
\hline Mean & -0.01 & 0.11 & 0.14 \\
\hline MAE = mean absolute error; RMSE = root mean square error \\
\hline
\end{tabular}

\subsubsection{Model Validation - Salinity}

Salinity calibration and validation at this site was particularly challenging. This was primarily due to two factors, (a) lack of detailed channel bathymetry over the Port Susan Bay tidal flats, and (b) lack of river flow distribution data between Hatt Slough which discharges fresh water to northwest corner of Port Susan Bay and Old Stillaguamish River Channel, which discharges fresh water near Leque Island. The ability of the model to transport freshwater away from the tributary mouths is governed by the carrying capacity of the distributary channels over the tidal flats. A similar split in the magnitude of fresh-water volumes between Hatt Slough and Stillaguamish River affects salinity levels near South Pass and Hatt Slough stations. Calibration effort therefore has relied on best professional judgment in adjustment of the bathymetry in these regions lacking flow and bathymetry data.

Figure 2-9 compares salinity time histories at the Kayak Point, Hatt Slough, and South Pass stations. Overall, predicted salinities matched the observed data reasonably well, similar to those in the Port Susan Bay model calibration. The predicted salinity at Kayak Point showed little variation, mainly because salinity at Kayak Point was controlled by the open-boundary condition, which was specified as constant at 30 ppt. However, the mean generally followed the trend of observed data, representing the salinity of Puget Sound water. Salinities at the South Pass station showed strong tidal fluctuations, varying from 0 ppt during low tide to 15 - 20 ppt during high tide in a full tidal cycle. At the Hatt Slough station, sharp salinity intrusion was observed during high tide. Salinities reduced significantly during the high-riverflow period (October 17, 2005 to October 21, 2005), indicating that most of the Stillaguamish River flow discharges into Port Susan Bay through Hatt Slough. 


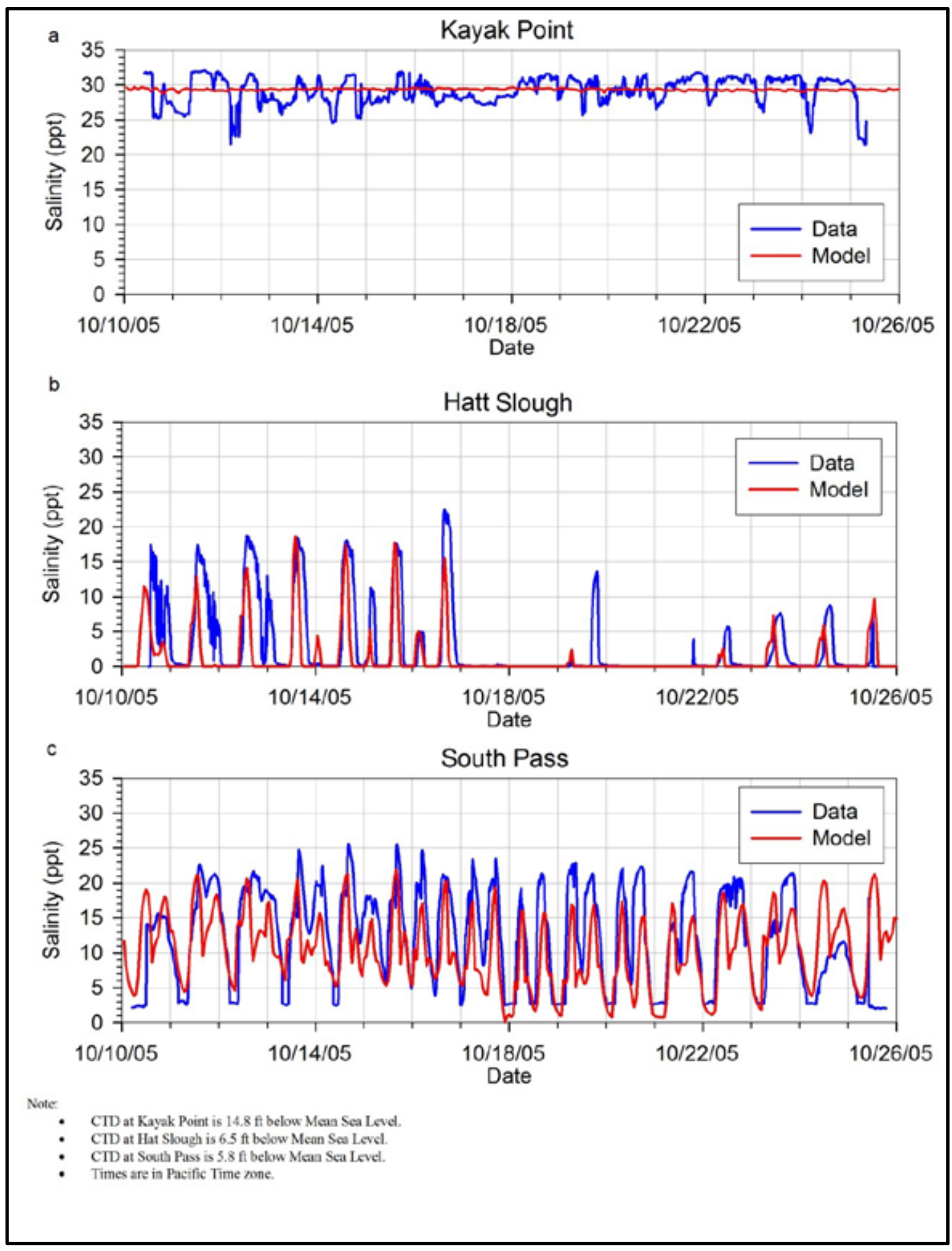

Figure 2-9: Comparison of predicted and measured salinity at the Kayak Point, Hatt Slough, and South Pass stations, respectively 
Table 2-3 below provides validation error statistics comparing measured salinity data to simulated results. Overall RMSE is 4 ppt with a negative bias of $1.3 \mathrm{ppt}$ and a mean absolute salinity error of 2.7 ppt.

Table 2-3: Model error statistics - Salinity

\begin{tabular}{|l|l|l|l|}
\hline \multicolumn{1}{|c|}{ Station } & ME (ppt) & MAE (ppt) & RMSE (ppt) \\
\hline Salinity, ppt \\
\hline Kayak Point & 0.48 & 1.51 & 1.83 \\
\hline Hatt Slough & -1.51 & 2.17 & 4.39 \\
\hline South Pass & -2.83 & 4.46 & 5.81 \\
\hline Mean & -1.29 & 2.71 & 4.01 \\
\hline \multicolumn{4}{|l}{ MAE = mean absolute error; RMSE = root mean square error } \\
\hline
\end{tabular}




\subsection{Design of Simulations for the Restoration Feasibility Assessment}

\subsection{Approach}

The overall objective of the modeling analysis for Leque Island and zis a ba restoration sites is to evaluate the feasibility of successfully restoring intertidal estuarine process and marsh habitat at the sites currently enclosed by dikes. Despite best intentions, efforts to restore near-shore habitats through actions such as dike removal can sometimes result in poor outcomes if impacts to water circulation and transport are not properly examined. Land use and budget constraints can also lead to selection of suboptimal restoration alternatives that may result in undesirable consequences, such as flooding, deterioration of water quality, and erosion, that require immediate remedies and costly repairs. Quantitative modeling helps reduce uncertainty associated with the coastal response to proposed actions, by simulation of oceanographic parameters during critical conditions. The results may then be evaluated to assess the feasibility of establishment of tidal exchange, potential sedimentation, erosion effects, and establishment of fish migration pathways.

Based on discussions with project partners and stakeholders it was determined that (a) flooding and inundation (restoration area, duration, and frequency), (b) salinity variations, and (c) potential for erosion were the parameters of most interest. Inundation response would help determine the risk of flooding nearby properties and provide spatial coverage of the restored region influenced by the tidal action. Salinity response would help inform habitat feasibility and vegetation predictions. Bottom velocities and bed shear stress values relative to critical stress would help determine if the restoration actions would lead to a depositional marsh land or erosional mudflat. To examine the above variables we developed an approach where by all proposed restoration scenarios would be examined for the following combination of hydrological and tidal conditions.

- Typical estuarine conditions (October 2005): These represent typical conditions of river flow and tides. Conditions experienced during field data collection in October 2005 were used previously in model calibration and were also selected to serve as the typical conditions.

- Stillaguamish River high flow conditions: High-river-flow conditions which represent maximum potential for sediment erosion, deposition, and geomorphological change are often associated with bank-full flow. Given tidally influenced regime in Hatt Slough and Stillaguamish River, bank-full flow was computed and used for October 2005 tidal conditions.

- Year-long simulation: To evaluate the frequency of inundation, flooding risk, long term salinity response, and maximum potential for shear, simulations were conducted for a year-long duration. This allows a natural combination of high river flow and high tidal ranges to be considered as they occurred naturally in Stillaguamish Estuary in the selected Year 2003. 


\subsection{Simulation of Typical Estuarine Conditions of October 2005}

The response of proposed restoration actions on hydrodynamics, salinity, velocity, water depth, and bed shear stress near the Leque Island restoration area were evaluated with the model. The model grid for the baseline conditions on Leque Island was modified to represent the restored-condition geometry and bathymetry for the various (8) scenarios. The model was applied using the same inputs of river flow and tides corresponding to October 2005 conditions which we designated as the typical conditions, representative of typical conditions in the Stillaguamish River estuary. Simulated parameters such as water-surface levels (inundation), salinity, and velocity distributions were compared. All other model parameters and forcing functions were retained at the same values as those set up for the model validation for the typical conditions for all scenarios.

Plots for each scenario were generated to show velocity vectors overlaid with salinity contours at high and low tide. This allows examination of the salinity values at the two extremes during flood and slack tide, from which areal extents of the tidal exposure may also be assessed. Additional plots show contours for bed shear stress during peak ebb and flood currents which provide visual comparison of areas most likely to experience highest bed shear stresses and potential for sediment erosion. All the plots correspond to October 17, 2005 because that day experienced the largest combination of tidal variation and highest river flows. Finally, time series graphs were created to show water-surface level (m), salinity (ppt), and velocity magnitude $(\mathrm{m} / \mathrm{s})$ at three stations on Leque Island and three stations on zis a ba over a period of 16 days. Time series plots show hourly fluctuations resulting from tidal and river flow forcing during the period from October 10-26, 2005. The desired characteristics for a tidal restoration project to support fish habitat are a depth range between 20 to $38 \mathrm{~cm}$ and a salinity range between 5-15 ppt per guidance provided by Skagit River System Cooperative (SRSC 2014).

Time series plots were generated at three stations along Leque Island and zis a ba, seen in Figure 3-1. These stations are meant to be representative of different locations along each restoration site to show variability across the islands. Plots show water-surface elevation, salinity, bottom velocity, and bed shear stress over the complete two week simulation. 


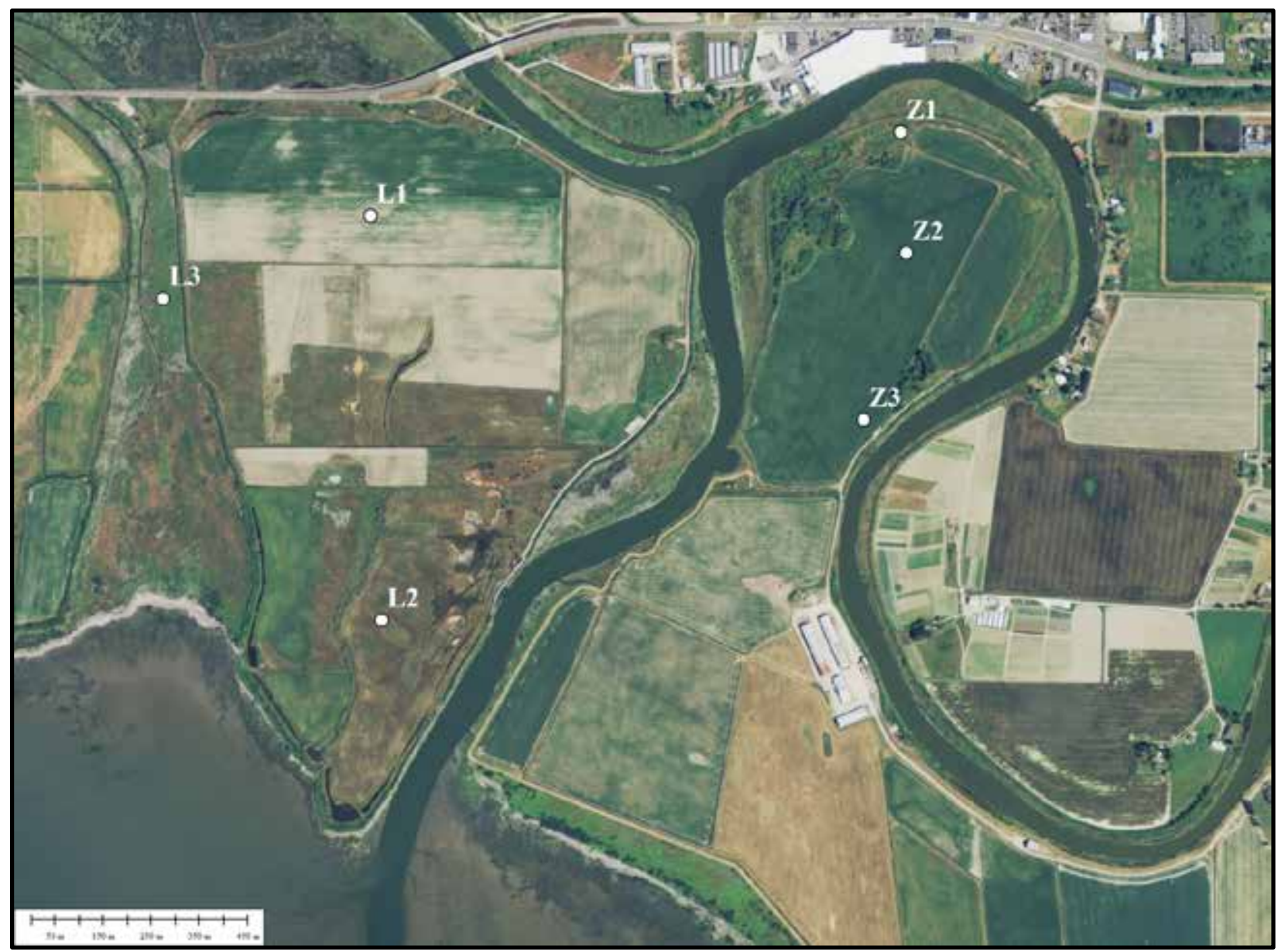

Figure 3-1: Three stations locations on Leque Island and three stations locations on zis a ba

A tide gate failure recently occurred along Davis Slough on Leque Island region north of Highway 532 on Leque Island, outside of this project area. This area is considered good fish habitat even though it is only inundated for approximately $20 \%$ of the time, indicating that infrequent inundation may not be a limitation. High bed velocities and bed shear are of concern not only from erosion concerns but also for habitat suitability for juvenile fish. Bed shear values are recorded in Pascals (Pa) and are examined as the best indicator of expected sediment transport given site-specific variability in bed characteristics and critical shear stress properties controlling erosion potential. An approximate correlation between size of sediment particle and critical shear stress for erosion are provided in Table 3-1 below. Assuming noncohesive sediments, particles will re-suspend and erode when bed shear stress exceeds critical shear stress values (Julien 1998).

It is noted that simulation results were saved only at hourly increments. As a result, when identifying high tide, low tide, peak ebb, and peak flood, the hour that most closely lined up with that event was selected. This is the reason why small velocity vectors may be seen on the high and low tide plots. 
Table 3-1: Critical Shear Stress for Different Particle Sizes (from Julien 1998)

\begin{tabular}{|c|c|c|}
\hline Sediment Type & Particle Size (mm) & Critical Shear Stress for Erosion (Pa) \\
\hline Silt & $0.016 \sim 0.0625$ & $0.065 \sim 0.11$ \\
\hline Sand & $0.0625 \sim 2$ & $0.11 \sim 1.26$ \\
\hline Gravel & $2 \sim 64$ & $1.26 \sim 53$ \\
\hline Cobble & $64 \sim 256$ & $53 \sim 111$ \\
\hline
\end{tabular}

\subsection{Simulation of Stillaguamish River High Flow Conditions}

Performance of the proposed restoration actions during high-river-flow conditions is of interest. High river flows can have significant impacts on the geomorphological features in the system. Major geomorphologic changes such as river channel erosion and enlargement of steep, incised channels often occur during extreme fluvial events. The study area is in the tidally influenced region of the estuary. The dikes in the system were constructed in the 1870s and are known to be overtopped at river flows well below the 100-year flood flow magnitudes at several locations, and well upstream of our study boundary. The remaining flows are eventually conveyed through the Stillaguamish River channels at bank-full elevations. Although sediment concentrations are an order of magnitude higher during storm event generated flows, their duration is relatively short. It turns out that, in many rivers, the modest flow regimes transport greater quantity of sediment material over time because of the higher frequency of occurrence for such events (Wolman and Miller 1960). In practice, 2-year return frequency flows or bank-full flows are used to represent effective flows or channel forming flows.

To determine the maximum river flow before overtopping would occur, the dike elevations were examined along the entire Old Stillaguamish River Channel and several kilometers of Hatt Slough. Because the absolute distances of the north and south river banks will differ, the benchmark for distance was river kilometers that were measured and provided by Snohomish County Public Works. The $0 \mathrm{~km}$ marker begins near the river mouth at Port Susan shoreline and the markers move upstream along the deepest channel of the stream. The line was hatched every $0.2 \mathrm{~km}$ for reference and measurements were taken along the dikes every $0.05 \mathrm{~km}$.

There is also some uncertainty as to which elevation along the dike represents the overtopping height. On average, the dike was about 3m wide along the top (Figure 3-2), while the lidar had a 1m resolution that averages all elevation values within that $1 \mathrm{~m}$ area. Dike cross sections were taken every $0.05 \mathrm{~km}$ along the river (Figure 3-3) and the maximum value was recorded and plotted to represent dike crest elevation at each cross section. Nearly $13 \mathrm{~km}$ of the Old Stillaguamish River and over $9 \mathrm{~km}$ of Hatt Slough were sampled from the lidar database. 


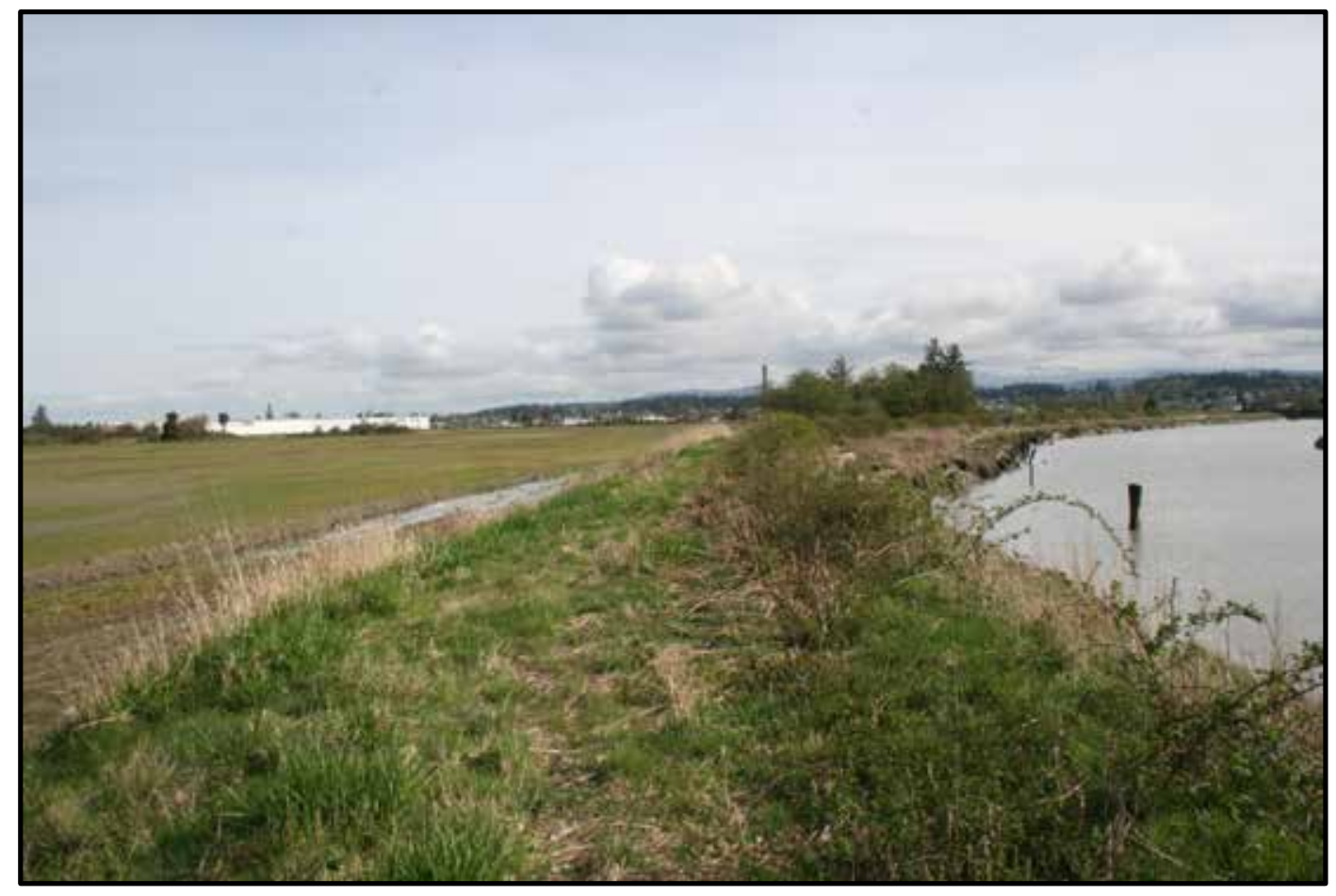

Figure 3-2: A dike along the east side of zis a ba, approximately 3m wide

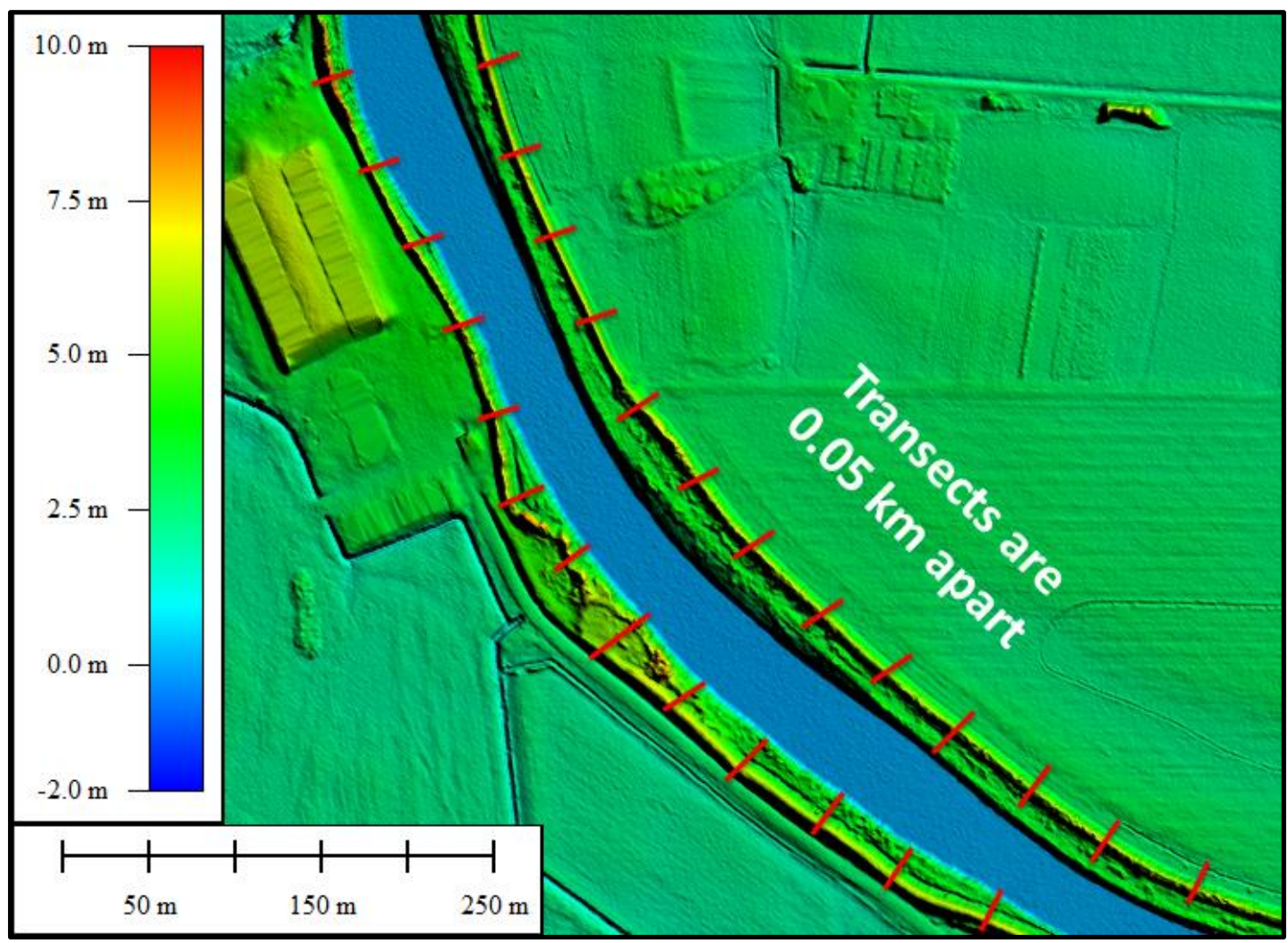

Figure 3-3: Example of the transect method used to determine dike crest elevations along the banks of the lower Stillaguamish River 
The 16-day period in October 2005 was then simulated with increasing daily average flow values, in increments of 20,000 cfs. Locations along both the Old Stillaguamish River and Hatt Slough were identified where overtopping seemed most likely. Water-surface elevations from the incremental runs were interpolated at these locations to estimate the flow at which the dikes would overtop. The Old Stillaguamish River Channel was estimated to overtop at a daily average flow of 28,426 cfs at a location $8.6 \mathrm{~km}$ upstream of the river mouth, while Hatt Slough was estimated to overtop at a daily average flow of 26,508 cfs at a location $5.76 \mathrm{~km}$ upstream of the slough mouth. Therefore, the lower value of 26,508 cfs was selected as the design high flow value that the river system could sustain before overtopping occurred. Figure 3-4 shows dike elevations along Hatt Slough and Old Stillaguamish River Channel plotted against maximum surface elevation heights as a function of distance upstream from the river mouths for various flows.

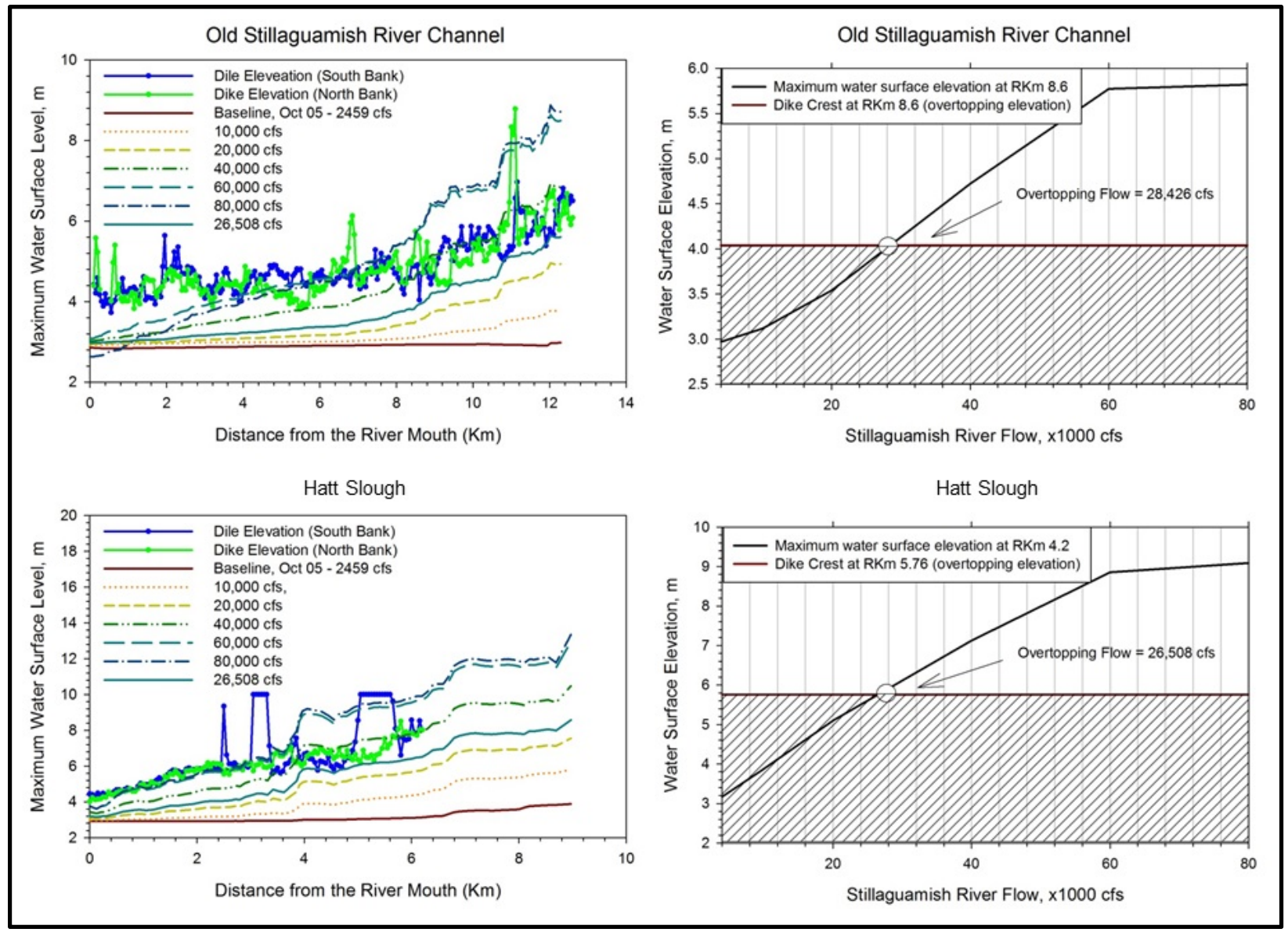

Figure 3-4: Plots used to determine bank-full high flow conditions in the Old Stillaguamish River and Hatt Slough

Simulations for the restoration scenarios were then conducted for the same period as the typical conditions from October 10-26, 2005 using river inflow values artificially set at a high daily average value of 26,508 cfs compared relative to average flow of 2,459 cfs that was recorded during October of 2005. All other model parameters and forcing functions were retained at the same values as those set up for the model validation for the typical conditions. The same contour plots and time series graphs that were generated for the typical (October 2005) conditions were also created for the high flow conditions. 
Comparing the restoration response during typical flow conditions to high flow conditions allows for a better understanding of system behavior.

\subsection{Year-Long Simulation - High Flow Year 2003}

When considering restoration scenarios, it is important to look at the full range of seasons during the course of a year. This provides important insight into the response of the restoration area, such as how often will the site be inundated, how deep will the water be at sites of interest and for how long, what is the range of salinity expected, and what range of bed shear can be expected? The first step was to identify a year that experienced some weather extremes in order to capture the full range of possibilities. According to local stakeholders and examination of flow records showed that, Year 2003 experienced particularly high number of flood flow events and was the only time in recent memory when both the Skagit and Stillaguamish rivers flooded simultaneously.

Water-surface elevation has a default value for each station that corresponds to the elevation without any water, so inundation is considered any increase in water-surface elevation past the bed elevation point. Salinity results occasionally show the initial condition of $30 \mathrm{ppt}$ when an area is rarely inundated, because the model requires several inundation cycles to dilute the salinity from its initial specified values.

The model was driven using year-long historical water-surface elevations at the boundaries. Figure 3-5 shows tidal elevations obtained from the NOAA X-Tide stations at the Swinomish Channel and Tulalip Station boundaries from Year 2003. The maximum tides, also sometimes referred to as King Tides in Puget Sound, typically occur in the winter months of December and January. The highest tidal elevation of 3.21m occurred on December 25, 2003. River flows for the same Year 2003 duration were specified as daily average flows based on data from the USGS gauge at Mt. Vernon on the Skagit and Arlington Gauge on the North Fork of Stillaguamish. Data from South Fork of Stillaguamish were not available during 2003 and the total flow was estimated using a correlation between total flow and North Fork flow in Stillaguamish described previously in the Phase I report (Yang et al. 2008).

Figure 3-6 shows time histories of river flows from the Stillaguamish and Skagit River entering the model domain. Peak daily average flow of 57,883 cfs occurred on October 21 in the Stillaguamish River while the Skagit River flow peaked a day later on October 22. Model results showed that although the flows on these days were high, water-surface elevations were affected only a small extent $(<20 \mathrm{~cm})$ because the project areas near the river mouths are tidally dominated. At these high flows, the river bank dikes would have been overtopped and result in conditions similar to that simulated previously in the high bank-full flow conditions. The response of the system during the highest tidal variation on December 25 is of particular interest. Contour plots for depth, bottom velocity, and bed shear were therefore created for December 25, 2003 for all the restoration scenarios. The depth and salinity plots corresponded to high tide to show maximum inundation, while the bed shear and velocity plots corresponded to peak ebb because of the greater forces experienced.

Frequency of exceedance plots were generated for all variables using hourly results for the entire Year 2003 simulation. The same stations that were used for plotting time histories previously on Leque Island and zis a ba were used to analyze water-surface elevation, salinity, bottom velocity, and bed shear stress. Values were sorted by magnitude and plotted to show the cumulative frequency. These plots give statistical information for these variables in terms of annual occurrence. 


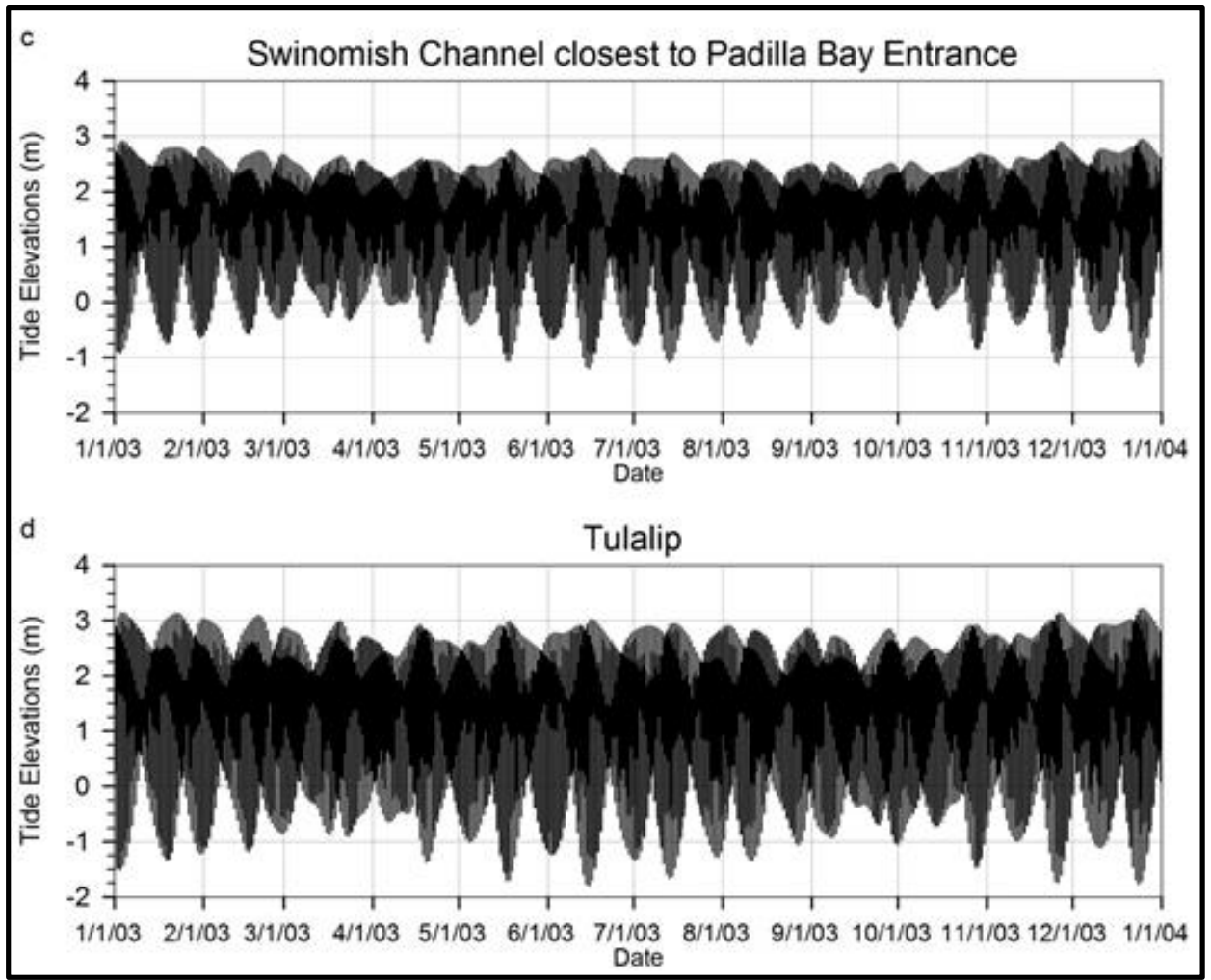

Figure 3-5: Tidal Elevations during 2003

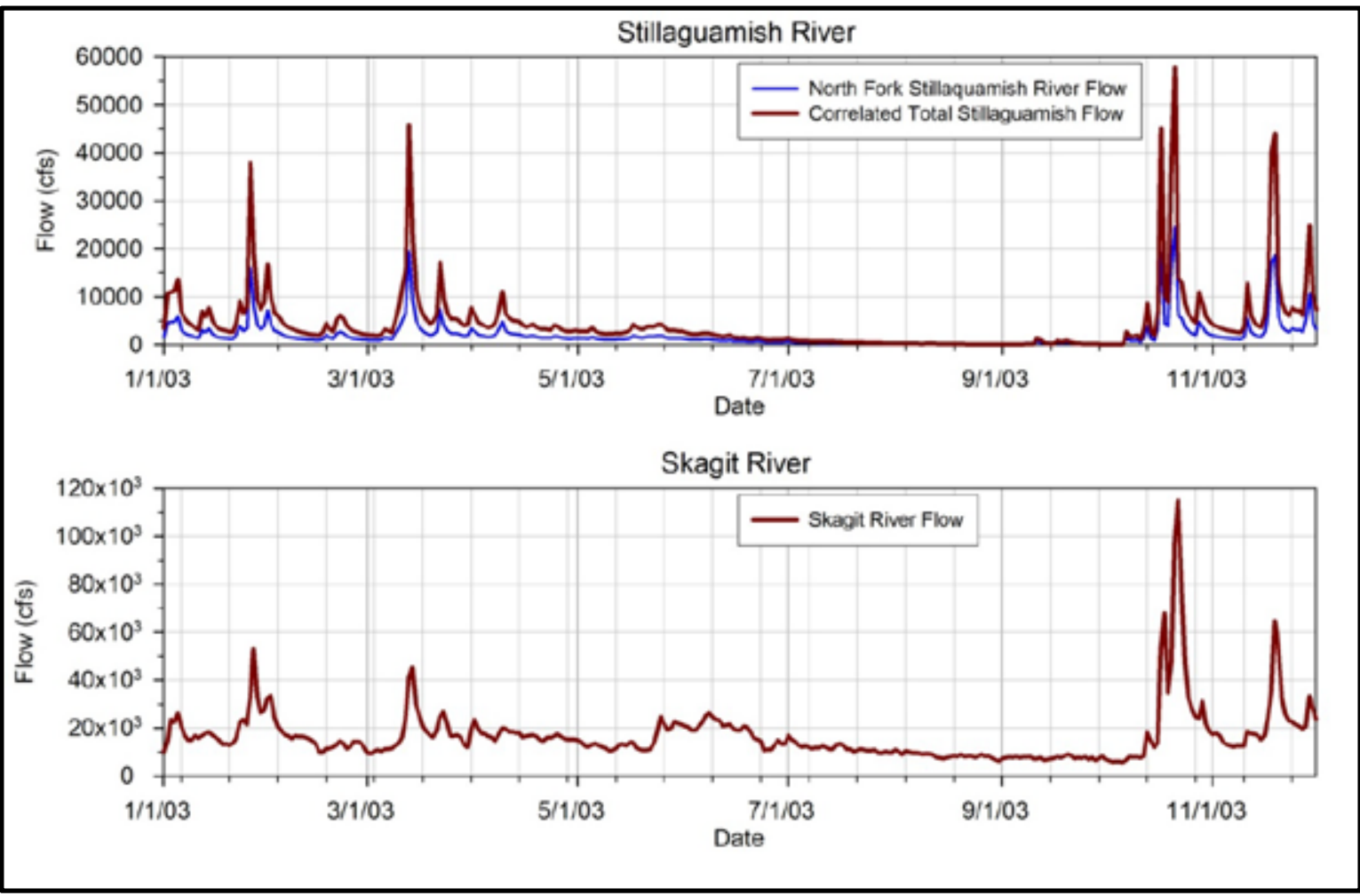

Figure 3-6: River flows during 2003 for the Stillaguamish and Skagit rivers 


\subsection{Results: Simulation of Restoration Scenarios}

This section summarizes the results of simulations conducted for assessing the feasibility of proposed restoration scenarios at Leque Island and zis a ba sites near the mouth of Stillaguamish River. These simulations include the baseline Scenario or existing conditions along with eight different restoration scenarios described in the introduction. The results examine predicted coastal estuarine response to the proposed restoration actions in terms oceanographic properties such as water-surface elevation, salinity, velocities, and bed shear stress over the study area. The performance and response for each scenario consisting of a combination of restoration alternative modifications and varying flow and tidal conditions is discussed. Comparisons are generally limited to the scenario and the baseline, unless relevant conclusions can be drawn from the inter-scenario comparison. The results are in the form of salinity, velocity vector, and bed shear contour plots. The results also include time series and frequency plots for the same variables of interest based on year-long simulations for each scenario. Selected plots and figures are presented in this section as part of the discussion.

A comprehensive compilation of all plots for all scenarios is included in the following Appendix sections.

- Appendix A: Time series - surface elevation, salinity, velocity, and bed shear (October 2005)

- Appendix B: Plan view contours - salinity, velocity, and inundation (October 2005)

- Appendix C: Time series - elevation, salinity, velocity, and bed shear (High flow)

- Appendix D: Plan view contours - salinity, velocity, and inundation. (High flow)

- Appendix E: Plan view contours - Bed shear stress (October 2005)

- Appendix F: Plan view contours - Bed shear stress (High flow)

- Appendix G: Cumulative frequency - surface elevation, salinity, velocity, bed shear (Y2003)

- Appendix H: Plan view contours - Depth (during highest tides of December 25, 2003).

\subsection{Baseline Scenario 0 - Existing Conditions}

Scenario 0 represents the baseline condition of the system as it exists today subject to tidal and stream flow forcing. Figure 4-1 shows the model grid for Scenario 0 covering Leque Island region surrounded by the perimeter dike. This alternative assumes that the existing dike will remain intact and would require permanent repairs on the temporary patches that were installed following recent failures in 2010. The perimeter dike completely isolates the inner Leque region and is not influenced by river flow or the tides. The baseline grid adopted from Phase I effort included Leque Island region. The zis a ba site, also behind the perimeter dike in existing conditions, was not part of the baseline Scenario 9 and was added in subsequent scenarios. 


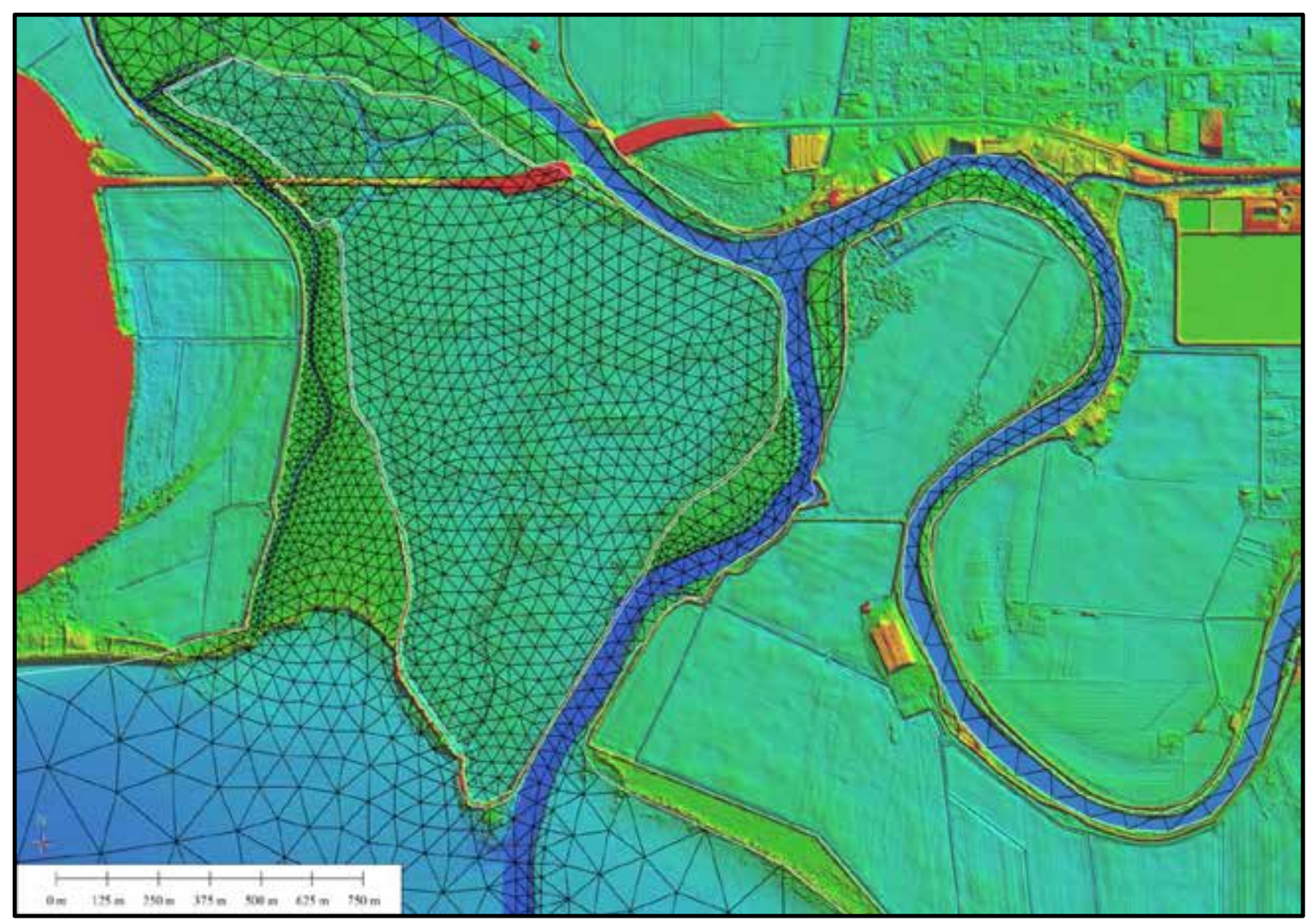

Figure 4-1: (Scenario 0 - Baseline) Model grid overlaying the lidar elevation map

\subsubsection{October 2005 Conditions}

The existing conditions in Port Susan Bay near the Leque Island project area are tidally influenced with tides moving the water upstream into the Stillaguamish River Channel during incoming flood tide. Tidal exchange also occurs between Skagit Bay and Port Susan Bay through West Pass along the northeastern boundary of Leque Island. The inundation and salinity contours plots at high and low tide are shown in Figure 4-2. During high tide the intertidal flats in Port Susan Bay and Skagit Bay are fully inundated, nearly reaching the toes of the perimeter dikes. Water also enters Davis Slough from the Skagit Bay side. However the bed elevations at the southern end of Davis Slough are high and are not overtopped during typical tides to complete the connection to Port Susan Bay. Intertidal flats are exposed during the ebb tide. The figure also shows the presence of small polygons beyond the water's edge that seem to indicate ponding, but these are only byproducts of the contouring method limitations in a relatively flat area. In reality, this sandy area is known to drain well. Leque Island and zis a ba sites are completely shielded from tidal influence by the perimeter dikes. 
Salinity variation in the channels around the Leque Island and zis a ba restoration sites is from 0-25 ppt depending on the location. Most of the Old Stillaguamish River Channel fresh water appears to exit along the eastern shore of Leque Island into Port Susan Bay through South Pass. Hatt Slough delivers fresh water to the southern parts of Port Susan Bay away from the Leque and zis a ba sites.

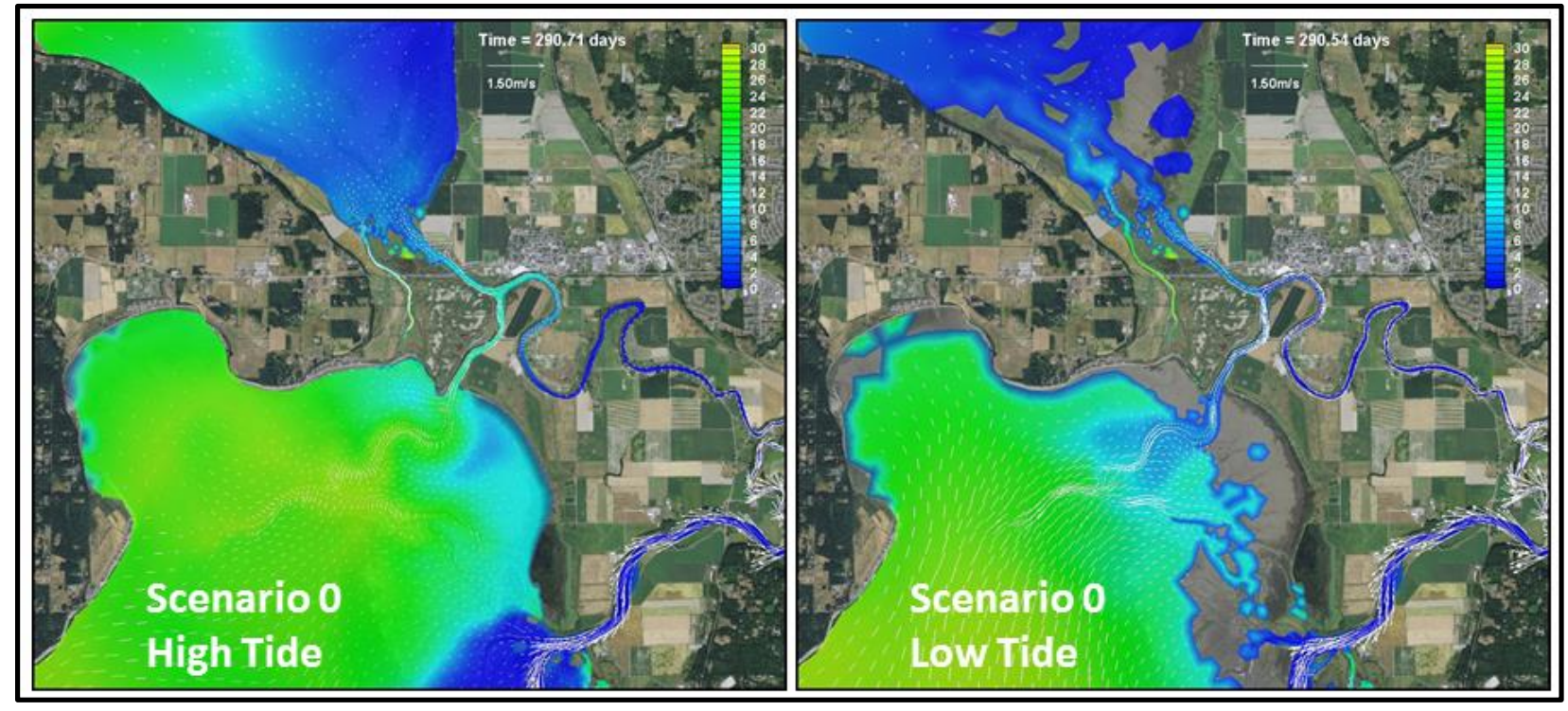

Figure 4-2: Salinity contours at high and low tide on October 17, 2005

\subsubsection{High Flow Conditions}

High-flow (bank full) conditions were simulated primarily to help examine and identify regions of high bed shear stress with potential for erosion. South Pass experiences very high stresses as it carries the bulk of the river and tidal exchange flow associated with the Old Stillaguamish River Channel.

Overtopping during high flows resulted in dike failure to the southwest of zis a ba that was repaired with a new dike seen in Figure 4-3. From an overhead view, the new dike appears as a small notch right where the bed shear stresses are the highest as South Pass bends to the west. 


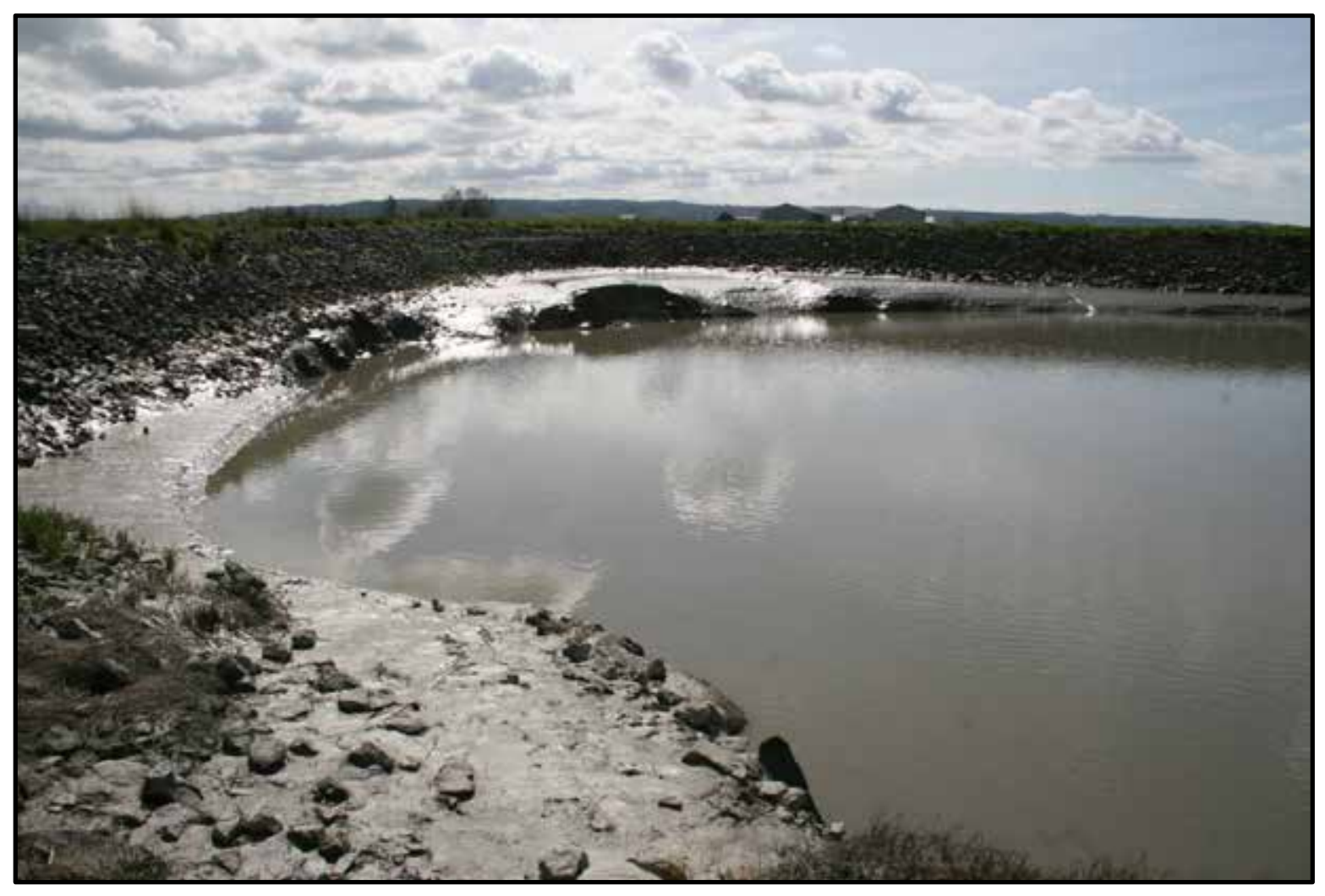

Figure 4-3: A location on the southwest corner of zis a ba where the dike failed and was then repaired with a new dike

Peak currents and resulting bed shear stresses are of interest for identifying regions with highest erosion potential. Figure 4-4 shows contour plots of bed shear stress during peak ebb and peak flood current conditions for typical river flows of October 2005 as well as at the high river flow of 26,506 cfs. It is apparent that the peak ebb experiences greater bed shear stress than the peak flood. This is expected as during ebb, tidal flow adds to the river flow. The highest bed shear stress is seen on the outside inflection of river bends.

Effects of high flow conditions on hydrodynamics are seen in the simulation results. Higher watersurface elevations, stronger currents, and reduced salinity levels are predicted over the entire project area relative to October 2005 conditions. Maximum water-surface levels or river stage increases as a function of distance from the river mouth as shown in Figure 3-4. Near the project site however, the water-surface levels at the high flow of 26,506 cfs are higher by only $20 \mathrm{~cm}$ near Leque Island relative to October 2005 river flow of 2,459 cfs.

During high flow simulation, the striking feature noted in the results was that the salinity was significantly lower in the river system and the surrounding Port Susan and Skagit Bays because of a massive amount of fresh river water pouring into the system over a period of two weeks simulated at constant high river flow. From habitat restoration perspective this result is of less significance as in reality, flood flow hydrographs last typically less than 48 hours. The salinity contour patterns were similar to those observed during October of 2005 but lower in values. 
Because the system is constrained by dikes, the effect of 26,504 cfs channeled through the river system resulted in increased bed shear stress. Comparison of bed shears between the October 17, 2005 condition and the high flow condition is shown in Figure 4-4. Shear stresses decrease significantly in South Pass during peak flood under high flow conditions because the pressure gradient from incoming tide matches the outflow forcing the water back to flow out through West Pass into Skagit. Consequently, this results in higher shear stresses in West Pass.

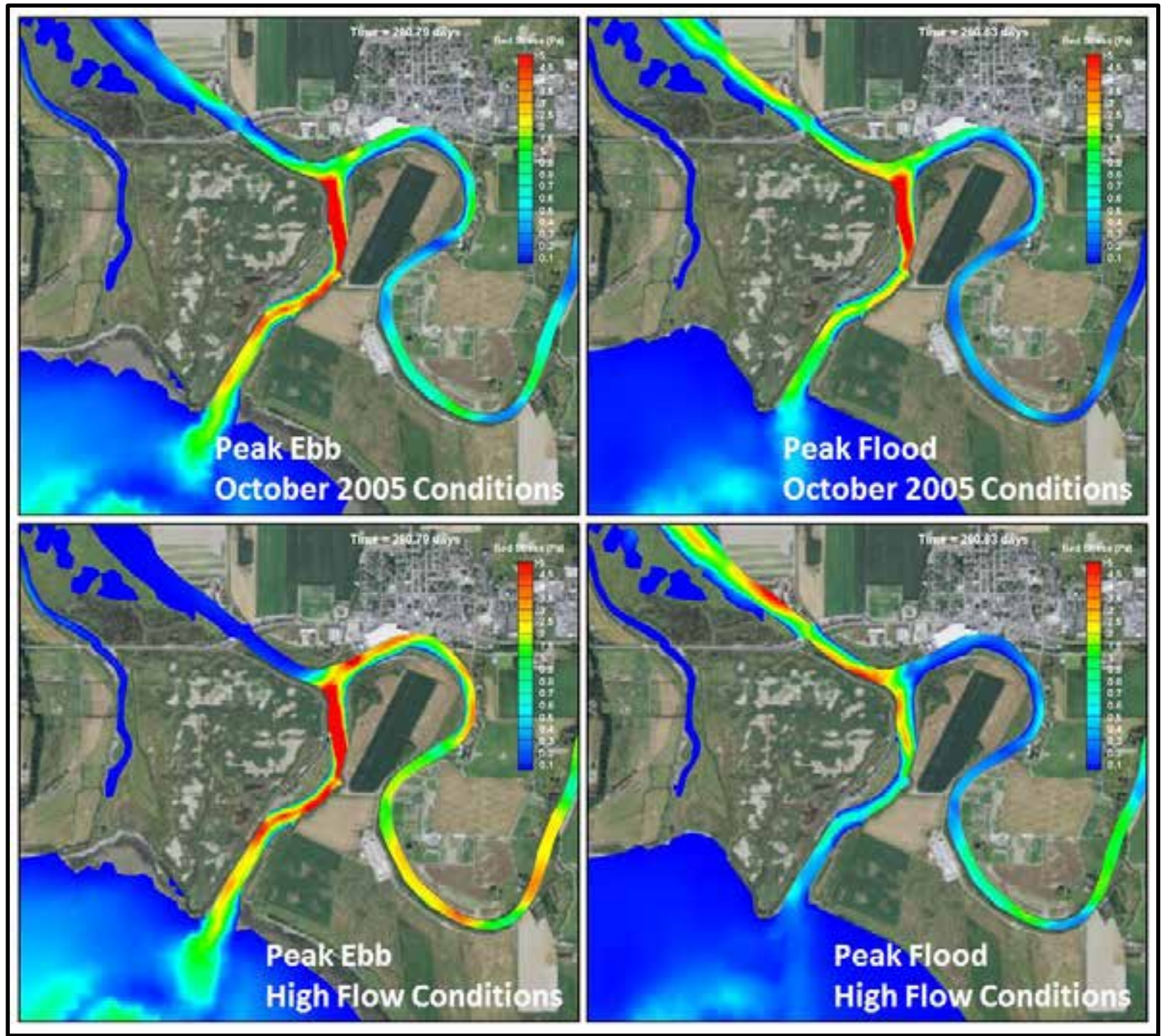

Figure 4-4: Comparison of bed shear stress at peak ebb and peak flood during typical and high flow conditions on October 17, 2005

\subsubsection{Year-Long Simulation}

Year-long simulations were completed for the baseline scenario (existing condition). The results were used in two ways (a) Mapping of maximum inundation to assess the potential for flooding nearby properties, and (b) Frequency analysis at selected sites to evaluate persistent and dominant oceanographic characteristics at the selected sites within the restoration project areas. Examination of simulated data showed that maximum water-surface levels were predicted to occur on December 25, 2003. Inundation, salinity, and bed shear contour maps for the December 25, 2003 are presented in Appendix H. 
Frequency analyses at the selected six stations L1, L2, L3 on Leque and Z1, Z2, and Z3 on zis a ba (see Figure 3-1 for station locations) were not conducted for this baseline Scenario 0 as the sites were not inundated due to the presence of the perimeter dikes.

\subsection{Restoration Scenario 1 - Partial Restoration at Leque Island}

The first scenario (Figure 4-5) involves removal of the southern portion of the dike on Leque Island and the construction of a new setback dike to retain the interior region as fresh-water wetland isolated from the marine water influence. The model grid was revised to reflect the removal of southern portion of the dike and the construction of the interior setback dike. In addition the model grid was refined and deepened along the historical drainage channel on the south end of the island. The channel has been filled over the years likely because of the combined effects of land use, sediment deposition, and subsidence but is expected to reform and deepen once tidal action is restored. Because all the dike failures on Leque Island have occurred on the southern portion, this restoration action would alleviate the need for dike maintenance and repair activities for the sections that are experiencing the most stress. Material from the removed dikes may be used to construct the new setback dike that will experience less stress as the restored southern portion of the island would dissipate energy. The expected result would be restoration of tidal marshland on the southern portion of Leque Island while maintaining and fresh-water wetlands on the northern region.

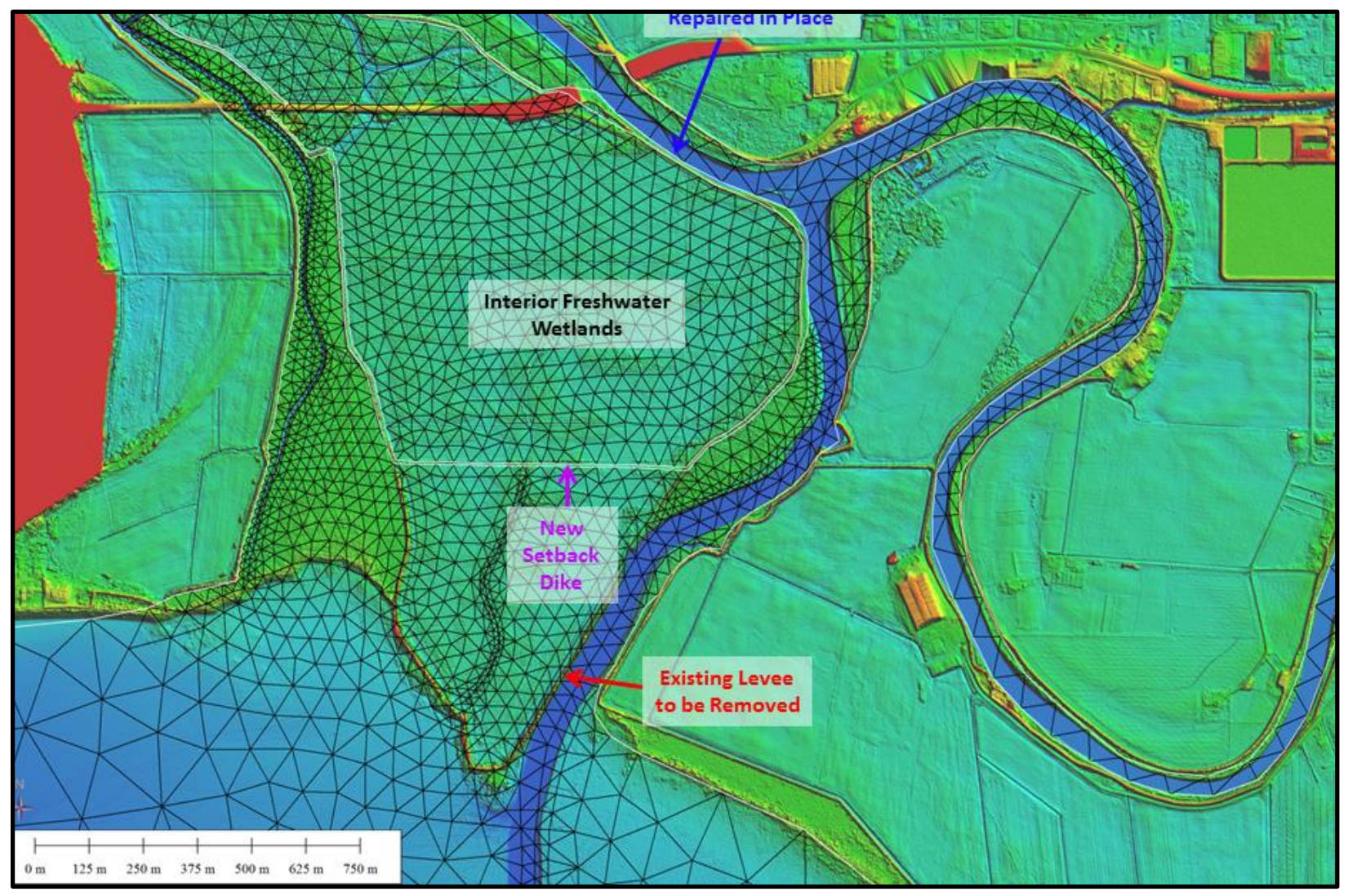

Figure 4-5: (Scenario 1 - Partial Restoration Leque) Model grid overlaying the lidar elevation map 


\subsubsection{October 2005 Conditions}

In Scenario 1, the dike removal action results in immediate restoration of tidal action over the southern portion of Leque Island. As seen in Figure 4-6, during high tide, the southern portion of Leque Island is fully inundated. The restored region previously behind the dike is relatively flat and drains out easily through the historic channel and by way of overland runoff. North of Leque Island on the West Pass and Skagit Bay side are relatively unaffected.

Salinity experiences only minor changes when compared to Scenario 0 . The predicted salinity over the restored area fluctuates between 9.2-16.1 ppt. During flood tidal movement, the estuarine brackish water consisting of the mixture of fresh river water and incoming marine tidal waters occupies the restoration area. Skagit Bay and Port Susan Bay experience small increases in salinity, which are likely caused by an increased tidal prism following restoration. While it may appear that the restoration area does not drain fully during low tide, those small wet polygons are a byproduct of the model resolution, contouring software, and the relatively flat intertidal zone with water depth less than $20 \mathrm{~cm}$. The region is relatively flat and expected to drain, with the help of drainage channels if needed.

\subsubsection{High Flow Conditions}

Focus of high flow simulation was to evaluate the impact of proposed action on bed shear stress during conditions critical for erosion. Very little change is predicted in the bed shear stress in upstream channels. As shown in Figure 4-7, relative to existing conditions (Scenario 0) a decrease in shear stress is predicted at locations along South Pass where the dike was removed along the eastern shore of the island, and shifted towards the eastern bank of South Pass. Other than this change, there is very little change in the bed shear stresses when comparing Scenario 1 to Scenario 0 . Some bed shear stress is predicted in the historic drainage channel that plays an important role in facilitating the drainage of the system and will likely deepen over time to a natural equilibrium depth with time as initially surmised.

During high flows the water-surface level response in Scenario 1 is similar the baseline Scenario 0, approximately $20 \mathrm{~cm}$ higher than the October 2005 conditions. In other words, there is no increase in the water-surface elevation in response to Scenario 1 when compared to existing conditions. Salinity also appears to follow trends similar to those obtained for the typical October 2005 conditions. The difference is that all the salinity values are significantly lower during high flow because of the high volumes of riverine freshwater discharged to the system. During high flows salinity in the restored region is between $0-5$ ppt for $78 \%$ of the time, reaching a maximum of 14.5 ppt. It is interesting to note that the salinity in Scenario 1 is a little lower in Port Susan Bay but noticeably higher at the Skagit Bay entrance to West Pass relative to baseline conditions. We believe this may be due to the effect of high volume of fresh water flowing out through South Pass drawing Skagit Bay water eastward through West Pass. During high flow runs Skagit River flow was left at the October 2005 levels and only Stillaguamish River flow increased to 26, 506 cfs. (See Appendix D for salinity response to high flow conditions). 


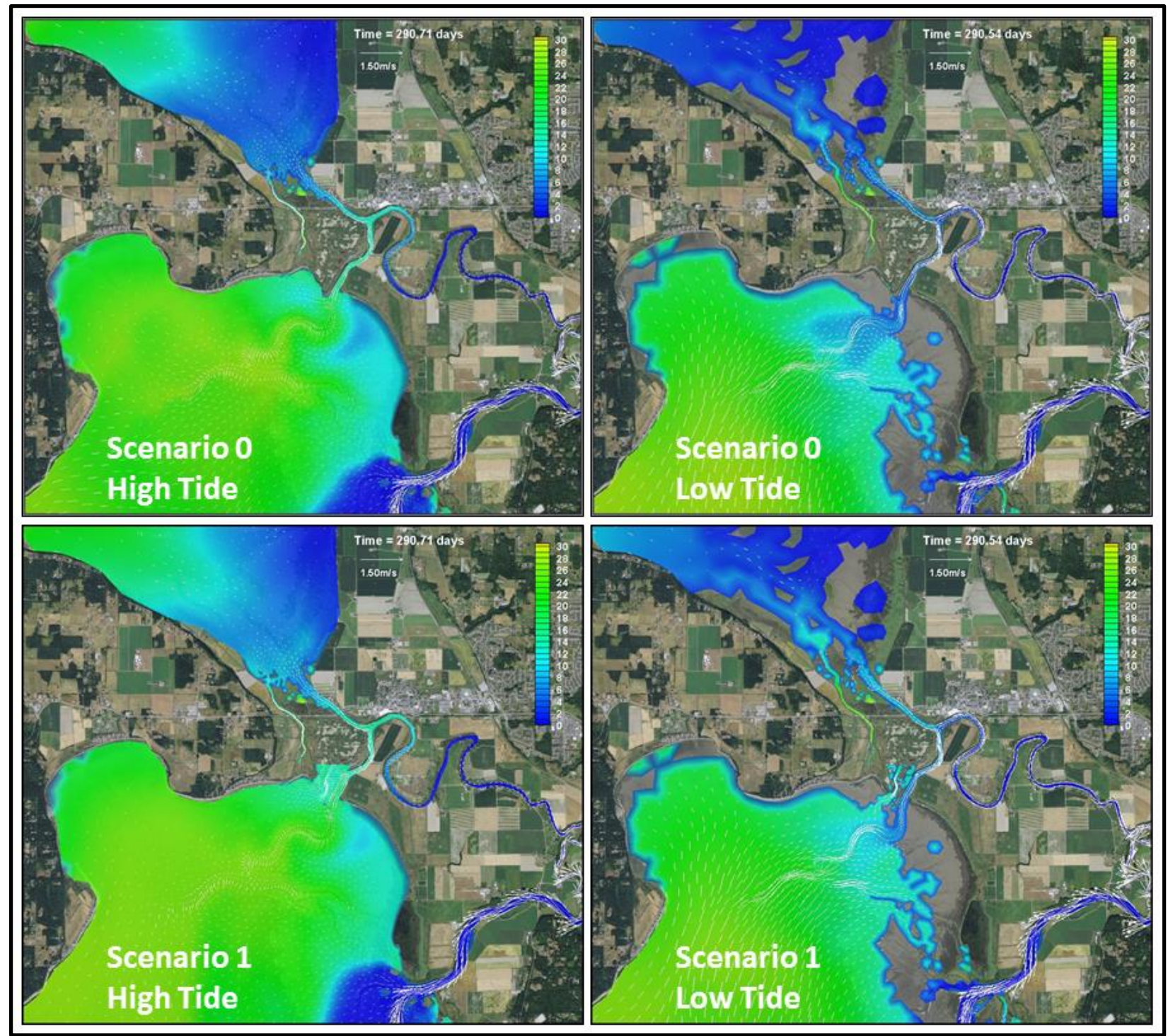

Figure 4-6: Comparison of salinity at high tide and low tide during Scenario 0 and Scenario 1 on October 17, 2005. 


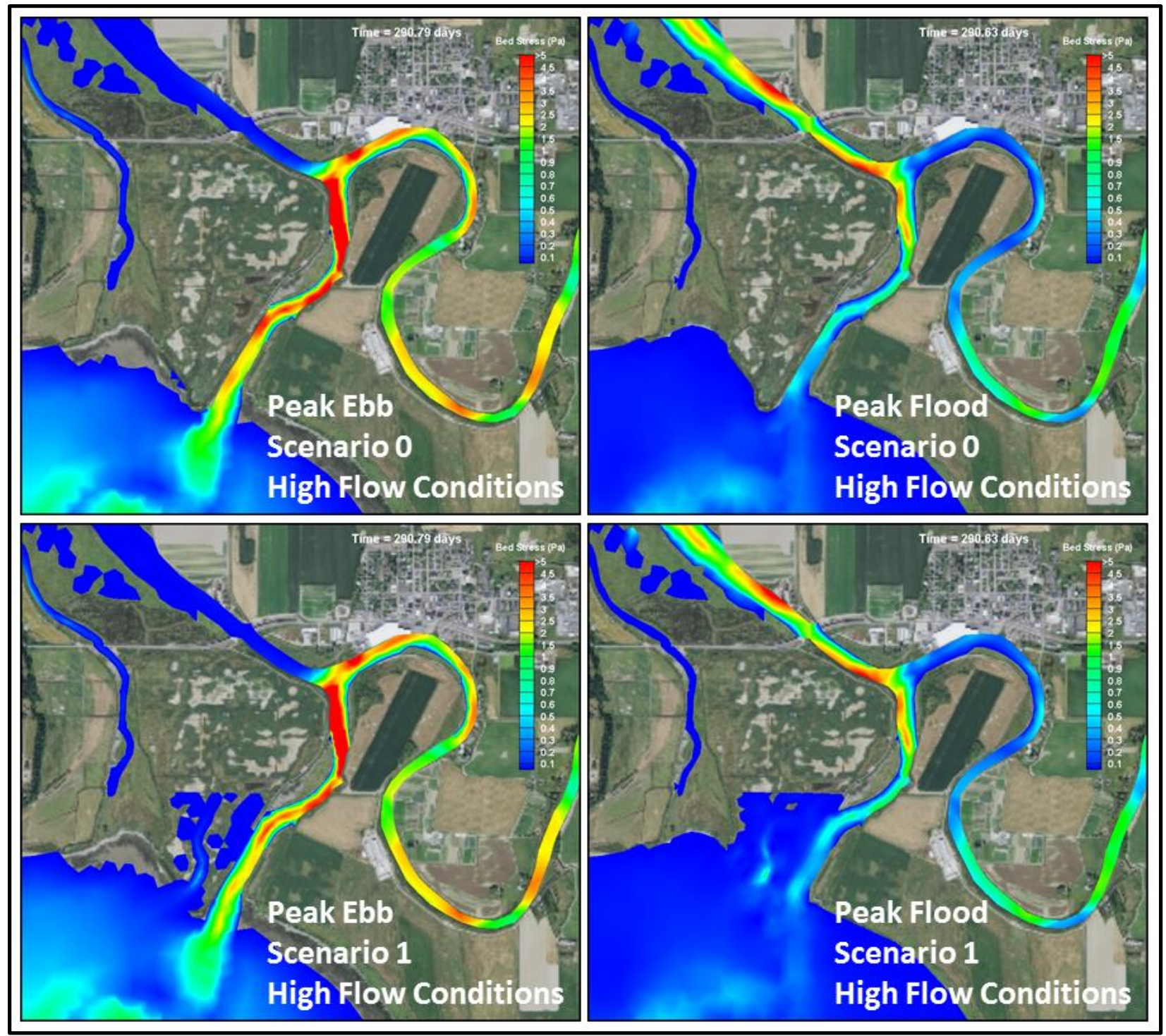

Figure 4-7: Comparison of bed shear stress at peak ebb and peak flood during Scenario 0 and Scenario 1 at high flow conditions

\subsubsection{Year-Long Simulation}

Results from Year 2003 simulation of Scenario 1 were processed and frequency analysis conducted at the selected six stations L1, L2, L3 and Z1, Z2, and Z3 on zis a ba on Leque (see Figure 3-1for station locations). This scenario does not include zis a ba site. Figure 4-8 shows frequency plots at a representative Leque Island station L2. Station L2 is located within the drainage channel. The results show that the Leque restoration area near L2 will be fully inundated $66.6 \%$ of the time, reaching a maximum water depth of $2.63 \mathrm{~m}$. Here the salinity is predicted to vary between $5-15$ ppt for $91.1 \%$ of the time, which is the desired salinity suitable for fish habitat. L1 is not inundated and Station L3 (near Davis Slough) is only inundated $1.2 \%$ of the time, reaching a maximum depth of $0.44 \mathrm{~m}$. 
Bed shear stress will be greater than $0.11 \mathrm{~Pa}$ (sand erosion) only for $23.2 \%$ of the time, during which period sand particles may experience re-suspension and erosion. Values greater than $1.26 \mathrm{~Pa}$, at which very small gravel may be eroded will occur for 3.3\% of the time. This indicates there are sufficient tidal currents at the L2 site within the channel to slowly deepen until equilibrium is reached. L1 is not inundated and Station L3 (near Davis Slough) is inundated only 1.3\% of the time, and will experience little bed shear stress. (See Appendix G for cumulative frequency graphs for water-surface elevation, salinity, bottom velocity, and bed shear at all stations).

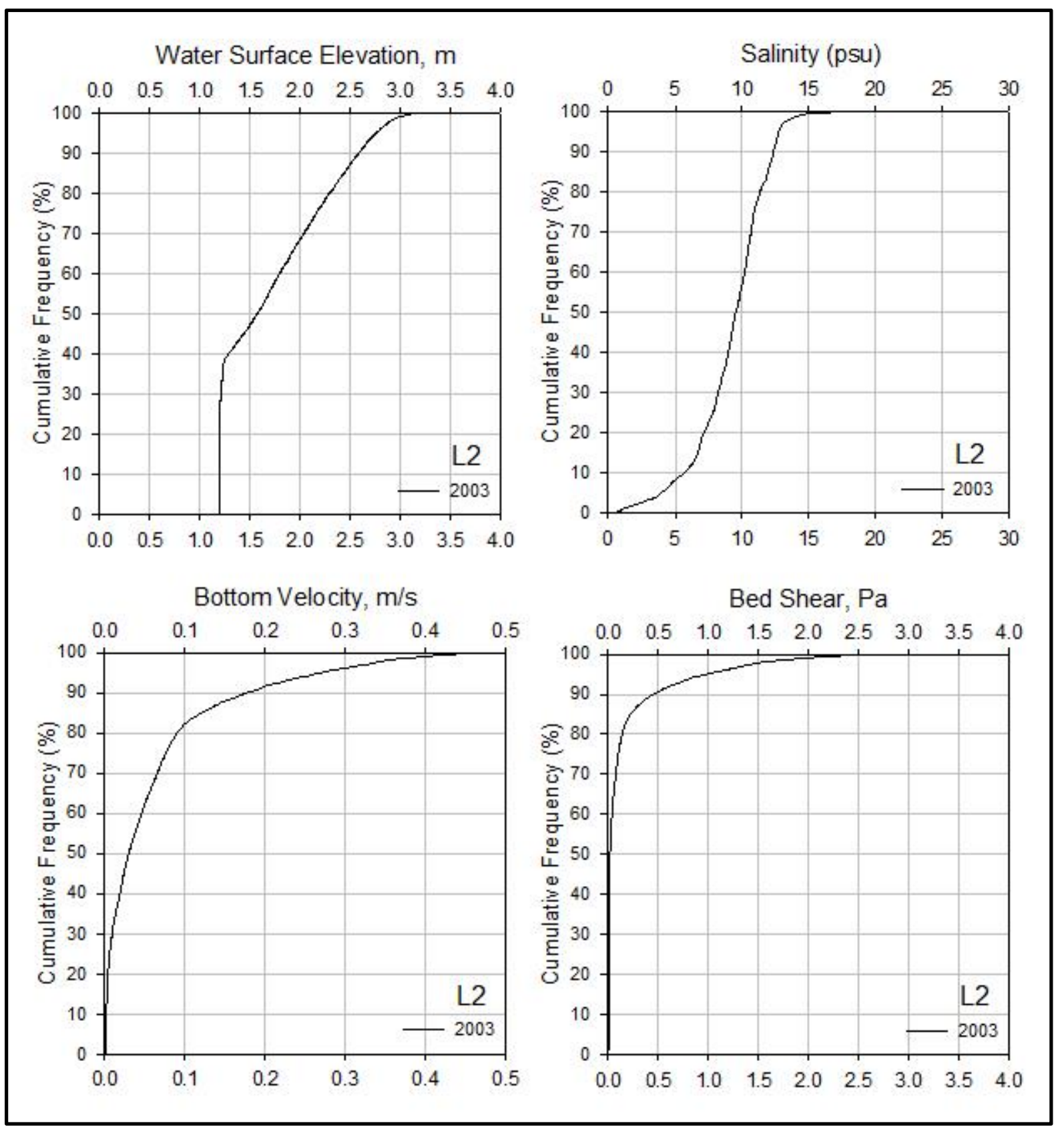

Figure 4-8: Cumulative frequency plots for Scenario 1 - Water-Surface Elevation, Salinity, Bottom Velocity, and Bed Shear at Station L2 on Leque Island 


\subsection{Restoration Scenario 2 - Four Levee Breaches at Leque Island}

The second scenario (Figure 4-9) considers the removal of three damaged and temporarily repaired dike segments along with an additional breach at the location of the same historic drainage channel discussed previously. The channel runs in a southerly direction from the center of Leque Island to the southern portion of the Leque perimeter dike. The northern breach on the east side is $145 \mathrm{~m}$ wide, the southern breach on the east side is $50 \mathrm{~m}$ wide, the northern breach on the west side is $30 \mathrm{~m}$ wide, and the new breach at the location of the historic drainage channel is $90 \mathrm{~m}$ wide. This alternative presents an economically attractive option of removing sections of the dike that have naturally failed so that they can reach equilibrium naturally.

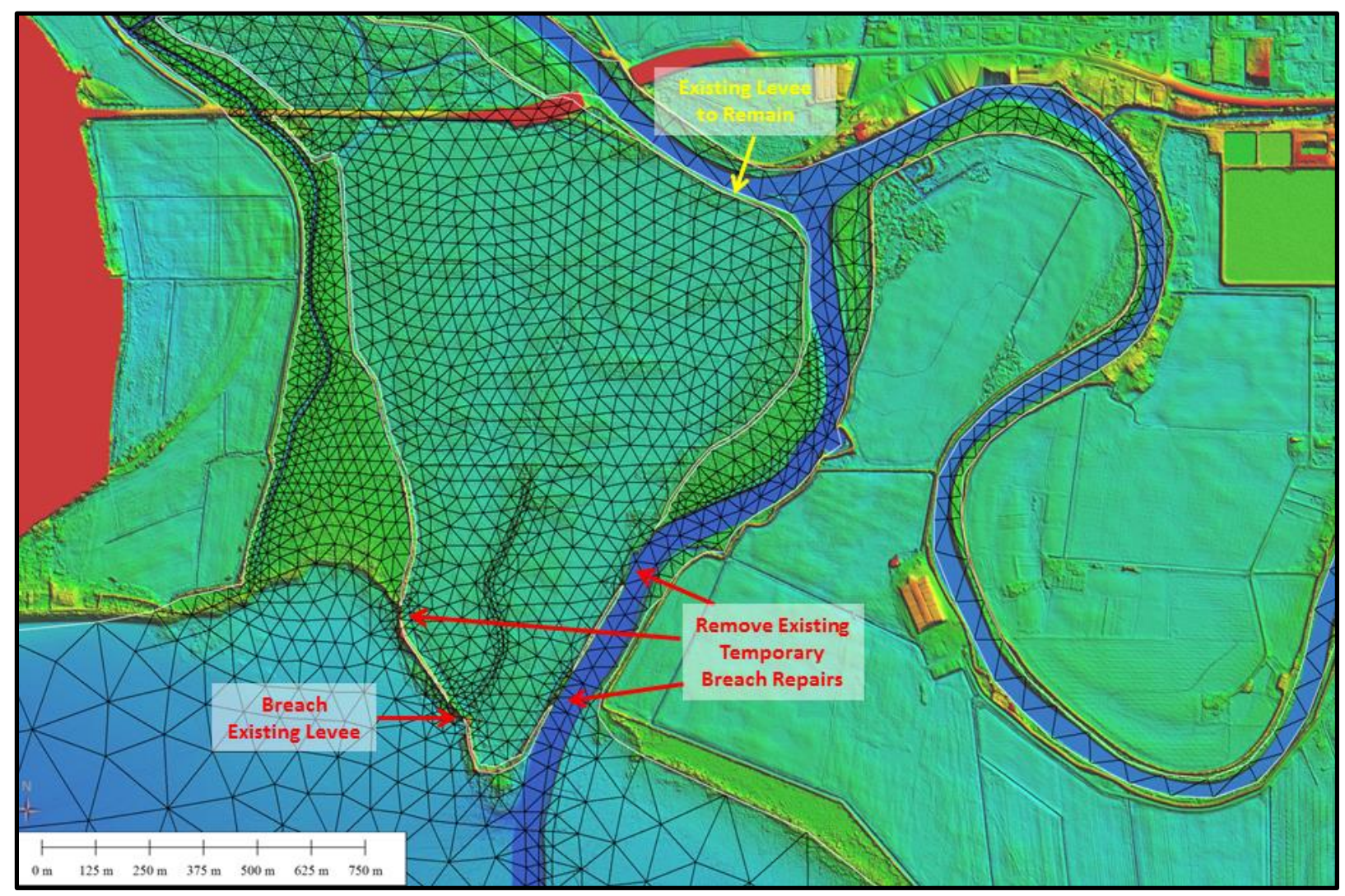

Figure 4-9: (Scenario 2 - Four Breaches) Model grid overlaying the lidar elevation map

\subsubsection{October 2005 Conditions}

Inundation response of Scenario 2 was of particular interest as it was not intuitively clear at the outset whether the selected design involving four breaches of varying lengths would be sufficient to provide free flowing tidal exchange or if a muted tidal condition would arise. Results shown in Figure 4-10 show that Leque Island is completely inundated during the flood and drained during the ebb. The drainage channel retains some water as the existing bathymetry near and seaward of the breach opening (without any additional dredging) is higher than the drainage channel. 
Salinity throughout the system outside of the restoration region in Scenario 2 shows minor variations relative to baseline Scenario 0 . The gradients in salinity are comparable to those in baseline conditions. Salinity within the restoration area while inundated remains fairly high, in the range of 14.1-21.7 ppt in the northern end of the island and 10.4-17.2 ppt near the breaches. This result indicates that the innermost reaches of restored area will experience delayed or weak flushing. The high salinity is the result of model startup which was setup with initial values of 30 ppt. After 32 days of model application, the initial values have not yet reached typical equilibrium levels varying from 5 to 15 ppt in South Pass. It is noted again that contour plots during the ebb tide show the presence of small wet polygons that are a byproduct of the model resolution, contouring software, and the relatively flat intertidal zone with water depth less than $20 \mathrm{~cm}$.
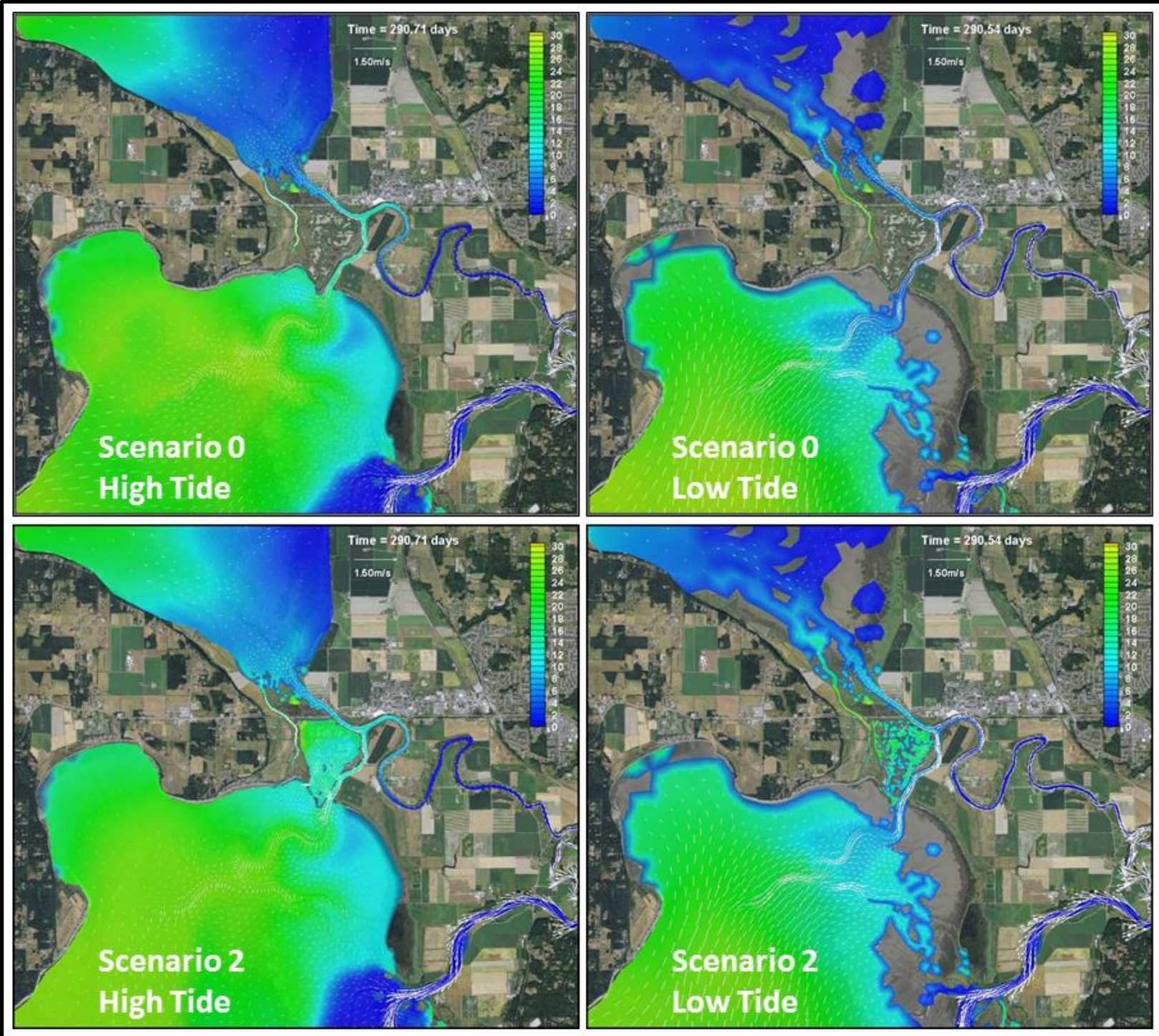

Figure 4-10: Comparison of salinity at high tide and low tide during Scenario 0 and Scenario 2 on October 17, 2005. 


\subsubsection{High Flow Conditions}

Focus of high flow simulation was to evaluate the impact of proposed action on bed shear stress during conditions critical for erosion. Very little change is predicted in the bed shear stress in upstream channels The results of simulation for Scenario 2 show that at the $145 \mathrm{~m}$ breach on the east side and the $90 \mathrm{~m}$ breach at the mouth of the historic channel locations bed shear stresses higher than $0.3 \mathrm{~Pa}$ are noted. These higher stresses are expected for the two primary drainage channels, which will likely deepen until equilibrium is reached. There are some concerns that drainage from the eastern exit enters perpendicular to South Pass and could exert additional bed shear stress on the dike opposite the exit. It is recommended that model results be extracted and examined further relative to baseline at the specific sensitive locations of interest. The velocities and shear stress distributions in the surrounding channels during high flow are a higher relative to October 2005 but exhibit similar features. Relative to existing conditions in Scenario 0 , the effect of the dike breaches is that tidal prism is increased resulting in higher bed shear stress noticeable in the South Pass channel below the drainage channels from the restoration area as shown in Figure 4-11.

Similar to the baseline Scenario 0, during high flows approximately $20 \mathrm{~cm}$ higher water-surface elevations are predicted in the West Pass and South Pass regions near Leque Island and zis a ba project sites for Scenario 2 . The salinity levels on the restoration site are significantly lower varying between 0 3.4 ppt.

\subsubsection{Year-Long Simulation}

Results from Year 2003 simulation of Scenario 2 were processed and frequency analysis conducted at the selected six stations L1, L2, L3 and Z1, Z2, and Z3 on zis a ba on Leque (see Figure 3-1 for station locations). This scenario does not include zis a ba site. Figure 4-12 shows frequency plots at a representative Leque Island station L2. Station L2 is located within the drainage channel. These results show that the restoration area near Station L2 will be fully inundated $53.0 \%$ of the time, reaching a maximum water depth of $2.63 \mathrm{~m}$. Unlike Scenario 1, the drainage channel retains water at $1.58 \mathrm{~m}$ elevation controlled by higher sill like average bed elevation of the simulated $50 \mathrm{~m}$ dike breach opening surrounded by the dikes. This ponding effect is restricted to the drainage channel in Scenario 2 only and may be easily eliminated by lowering the average bed elevation at the channel opening. The salinity is predicted to vary between 5-15 ppt for $94.4 \%$ of the time, which is the desired salinity suitable for fish habitat and is similar to the variation seen in Scenario 1. Station L1 (upper Leque) is on the northern side of the island and shows inundation $28.4 \%$ of the time, reaching a maximum water depth of $1.08 \mathrm{~m}$. Here, the salinity is predicted to vary between $5-15$ ppt for $98.0 \%$ of the time. Station L3 (near Davis Slough) is only inundated $1.2 \%$ of the time, reaching a maximum depth of $0.49 \mathrm{~m}$. These results indicate that the four breaches provide sufficient estuarine exchange to occur over a year and that impact on salinity response is not significant relative to dike removal.

Bed shear stress at Station L2 is significantly lower because of the smaller velocities and higher water depth in the channel. Bed shear will be greater than $0.11 \mathrm{~Pa}$ (sand erosion) for only $4.5 \%$ of the time, during which period sand particles may experience re-suspension and erosion. Values greater than 1.26 $\mathrm{Pa}$, at which very small gravel may be eroded are not likely in Scenario 2. Station L1 (upper Leque) only surpasses $0.11 \mathrm{~Pa}$ (sand erosion) for $0.4 \%$ of the time. Station L3 (near Davis Slough) is inundated only 
1.2\% of the time, and will experience little bed shear stress. (See Appendix G for cumulative frequency graphs for water-surface elevation, salinity, bottom velocity, and bed shear at all stations).

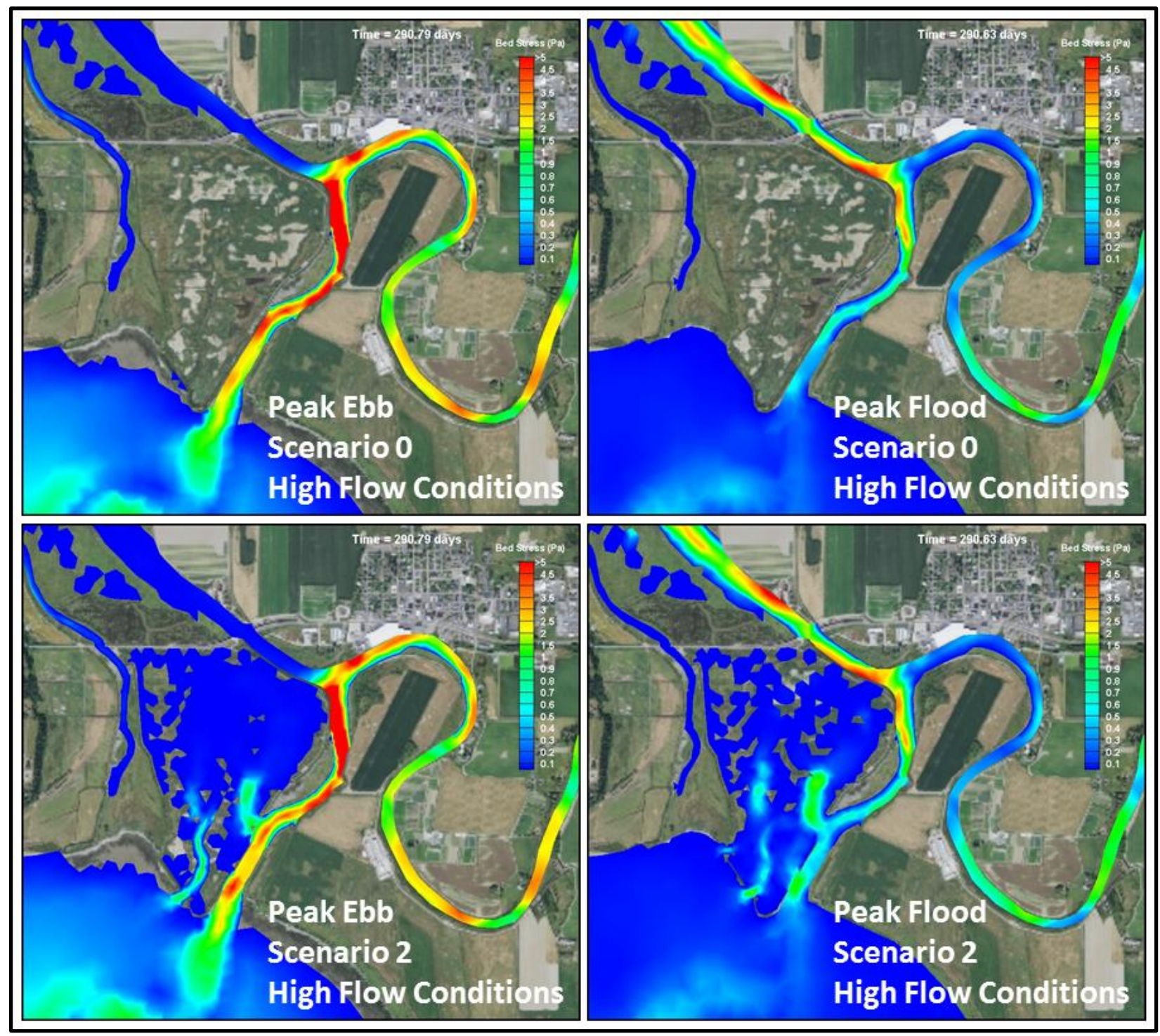

Figure 4-11: Comparison of bed shear stress at peak ebb and peak flood during Scenario 0 and Scenario 2 at high flow conditions 

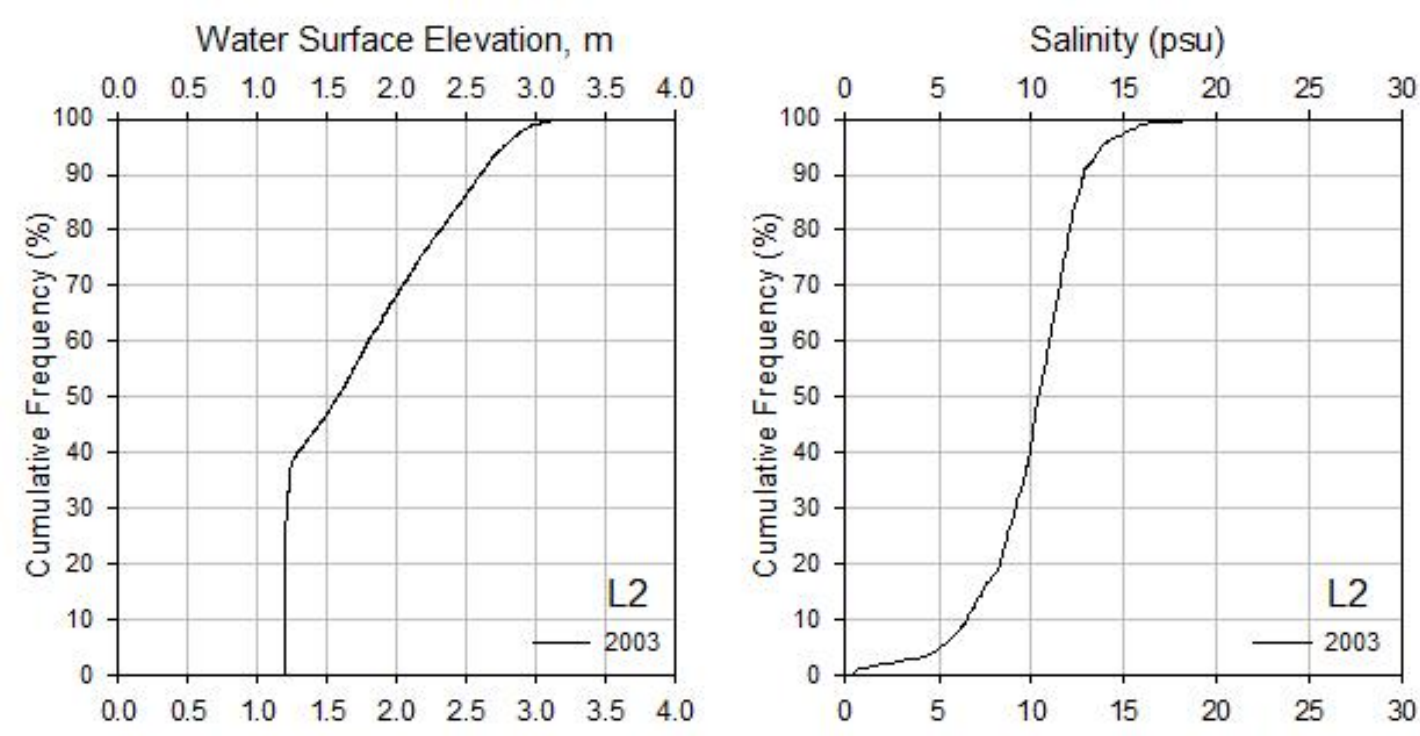

Bottom Velocity, $\mathrm{m} / \mathrm{s}$
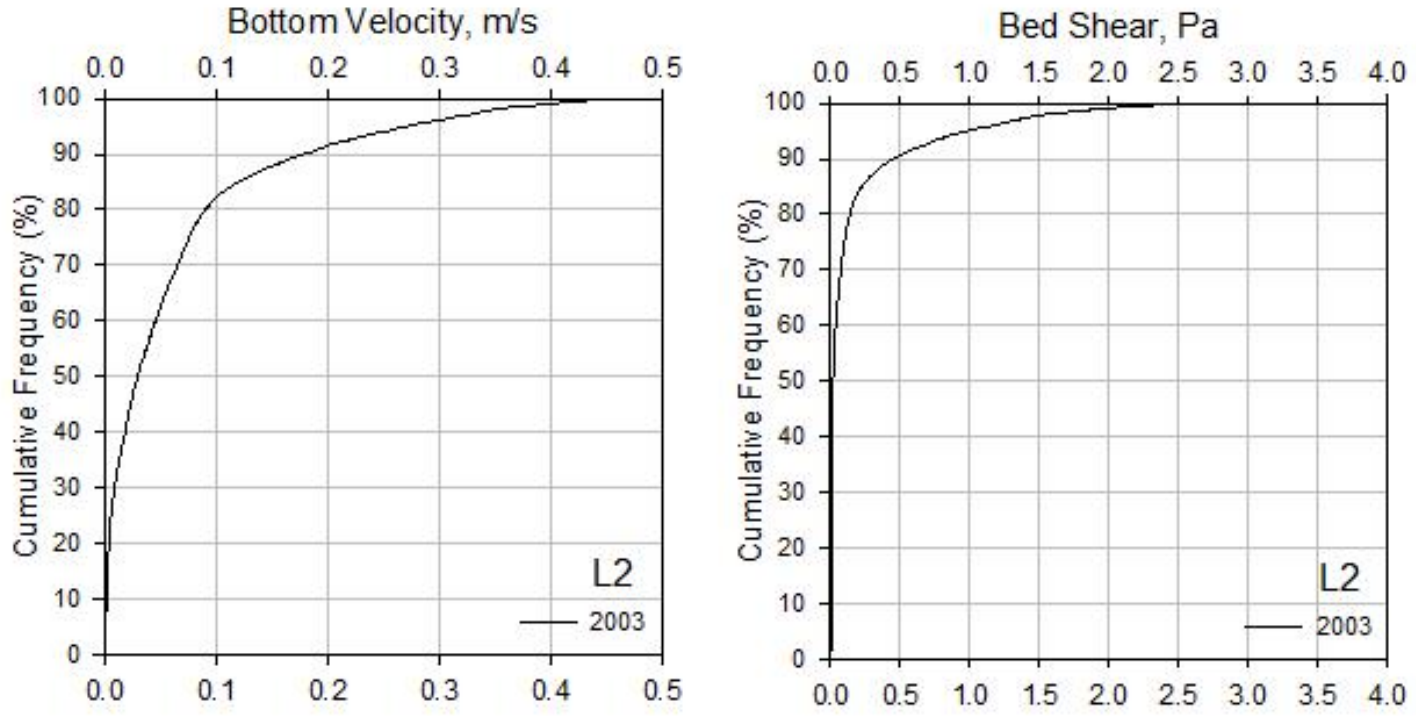

Figure 4-12: Cumulative frequency plots for Scenario 2 - Water-Surface Elevation, Salinity, Bottom Velocity, and Bed Shear at Station L2 on Leque Island

\subsection{Restoration Scenario 3 - Full Removal of Dike at Leque Island (Alternative 1)}

The third scenario (Figure 4-13) involves the complete removal of the Leque Island perimeter dike south of Highway 532, and includes the same historic drainage channel discussed previously. This option provides opportunity for water during ebb to enter Leque Island from the north carrying lower salinity Stillaguamish water as well as from Port Susan Bay and South Pass during flood. Although requiring higher level of construction and excavation effort, it will provide a much higher level of connectivity between the waterbodies and result in a fully restored tidal marshland. The daily tidal inundation in the full restoration alternative is expected to reach the toe of Highway 532 dike. 


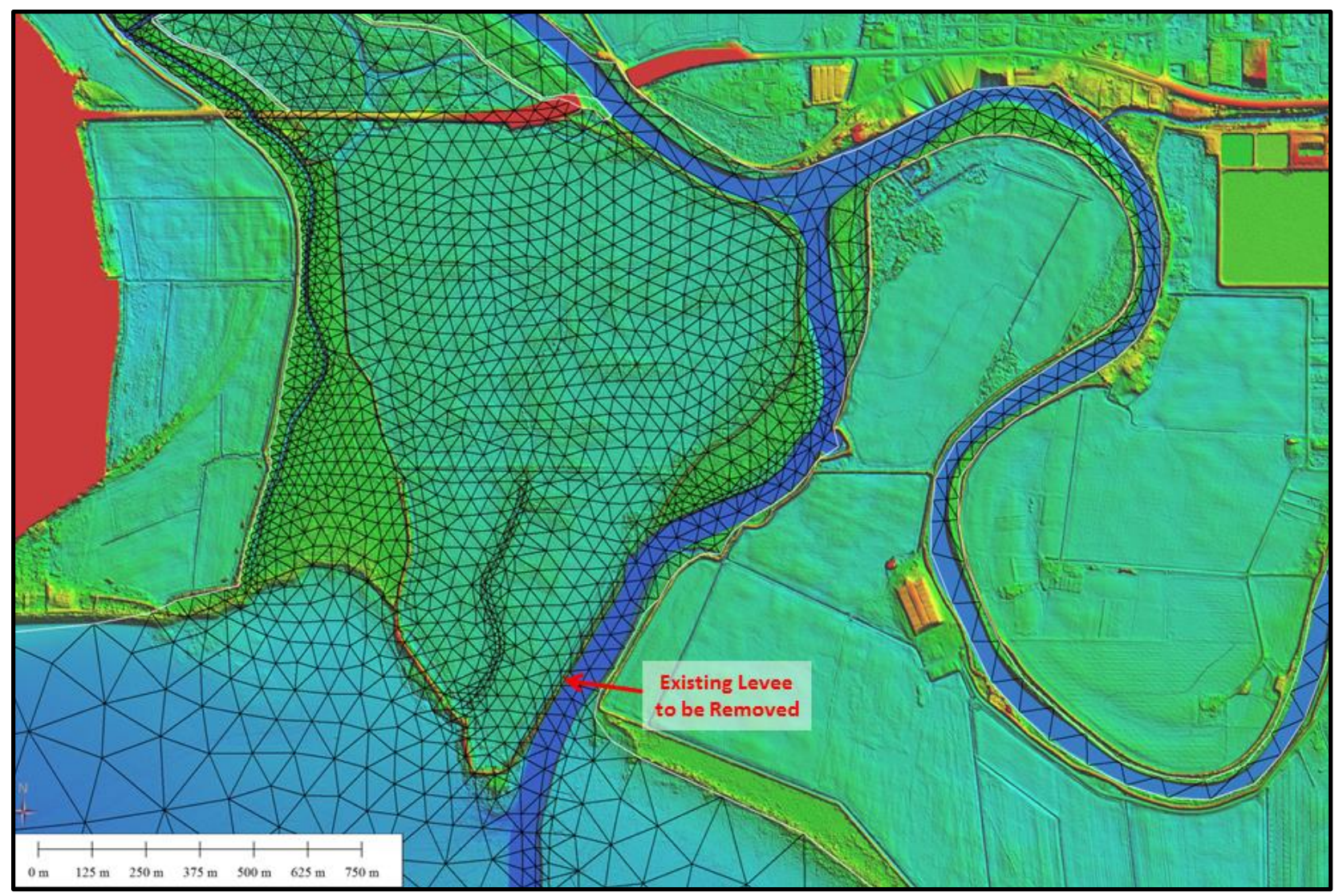

Figure 4-13: (Scenario 3 - Full Restoration Leque, Alternative 1) Model grid overlaying the lidar elevation map

\subsubsection{October 2005 Conditions}

In Scenario 3, the dike removal action results in immediate restoration of tidal action over the entire Leque Island south of Highway 532. Figure 4-14 shows snap shots of inundation and salinity during high tide and low tide for Scenario 3 along with Scenario 0 plots for comparison. In Scenario 3, the rising tide from Port Susan Bay fills up Leque Island and connects to West Pass over the northeastern boundary near the bifurcation of Old Stillaguamish River Channel. As the tide in Port Susan Bay begins to ebb, river flow reverses back. The high tide in Skagit Bay lagging Port Susan tide then reaches a peak pushing West Pass flow eastwards towards Port Susan. The two flows combine and flow south over Leque Island for a short period before receding waters loose connection and the ebb outflow continues through South Pass and the drainage over restored Leque Island. As mentioned previously, the restored region is relatively flat and drains out easily through the historic channel and by way of overland runoff. It is noted again that contour plots during the ebb tide show the presence of small wet polygons that are a byproduct of the model resolution, contouring software, and the relatively flat intertidal zone with water depth less than $20 \mathrm{~cm}$.

Overall salinity in Port Susan Bay and Skagit Bay are relatively unchanged. Relative to baseline, small increases in salinity are observed in in Port Susan Bay. These increases are likely due to an 
increased tidal prism associated with occupation of the restoration area during high tide. During flood tidal movement, the estuarine brackish water consisting of river fresh water mixed with marine incoming tidal waters occupies the restoration area. Salinity within the upper restoration area is between 6.5-14.6 ppt, while the lower restoration area is between 7.2-13.6 ppt. These values are comparable to that of the water in South Pass, indicating that there is good exchange happening between the river and restoration area to achieve the desired salinity for fish habitat. While this scenario removes all constraining dikes along Leque Island south of Highway 532, it is noted that there is a region along the eastern shore of Leque Island with high bed elevation that is not fully inundated during high tide.

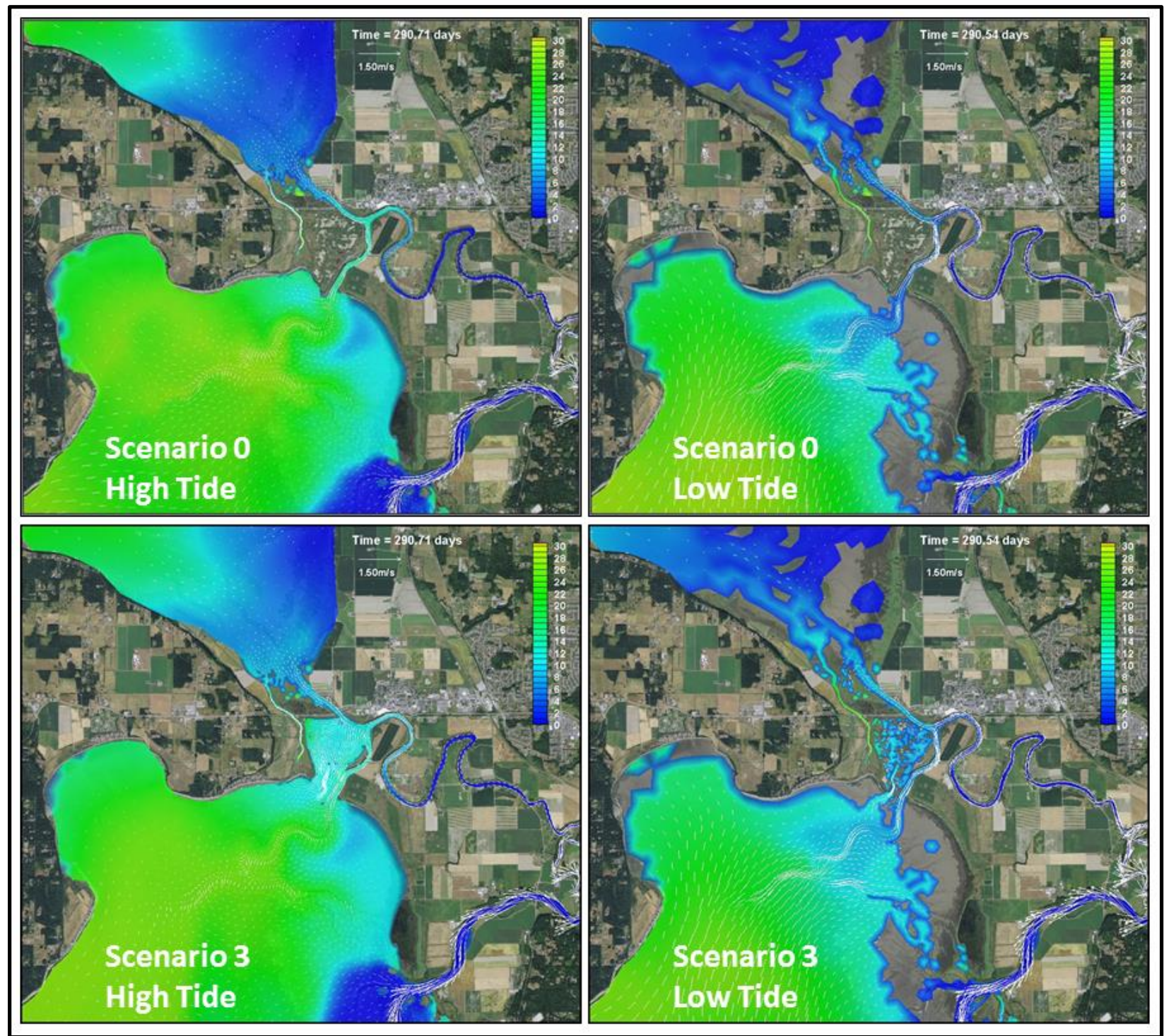

Figure 4-14: Comparison of salinity at high tide and low tide during Scenario 0 and Scenario 3 on October 17, 2005. 


\subsubsection{High Flow Conditions}

Focus of high flow simulation was to evaluate the impact of proposed action on bed shear stress during conditions critical for erosion. Peak ebb shows two main locations where water enters Leque Island from the north. During this period bed shear stress levels show up as spikes of approximately 0.6 $\mathrm{Pa}$, sufficient to move medium sized sand. Erosion may be expected during these events of overland flow. On the southern end of Leque Island, the drainage flow is seen to occur through two major locations which experience shear stresses greater than $1 \mathrm{~Pa}$ and will likely result in new intertidal channel formation for the restored area. One concern from the eastern drainage channel is that the direction of this flow as it enters South Pass results in increases of the bed shear stress against the dike on the opposite side of the river by 1-2 Pa into a range that can displace very small gravel. As shown in Figure 4-15, the South Pass reach downstream of the eastern outflow from the restoration area show increased bed shear stress compared to October 2005 conditions. Stress imposed on the eastern bank shows an increase compared to Scenario 0, even more so than Scenario 2 with the dike breaches. This increase is partly due to higher river flow and partly due to increased tidal prism draining out of the restoration area.

As in previous scenarios, salinity appears to follow trends similar to those in October 2005 conditions, except that all the salinity values are significantly lower because the system is flooded with large volumes of fresh water. Low salinity values less than 4.3 ppt are seen across most of Leque Island, which are similar to the salinity levels in South Pass during Scenario 3.

\subsubsection{Year-Long Simulation}

Results from Year 2003 simulation of Scenario 3 were processed and frequency analysis conducted at the selected six stations L1, L2, L3 and Z1, Z2, and Z3 on zis a ba on Leque (see Figure 3-1 for station locations). This scenario does not include zis a ba site. Figure 4-16 shows frequency plots at the same representative Leque Island station L2. Station L2 as mentioned previously is located within the drainage channel. These results show that the restoration area near Station L2 will be fully inundated $66.8 \%$ of the time, reaching a maximum water depth of $2.63 \mathrm{~m}$. The salinity is predicted to vary between 5-15 ppt for 93.2\% of the time, which is the desired salinity suitable for fish habitat. These results indicate that strong estuarine exchange may be expected. Station L1 (upper Leque) is on the northern side of the island and shows inundation $18.4 \%$ of the time, reaching a maximum water depth of $1.09 \mathrm{~m}$. Here, the salinity is predicted to vary between 5-15 ppt for 92.5\% of the time. Station L3 (near Davis Slough) is only inundated $1.2 \%$ of the time, reaching a maximum depth of $0.43 \mathrm{~m}$.

Bed shear stress at Station L2 will be greater than $0.11 \mathrm{~Pa}$ (sand erosion) for $24.4 \%$ of the time, during which period sand particles may experience re-suspension and erosion. Values greater than 1.26 $\mathrm{Pa}$, at which very small gravel may be eroded will occur for $3.7 \%$ of the time. Station L1 (upper Leque) only surpasses $0.11 \mathrm{~Pa}$ (sand erosion) for $5.7 \%$ of the time. Station L3 (near Davis Slough) is only inundated only $1.2 \%$ of the time, and will experience little bed shear stress. (See Appendix $G$ for cumulative frequency graphs for water-surface elevation, salinity, bottom velocity, and bed shear at all stations). 


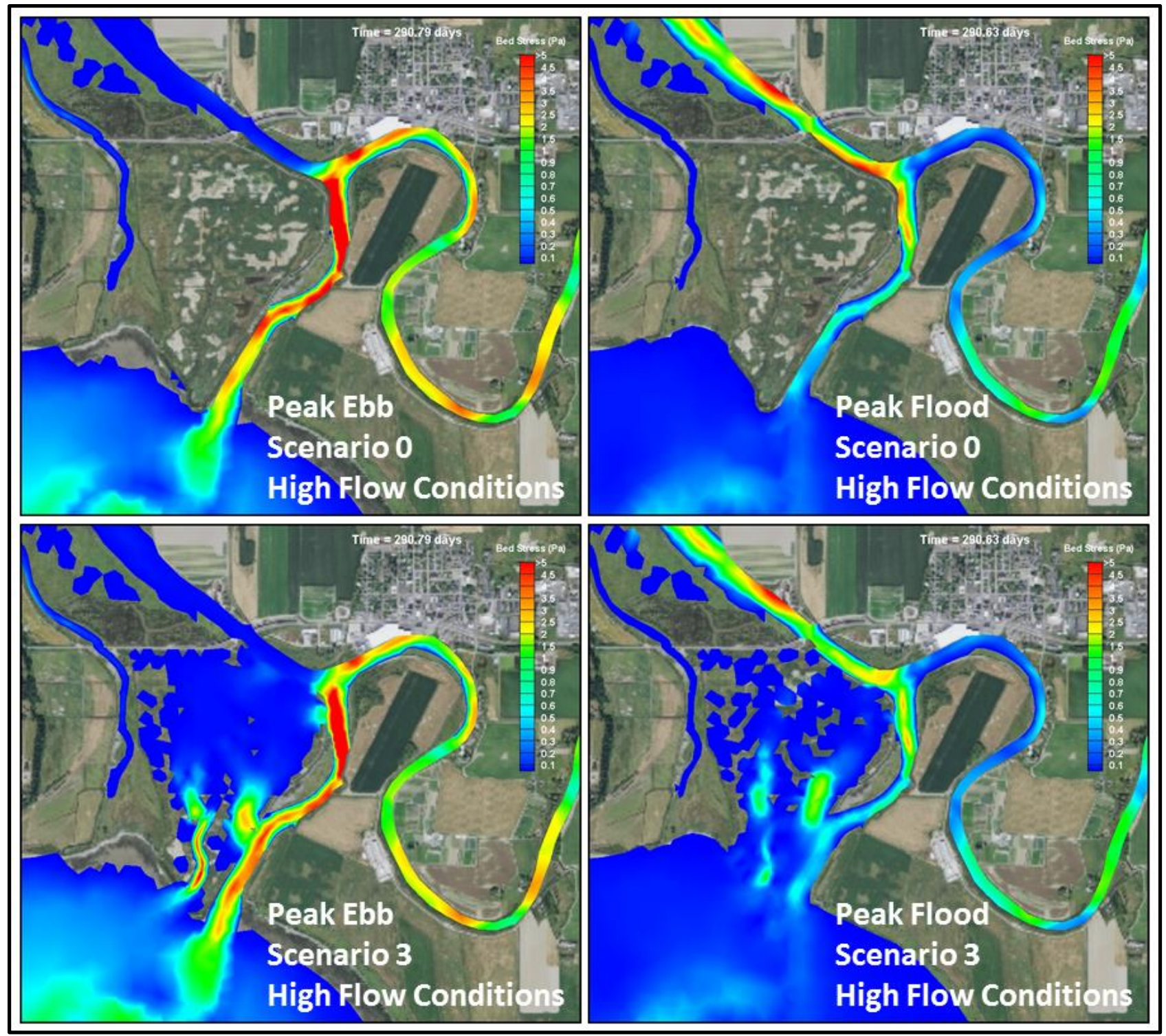

Figure 4-15: Comparison of bed shear stress at peak ebb and peak flood during Scenario 0 and Scenario 3 at high flow conditions 

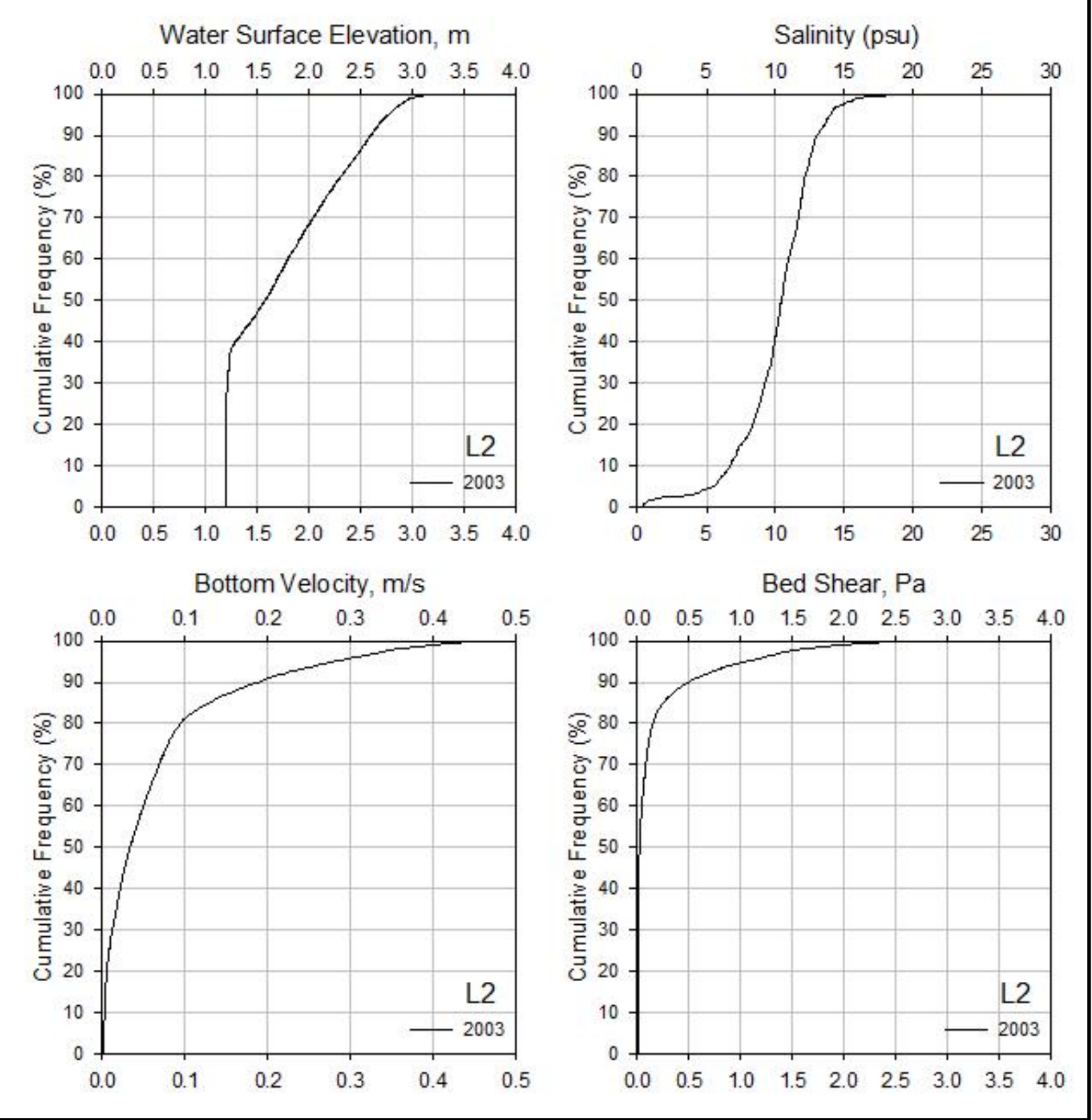

Figure 4-16: Cumulative frequency plots for Scenario 3 - Water-Surface Elevation, Salinity, Bottom Velocity, and Bed Shear at Station L2 on Leque Island 


\subsection{Restoration Scenario 4 - Full Removal of Lower Dike at Leque Island}

The fourth scenario (Figure 4-17) involves the removal of the Leque Island perimeter dike south of Highway 532 except the upper half of the eastern perimeter dike is repaired and left intact. It includes the same historic drainage channel discussed previously. The presence of the eastern perimeter dike ensures that the Stillaguamish River tidal flow is trained and routed through West Pass and South Pass. The dike section is also seen as barrier providing some measure of protection against storm surge events. The daily tidal inundation in the full restoration alternative is expected to reach the toe of Highway 532 dike.

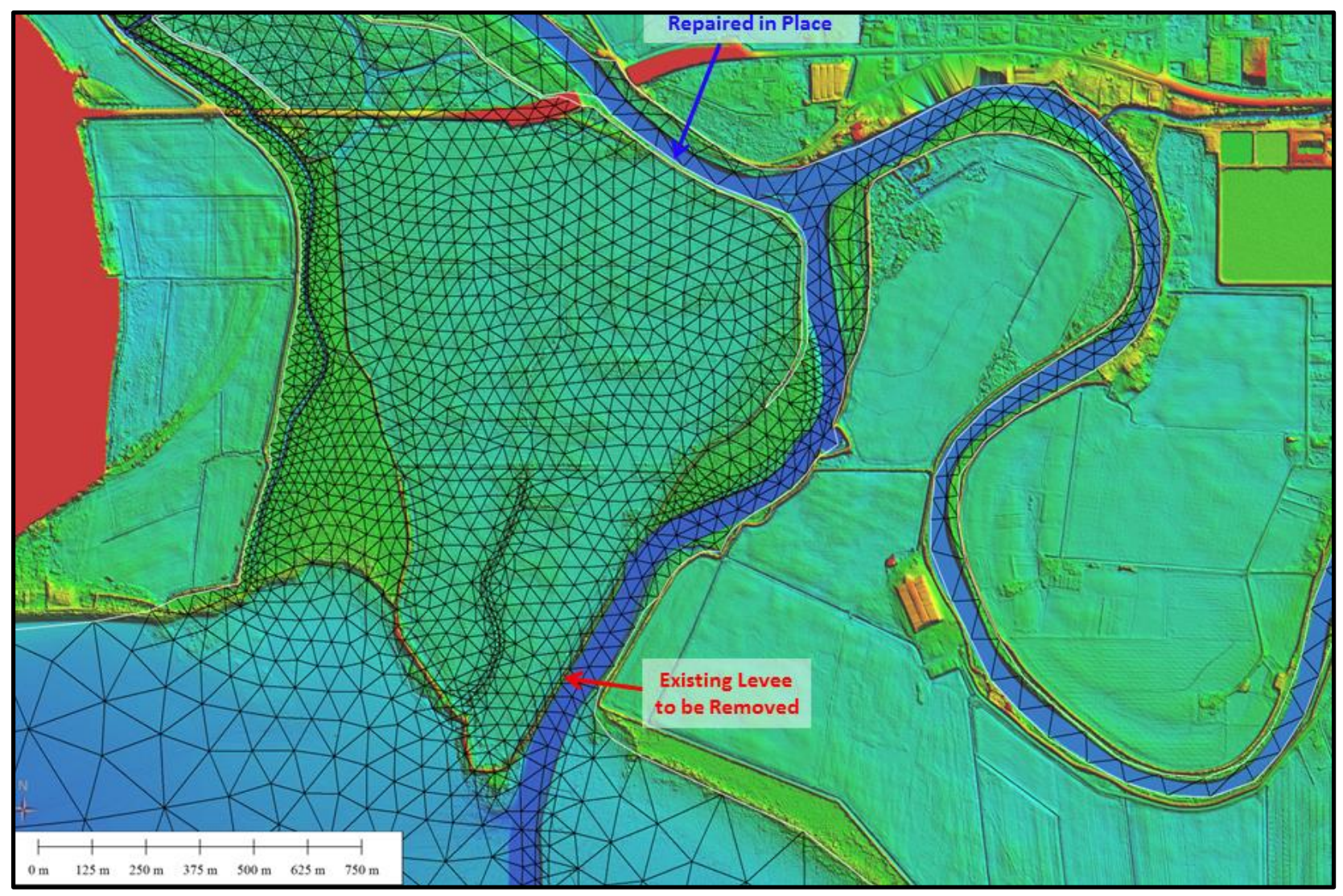

Figure 4-17: (Scenario 4 - Full Restoration Leque, Alternative 2) Model grid overlaying the lidar elevation map

\subsubsection{October 2005 Conditions}

As in Scenario 3, the dike removal action in Scenario 4 results in immediate restoration of tidal action over the entire Leque Island south of Highway 532. Figure 4-18 shows snap shots of inundation and salinity during high tide and low tide for Scenario 4 along with Scenario 0 plots for comparison. The results in Scenario 4 look very similar and comparable to those obtained for Scenario 3. The rising tide 
from Port Susan Bay fills up Leque Island but is prevented from connecting to West Pass over the northeastern boundary near the bifurcation of Old Stillaguamish River Channel by the section of the dike that was left intact. As the tide in Port Susan Bay begins to ebb, river flow reverses back. The high tide in Skagit Bay lagging Port Susan tide then reaches a peak pushing West Pass flow eastwards towards Port Susan. The two flows combine and flow south into Port Susan through South Pass. The inundated Leque Island region drains out to South Pass. As mentioned previously, the restored region is relatively flat and drains out easily through the historic channel and by way of overland runoff. The presences of small wet polygons which remain during the ebb are byproduct of the model resolution, contouring software, and the relatively flat intertidal zone with water depth less than $20 \mathrm{~cm}$.

Similar to Scenario 3, overall salinity in Port Susan Bay and Skagit Bay are relatively unchanged. Relative to baseline, small increases in salinity are observed in Port Susan Bay. These increases are likely due to an increased tidal prism associated with occupation of the restoration area during high tide. During flood tidal movement, the estuarine brackish water consisting of river fresh water mixed with marine incoming tidal waters occupies the restoration area. Salinity within the upper restoration area is between 10.5-22.5 ppt, while the lower restoration area is between 7.4-13.5 ppt. These lower values are comparable to that of the water in South Pass, indicating that there is good exchange happening between the river and restoration area to achieve the desired salinity for fish habitat. The salinity is slightly higher on the north end of the island because the remaining dike hampers exchange with the river at this location. While this scenario removes all constraining dikes along Leque Island south of Highway 532, it is noted that there is a region along the eastern shore of Leque Island with high bed elevation that is not fully inundated during high tide. Salinities in Scenario 4 over the Leque Island restoration area are noticeably higher than Scenario 0 during high tide as well as low tide as direct connection to fresh water from West Pass is not available. 


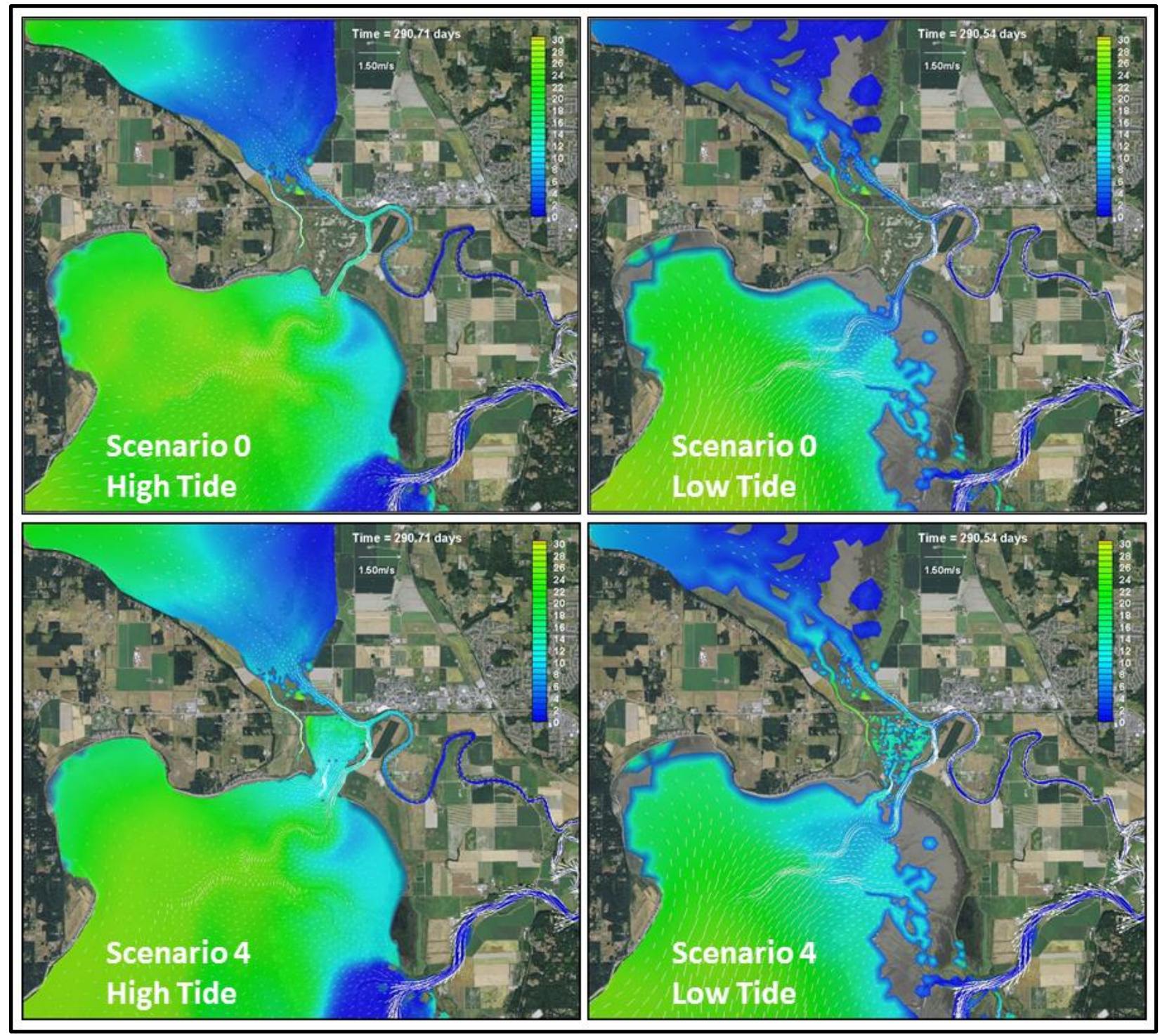

Figure 4-18: Comparison of salinity at high tide and low tide during Scenario 0 and Scenario 4 on October 17, 2005.

\subsubsection{High Flow Conditions}

Focus of high flow simulation was to evaluate the impact of proposed action on bed shear stress during conditions critical for erosion. Bed shear stress contour plots show patterns over the Leque Island restoration area that are very similar to Scenario 3 along the south side of the island, but at a lesser magnitude because water is unable to enter the island from the north because of the dike. The simulation results show that bed shear stress varies from 0.4 to $0.8 \mathrm{~Pa}$. The comparison between bed shear stress for the baseline scenario and Scenario 4 seen in Figure 4-19 shows that the stresses experienced upstream of where the dike was removed are relatively unchanged. The remainder of South Pass that borders the restoration area experiences a little less stress than the baseline condition, which shows that the restoration area absorbs some of the local tidal energy. The historic drainage channel to the south and the second channel to the east again show high shear indicating potential for channel evolution over time. 
There are some concerns that drainage from the eastern exit enters perpendicular to South Pass and could exert additional bed shear stress on the dike opposite the exit. It is recommended that model results be extracted and examined further relative to baseline at the specific sensitive locations of interest.

Salinity during high flows follows trends similar to those seen in the October 2005 conditions, except that now all the values are significantly less because the system is flooded with large volumes of fresh water. Salinity values range from 0.8-12.8 ppt across the southern half of Leque Island.
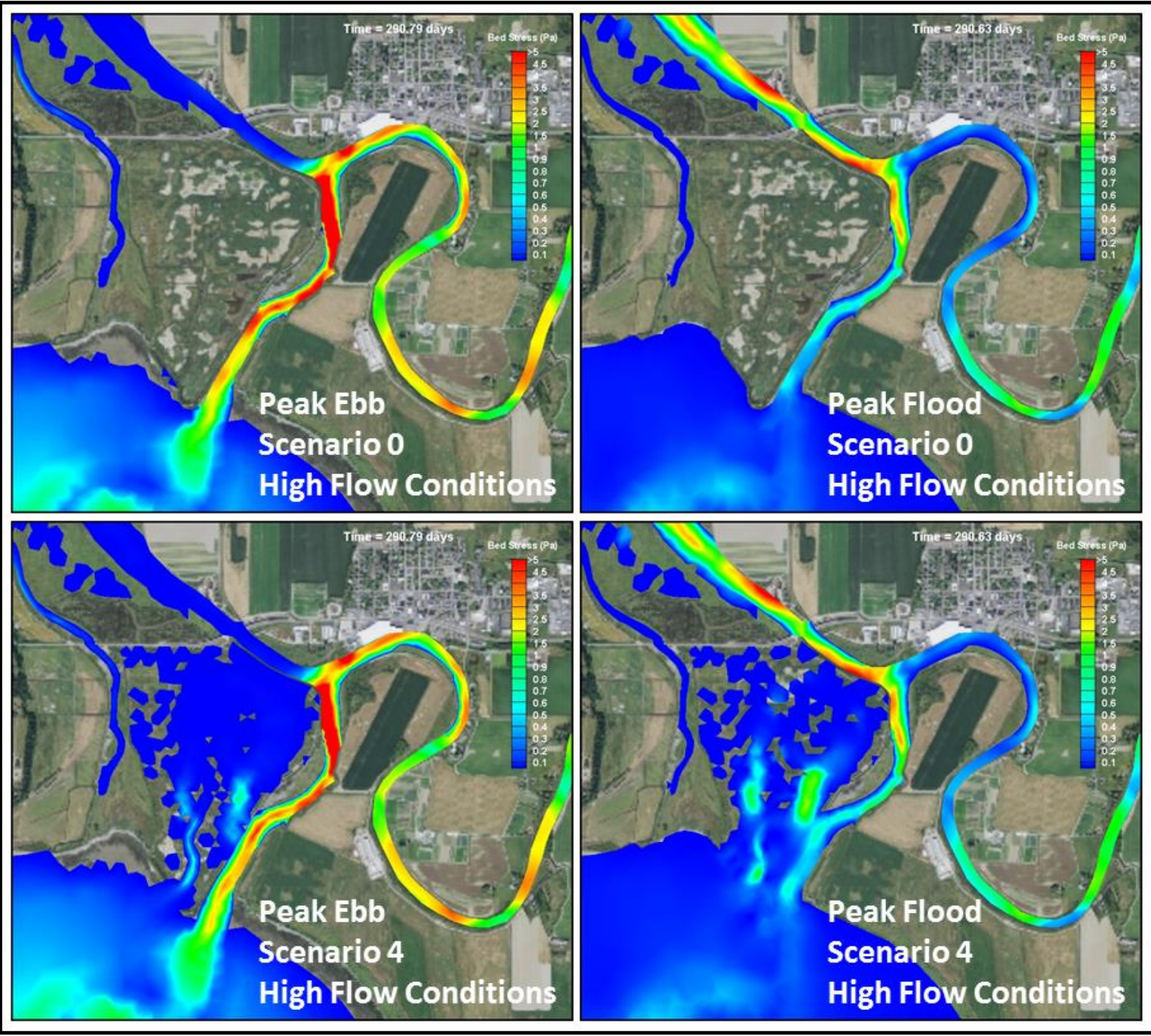

Figure 4-19: Comparison of bed shear stress at peak ebb and peak flood during Scenario 0 and Scenario 4 at high flow conditions. 


\subsubsection{Year-Long Simulation}

Results from Year 2003 simulation of Scenario 4 were processed and frequency analysis conducted at the selected six stations L1, L2, L3 and Z1, Z2, and Z3 on zis a ba on Leque (see Figure 3-1 for station locations). This scenario does not include zis a ba site. Figure 4-20 shows frequency plots at the same representative Leque Island station L2. Station L2 as mentioned previously is located within the drainage channel. These results show that the restoration area near Station L2 will be fully inundated $67.8 \%$ of the time, reaching a maximum water depth of $2.63 \mathrm{~m}$. The salinity is predicted to vary between 5-15 ppt for 91.6\% of the time, which is the desired salinity suitable for fish habitat. These results indicate that strong estuarine exchange may be expected. Station L1 (upper Leque) is on the northern side of the island and shows inundation $28.6 \%$ of the time, reaching a maximum water depth of $1.08 \mathrm{~m}$. Here, the salinity is predicted to vary between 5-15 ppt for $90.9 \%$ of the time. Station L3 (near Davis Slough) is only inundated $1.2 \%$ of the time, reaching a maximum depth of $0.43 \mathrm{~m}$.

The bed shear stress values for Scenario 4 are similar but slightly lower than Scenario 3. Bed shear stress at Station L2 will be greater than $0.11 \mathrm{~Pa}$ (sand erosion) for $23.6 \%$ of the time, during which period sand particles may experience re-suspension and erosion. Values greater than $1.26 \mathrm{~Pa}$, at which very small gravel may be eroded will occur for $3.4 \%$ of the time. Station L1 (upper Leque) only surpasses $0.11 \mathrm{~Pa}$ (sand erosion) for $5.3 \%$ of the time. Station L3 (near Davis Slough) is only inundated only $1.2 \%$ of the time, and will experience little bed shear stress. (See Appendix G for cumulative frequency graphs for water-surface elevation, salinity, bottom velocity, and bed shear at all stations).

\subsection{Restoration Scenario 5 - Partial Restoration at Leque Island with Full Restoration at zis a ba}

The fifth scenario includes restoration at zis a ba in combination with restoration action at Leque. As shown in Figure 4-21, Scenario 5 involves partial restoration of Leque as described in Scenario 1 along with restoration of zis a ba site located west of Leque surrounded by the Old Stillaguamish River Cannel and South Pass. In this scenario, the southern portion of the Leque Island dike will be removed and a new setback dike constructed. On zis a ba, the perimeter dike will be removed except for a section along the southeast end that brings the river to its point of inflection, and a new setback dike will be constructed along the southern boundary of the site. The design and placement of the dikes on zis aba was developed with the intent of preventing the formation of an Oxbo and to provide protection to the interior agricultural lands. Simulation of these two sites simultaneously would help provide an understanding of cumulative effects on estuarine hydrodynamics. This restoration alternative with the retention of the training dike for zis a ba was the only design considered in response to stakeholder concerns regarding the possibility that the City of Stanwood stormwater drainage to the river channel would be adversely affected if the river channel were to migrate. 


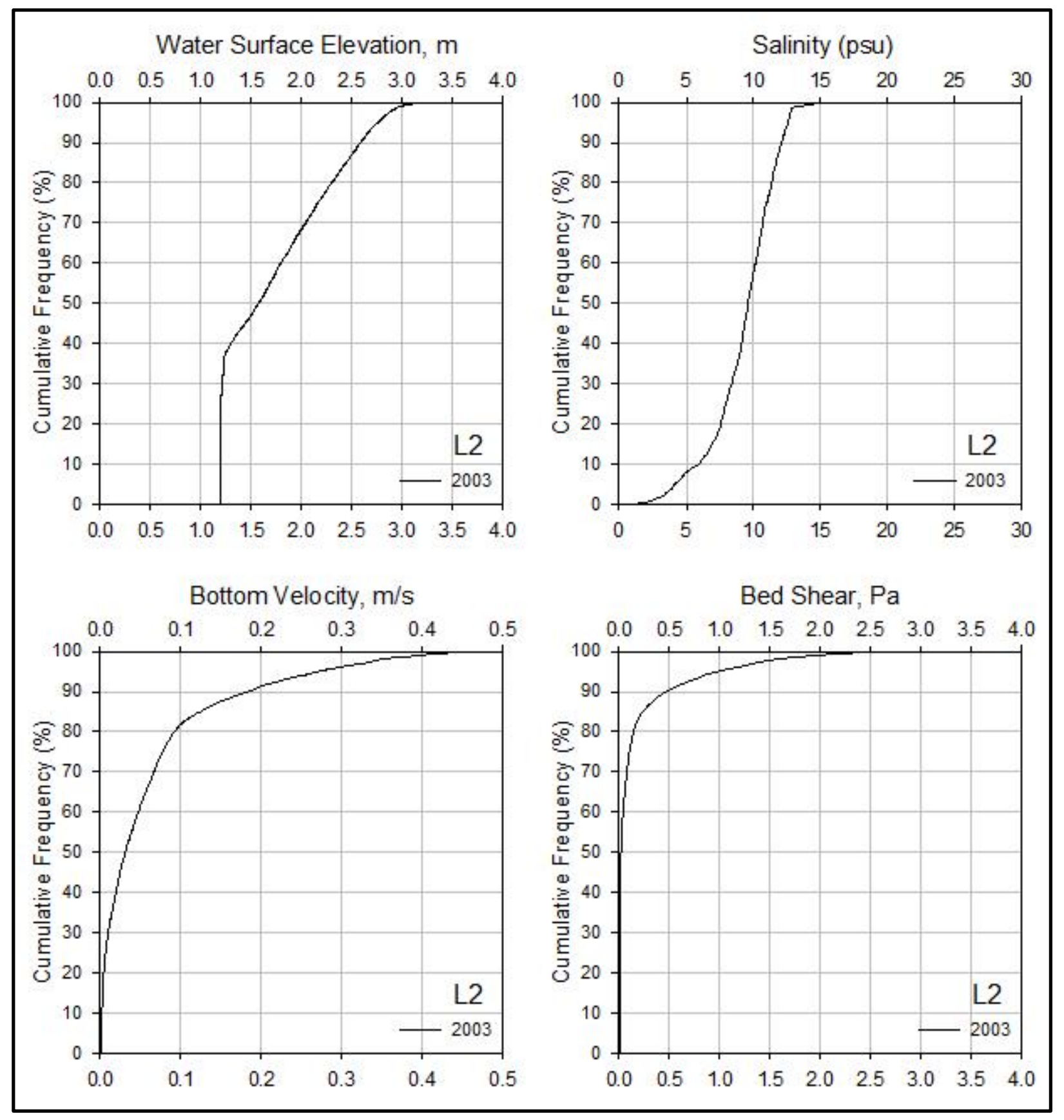

Figure 4-20: Cumulative frequency plots for Scenario 4 - Water-Surface Elevation, Salinity, Bottom Velocity, and Bed Shear at Station L2 on Leque Island 


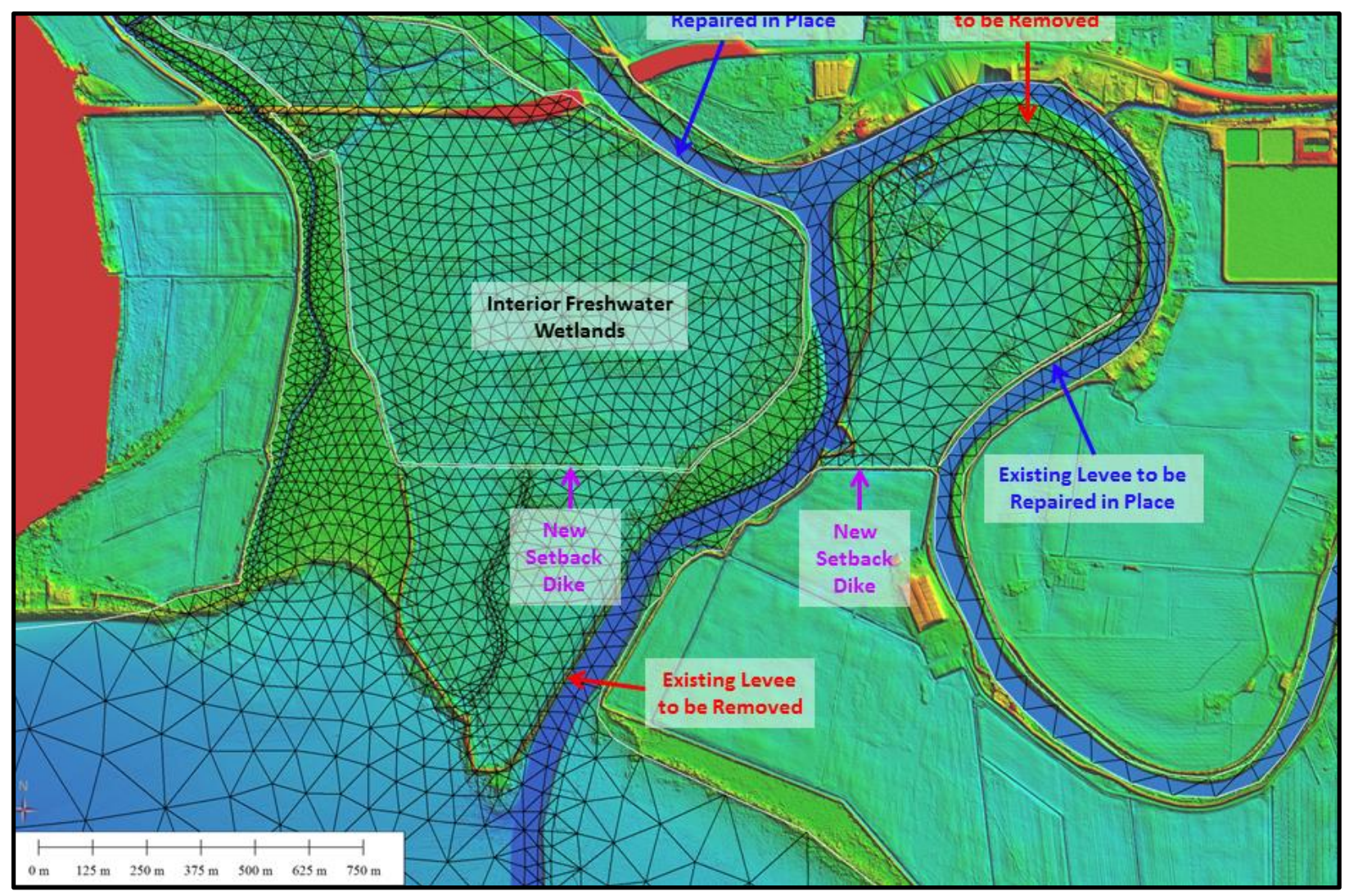

Figure 4-21: (Scenario 5 - zis a ba Restoration + SCN1) Model grid overlaying the lidar elevation map

\subsubsection{October 2005 Conditions}

In Scenario 5 the removal of the dike section from zis a ba results in immediate restoration of tidal action and inundation. Figure 4-22 shows snap shots of simulated inundation and salinity during high tide and low tide for Scenario 5 along with Scenario 0 plots for comparison. The results show that zis a ba site is inundated with rising tides from Port Susan moving up South Pass and entering zis a ba from the southwest. The water also subsequently enters the site from the northern boundary of the zis a ba site along the Old Stillaguamish River Channel. The drainage of zis a ba site is primarily to South Pass through existing deeper pathways towards the southwest corner which would likely develop into dominant a drainage channel. This scenario is a combination of Scenario 1 and zis a ba restoration. Results show that estuarine response at Leque Island in Scenario 5 is similar to Scenario 1 and does not appear to be affected by restoration at zis a ba. Similar to Leque Island, the restored region at zis a ba is also relatively flat and drains out easily through the existing low lying regions by way of overland runoff. The presences of small wet polygons which remain during the ebb are byproduct of the model resolution, contouring software, and the relatively flat intertidal zone with water depth less than $20 \mathrm{~cm}$.

Similar to previous scenarios, overall salinity in Port Susan Bay and Skagit Bay are mostly unchanged. Relative to baseline, small increases in salinity are observed in Port Susan Bay. These increases are likely due to an increased tidal prism associated with occupation of the restoration area during high tide. In Scenario 5, the tidal prism is increased due to availability of zis a ba region for tidal inundation. The mean bed elevation of zis a ba site is $\approx 2.26 \mathrm{~m}$ and is inundated for a short duration in 
each tidal cycle. The associated tidal prism with zis a ba is smaller than Leque Island. Salinity within the lower Leque restoration area is between 8.9-15.0 ppt while all three stations on zis a ba remain within the range of 8.2-15.9 ppt. These values are comparable to that of the water in South Pass, indicating that there is good exchange happening between the river and restoration area in both cases that allow the desired salinity range for fish habitat

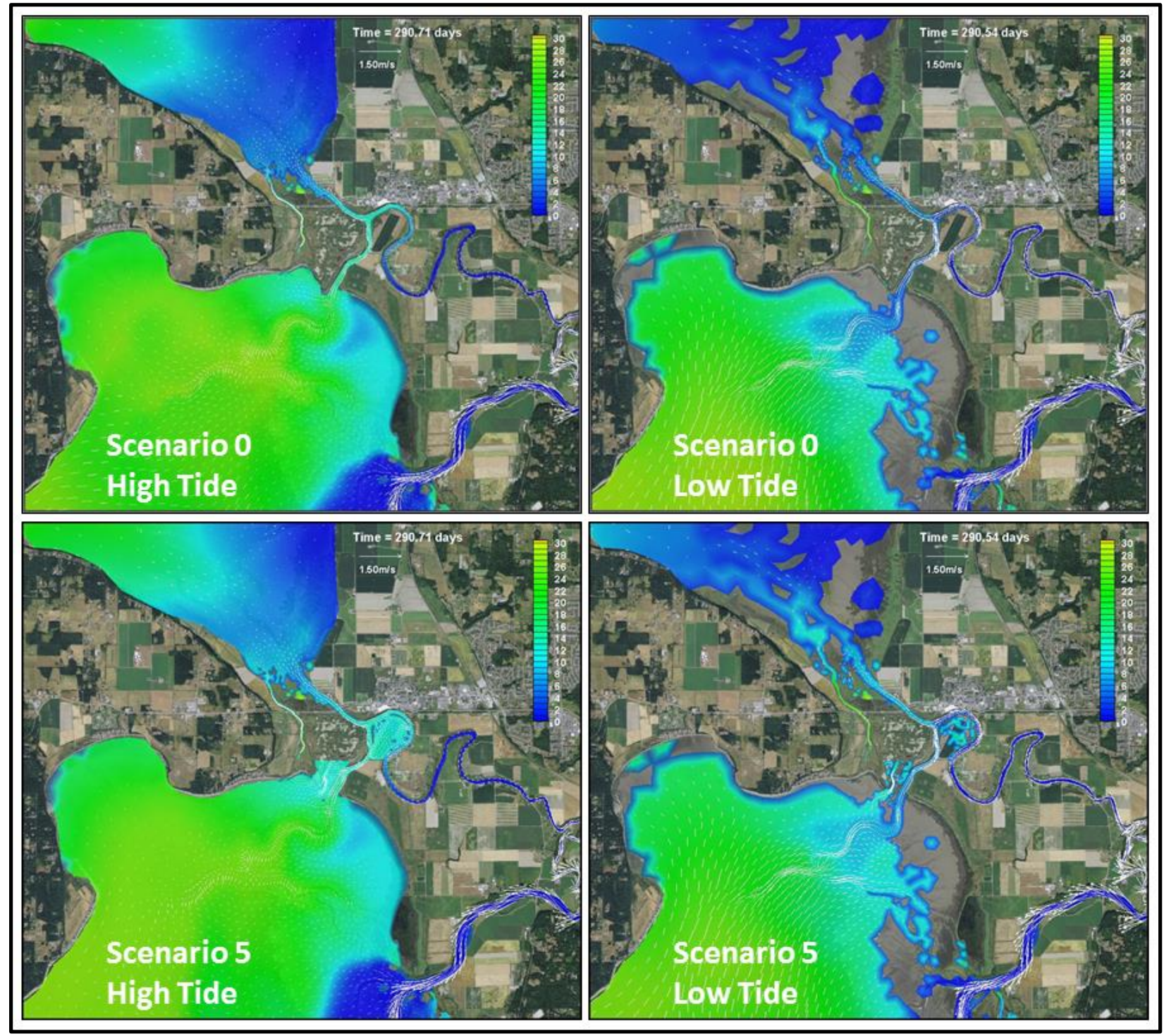

Figure 4-22: Comparison of salinity at high tide and low tide during Scenario 0 and Scenario 5 on October 17, 2005. 


\subsubsection{High Flow Conditions}

Focus of high flow simulation was to evaluate the impact of proposed action on bed shear stress during conditions critical for erosion. Bed shear stress during peak ebb and flood shown on Figure 4-23 on the Leque Island restoration area seems mostly unchanged compared to Scenario 1 presented previously indicating that the zis a ba restoration has little cumulative impact on the Leque Island restoration. The bed shear stress on zis a ba is strongly associated with ebb and flood flow channel on the southwest part of the zis a ba site, where stresses between 1.0-1.5 are experienced. The results also show that the portion of inundation from the Stillaguamish River Channel northern boundaries is spread out over a larger area and enters the site at lower velocities. The water from the inundated zis a ba site drains to the southwest where it enters South Pass at an angle aligned in the direction of the river flow naturally. With ebb and flood movement of water across zis a ba site, there is potential for erosion or channel formation on zis a ba. To prevent exposure of the buried wastewater flow pipeline from the food processing plant, this alternative design may include the construction of a berm over the pipeline as a protective measure. This modification could also reduce the bed shear stresses on the island by diverting a fraction of the tidal prism drainage out through an alternate pathway.

During high flow, salinity appears to follow similar trends to that of the October 2005 conditions, except that all the salinity values are significantly lower because the system is flooded with fresh river water. Low salinity values less than 4 ppt are seen across the entire zis a ba restoration area, which is similar to the salinity in the river flow, indicating good exchange. Inundation and salinity on Leque Island seem unchanged compared to Scenario 1, which indicates that the restoration on zis a ba has very little effect on the estuarine functions at the Leque Island site.

\subsubsection{Year-Long Simulation}

Results from Year 2003 simulation of Scenario 5 were processed and frequency analysis conducted at the selected six stations L1, L2, L3 and Z1, Z2, and Z3 on zis a ba on Leque (see Figure 3-1 for station locations). Figure 4-24 shows frequency plots at the same representative Leque Island station L2. Station L2 as mentioned previously is located within the drainage channel. These results show that the restoration area near Station L2 will be fully inundated $66.7 \%$ of the time, reaching a maximum water depth of $2.63 \mathrm{~m}$. The salinity is predicted to vary between $5-15 \mathrm{ppt}$ for $91.2 \%$ of the time, which is the desired salinity suitable for fish habitat and is similar to the variation seen in Scenario 1. These results

indicate that strong estuarine exchange may be expected. Station L1 is not inundated and Station L3 (near Davis Slough) is only inundated $1.2 \%$ of the time, reaching a maximum depth of $0.44 \mathrm{~m}$.

The bed shear stress values for Scenario 5 on Leque Island are very similar to that of Scenario 1, indicating little combined effect between the two scenarios. Bed shear stress at Station L2 will be greater than $0.11 \mathrm{~Pa}$ (sand erosion) for $23.0 \%$ of the time, during which period sand particles may experience resuspension and erosion. Values greater than $1.26 \mathrm{~Pa}$, at which very small gravel may be eroded will occur for 3.3\% of the time. Station L1 is not inundated and Station L3 (near Davis Slough) is only inundated only $1.2 \%$ of the time, and will experience little bed shear stress. (See Appendix G for cumulative frequency graphs for water-surface elevation, salinity, bottom velocity, and bed shear at all stations).

Figure 4-25 shows frequency plots at the same representative zis a ba station Z2, which is located near the middle of the island. These results show that the restoration area near Station Z2 will be fully 
inundated $17.8 \%$ of the time, reaching a maximum water depth of $1.08 \mathrm{~m}$. The salinity is predicted to vary between $5-15 \mathrm{ppt}$ for $88.1 \%$ of the time, which is the desired salinity suitable for fish habitat. Station Z1 (northern zis a ba) will be fully inundated $17.4 \%$ of the time, reaching a maximum water depth of $1.28 \mathrm{~m}$ and will remain within the $5-15$ ppt range for $87.3 \%$ of the time. Station Z3 (southern zis a ba) will be fully inundated $16.7 \%$ of the time, reaching a maximum water depth of $1.10 \mathrm{~m}$ and will remain within the $5-15$ ppt range for $87.3 \%$ of the time. These results demonstrate that zis a ba has a flat profile that will experience similar results across all stations.

Bed shear stresses at stations Z1 (northern zis a ba), Z2 (middle zis a ba), and Z3 (southern zis a ba) were only greater than $0.11 \mathrm{~Pa}$ (sand erosion) for $3.6 \%, 9.0 \%$, and $8.1 \%$ of the time respectively. These values are similar across all stations, indicating that erosion across most of zis a ba will be limited.
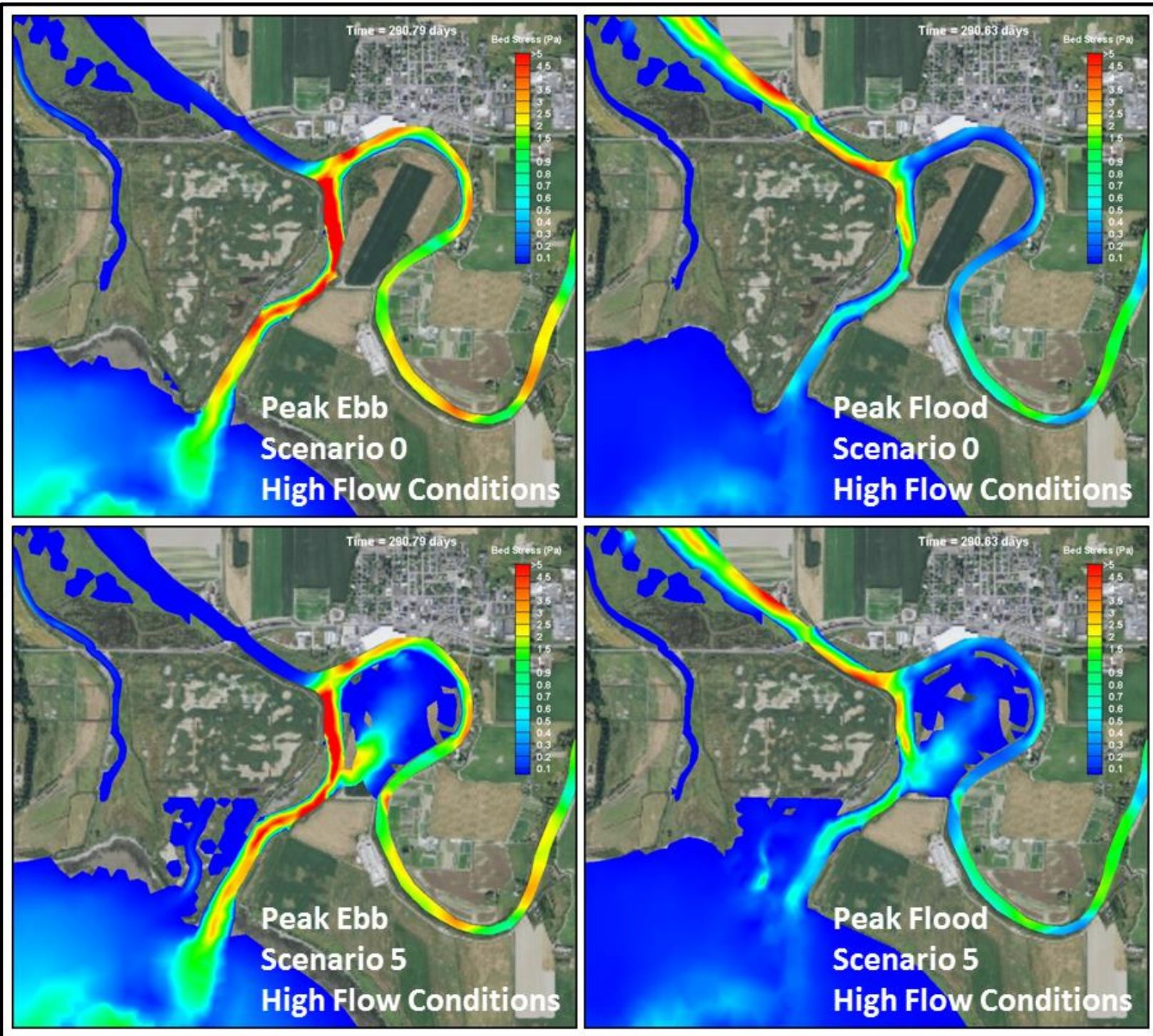

Figure 4-23: Comparison of bed shear stress at peak ebb and peak flood during Scenario 0 and Scenario 5 at high flow conditions. 


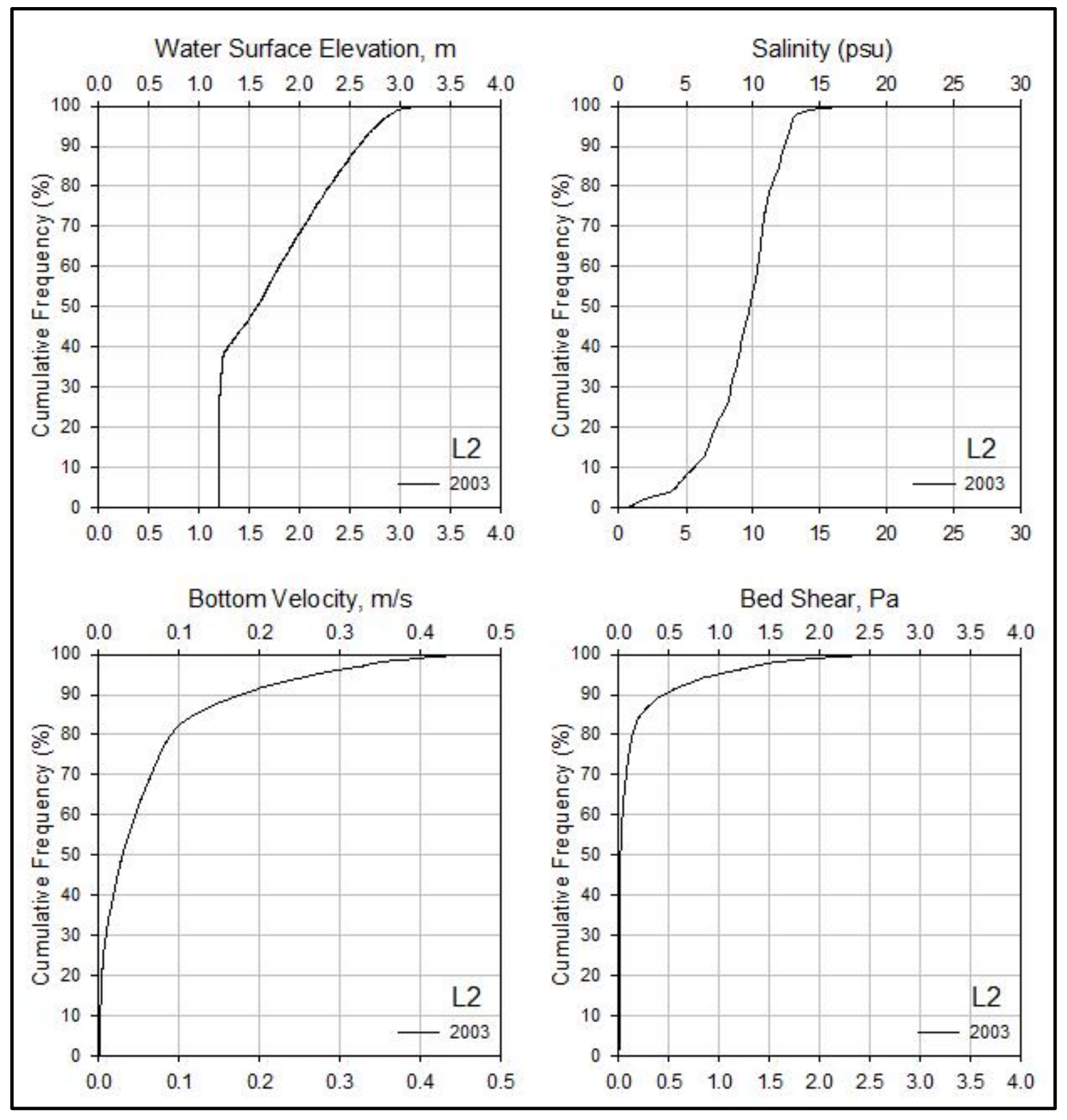

Figure 4-24: Cumulative frequency plots for Scenario 5 - Water-Surface Elevation, Salinity, Bottom Velocity, and Bed Shear at Station L2 on Leque Island 


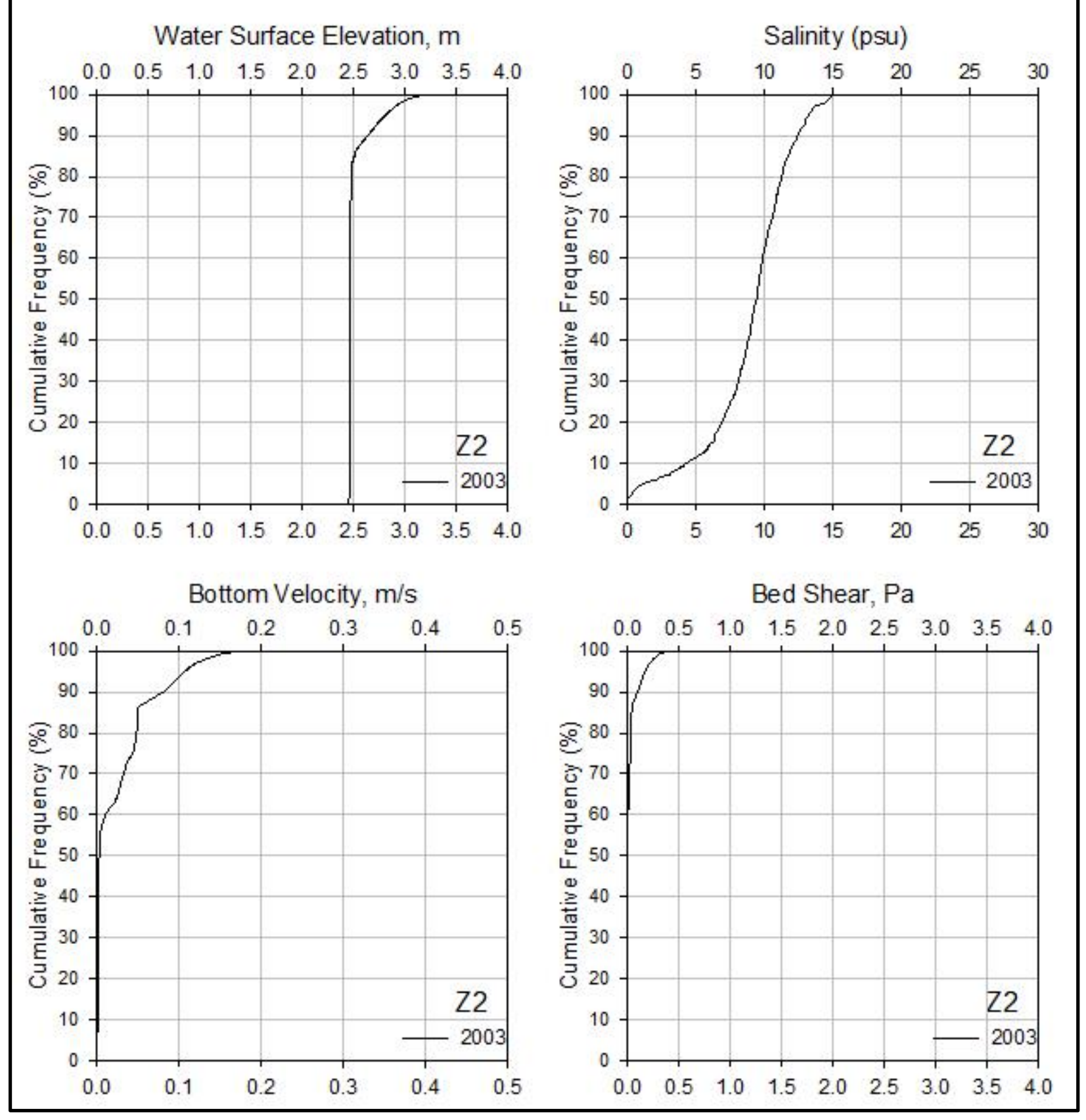

Figure 4-25: Cumulative frequency plots for Scenario 5 - Water-Surface Elevation, Salinity, Bottom Velocity, and Bed Shear at Station Z2 on zis a ba

\subsection{Restoration Scenario 6 - Full Removal of Lower Dike at Leque Island with Full Restoration at zis a ba}

The sixth scenario includes restoration at zis a ba in combination with restoration action at Leque. As shown in Figure 4-26, Scenario 6 involves full restoration of Leque Island (Alternative 2) as described in Scenario 4, along with restoration of zis a ba site. Here, Leque Island will be fully restored by the removal of the perimeter dike except for the northeast section as described in Scenario 4. On zis a ba, the 
dike will be removed except for a section along the southeast end that brings the river to its point of inflection, and a new setback dike will be constructed on the southern end of the island as described in Scenario 5 previously. This simulation allows examination of the cumulative effects of the two restoration projects on the estuarine response at project sites as well as estuary-wide effects on tidal hydrodynamics.

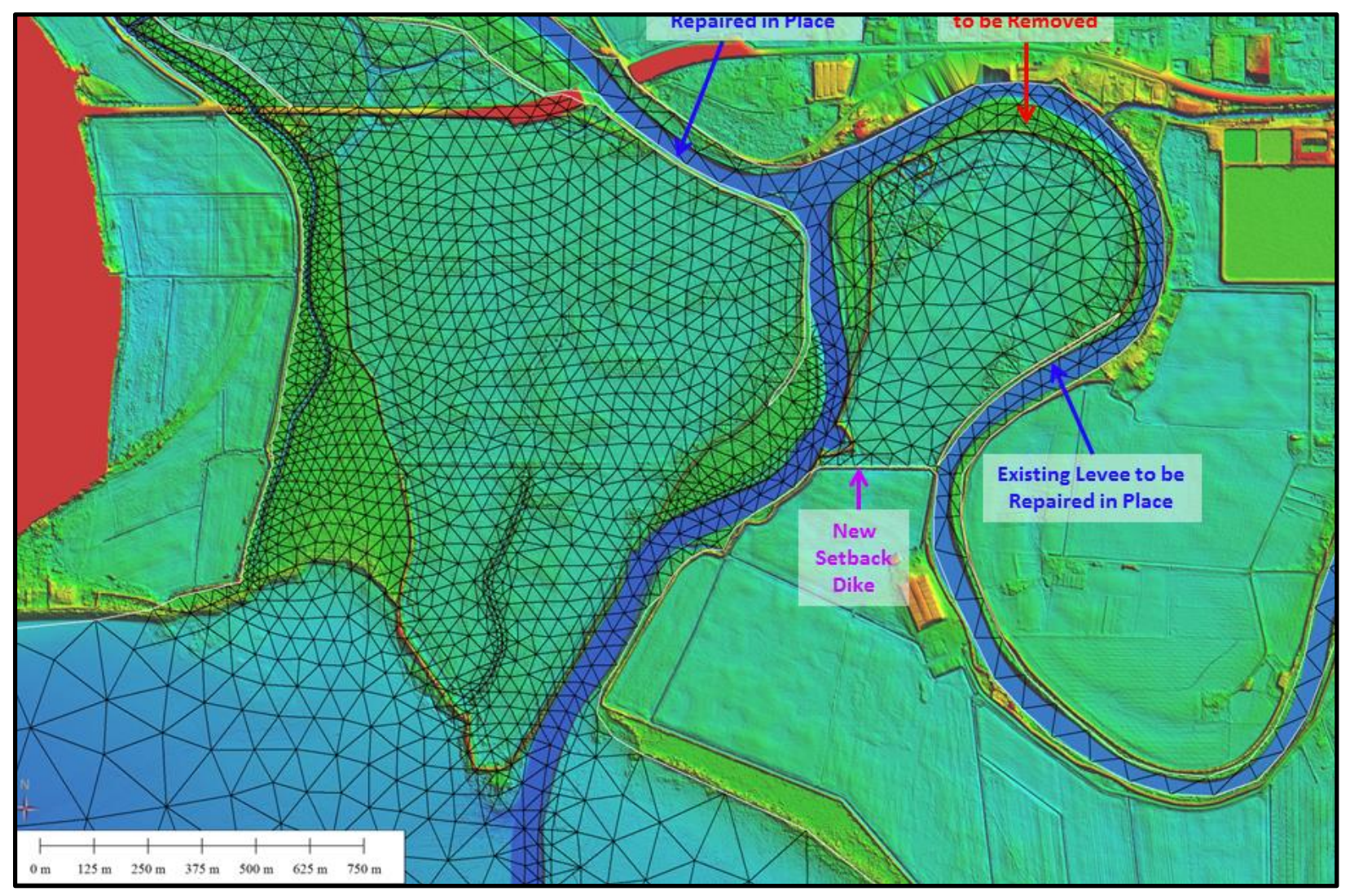

Figure 4-26: (Scenario 6 - zis a ba Restoration + SCN4) Model grid overlaying the lidar elevation map

\subsubsection{October 2005 Conditions}

Scenario 6 is a combination of Scenario 4 and zis a ba restoration as described in Scenario 5. Removal of dikes at both locations results in immediate tidal inundation response at both sites and the presence of the dike sections left intact function effectively providing the envisioned flood protection and river training benefits. Examination of Scenario 6 results showed that response of zis a ba site was very similar to that obtained for Scenario 5. Similarly response on the Leque Island site was similar that described in Scenario 4.

Figure 4-27 shows snap shots of simulated inundation and salinity during high tide and low tide for Scenario 5 along with Scenario 0 plots for comparison. Salinity within the upper restoration area is between 10.0 ppt to $22.4 \mathrm{ppt}$, salinity within the lower Leque restoration area is between 6.9 to $12.9 \mathrm{ppt}$, and the salinity on all three stations on zis a ba remains within 
the range of 5.8-14.4 ppt. The respective restoration sites do not appear to be affected by cumulative effects. The South Pass channel now carries additional flow corresponding to the increased tidal prism from the respective projects.

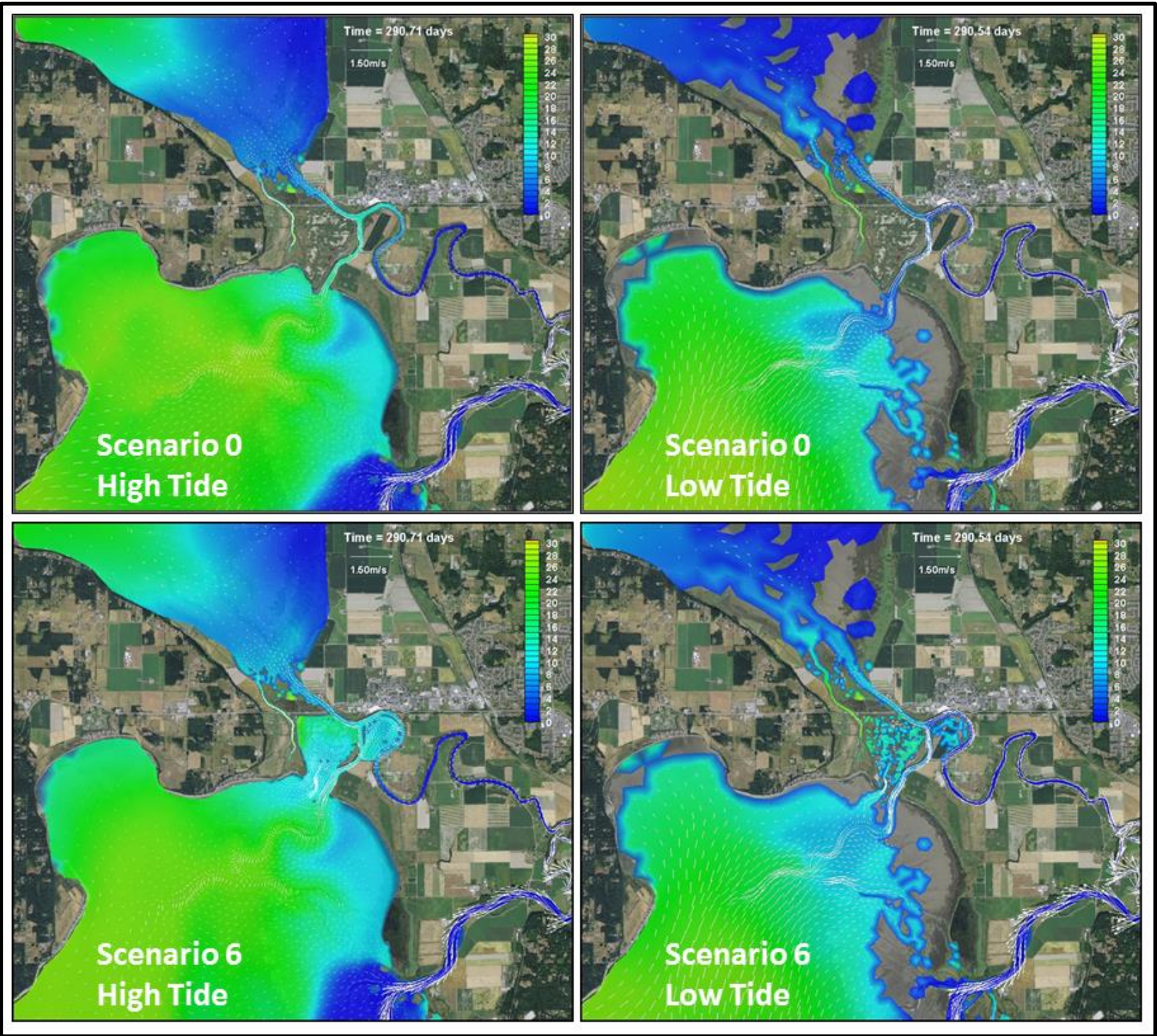

Figure 4-27: Comparison of salinity at high tide and low tide during Scenario 0 and Scenario 6 on October 17, 2005.

\subsubsection{High Flow Conditions}

Focus of high flow simulation was to evaluate the impact of proposed action on bed shear stress during conditions critical for erosion. Bed shear stress results are nearly identical to those obtained for Scenario 5 near zis a ba, and Scenario 4 near Leque Island. Figure 4-28 shows snap shots of simulated bed shear stress during peak ebb and peak flood along with Scenario 0 plots for comparison. 


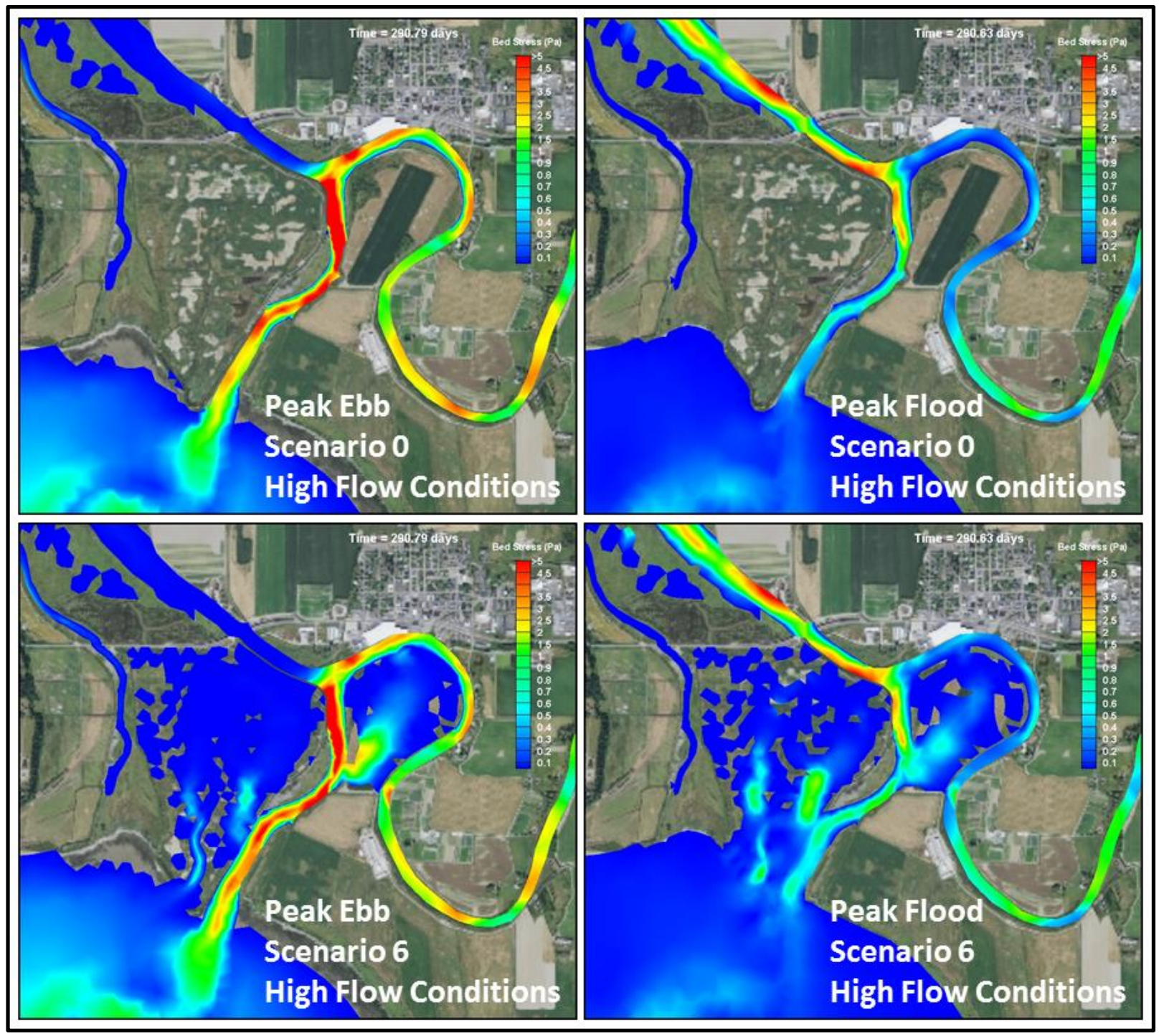

Figure 4-28: Comparison of bed shear stress at peak ebb and peak flood during Scenario 0 and Scenario 6 at high flow conditions

\subsubsection{Year-Long Simulation}

Results from Year 2003 simulation of Scenario 6 were processed and frequency analysis conducted at the selected six stations L1, L2, L3 and Z1, Z2, and Z3 on zis a ba on Leque (see Figure 3-1 for station locations). Figure 4-29 shows frequency plots at the same representative Leque Island station L2. Station L2 as mentioned previously is located within the drainage channel. These results show that the restoration area near Station L2 will be fully inundated $68.2 \%$ of the time, reaching a maximum water depth of $2.63 \mathrm{~m}$. The salinity is predicted to vary between $5-15 \mathrm{ppt}$ for $91.2 \%$ of the time, which is the desired salinity suitable for fish habitat and is similar to the variation seen in Scenario 4. These results indicate that strong estuarine exchange may be expected. Station L1 (upper Leque) is on the northern side of the island and shows inundation $28.2 \%$ of the time, reaching a maximum water depth of $1.09 \mathrm{~m}$. Here, the salinity is predicted to vary between 5-15 ppt for 91.4\% of the time. Station L3 (near Davis Slough) is only inundated $1.2 \%$ of the time, reaching a maximum depth of $0.43 \mathrm{~m}$. 
The bed shear stress values for Scenario 6 on Leque Island are very similar to that of Scenario 4, indicating little combined effect between the two scenarios. Bed shear stress at Station L2 will be greater than $0.11 \mathrm{~Pa}$ (sand erosion) for $23.8 \%$ of the time, during which period sand particles may experience resuspension and erosion. Values greater than $1.26 \mathrm{~Pa}$, at which very small gravel may be eroded will occur for 3.4\% of the time. Station L1 (upper Leque) only surpasses 0.11 Pa (sand erosion) for 5.3\% of the time. Station L3 (near Davis Slough) is only inundated only 1.2\% of the time, and will experience little bed shear stress. (See Appendix $\mathrm{G}$ for cumulative frequency graphs for water-surface elevation, salinity, bottom velocity, and bed shear at all stations).

Figure 4-30 shows frequency plots at the same representative zis a ba station Z2, which is located near the middle of the island. These results show that the restoration area near Station $\mathrm{Z} 2$ will be fully inundated $17.8 \%$ of the time, reaching a maximum water depth of $1.09 \mathrm{~m}$. The salinity is predicted to vary between $5-15$ ppt for $87.5 \%$ of the time, which is the desired salinity suitable for fish habitat. Station Z1 (northern zis a ba) will be fully inundated $23.5 \%$ of the time, reaching a maximum water depth of $1.28 \mathrm{~m}$ and will remain within the $5-15$ ppt range for $87.1 \%$ of the time. Station Z3 (southern zis a ba) will be fully inundated $16.7 \%$ of the time, reaching a maximum water depth of $1.10 \mathrm{~m}$ and will remain within the $5-15$ ppt range for $87.6 \%$ of the time. These results demonstrate that zis a ba has a flat profile that will experience similar results across all stations.

Bed shear stresses at stations Z1 (northern zis a ba), Z2 (middle zis a ba), and Z3 (southern zis a ba) were only greater than $0.11 \mathrm{~Pa}$ (sand erosion) for $3.6 \%, 9.3 \%$, and $8.4 \%$ of the time respectively. These values are similar across all stations, indicating that erosion across most of zis a ba will be limited. 


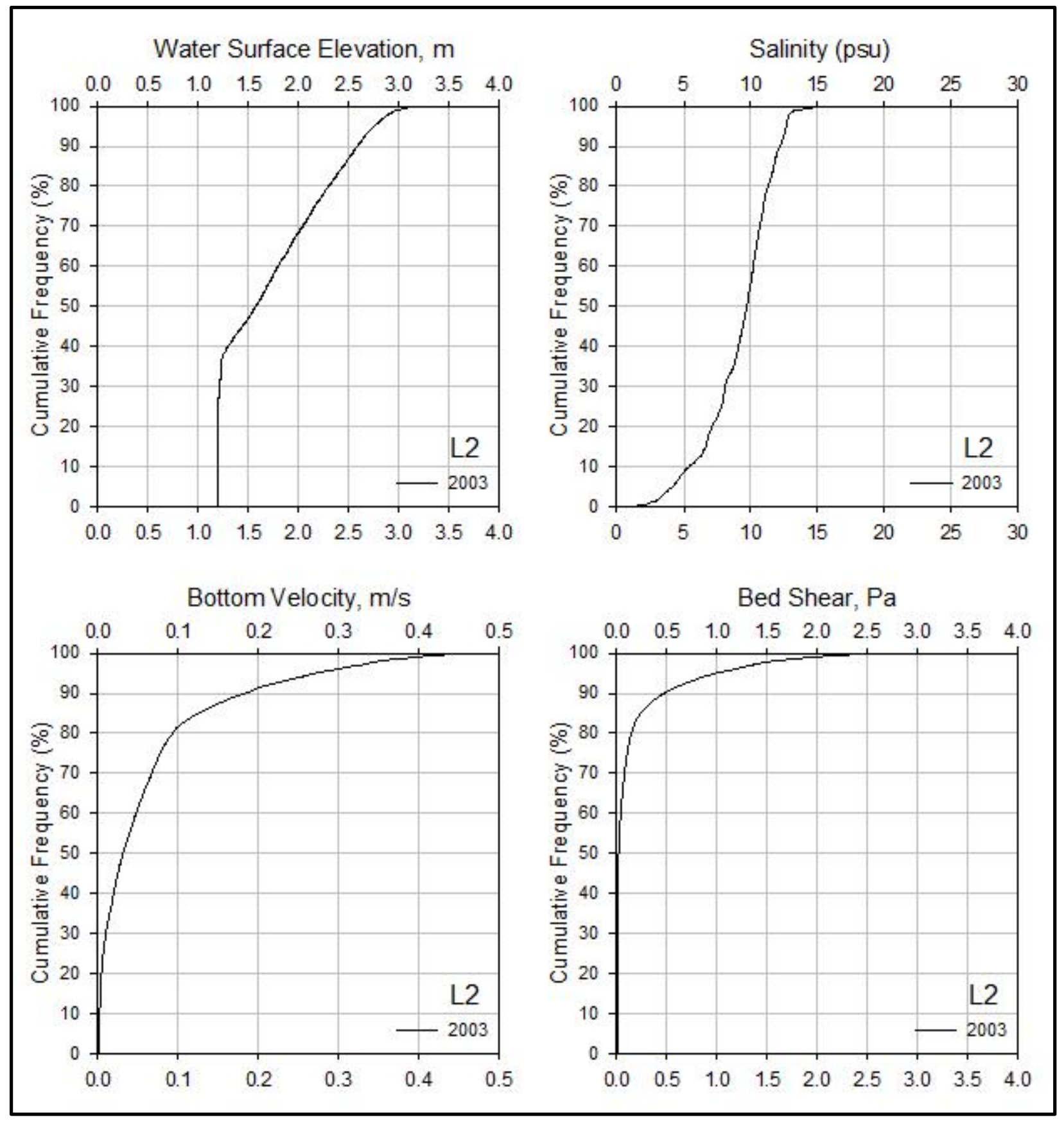

Figure 4-29: Cumulative frequency plots for Scenario 6 - Water-Surface Elevation, Salinity, Bottom Velocity, and Bed Shear at Station L2 on Leque Island 


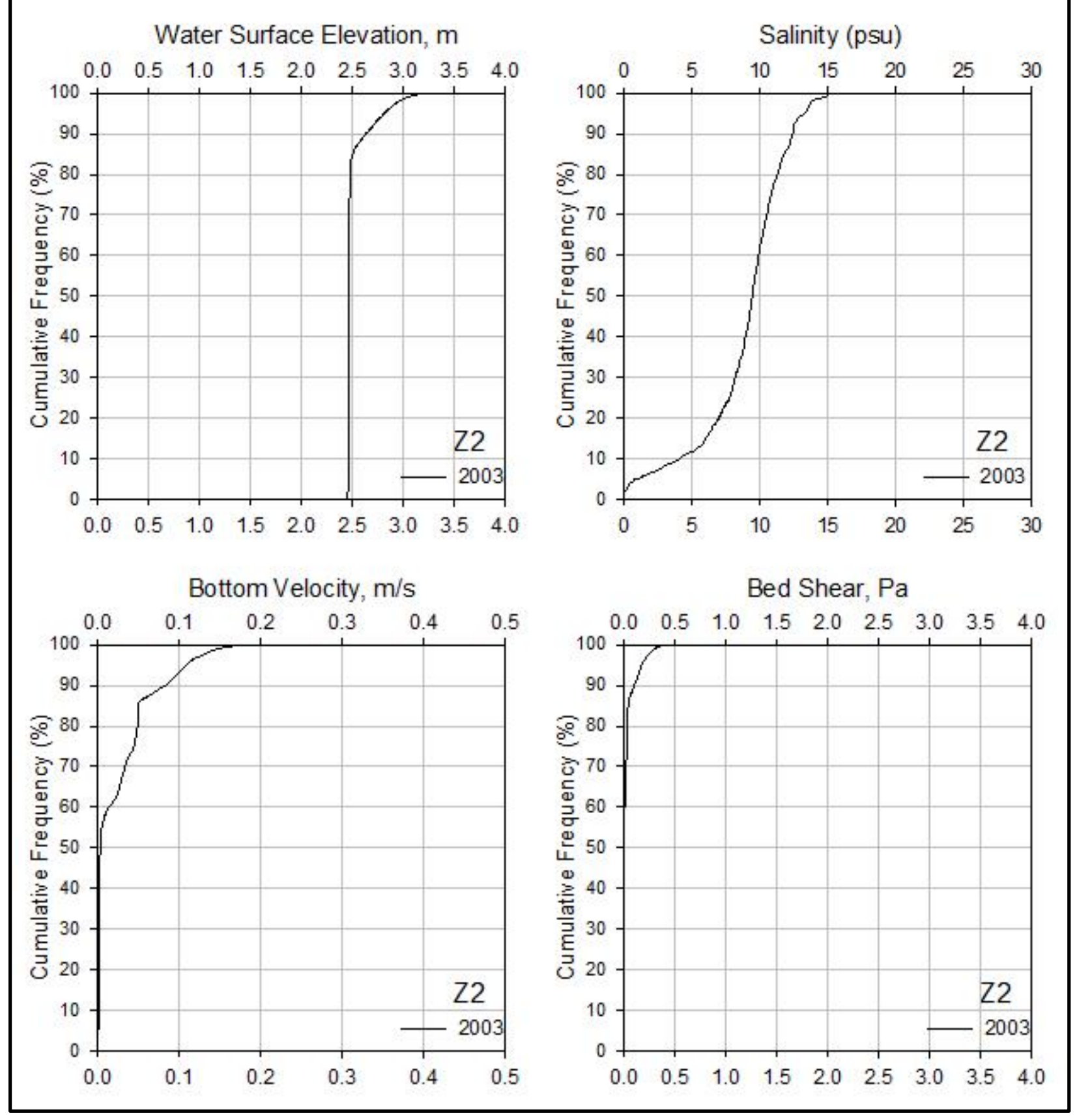

Figure 4-30: Cumulative frequency plots for Scenario 6 - Water-Surface Elevation, Salinity, Bottom Velocity, and Bed Shear at Station Z2 on zis a ba

\subsection{Restoration Scenario 7 - Full Removal of Dike at Leque Island with Full Restoration at zis a ba}

The seventh scenario includes restoration at zis a ba in combination with restoration action at Leque. As shown in Figure 4-31, Scenario 7 involves full restoration of Leque Island (Alternative 1) as described in Scenario 3, along with restoration of zis a ba site. Here, Leque Island will be fully restored 
by the removal of the perimeter dike. On zis a ba, the dike will be removed except for a section along the southeast end that brings the river to its point of inflection, and a new setback dike will be constructed on the southern end of the island as described in Scenario 5 (or 6) previously. This simulation allows examination of the cumulative effects of the two restoration projects on the estuarine response at project sites as well as estuary-wide effects on tidal hydrodynamics.

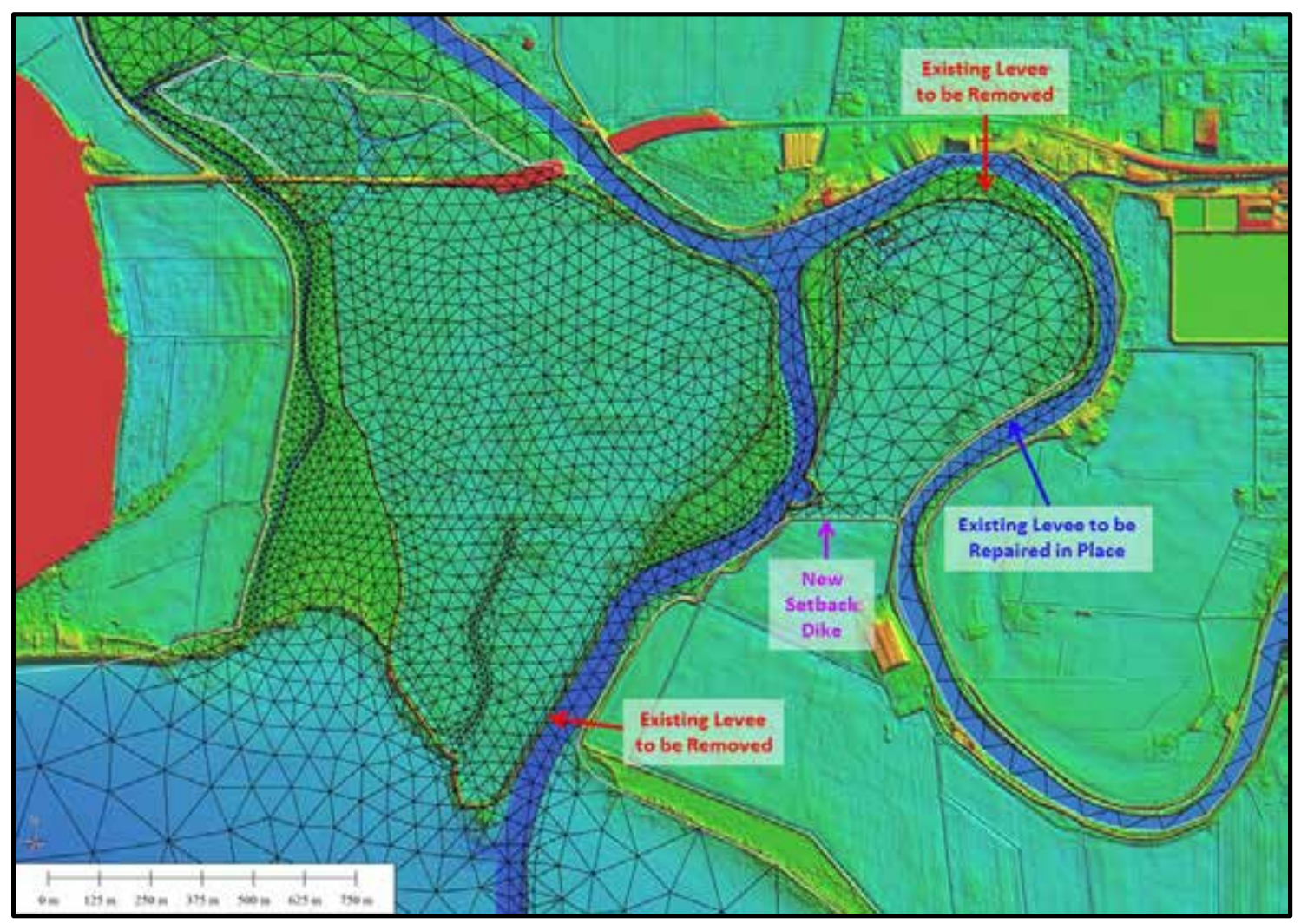

Figure 4-31: (Scenario 7 - zis a ba Restoration + SCN3) Model grid overlaying the lidar elevation map

\subsubsection{October 2005 Conditions}

Scenario 7 is a combination of Scenario 3 and zis a ba restoration as described in Scenario 5. Removal of dikes at both locations results in immediate tidal inundation response at both sites and the presence of the dike sections left intact on zis a ba functions effectively providing the envisioned flood protection and river training benefits. Examination of Scenario 7 results showed that response of zis a ba site was very similar to that obtained for Scenario 5. Similarly response on the Leque Island site was similar that described in Scenario 3.

Figure 4-32 shows snap shots of simulated inundation and salinity during high tide and low tide for Scenario 7 along with Scenario 0 plots for comparison. Salinity within the upper restoration area is between 6.5-14.6 ppt, salinity within the lower Leque restoration area is between 7.2-13.3 ppt, and the salinity on all three stations on zis a ba remains within the range of 6.3-15.7 ppt. The respective restoration sites do not appear to be affected by cumulative effects. The South Pass channel now carries additional flow corresponding to the increased tidal prism from the respective projects. 


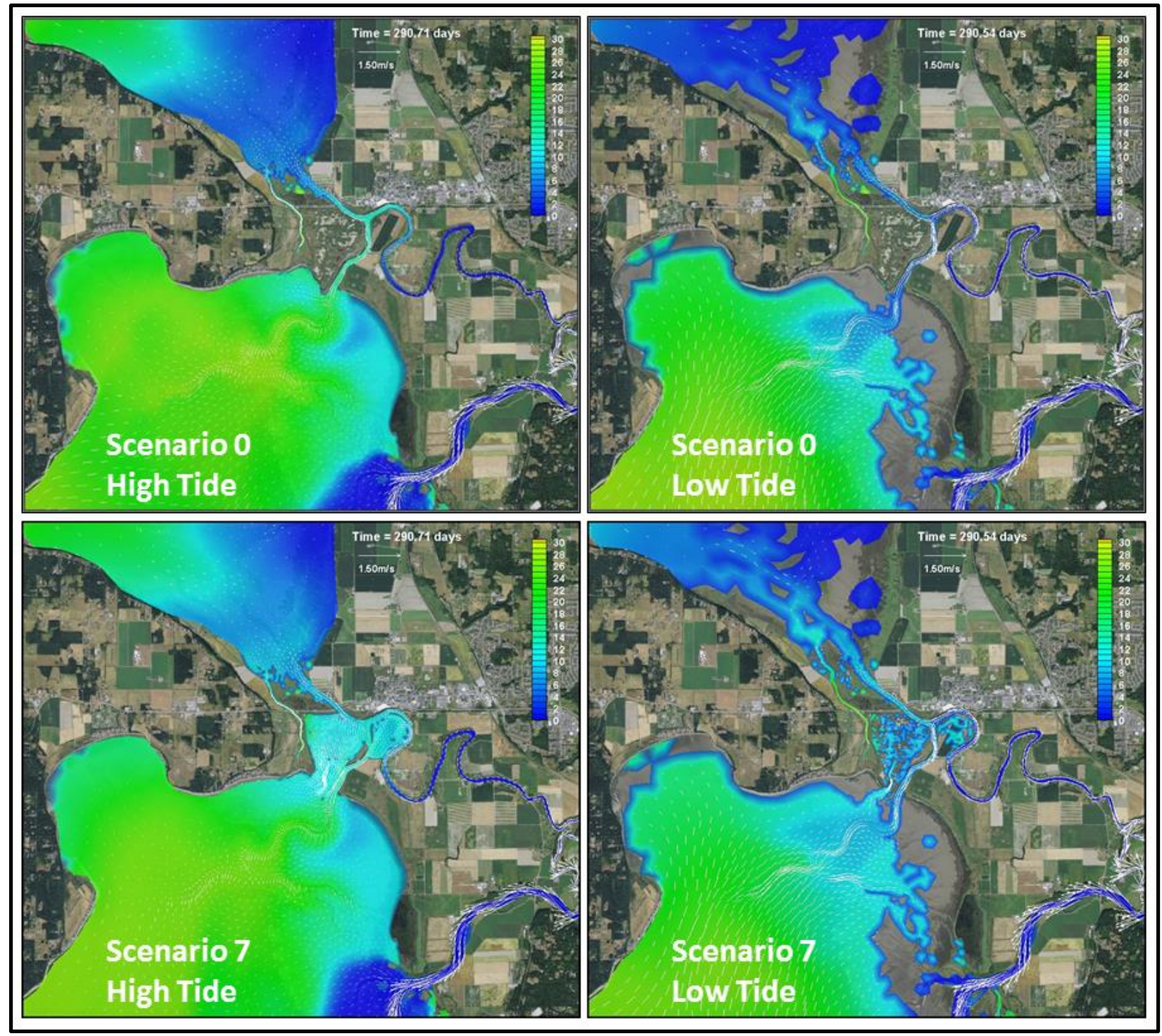

Figure 4-32: Comparison of salinity at high tide and low tide during Scenario 0 and Scenario 7 on October 17, 2005.

\subsubsection{High Flow Conditions}

Focus of high flow simulation was to evaluate the impact of proposed action on bed shear stress during conditions critical for erosion. Bed shear stress results are nearly identical to those obtained for Scenario 5 near zis a ba, and Scenario 3 near Leque Island. Figure 4-33 shows snap shots of simulated bed shear stress during peak ebb and peak flood along with Scenario 0 plots for comparison. 


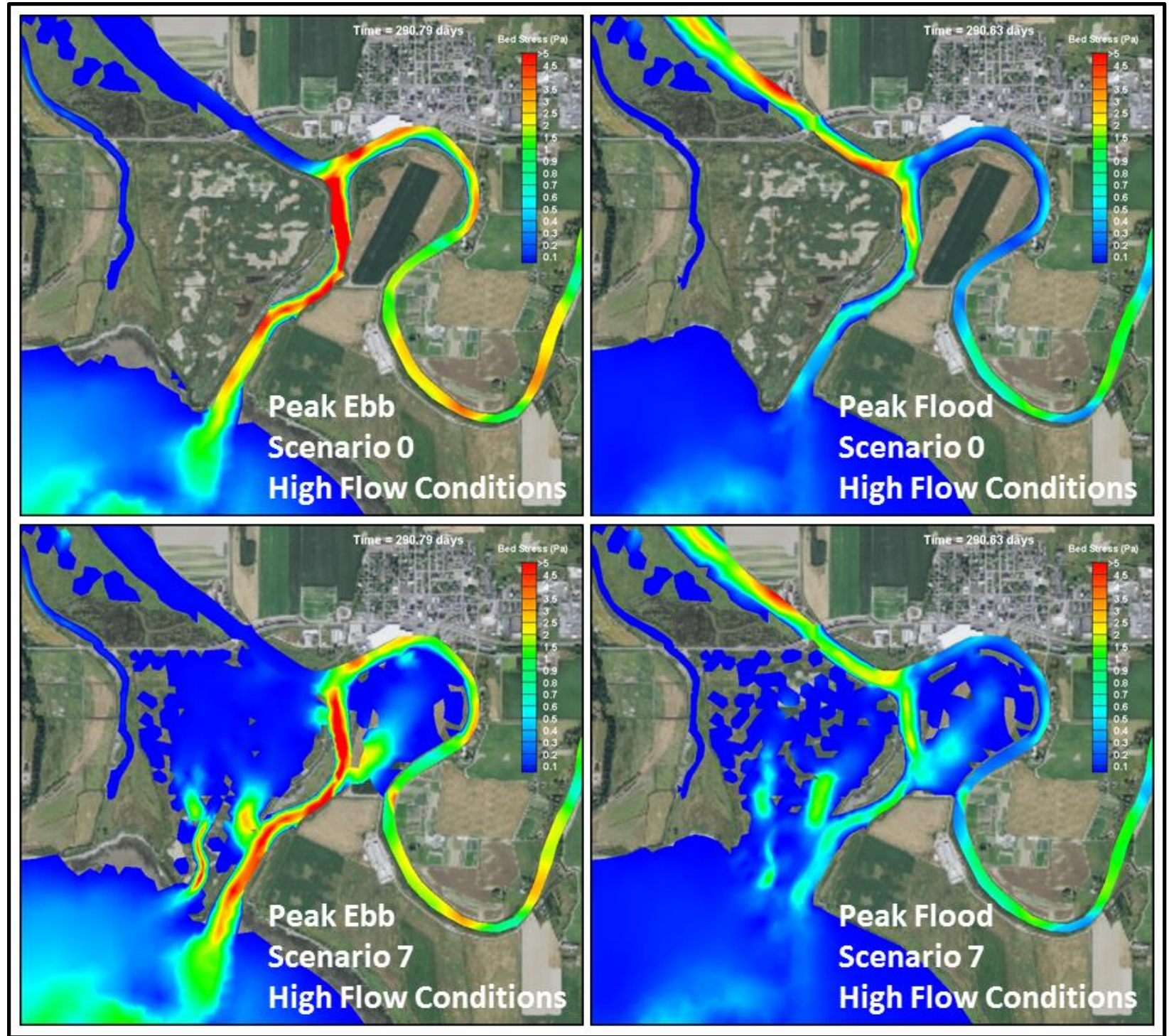

Figure 4-33: Comparison of bed shear stress at peak ebb and peak flood during Scenario 0 and Scenario 7 at high flow conditions

\subsubsection{Year-Long Simulation}

Results from Year 2003 simulation of Scenario 7 were processed and frequency analysis conducted at the selected six stations L1, L2, L3 and Z1, Z2, and Z3 on zis a ba on Leque (see Figure 3-1 for station locations). Figure 4-34 shows frequency plots at the same representative Leque Island station L2. Station L2 as mentioned previously is located within the drainage channel. These results show that the restoration area near Station L2 will be fully inundated $66.9 \%$ of the time, reaching a maximum water depth of $2.64 \mathrm{~m}$. The salinity is predicted to vary between $5-15 \mathrm{ppt}$ for $92.5 \%$ of the time, which is the desired salinity suitable for fish habitat and is similar to the variation seen in Scenario 3. These results indicate that strong estuarine exchange may be expected. Station L1 (upper Leque) is on the northern side of the island and shows inundation $18.7 \%$ of the time, reaching a maximum water depth of $1.09 \mathrm{~m}$. Here, 
the salinity is predicted to vary between $5-15$ ppt for $92.1 \%$ of the time. Station L3 (near Davis Slough) is only inundated $1.2 \%$ of the time, reaching a maximum depth of $0.43 \mathrm{~m}$.

The bed shear stress values for Scenario 7 on Leque Island are very similar to that of Scenario 3, indicating little combined effect between the two scenarios. Bed shear stress at Station L2 will be greater than $0.11 \mathrm{~Pa}$ (sand erosion) for $23.1 \%$ of the time, during which period sand particles may experience resuspension and erosion. Values greater than $1.26 \mathrm{~Pa}$, at which very small gravel may be eroded will occur for 3.4\% of the time. Station L1 (upper Leque) only surpasses $0.11 \mathrm{~Pa}$ (sand erosion) for $5.4 \%$ of the time. Station L3 (near Davis Slough) is only inundated only $1.2 \%$ of the time, and will experience little bed shear stress. (See Appendix $\mathrm{G}$ for cumulative frequency graphs for water-surface elevation, salinity, bottom velocity, and bed shear at all stations).

Figure 4-35 shows frequency plots at the same representative zis a ba station Z2, which is located near the middle of the island. These results show that the restoration area near Station Z2 will be fully inundated $18.1 \%$ of the time, reaching a maximum water depth of $1.08 \mathrm{~m}$. The salinity is predicted to vary between $5-15$ ppt for $87.5 \%$ of the time, which is the desired salinity suitable for fish habitat. Station Z1 (northern zis a ba) will be fully inundated $17.4 \%$ of the time, reaching a maximum water depth of $1.27 \mathrm{~m}$ and will remain within the $5-15$ ppt range for $86.2 \%$ of the time. Station Z3 (southern zis a ba) will be fully inundated $16.8 \%$ of the time, reaching a maximum water depth of $1.10 \mathrm{~m}$ and will remain within the $5-15$ ppt range for $87.2 \%$ of the time. These results demonstrate that zis a ba has a flat profile that will experience similar results across all stations.

Bed shear stresses at stations Z1 (northern zis a ba), Z2 (middle zis a ba), and Z3 (southern zis a ba) were only greater than $0.11 \mathrm{~Pa}$ (sand erosion) for 3.6\%, 9.0\%, and $8.2 \%$ of the time respectively. These values are similar across all stations, indicating that erosion across zis a ba will be limited. 


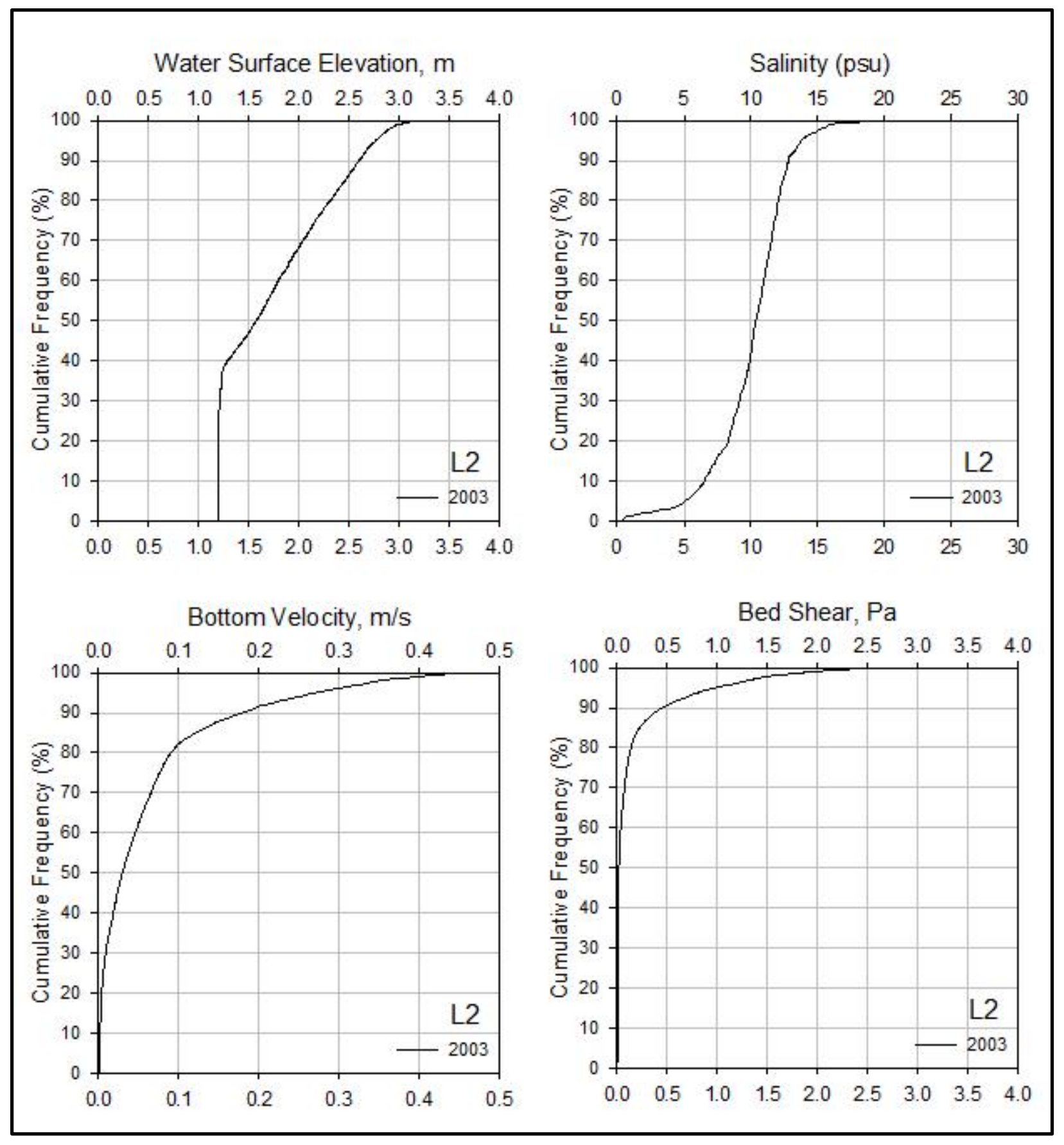

Figure 4-34: Cumulative frequency plots for Scenario 7 - Water-Surface Elevation, Salinity, Bottom Velocity, and Bed Shear at Station L2 on Leque Island 

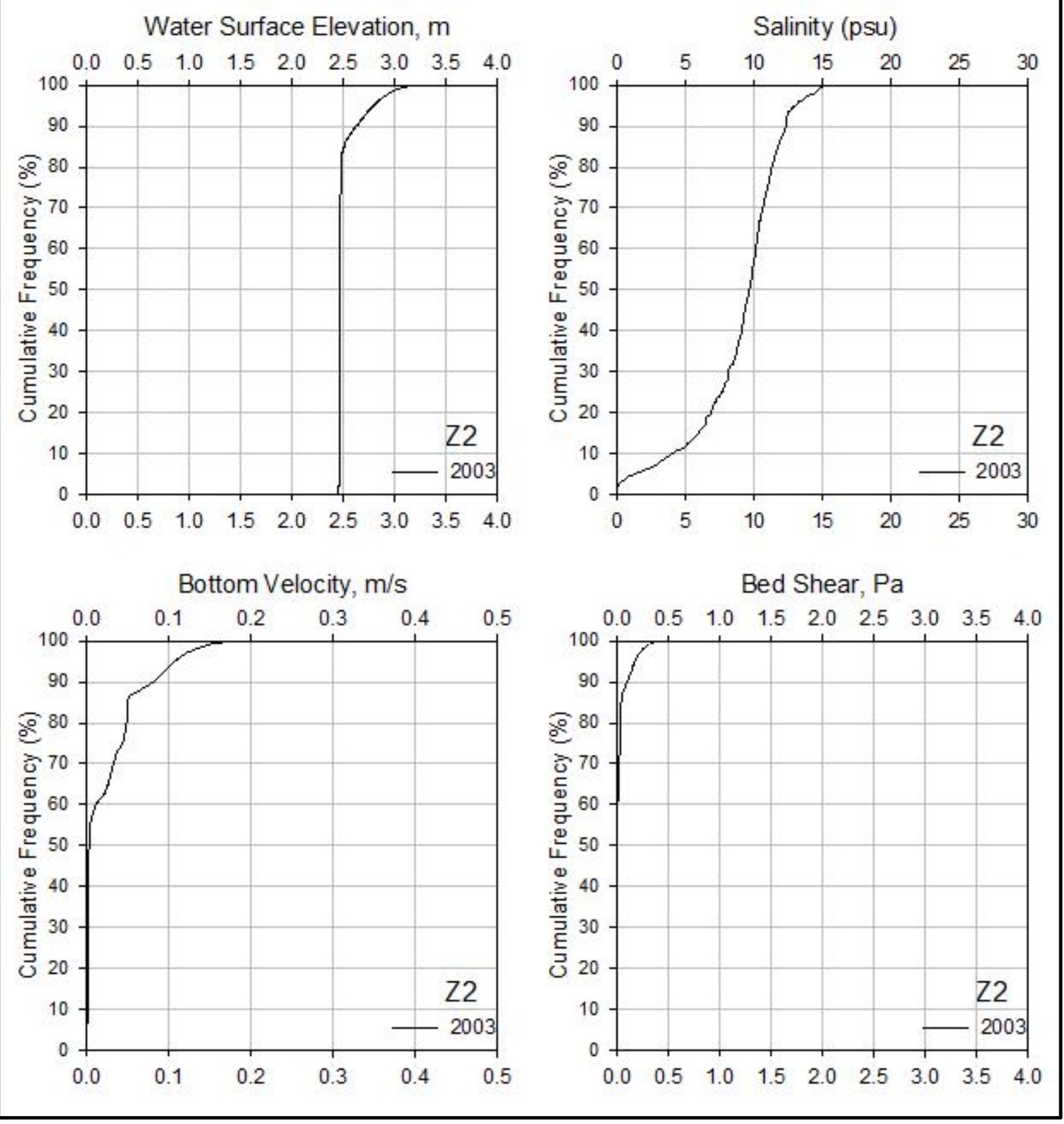

Figure 4-35: Cumulative frequency plots for Scenario 7 - Water-Surface Elevation, Salinity, Bottom Velocity, and Bed Shear at Station Z2 on zis a ba

\subsection{Restoration Scenario 8 - Three Levee Breaches at Leque Island}

Scenario 8 as shown in Figure 4-36 considers the removal of three damaged and temporarily repaired dike segments. Unlike Scenario 2, Scenario 8 does not include the breach at the location of the historic drainage channel which runs in a southerly direction from the center of Leque Island to the southern portion of the Leque perimeter dike. The northern breach on the east side is $145 \mathrm{~m}$ wide, the southern 
breach on the east side is $50 \mathrm{~m}$ wide, the northern breach on the west side is $30 \mathrm{~m}$ wide. This alternative also presents an economically attractive option of removing sections of the dike that have naturally failed so that they can reach equilibrium naturally.

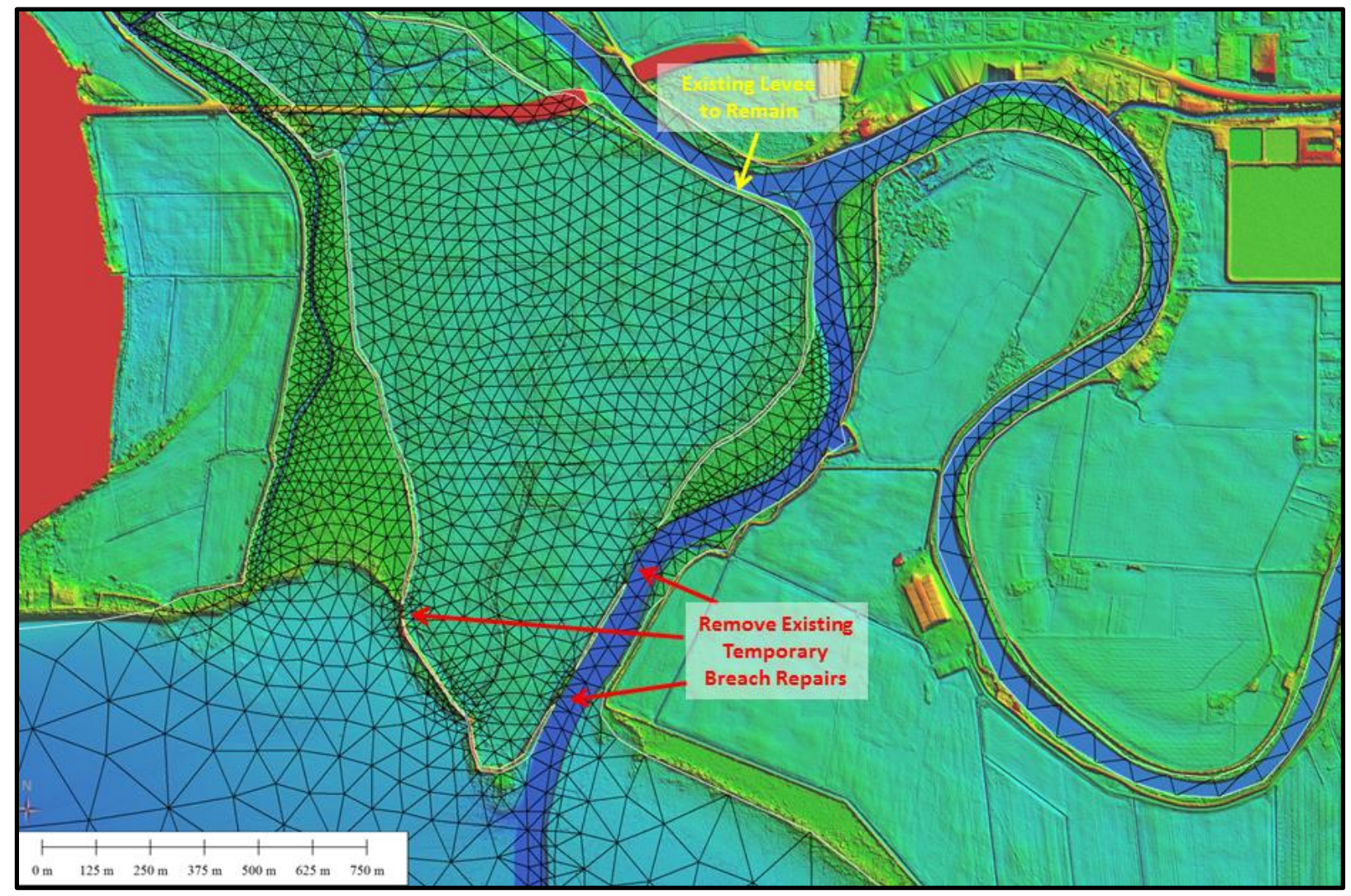

Figure 4-36: (Scenario 8 - Three Breaches) Model grid overlaying the lidar elevation map

\subsubsection{October 2005 Conditions}

Inundation response of Scenario 8 similar to Scenario 2 was of particular interest as it was not intuitively clear at the outset whether the selected design involving only three breaches of varying lengths would be sufficient to provide free flowing tidal exchange or if a muted tidal condition would arise. Results shown in Figure 4-37 show that entire Leque Island is inundated during the flood and drained during the ebb. The drainage channel and similar deeper areas in the southern portion of Leque Island may retains some water as the benefit of direct outlet for low lying areas near the south eastern boundary of Leque Island is not available in this scenario.

Salinity throughout the system outside of the restoration region in Scenario 2 shows minor variations relative to baseline Scenario 0 . The gradients in salinity are comparable to those in baseline conditions. Salinity within the restoration area while inundated remains fairly high, in the range of $12.3 \mathrm{ppt}$ to 22.0 ppt in the northern end of the island and $9.2 \mathrm{ppt}$ to $18.3 \mathrm{ppt}$ near the breaches. This result indicates that the innermost reaches of restored area will experience delayed or weak flushing. This effect is more pronounced in Scenario 8 (with three breaches) relative to Scenario 2 (with four breaches). The high salinity is the result of model startup which was setup with initial values of $30 \mathrm{ppt}$. After 32 days of 
model application, the initial values have not yet reached typical equilibrium levels varying from 5 to 15 ppt in South Pass. It is noted again that contour plots during the ebb tide shows the presence of small wet polygons that are likely a byproduct of the model resolution, contouring software, and the relatively flat intertidal zone with water depth less than $20 \mathrm{~cm}$ restoration.

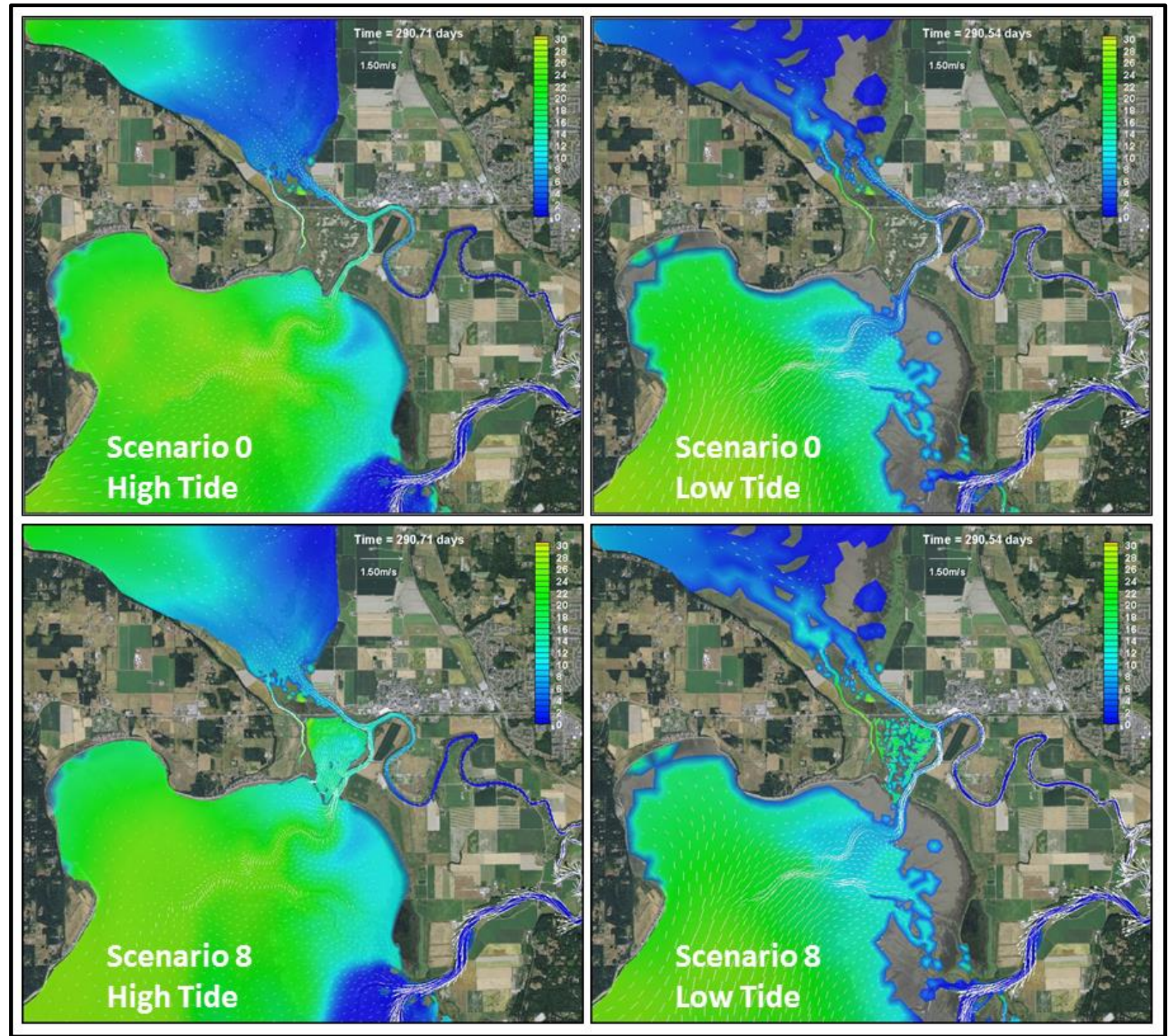

Figure 4-37: Comparison of salinity at high tide and low tide during Scenario 0 and Scenario 8 on October 17, 2005.

\subsubsection{High Flow Conditions}

Focus of high flow simulation was to evaluate the impact of proposed action on bed shear stress during conditions critical for erosion. Very little change is predicted in the bed shear stress in upstream channels. The results of simulation for Scenario 8 shown in Figure 4-38 indicate that the majority of the drainage of Leque Island in this scenario will occur through the breaches along the eastern perimeter through the furthest north breach and to a smaller extent the southern breach. Bed shear stress at these 
opening s are greater than $3 \mathrm{~Pa}$ (north breach), which is enough to displace very small gravel. It is noted that the bed shear at the openings for Scenario 8 in Figure 4-38 are higher than those predicted for Scenario 2 with 4 breaches with the benefit of the historical drainage channel. Predicted Bed shear stresses over most of Leque Island are relatively small. The site drains primarily to South Pass through eastern breaches. This flow combined with South Pass tidal river flow, creates bed shear stresses in excess of $3 \mathrm{~Pa}$ entering the main river channel normal to the flow. This combination of two flows causes an increase in bed shear in South Pass. There are some concerns that drainage from the eastern exit enters perpendicular to South Pass and could exert additional bed shear stress in excess of 3 Pa near the dike opposite the exit. It is recommended that model results be extracted and examined further relative to baseline at the specific sensitive locations of interest.
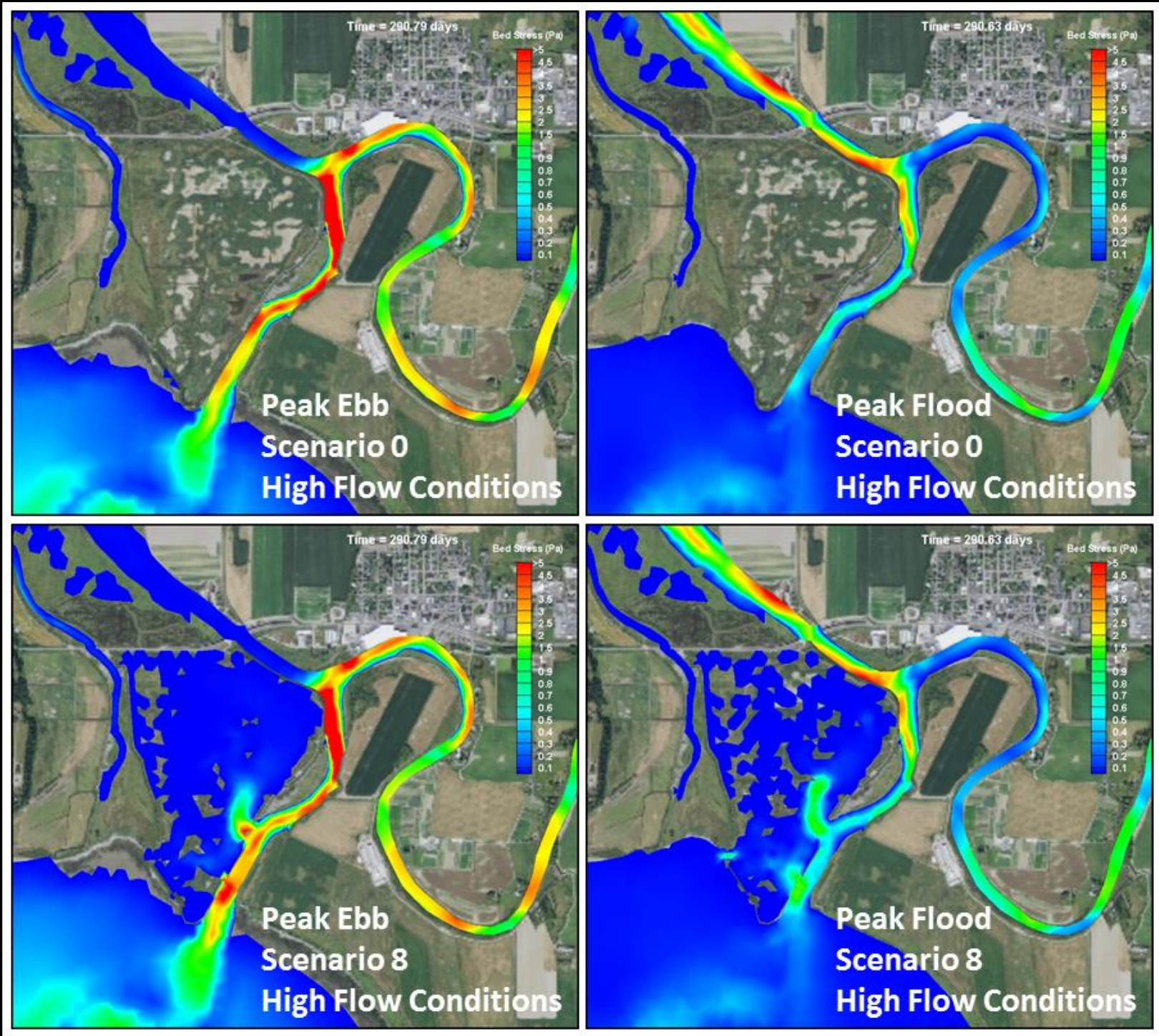

Figure 4-38: Comparison of bed shear stress at peak ebb and peak flood during Scenario 0 and Scenario 8 at high flow conditions 


\subsubsection{Year-Long Simulation}

Results from Year 2003 simulation of Scenario 8 were processed and frequency analysis conducted at the selected six stations L1, L2, L3 and Z1, Z2, and Z3 on zis a ba on Leque (see Figure 3-1 for station locations). This scenario does not include zis a ba site. Figure 4-39 shows frequency plots at a representative Leque Island station L2. Station L2 is located within the drainage channel. These results show that the restoration area will be fully inundated reaching a maximum water elevation of $2.09 \mathrm{~m}$ at station L2. The bed elevation at this site is $1.19 \mathrm{~m}$ showing ponding depth of (2.43-1.19) $1.24 \mathrm{~m}$ and a variation of $0.85 \mathrm{~m}$ from $2.43 \mathrm{~m}$ to $3.28 \mathrm{~m}$ for $23.4 \%$ of the time. These results from L2 indicate that the drainage channel will not be drained and will retain water unless a drainage outlet is created to route the water out of the channel. This reduced flushing creates relatively high salinity reaching a maximum of $24.7 \mathrm{ppt}$, and is predicted to vary between $5-15 \mathrm{ppt}$ for only $68.8 \%$ of the time, which is the desired salinity suitable for fish habitat. Station L1 (upper Leque) is on the northern side of the island and shows inundation $32.9 \%$ of the time, reaching a maximum water depth of $1.09 \mathrm{~m}$. Here, the salinity is predicted to vary between $5-15$ ppt for $79.2 \%$ of the time. This also indicates that the drainage of water out of Leque is slightly slower relative to Scenario 2 with four breaches, resulting in longer time inundated and higher salinity.

The bed shear stresses across the island are comparable to Scenario 2 and other alternatives away from the dike breach locations. Bed shear stress at Station L2 is lower due to smaller velocities and higher water depth in the channel. Bed shear will be greater than $0.11 \mathrm{~Pa}$ (sand erosion) for $23.0 \%$ of the time, during which period sand particles may experience re-suspension and erosion. Values greater than 1.26 Pa, at which very small gravel may be eroded, are predicted around 3.3\% of the time. Station L1 (upper Leque) only surpasses $0.11 \mathrm{~Pa}$ (sand erosion) for $5.3 \%$ of the time. Station L3 (near Davis Slough) is inundated only $1.2 \%$ of the time, and will experience little bed shear stress. (See Appendix G for cumulative frequency graphs for water-surface elevation, salinity, bottom velocity, and bed shear at all stations). 

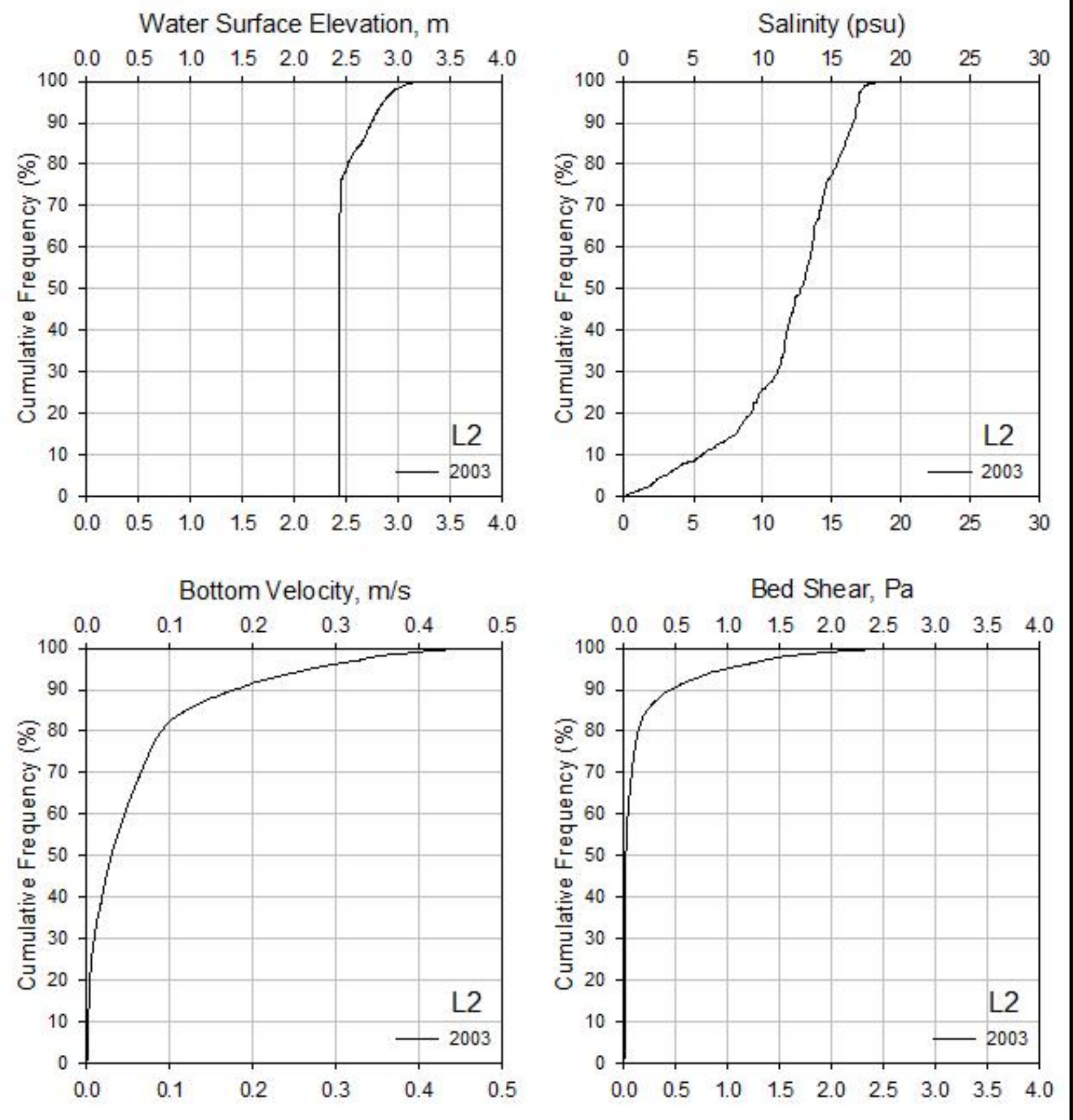

Figure 4-39: Cumulative frequency plots for Scenario 8 - Water-Surface Elevation, Salinity, Bottom Velocity, and Bed Shear at Station L2 on Leque Island 



\subsection{Conclusions}

A three-dimensional hydrodynamic model of Port Susan Bay, Skagit Bay, and the interconnecting Leque Island region was developed with the objective of generating quantitative oceanographic information for various habitat restoration scenarios as part of feasibility assessment. DU in collaboration with WDFW and the Stillaguamish Tribe are evaluating dike removal and dike breaching actions as part of near-shore restoration at Leque Island and zis a ba sites near the mouth of Old Stillaguamish River Channel. Eight restoration scenarios involving combinations of breaching and removal of sections of dikes from the Leque Island and zis a ba sites were evaluated and compared with baseline (existing) conditions. The baseline simulation reproduced coastal hydrodynamics in the intertidal region of interest in Port Susan Bay near the mouth of the Stillaguamish River that is tidally dominated with large variations in water-surface levels $(\approx 3 \mathrm{~m}$ range) and salinity $(0-25 \mathrm{ppt})$. The baseline simulation also showed that the water levels in the Stillaguamish River distributaries entering Port Susan Bay (Hatt Slough and Old Stillaguamish River Channels) are sensitive to the respective distributary channel characteristics over the tidal flats in Port Susan Bay. The tests during model validation also showed that salinity levels and intrusion upriver near the project sites at Leque and zis a ba on Old Stillaguamish River Channel were sensitive to the fraction of the fresh water split between Old Stillaguamish River and Hatt Slough.

Application of the model to the respective scenarios provided several insights on system response to proposed changes. Examination of the simulation results for the typical estuarine conditions of October 2005 leads to the overall conclusion that all restoration scenarios at Leque Island and zis a ba considering removing or breaching of the dikes would result in immediate tidal response and restoration of estuarine functions in the Leque Island and zis a ba project sites. The mean bed elevations at the Leque Island and zis a ba sites behind the dikes are at $2.1 \mathrm{~m}$ and $2.26 \mathrm{~m}$ above NAVD 88 datum, respectively, subject to tides that typically vary from $-1 \mathrm{~m}$ to $2.9 \mathrm{~m}$ in Port Susan Bay, inundating the project sites with 50 to 80 $\mathrm{cm}$ of water every high tide.

All scenarios were also subjected to a bank-full river flow condition and a year-long simulation to examine the potential for erosion and flooding related damage. Simulation results using the Year 2003 conditions, known for a high number of flood flows, show that all scenarios continue to function similar to their predicted response during typical conditions. The location of the restoration sites on Leque Island and zis a ba are at the river mouth and, therefore, dominated by the influence of tidal exchange flow. Other than experiencing lower salinities during the periods of high river flow, increase in water-surface elevation of $20 \mathrm{~cm}$, slightly higher velocities and bed shear stresses, all scenarios show behavior and gradients similar to those predicted during typical conditions. Results do not show a further increase in water-surface levels or inundation as a result of restoration related change relative to the baseline for high flow conditions. The results do however show a small increase in velocities and bed shear in Old Stillaguamish River West Pass and South Pass which appears to be a result of increase in tidal prism associated with the restoration action. 
Highest elevations for the restoration sites were predicted for winter months (December 25, 2003) during which Puget Sound is subjected to highest incoming tides from the Pacific Ocean. The water levels during this period reached heights capable of inundating most of Davis Slough and connected to Port Susan Bay.

Specific comments and conclusions as they pertain to each restoration scenario are discussed below.

- Scenario 1 - Partial Restoration at Leque Island: Removal of the southern portion of the Leque Island levee and the construction of an inner setback levee results in restoration of intertidal flow over Leque Island up to the setback dike. This scenario includes the presence of a historic drainage channel. The predicted result is an intertidal region that is inundated with tides from Port Susan which merges with South Pass at high tide and drains out through the historic channel.

- Scenario 2 - Four Levee Breaches at Leque Island: Four breaches along the southern end of the Leque Island levee, three at previous locations of failure and one at the exit to the historic drainage channel appear to provide sufficient conveyance to allow intertidal exchange to occur. The simulations show minor signs of muted tidal conditions. The drainage channel in this scenario alone was affected by shallow sill like depths near the openings associated with proximity to the dike structure and results in some ponding. This may be eliminated by ensuring that sediment channel openings are cleared through dredging.

- Scenario 3 - Full Removal of Dike at Leque Island (Alternative 1). The full removal of the perimeter dike allows tidal inundation of the Leque Island. During high tide the water surfaces of Leque Island, West Pass, and South Pass merge forming large contiguous pool leaving only a high elevation region along South Pass to remain as an Island. Davis Slough remains unaffected except during extreme high tides which occur during the winter. Ebbing waters from Old Stillaguamish River and West Pass flow over Leque Island for a short duration with potential for bank erosion but also potential benefit of river sediment delivery over the marsh.

- Scenario 4 - Full Removal of Lower Dike at Leque Island (Alternative 2): Removal of the southern and western segments of the Leque Island levee only, allowing the levee along the northeast corner to remain restricts the tidal inundation via Port Susan only. The presence of the northeast segments of the Leque Island dike retained in this scenario prevents Skagit Bay tidal water access to Leque and overland ebbing of West Pass and Old Stillaguamish River. The simulated behavior of Scenario 4 is otherwise comparable to Scenario 3, resulting in full restoration of tidal inundation.

- Scenario 5 - Partial Restoration at Leque Island with Full Restoration at zis a ba: Removal of the southern portion of the Leque Island levee and the construction of an inner setback levee as in Scenario 1 is included in this scenario and appears to function well independent of the restoration action at zis a ba. Removal of zis a ba levee except for the southeast corner and the construction of a setback levee along the south end results in complete inundation of the site during high tides. Zis a ba is inundated with tidal flood water mostly from South Pass but also influenced by mixed water from West Pass. The site ebbs primarily from its connection to South Pass. 
- Scenario 6 - Full Removal of Lower Dike at Leque Island with Full Restoration at zis a ba: Removal of the southern and western segments of the Leque Island levee only, allowing the levee along the northeast corner to remain (as in Scenario 4) is included in this scenario and appears to function well independent of the restoration action at zis a ba. Removal of zis a ba levee results in complete inundation of the site during high tides as in Scenario 5 and is unaffected by the restoration action at Leque Island. Zis a ba is inundated with tidal flood water mostly from South Pass but also influenced by mixed water from West Pass. The site ebbs primarily from its connection to South Pass.

- Scenario 7 - Full Removal of Dike at Leque Island with Full Restoration at zis a ba. Full removal of the existing Leque Island levee south of Highway 532 (as in Scenario 3) is included in this scenario and appears to function well independent of the restoration action at zis a ba. Removal of zis a ba levee results in complete inundation of the site during high tides as in Scenario 5 and 6 and also is unaffected by the restoration action at Leque Island. Removal of zis a ba levee as described previously results in complete inundation of the site during high tides. Zis a ba is inundated with tidal flood water mostly from South Pass but also influenced by mixed water from West Pass. The site ebbs primarily from its connection to South Pass.

- Scenario 8 - Three Levee Breaches at Leque Island: Three breaches along the southern end of the Leque Island levee at previous locations of failure. This scenario is also sometimes referred to as the no-action alternative in which the dikes would be allowed to fail naturally, resulting in breaches. This scenario does not include the natural drainage channel and as a result shows signs of ponded water along the southern perimeter. The openings are sufficiently large such that they do not cause major muted tidal conditions but tidal exchange and flushing are reduced relative to Scenario 2 with four breaches.

To facilitate quantitative comparison of scenarios, cumulative frequency statistics were generated for parameters of interest (Appendix G). The resulting numbers are summarized here, tabulated with reference to preferred habitat goals in terms of inundation periods, preferred salinity ranges, and bed shear levels. Table 5-1 provides the percentage of time that representative stations on Leque Island and zis a ba were inundated and the maximum depth achieved. Table 5-2 indicates the percentage of time during which salinity values remained between 5-15 ppt.

Table 5-1: Water-surface level response for year-long simulation across all scenarios

\begin{tabular}{|c|c|c|c|c|c|}
\hline \multirow{2}{*}{ Scenario } & \multicolumn{5}{|c|}{ Percentage of Time Inundated (and maximum depth) } \\
\cline { 2 - 6 } & L1 (upper) & L2 (lower) & Z1 (upper) & Z2 (middle) & Z3 (lower) \\
\hline SCN1 & - & $66.6 \%(2.63 \mathrm{~m})$ & - & - & - \\
\hline SCN2 & $28.4 \%(1.08 \mathrm{~m})$ & $53.0 \%(2.63 \mathrm{~m})$ & - & - & - \\
\hline SCN3 & $18.4 \%(1.09 \mathrm{~m})$ & $66.8 \%(2.63 \mathrm{~m})$ & - & - & - \\
\hline SCN4 & $28.6 \%(1.08 \mathrm{~m})$ & $67.8 \%(2.63 \mathrm{~m})$ & - & - & - \\
\hline SCN5 & - & $66.7 \%(2.63 \mathrm{~m})$ & $17.4 \%(1.28 \mathrm{~m})$ & $17.8 \%(1.08 \mathrm{~m})$ & $16.7 \%(1.10 \mathrm{~m})$ \\
\hline SCN6 & $28.2 \%(1.09 \mathrm{~m})$ & $68.2 \%(2.63 \mathrm{~m})$ & $23.5 \%(1.28 \mathrm{~m})$ & $17.8 \%(1.09 \mathrm{~m})$ & $16.7 \%(1.10 \mathrm{~m})$ \\
\hline SCN7 & $18.7 \%(1.09 \mathrm{~m})$ & $66.9 \%(2.64 \mathrm{~m})$ & $17.4 \%(1.27 \mathrm{~m})$ & $18.1 \%(1.08 \mathrm{~m})$ & $16.8 \%(1.10 \mathrm{~m})$ \\
\hline SCN8 & $32.9 \%(1.09 \mathrm{~m})$ & $23.4 \%(2.64 \mathrm{~m})$ & - & - & - \\
\hline Note: Station L3 (near Davis Slough) was inundated $1.3 \%$ of the time at $0.43 \mathrm{~m}$ depth, and did not change. \\
\hline
\end{tabular}


Table 5-2: Salinity response for year-long simulation across all scenarios

\begin{tabular}{|c|c|c|c|c|c|}
\hline \multirow{2}{*}{ Scenario } & \multicolumn{5}{|c|}{ Percentage of Time Salinity Ranges between 5 - 15 ppt } \\
\cline { 2 - 6 } & L1 (upper) & L2 (lower) & Z1 (upper) & Z2 (middle) & Z3 (lower) \\
\hline SCN1 & - & $91.1 \%$ & - & - & - \\
\hline \multirow{2}{*}{ SCN2 } & $98.0 \%$ & $94.4 \%$ & - & - & - \\
& & & & - & - \\
\hline SCN3 & $92.5 \%$ & $93.2 \%$ & - & - & - \\
\hline SCN4 & $90.9 \%$ & $91.6 \%$ & - & $87.1 \%$ & $87.3 \%$ \\
\hline SCN5 & - & $91.2 \%$ & $87.3 \%$ & $87.5 \%$ & $87.6 \%$ \\
\hline SCN6 & $91.4 \%$ & $91.2 \%$ & $87.1 \%$ & $87 \%$ & $87.2 \%$ \\
\hline SCN7 & $92.1 \%$ & $92.5 \%$ & $86.2 \%$ & $87.5 \%$ & - \\
\hline SCN8 & $79.2 \%$ & $68.8 \%$ & - & - & \\
\hline $\begin{array}{l}\text { Note: Station L3 (near Davis Slough) was only inundated for 1.2\% of the time, so the } \\
\text { model could not accurately predict salinity at this station. }\end{array}$
\end{tabular}

Table 5-3 provides the percentage of time that bed shear stresses exceed $0.11 \mathrm{~Pa}$ (sand erosion) and $1.26 \mathrm{~Pa}$ (gravel erosion).

Table 5-3: Bed shear stress response for year-long simulation across all scenarios

\begin{tabular}{|c|c|c|c|c|c|c|}
\hline \multirow[t]{2}{*}{ Scenario } & \multicolumn{6}{|c|}{$\begin{array}{c}\text { Percentage of Time that Bed Shear Stress will be greater than } 0.11 \mathrm{~Pa} \text { (sand erosion) and } 1.26 \mathrm{~Pa} \\
\text { (gravel erosion) }\end{array}$} \\
\hline & L1 (>0.11Pa) & L2 (>0.11Pa) & L2 (>1.26Pa) & $\mathrm{Z1}(>0.11 \mathrm{~Pa})$ & $\mathrm{Z2}$ (>0.11Pa) & $\mathrm{Z3}(>0.11 P a)$ \\
\hline SCN1 & - & $23.2 \%$ & $3.3 \%$ & - & - & - \\
\hline SCN2 & $0.4 \%$ & $4.5 \%$ & $0.0 \%$ & - & - & - \\
\hline SCN3 & $5.7 \%$ & $24.4 \%$ & $3.7 \%$ & - & - & - \\
\hline SCN4 & $5.3 \%$ & $23.6 \%$ & $3.4 \%$ & - & - & - \\
\hline SCN5 & - & $23.0 \%$ & $3.3 \%$ & $3.6 \%$ & $9.0 \%$ & $8.1 \%$ \\
\hline SCN6 & $5.3 \%$ & $23.8 \%$ & $3.4 \%$ & $3.6 \%$ & $9.3 \%$ & $8.4 \%$ \\
\hline SCN7 & $5.4 \%$ & $23.1 \%$ & $3.4 \%$ & $3.6 \%$ & $9.0 \%$ & $8.2 \%$ \\
\hline SCN8 & $5.3 \%$ & $23.0 \%$ & $3.3 \%$ & - & - & - \\
\hline
\end{tabular}

From an ecological standpoint, the simulation results were very promising. In all except Scenario 8, salinity ranged between the desired $5-15$ ppt for $\approx 92 \%$ of the time. Scenario 8 showed signs of reduced flushing and tidal exchange that resulted in longer time for salinity to reach equilibrium. Both Scenarios 2 and 8 show potential signs for ponding to occur associated with blockage of drainage channels or insufficient conveyance. This ponding may be mitigated by ensuring that drainage channels are designed with depth below mean lower low water and large breach sizes. All other scenarios show inundation between $20-60 \%$ of the time depending on the bed elevation moving from north to south along Leque Island. It is noted that all scenarios result in significant drainage flow from Leque Island to South Pass. The result is increased bed shear stress near the entrances, so further examination and design consideration is recommended to ensure flows draining from the restoration area do not impact neighboring dikes along the opposite banks.

Only one zis a ba alternative was simulated in conjunction with other Leque Island alternatives and found to provide the desired intertidal marsh restoration response. The bed elevation of the entire zis a ba restoration area is relatively flat, resulting in uniform conditions and a response that is similar at all three stations examined. Salinity levels are consistently within the desired range of $5-15 \mathrm{ppt} \approx 87 \%$ of the time and do not exceed 15 ppt. Zis a ba will be inundated less than $20 \%$ of the time at depths under 1.3 meters. 
While this does not appear as adequate inundation time it is noted that a similar restored habitat was created to the north of Leque Island as a result of a tidal gate failure, and the area has been well utilized by local wildlife. As in Leque Island, bed shear stress on zis a ba also is also predicted to be highest near the exit at the southwest corner of site. The southwest entrance to the site will likely evolve until an equilibrium cross section is reached. It is noted that the alignment of the channel based on shear stress contours is in the direction of tidal flow in South Pass, which may prevent additional shear stresses on remaining dikes.

Simulation results indicate that all scenarios provide estuarine response consistent with the planned design. None of the simulations showed a measurable increase in water-surface levels in the surrounding regions relative to existing conditions as a result of restoration action. An increase in velocities and bed shear was noted for all scenarios associated with the increase in tidal prism, especially in channels downstream of the restoration sites. The degree to which these increases were noted varied among the different scenarios. Another important finding was that restoration actions at Leque and zis a ba appear to function independent of one another and cumulative effects were not found to be significant. The overall conclusion based on these results is that restoration of estuarine functions and marsh habitat is feasible through the proposed actions at Leque Island and zis a ba sites. To better address site-specific questions and concerns related to impacts of the proposed restoration on neighboring infrastructure such as dikes, outfalls, docks, and pipelines with respect to inundation, sedimentation, and erosion, it is recommended that model results be extracted and examined further relative to baseline at the specific sensitive locations of interest. 



\subsection{References}

Cereghino P, J Toft, C Simenstad, E Iverson, S Campbell, C Behrens, J Burke. 2012. Strategies for Nearshore Protection and Restoration in Puget Sound. Prepared for the Puget Sound Nearshore Ecosystem Restoration Project. Technical Report 2012-01

Conroy D. 2004. Brief History of Leque Island. Stanwood Area Echoes, Issue 27.

Fresh K, M Dethier, C Simenstad, M Logsdon, H Shipman, C Tanner, T Leschine, T Mumford, G Gelfenbaum, R Shuman, J Newton. 2011. Implications of Observed Changes to the Nearshore Ecosystems in Puget Sound. Prepared for the Puget Sound Nearshore Ecosystem Restoration Project. Technical Report 2011-03.

Julien, P. Y. 1998. Erosion and Sedimentation. Cambridge University Press.

Stillaguamish Implementation Review Committee (SIRC). 2005. Stillaguamish Watershed Chinook Recovery Plan. Published by Snohomish County Department of Public Works, Surface Water Management Division. Everett, WA.

Skagit River System Cooperative. 2014. Logic Model for Juvenile Chinook-Hydrodynamics Interactions. Personal communication from Greg Hood of Skagit River System Cooperative to Tarang Khangaonkar of Pacific Northwest National Laboratory (e-mail communication 11/4/2014).

Washington Department of Fish and Wildlife. 2014. Wildlife Areas: Leque Island Unit. http://wdfw.wa.gov/lands/wildlife_areas/skagit/Leque\%20Island/, Accessed 11/19/14.

Washington Department of Fish and Wildlife. 2Wolman, MG, and JP Miller. 1960. Magnitude and frequency of forces in geomorphic processes. Journal of Geology 68(1):54-74.

Yang Z, T Khangaonkar, C Lee. 2008. Hydrodynamic Modeling Analysis for Leque Island Restoration Feasibility Study. Prepared for Ducks Unlimited, Inc. Document Number PNWD-3813. 



\section{Appendix A}

Time Series Plots - October 2005 Conditions - WSL, Salinity, Velocity, Bed Shear 



\section{Appendix A}

\section{Time Series Plots - October 2005 Conditions - WSL, Salinity, Velocity, Bed Shear}

October 2005 water-surface elevations, salinities, velocities, and bed sheers for Leque Island and zis a ba are provided in this appendix.

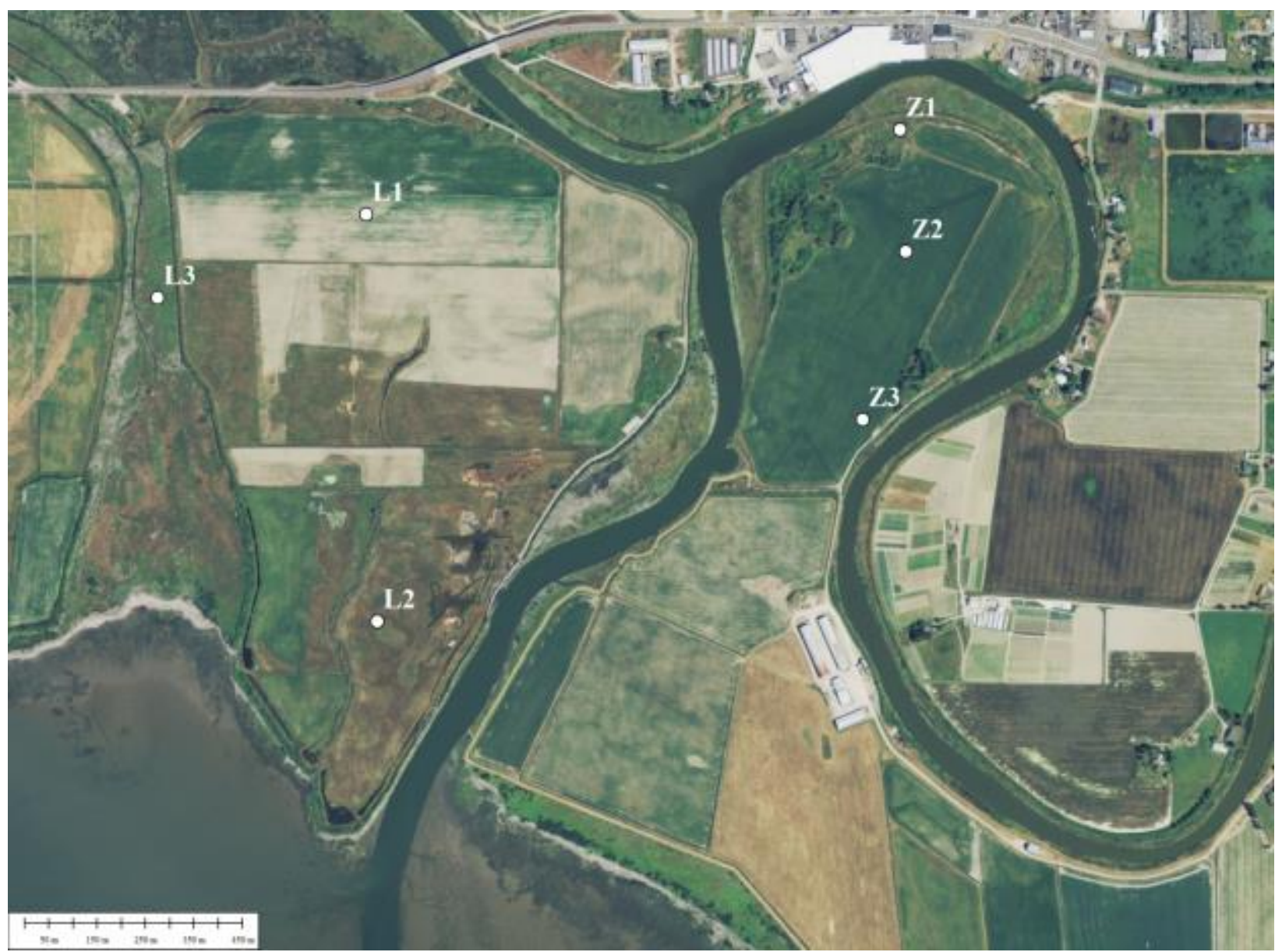

Figure A-1: Leque and zis a ba restoration site plan view and time series station locations 


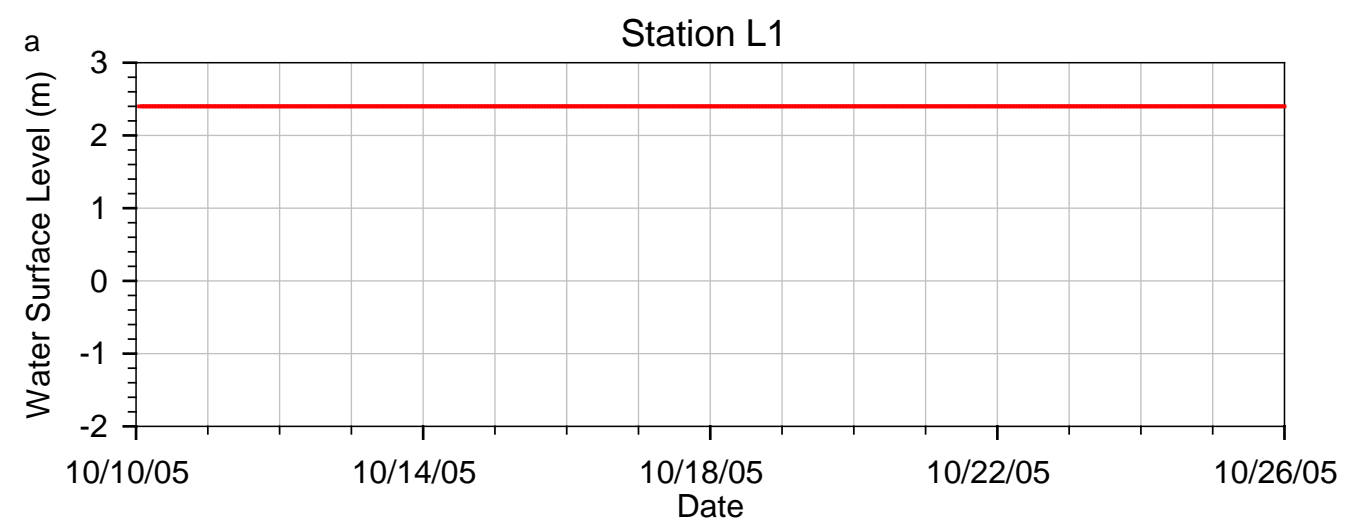

b
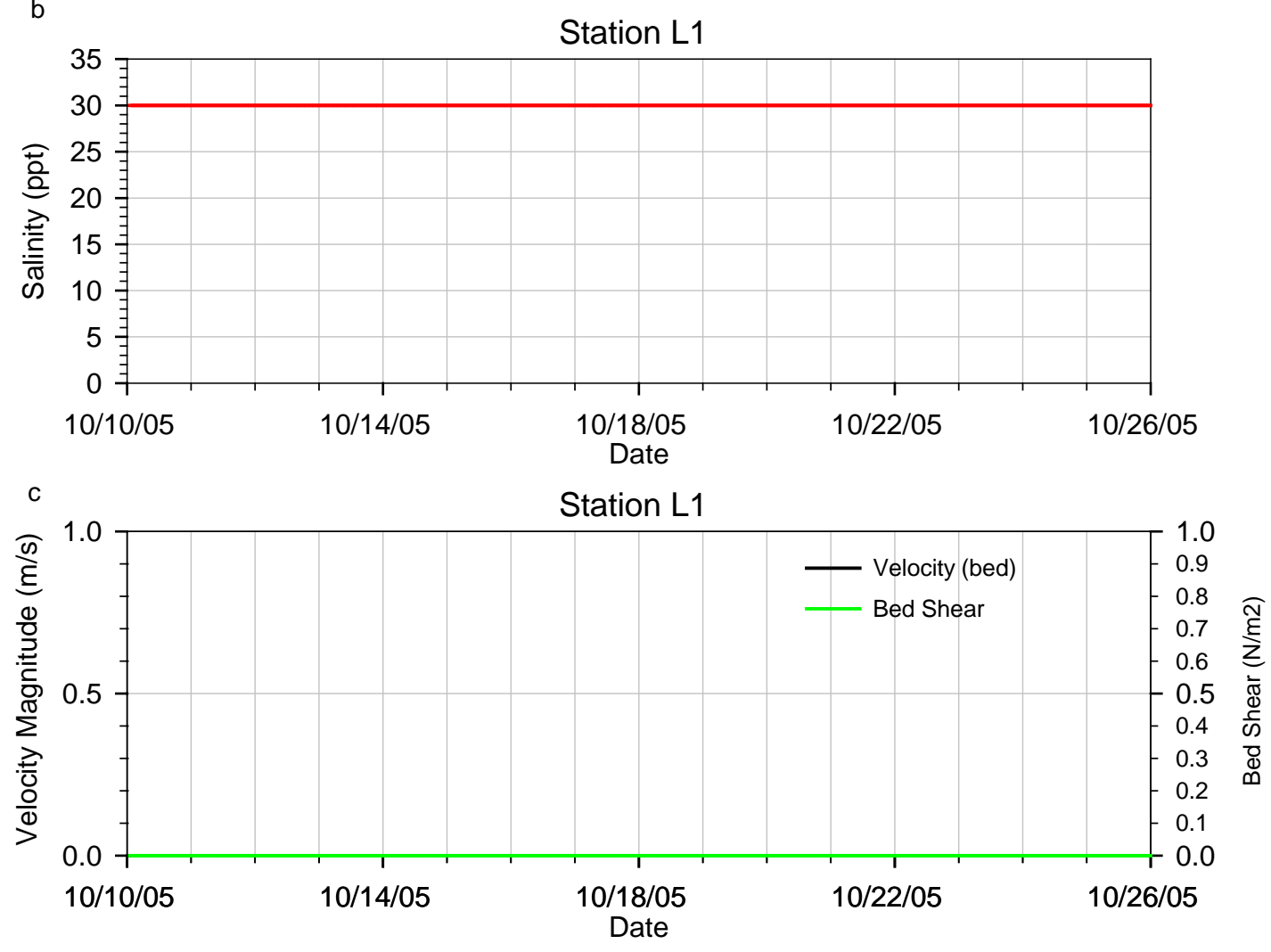

Figure A-2: Scenario 0 (Baseline Condition) - Water-surface elevation, salinity, velocity magnitude, and bed shear stress at Leque Island restoration station L1, October 2005 period 


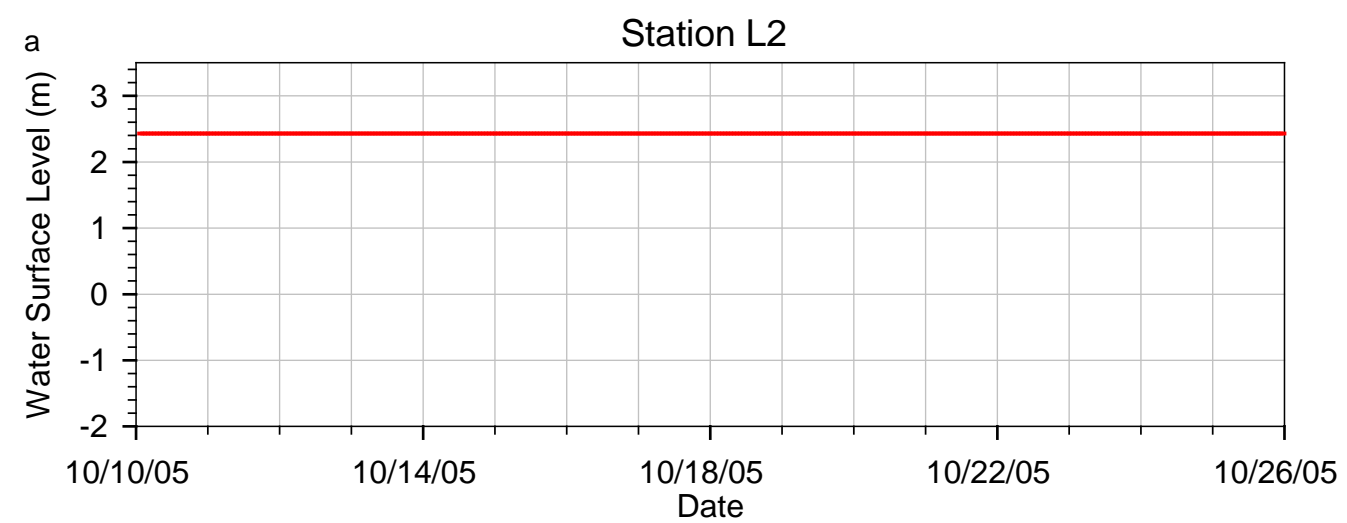

b
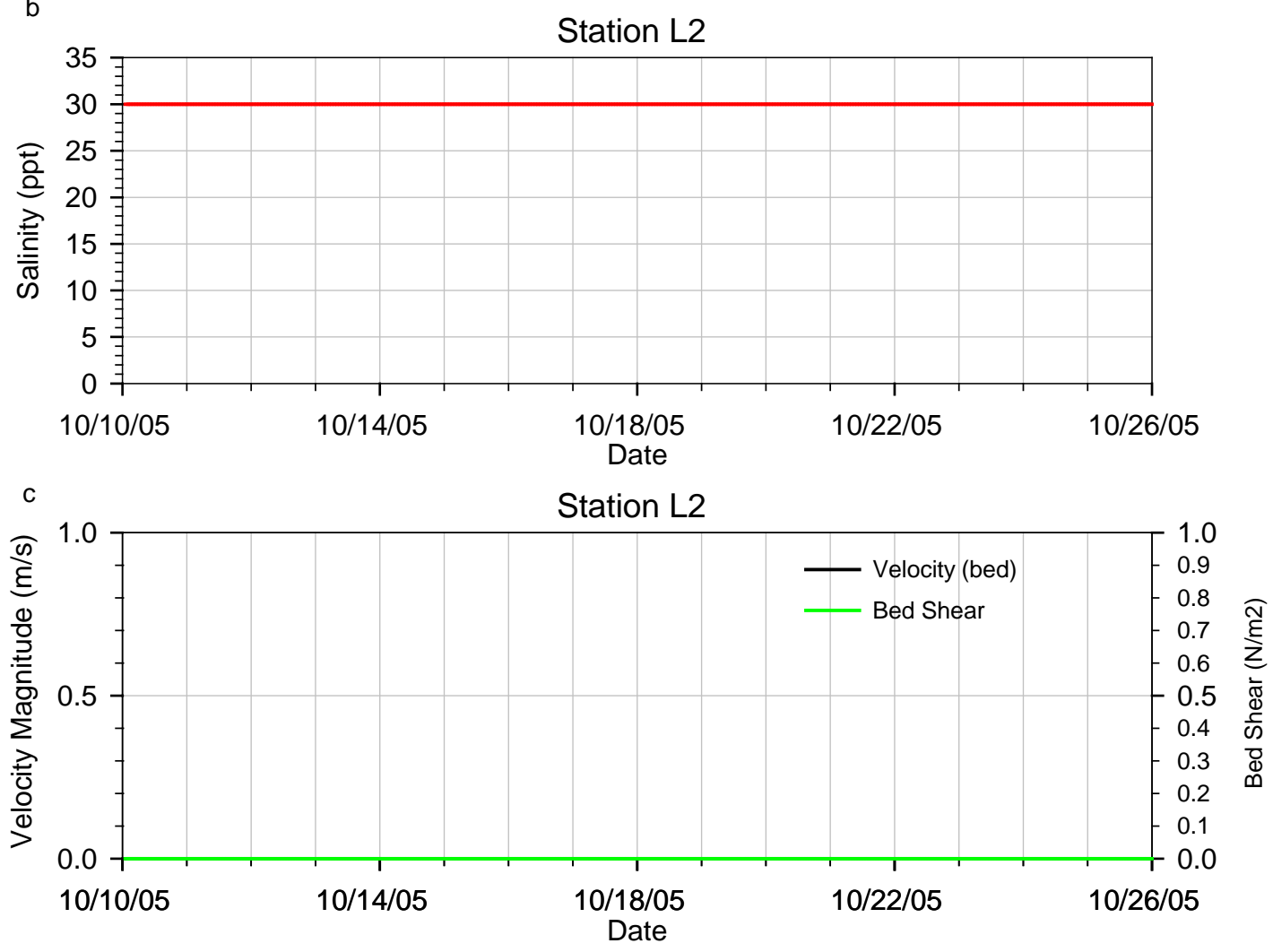

Figure A-3 : Scenario 0 (Baseline Condition) - Water-surface elevation, salinity, velocity magnitude, and bed shear stress at Leque Island restoration station L2, October 2005 period 


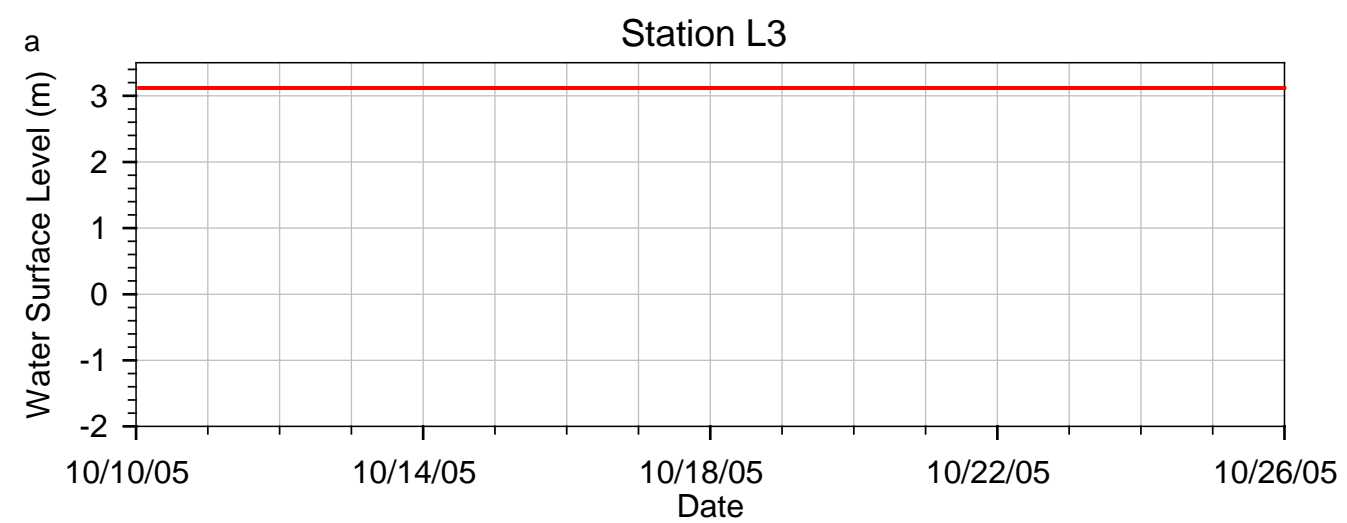

b
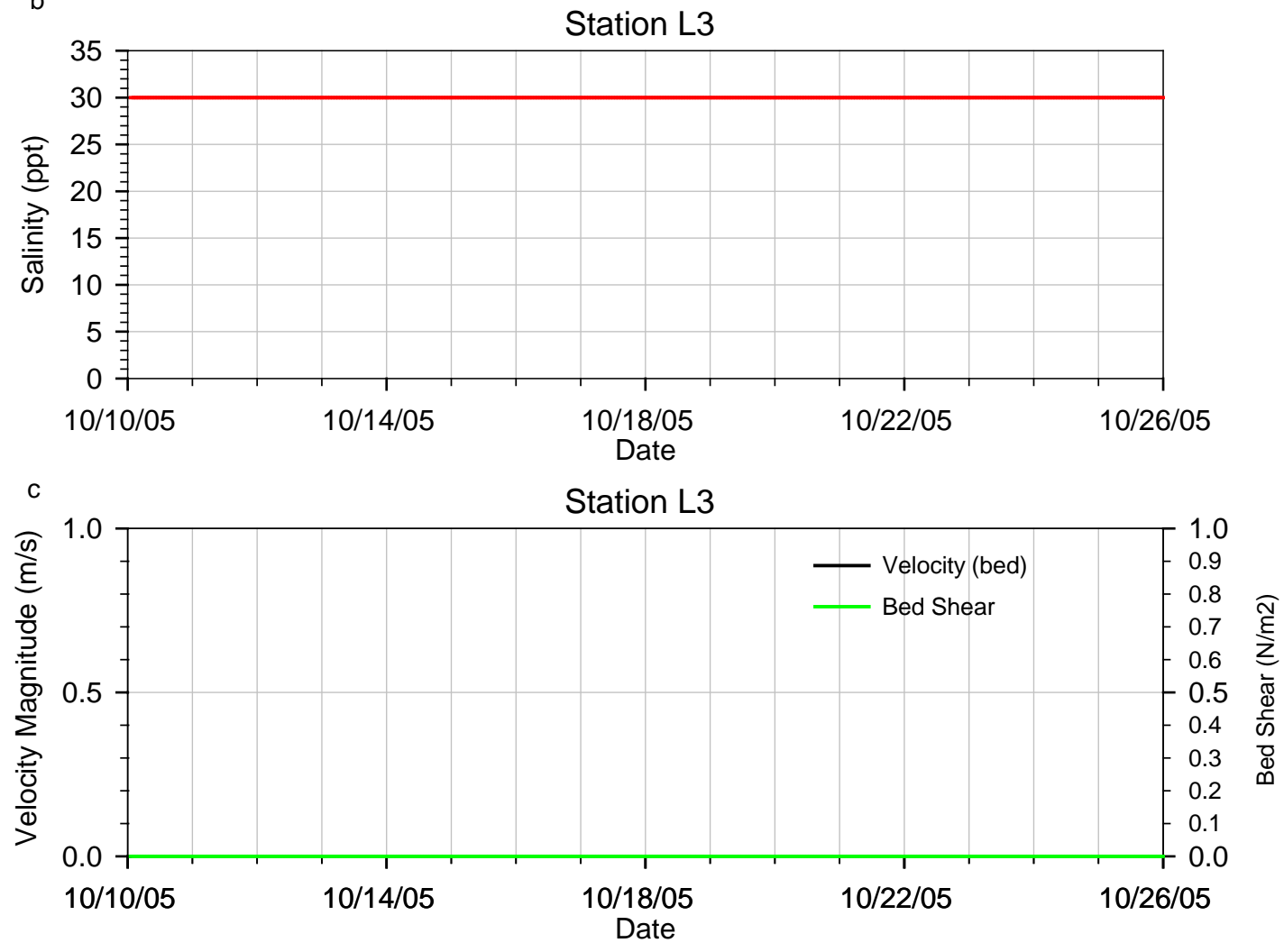

Figure A-4: Scenario 0 (Baseline Condition) - Water-surface elevation, salinity, velocity magnitude, and bed shear stress at Leque Island restoration station L3, October 2005 period 


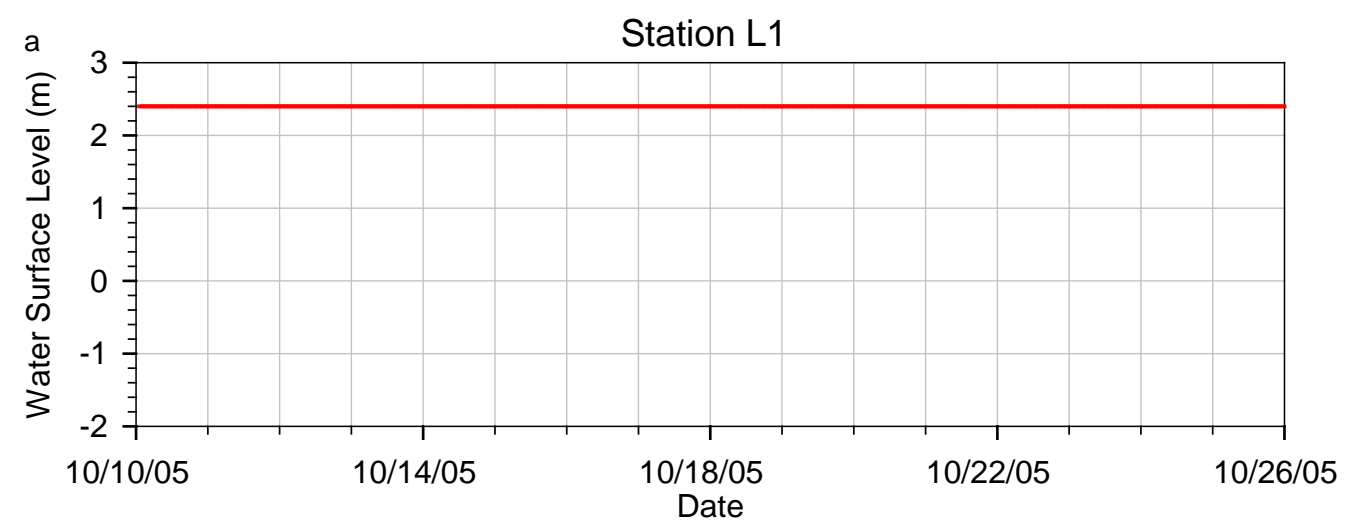

b
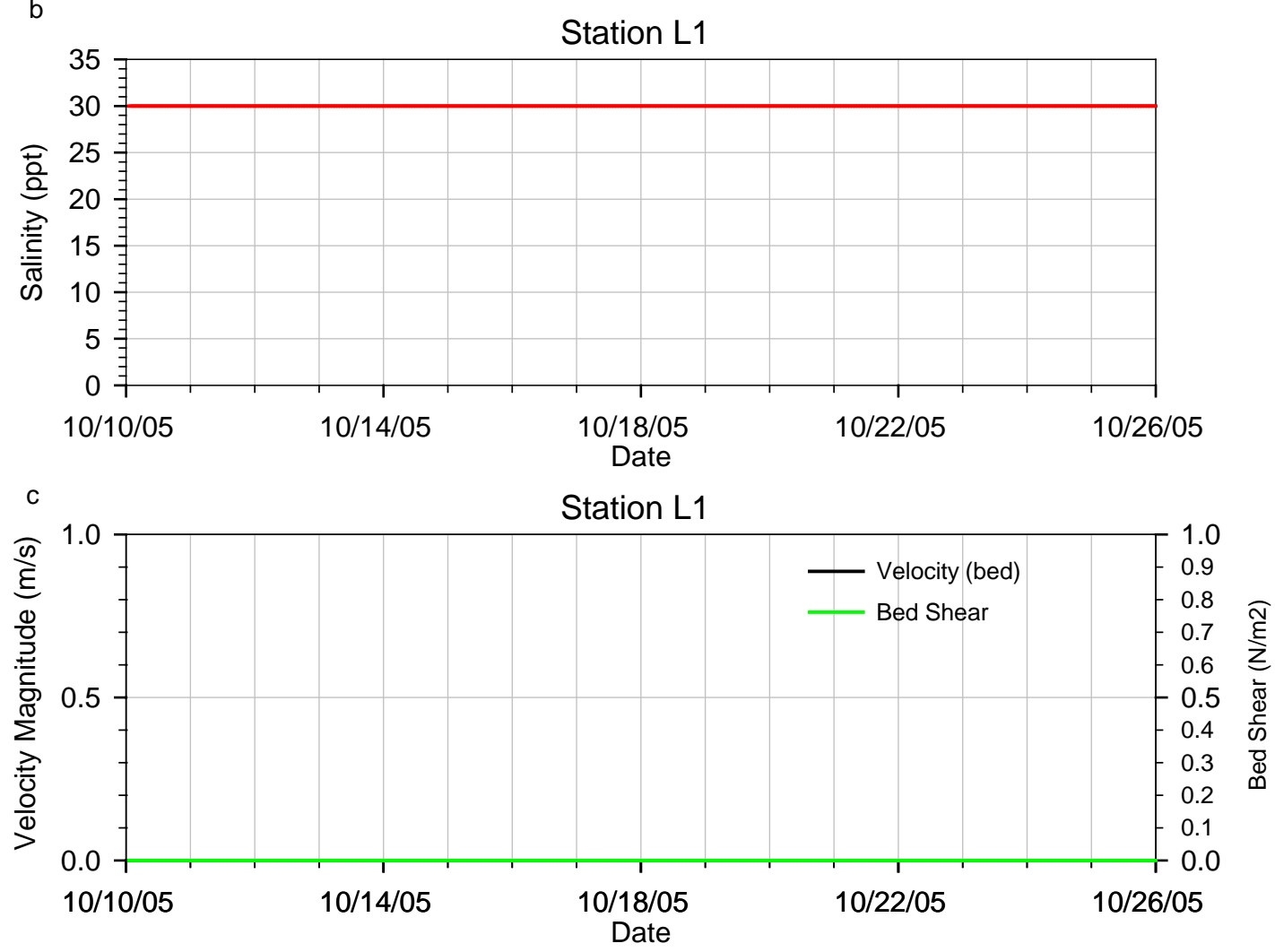

Figure A-5: Scenario 1 (Partial Restoration Leque) - Water-surface elevation, salinity, velocity magnitude, and bed shear stress at Leque Island restoration station L1, October 2005 period 


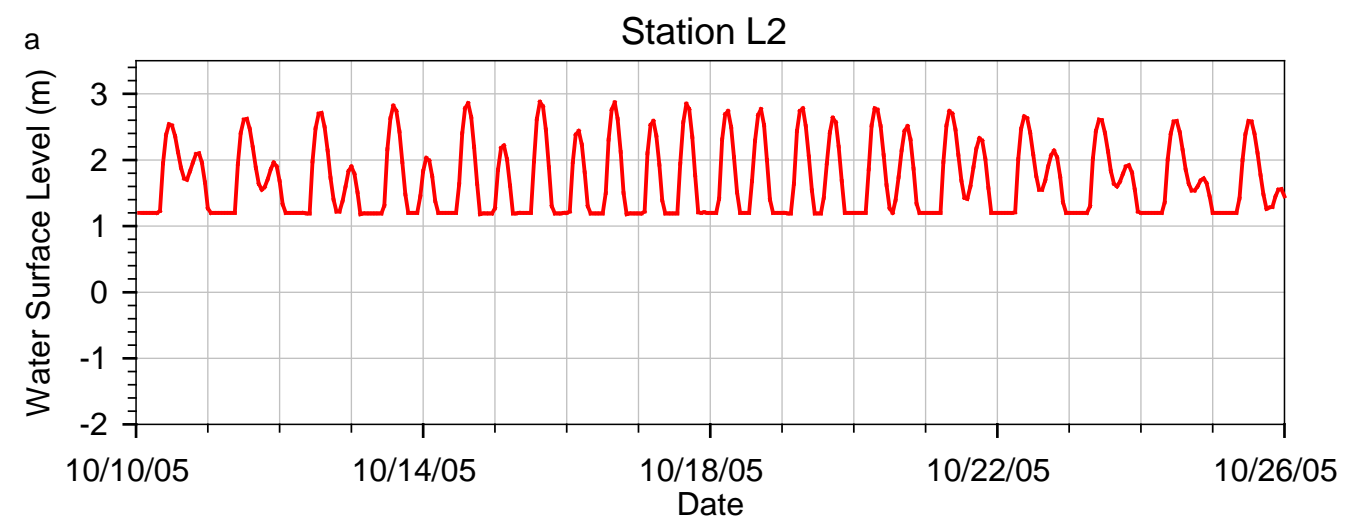

b
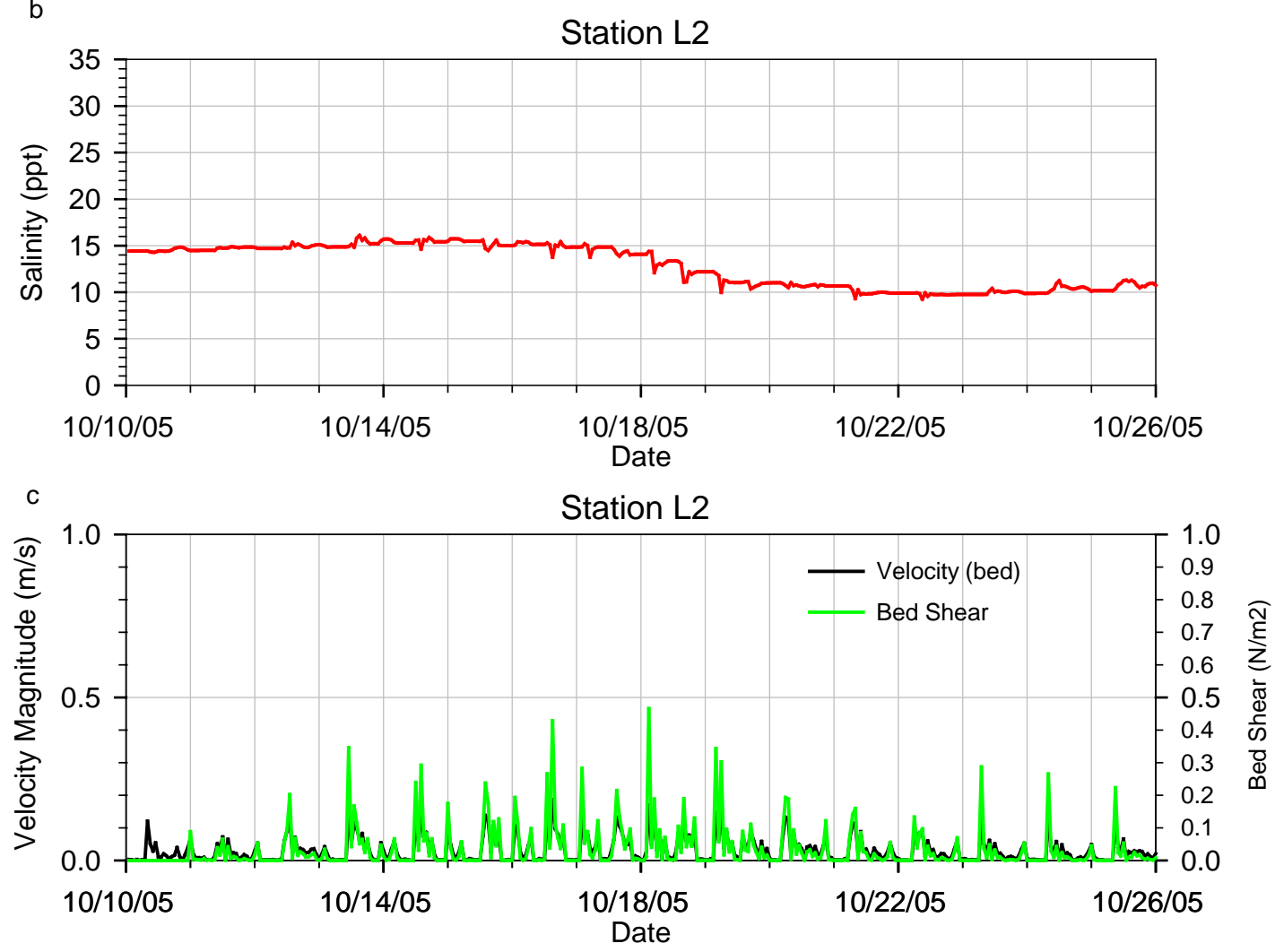

Figure A-6: Scenario 1 (Partial Restoration Leque) - Water-surface elevation, salinity, velocity magnitude, and bed shear stress at Leque Island restoration station L2, October 2005 period 


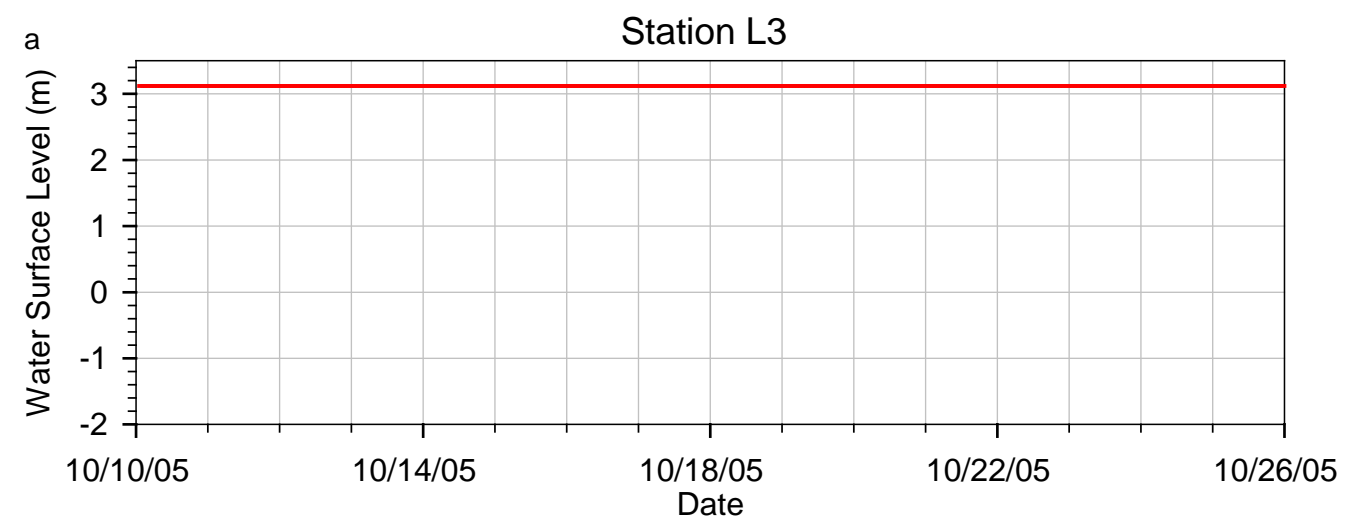

b
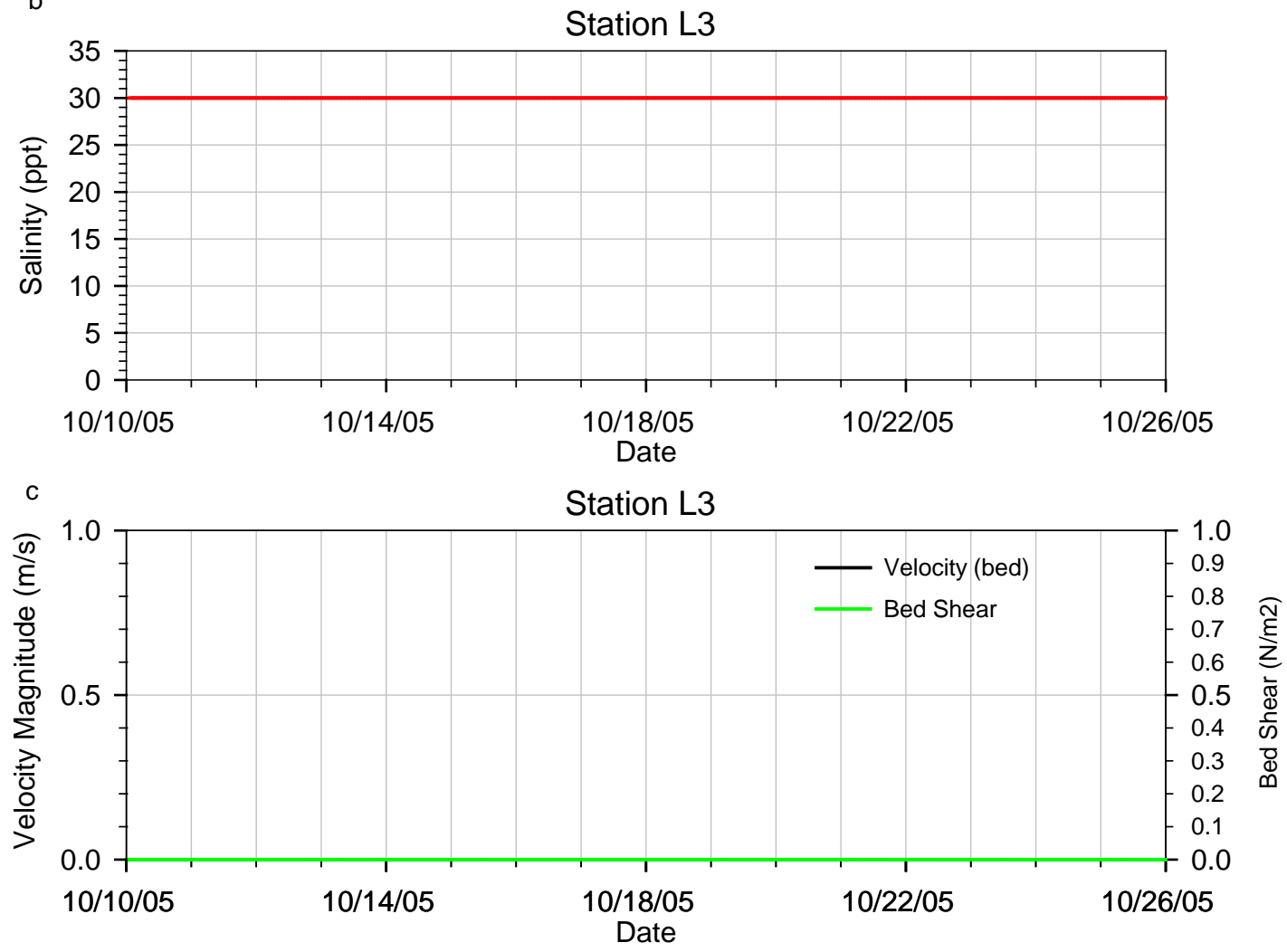

Figure A-7: Scenario 1 (Partial Restoration Leque) - Water-surface elevation, salinity, velocity magnitude, and bed shear stress at Leque Island restoration station L3, October 2005 period 


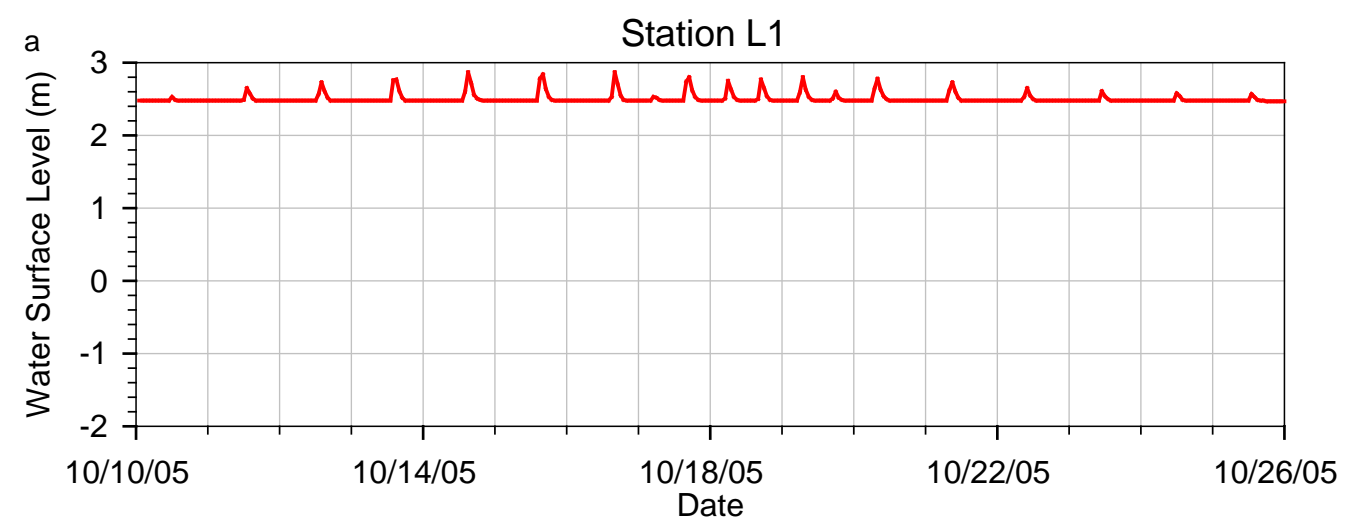

b
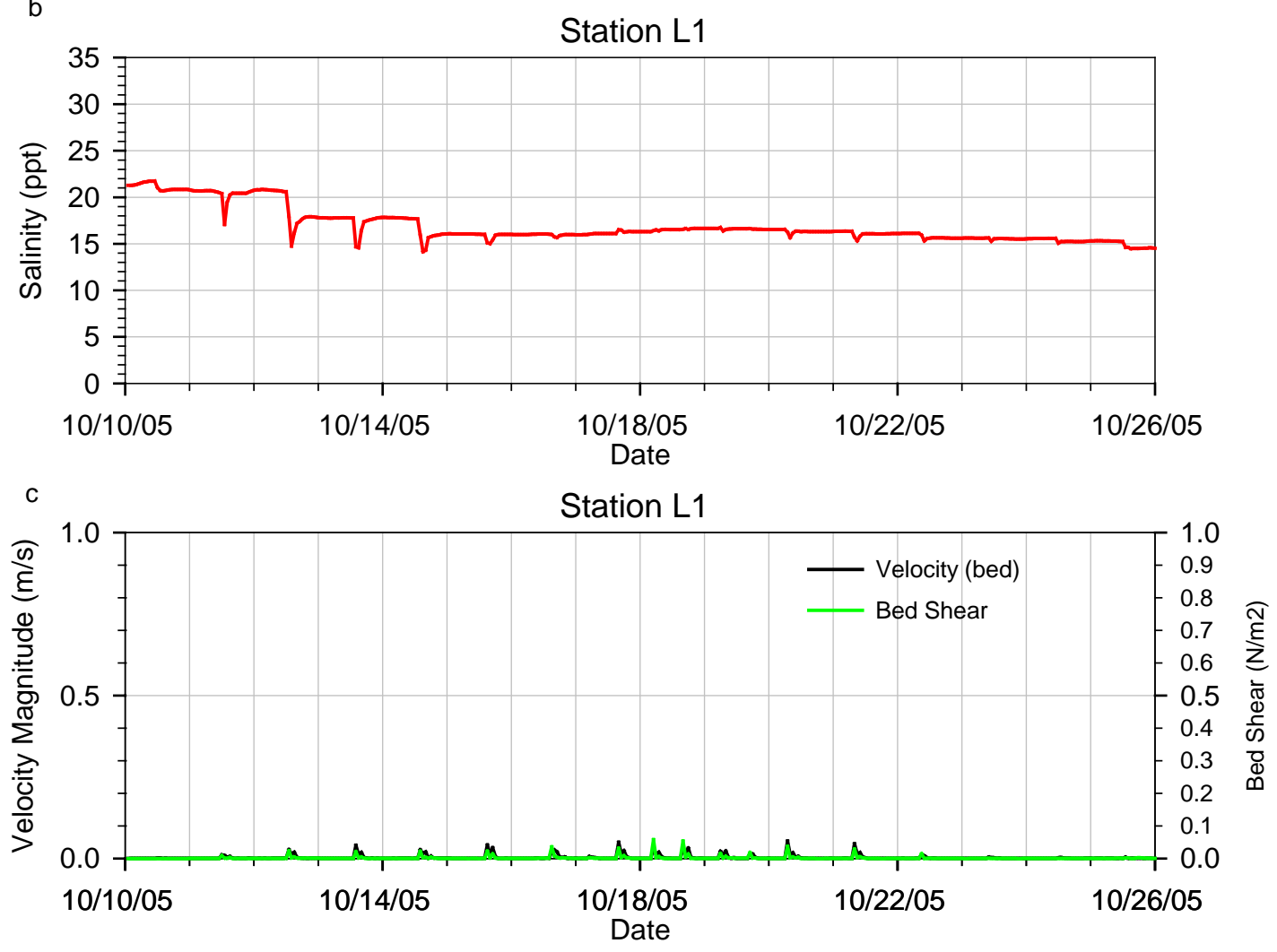

Figure A-8: Scenario 2 (4 Levee Breach Leque) - Water-surface elevation, salinity, velocity magnitude, and bed shear stress at Leque Island restoration station L1, October 2005 period 


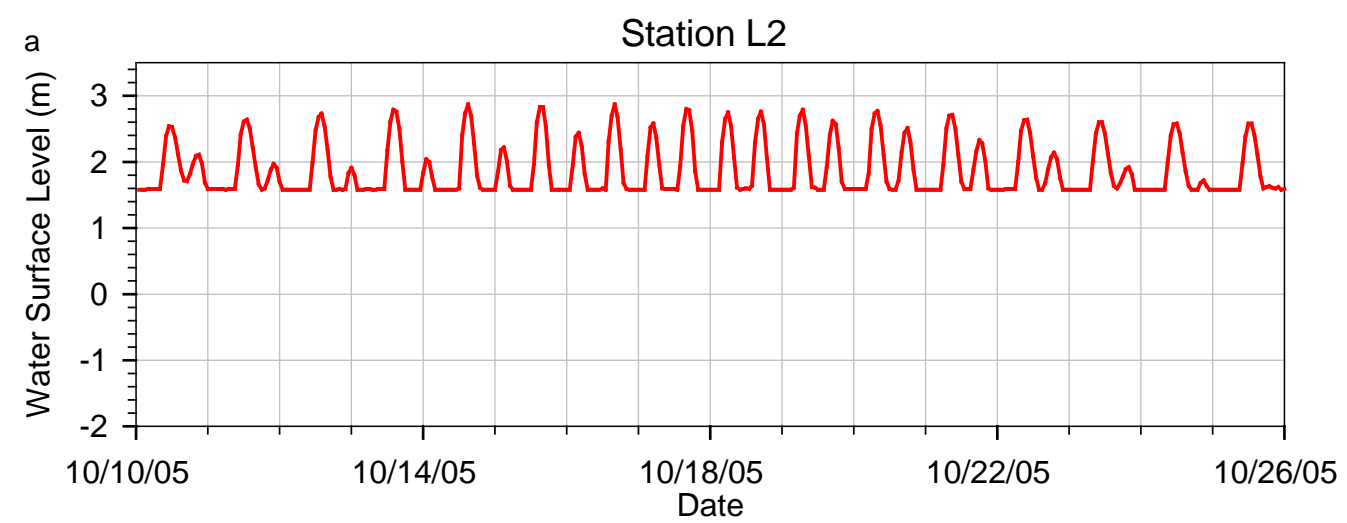

b
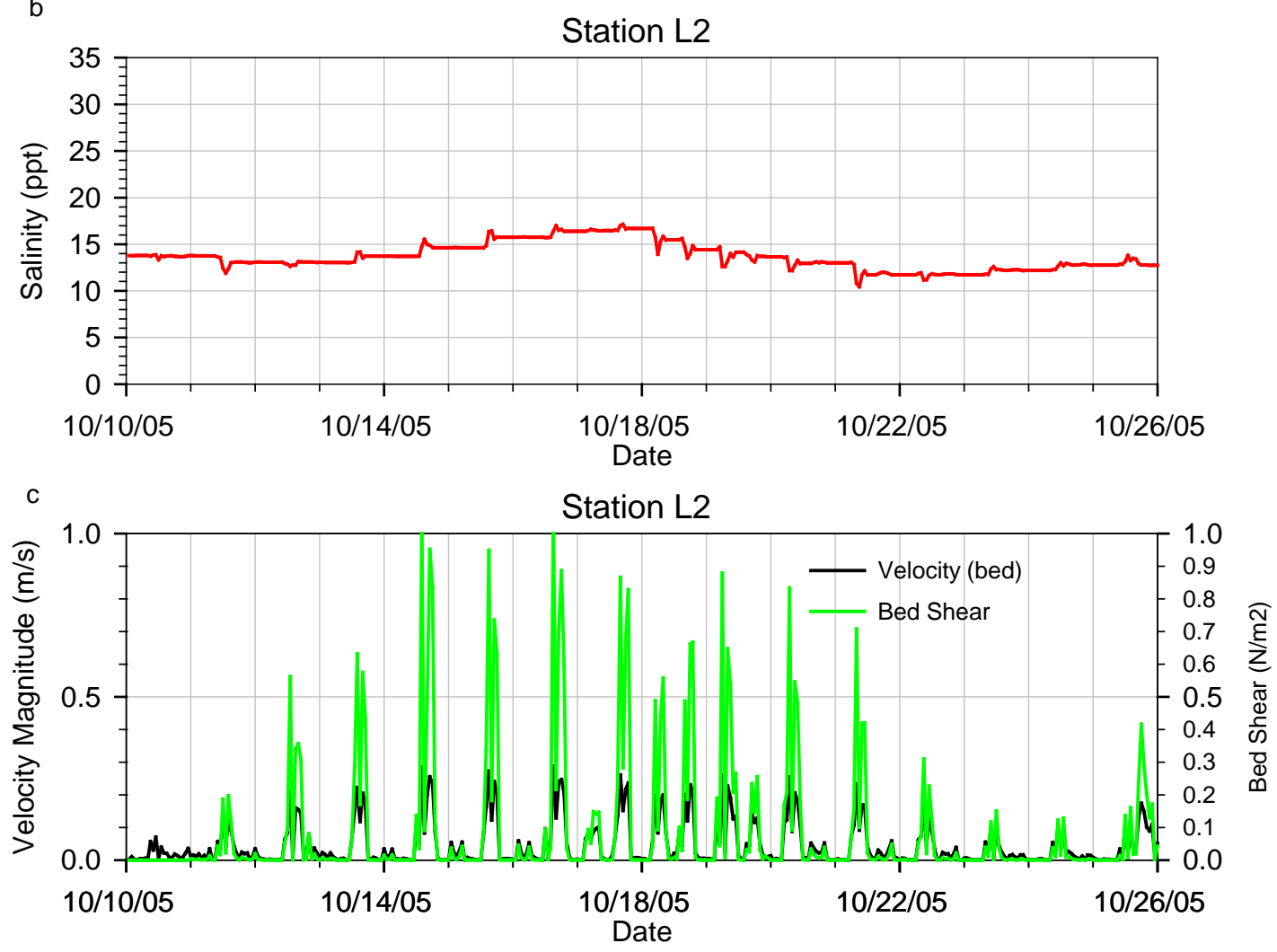

Figure A-9: Scenario 2 (4 Levee Breach Leque) - Water-surface elevation, salinity, velocity magnitude, and bed shear stress at Leque Island restoration station L2, October 2005 period 


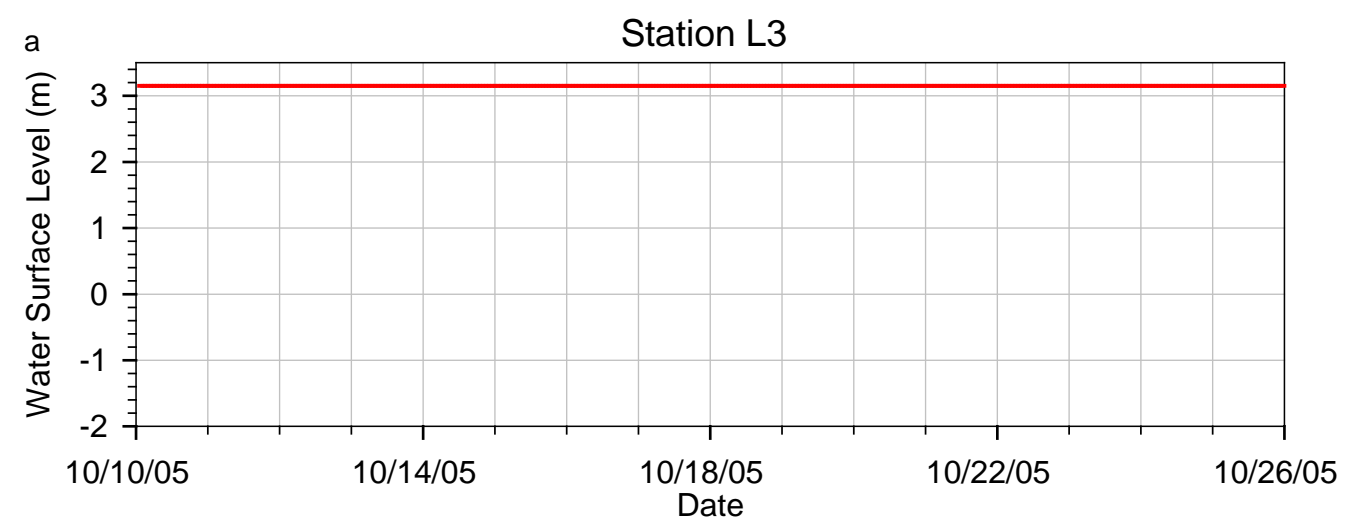

b
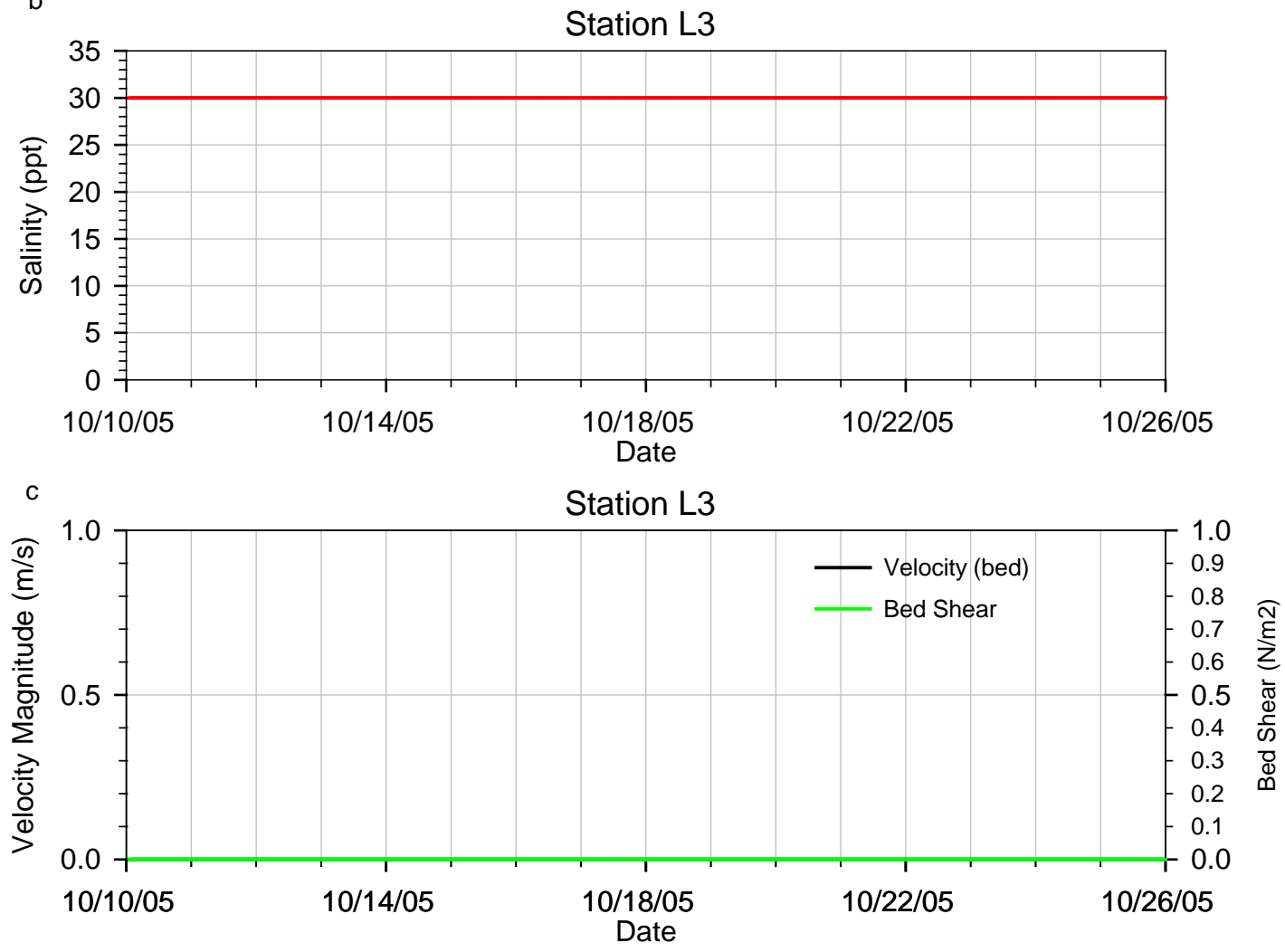

Figure A-10: Scenario 2 (4 Levee Breach Leque) - Water-surface elevation, salinity, velocity magnitude, and bed shear stress at Leque Island restoration station L3, October 2005 period 


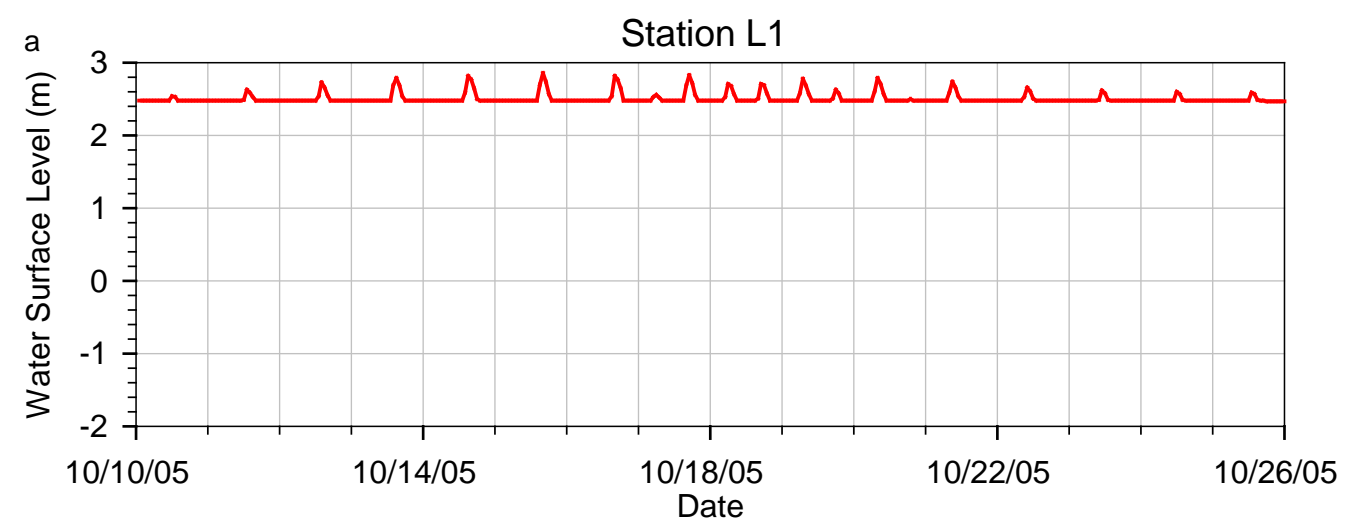

b
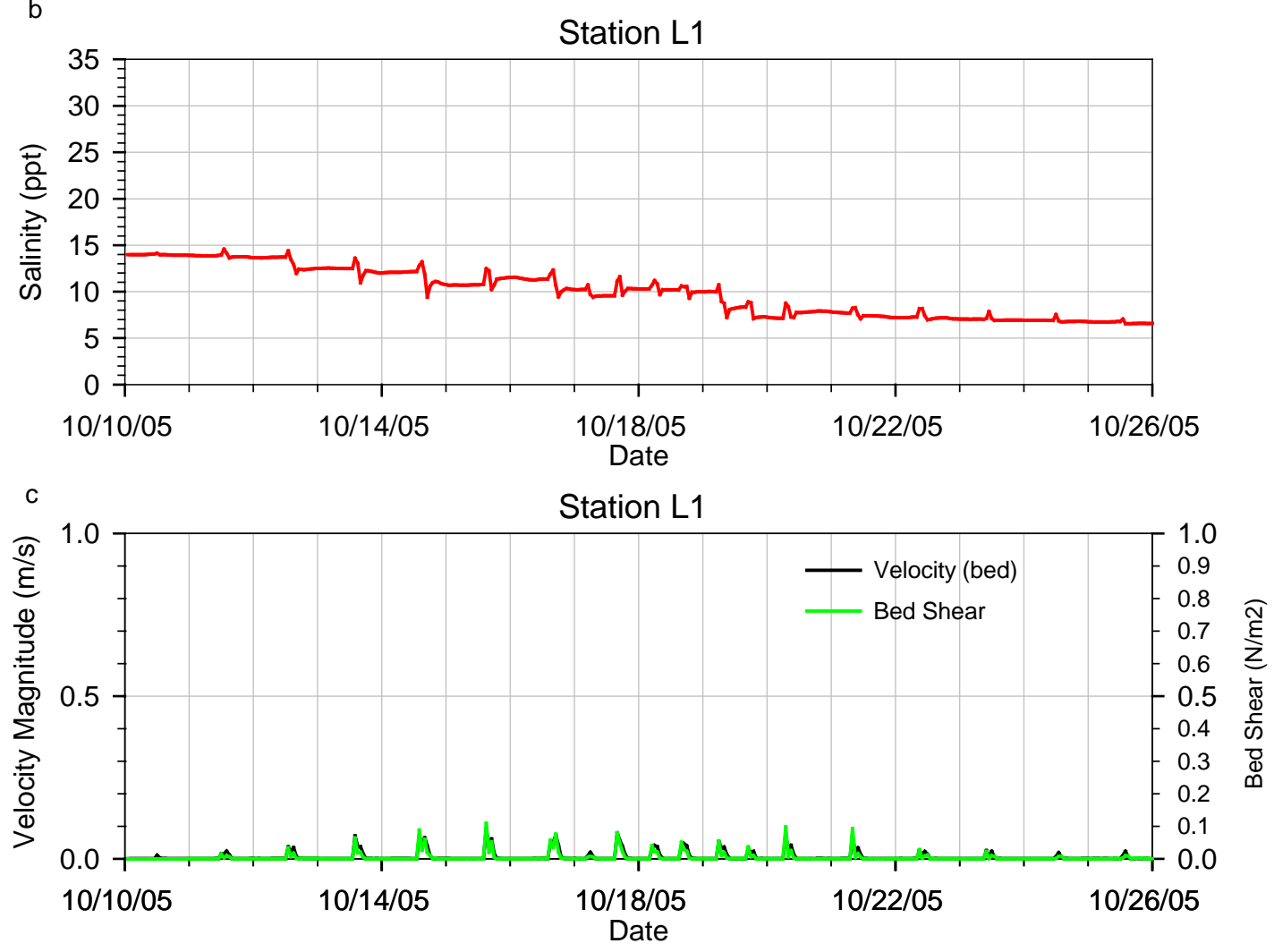

Figure A-11: Scenario 3 (Full Restoration Leque 1) - Water-surface elevation, salinity, velocity magnitude, and bed shear stress at Leque Island restoration station L1, October 2005 period 


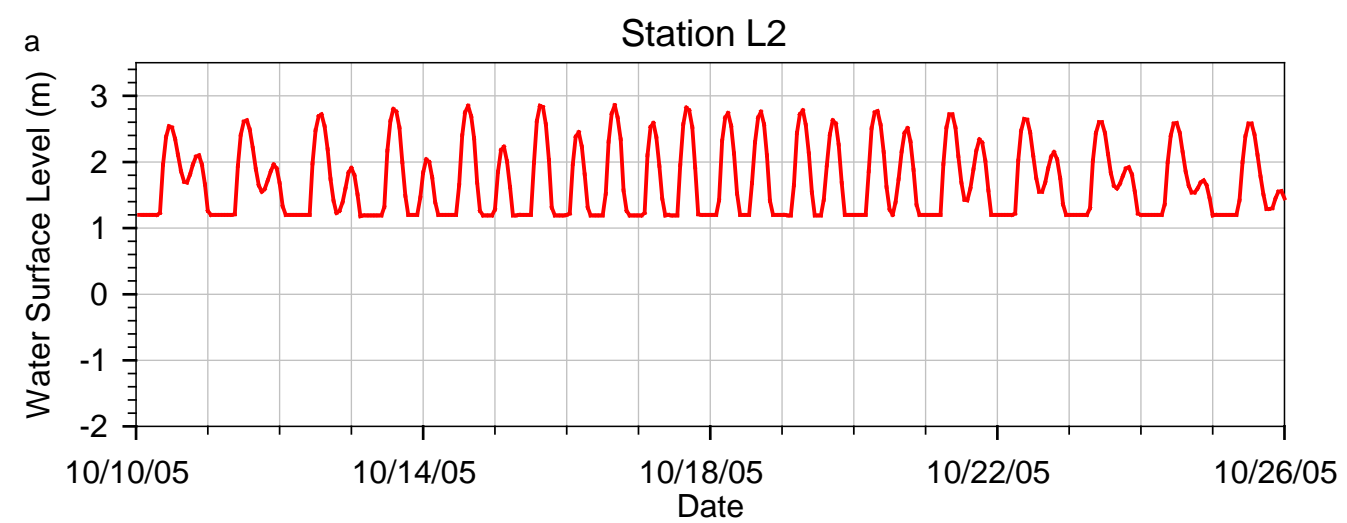

b
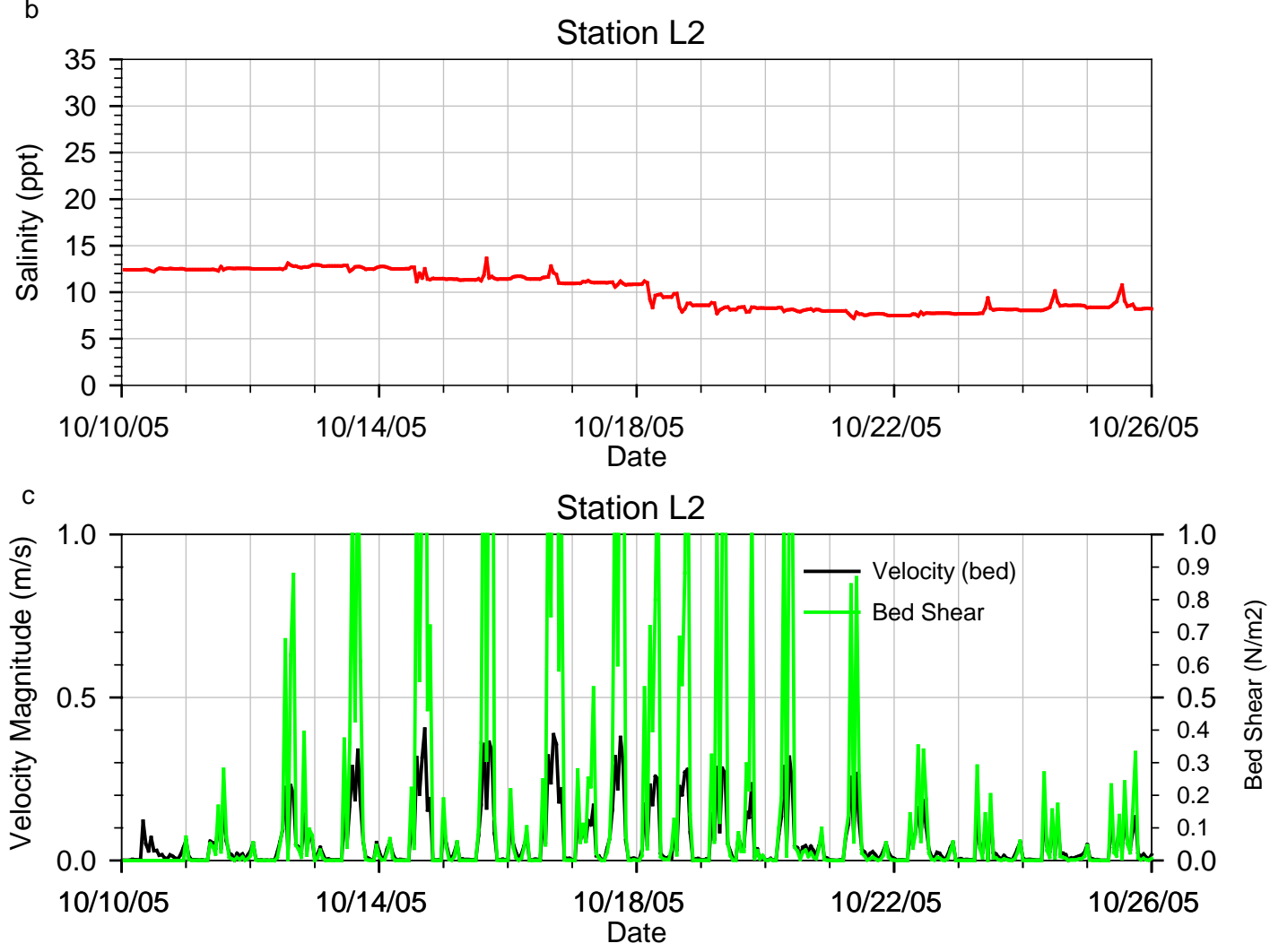

Figure A-12: Scenario 3 (Full Restoration Leque 1) - Water-surface elevation, salinity, velocity magnitude, and bed shear stress at Leque Island restoration station L2, October 2005 period 


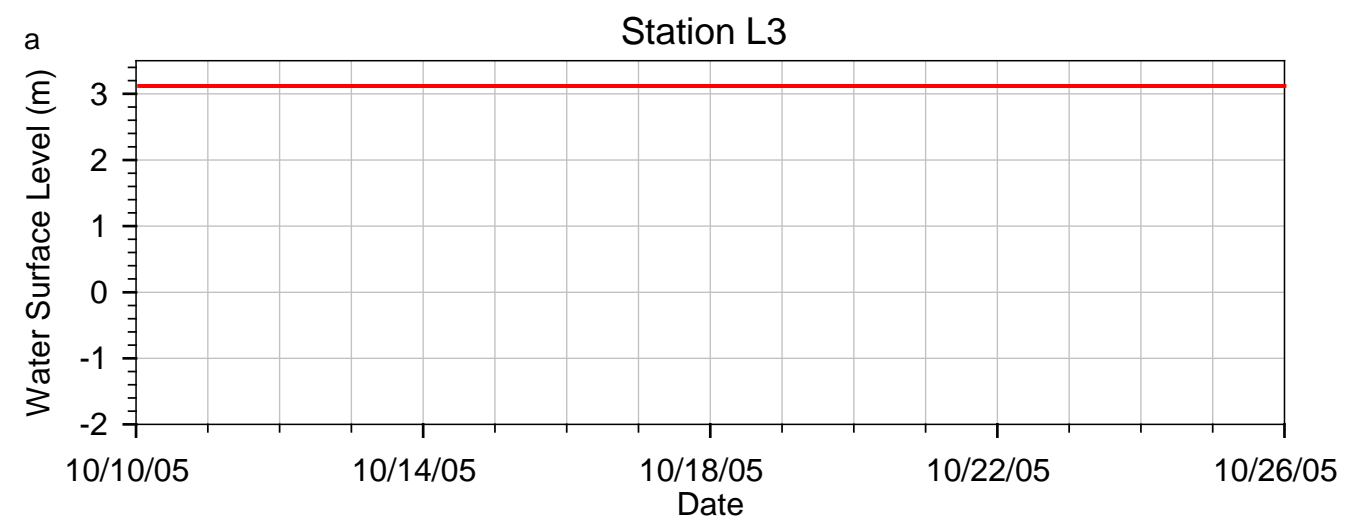

b
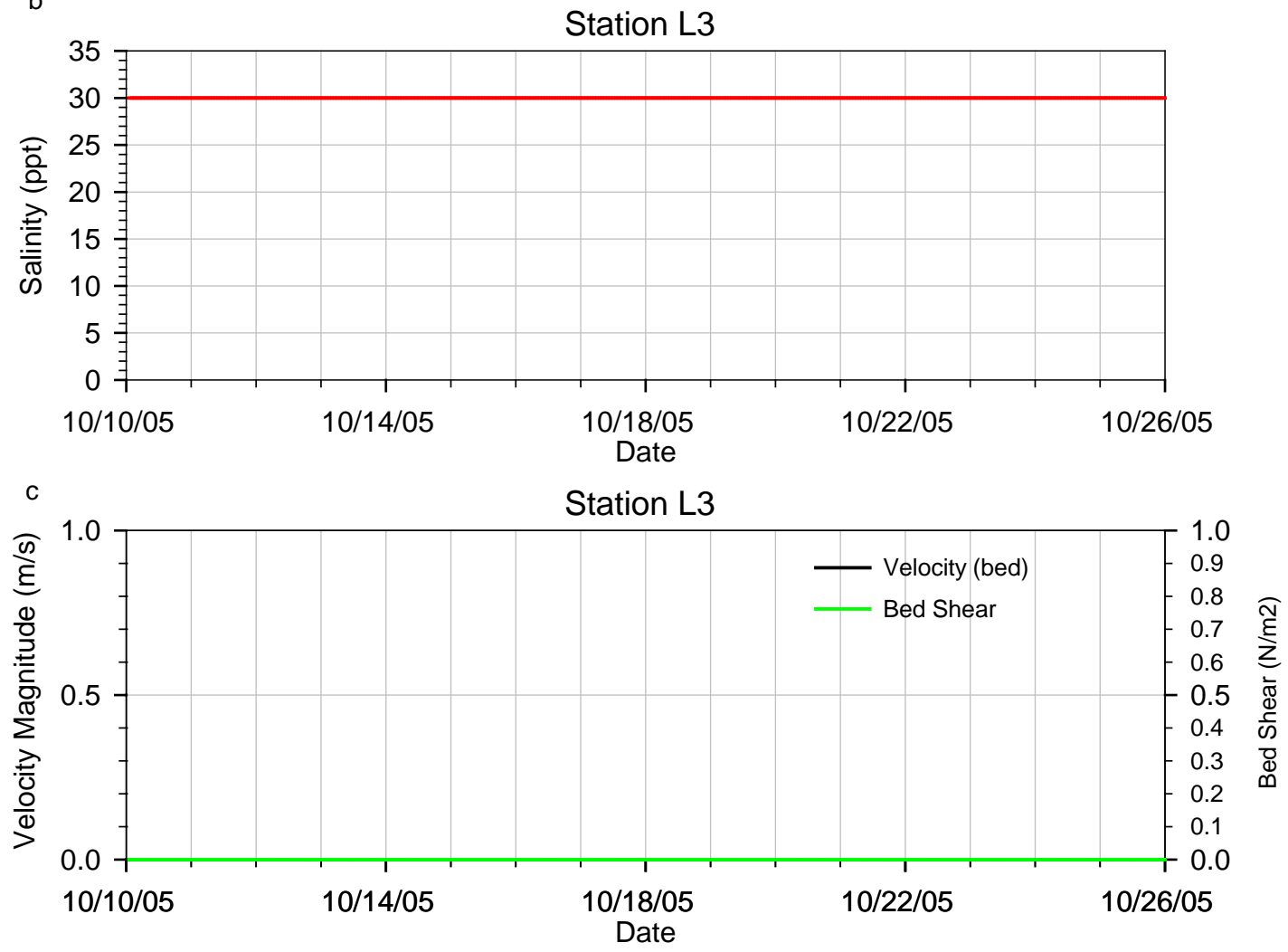

Figure A-13: Scenario 3 (Full Restoration Leque 1) - Water-surface elevation, salinity, velocity magnitude, and bed shear stress at Leque Island restoration station L3, October 2005 period 


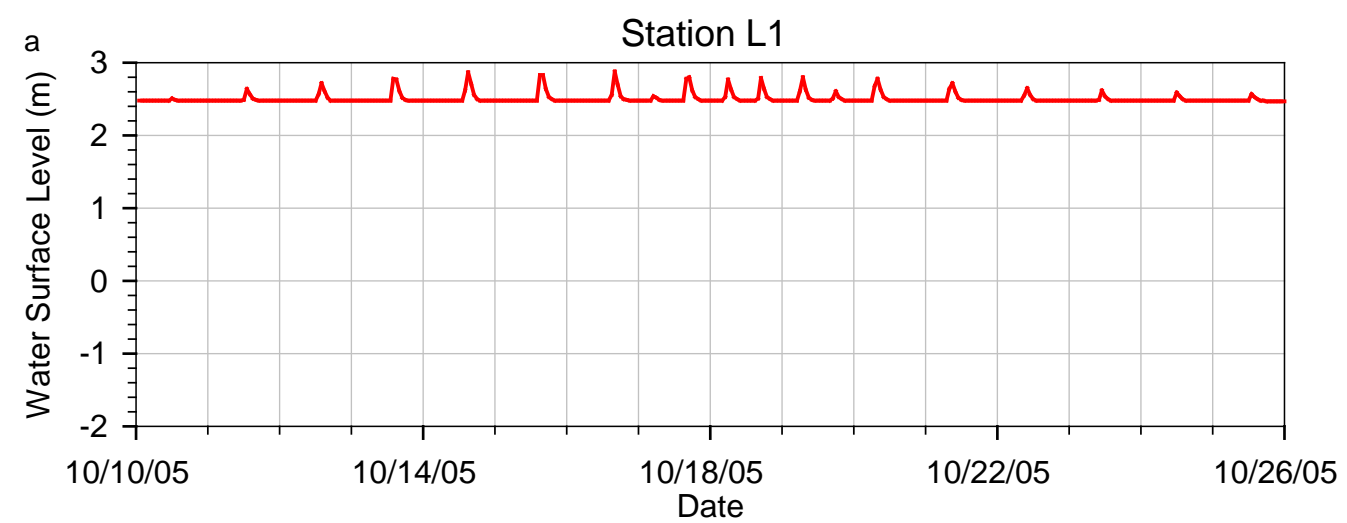

b
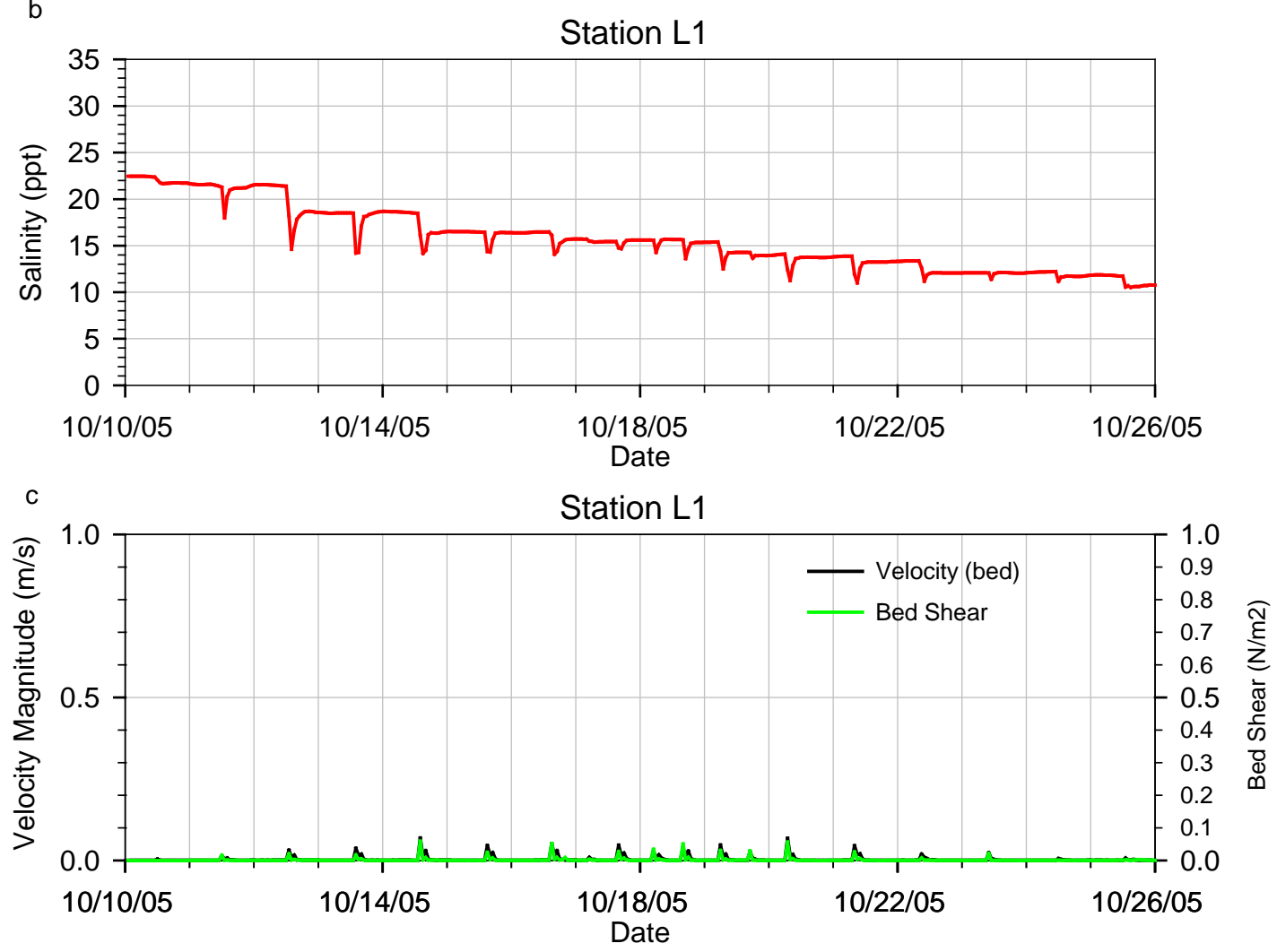

Figure A-14: Scenario 4 (Full Restoration Leque 2) - Water-surface elevation, salinity, velocity magnitude, and bed shear stress at Leque Island restoration station L1, October 2005 period 


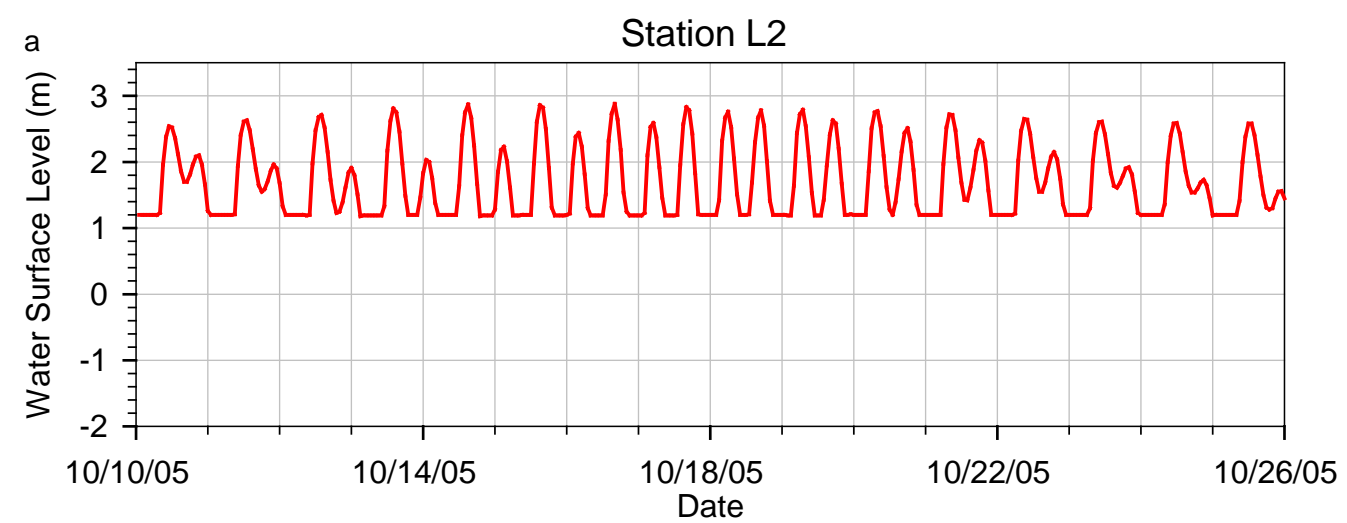

b
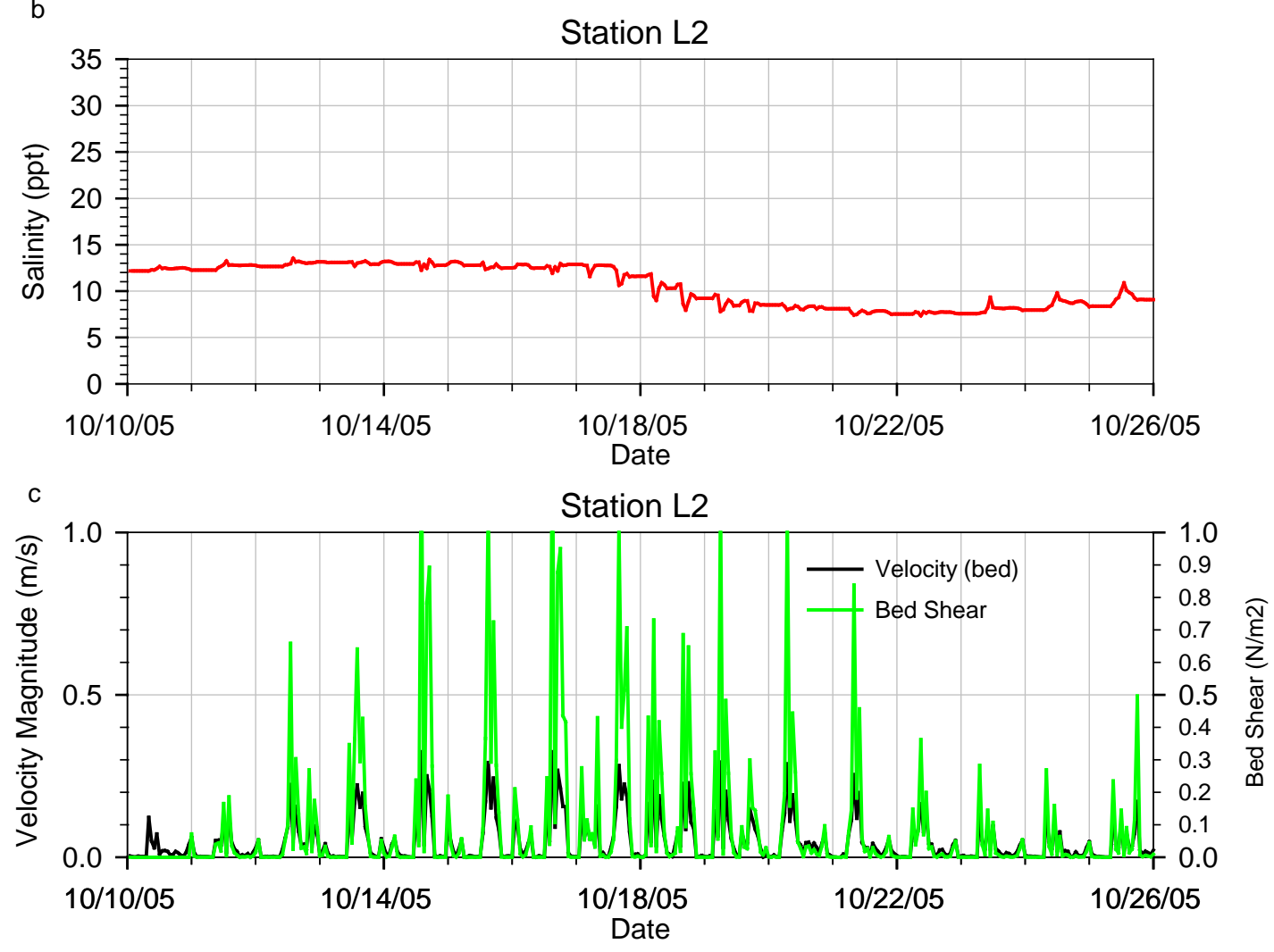

Figure A-15: Scenario 4 (Full Restoration Leque 2) - Water-surface elevation, salinity, velocity magnitude, and bed shear stress at Leque Island restoration station L2, October 2005 period 


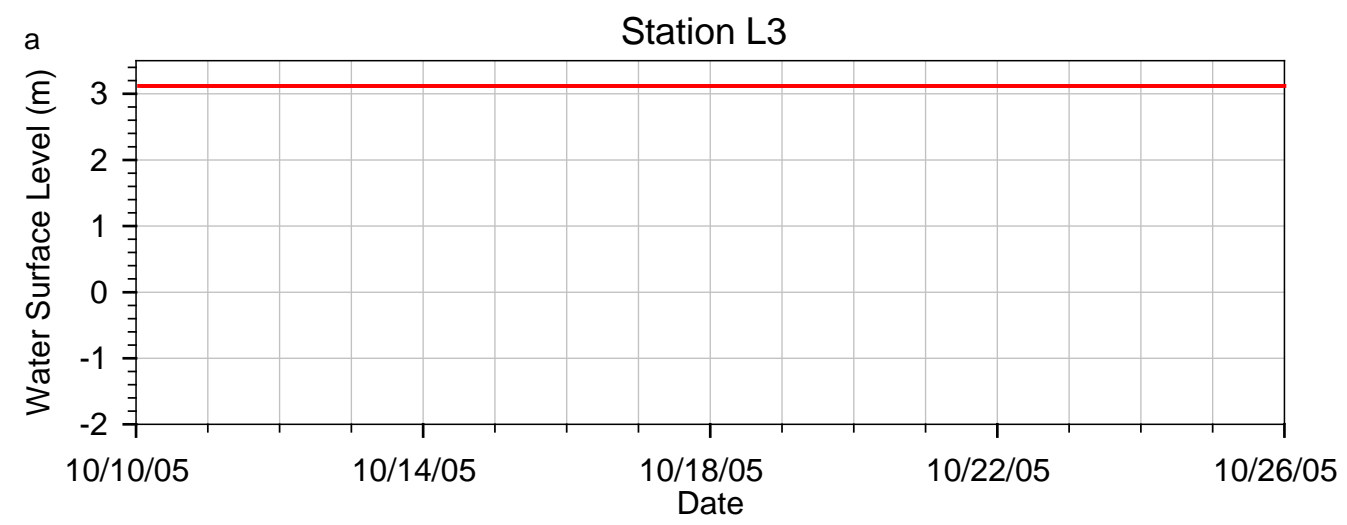

b
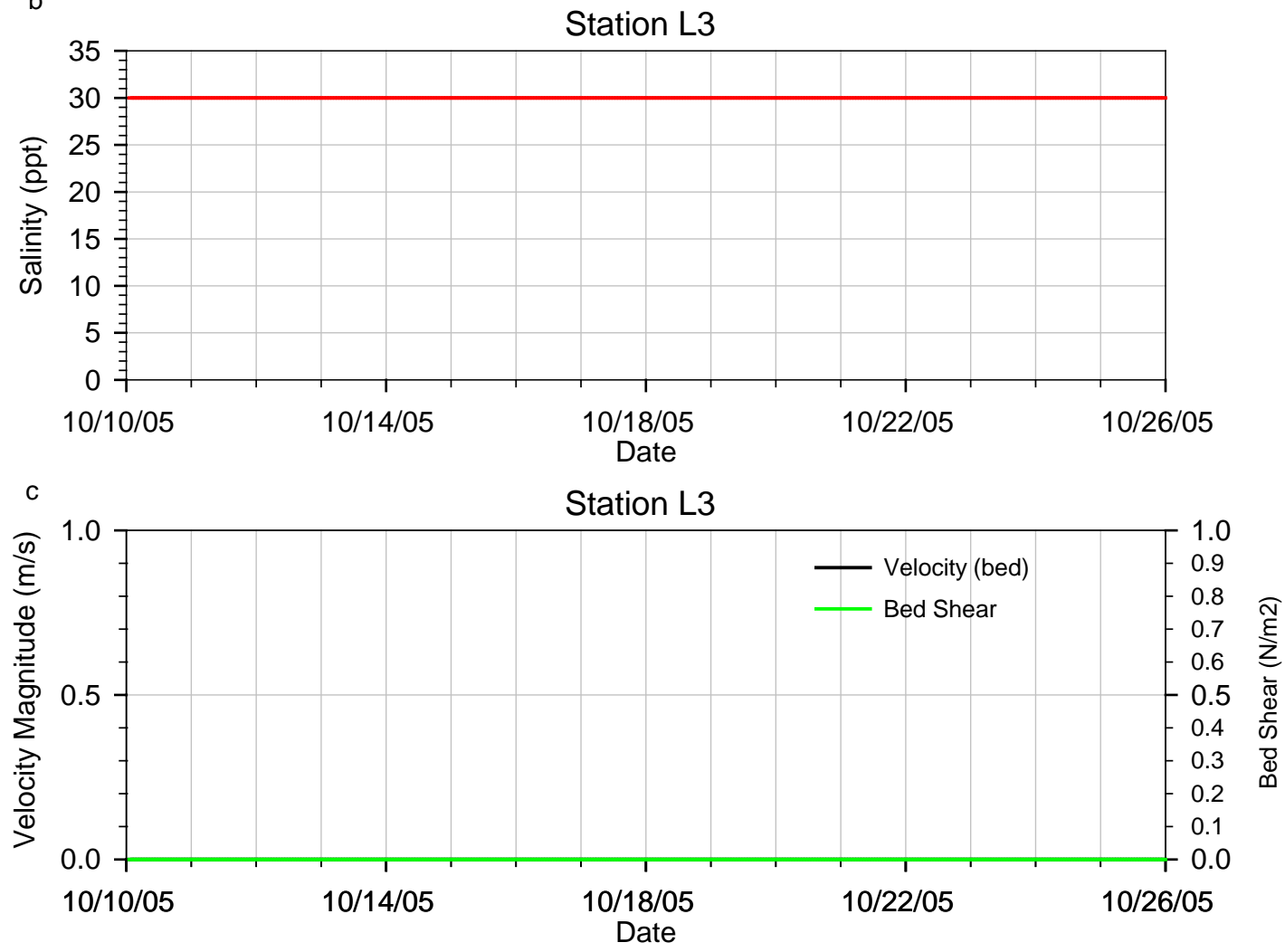

Figure A-16: Scenario 4 (Full Restoration Leque 2) - Water-surface elevation, salinity, velocity magnitude, and bed shear stress at Leque Island restoration station L3, October 2005 period 


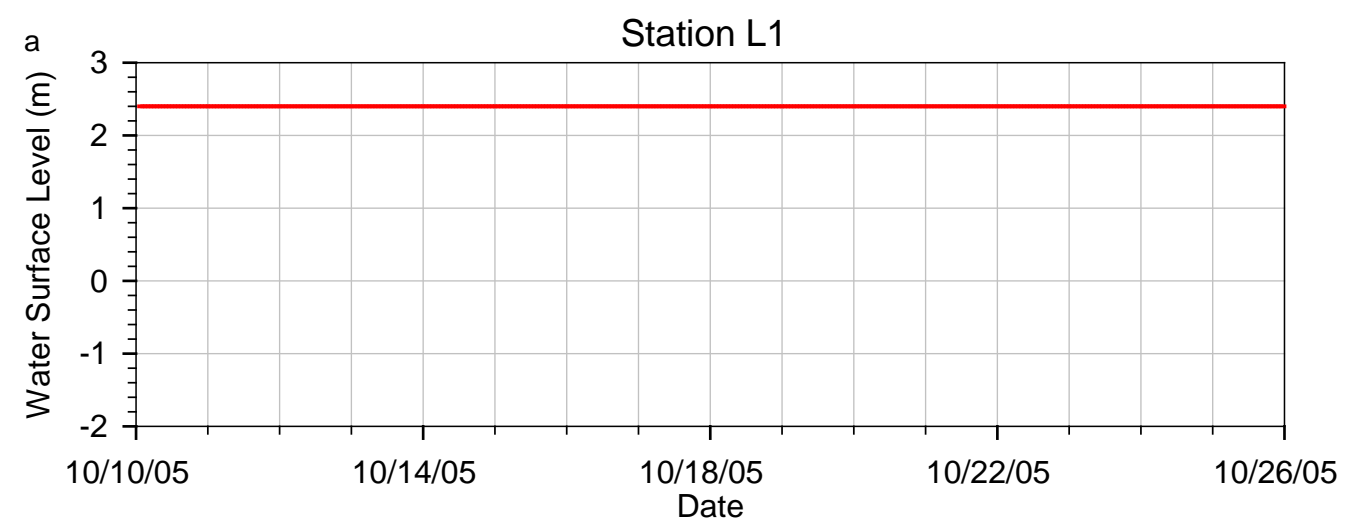

b
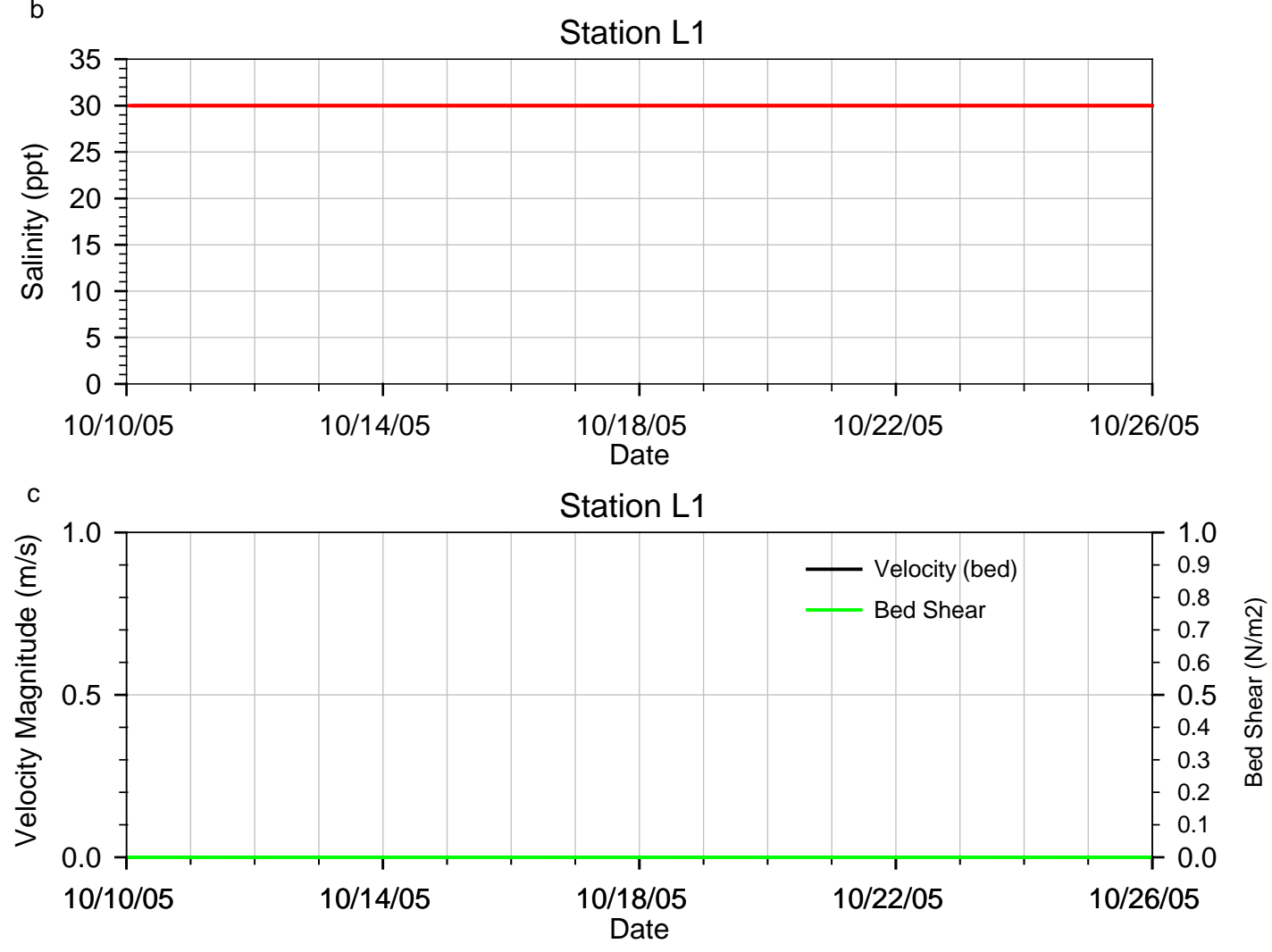

Figure A-17: Scenario 5 (Full Restoration zis a ba + SCN1) - Water-surface elevation, salinity, velocity magnitude, and bed shear stress at Leque Island restoration station L1, October 2005 period 


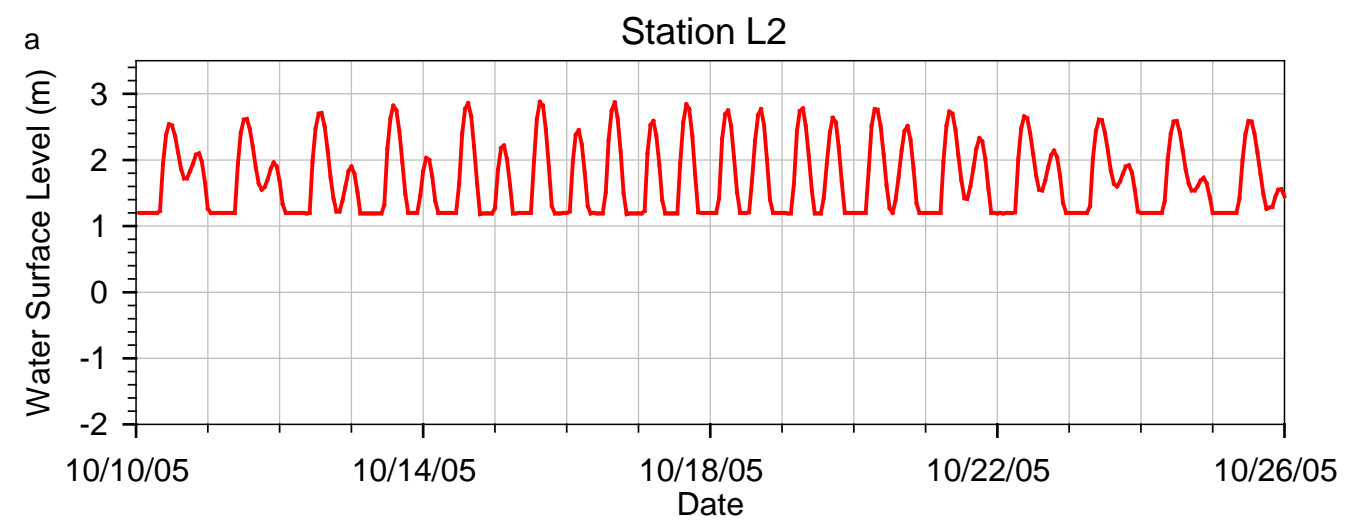

b
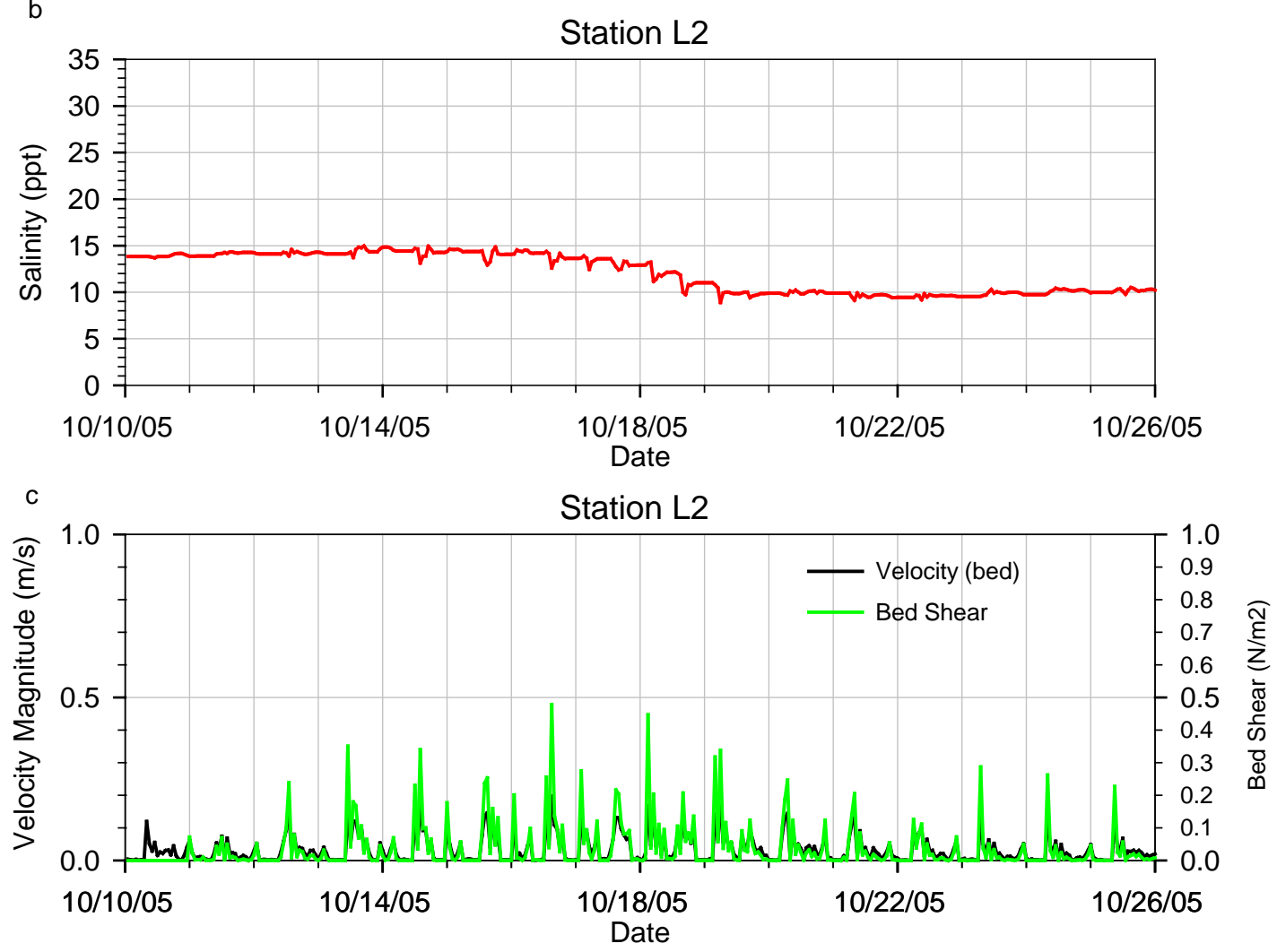

Figure A-18: Scenario 5 (Full Restoration zis a ba + SCN1) - Water-surface elevation, salinity, velocity magnitude, and bed shear stress at Leque Island restoration station L2, October 2005 period 


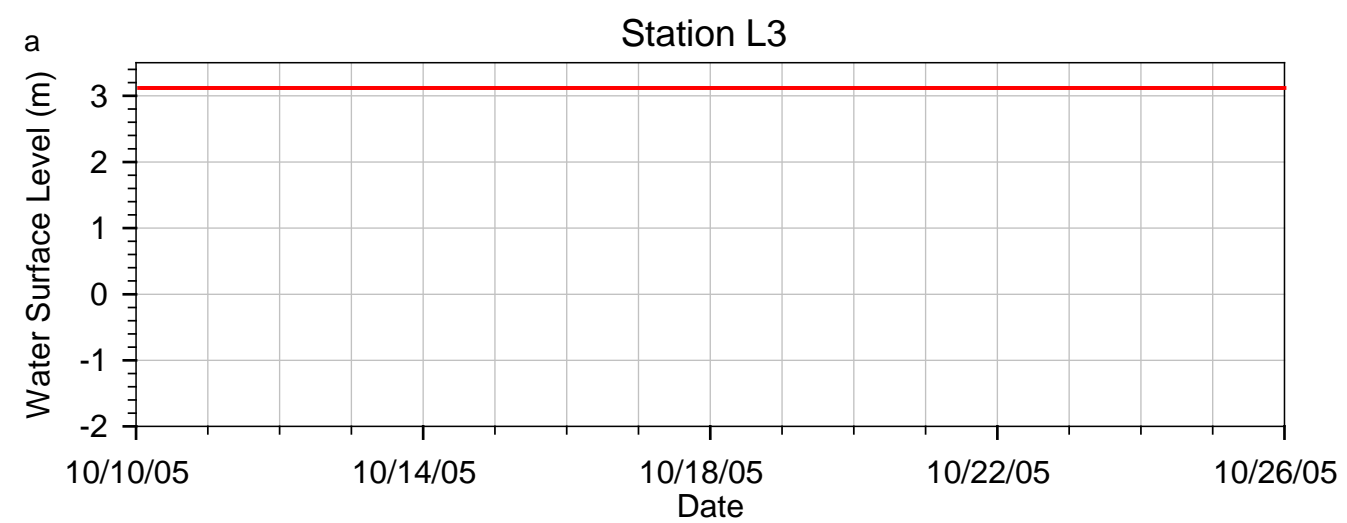

b
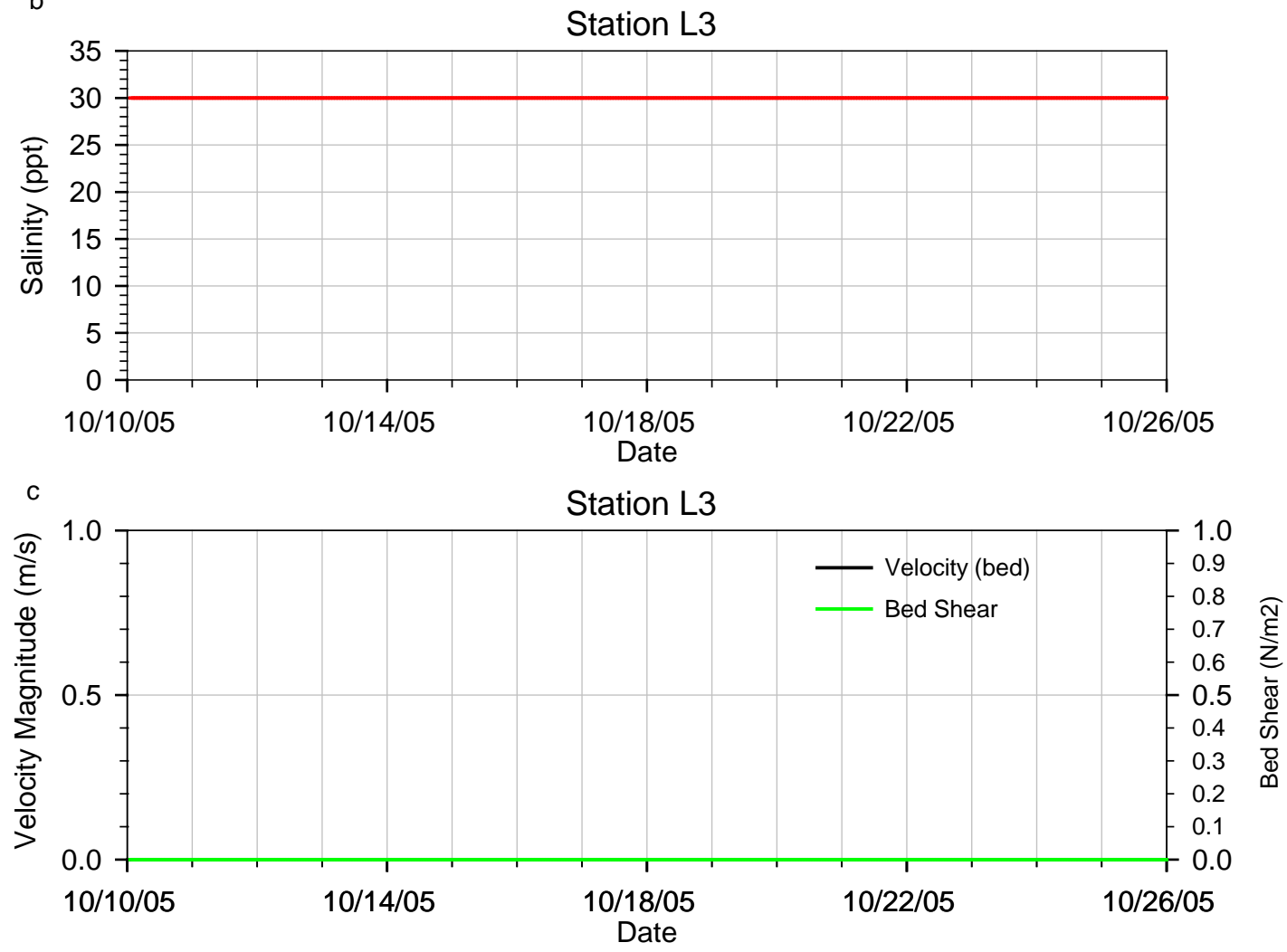

Figure A-19: Scenario 5 (Full Restoration zis a ba + SCN1) - Water-surface elevation, salinity, velocity magnitude, and bed shear stress at Leque Island restoration station L3, October 2005 period 


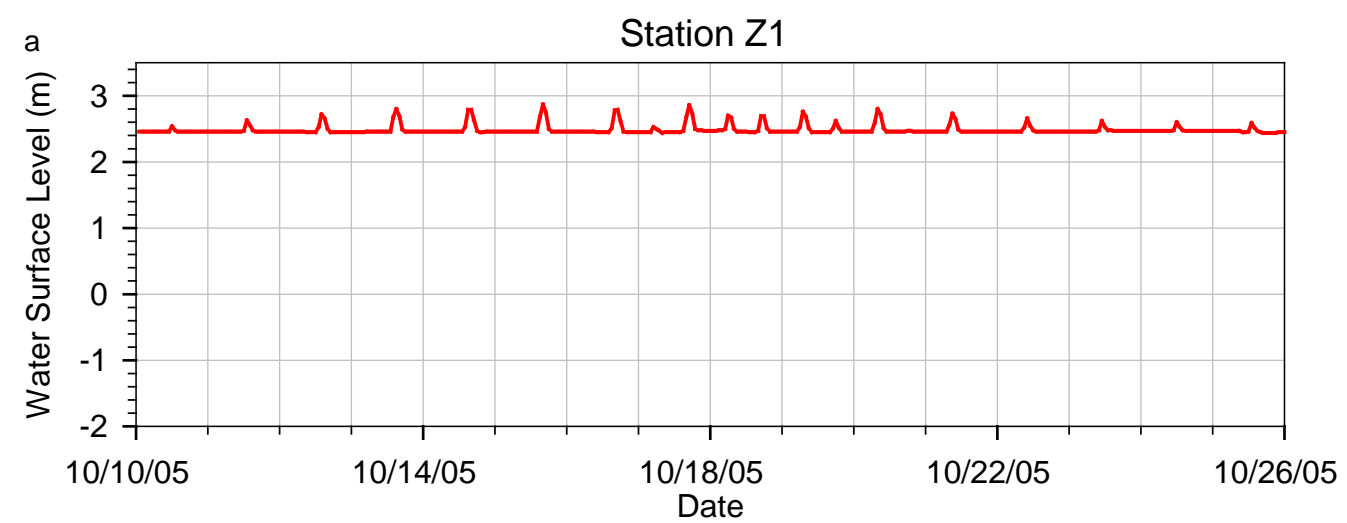

b
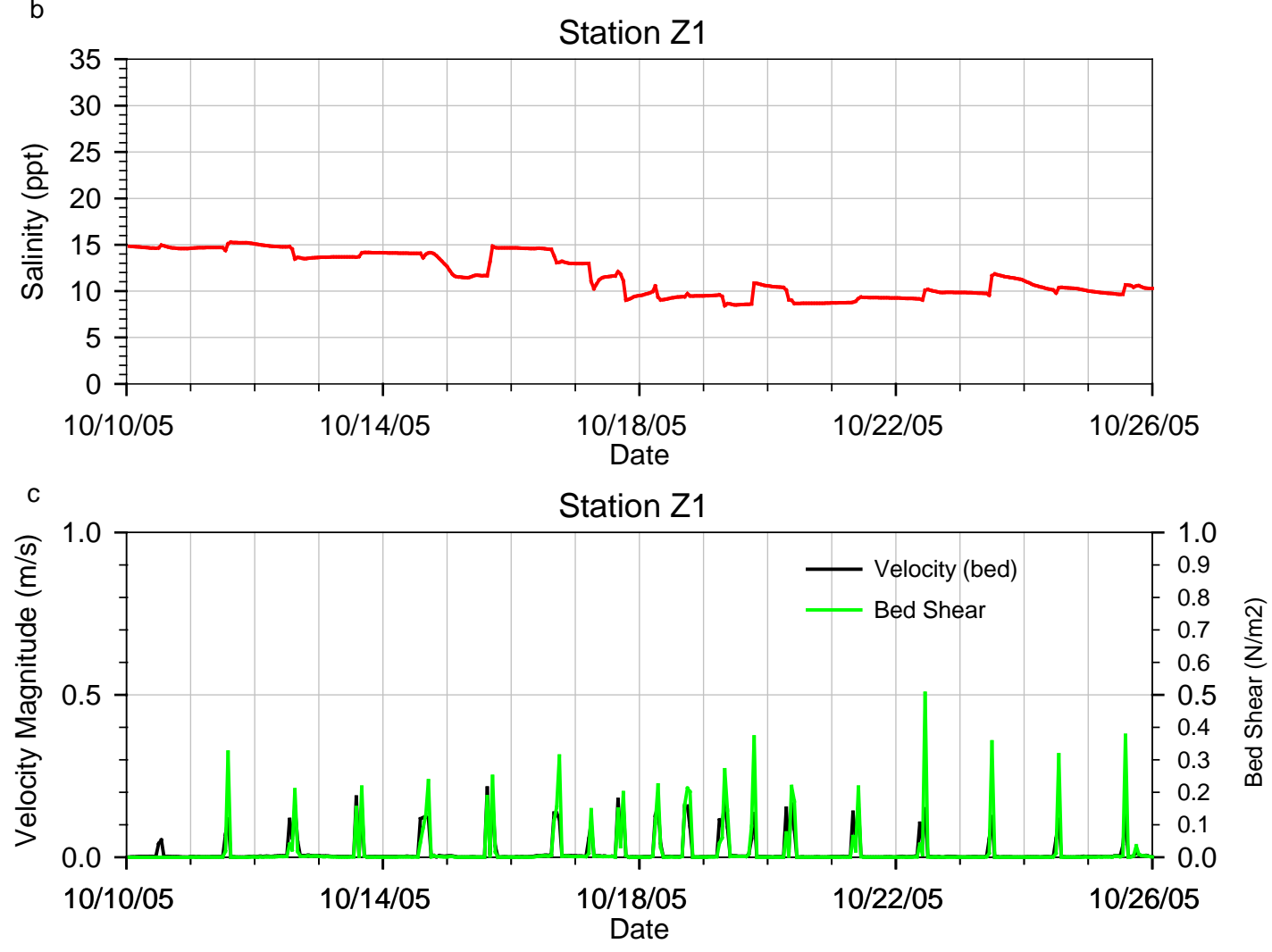

Figure A-20: Scenario 5 (Full Restoration zis a ba + SCN1) - Water-surface elevation, salinity, velocity magnitude, and bed shear stress at zis a ba restoration station Z1, October 2005 period 


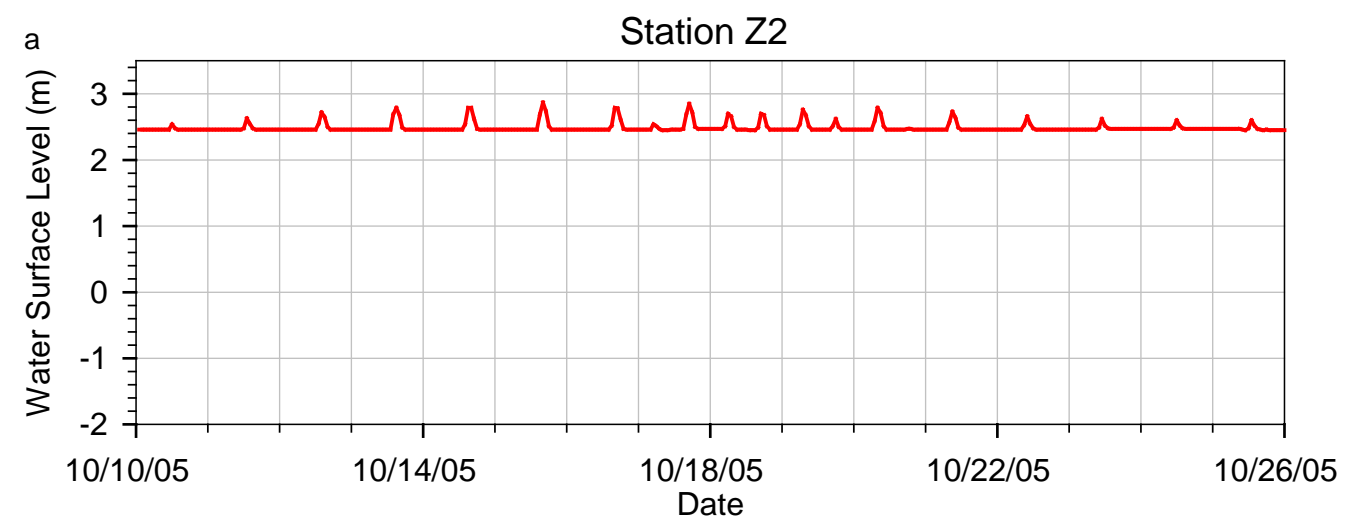

b
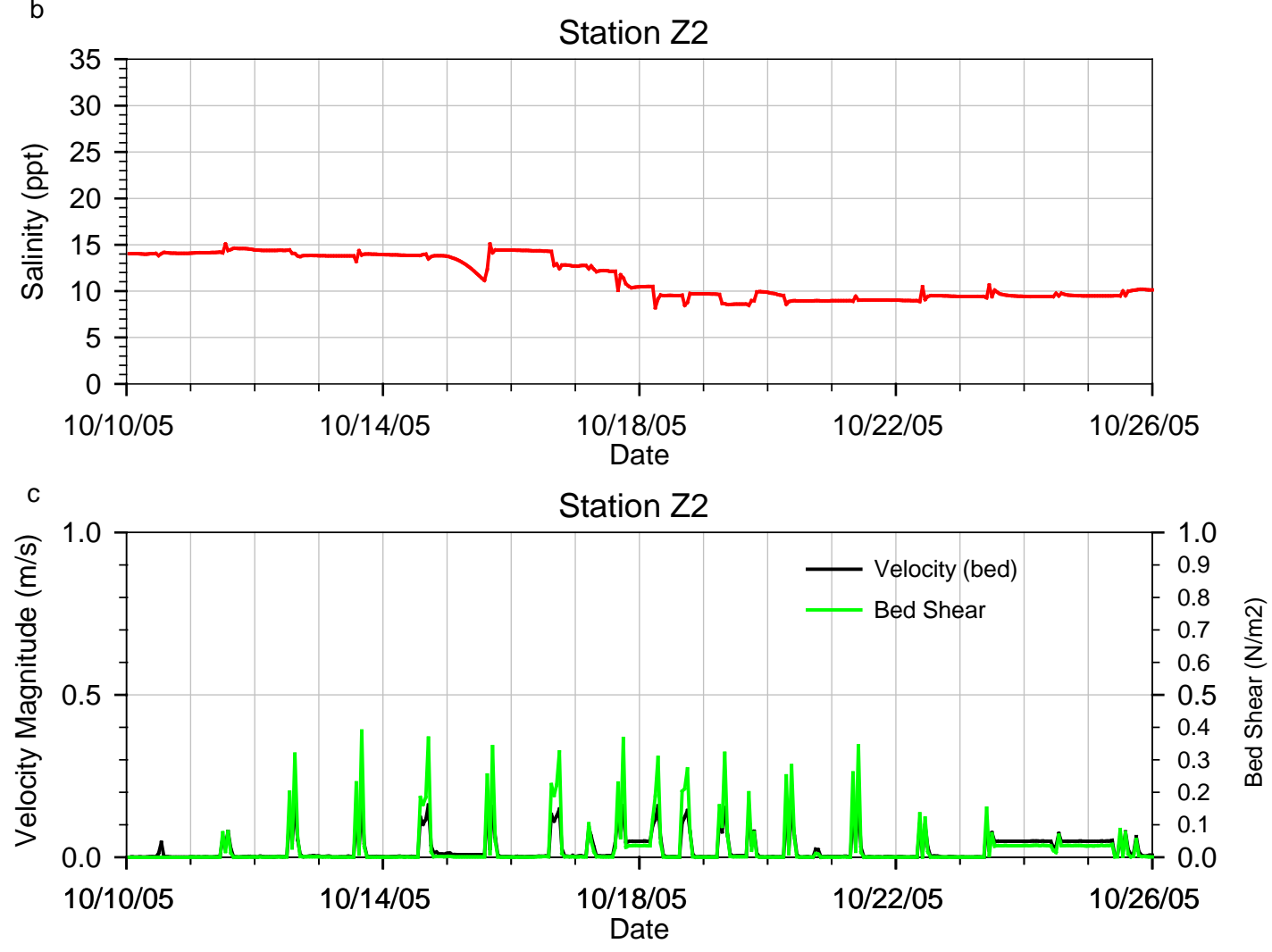

Figure A-21: Scenario 5 (Full Restoration zis a ba + SCN1) - Water-surface elevation, salinity, velocity magnitude, and bed shear stress at zis a ba restoration station Z2, October 2005 period 


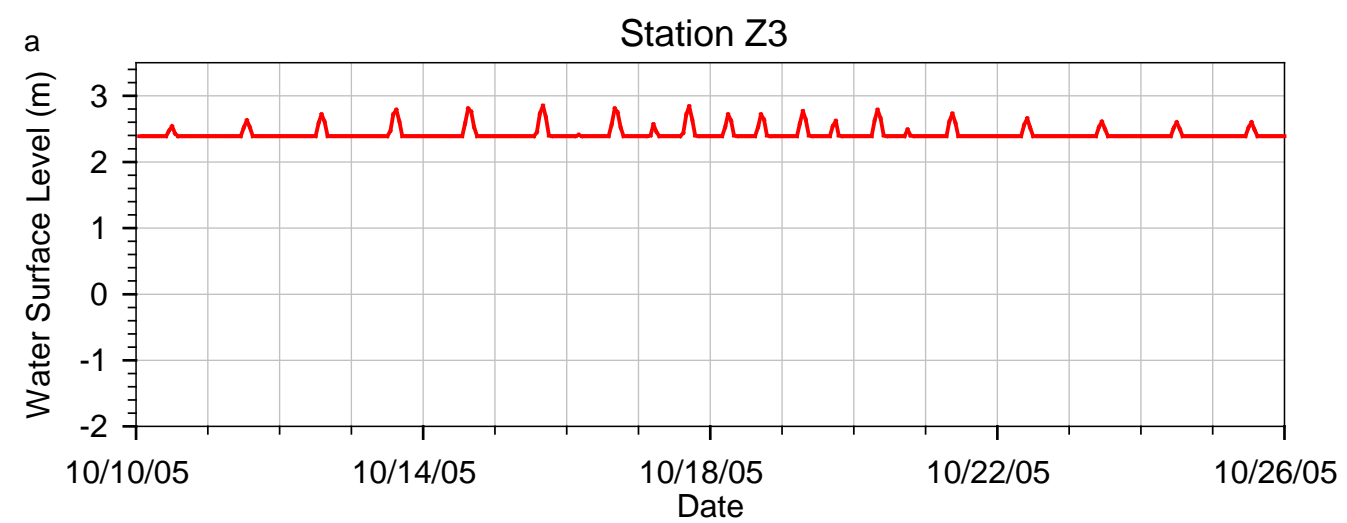

b
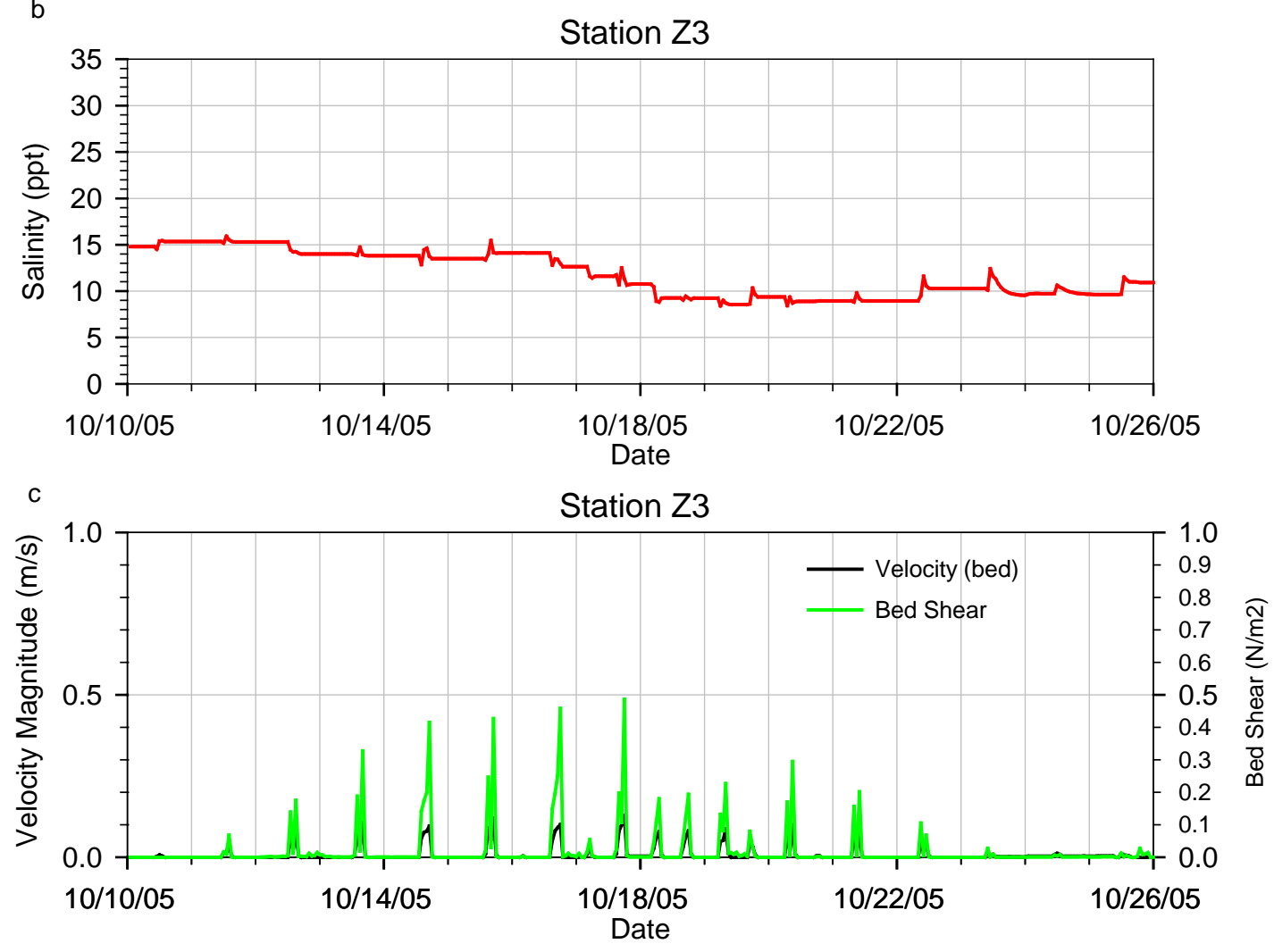

Figure A-22: Scenario 5 (Full Restoration zis a ba + SCN1) - Water-surface elevation, salinity, velocity magnitude, and bed shear stress at zis a ba restoration station Z3, October 2005 period 


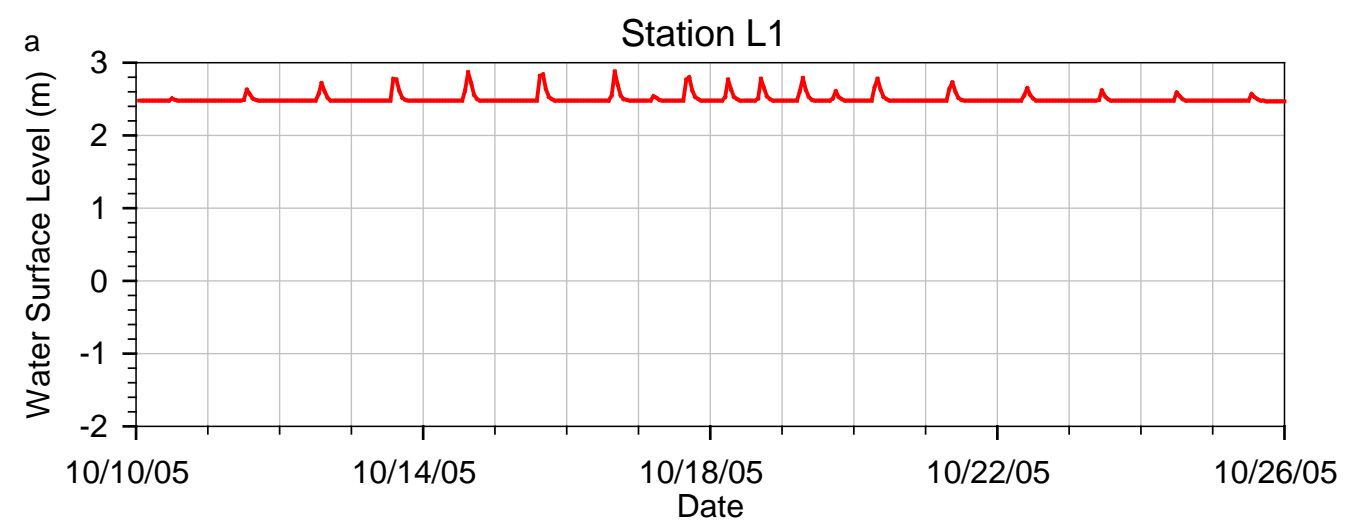

b
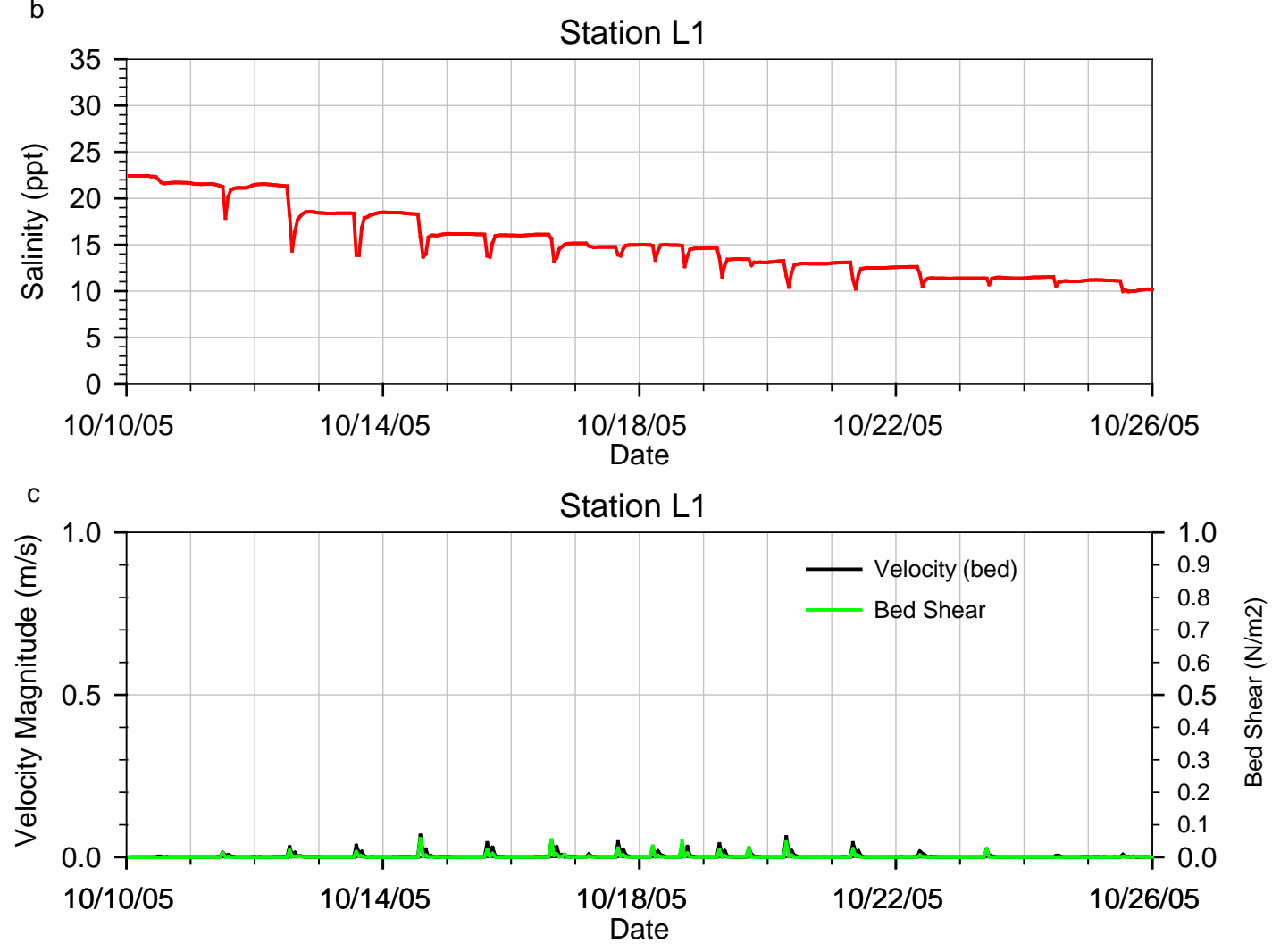

Figure A-23: Scenario 6 (Full Restoration zis a ba + SCN4) - Water-surface elevation, salinity, velocity magnitude, and bed shear stress at Leque Island restoration station L1, October 2005 period 


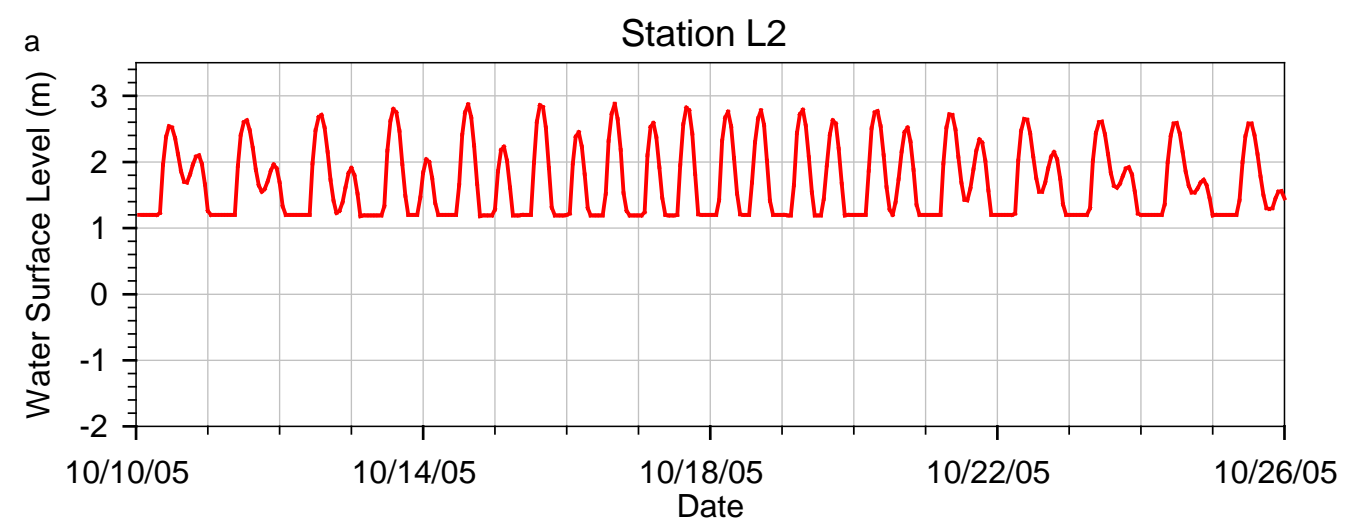

b
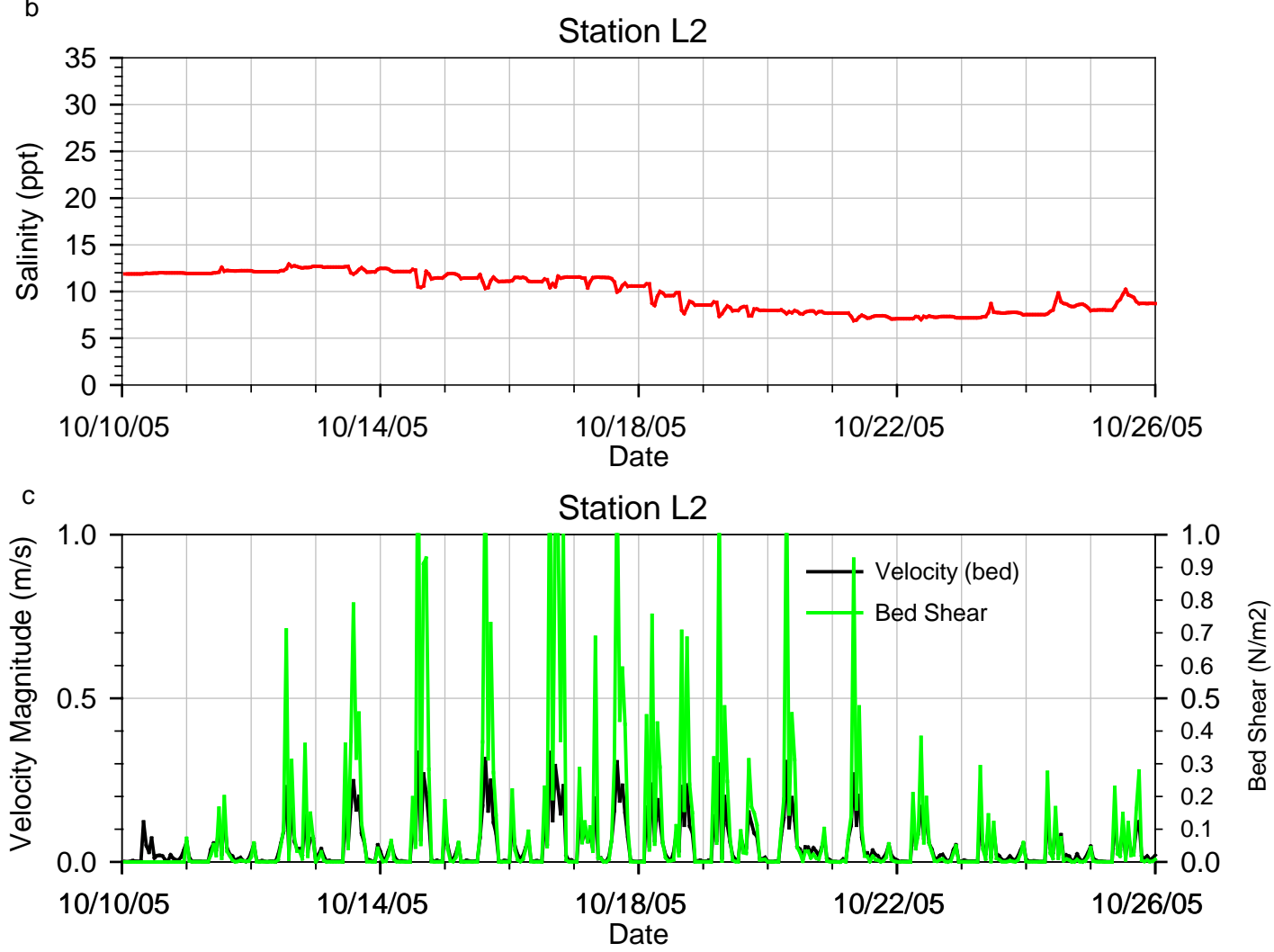

Figure A-24: Scenario 6 (Full Restoration zis a ba + SCN4) - Water-surface elevation, salinity, velocity magnitude, and bed shear stress at Leque Island restoration station L2, October 2005 period 


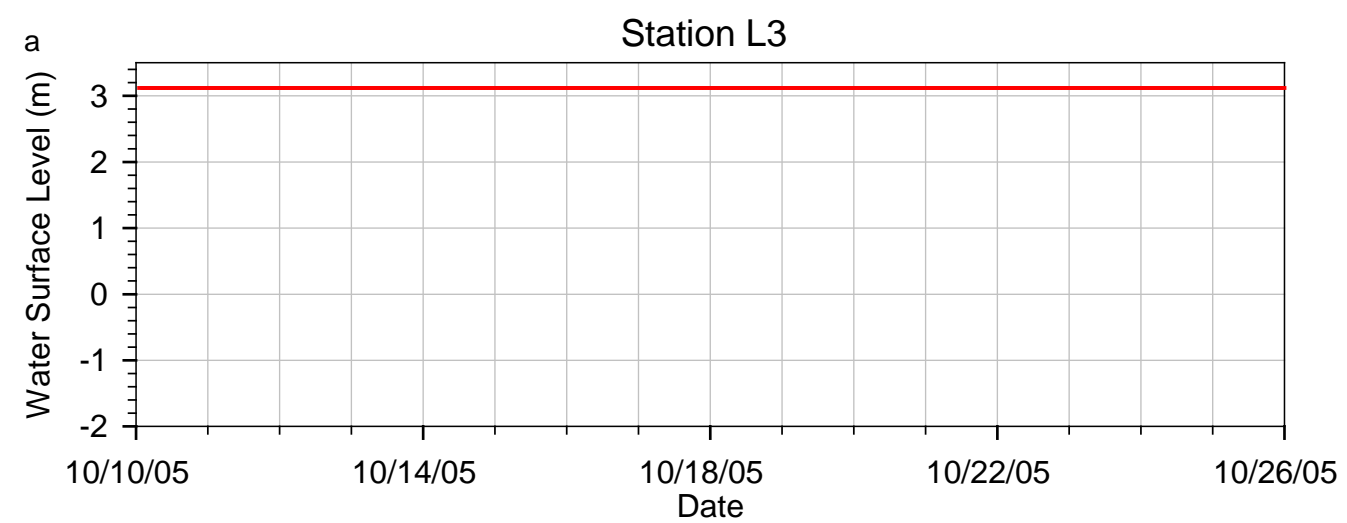

b
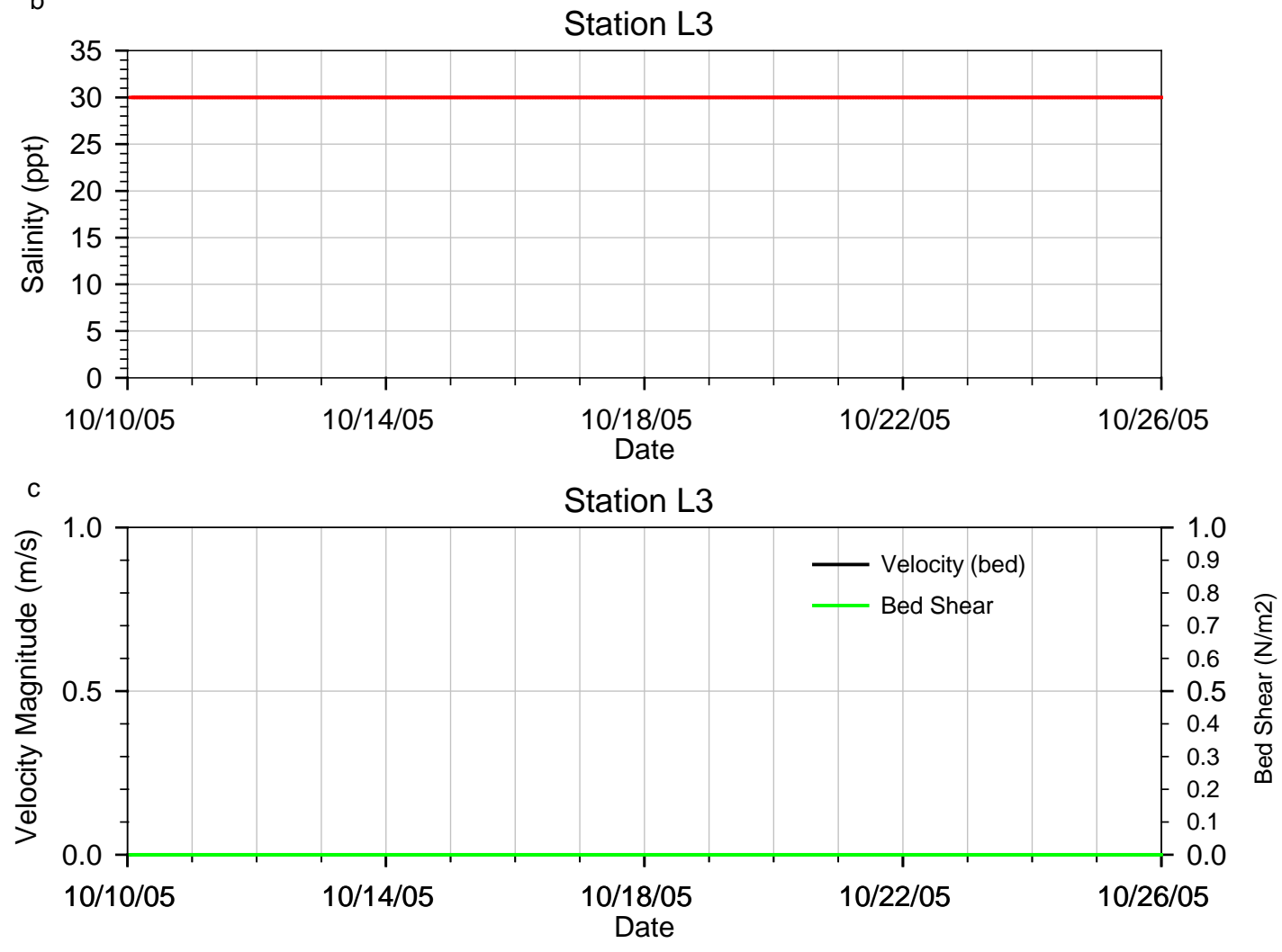

Figure A-25: Scenario 6 (Full Restoration zis a ba + SCN4) - Water-surface elevation, salinity, velocity magnitude, and bed shear stress at Leque Island restoration station L3, October 2005 period 


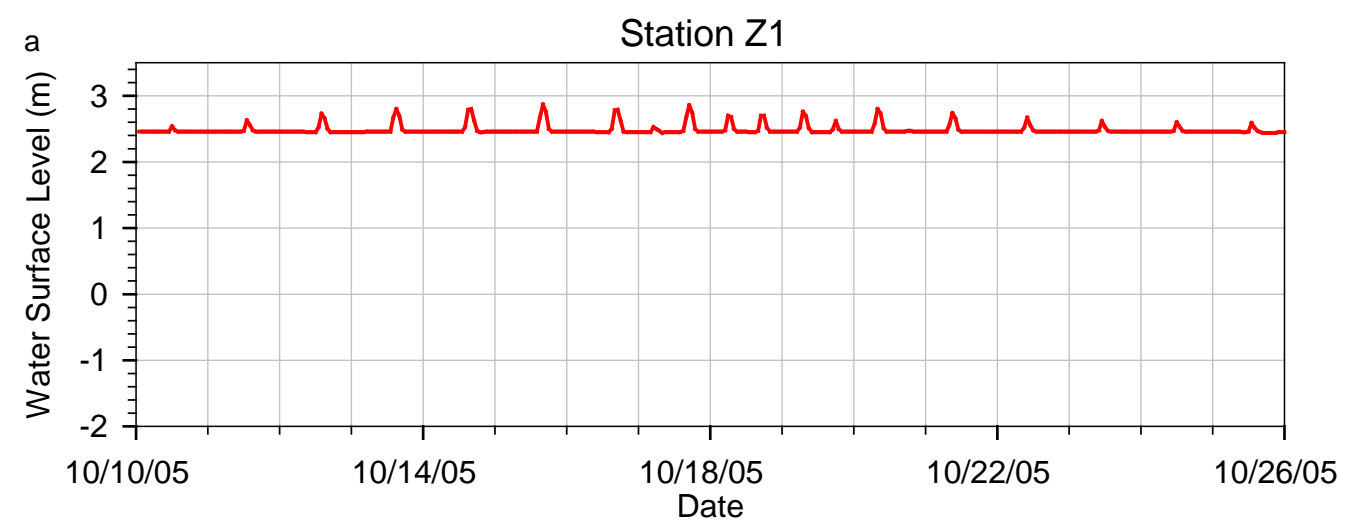

b
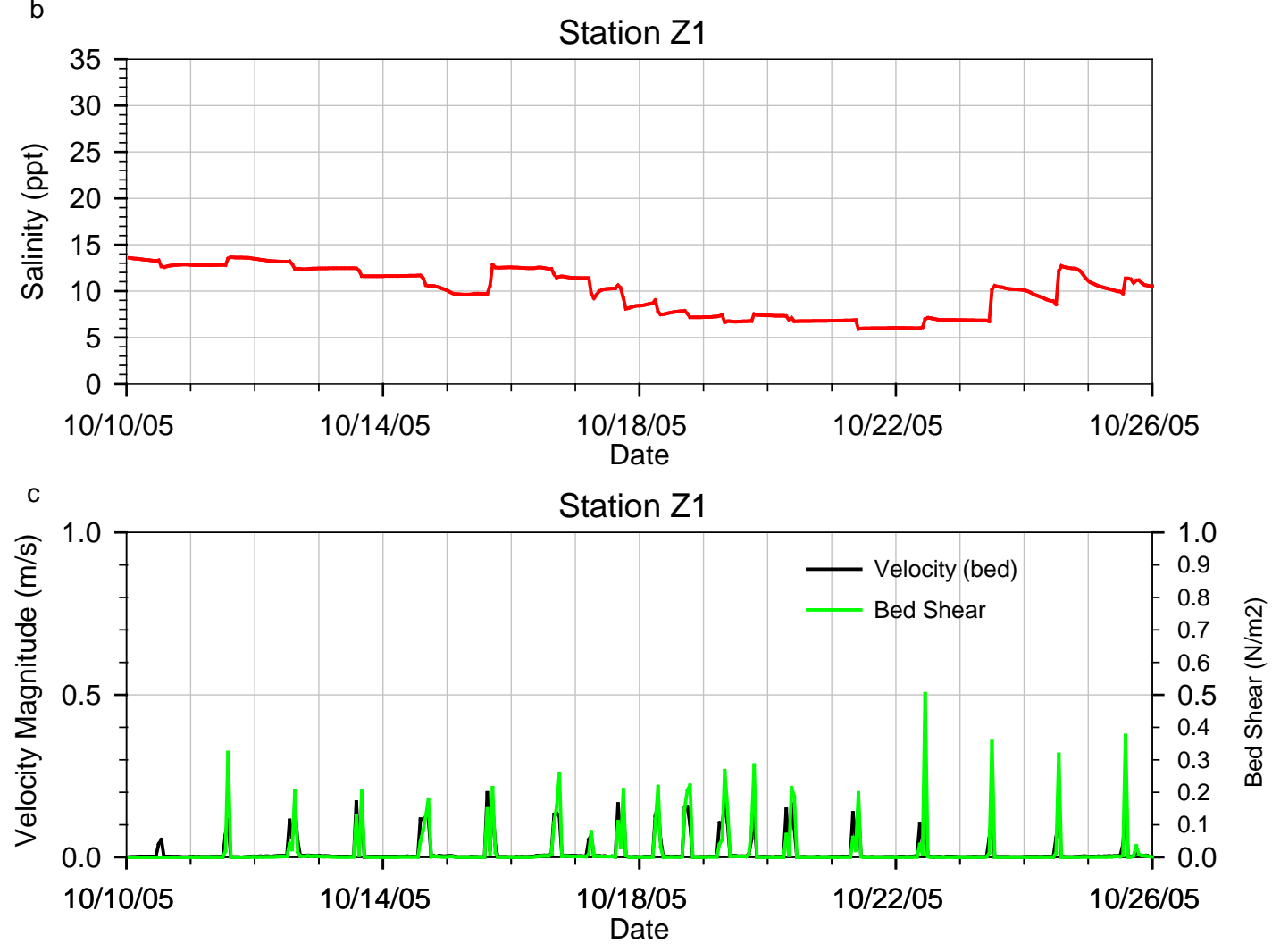

Figure A-26: Scenario 6 (Full Restoration zis a ba + SCN4) - Water-surface elevation, salinity, velocity magnitude, and bed shear stress at zis a ba restoration station Z1, October 2005 period 


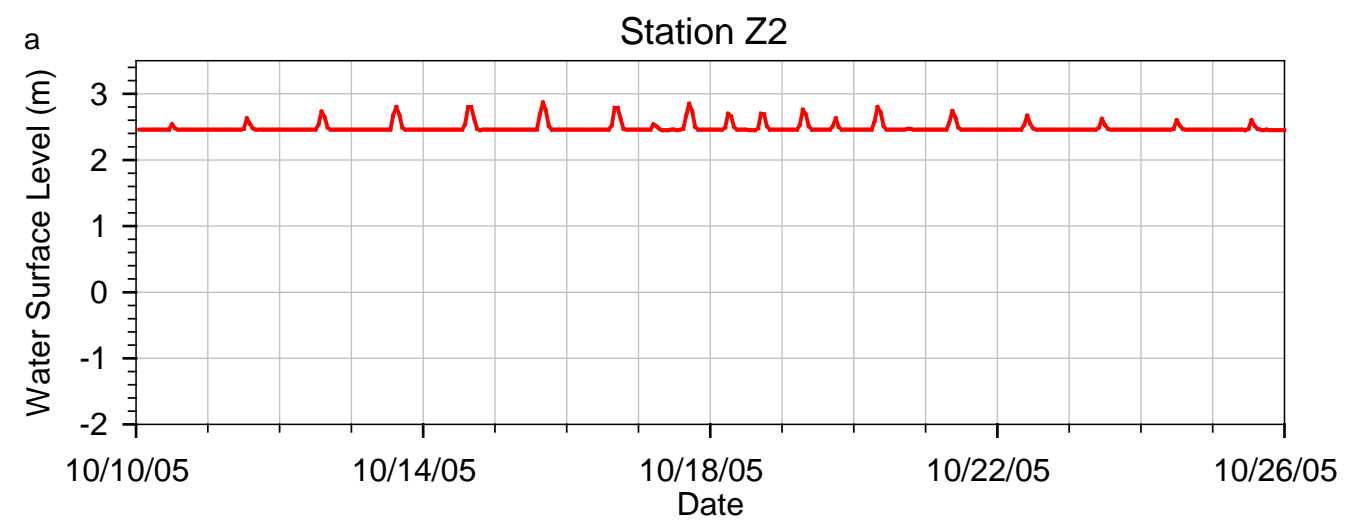

b
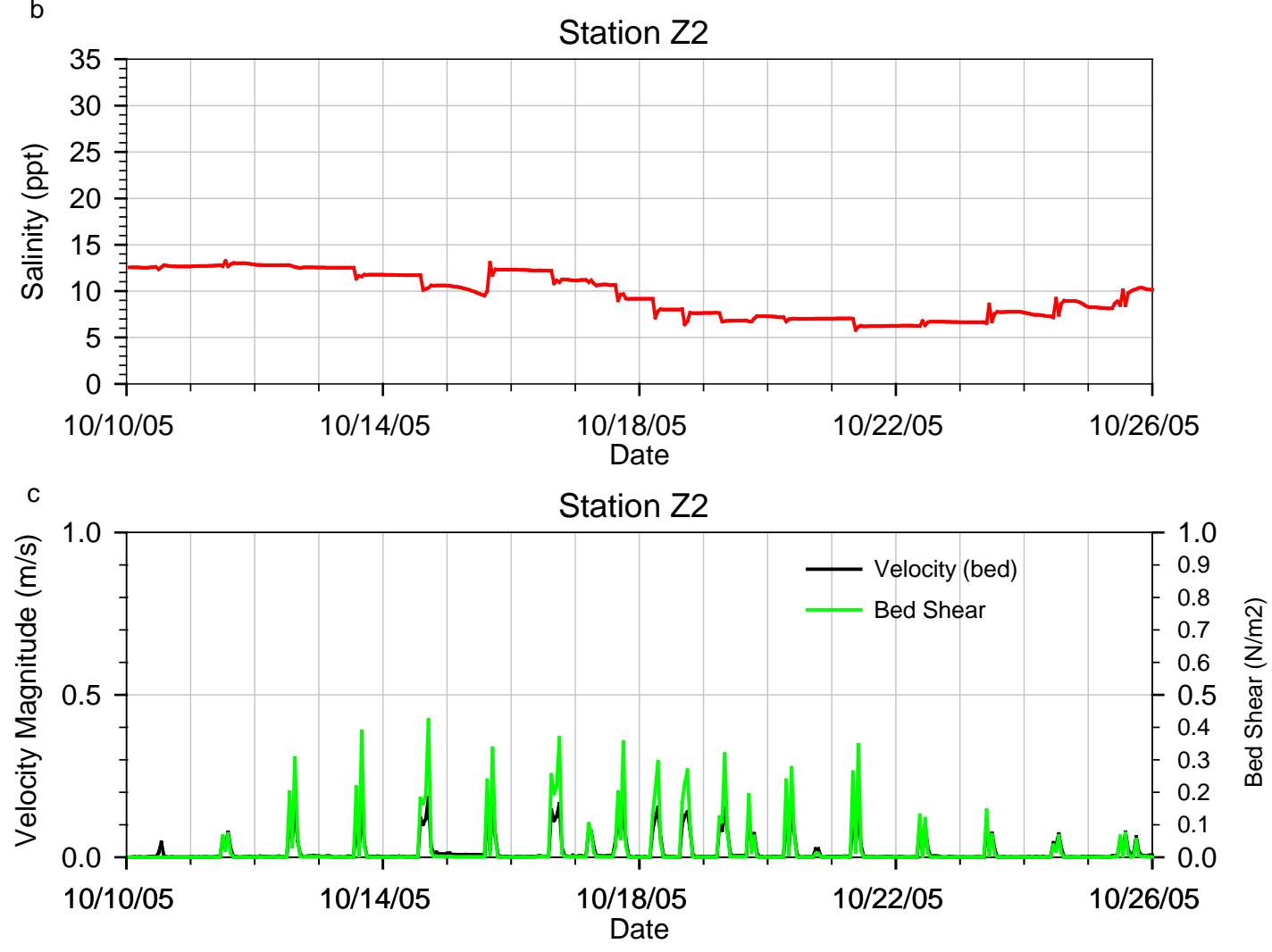

Figure A-27: Scenario 6 (Full Restoration zis a ba + SCN4) - Water-surface elevation, salinity, velocity magnitude, and bed shear stress at zis a ba restoration station Z2, October 2005 period 


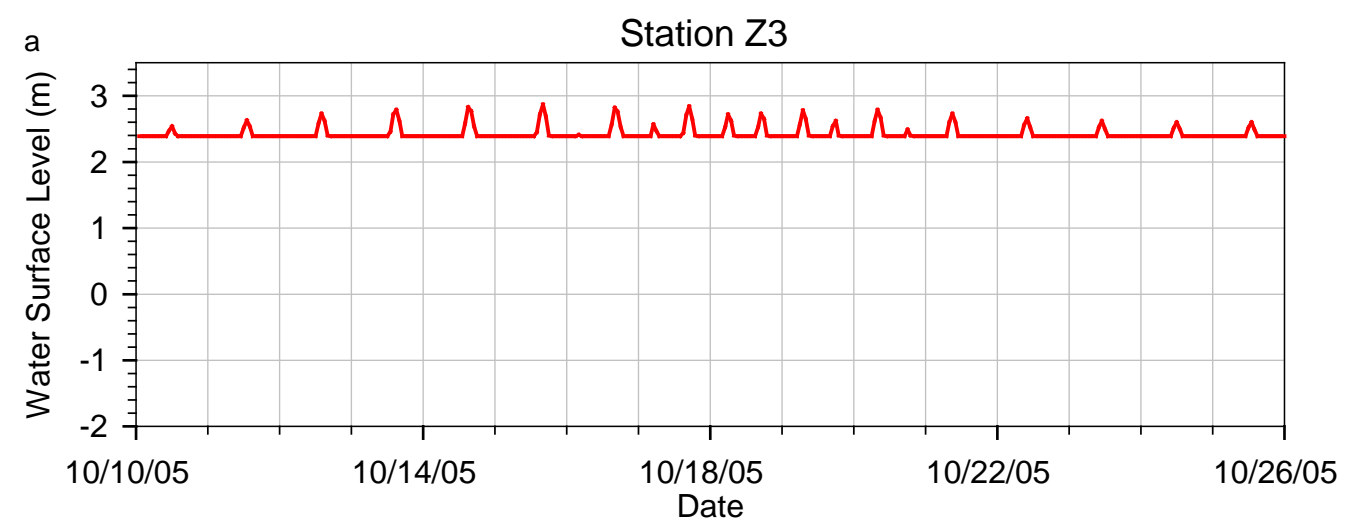

b
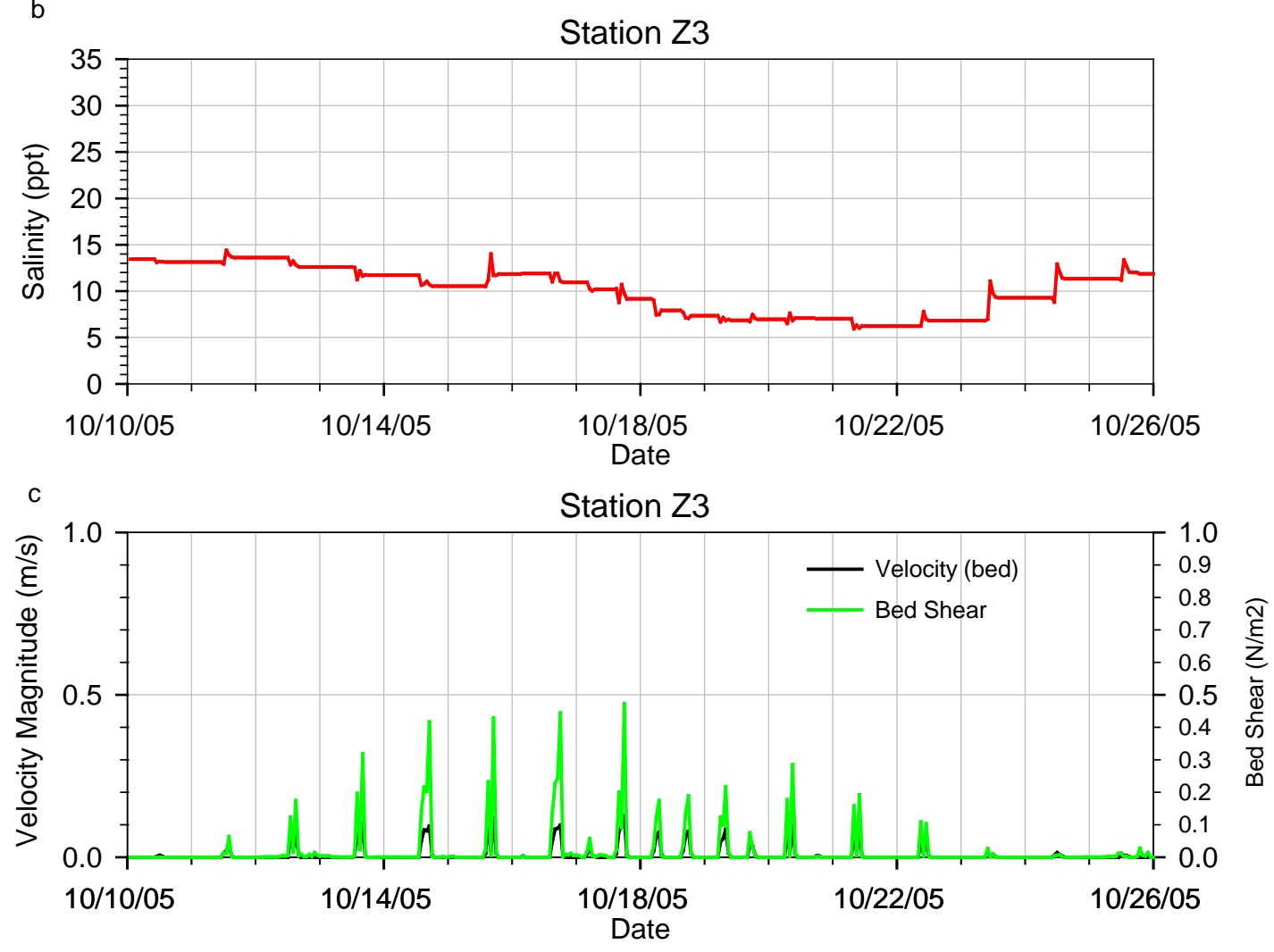

Figure A-28: Scenario 6 (Full Restoration zis a ba + SCN4) - Water-surface elevation, salinity, velocity magnitude, and bed shear stress at zis a ba restoration station Z3, October 2005 period 


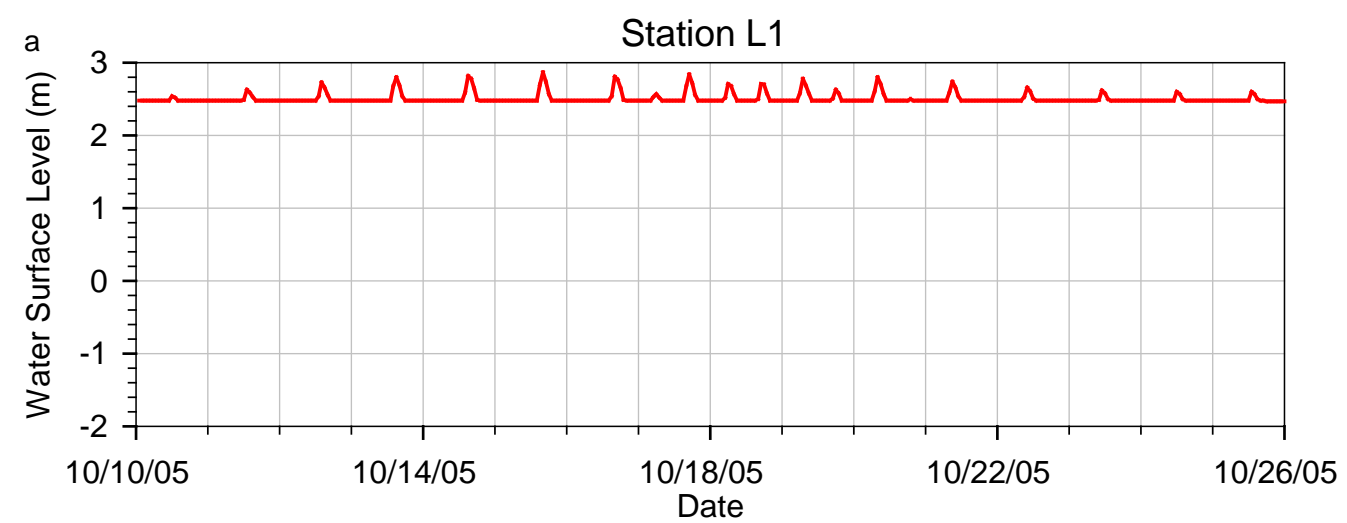

b
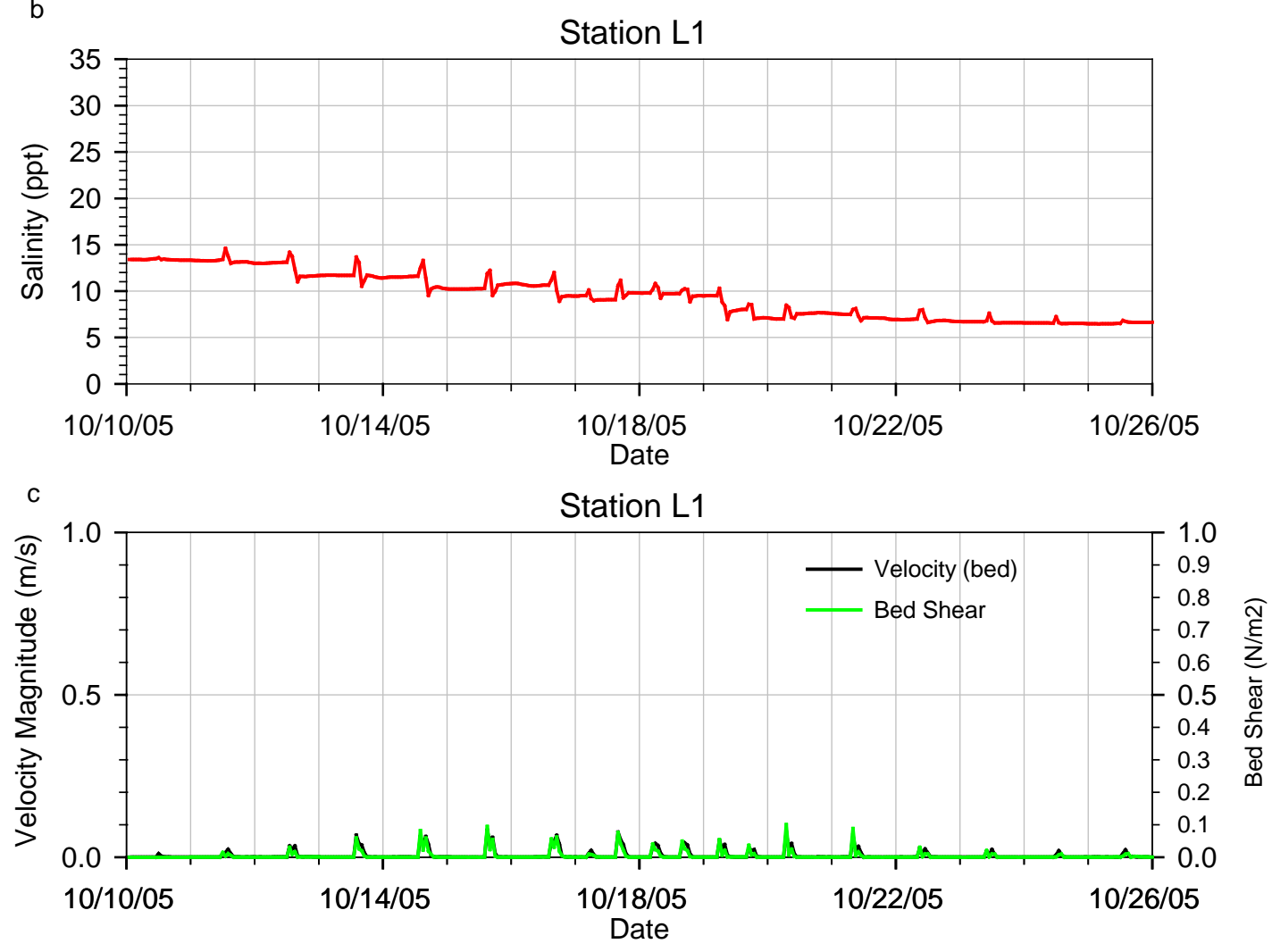

Figure A-29: Scenario 7 (Full Restoration zis a ba + SCN3) - Water-surface elevation, salinity, velocity magnitude, and bed shear stress at Leque Island restoration station L1, October 2005 period 


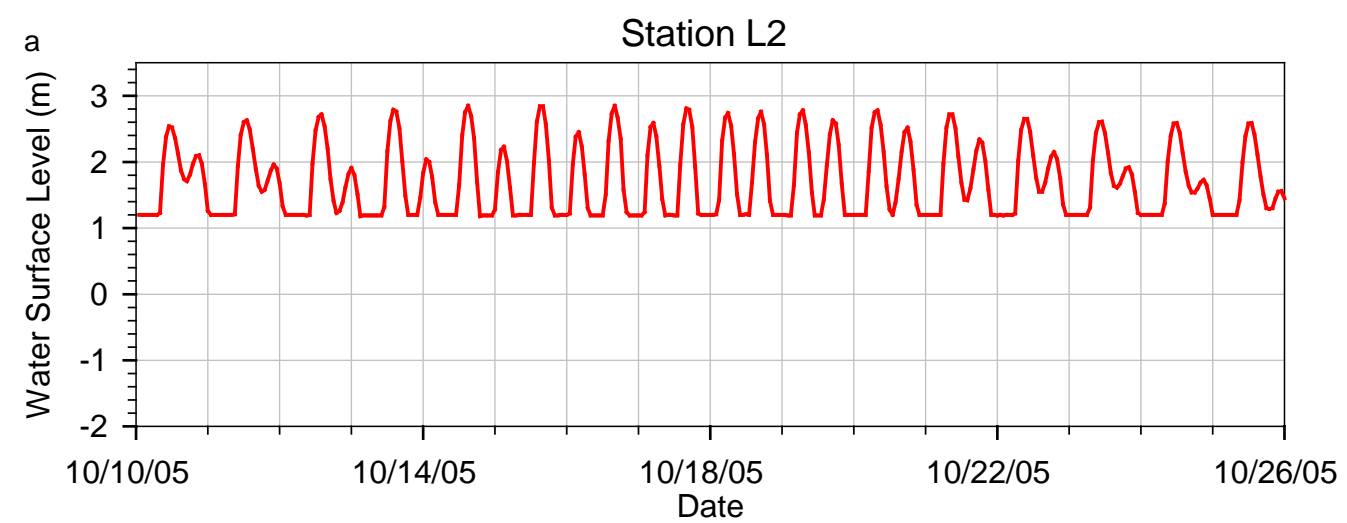

b
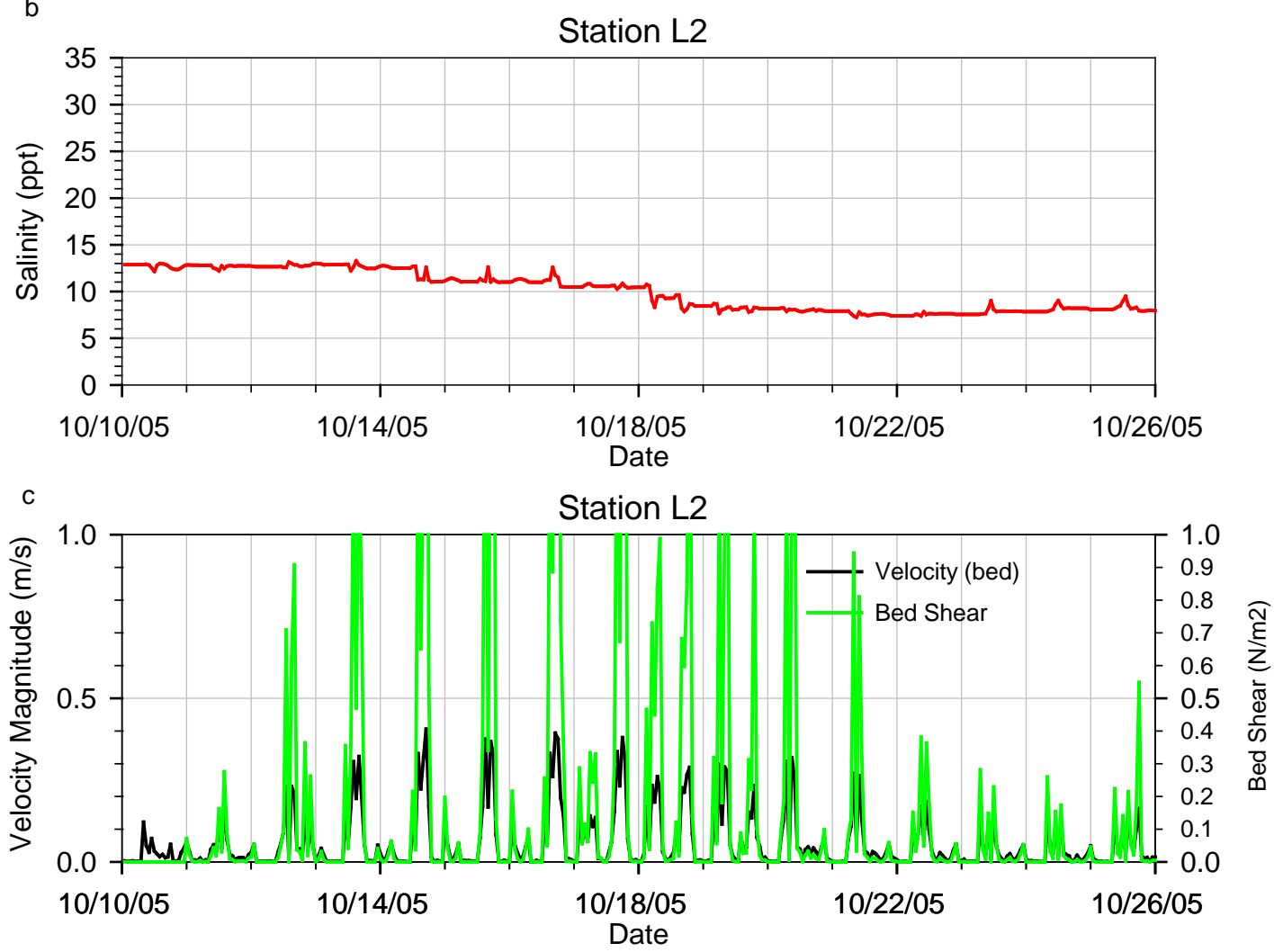

Figure A-30: Scenario 7 (Full Restoration zis a ba + SCN3) - Water-surface elevation, salinity, velocity magnitude, and bed shear stress at Leque Island restoration station L2, October 2005 period 


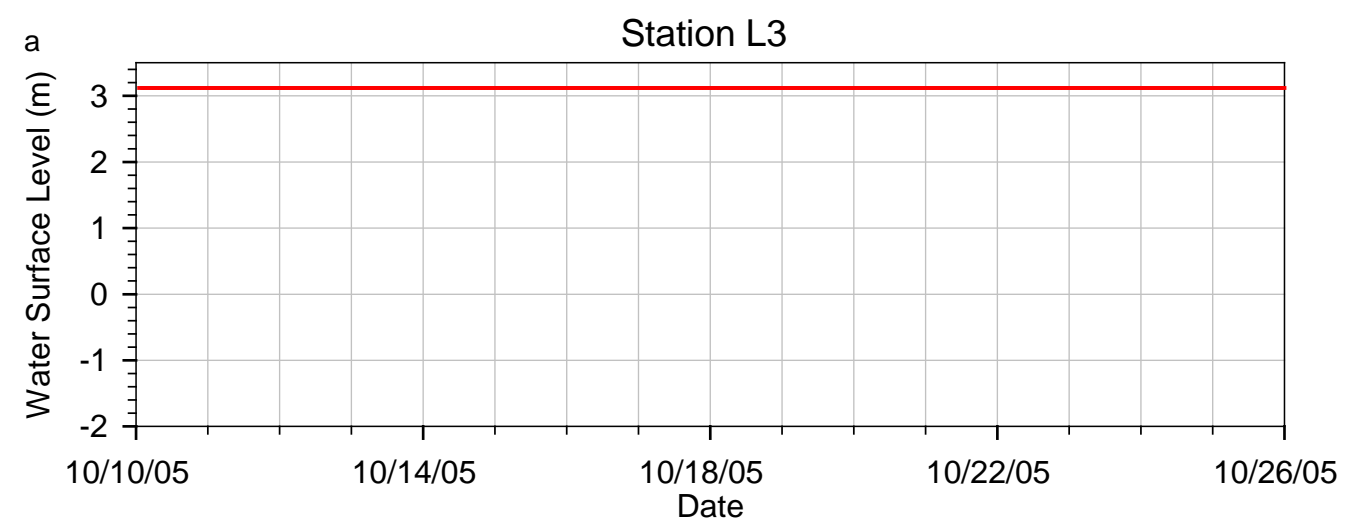

b
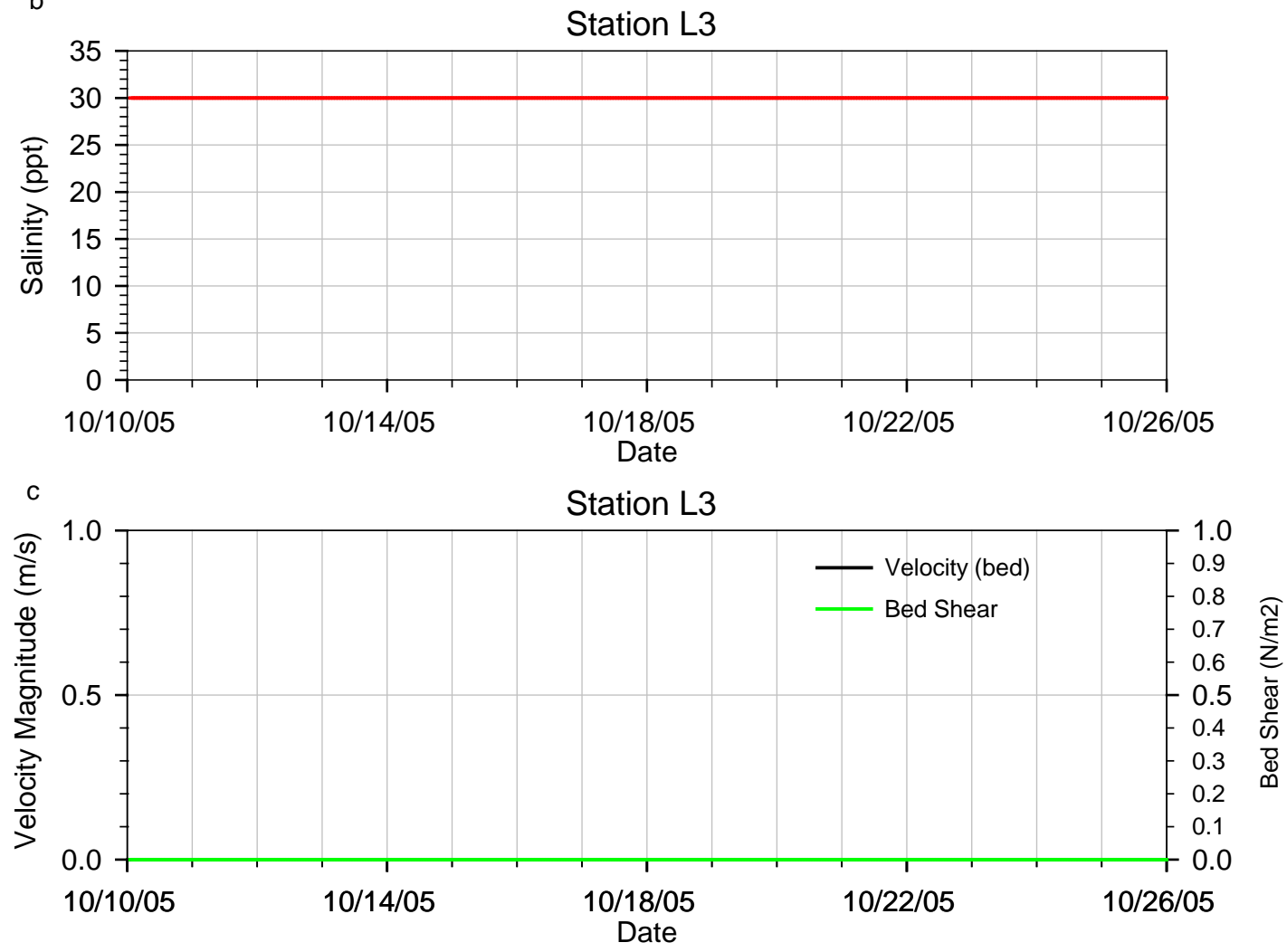

Figure A-31: Scenario 7 (Full Restoration zis a ba + SCN3) - Water-surface elevation, salinity, velocity magnitude, and bed shear stress at Leque Island restoration station L3, October 2005 period 


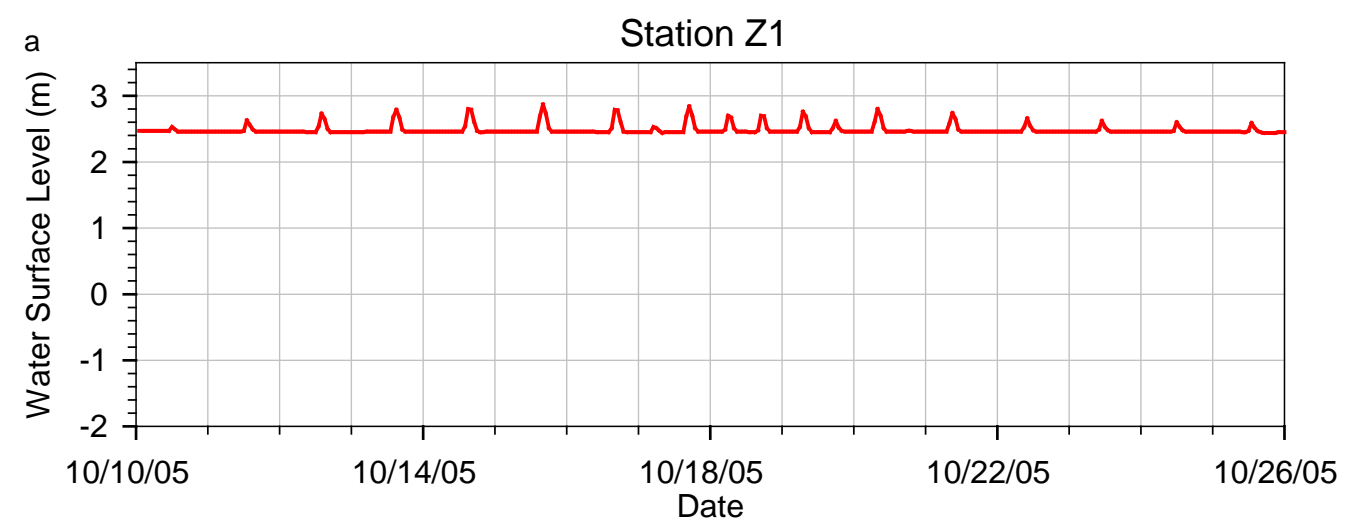

b
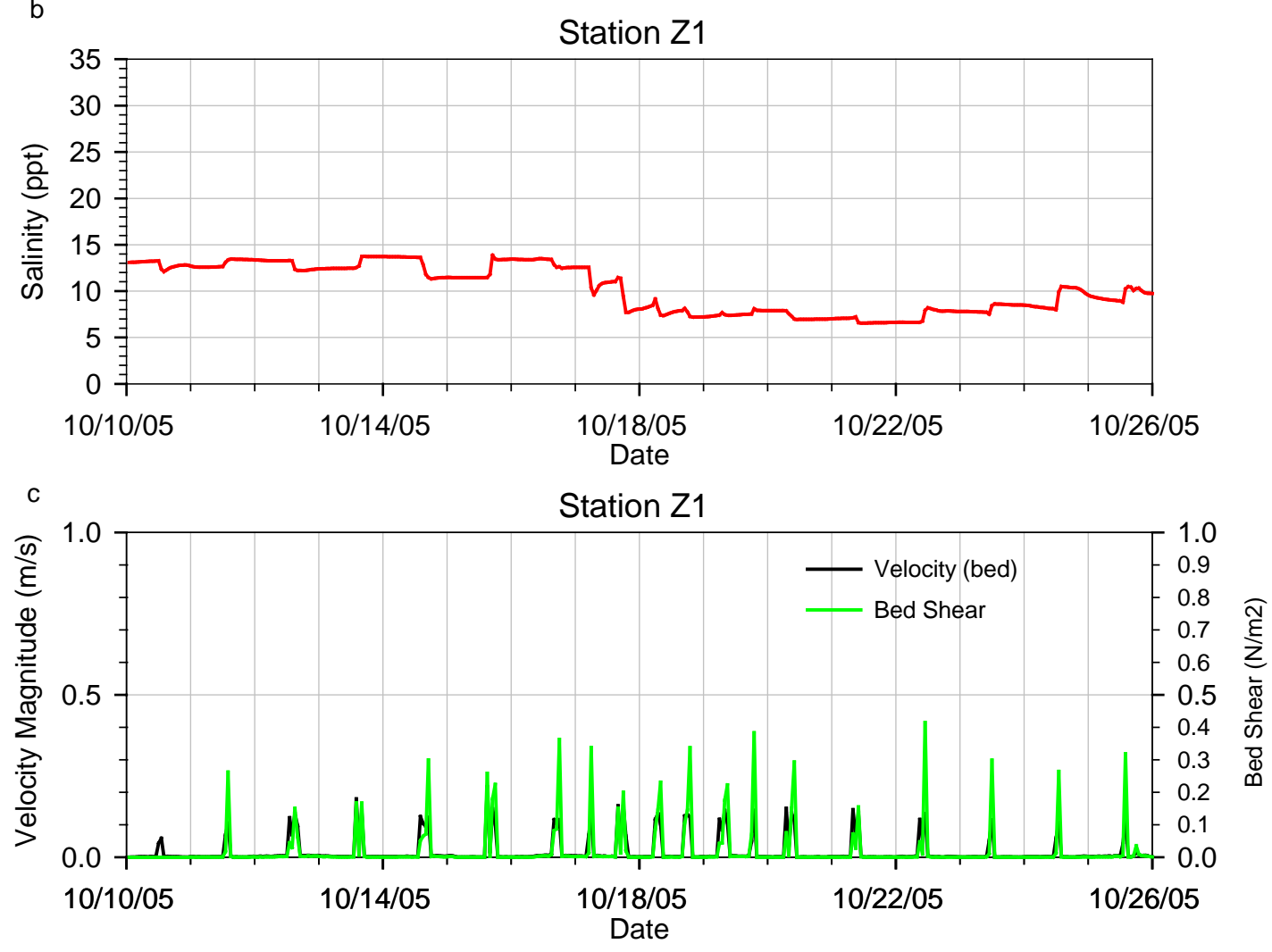

Figure A-32: Scenario 7 (Full Restoration zis a ba + SCN3) - Water-surface elevation, salinity, velocity magnitude, and bed shear stress at zis a ba restoration station Z1, October 2005 period 


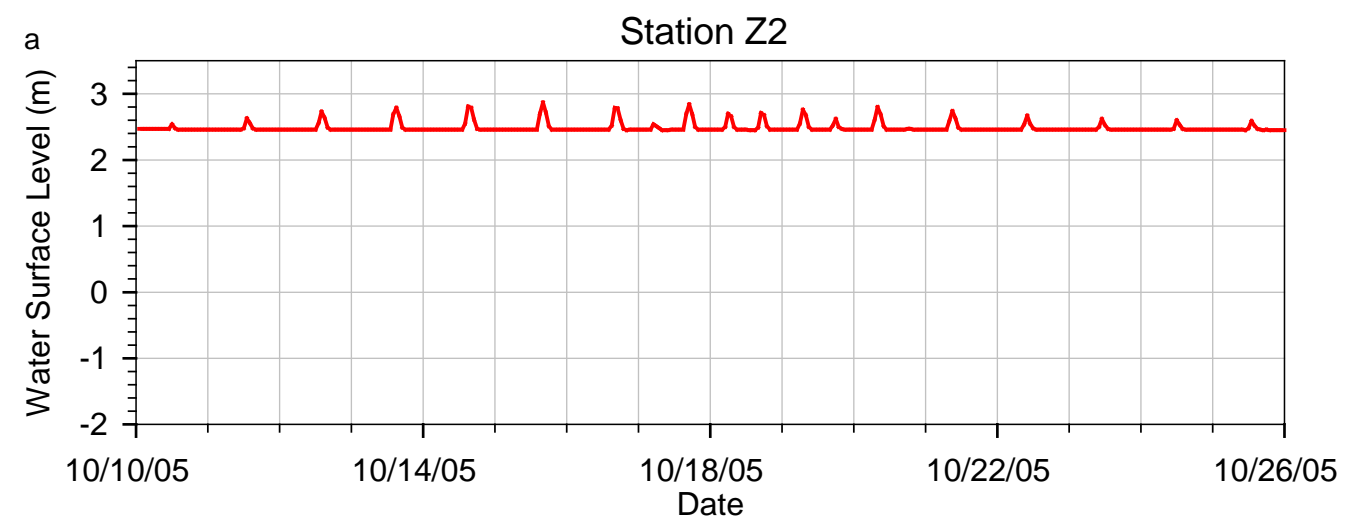

b
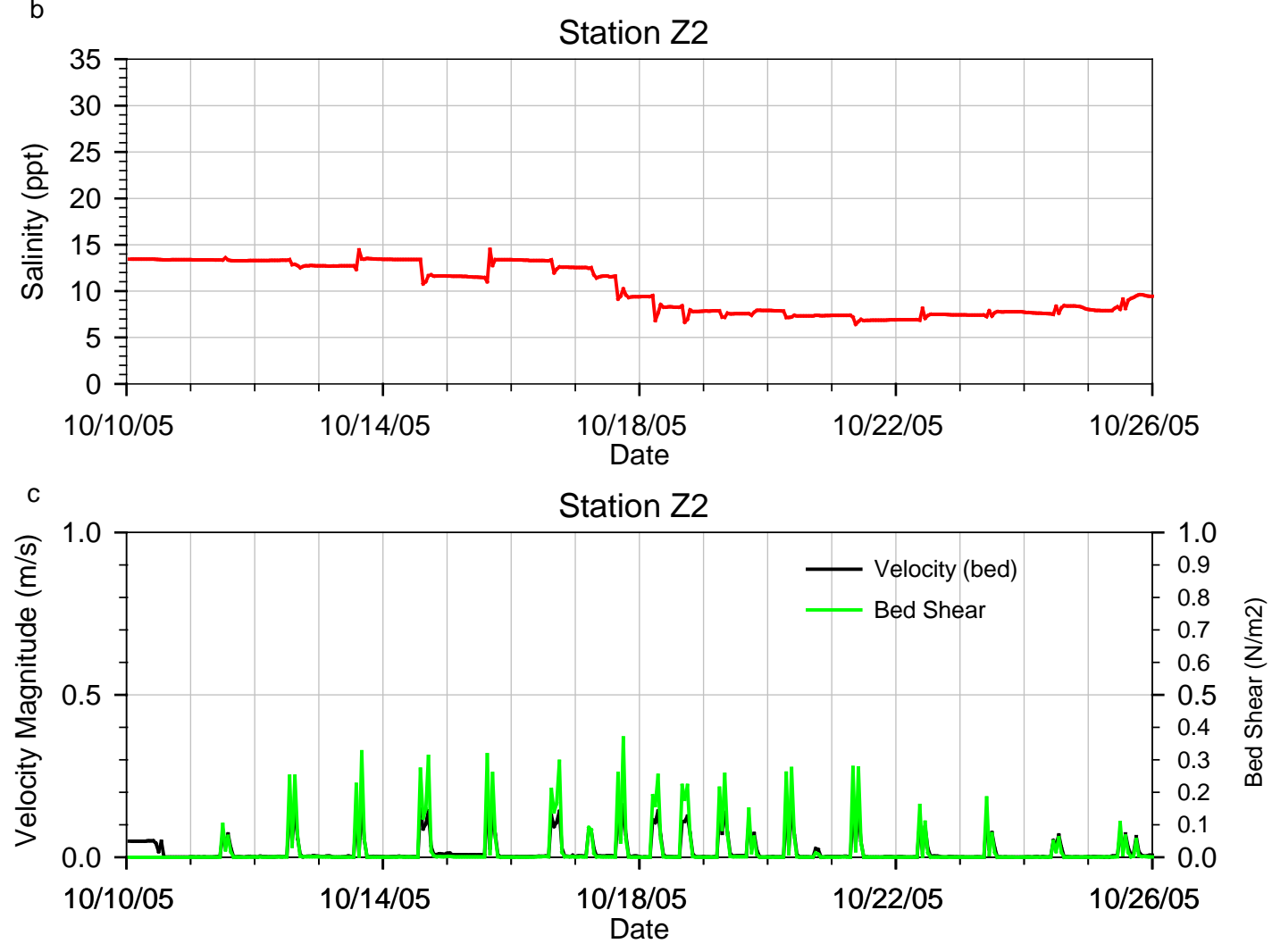

Figure A-33: Scenario 7 (Full Restoration zis a ba + SCN3) - Water-surface elevation, salinity, velocity magnitude, and bed shear stress at zis a ba restoration station Z2, October 2005 period 


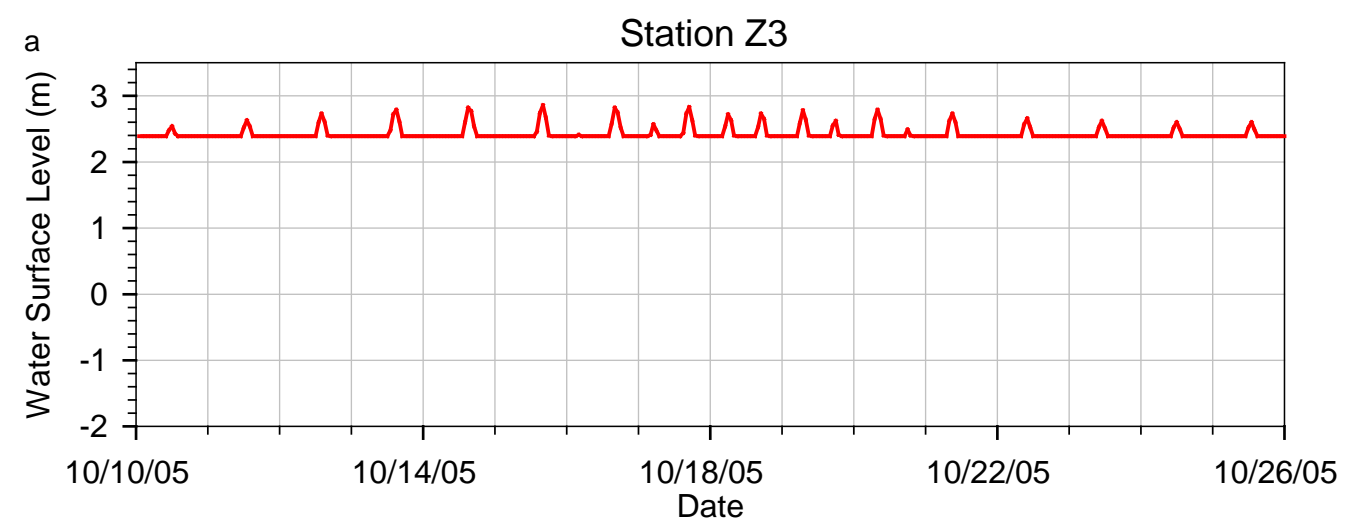

b
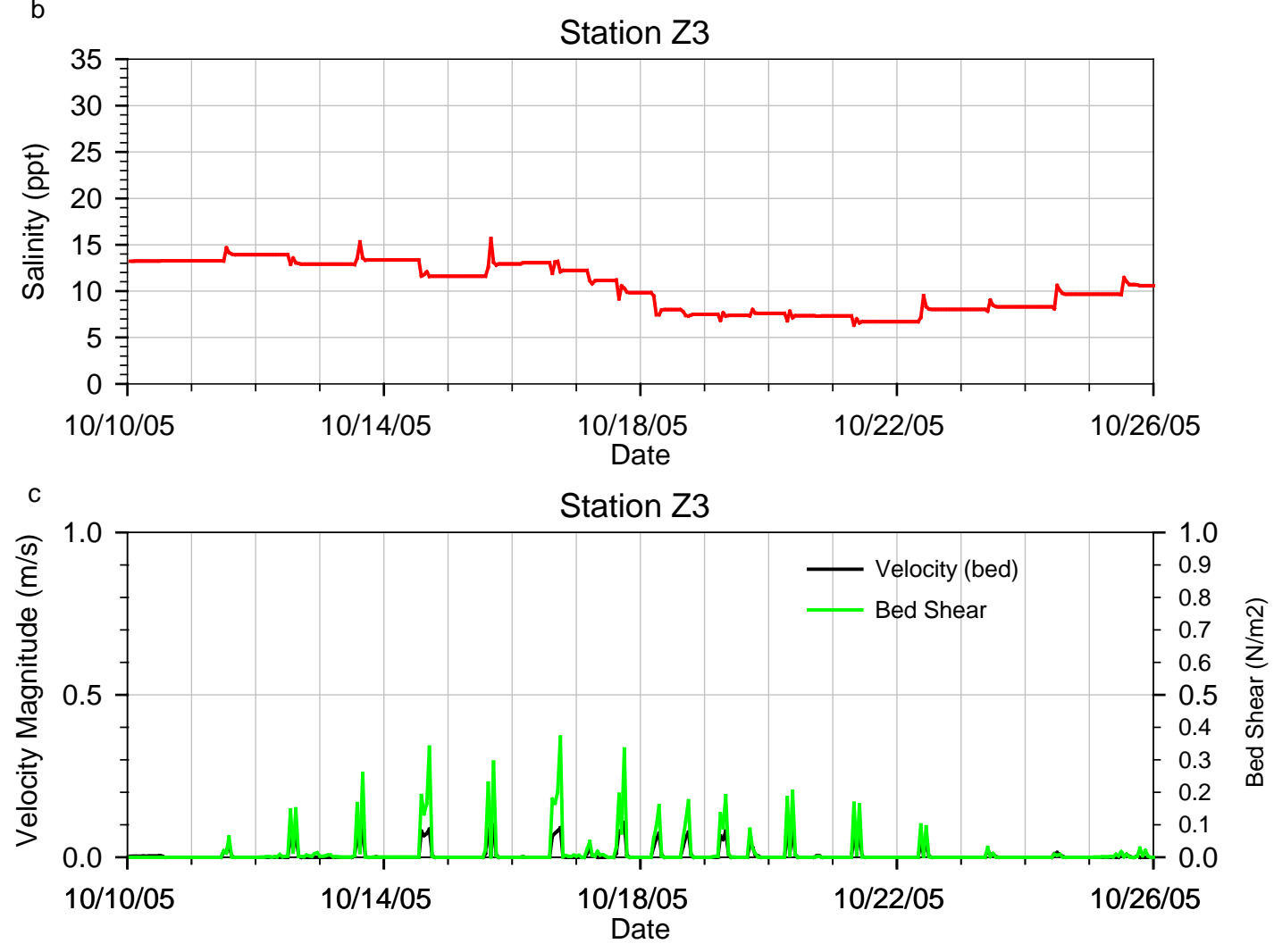

Figure A-34: Scenario 7 (Full Restoration zis a ba + SCN3) - Water-surface elevation, salinity, velocity magnitude, and bed shear stress at zis a ba restoration station Z3, October 2005 period 


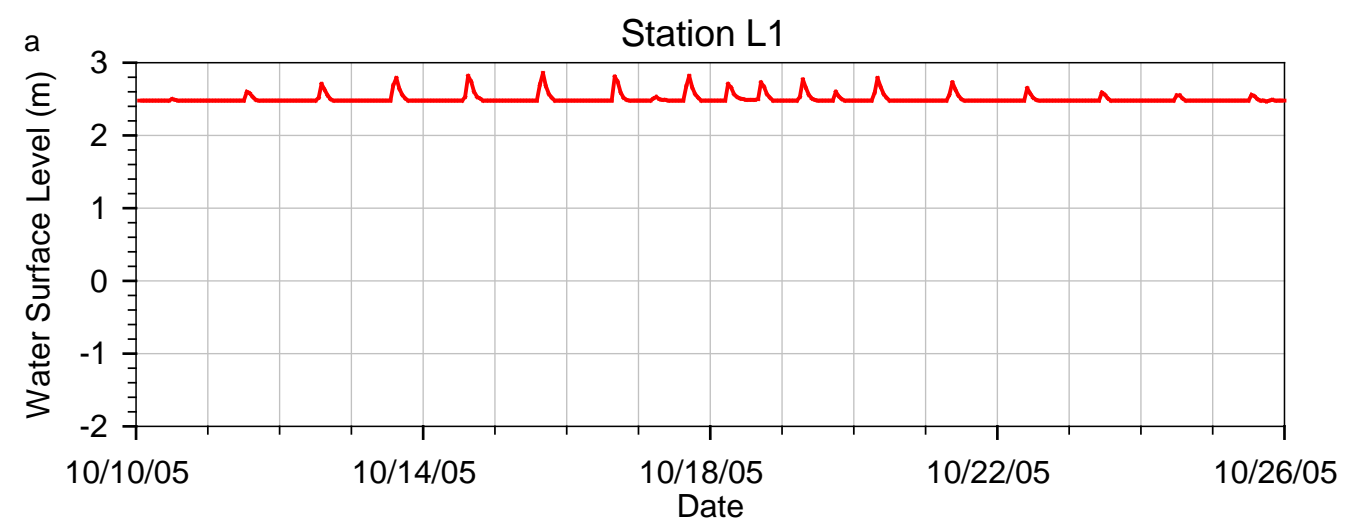

b
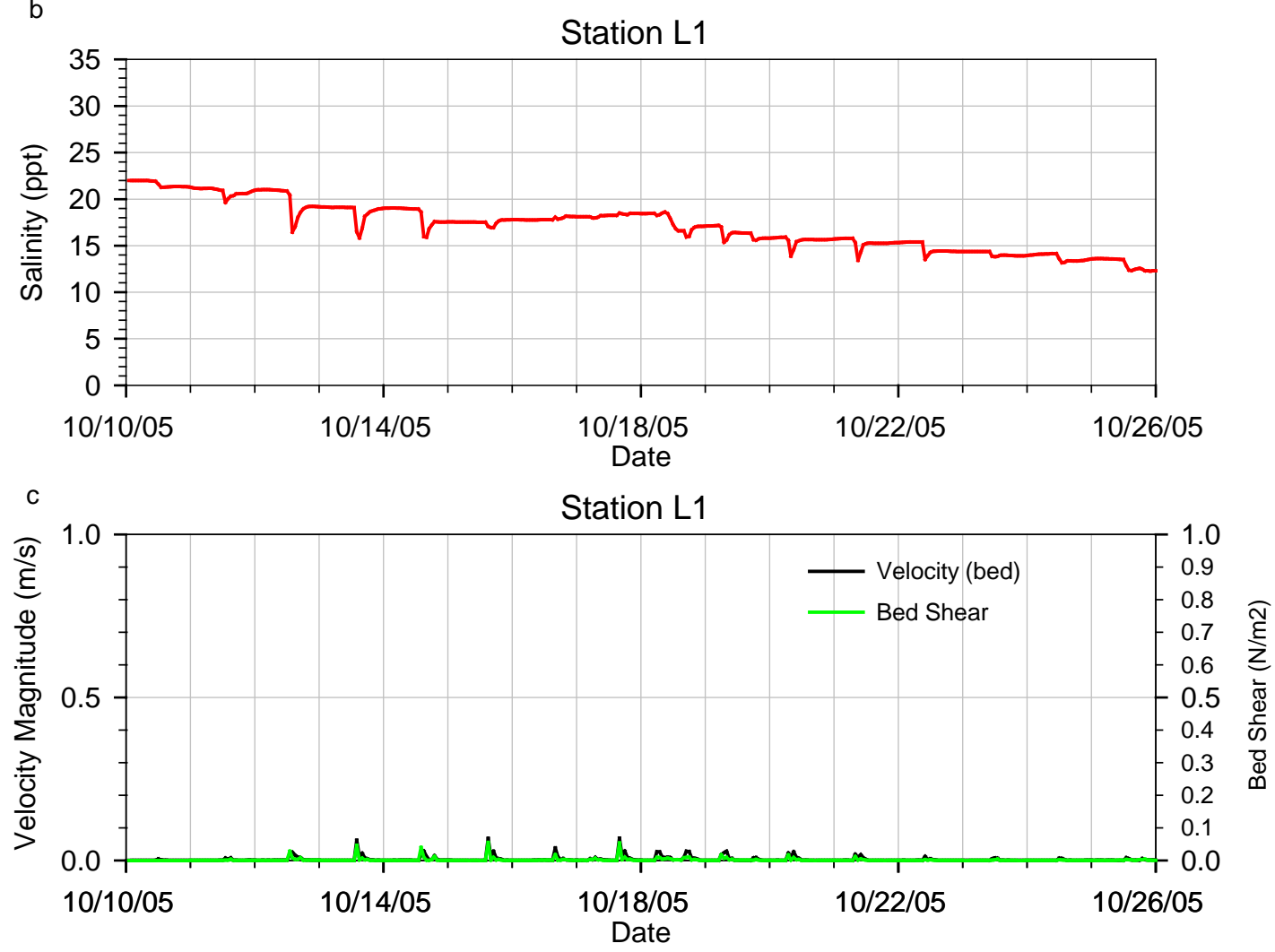

Figure A-35: Scenario 8 (3 Levee Breaches Leque) - Water-surface elevation, salinity, velocity magnitude, and bed shear stress at Leque Island restoration station L1, October 2005 period 


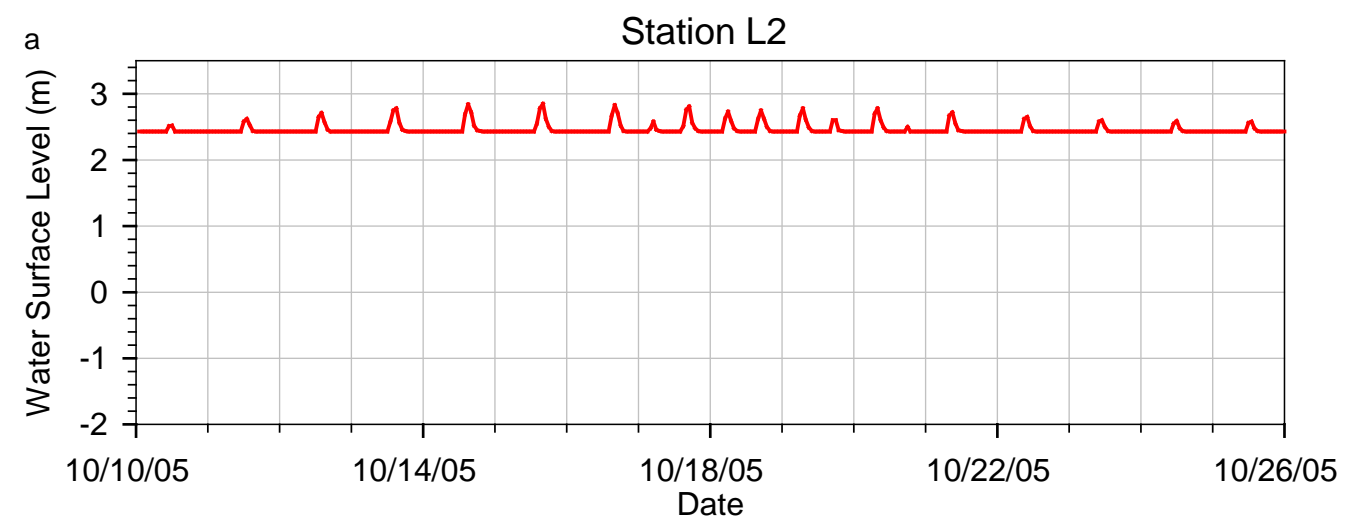

b
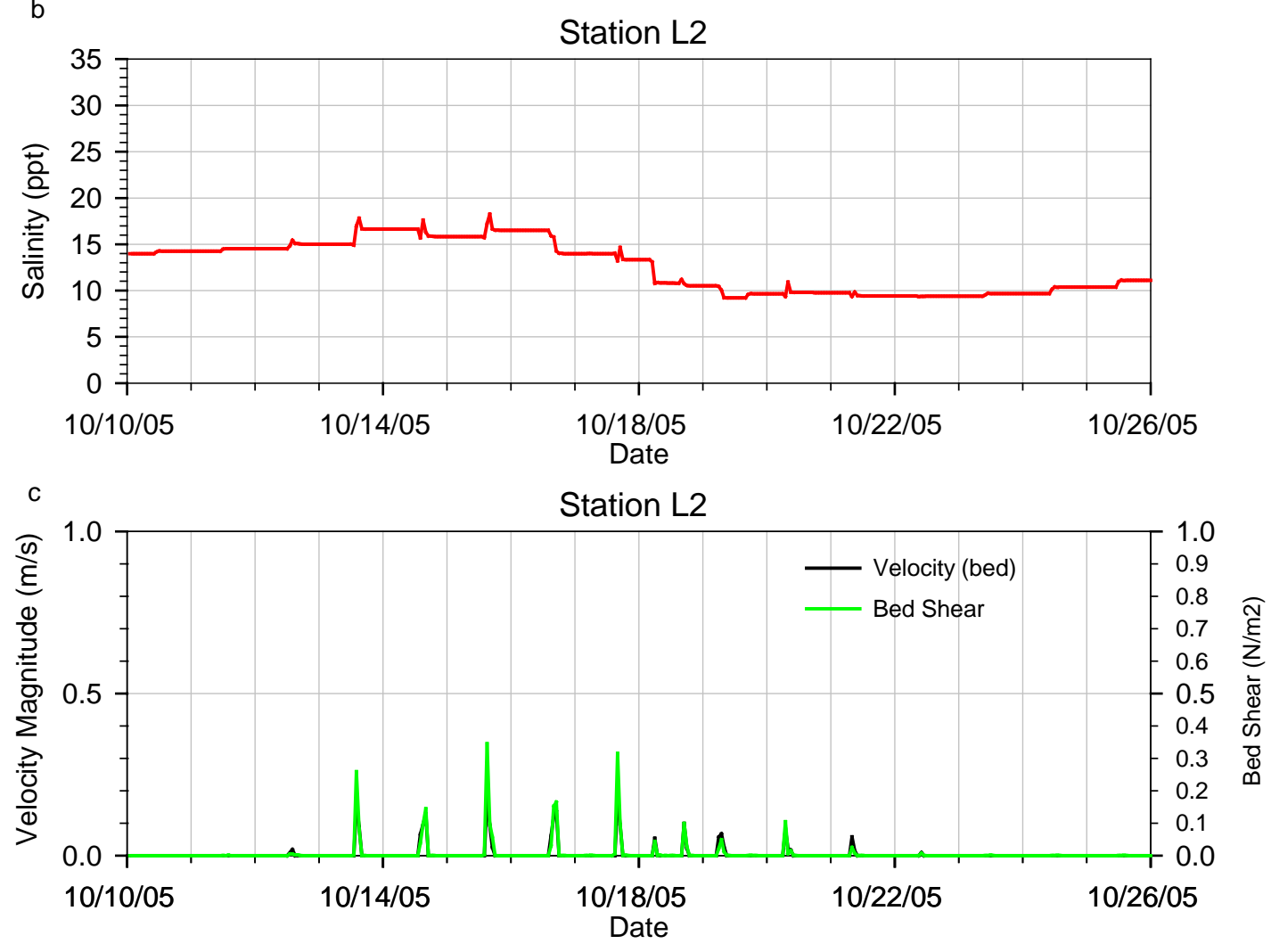

Figure A-36: Scenario 8 (3 Levee Breaches Leque) - Water-surface elevation, salinity, velocity magnitude, and bed shear stress at Leque Island restoration station L2, October 2005 period 


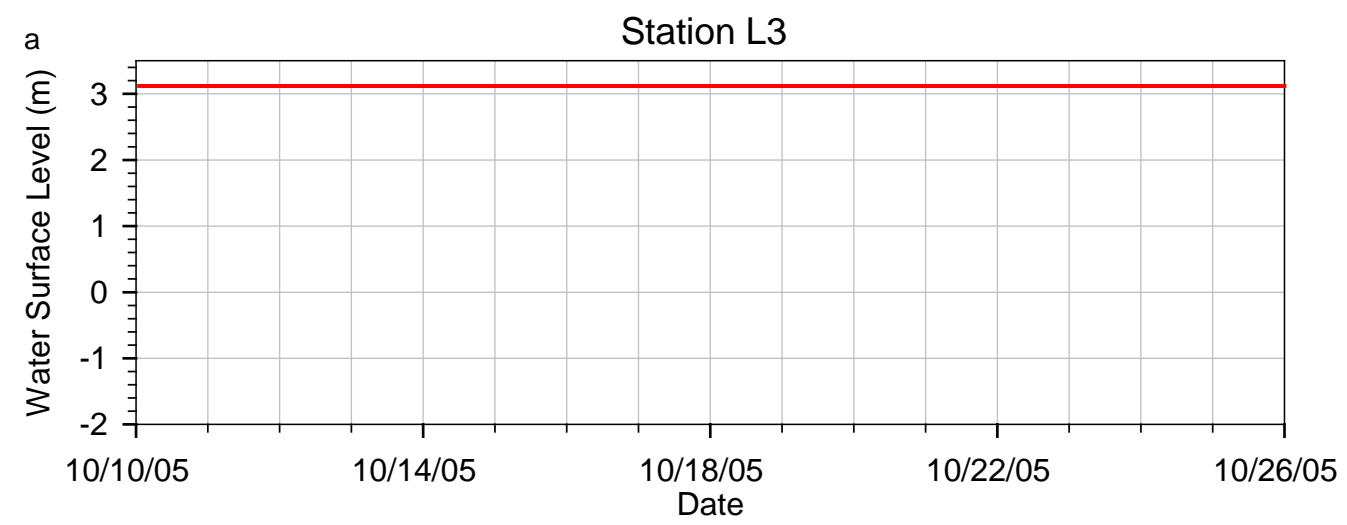

b
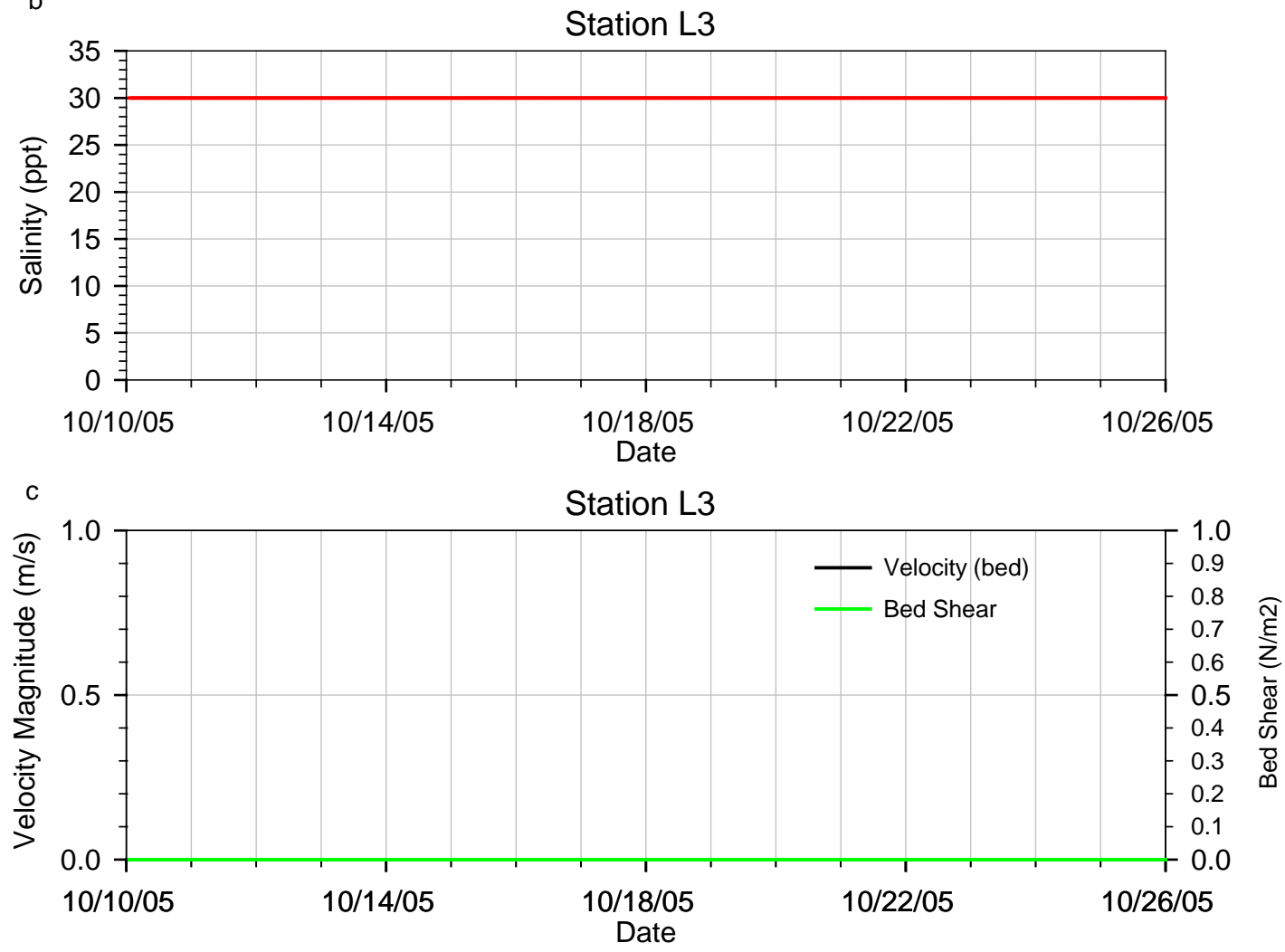

Figure A-37: Scenario 8 (3 Levee Breaches Leque) - Water-surface elevation, salinity, velocity magnitude, and bed shear stress at Leque Island restoration station L3, October 2005 period 



\section{Appendix B}

\section{Plan View Contour Plots - October 2005 Conditions - Salinity, Velocity}





\section{Appendix B}

\section{Plan View Contour Plots - October 2005 Conditions - Salinity, Velocity}

Plan view contour plots of the October 2005 water-surface elevations, salinities, velocities, and bed sheers for the Leque Island and zis a ba restoration sites are provided in this appendix.

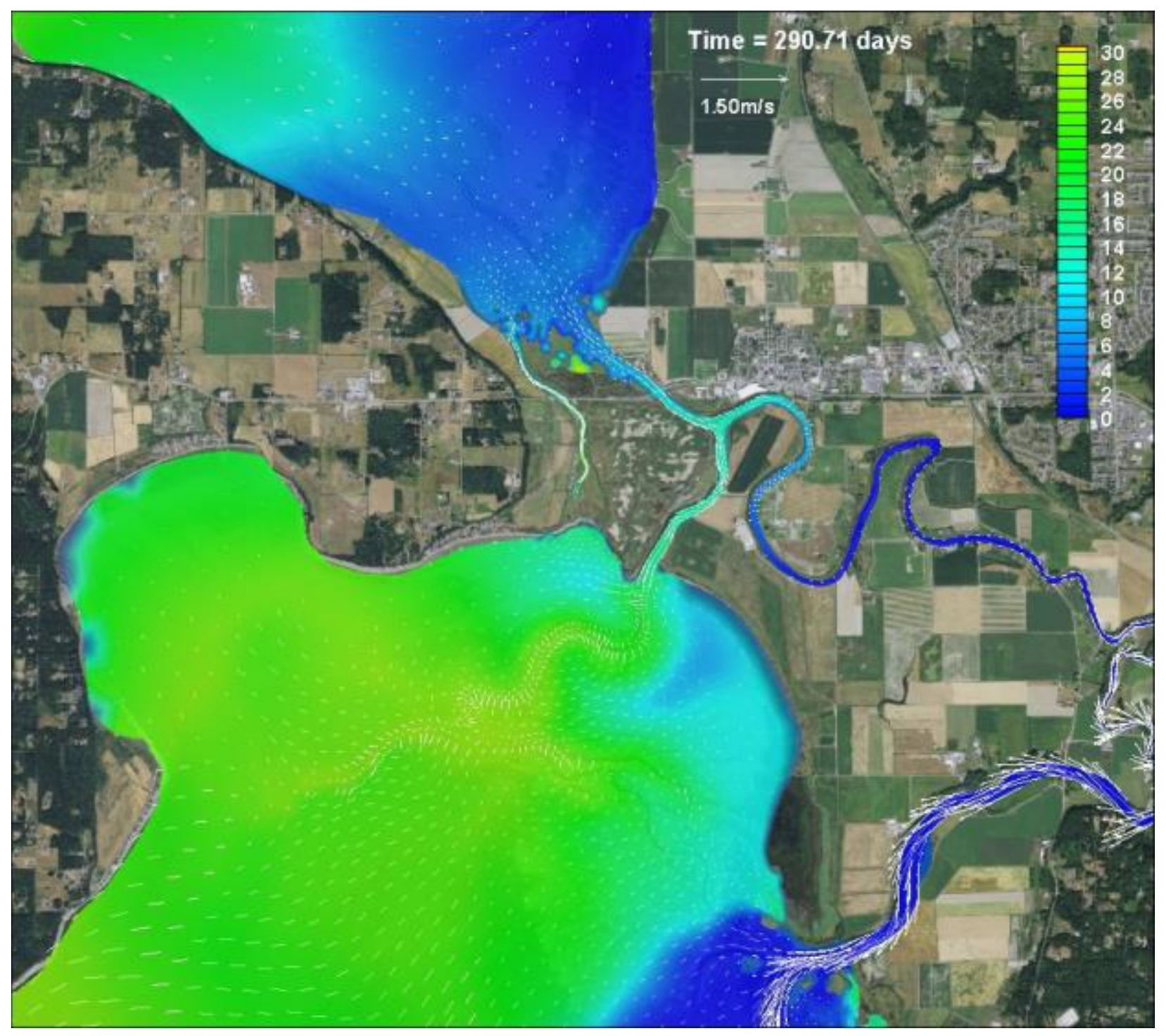

Figure B-1: Scenario 0 (Baseline Condition) - Salinity contours and velocity vectors, October 17, 2005, high tide 


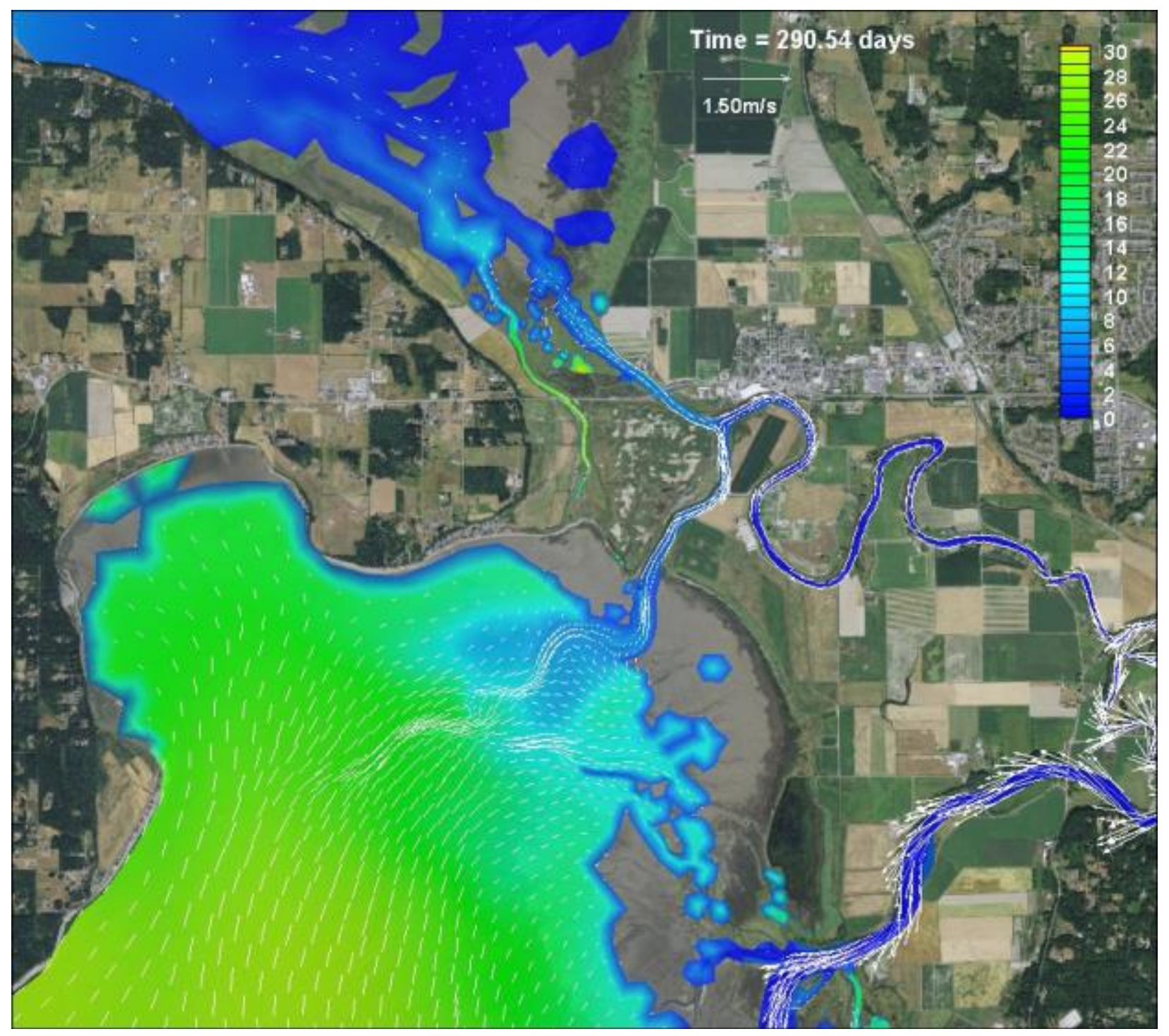

Figure B-2: Scenario 0 (Baseline Condition) - Salinity contours and velocity vectors, October 17, 2005, low tide 


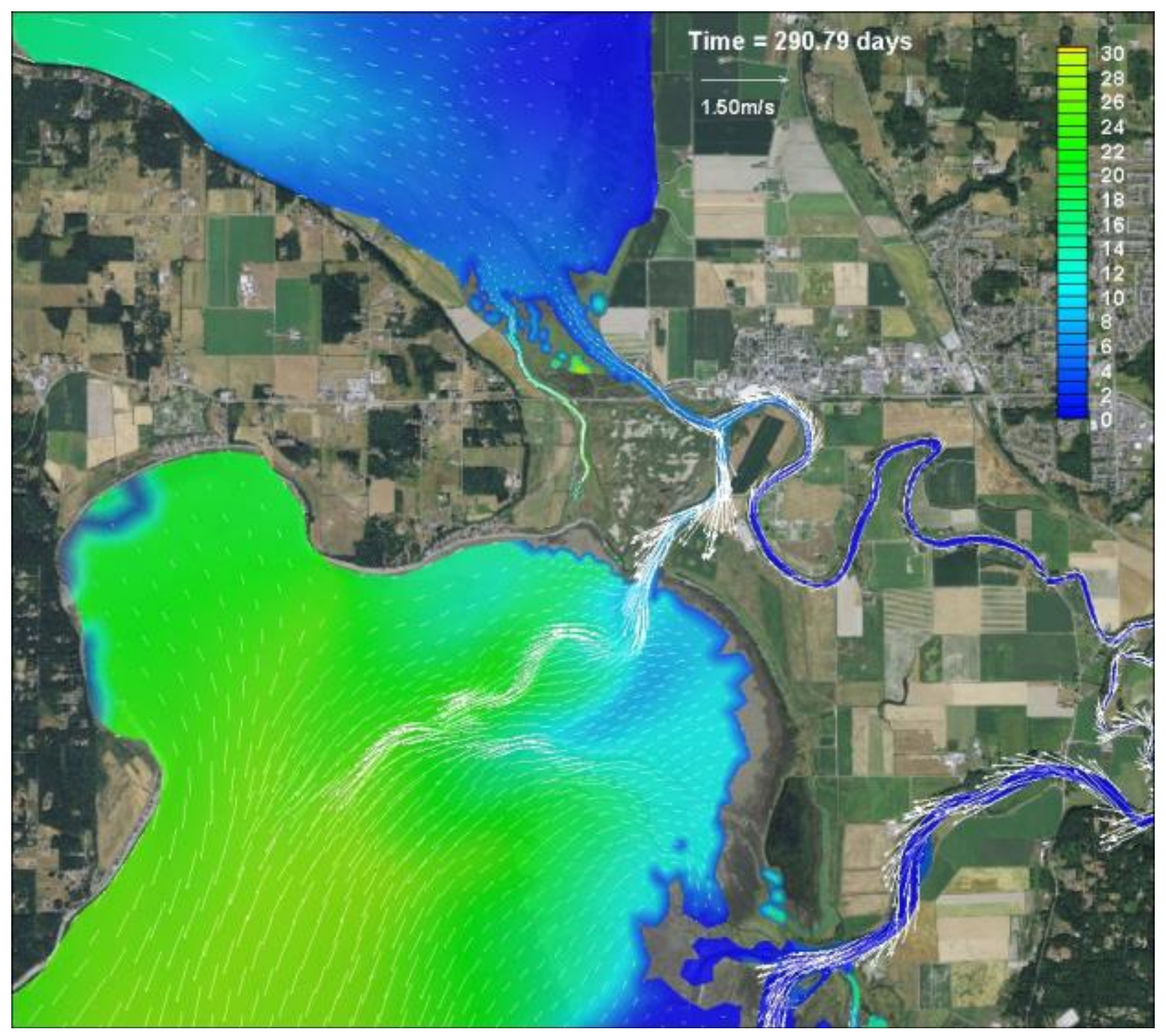

Figure B-3: Scenario 0 (Baseline Condition) - Salinity contours and velocity vectors, October 17, 2005 peak ebb 


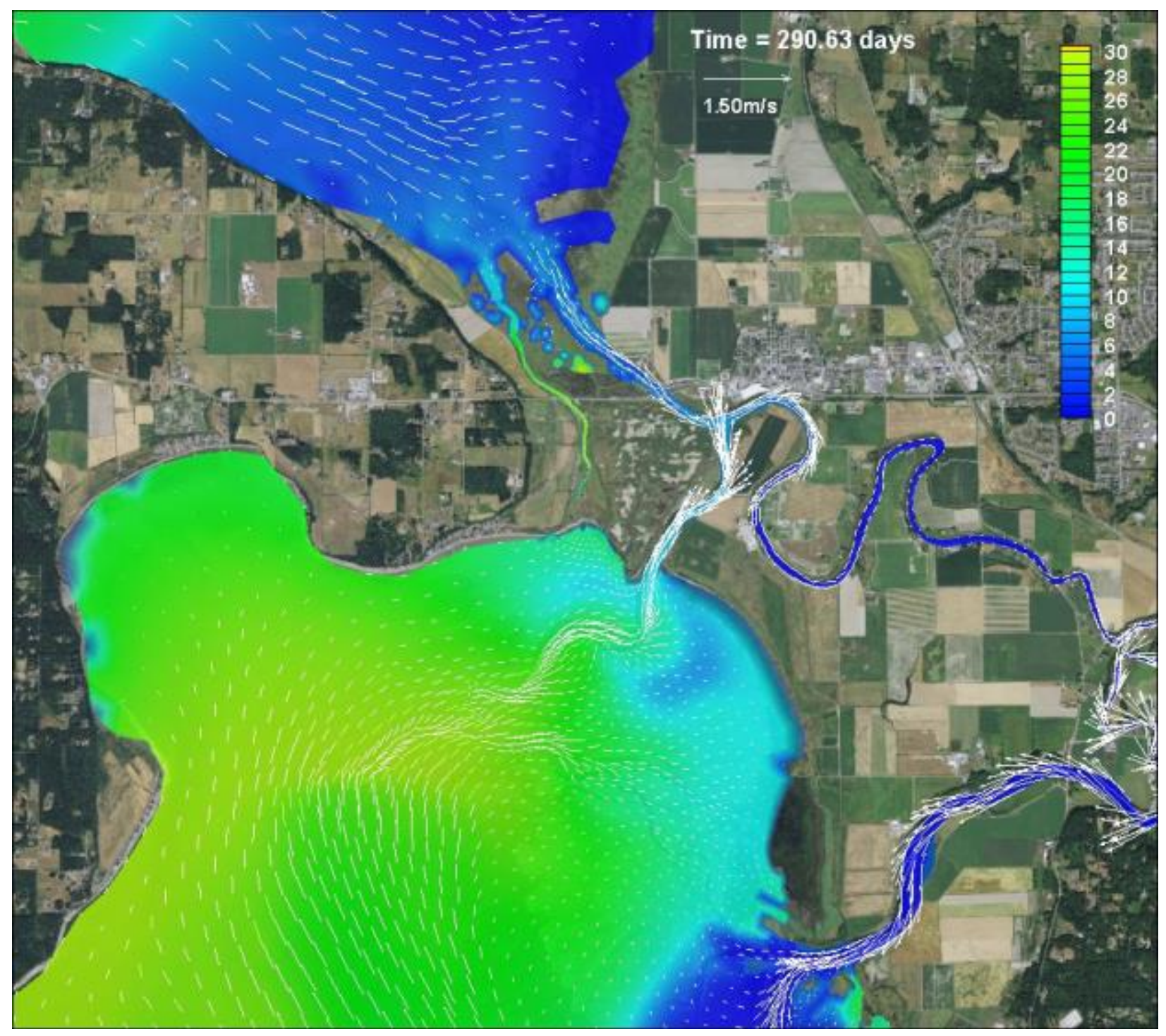

Figure B-4: Scenario 0 (Baseline Condition) - Salinity contours and velocity vectors, October 17, 2005, peak flood 


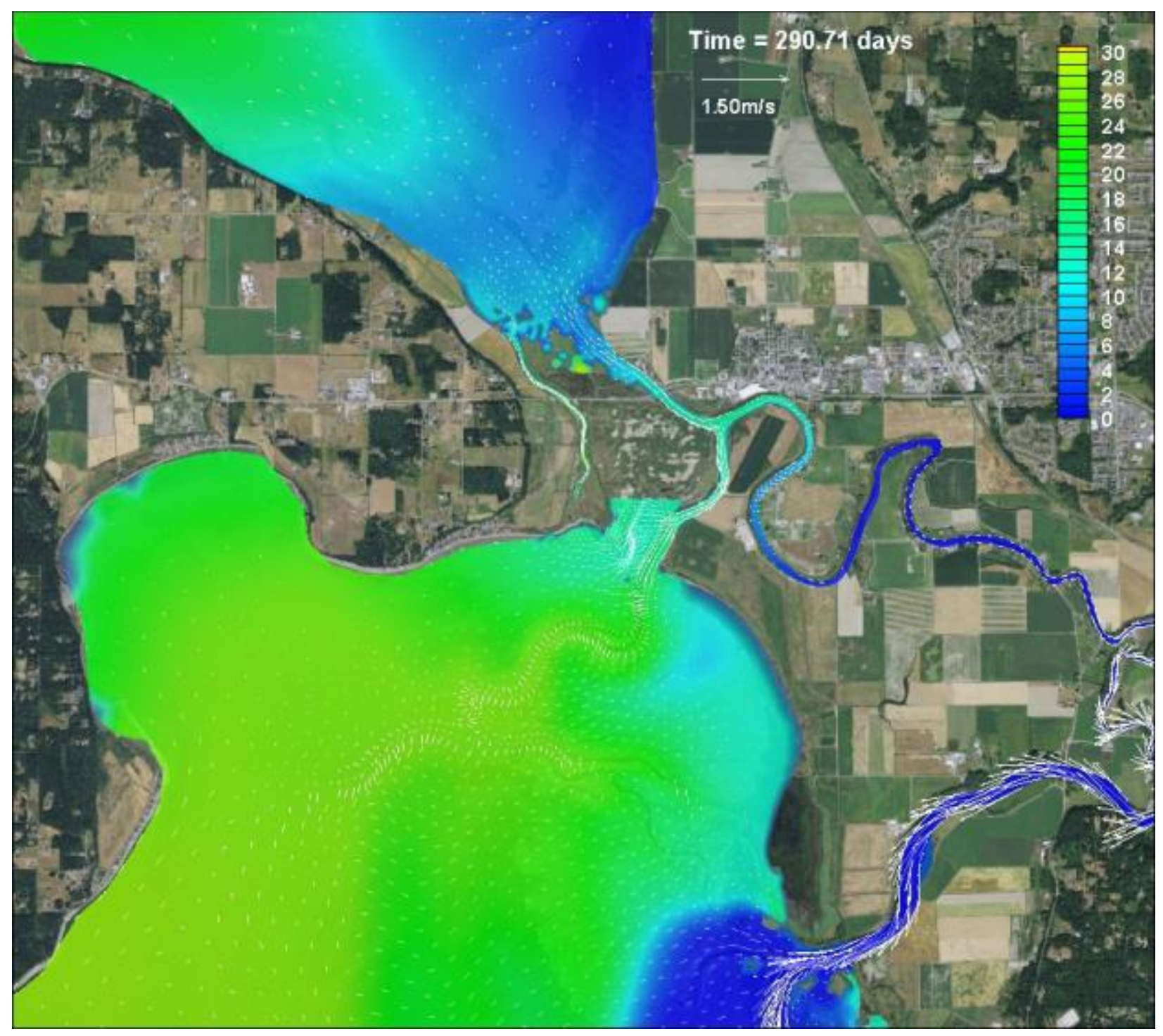

Figure B-5: Scenario 1 (Partial Restoration Leque) - Salinity contours and velocity vectors, October 17, 2005, high tide 


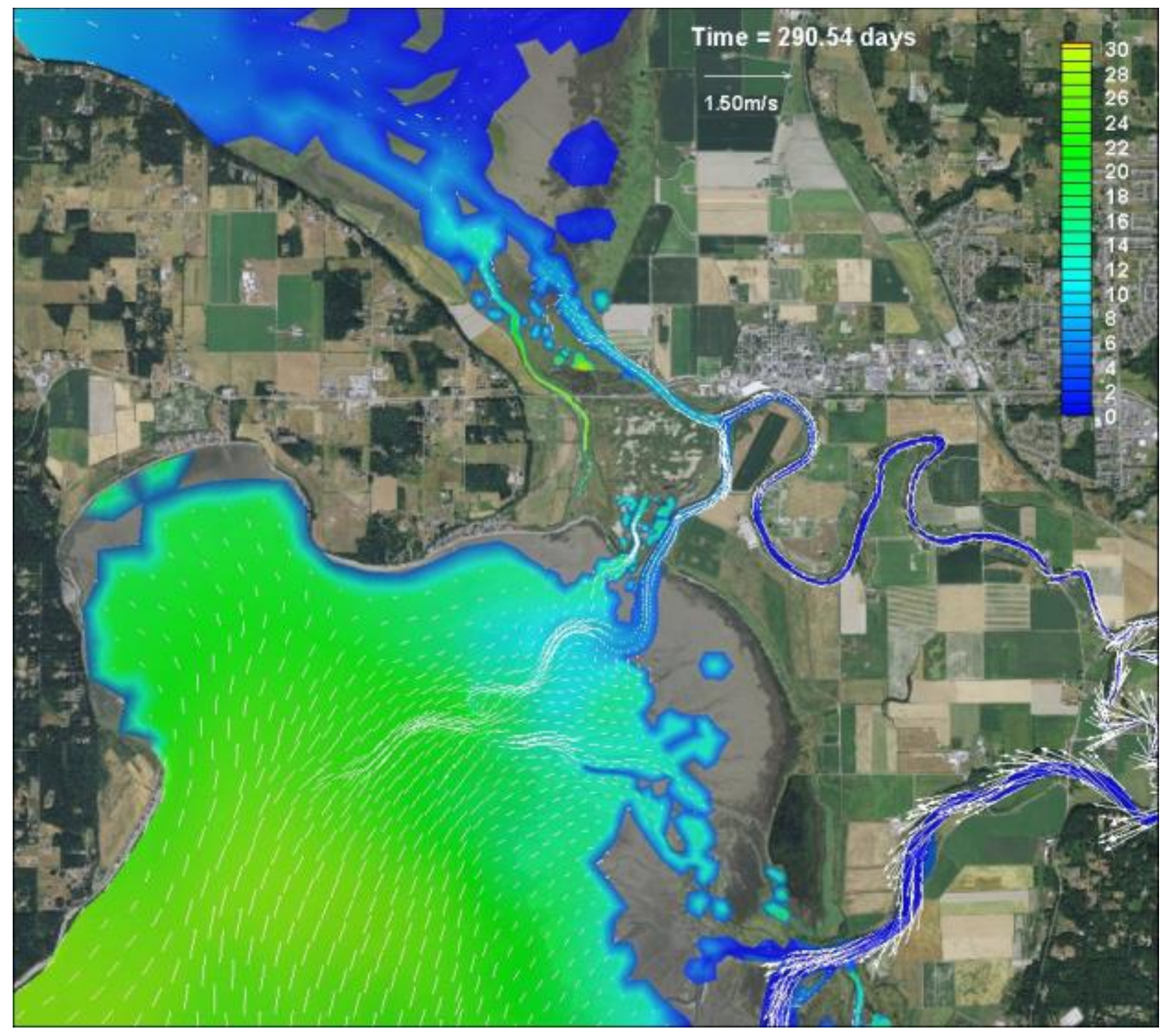

Figure B-6: Scenario 1 (Partial Restoration Leque) - Salinity contours and velocity vectors, October 17, 2005, low tide 


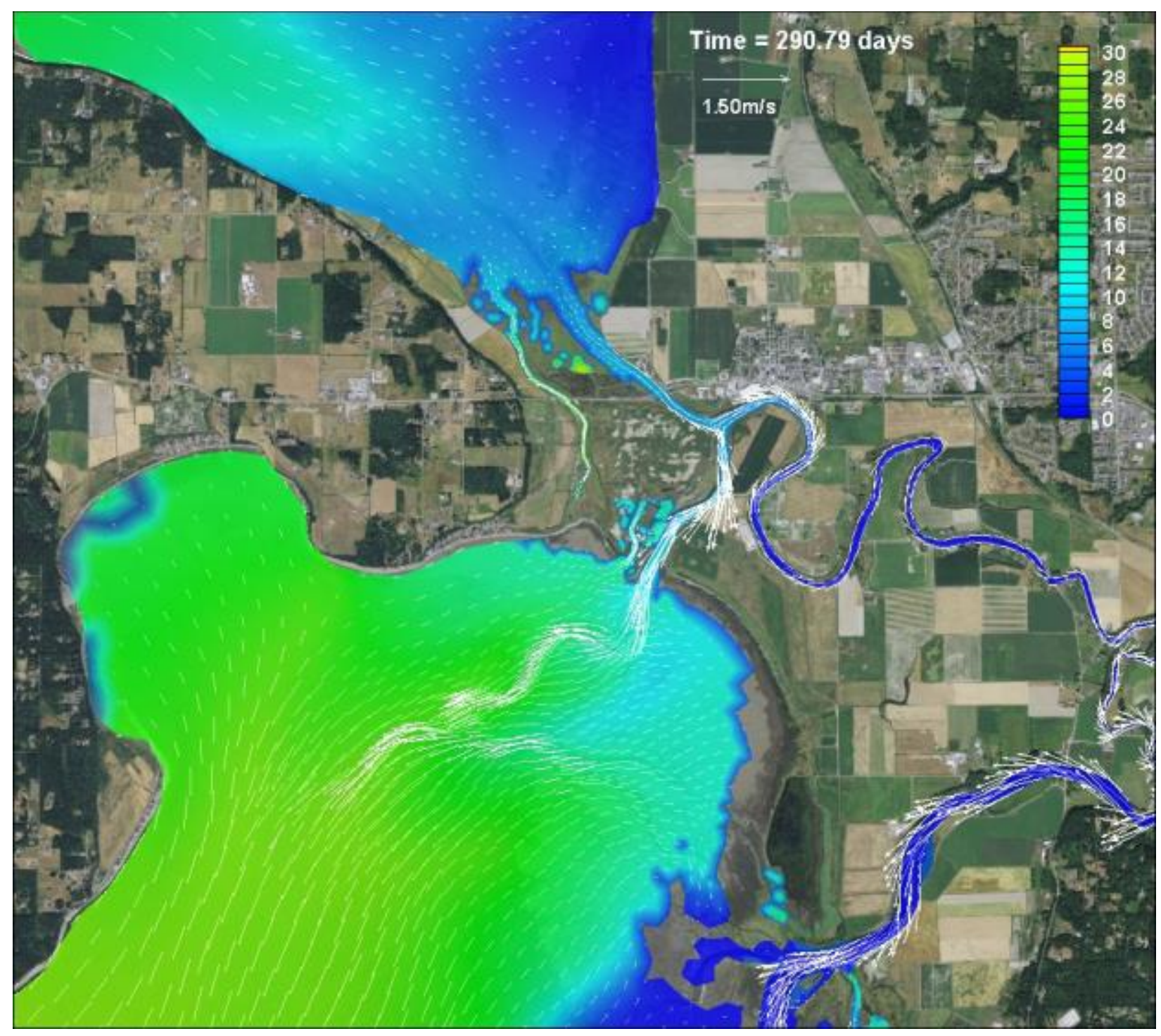

Figure B-7: Scenario 1 (Partial Restoration Leque) - Salinity contours and velocity vectors, October 17, 2005, peak ebb 


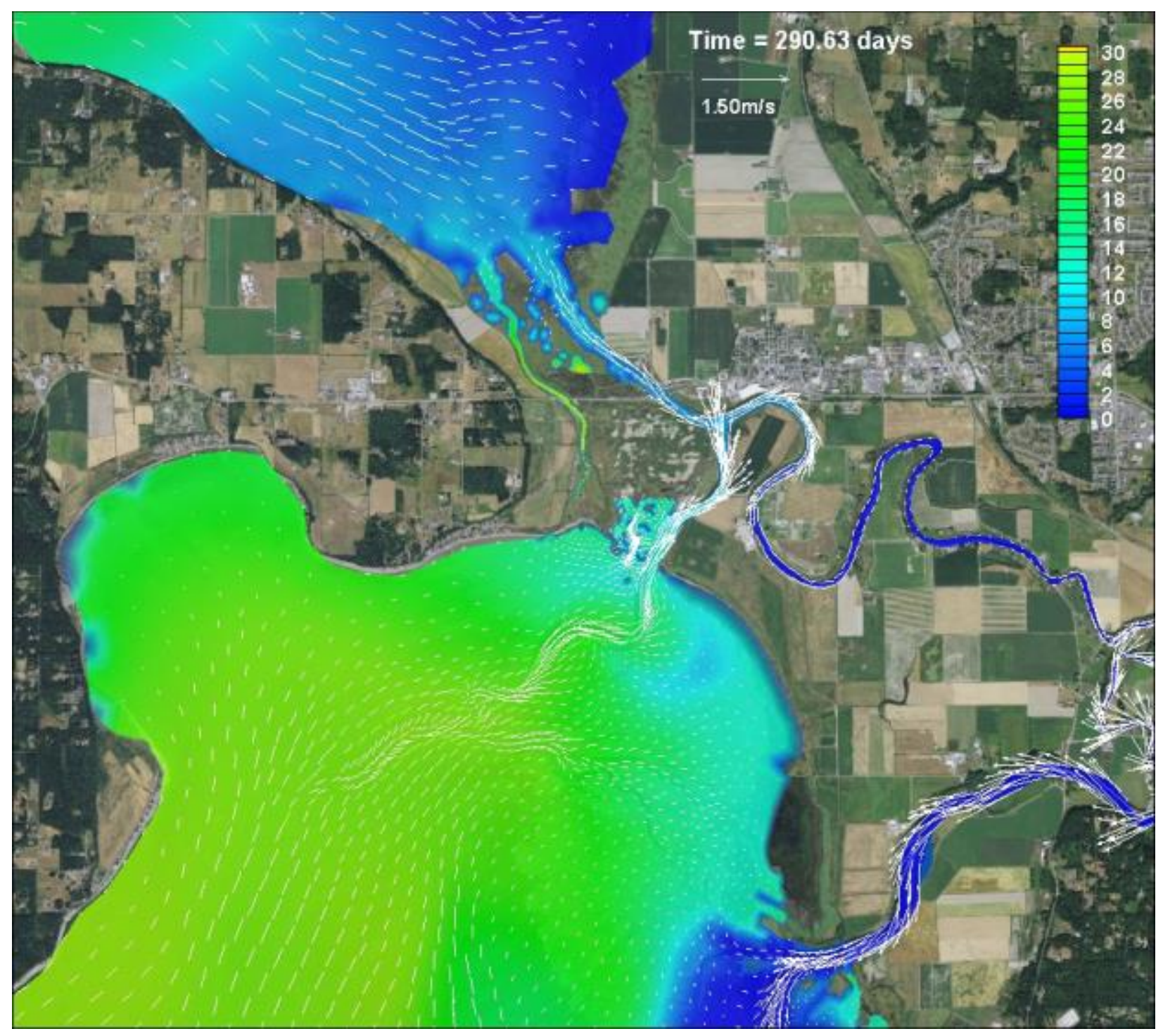

Figure B-8: Scenario 1 (Partial Restoration Leque) - Salinity contours and velocity vectors, October 17, 2005, peak flood 


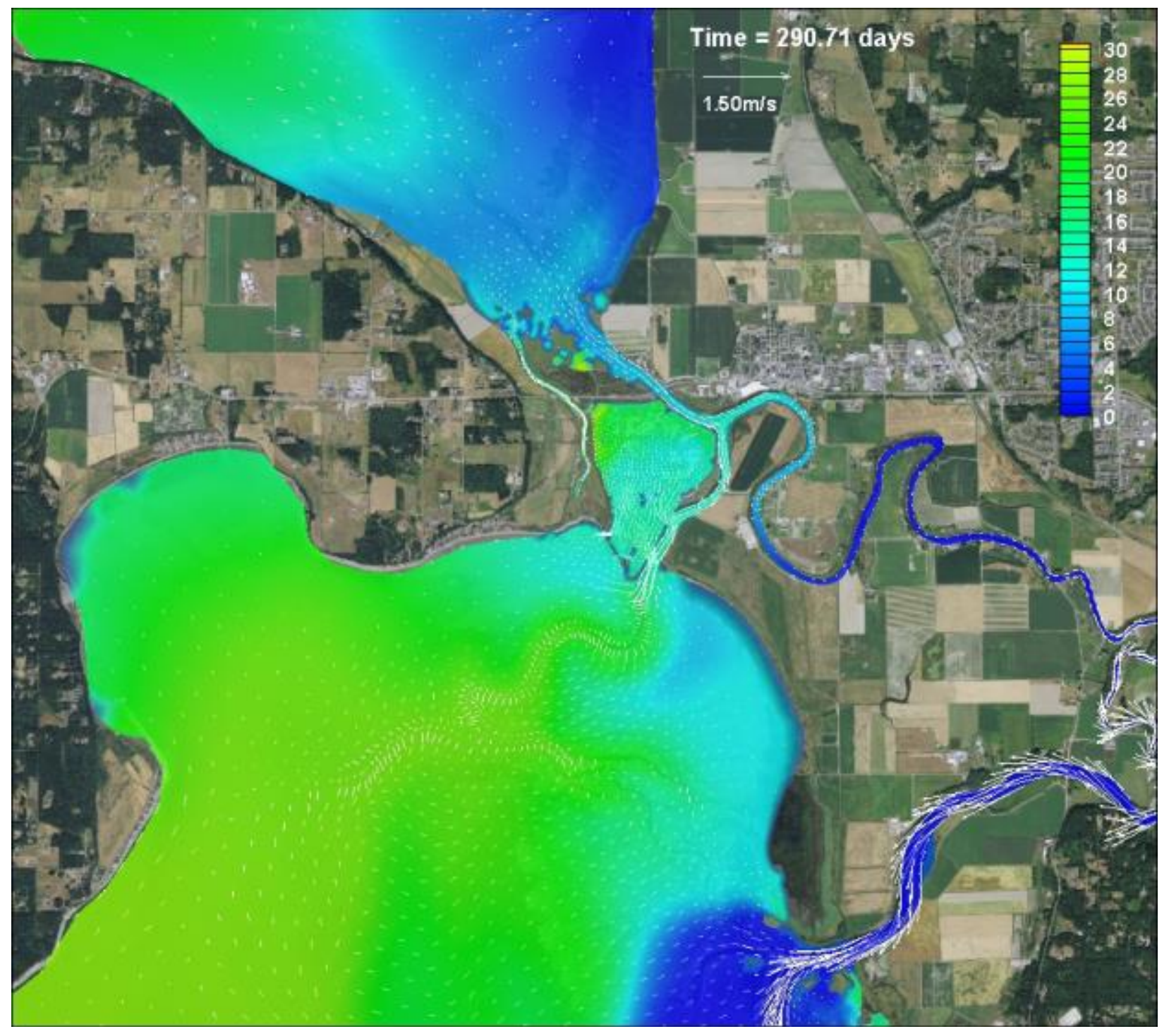

Figure B-9: Scenario 2 (4 Levee Breach Leque) - Salinity contours and velocity vectors, October 17, 2005, high tide 


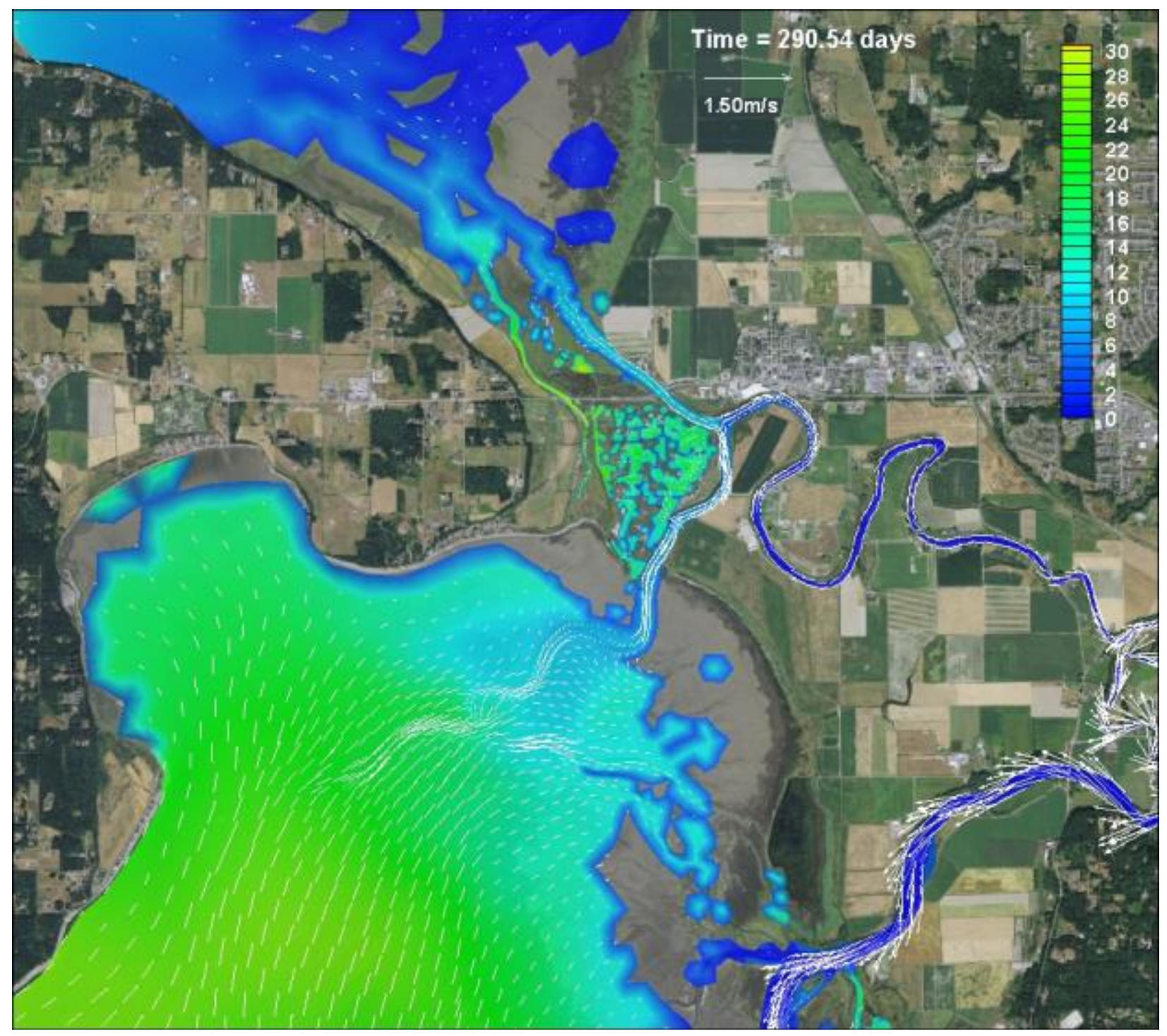

Figure B-10: Scenario 2 (4 Levee Breach Leque) - Salinity contours and velocity vectors, October 17, 2005, low tide 


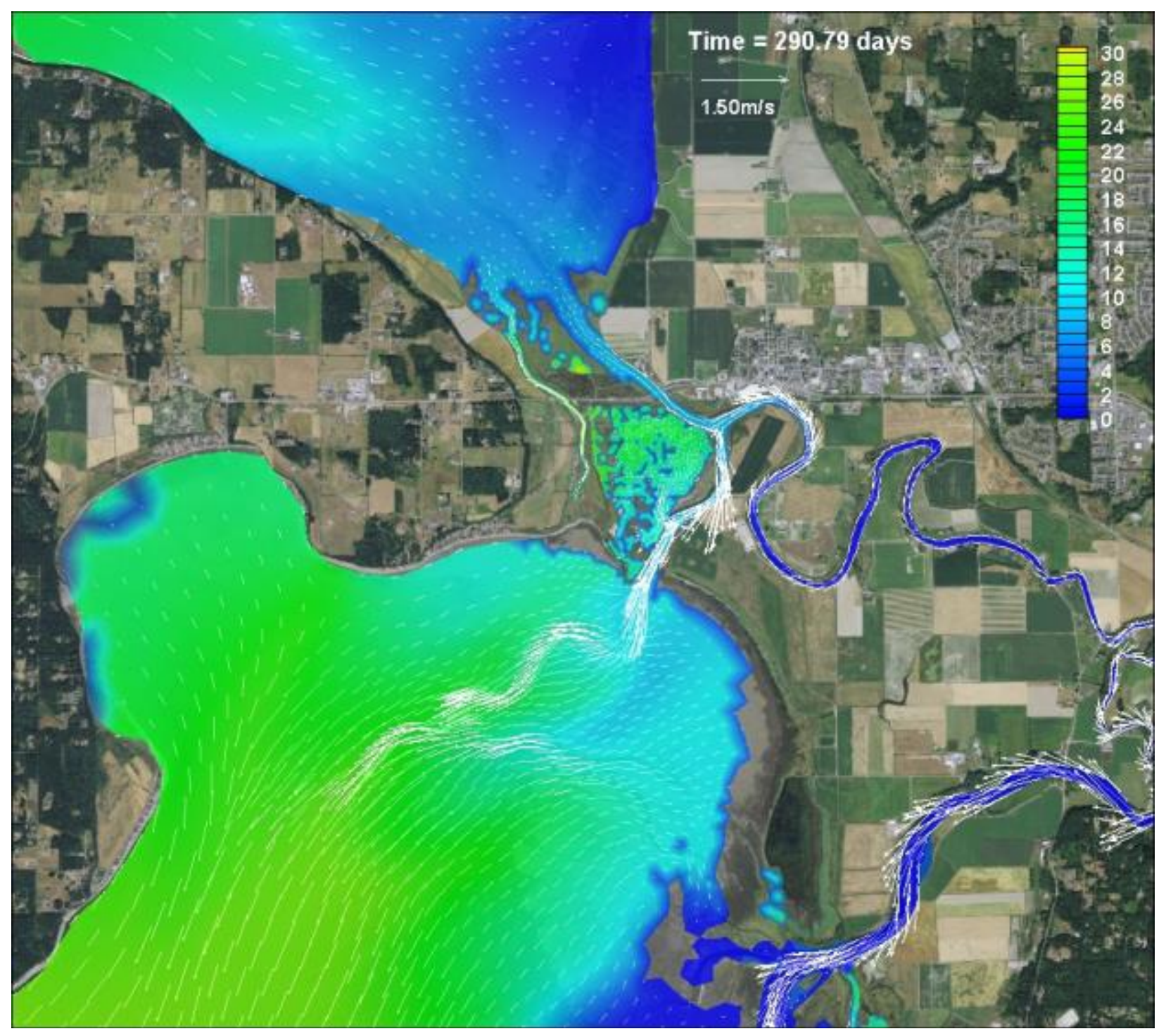

Figure B-11: Scenario 2 (4 Levee Breach Leque) - Salinity contours and velocity vectors, October 17, 2005, peak ebb 


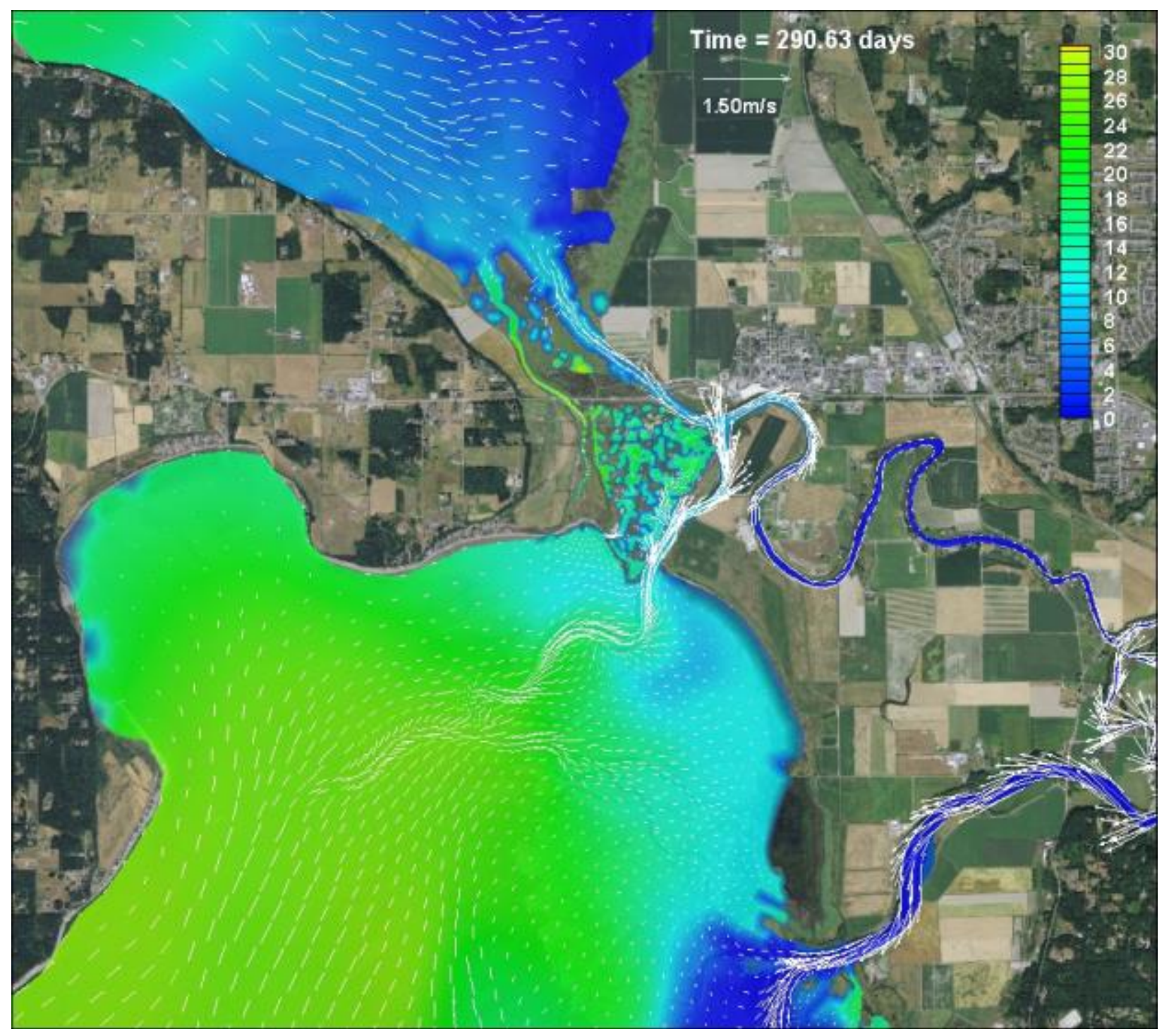

Figure B-12: Scenario 2 (4 Levee Breach Leque) - Salinity contours and velocity vectors, October 17, 2005, peak flood 


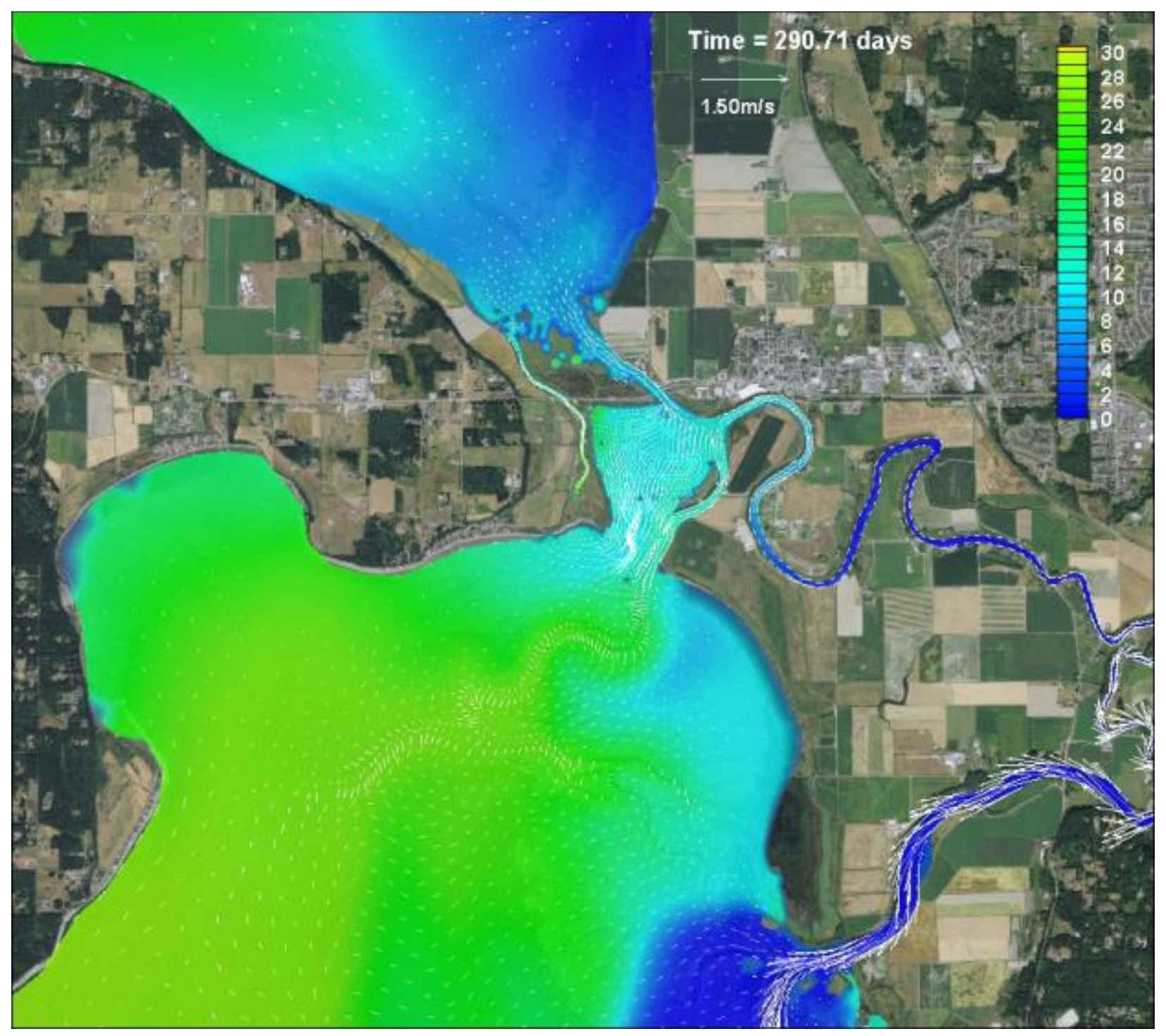

Figure B-13: Scenario 3 (Full Restoration Leque 1) - Salinity contours and velocity vectors, October 17, 2005, high tide 


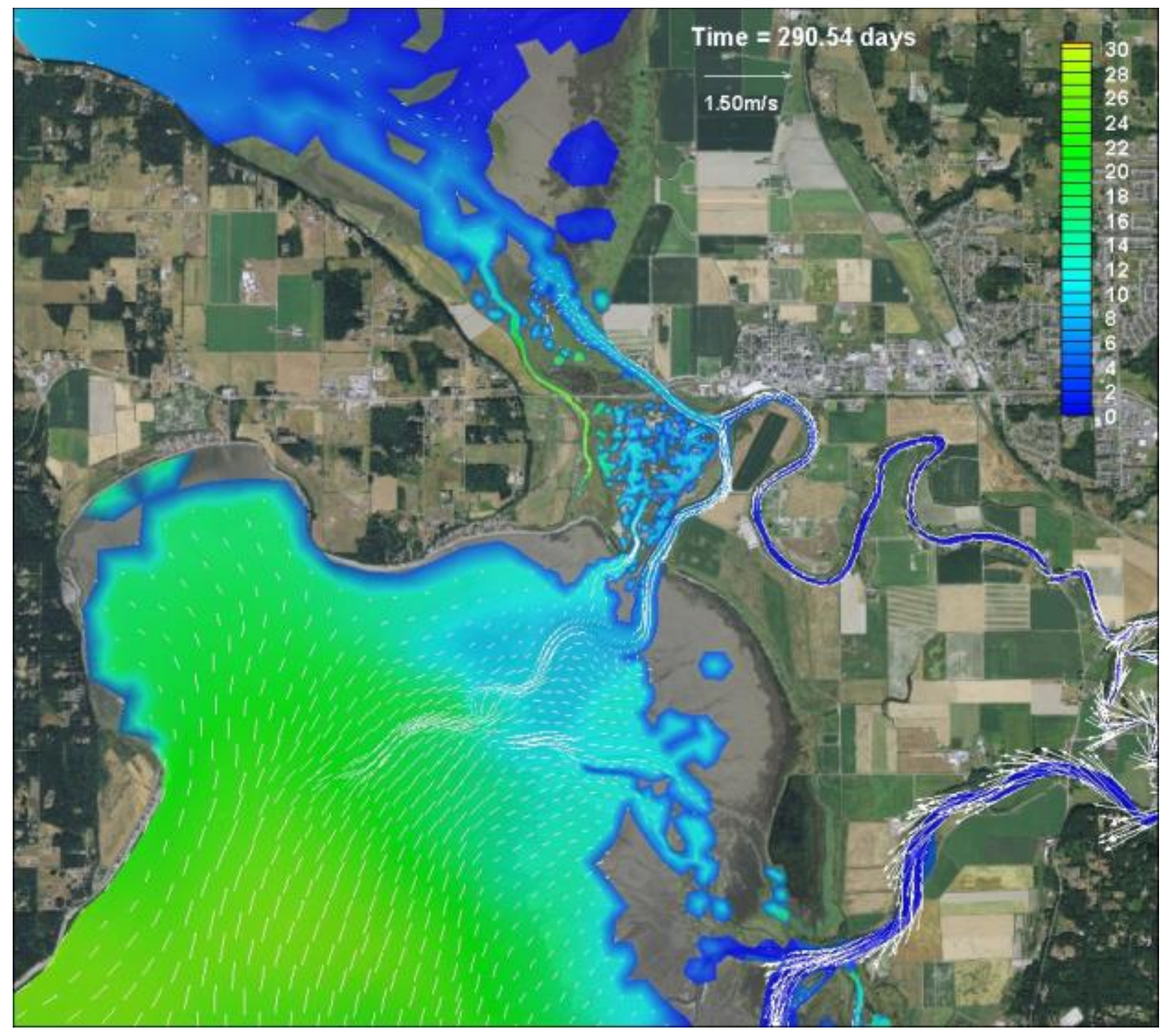

Figure B-14: Scenario 3 (Full Restoration Leque 1) - Salinity contours and velocity vectors, October 17, 2005, low tide 


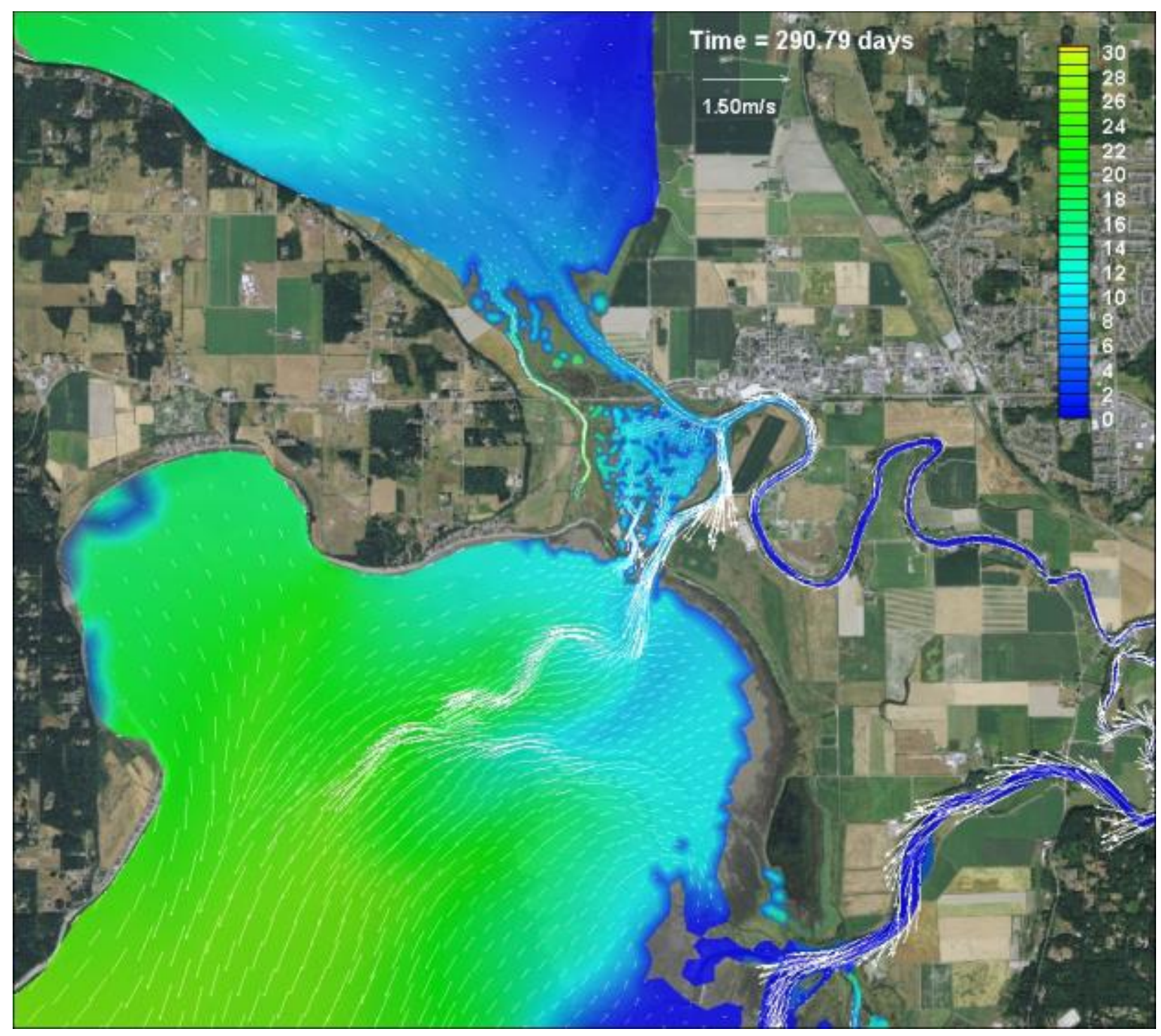

Figure B-15: Scenario 3 (Full Restoration Leque 1) - Salinity contours and velocity vectors, October 17, 2005, peak ebb 


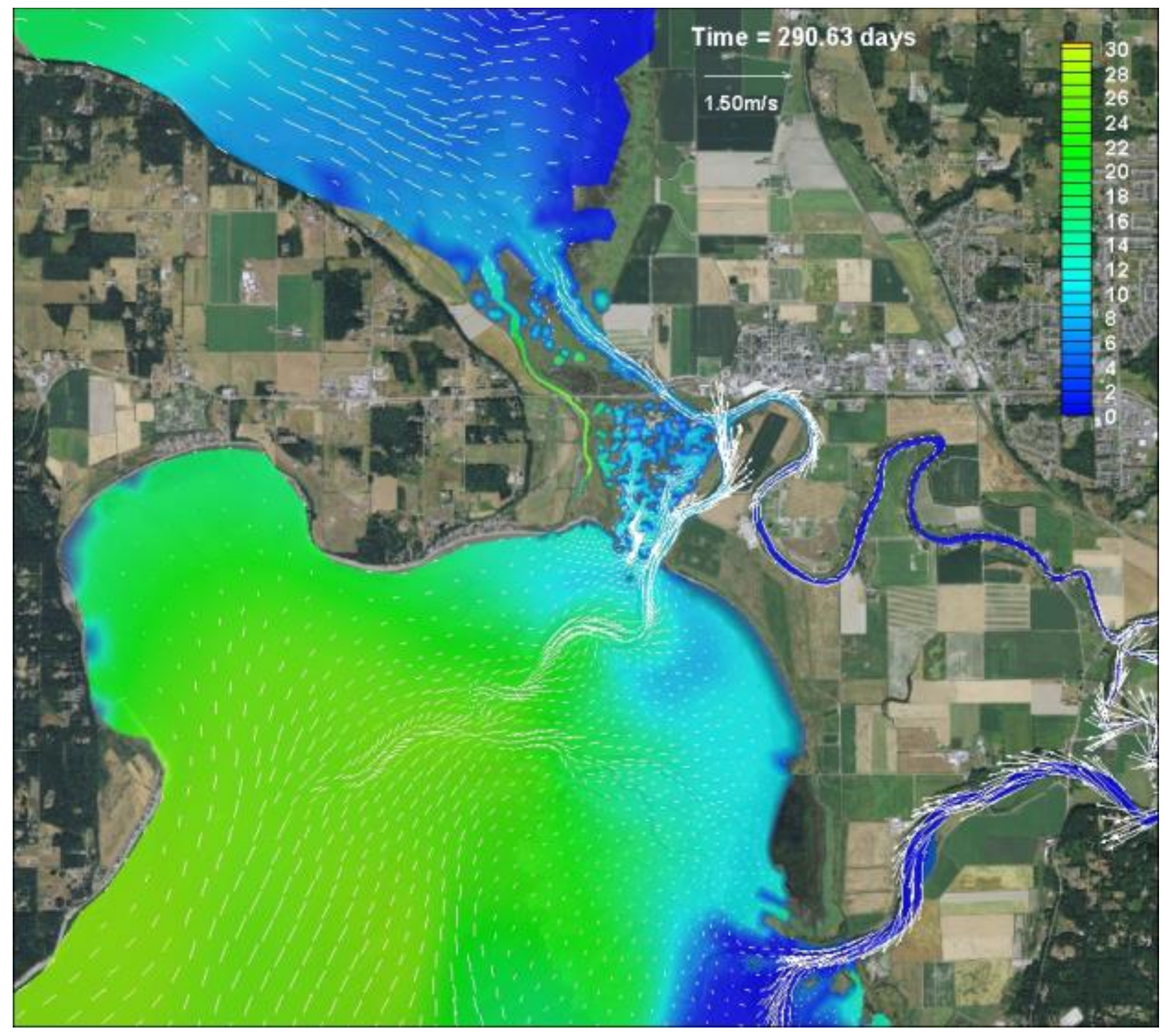

Figure B-16: Scenario 3 (Full Restoration Leque 1) - Salinity contours and velocity vectors, October 17, 2005, peak flood 


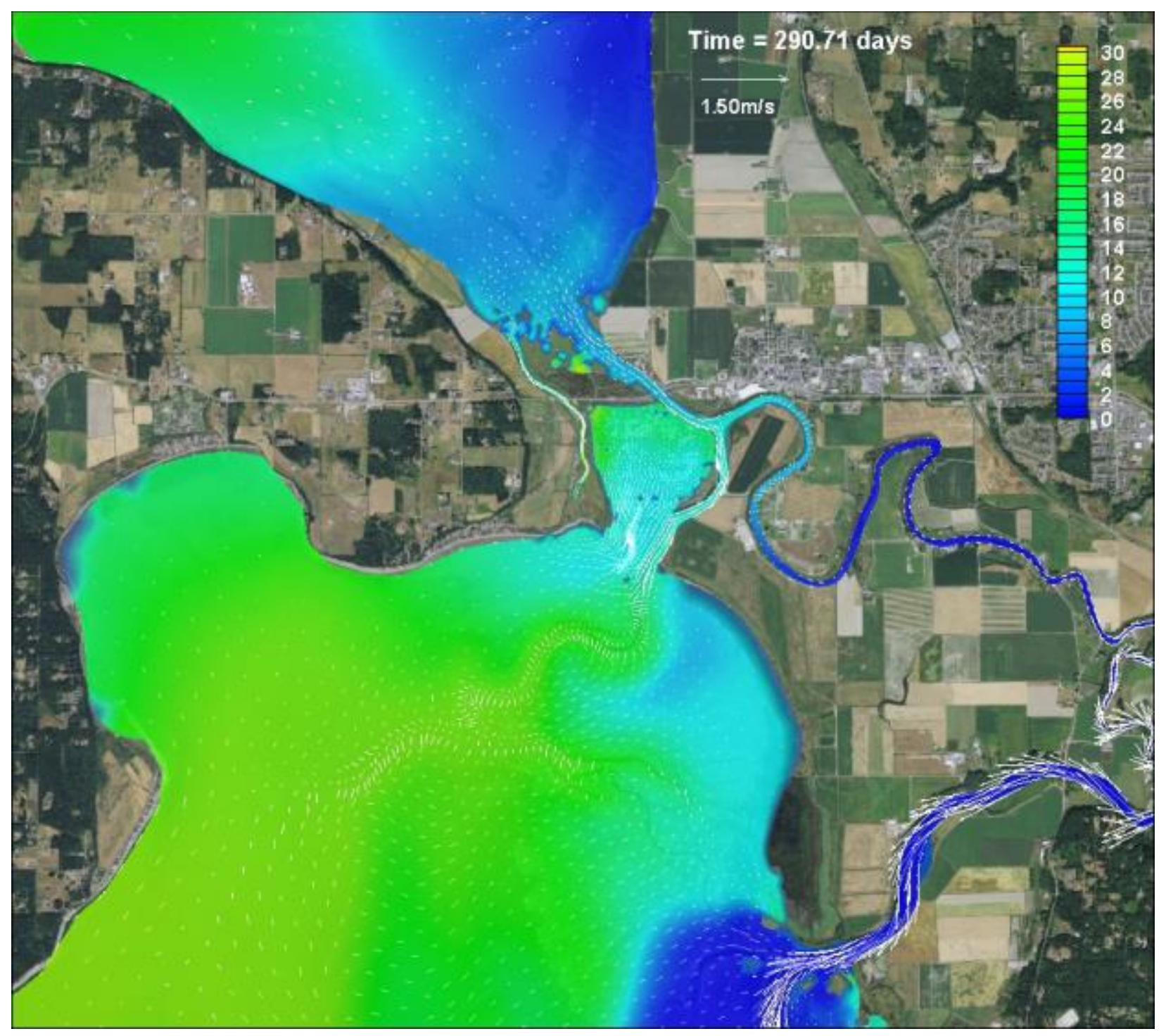

Figure B-17: Scenario 4 (Full Restoration Leque 2) - Salinity contours and velocity vectors, October 17, 2005, high tide 


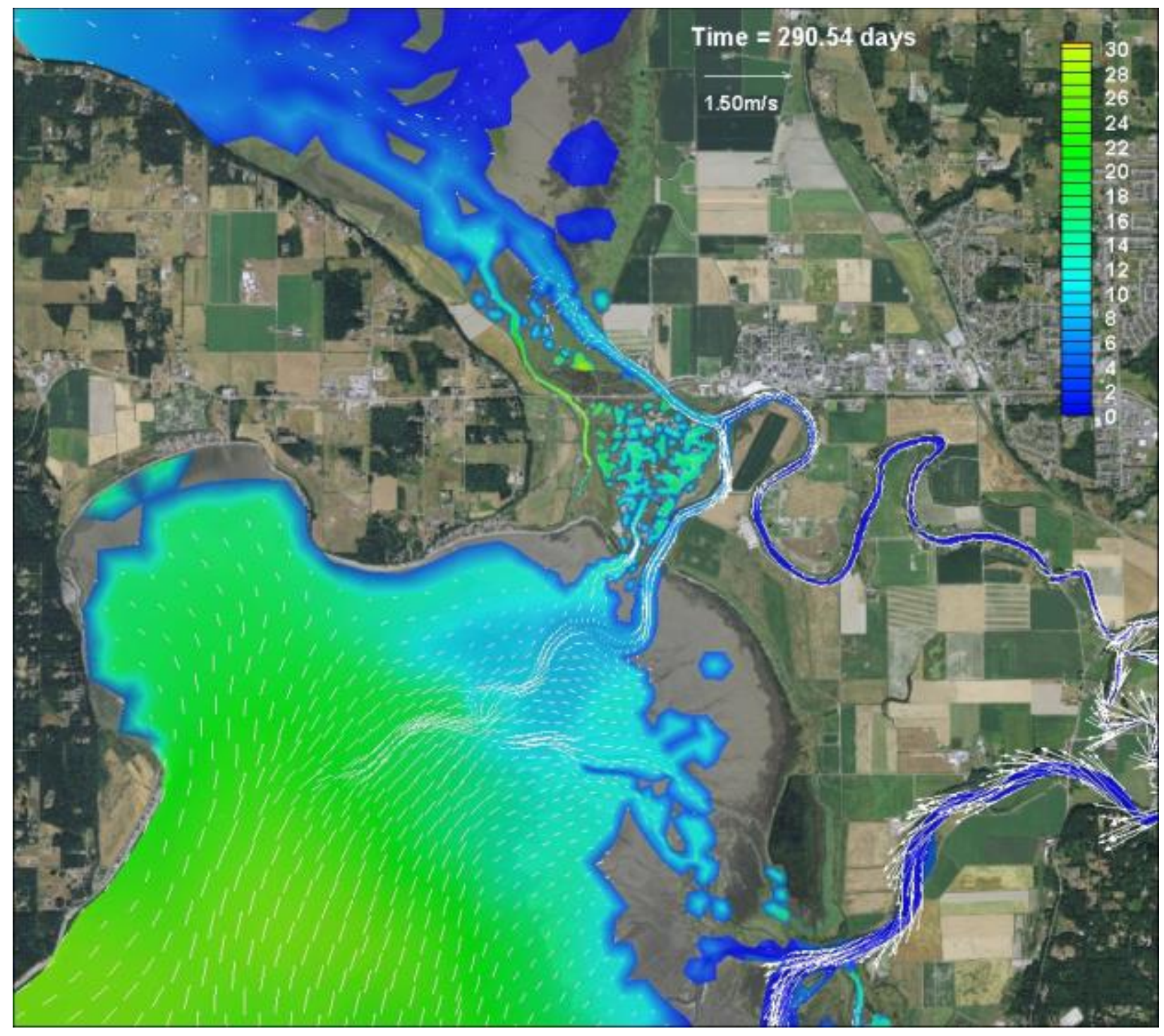

Figure B-18: Scenario 4 (Full Restoration Leque 2) - Salinity contours and velocity vectors, October 17, 2005, low tide 


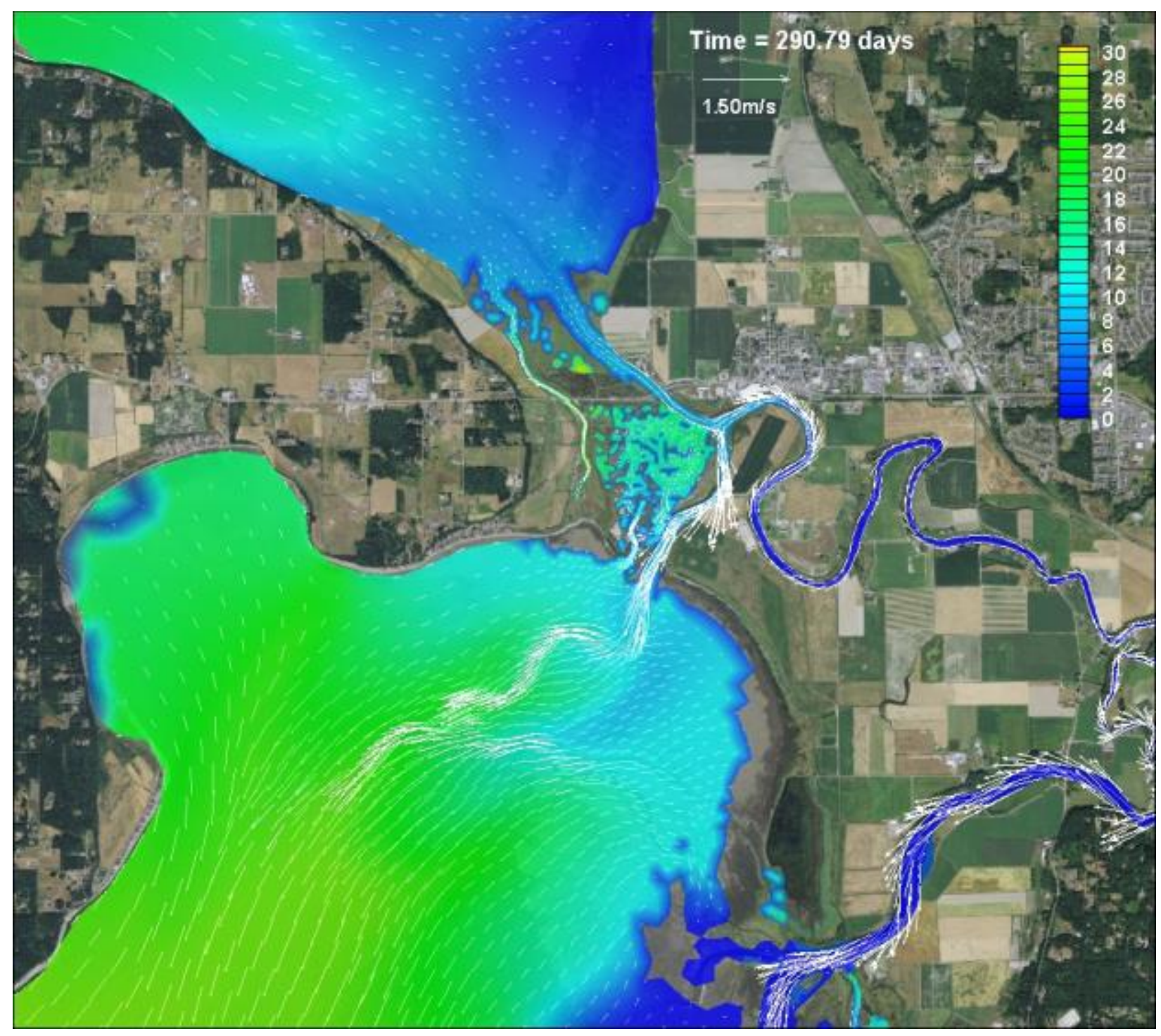

Figure B-19: Scenario 4 (Full Restoration Leque 2) - Salinity contours and velocity vectors, October 17, 2005, peak ebb 


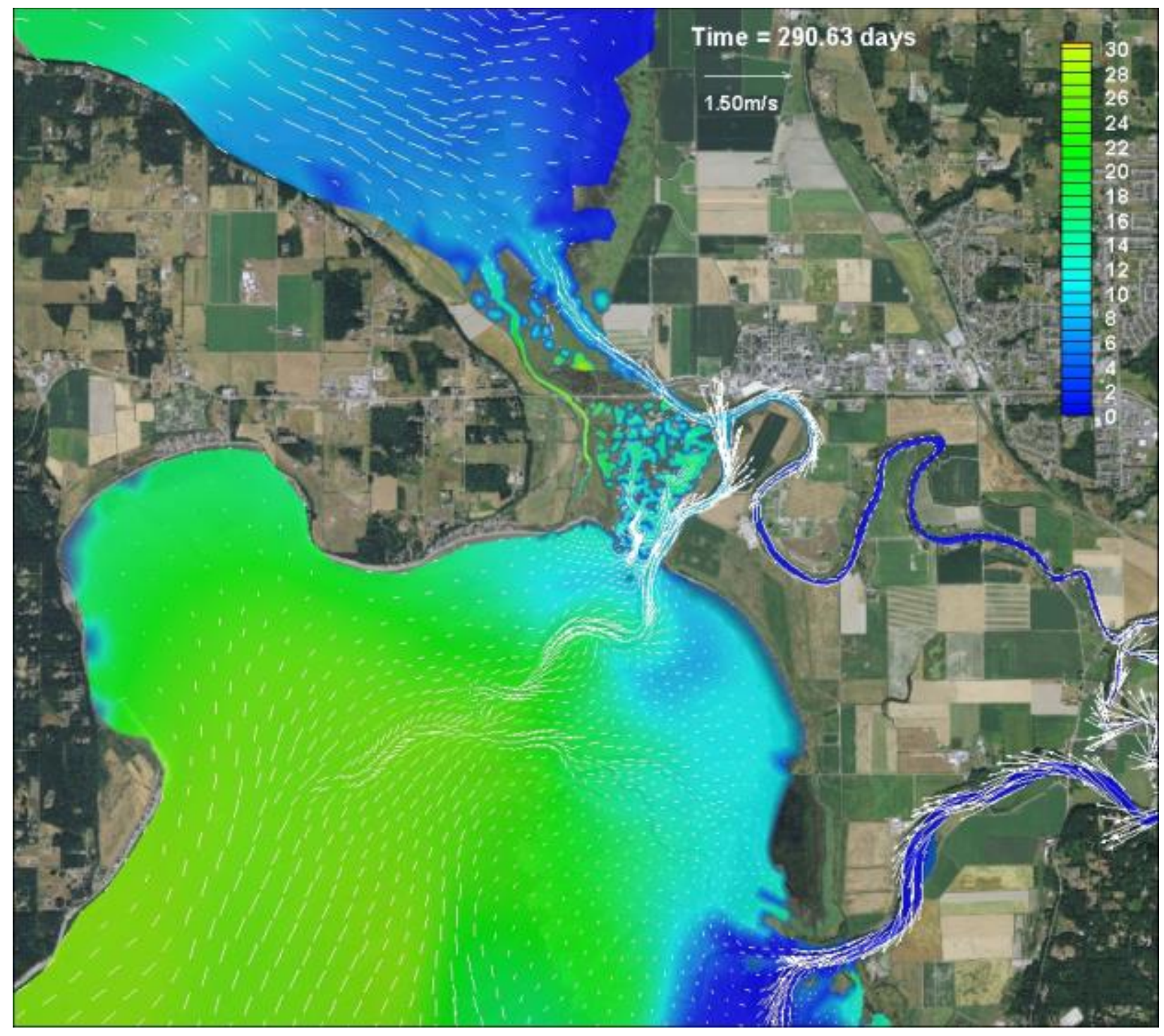

Figure B-20: Scenario 4 (Full Restoration Leque 2) - Salinity contours and velocity vectors, October 17, 2005, peak flood 


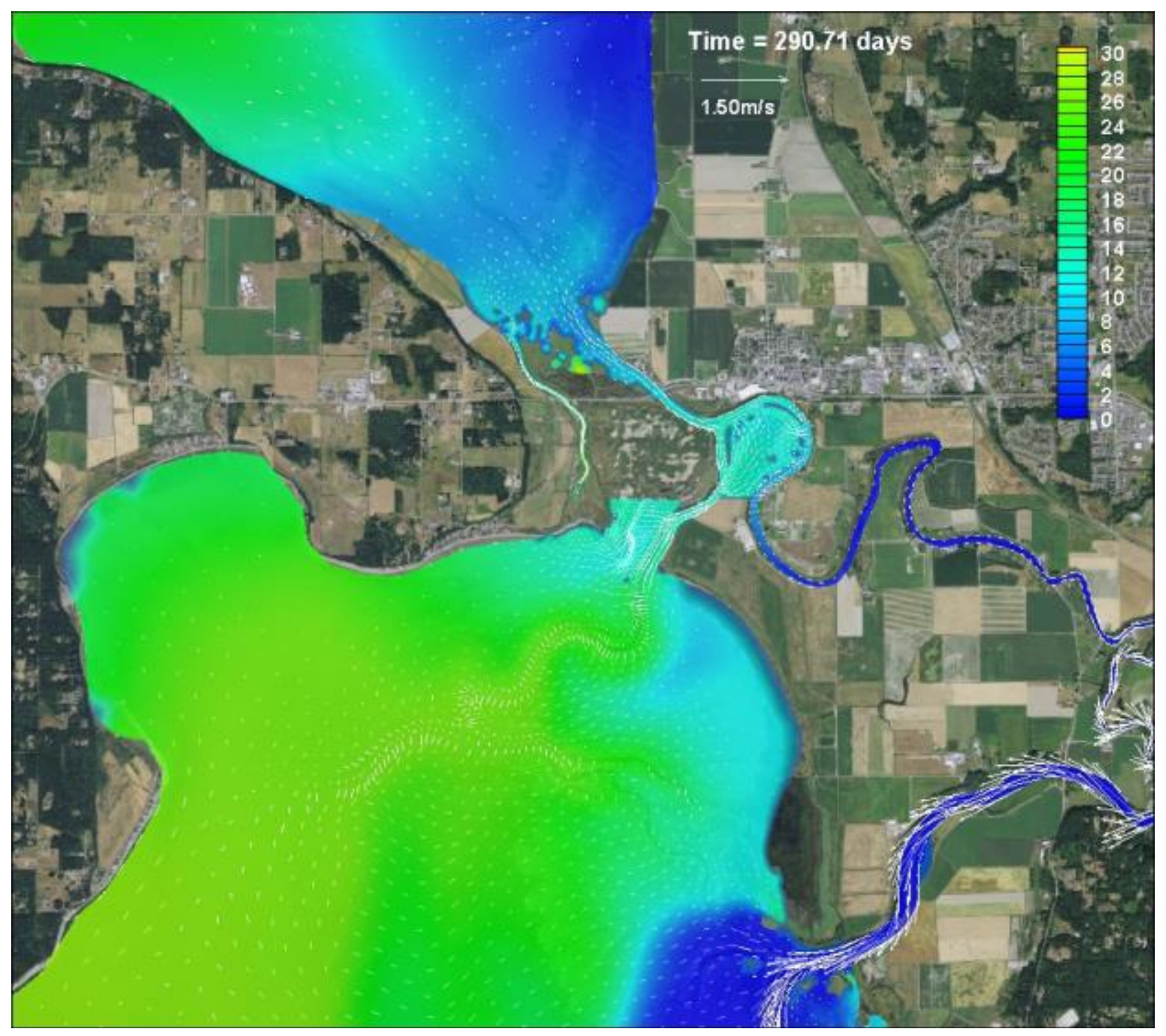

Figure B-21: Scenario 5 (Full Restoration zis a ba + SCN1) - Salinity contours and velocity vectors, October 17, 2005, high tide 


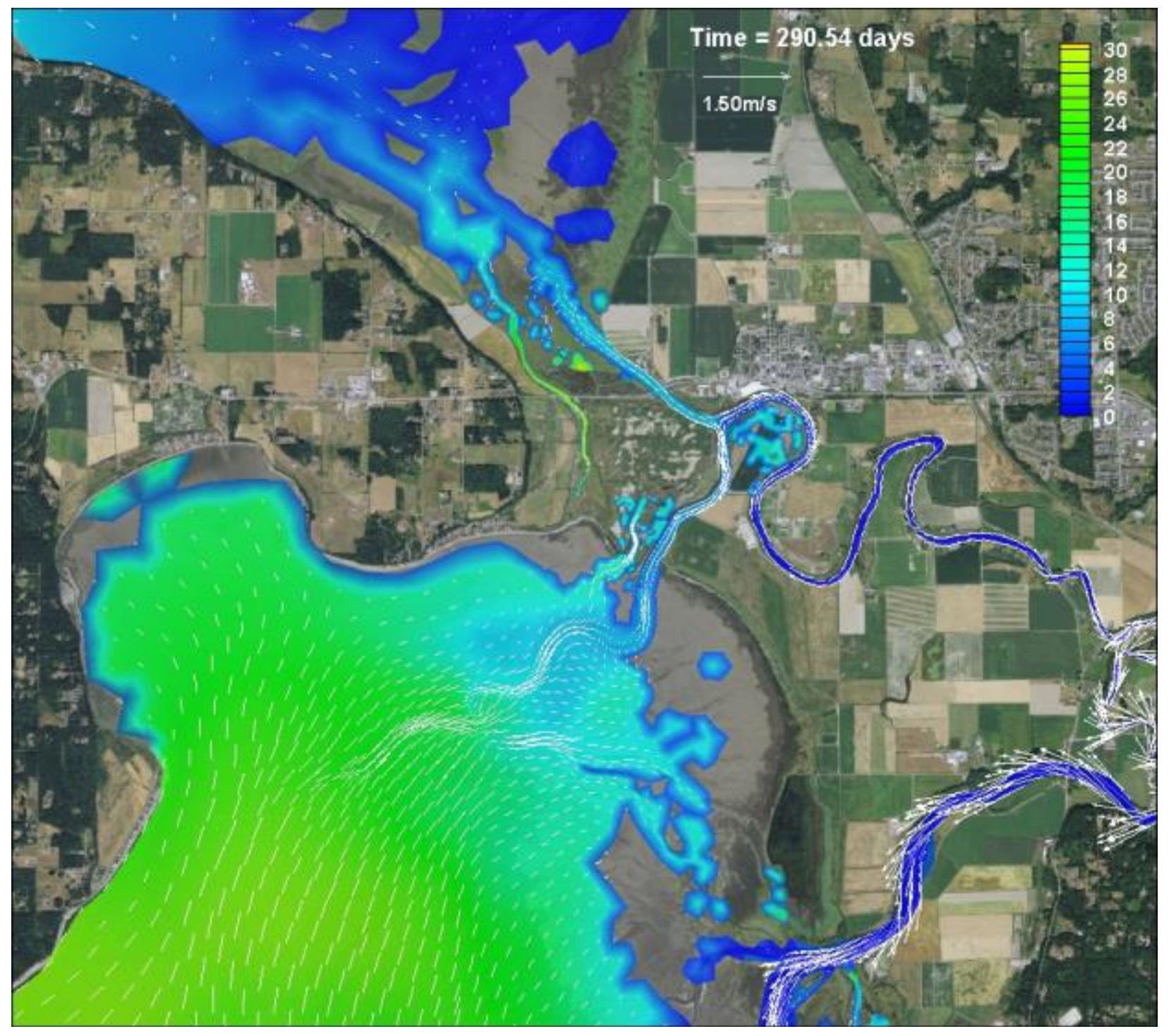

Figure B-22: Scenario 5 (Full Restoration zis a ba + SCN1) - Salinity contours and velocity vectors, October 17, 2005, low tide 


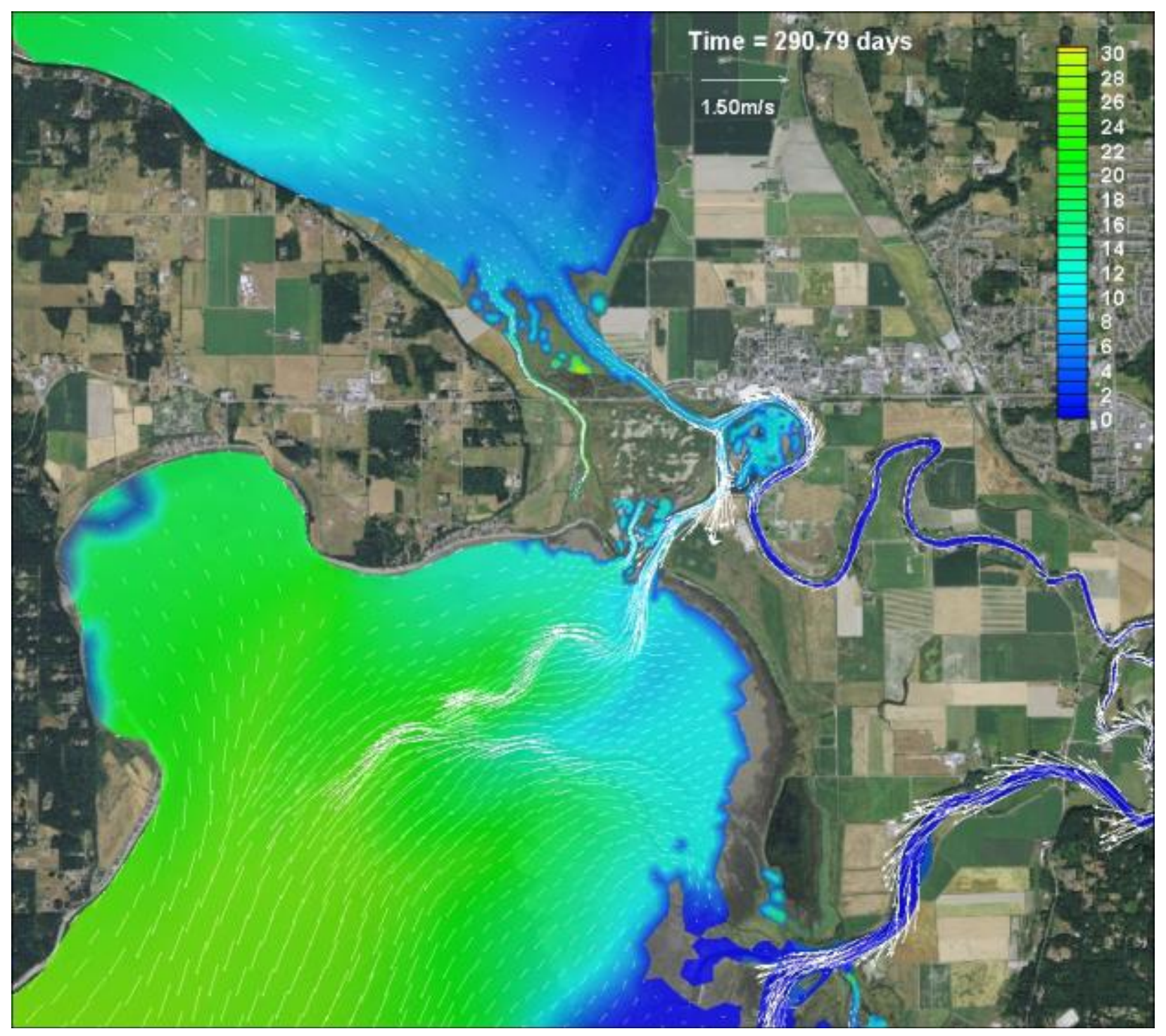

Figure B-23: Scenario 5 (Full Restoration zis a ba + SCN1) - Salinity contours and velocity vectors, October 17, 2005, peak ebb 


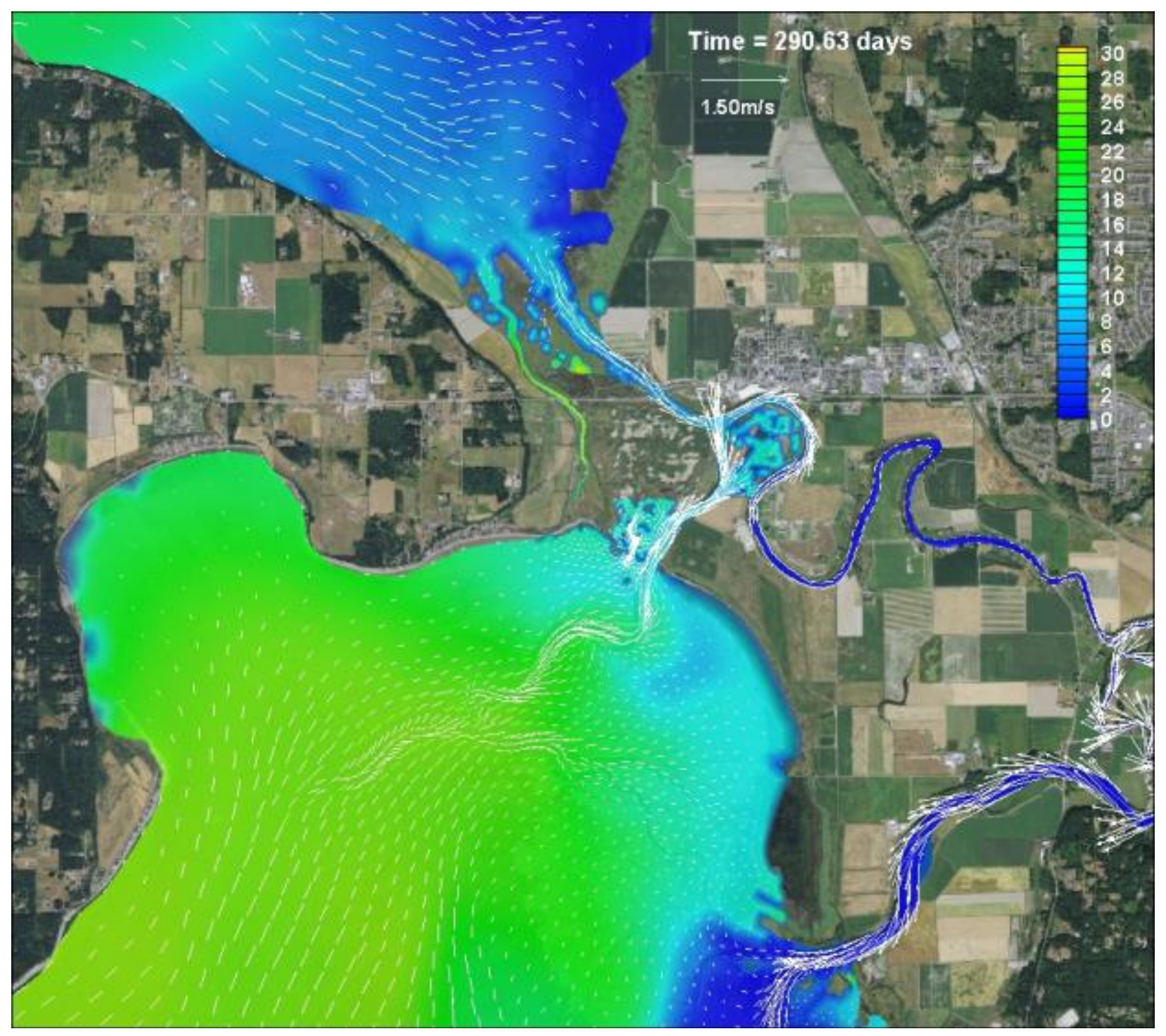

Figure B-24: Scenario 5 (Full Restoration zis a ba + SCN1) - Salinity contours and velocity vectors, October 17, 2005, peak flood 


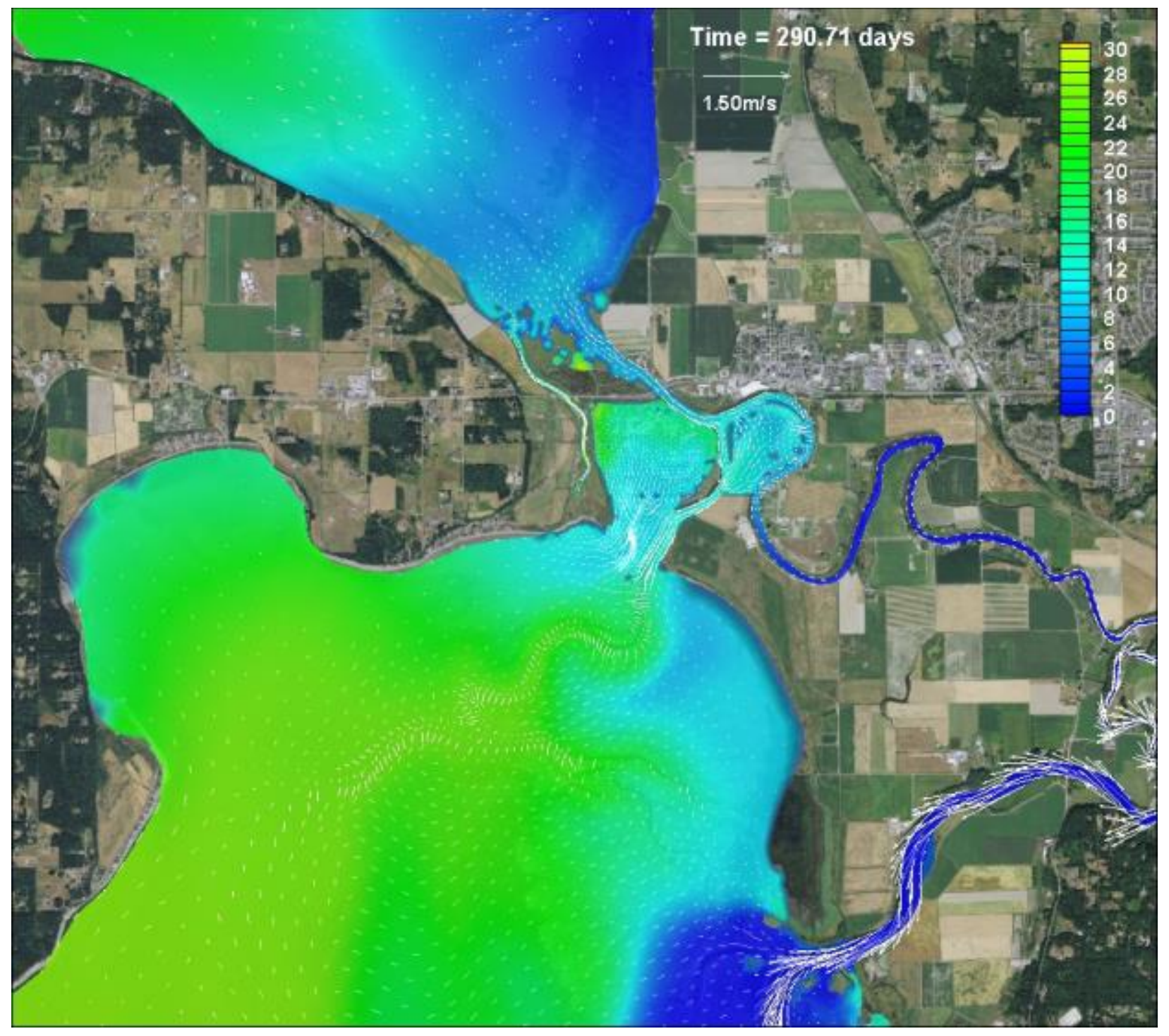

Figure B-25: Scenario 6 (Full Restoration zis a ba + SCN4) - Salinity contours and velocity vectors, October 17, 2005, high tide 


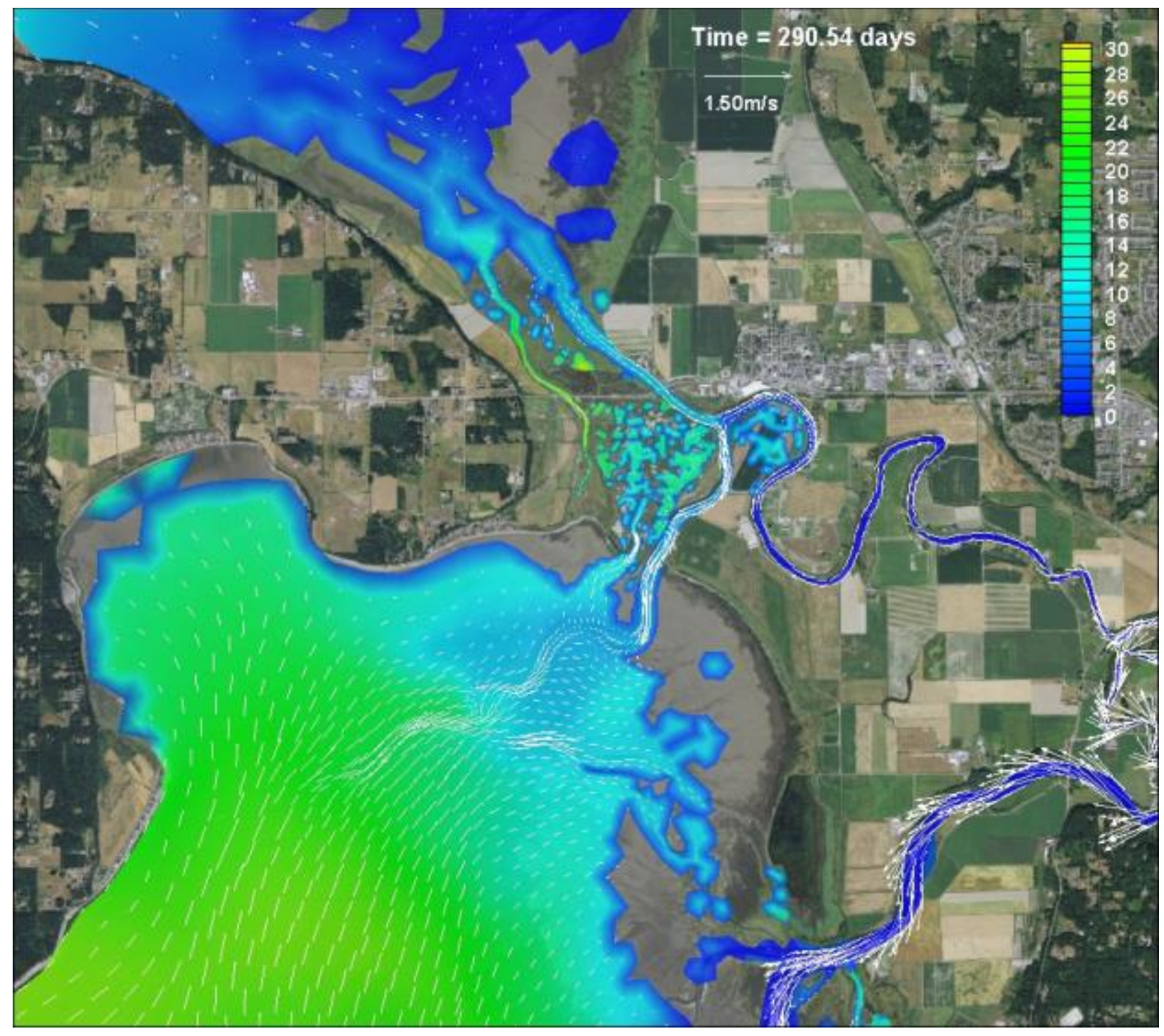

Figure B-26: Scenario 6 (Full Restoration zis a ba + SCN4) - Salinity contours and velocity vectors, October 17, 2005, low tide 


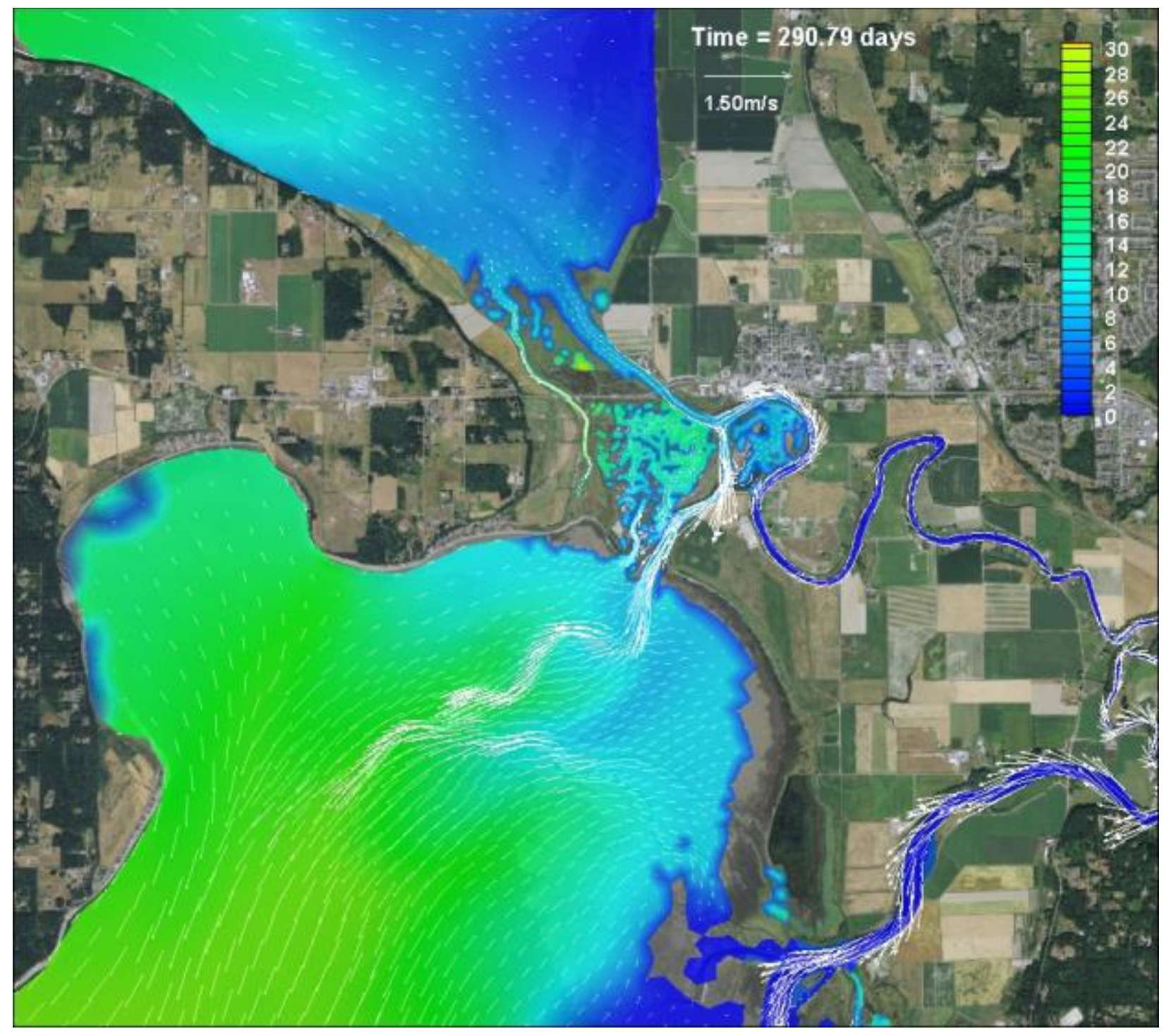

Figure B-27: Scenario 6 (Full Restoration zis a ba + SCN4) - Salinity contours and velocity vectors, October 17, 2005, peak ebb 


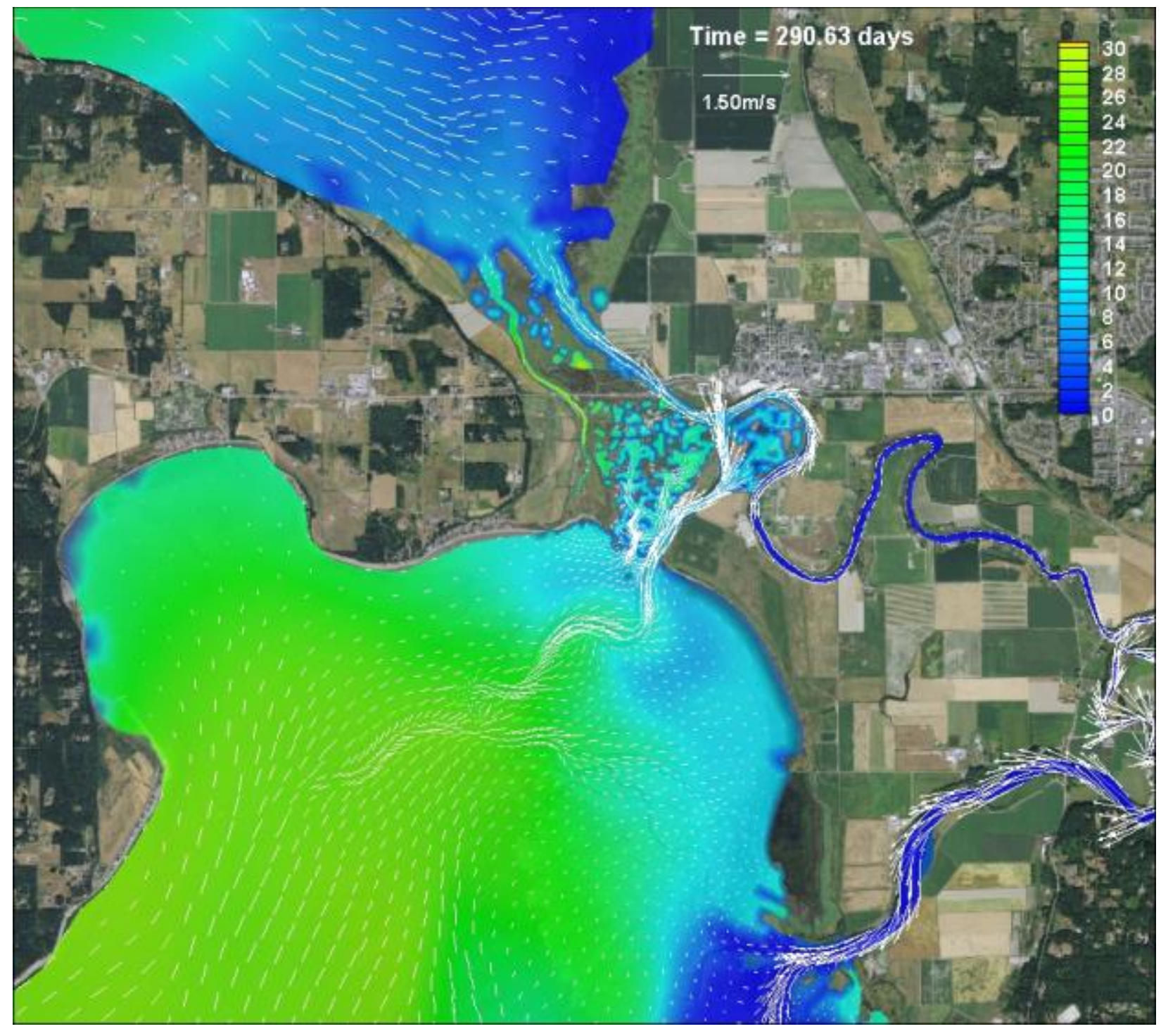

Figure B-28: Scenario 6 (Full Restoration zis a ba + SCN4) - Salinity contours and velocity vectors, October 17, 2005, peak flood 


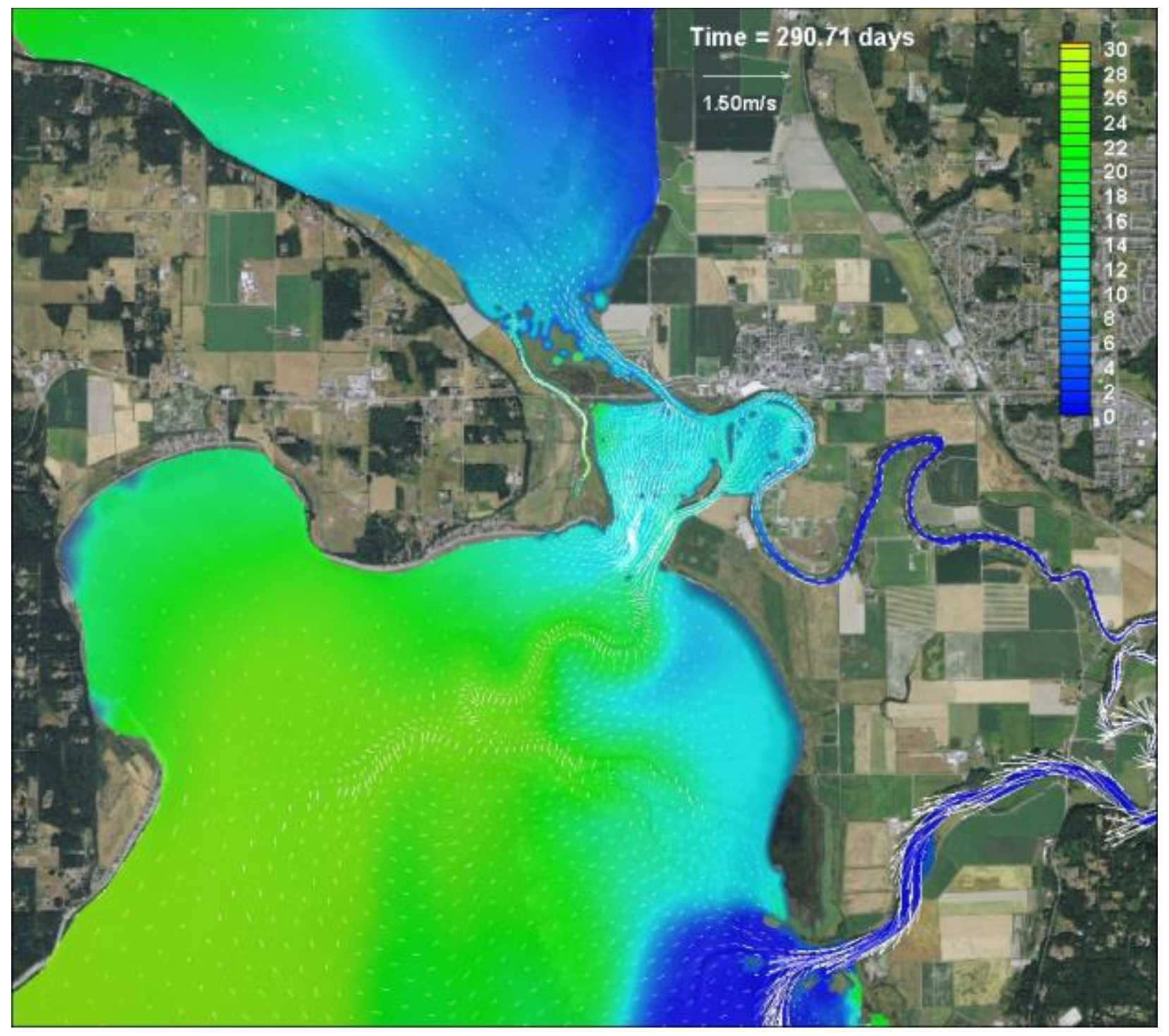

Figure B-29: Scenario 7 (Full Restoration zis a ba + SCN3) - Salinity contours and velocity vectors, October 17, 2005, high tide 


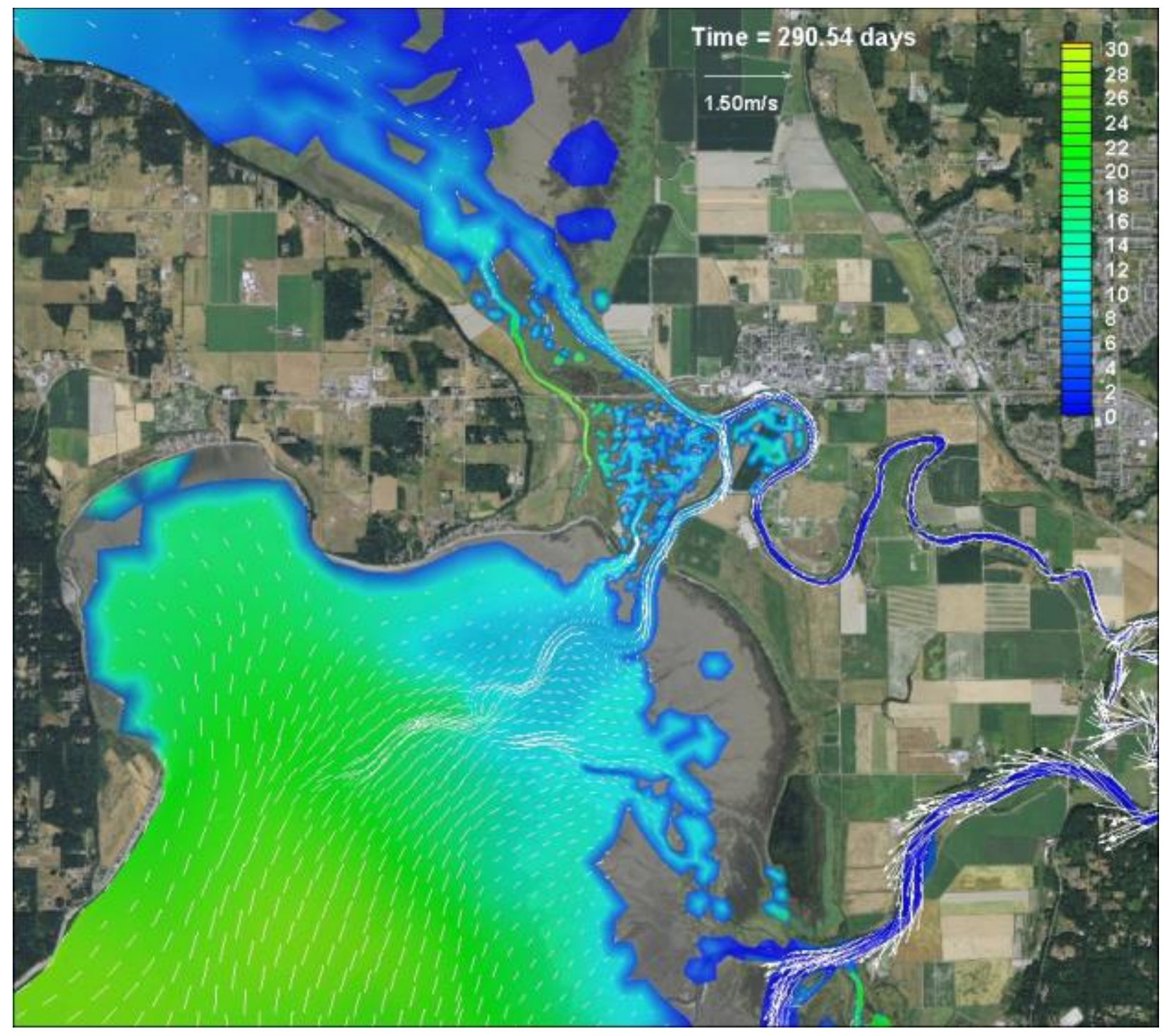

Figure B-30: Scenario 7 (Full Restoration zis a ba + SCN3) - Salinity contours and velocity vectors, October 17, 2005, low tide 


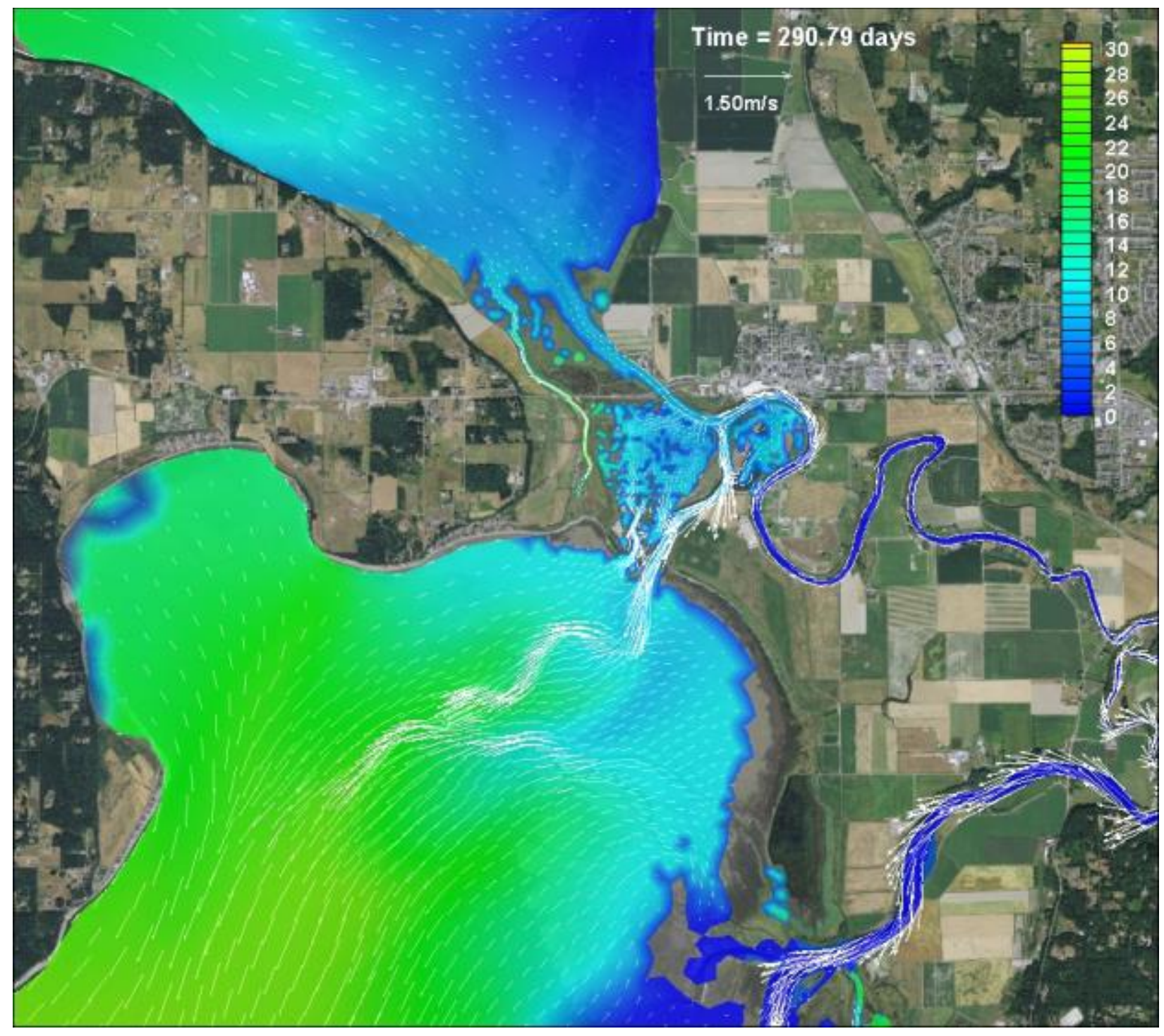

Figure B-31: Scenario 7 (Full Restoration zis a ba + SCN3) - Salinity contours and velocity vectors, October 17, 2005, peak ebb 


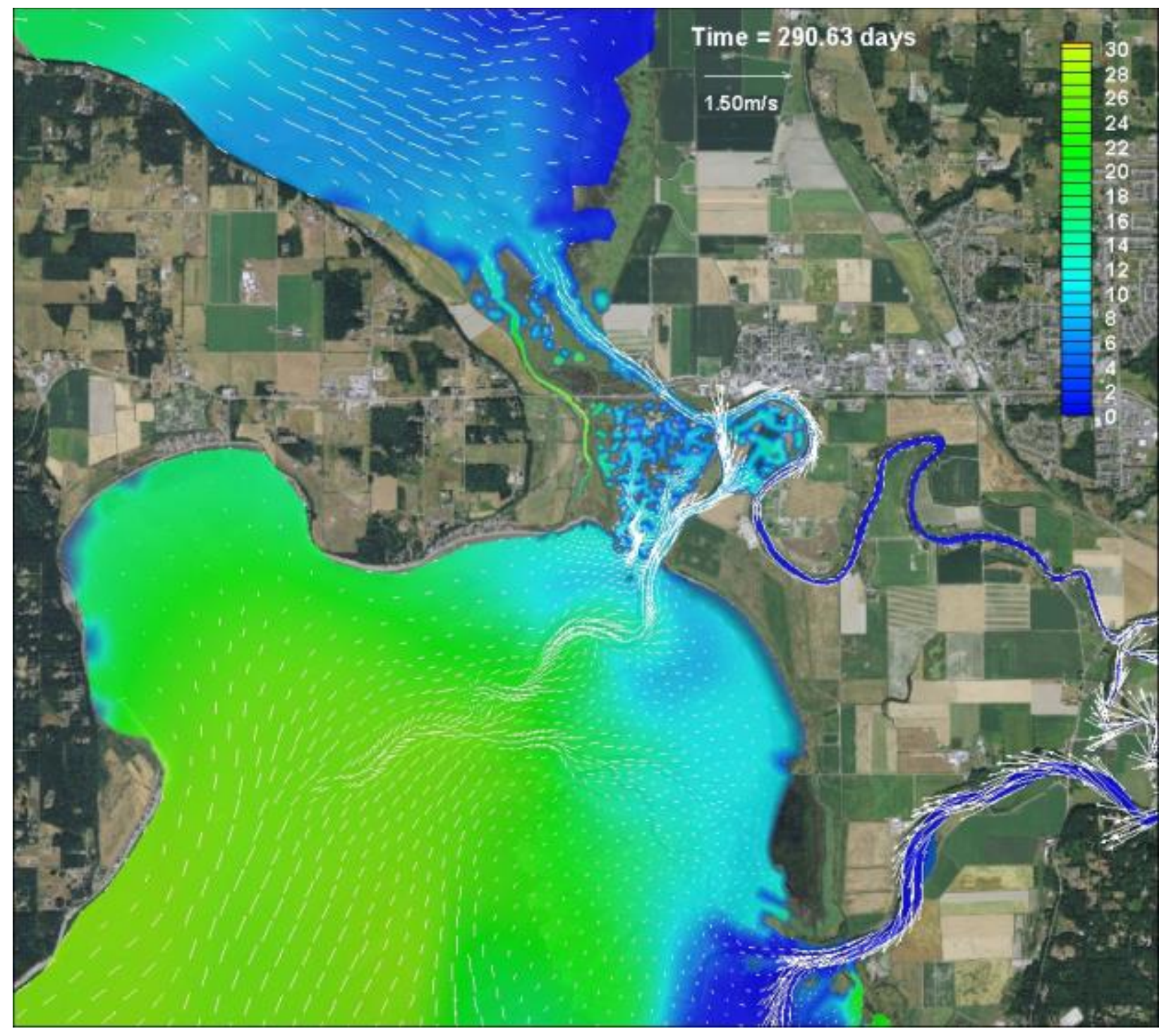

Figure B-32: Scenario 7 (Full Restoration zis a ba + SCN3) - Salinity contours and velocity vectors, October 17, 2005, peak flood 


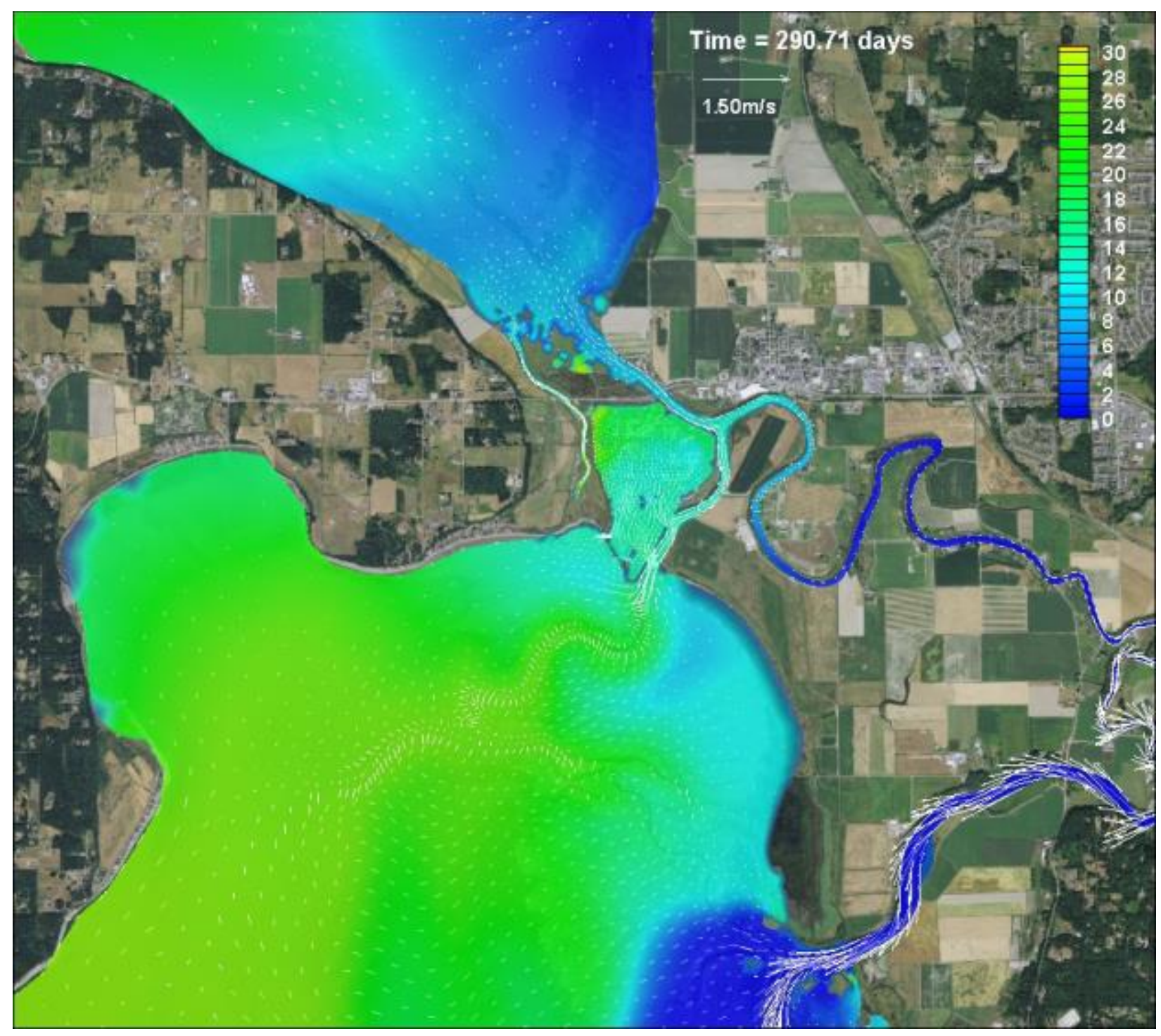

Figure B-33: Scenario 8 (3 Levee Breaches Leque) - Salinity contours and velocity vectors, October 17, 2005, high tide 


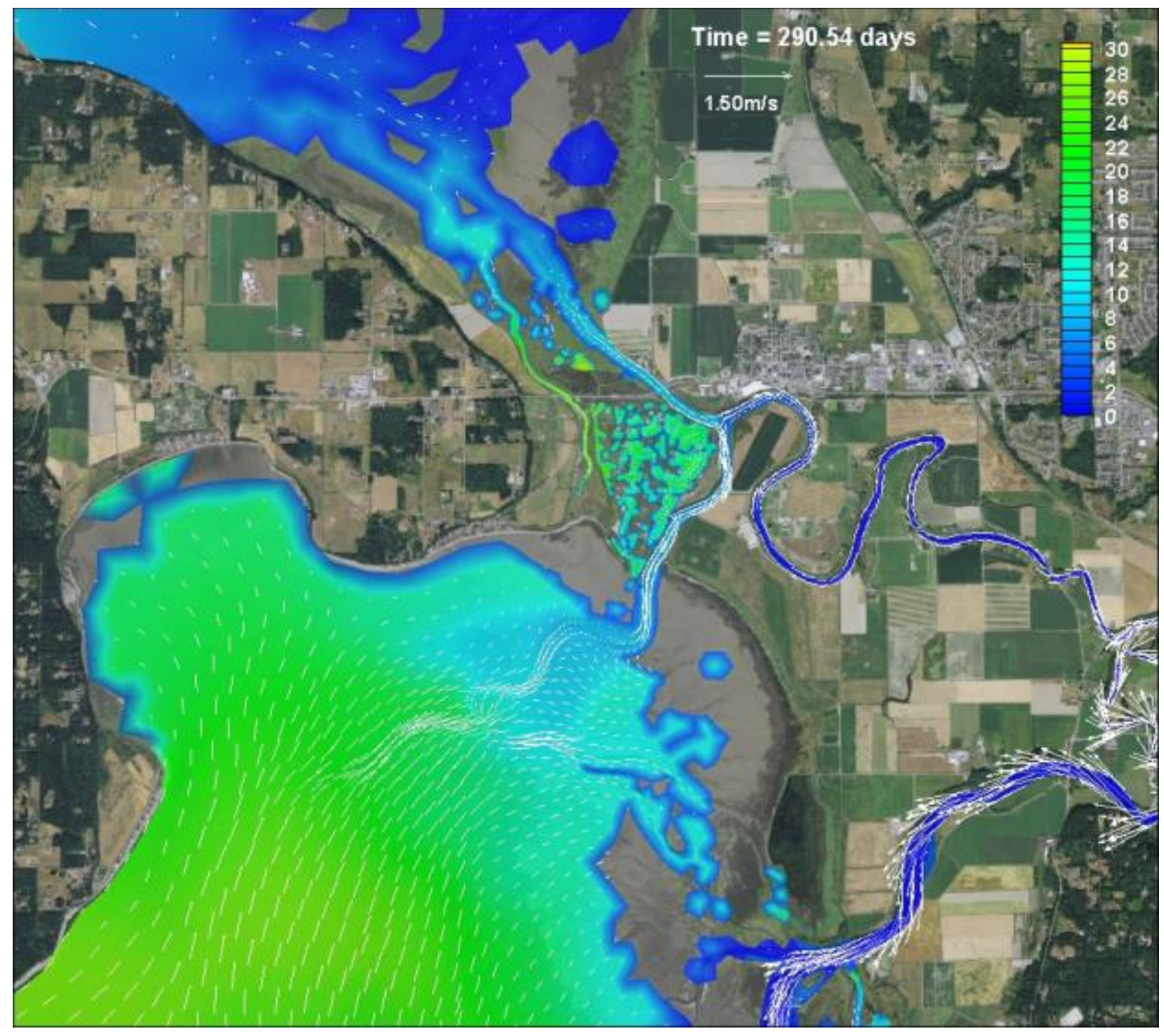

Figure B-34: Scenario 8 (3 Levee Breaches Leque) - Salinity contours and velocity vectors, October 17, 2005, low tide 


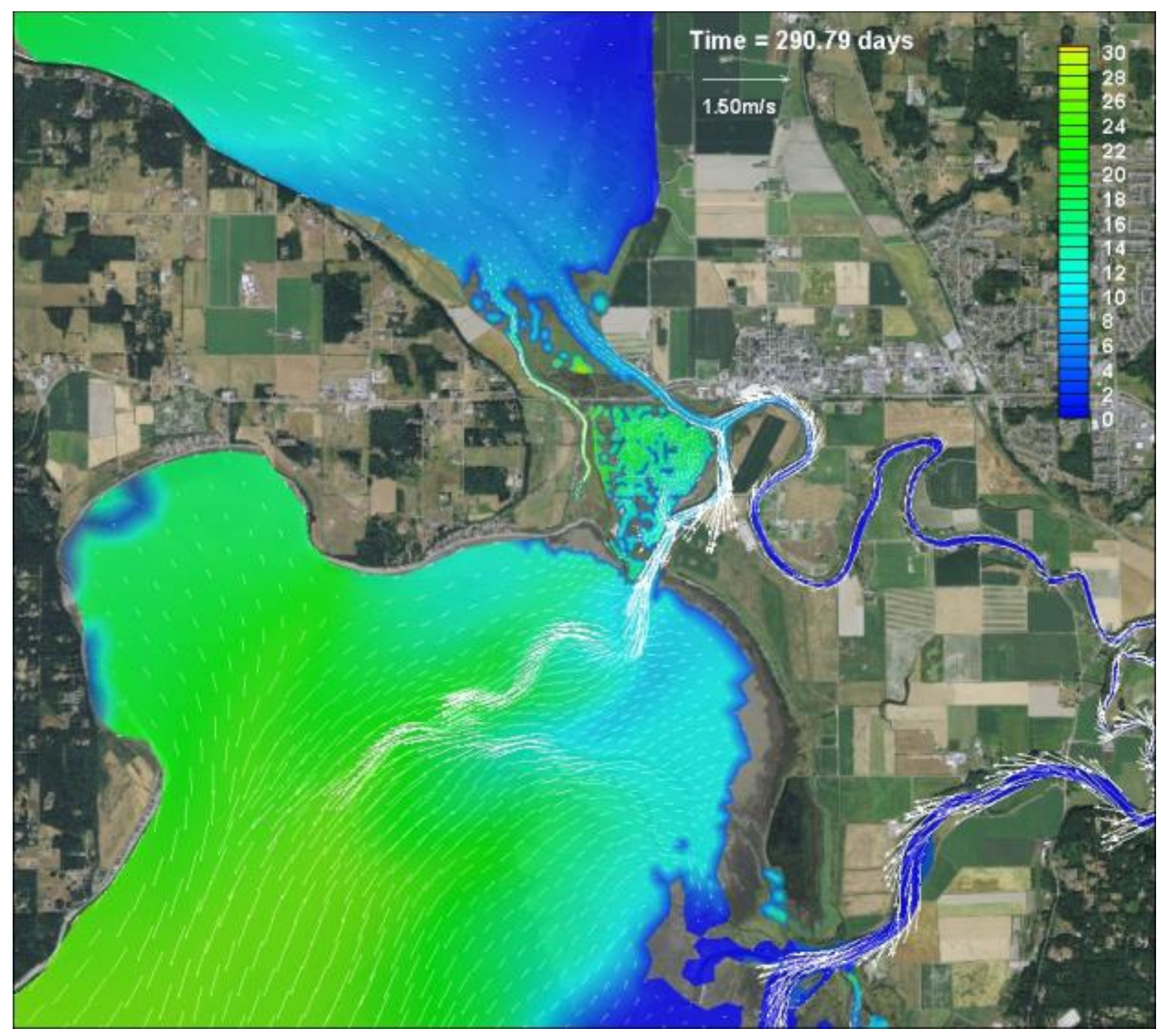

Figure B-35: Scenario 8 (3 Levee Breaches Leque) - Salinity contours and velocity vectors, October 17, 2005, peak ebb 

Appendix C

Time Series Plots - High-Flow (bank full) Conditions - WSL, Salinity, Velocity, Bed Shear 



\section{Appendix C}

\section{Time Series Plots - High-Flow (bank full) Conditions - WSL, Salinity, Velocity, Bed Shear}

Time series plots at high-flow (i.e., bank full) condition water-surface elevations, salinities, velocities, and bed sheers for Leque Island and zis a ba restoration site stations are provided in this appendix.

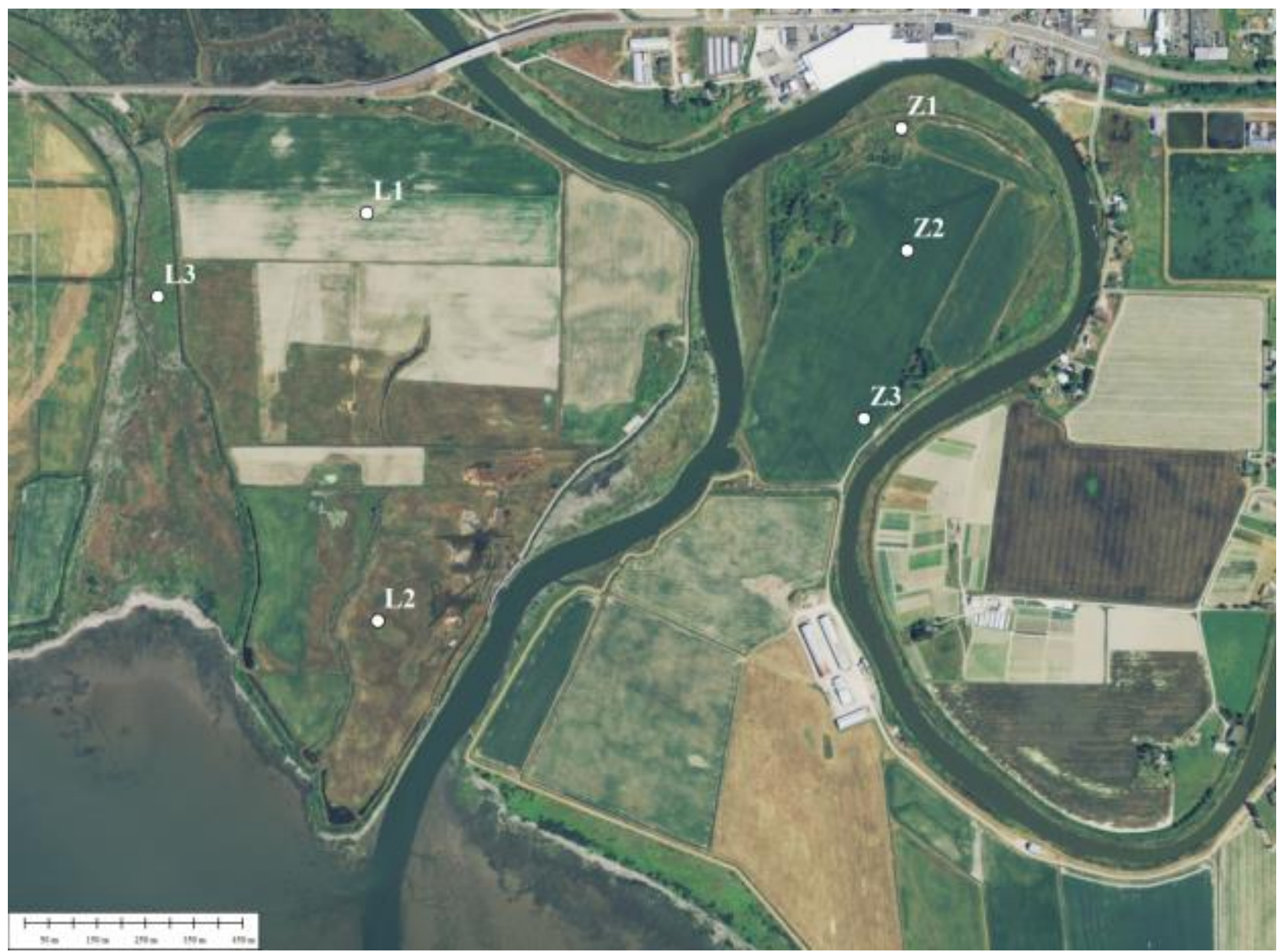

Figure C-1: Leque and zis a ba restoration site plan view and time series station locations 


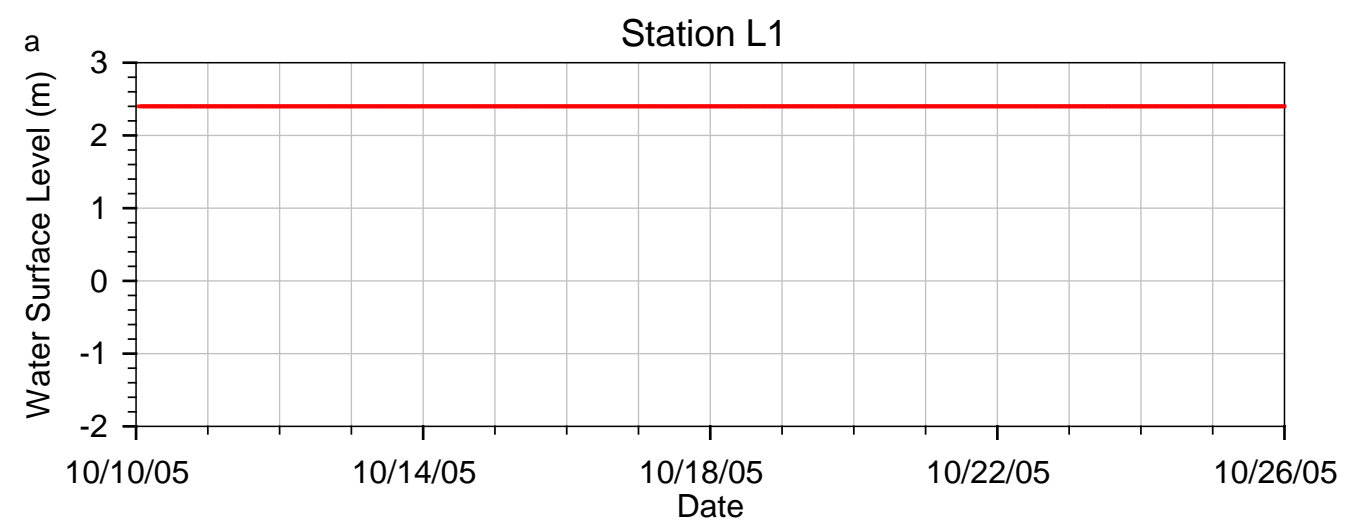

b
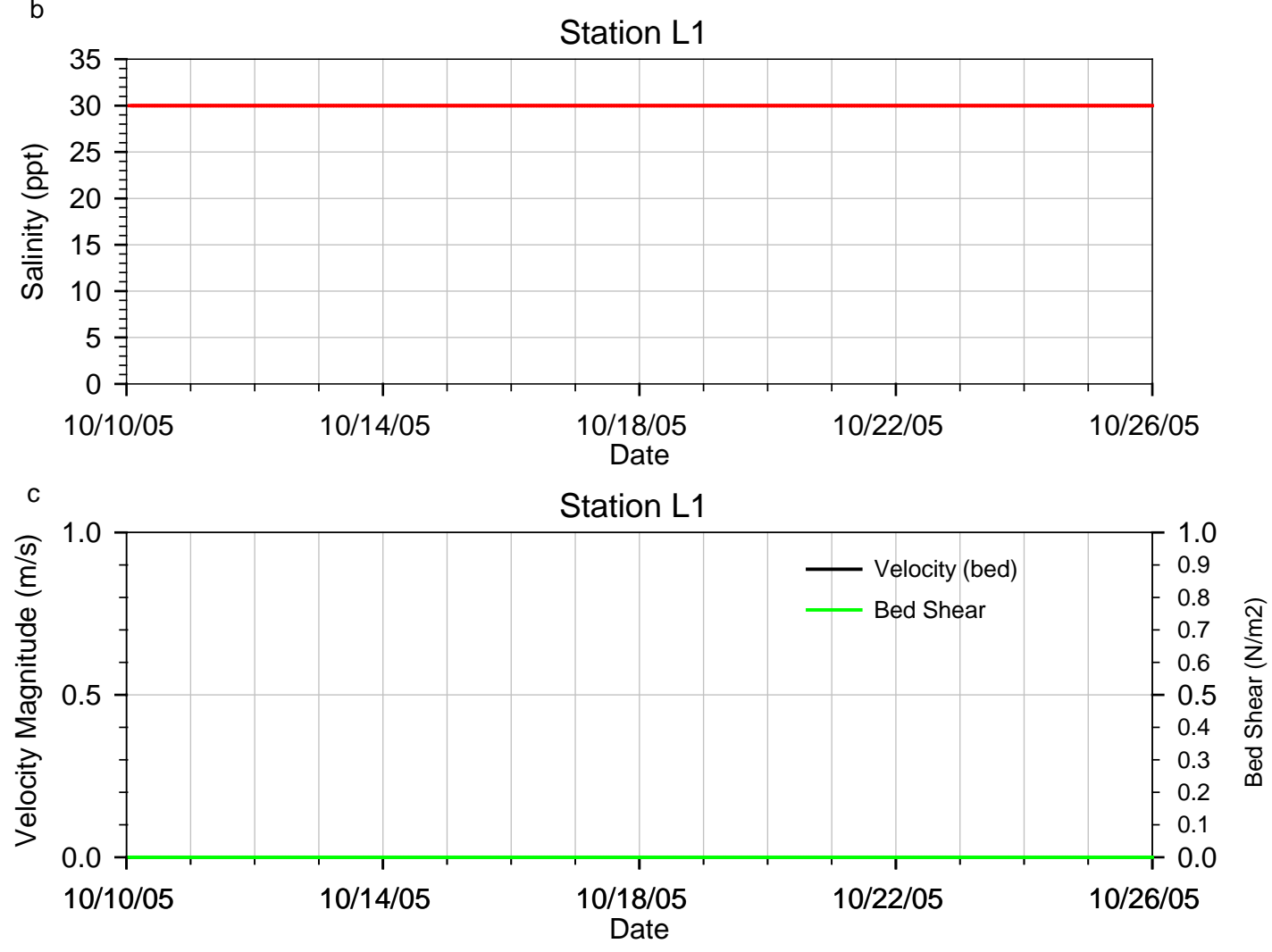

Figure C-2: Scenario 0 (Baseline Condition) - Water-surface elevation, salinity, velocity magnitude, and bed shear stress at Leque Island restoration station L1, full bank conditions at 26,508 cfs river flow (tides and wind corresponding to October 2005) 


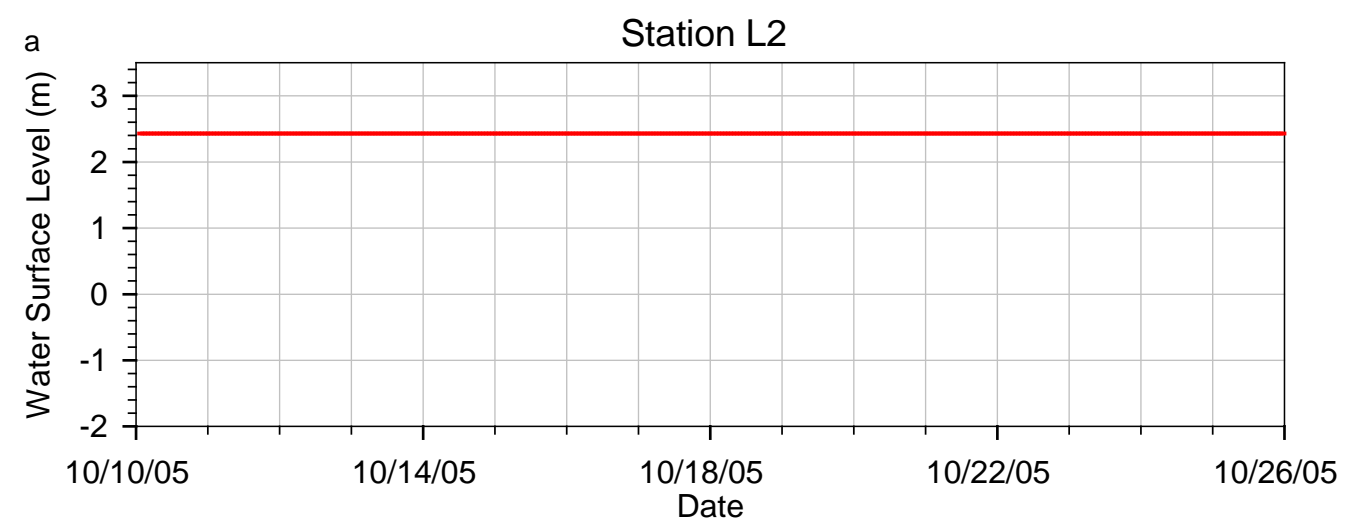

b
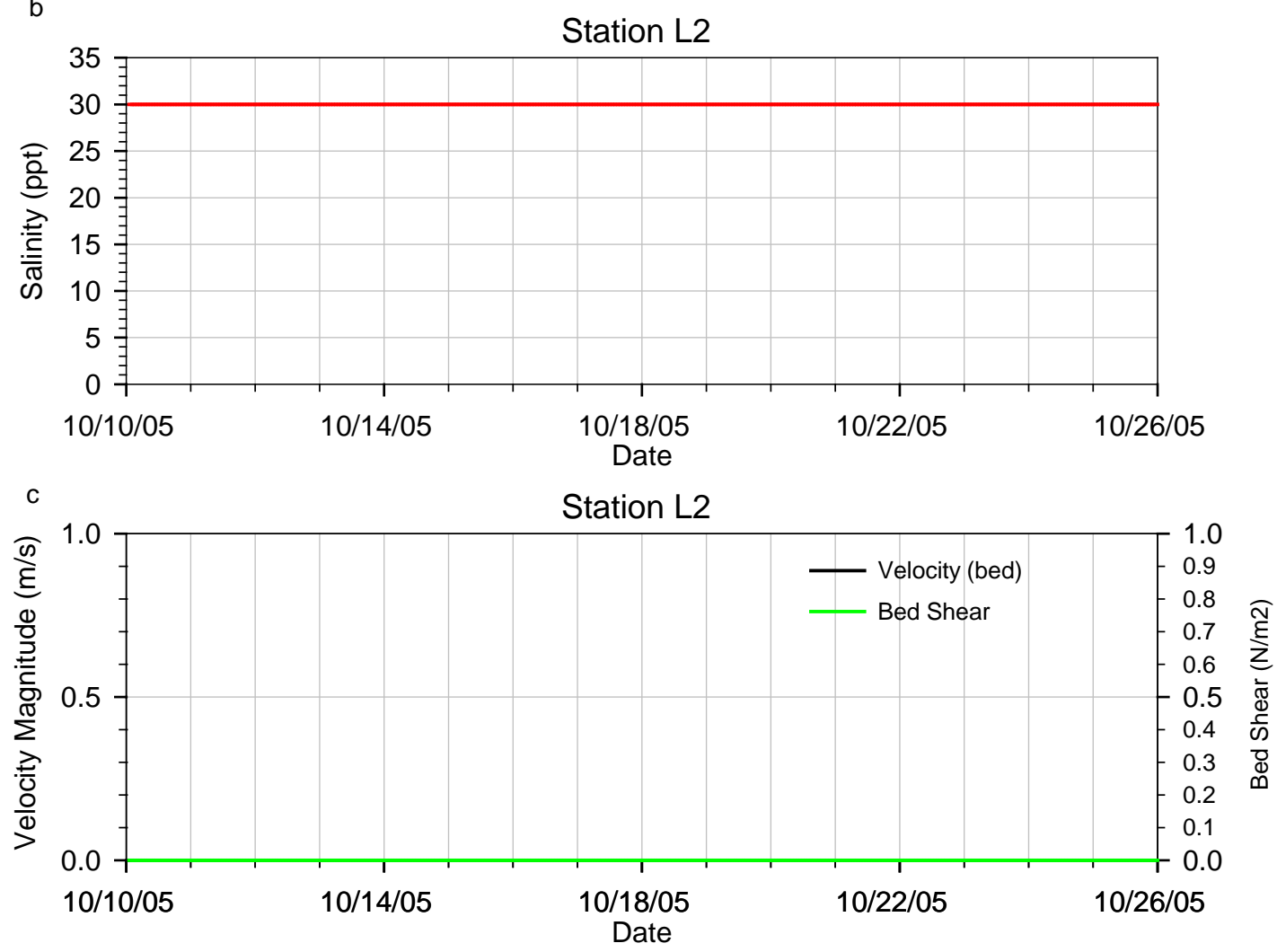

Figure C-3: Scenario 0 (Baseline Condition) - Water-surface elevation, salinity, velocity magnitude, and bed shear stress at Leque Island restoration station L2, full bank conditions at 26,508 cfs river flow (tides and wind corresponding to October 2005) 


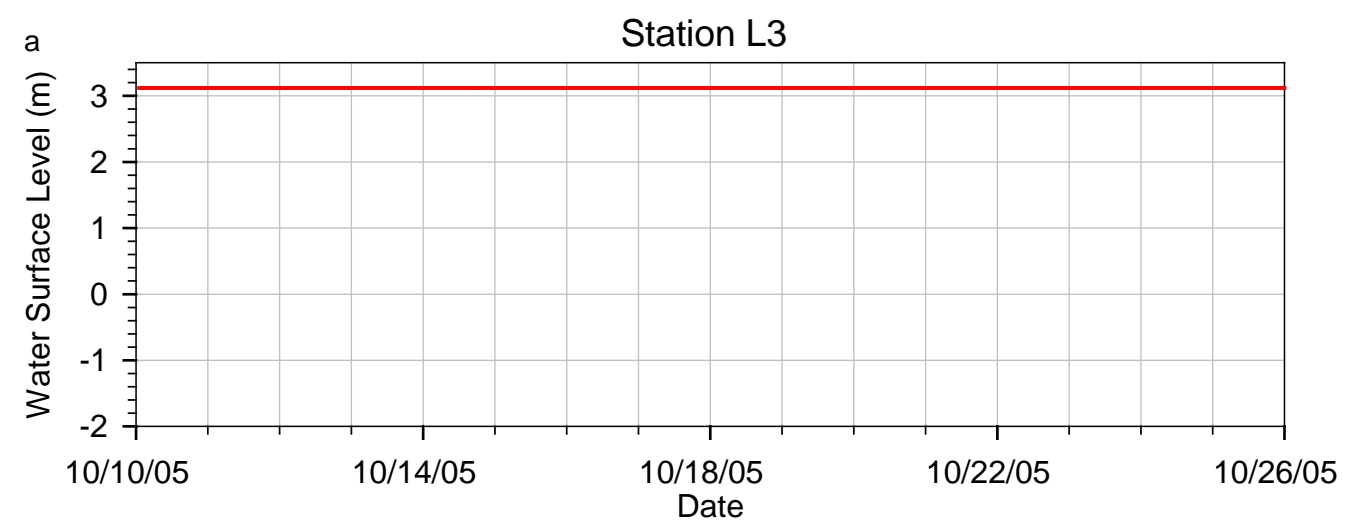

b
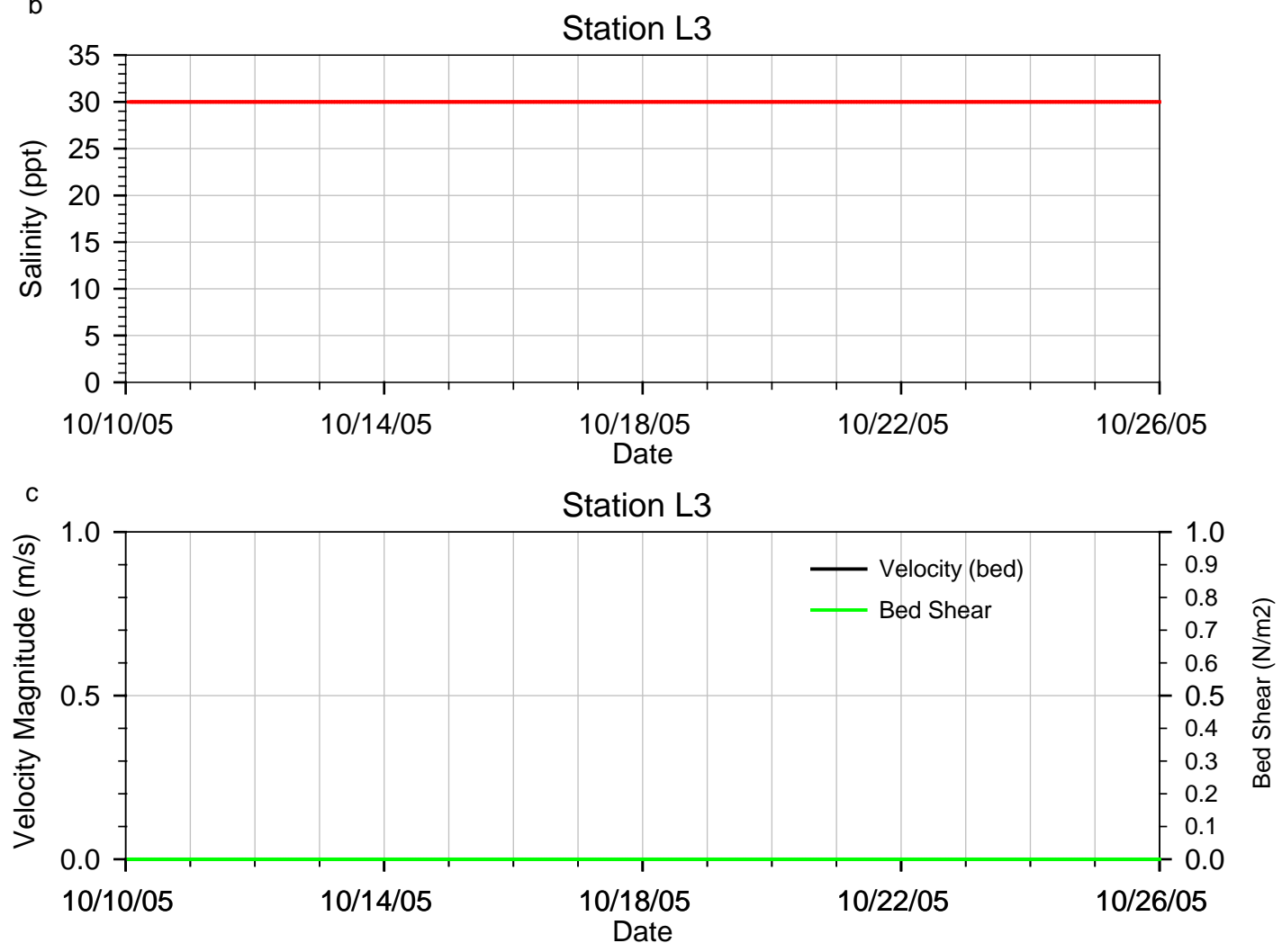

Figure C-4: Scenario 0 (Baseline Condition) - Water-surface elevation, salinity, velocity magnitude, and bed shear stress at Leque Island restoration station L3, full bank conditions at 26,508 cfs river flow (tides and wind corresponding to October 2005) 


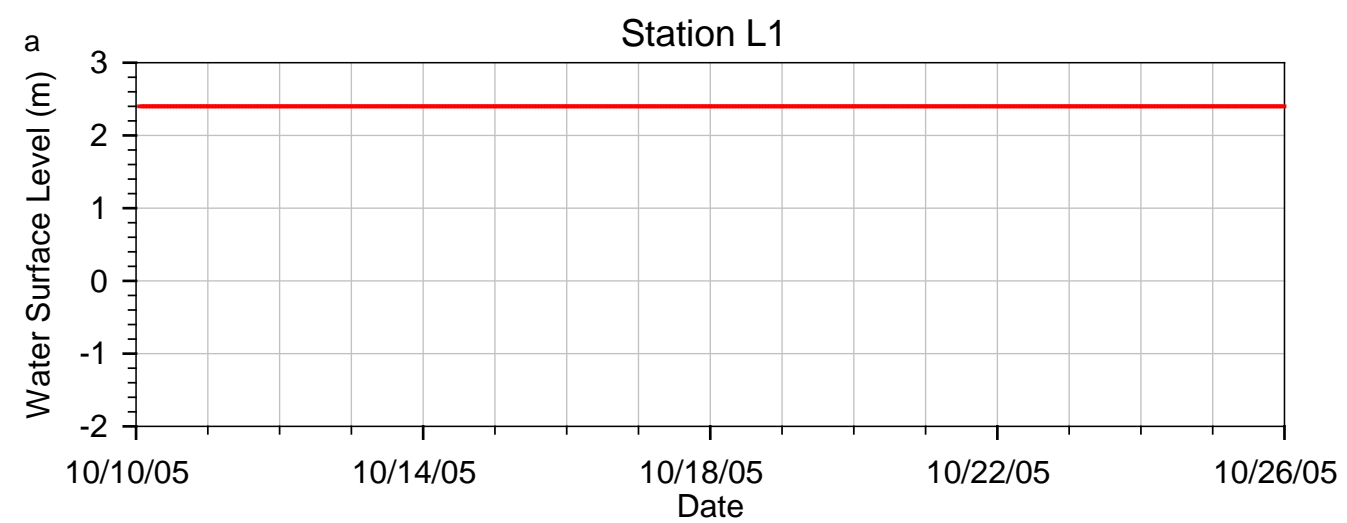

b
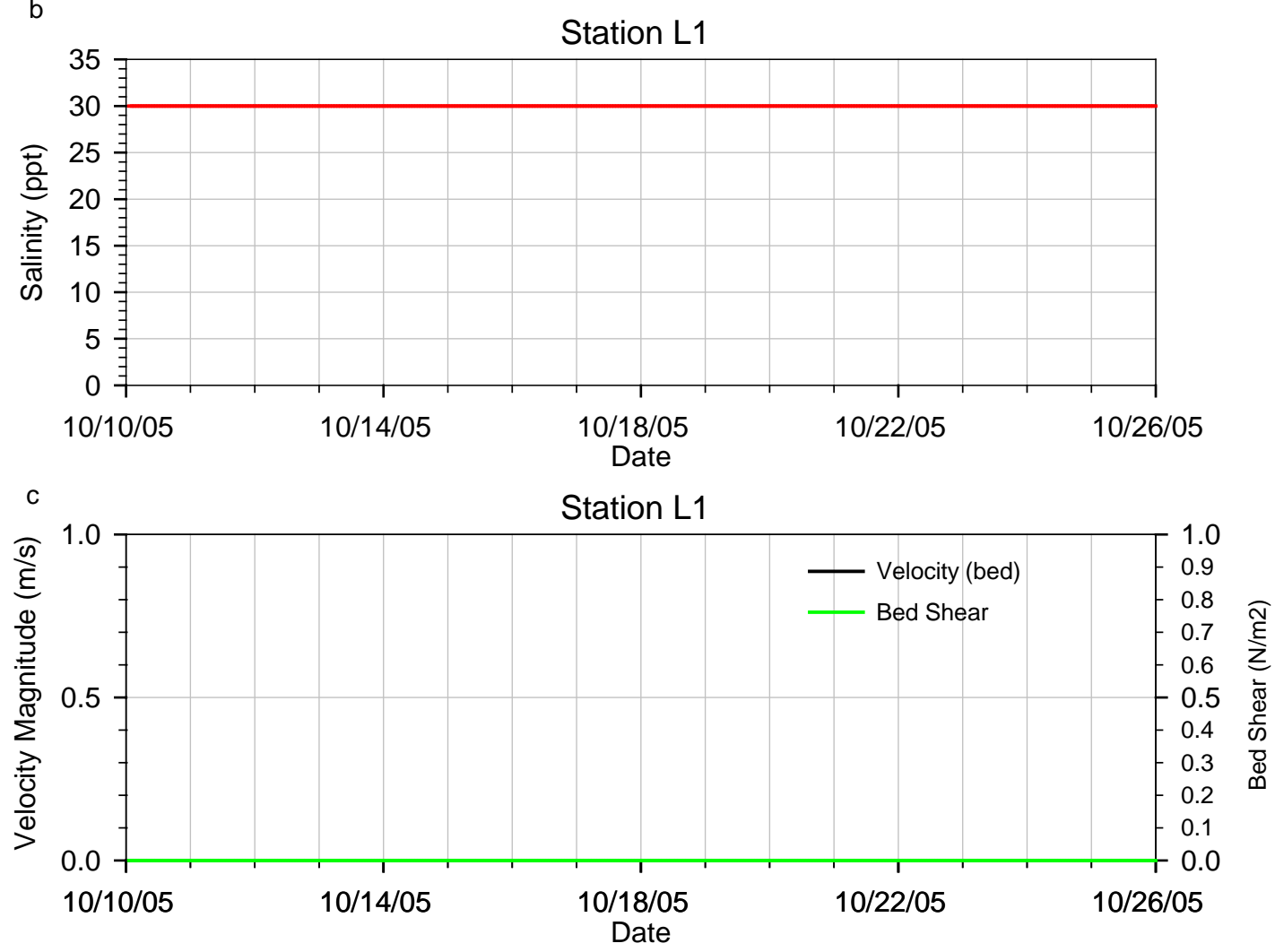

Figure C-5: Scenario 1 (Partial Restoration Leque) - Water-surface elevation, salinity, velocity magnitude, and bed shear stress at Leque Island restoration station L1, full bank conditions at 26,508 cfs river flow (tides and wind corresponding to October 2005) 


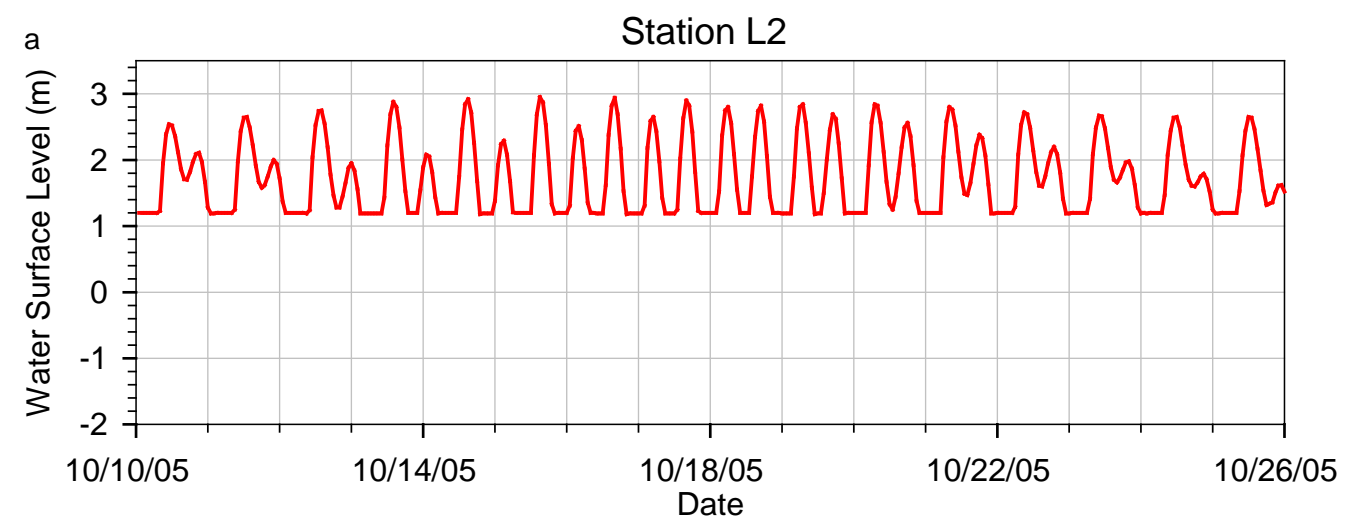

b
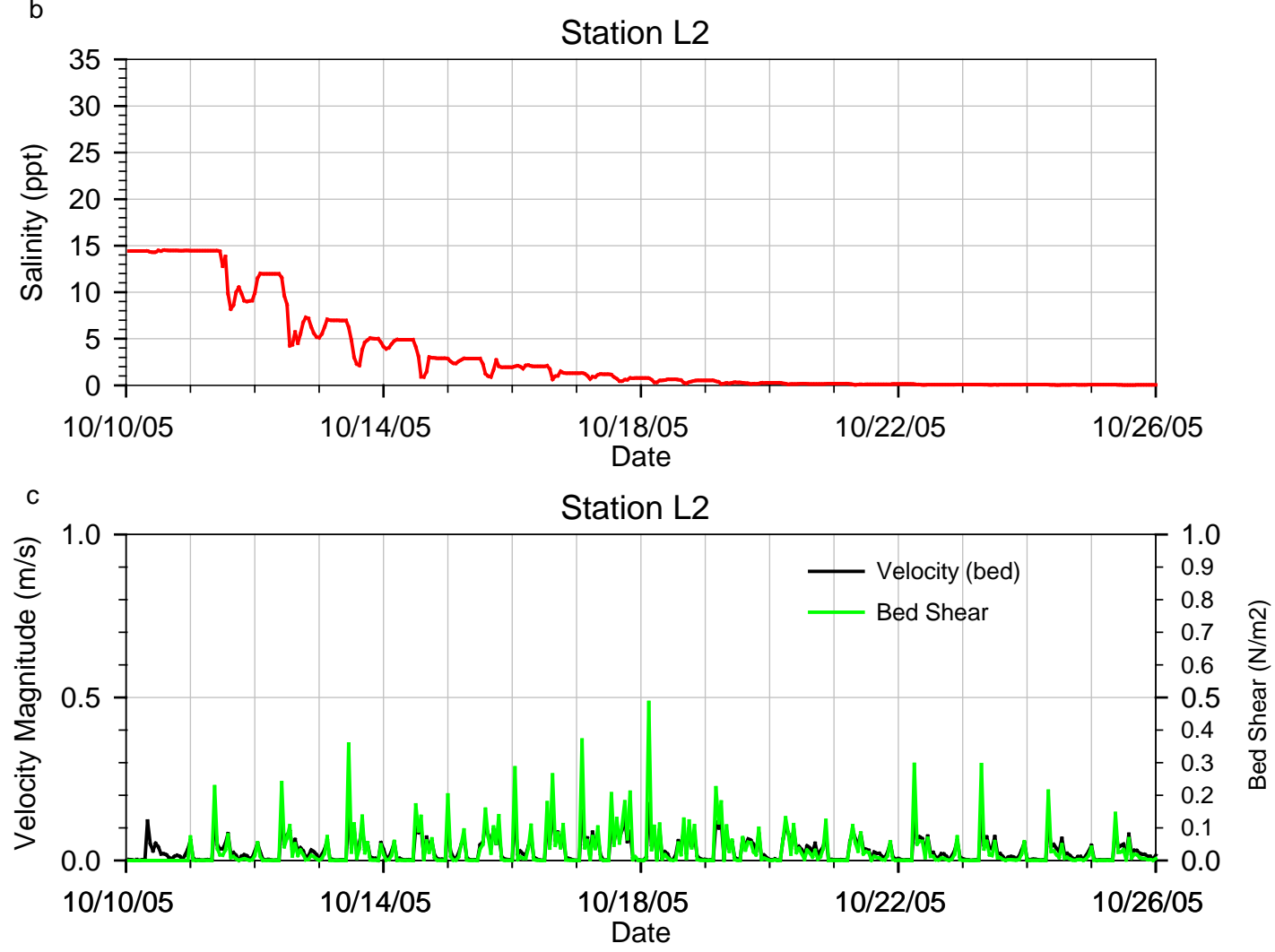

Figure C-6: Scenario 1 (Partial Restoration Leque) - Water-surface elevation, salinity, velocity magnitude, and bed shear stress at Leque Island restoration station L2, full bank conditions at 26,508 cfs river flow (tides and wind corresponding to October 2005) 


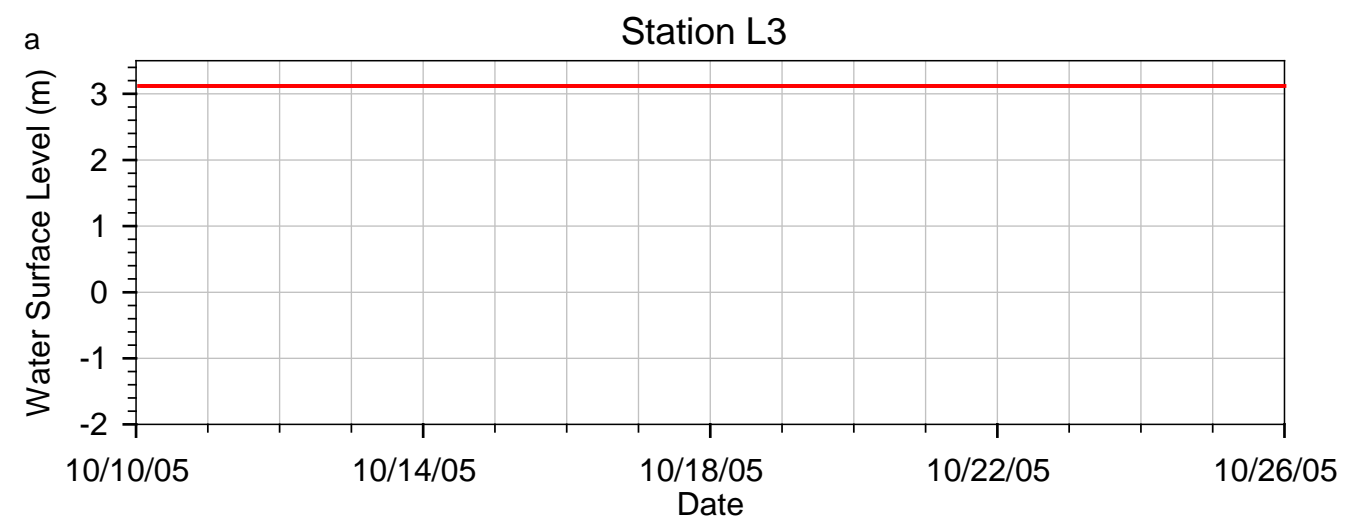

b
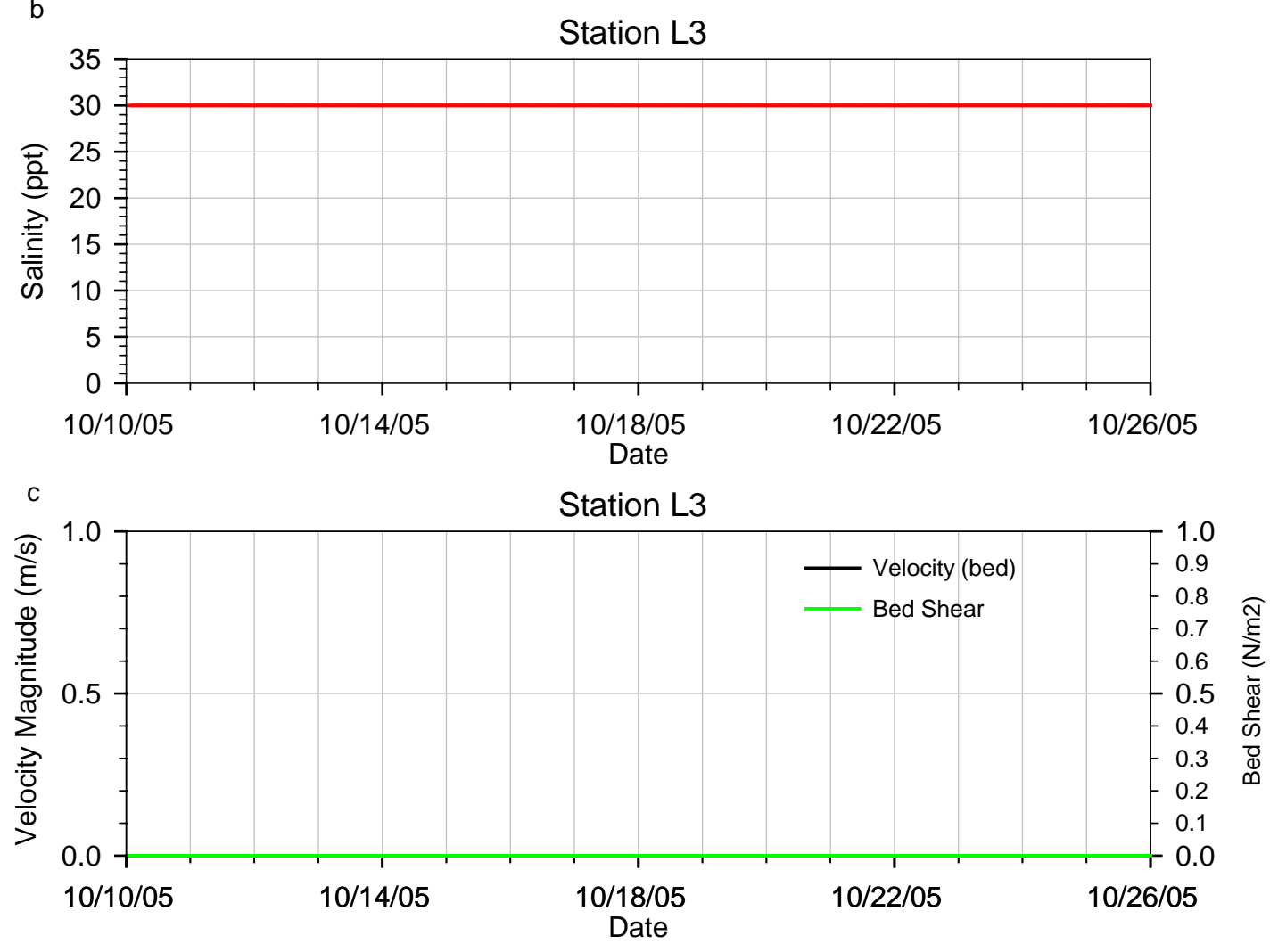

Figure C-7: Scenario 1 (Partial Restoration Leque) - Water-surface elevation, salinity, velocity magnitude, and bed shear stress at Leque Island restoration station L3, full bank conditions at 26,508 cfs river flow (tides and wind corresponding to October 2005) 


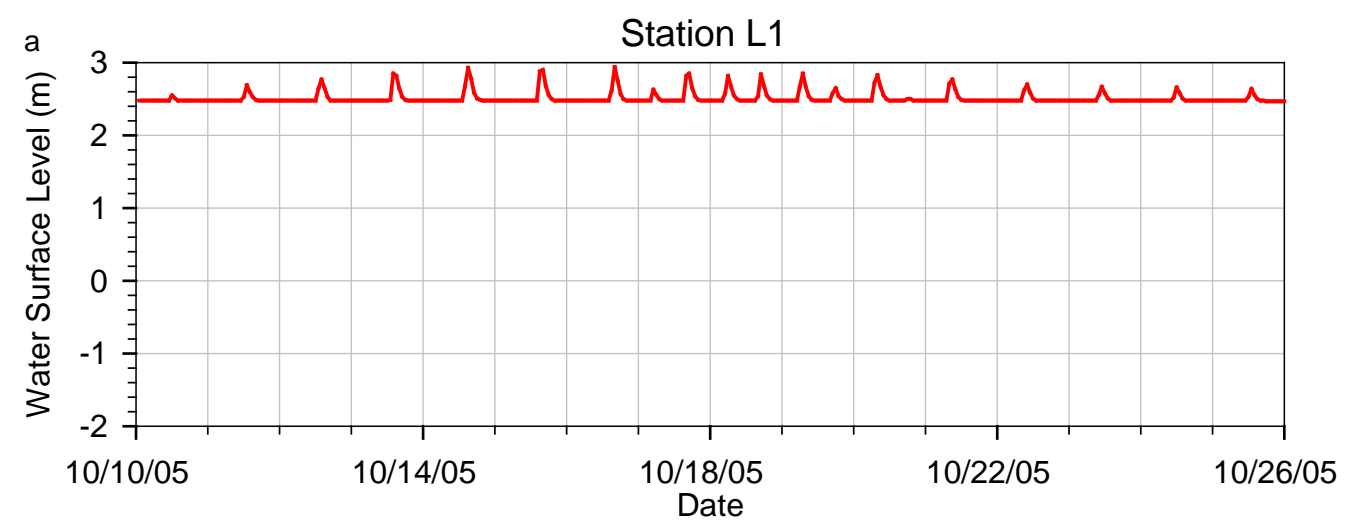

b
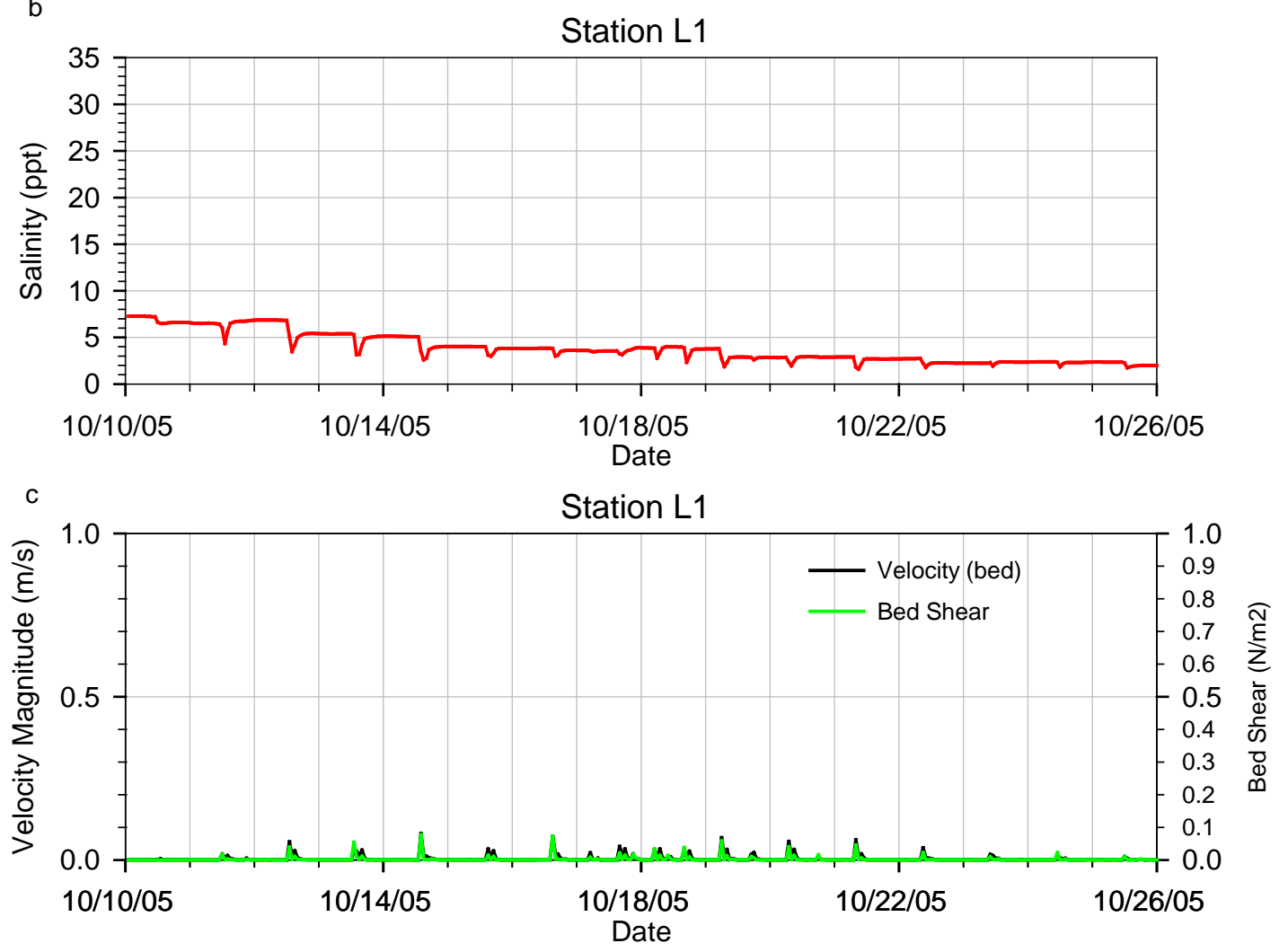

Figure C-8: Scenario 2 (4 Levee Breach Leque) - Water-surface elevation, salinity, velocity magnitude, and bed shear stress at Leque Island restoration station L1, full bank conditions at 26,508 cfs river flow (tides and wind corresponding to October 2005) 


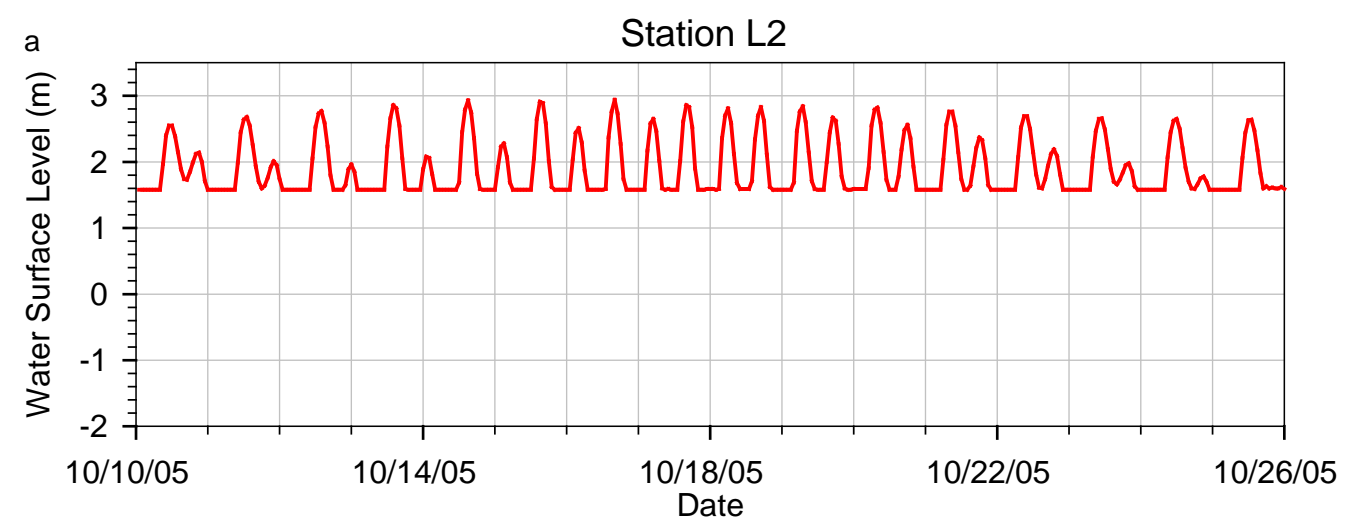

b
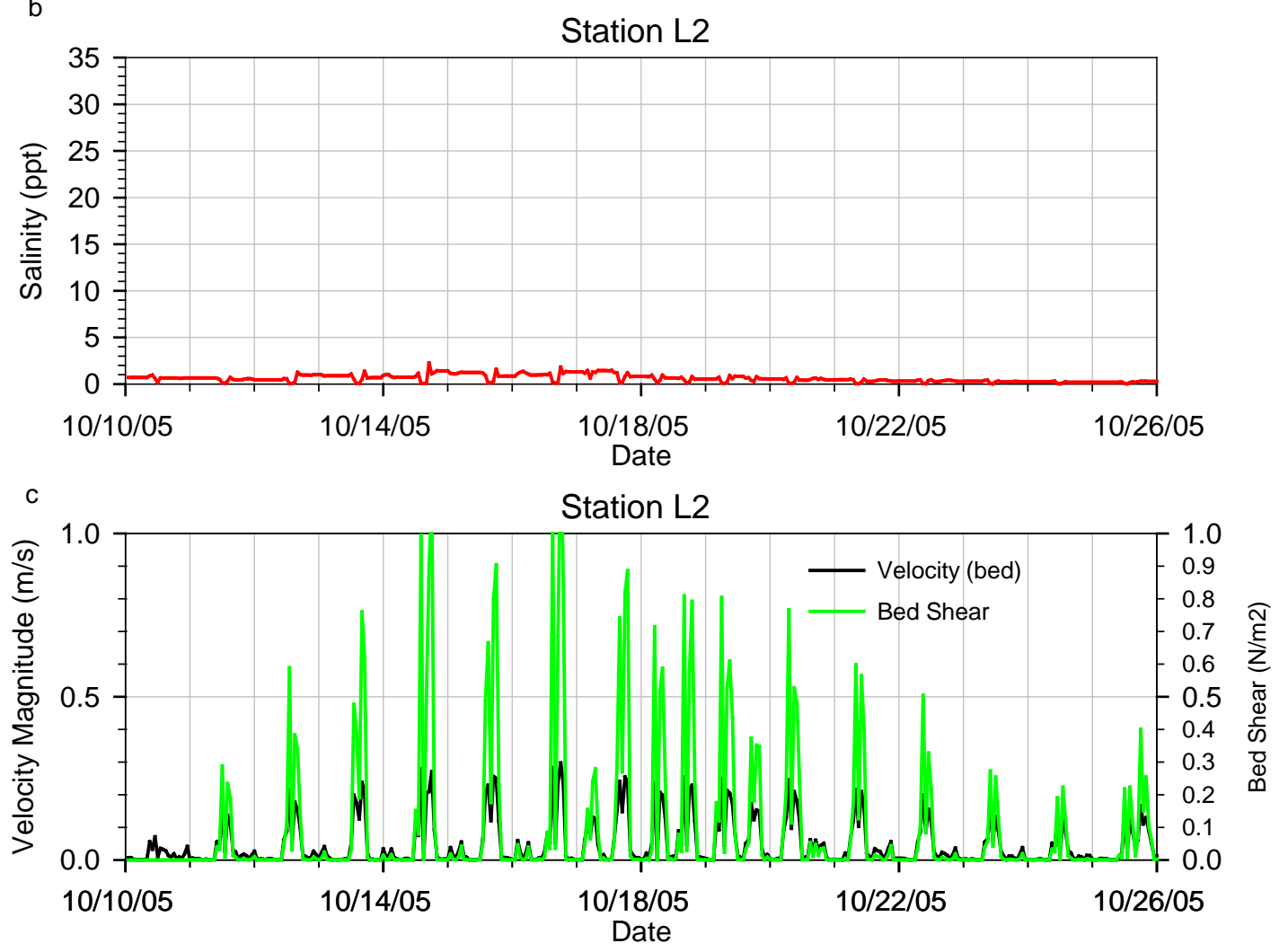

Figure C-9: Scenario 2 (4 Levee Breach Leque) - Water-surface elevation, salinity, velocity magnitude, and bed shear stress at Leque Island restoration station L2, full bank conditions at 26,508 cfs river flow (tides and wind corresponding to October 2005) 


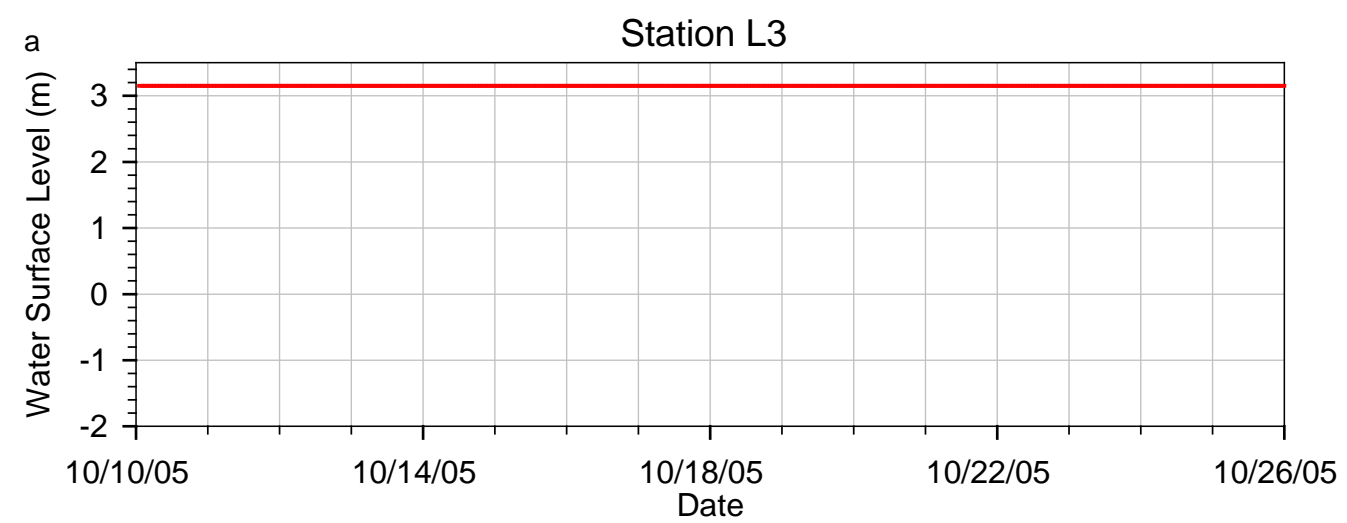

b
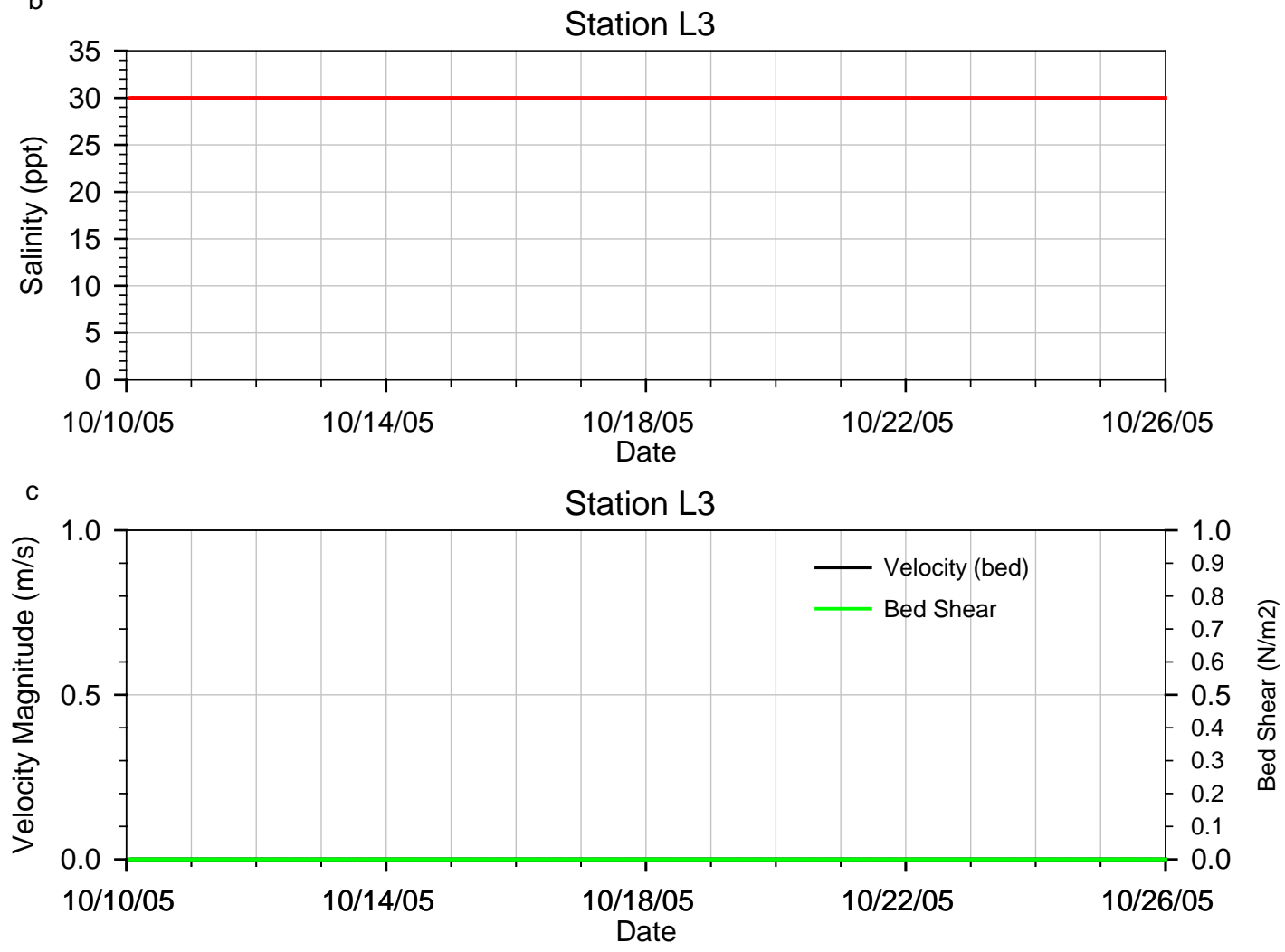

Figure C-10: Scenario 2 (4 Levee Breach Leque) - Water-surface elevation, salinity, velocity magnitude, and bed shear stress at Leque Island restoration station L3, full bank conditions at 26,508 cfs river flow (tides and wind corresponding to October 2005) 


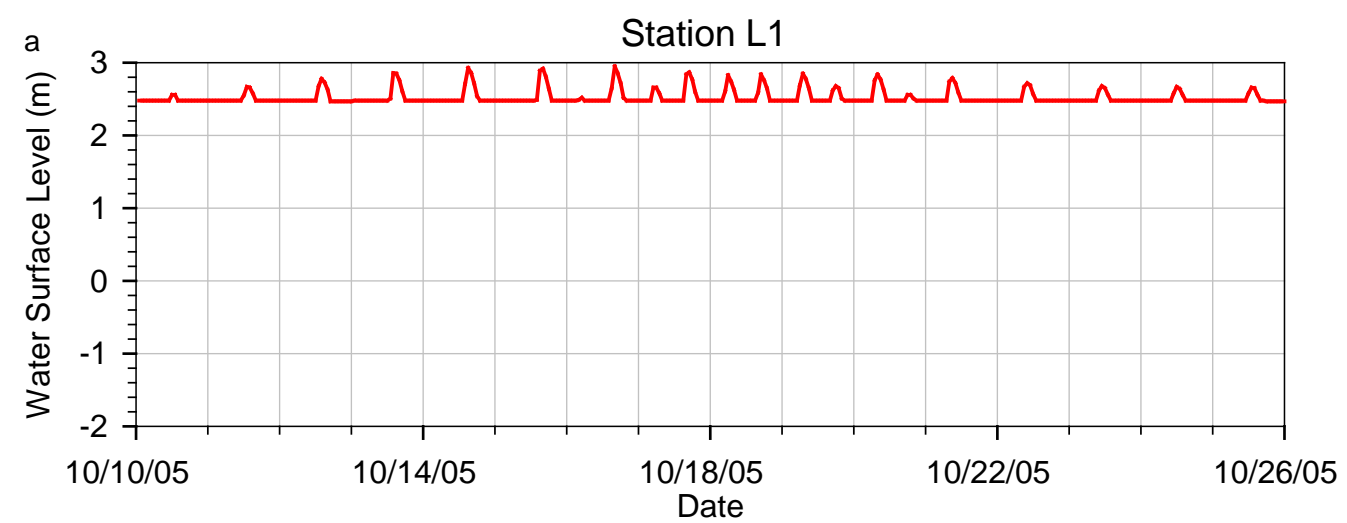

b
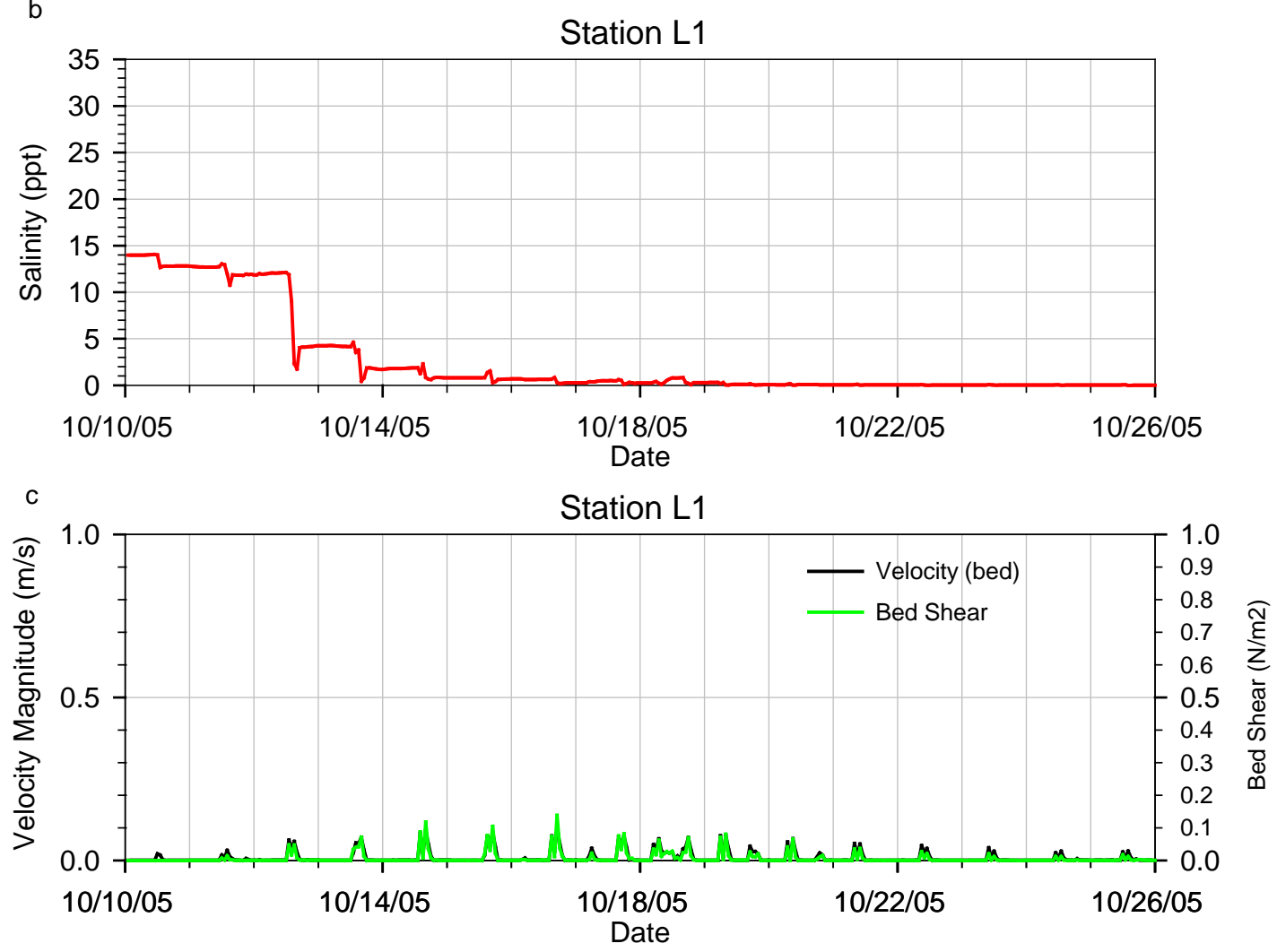

Figure C-11: Scenario 3 (Full Restoration Leque 1) - Water-surface elevation, salinity, velocity magnitude, and bed shear stress at Leque Island restoration station L1, full bank conditions at 26,508 cfs river flow (tides and wind corresponding to October 2005) 


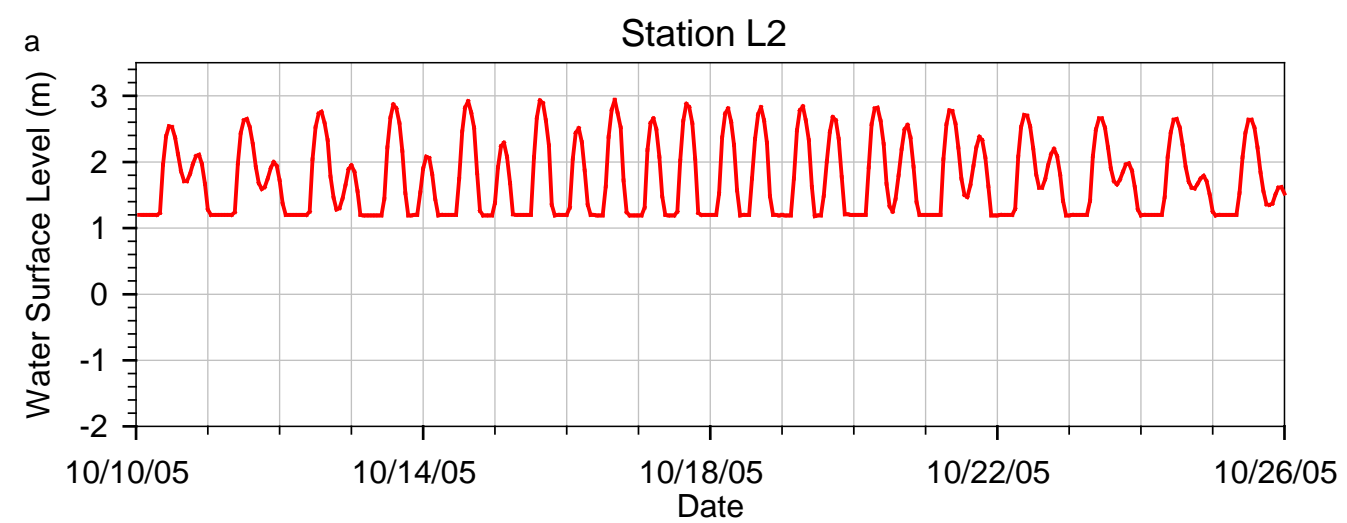

b
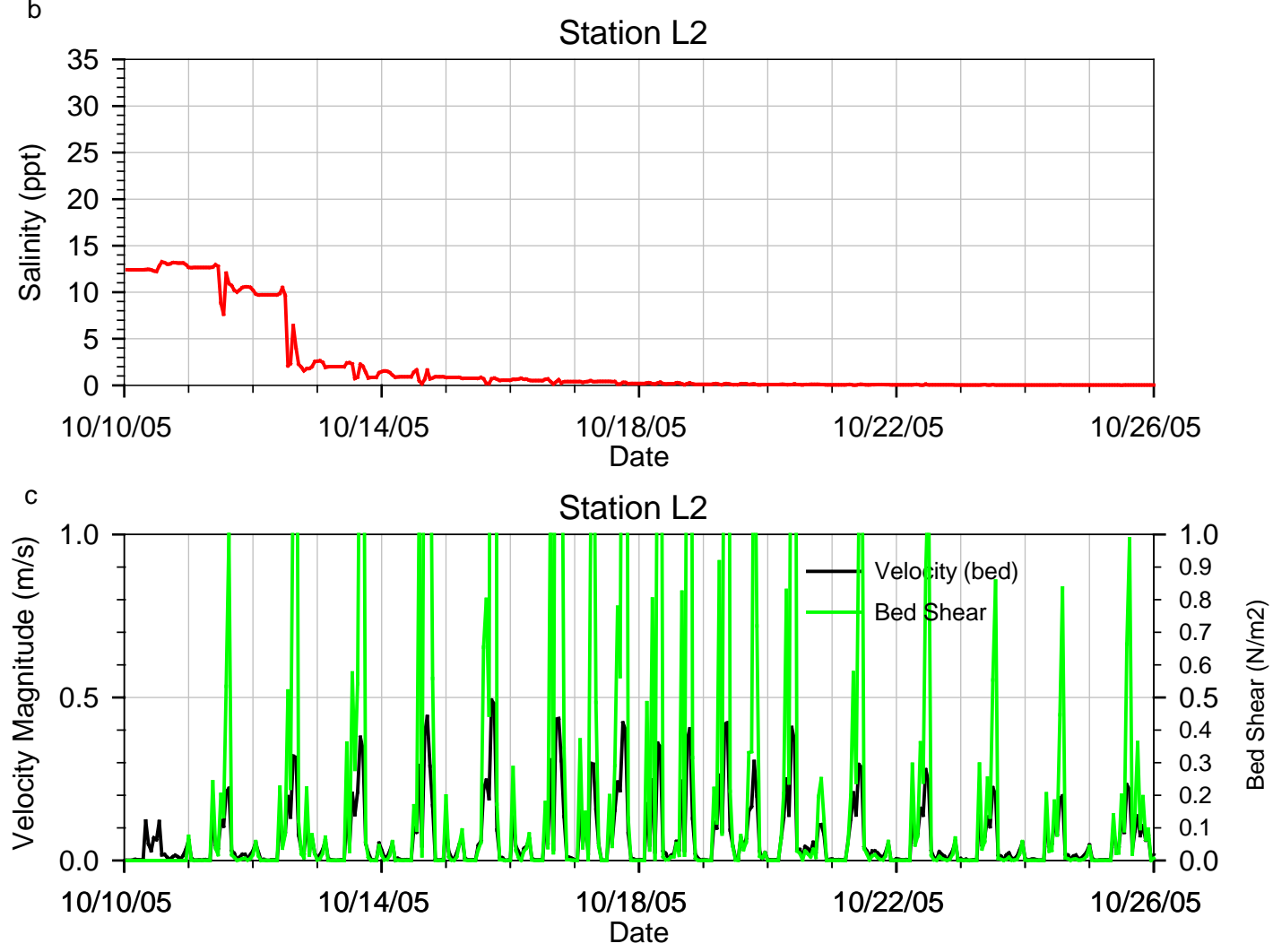

Figure C-12: Scenario 3 (Full Restoration Leque 1) - Water-surface elevation, salinity, velocity magnitude, and bed shear stress at Leque Island restoration station L2, full bank conditions at 26,508 cfs river flow (tides and wind corresponding to October 2005) 


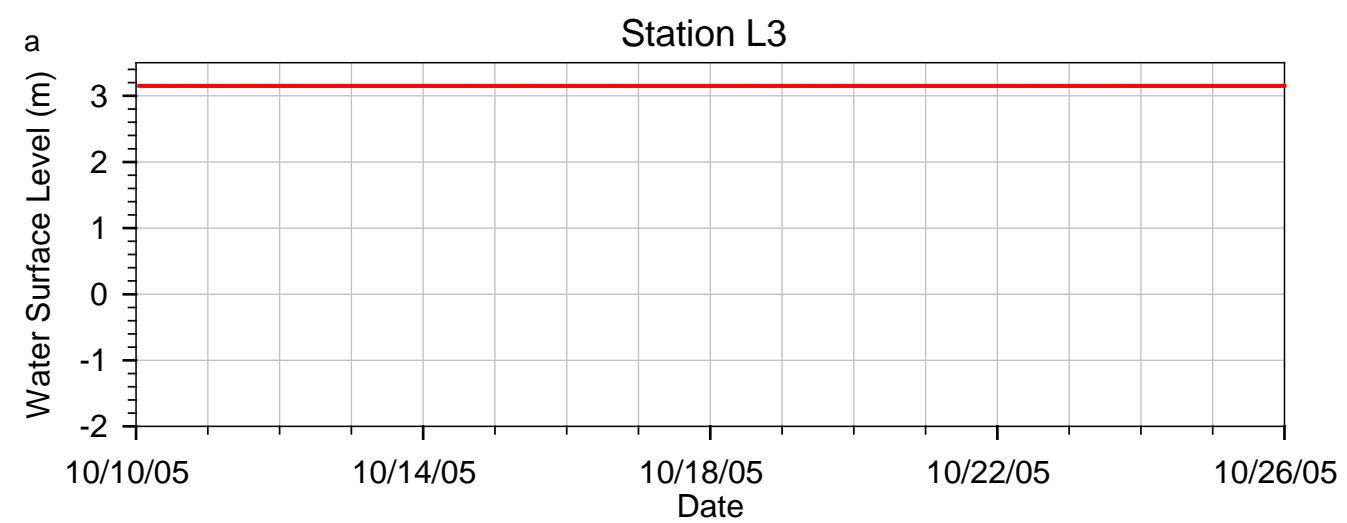

b
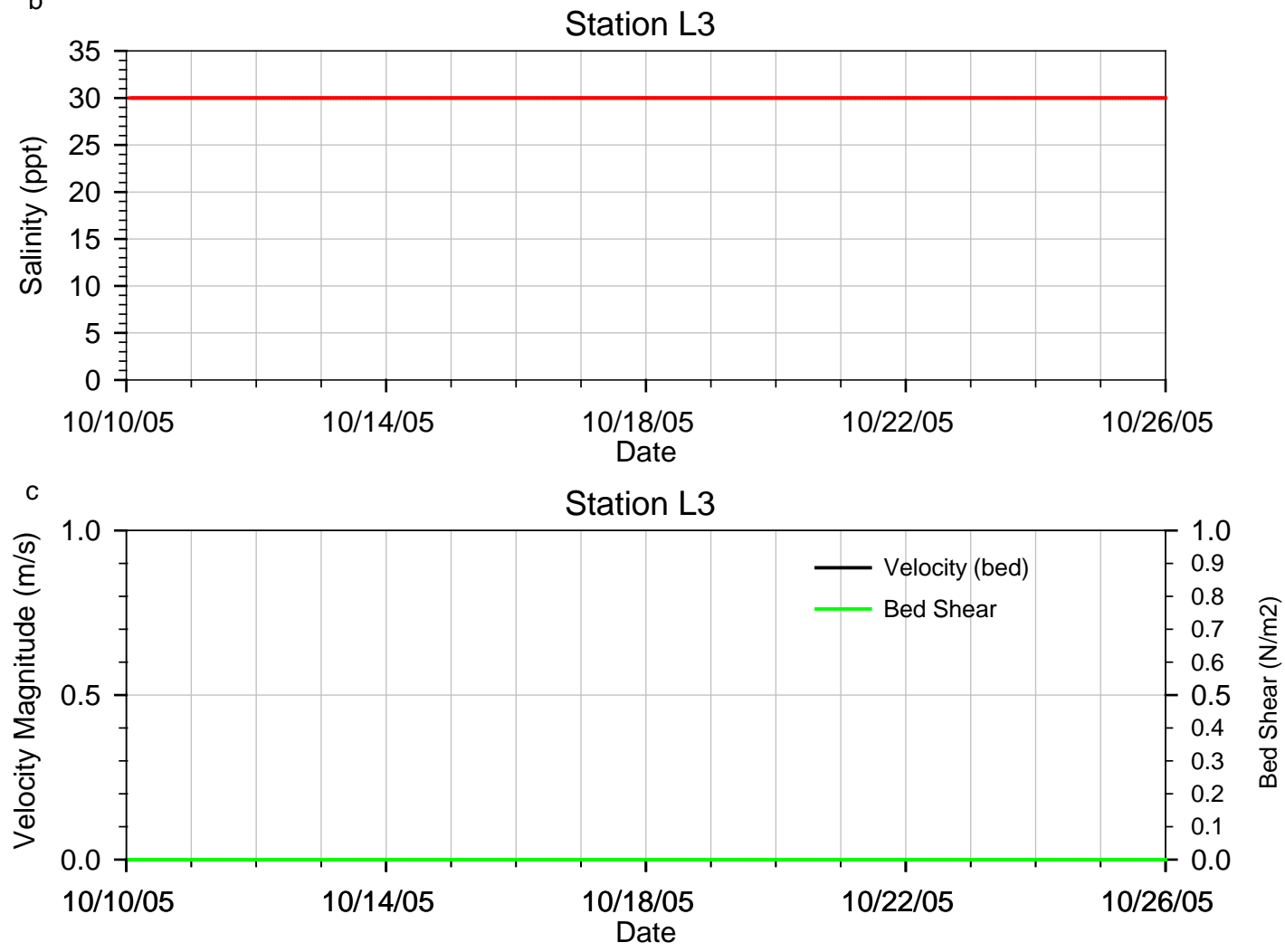

Figure C-13: Scenario 3 (Full Restoration Leque 1) - Water-surface elevation, salinity, velocity magnitude, and bed shear stress at Leque Island restoration station L3, full bank conditions at 26,508 cfs river flow (tides and wind corresponding to October 2005) 


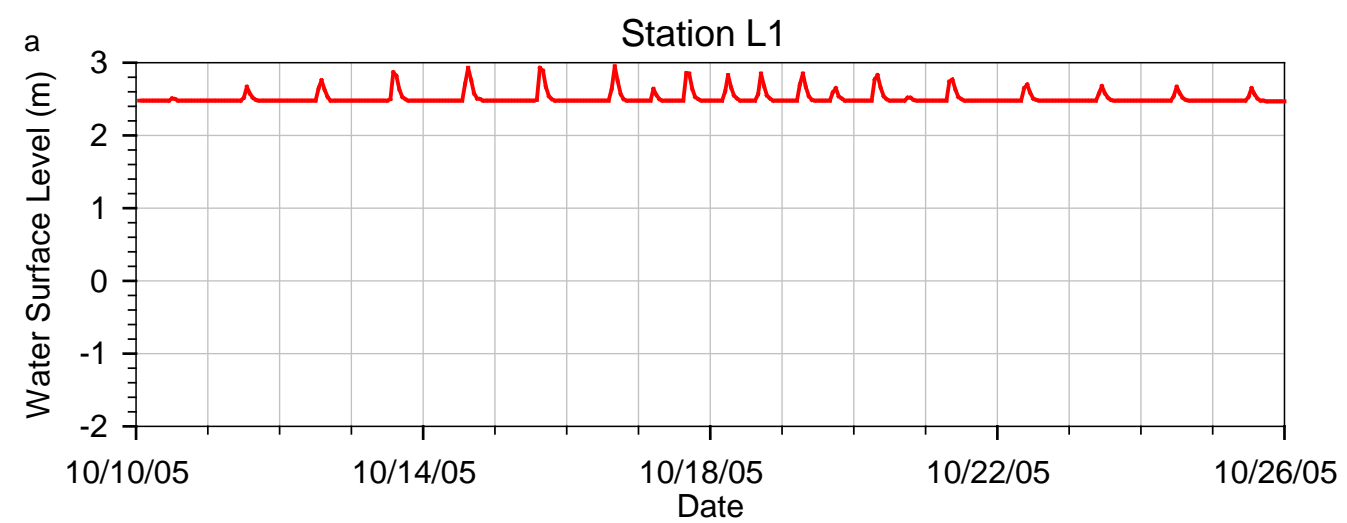

b
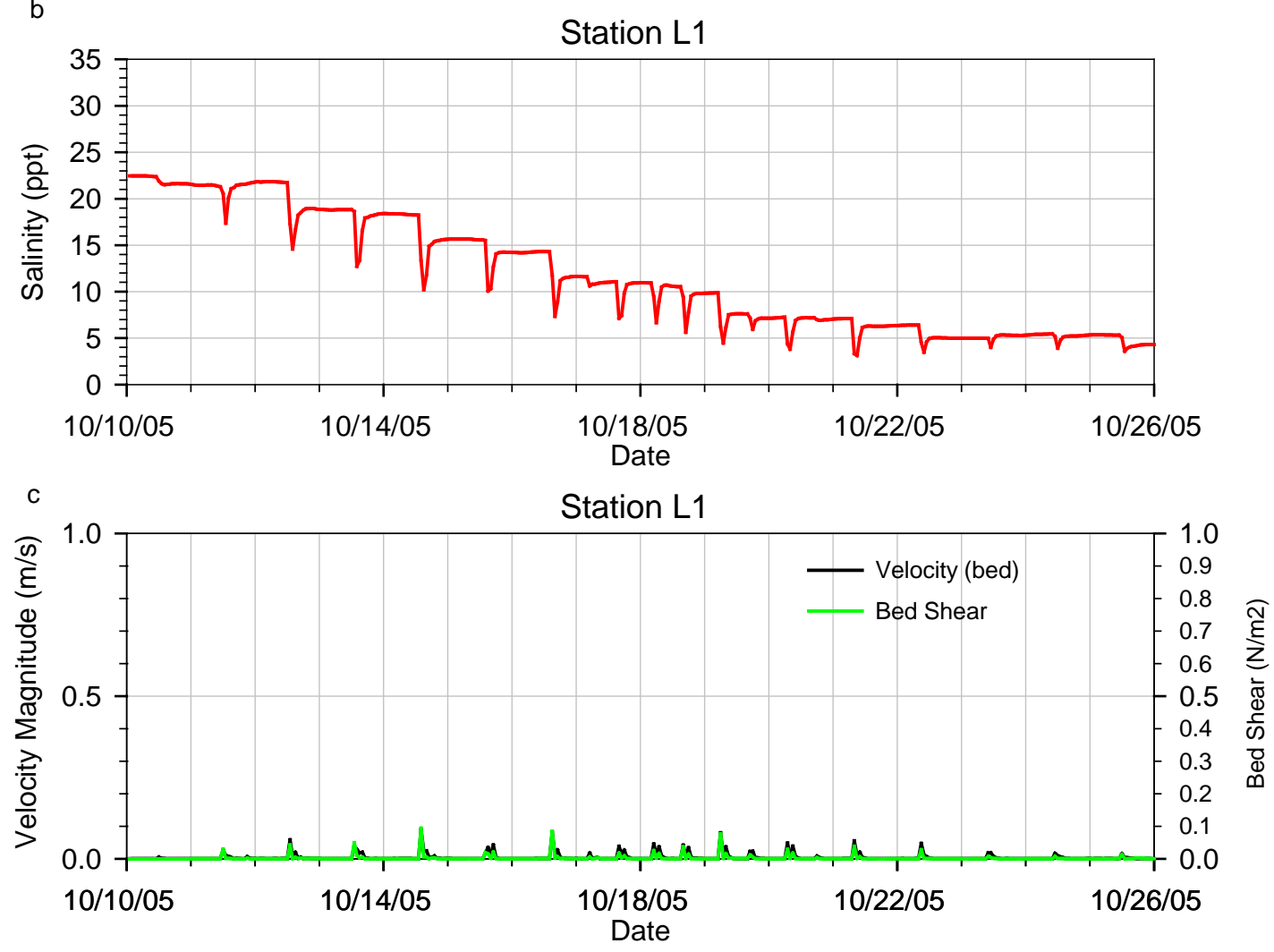

Figure C-14: Scenario 4 (Full Restoration Leque 2) - Water-surface elevation, salinity, velocity magnitude, and bed shear stress at Leque Island restoration station L1, full bank conditions at 26,508 cfs river flow (tides and wind corresponding to October 2005) 


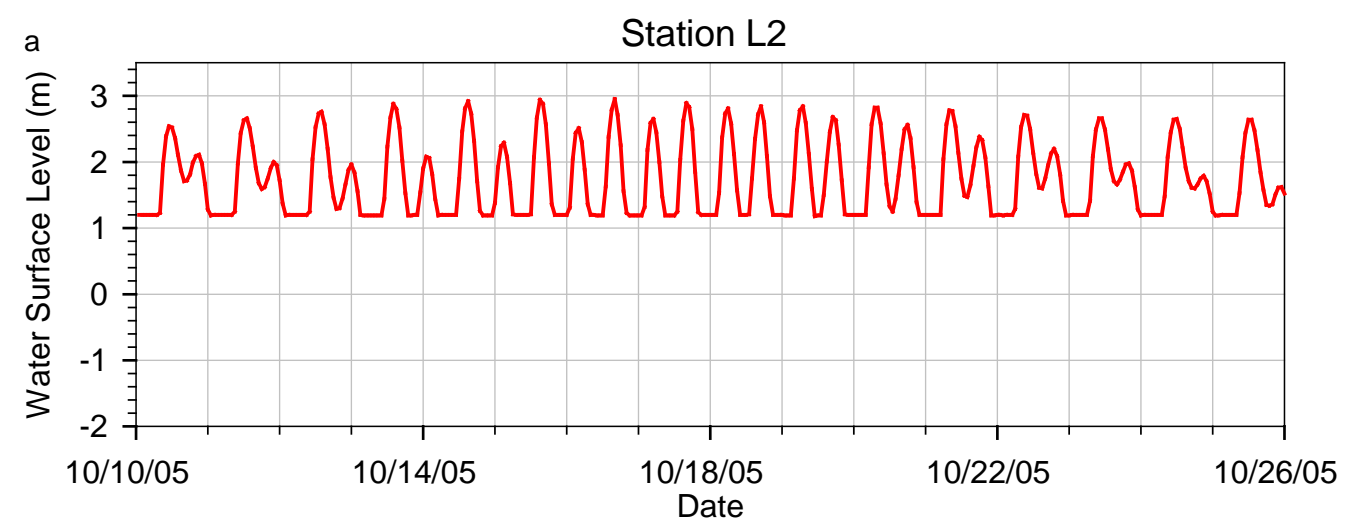

b
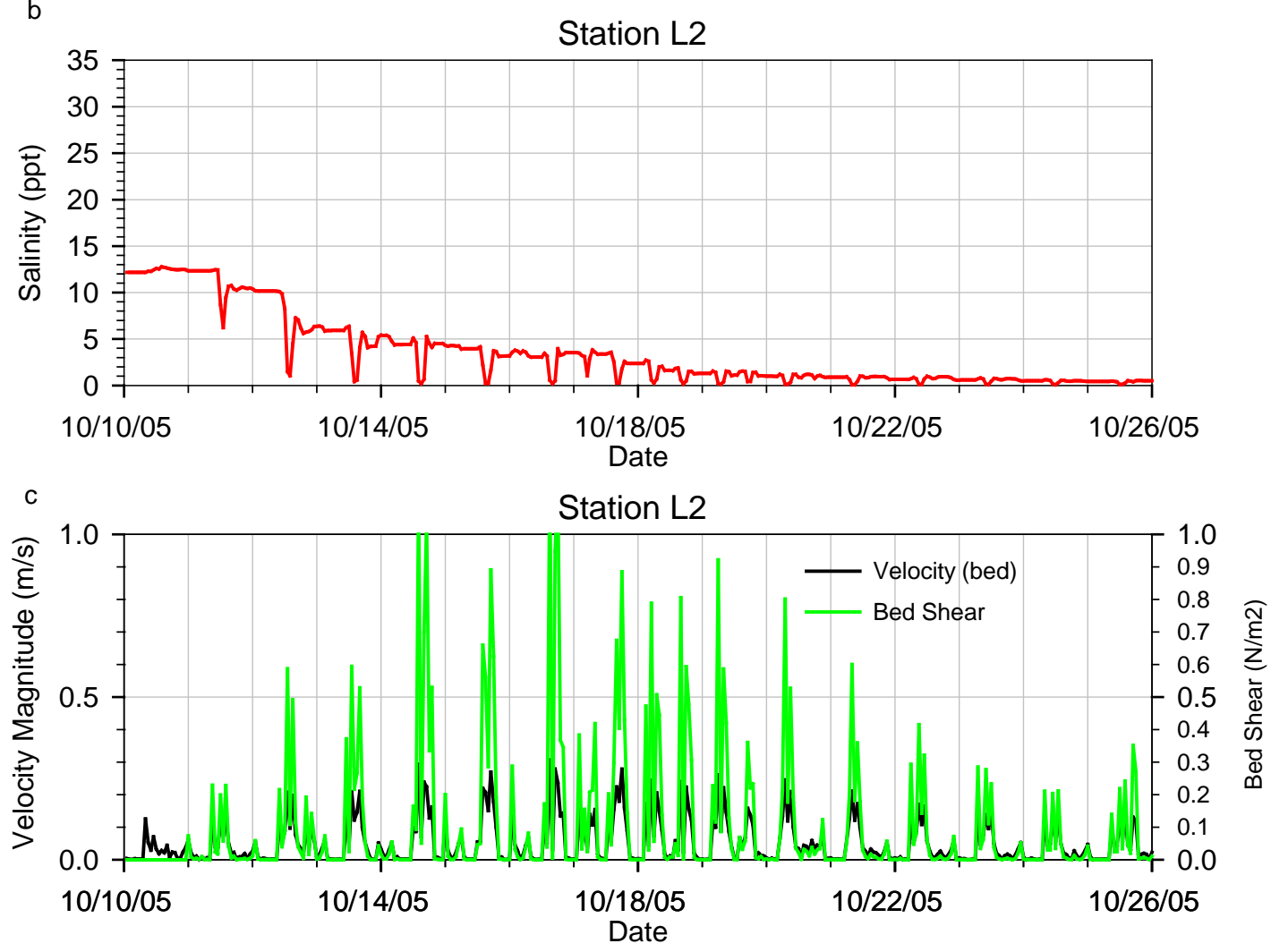

Figure C-15: Scenario 4 (Full Restoration Leque 2) - Water-surface elevation, salinity, velocity magnitude, and bed shear stress at Leque Island restoration station L2, full bank conditions at 26,508 cfs river flow (tides and wind corresponding to October 2005) 


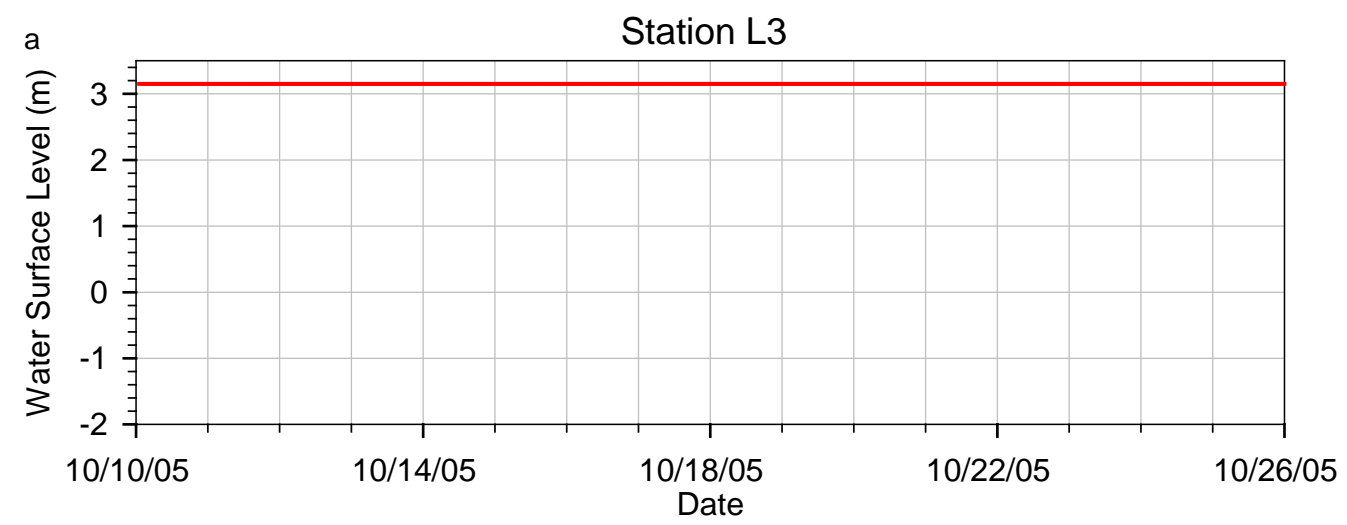

b
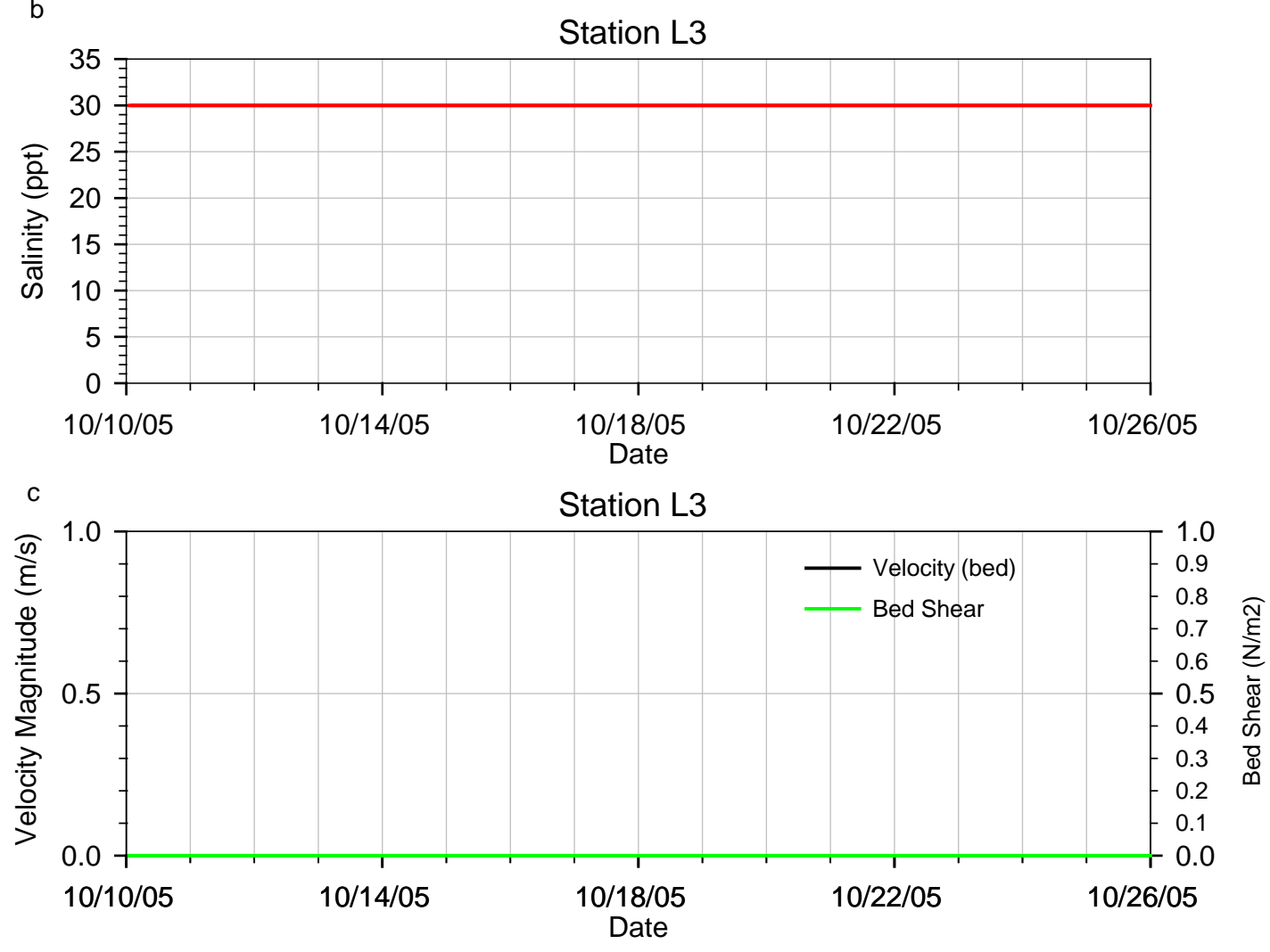

Figure C-16: Scenario 4 (Full Restoration Leque 2) - Water-surface elevation, salinity, velocity magnitude, and bed shear stress at Leque Island restoration station L3, full bank conditions at 26,508 cfs river flow (tides and wind corresponding to October 2005) 


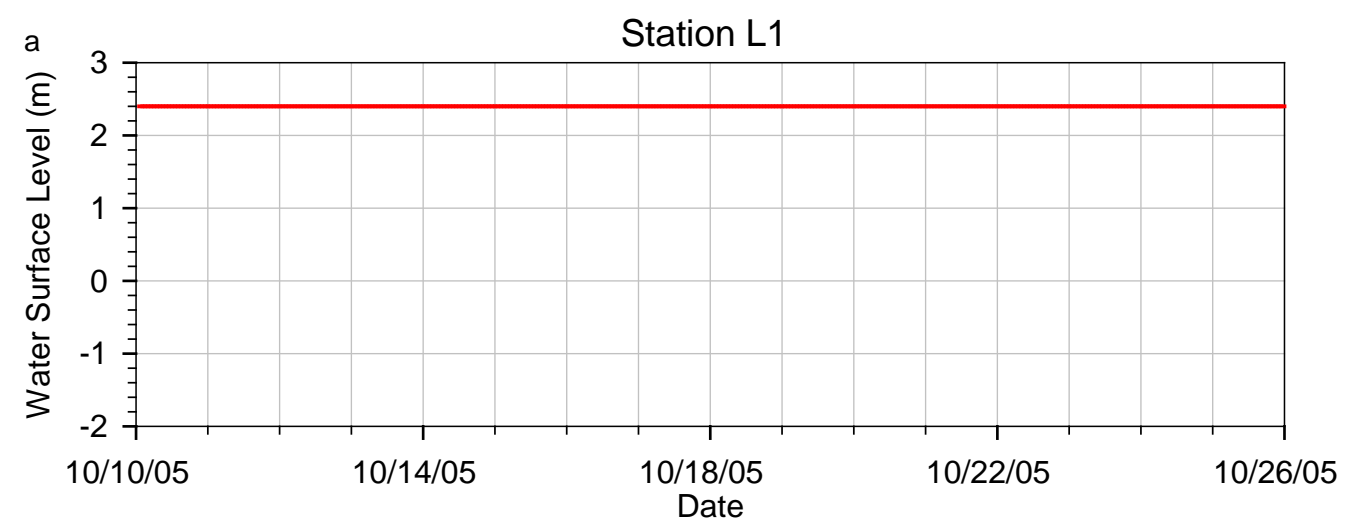

b
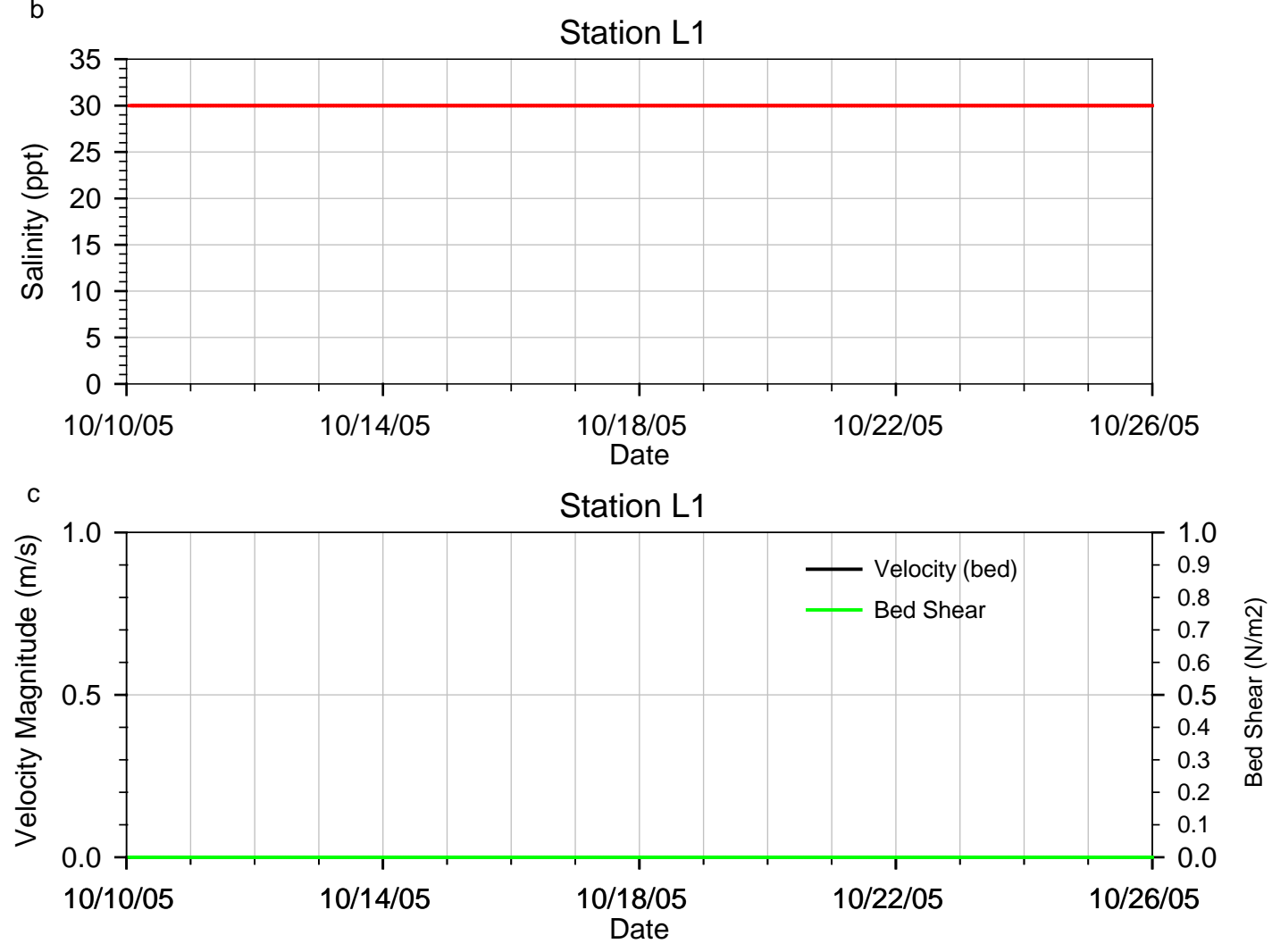

Figure C-17: Scenario 5 (Full Restoration zis a ba + SCN1) - Water-surface elevation, salinity, velocity magnitude, and bed shear stress at Leque Island restoration station L1, full bank conditions at 26,508 cfs river flow (tides and wind corresponding to October 2005) 

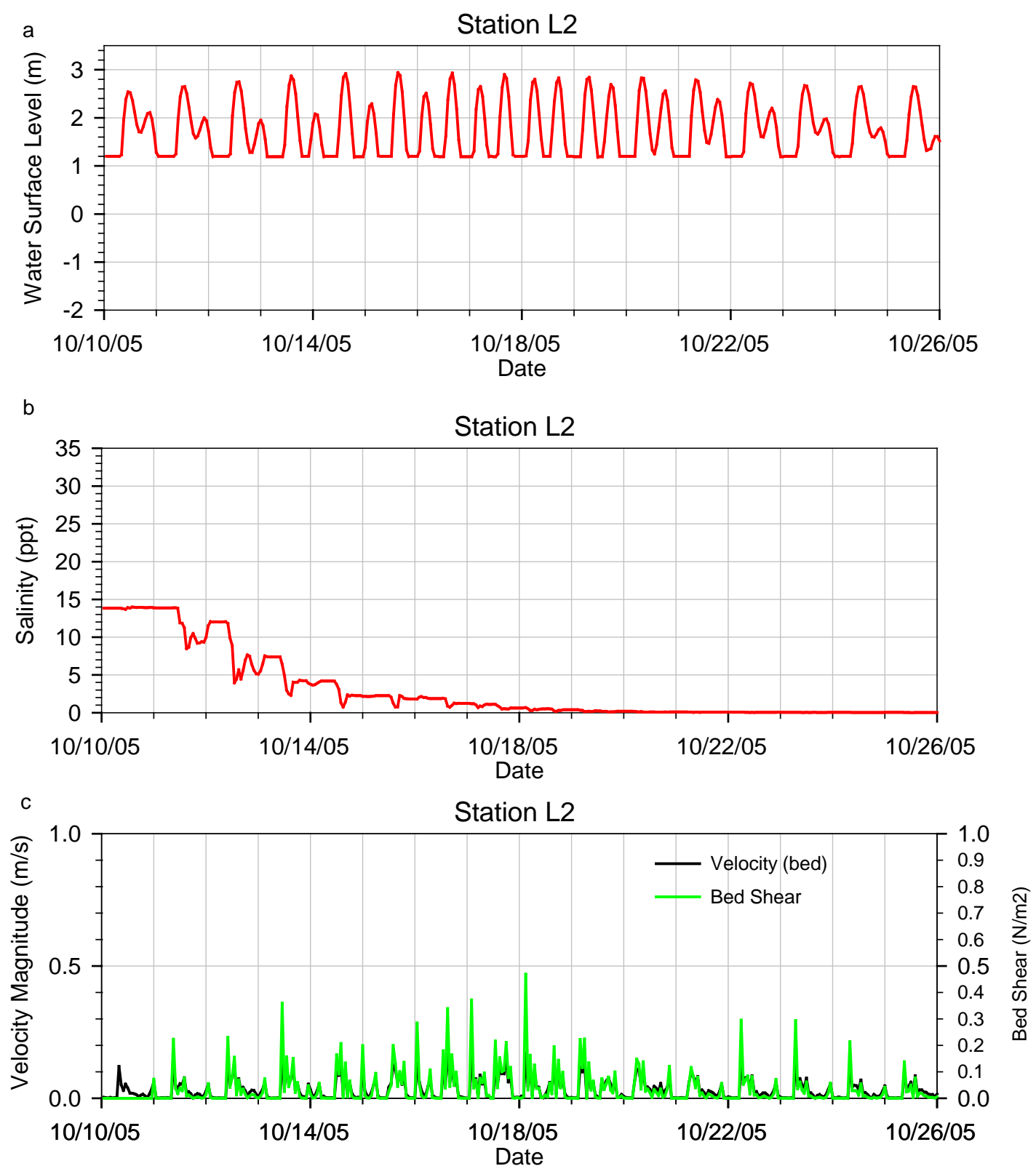

Figure C-18: Scenario 5 (Full Restoration zis a ba + SCN1) - Water-surface elevation, salinity, velocity magnitude, and bed shear stress at Leque Island restoration station L2, full bank conditions at 26,508 cfs river flow (tides and wind corresponding to October 2005) 


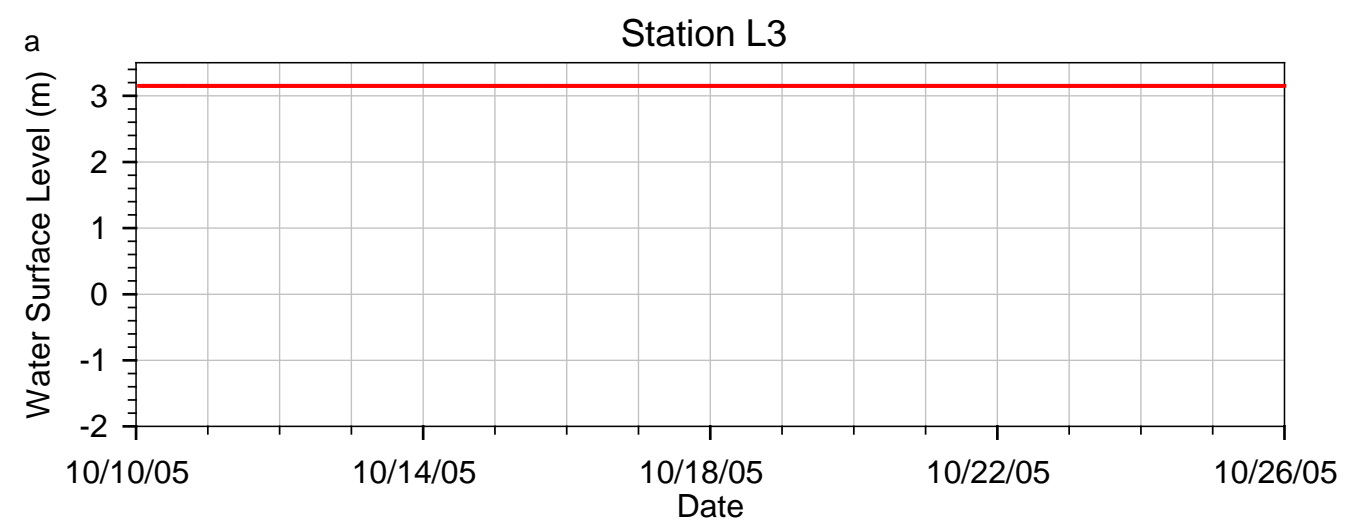

b
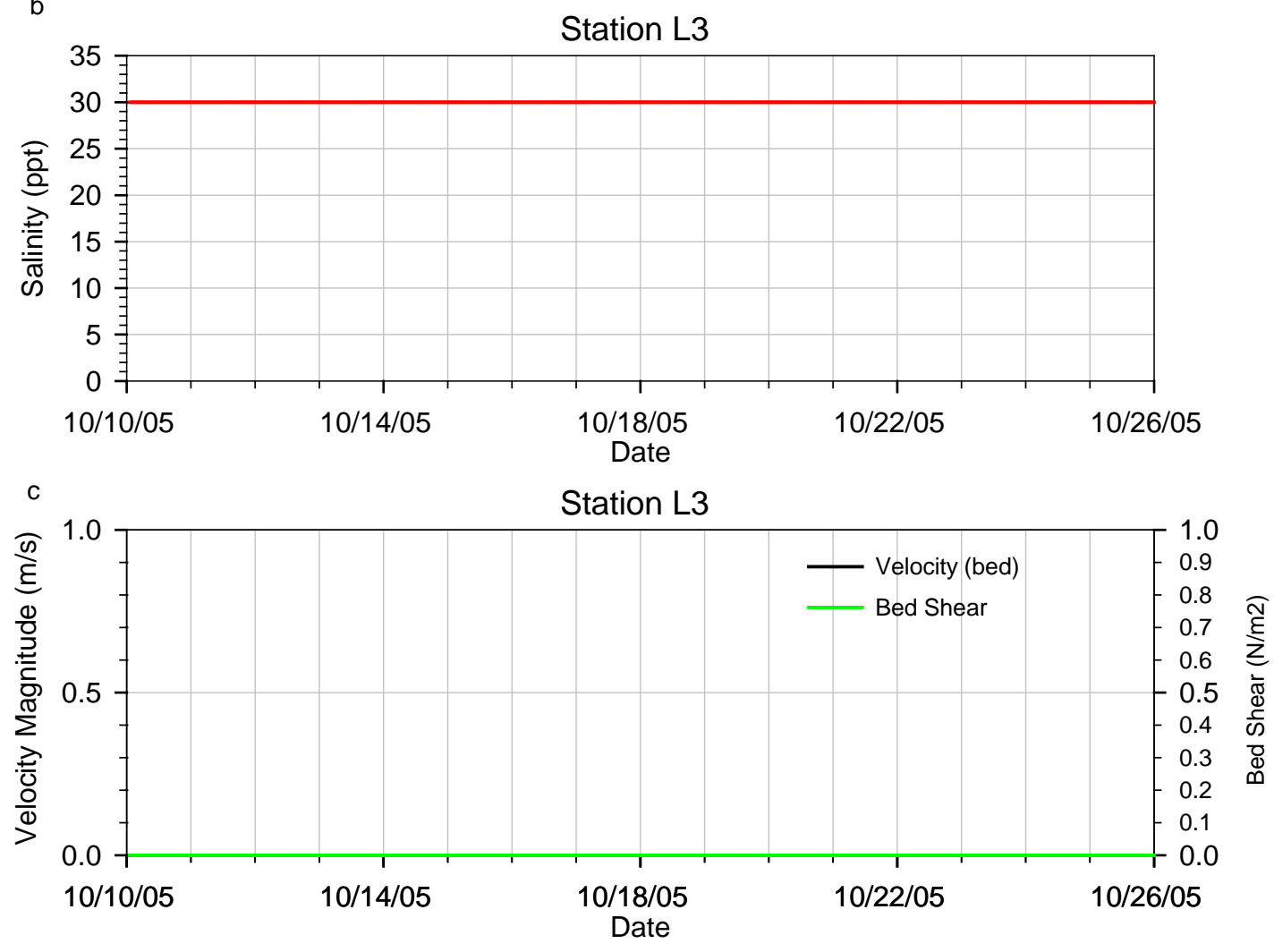

Figure C-19: Scenario 5 (Full Restoration zis a ba + SCN1) - Water-surface elevation, salinity, velocity magnitude, and bed shear stress at Leque Island restoration station L3, full bank conditions at 26,508 cfs river flow (tides and wind corresponding to October 2005) 

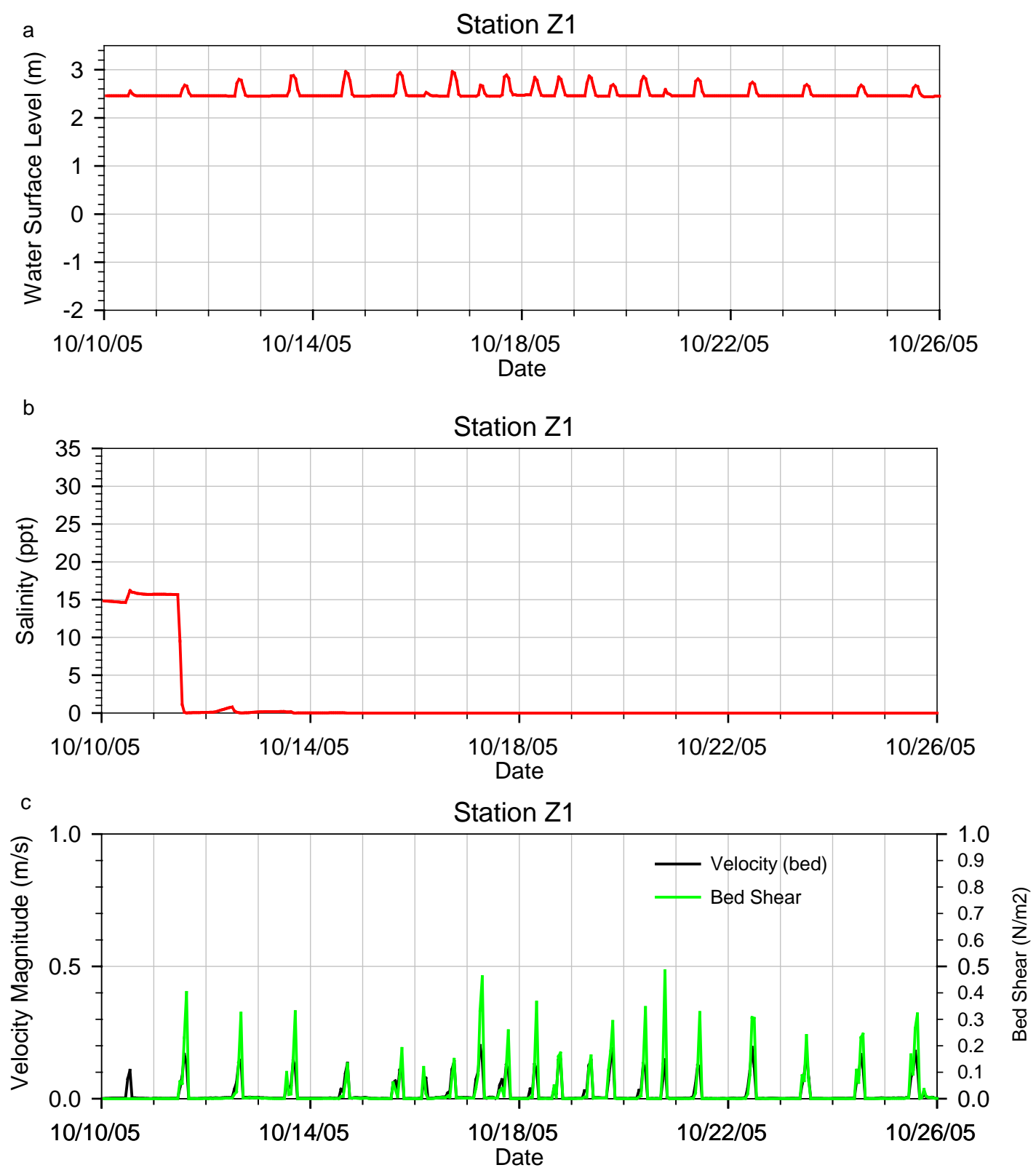

Figure C-20: Scenario 5 (Full Restoration zis a ba + SCN1) - Water-surface elevation, salinity, velocity magnitude, and bed shear stress at zis a ba restoration station Z1, full bank conditions at 26,508 cfs river flow (tides and wind corresponding to October 2005) 

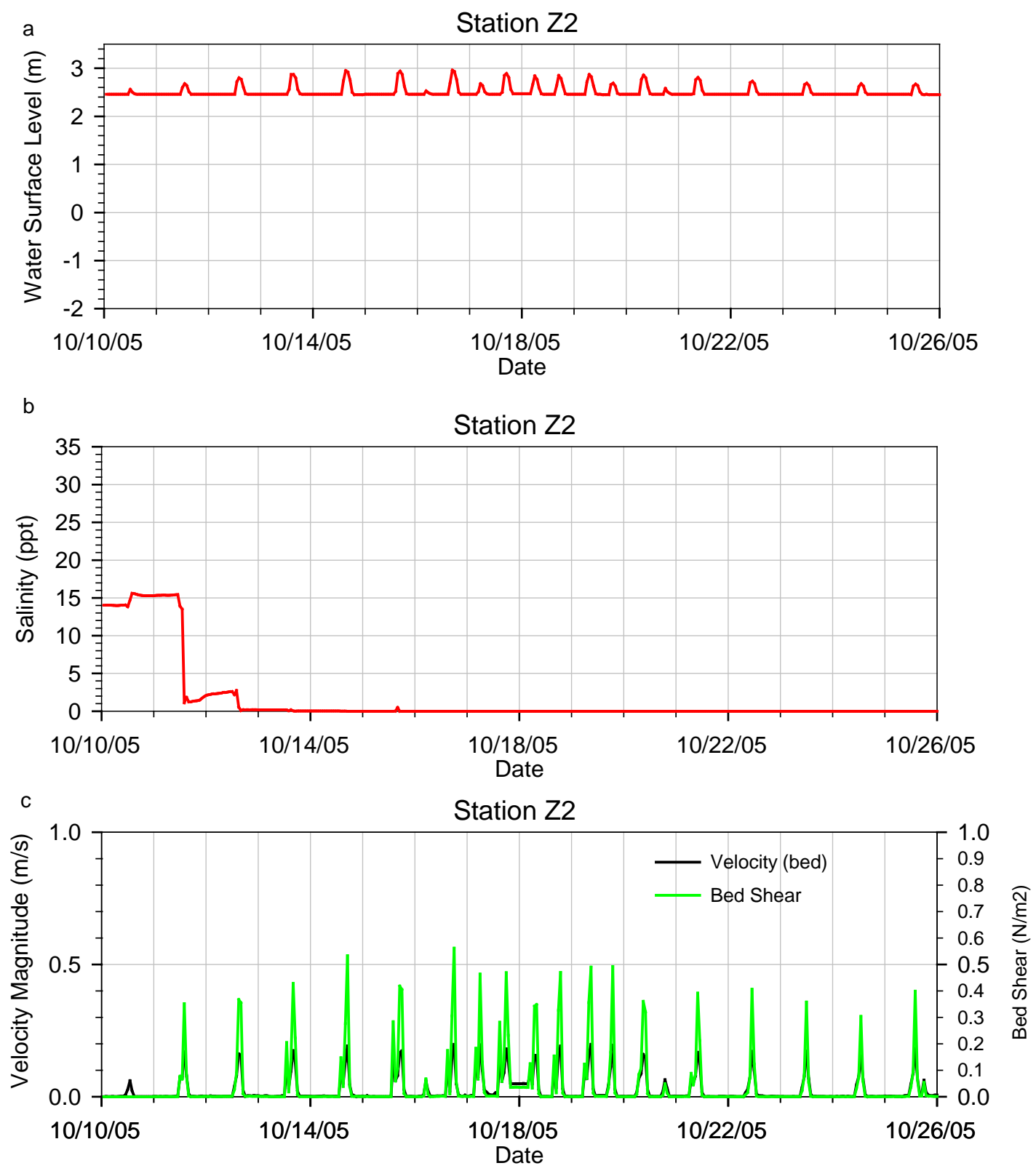

Figure C-21: Scenario 5 (Full Restoration zis a ba + SCN1) - Water-surface elevation, salinity, velocity magnitude, and bed shear stress at zis a ba restoration station Z2, full bank conditions at 26,508 cfs river flow (tides and wind corresponding to October 2005) 

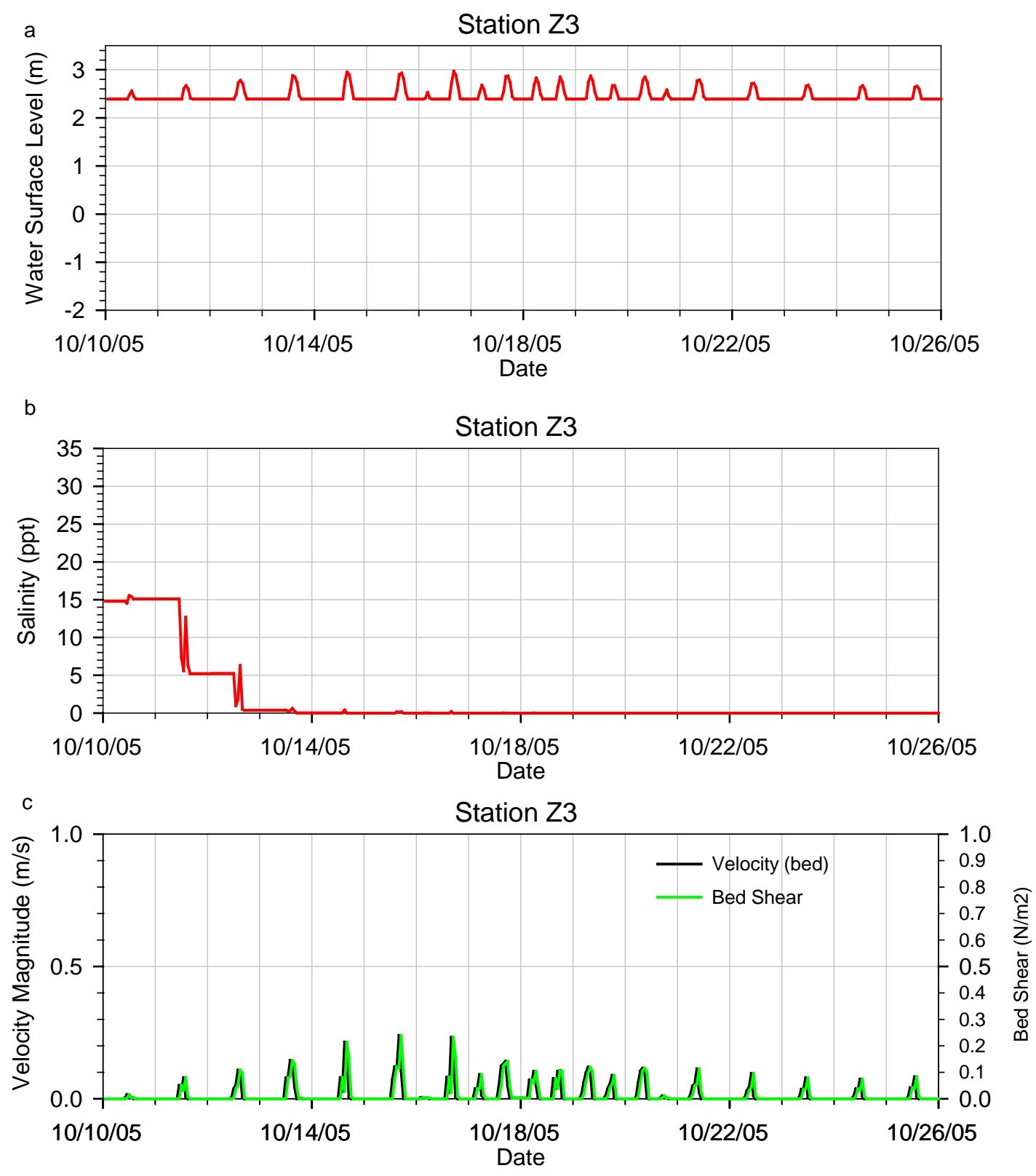

Figure C-22: Scenario 5 (Full Restoration zis a ba + SCN1) - Water-surface elevation, salinity, velocity magnitude, and bed shear stress at zis a ba restoration station Z3, full bank conditions at 26,508 cfs river flow (tides and wind corresponding to October 2005) 


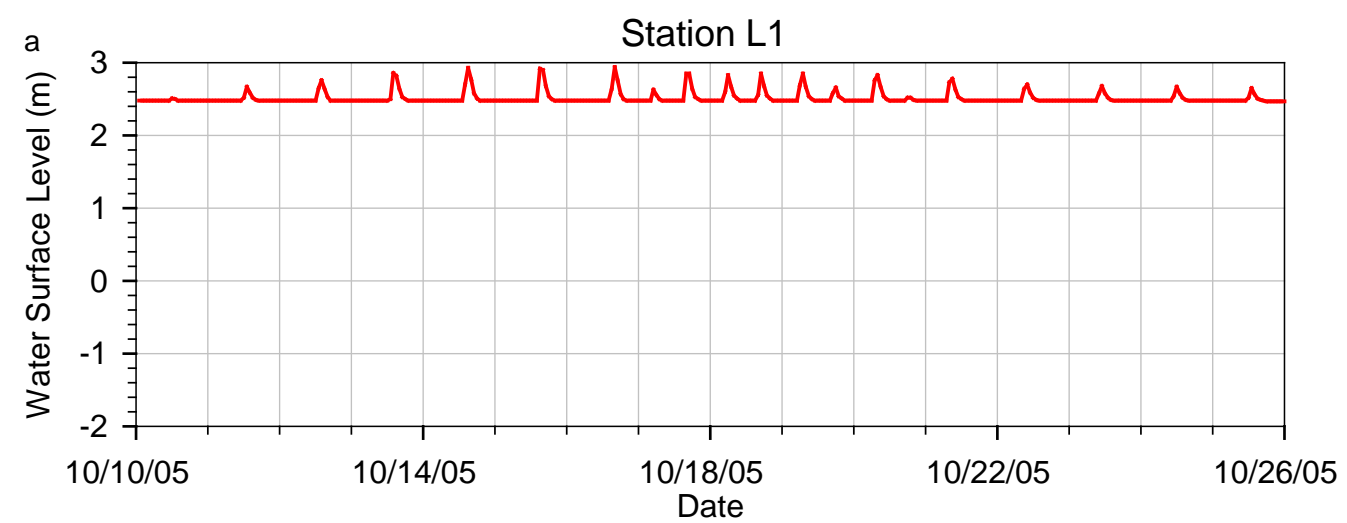

b
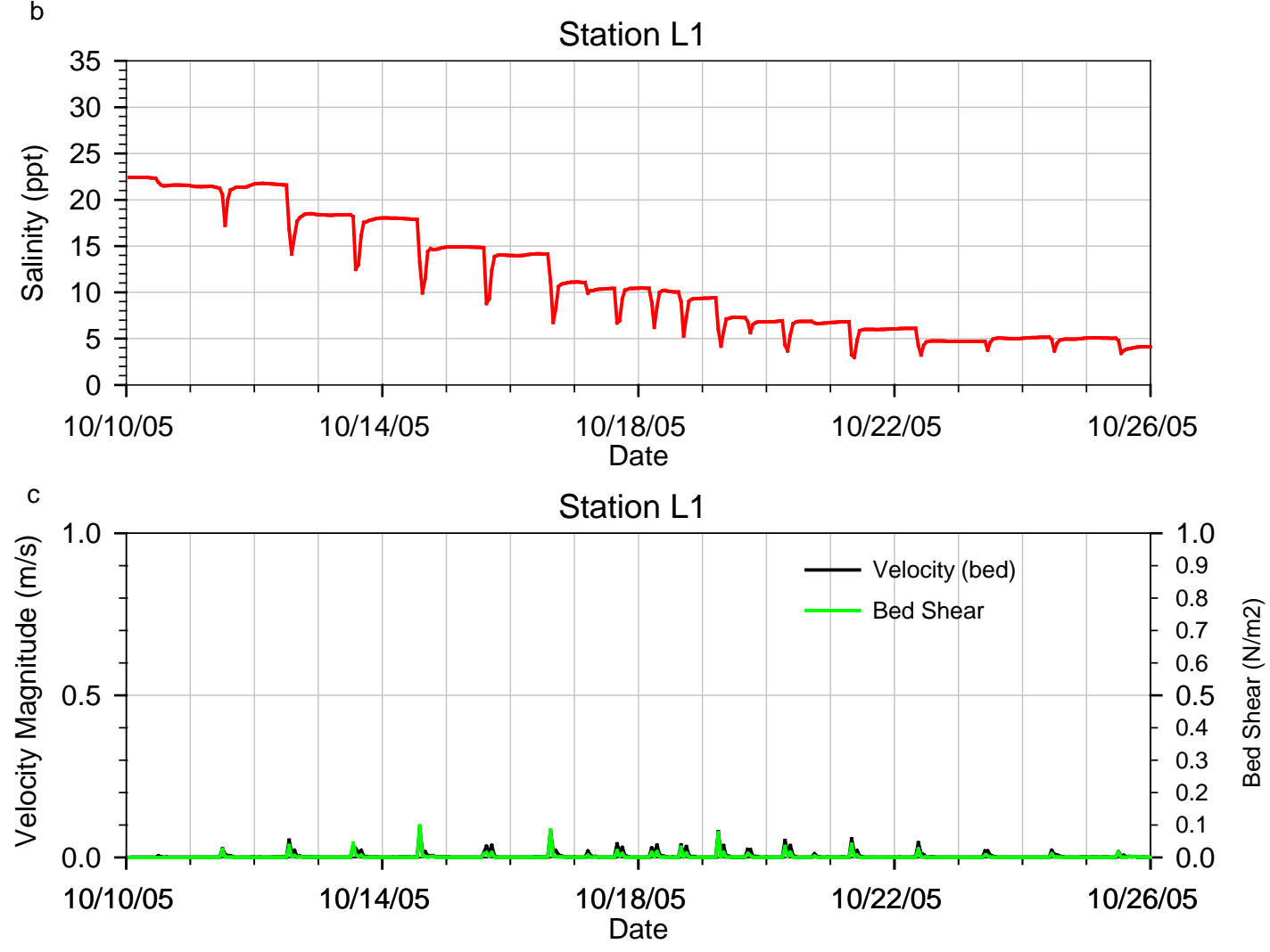

Figure C-23: Scenario 6 (Full Restoration zis a ba + SCN4) - Water-surface elevation, salinity, velocity magnitude, and bed shear stress at Leque Island restoration station L1, full bank conditions at 26,508 cfs river flow (tides and wind corresponding to October 2005) 


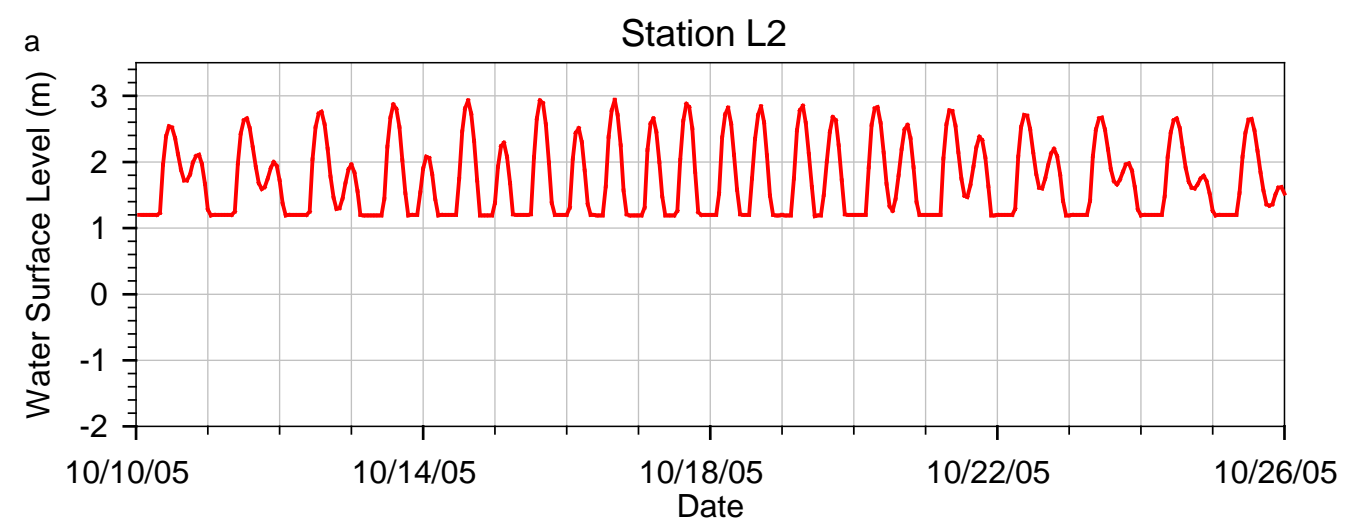

b
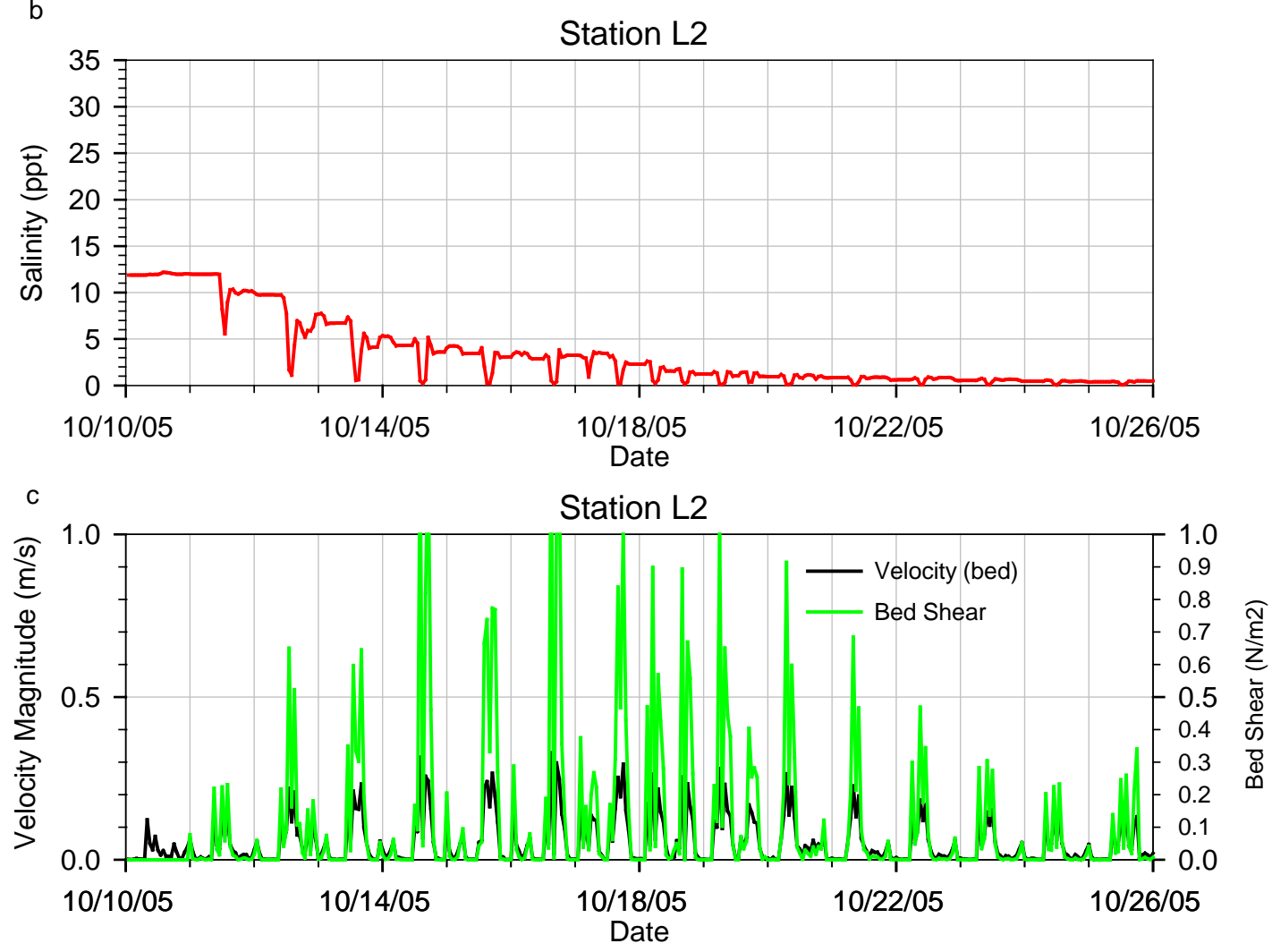

Figure C-24: Scenario 6 (Full Restoration zis a ba + SCN4) - Water-surface elevation, salinity, velocity magnitude, and bed shear stress at Leque Island restoration station L2, full bank conditions at 26,508 cfs river flow (tides and wind corresponding to October 2005) 


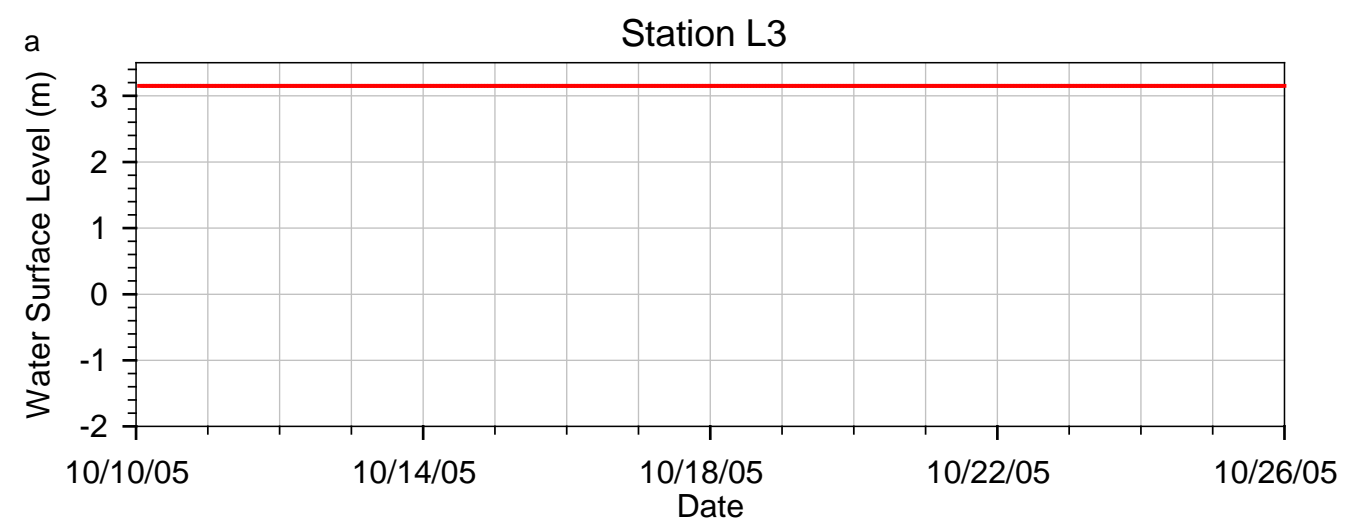

b
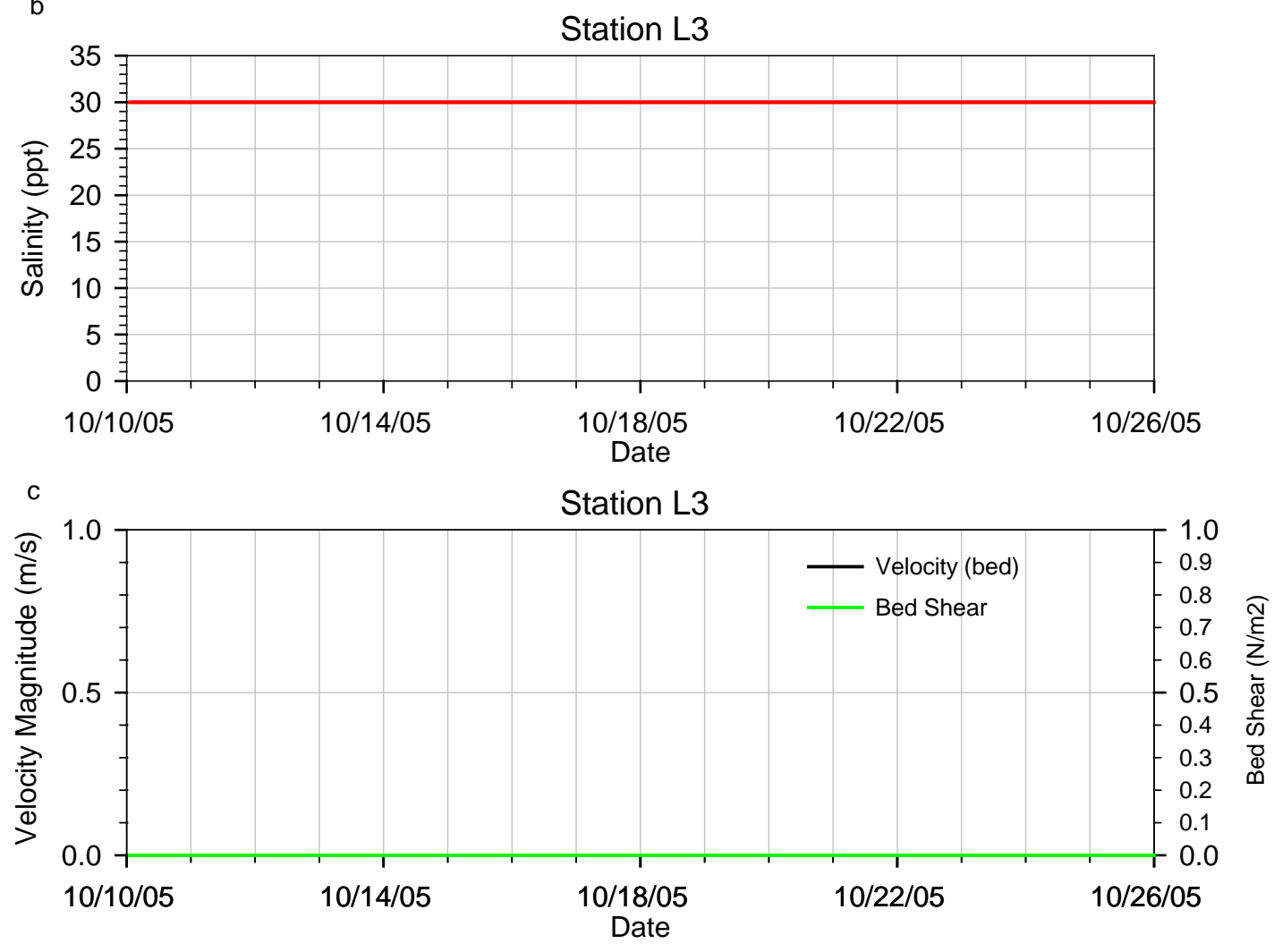

Figure C-25: Scenario 6 (Full Restoration zis a ba + SCN4) - Water-surface elevation, salinity, velocity magnitude, and bed shear stress at Leque Island restoration station L3, full bank conditions at 26,508 cfs river flow (tides and wind corresponding to October 2005) 

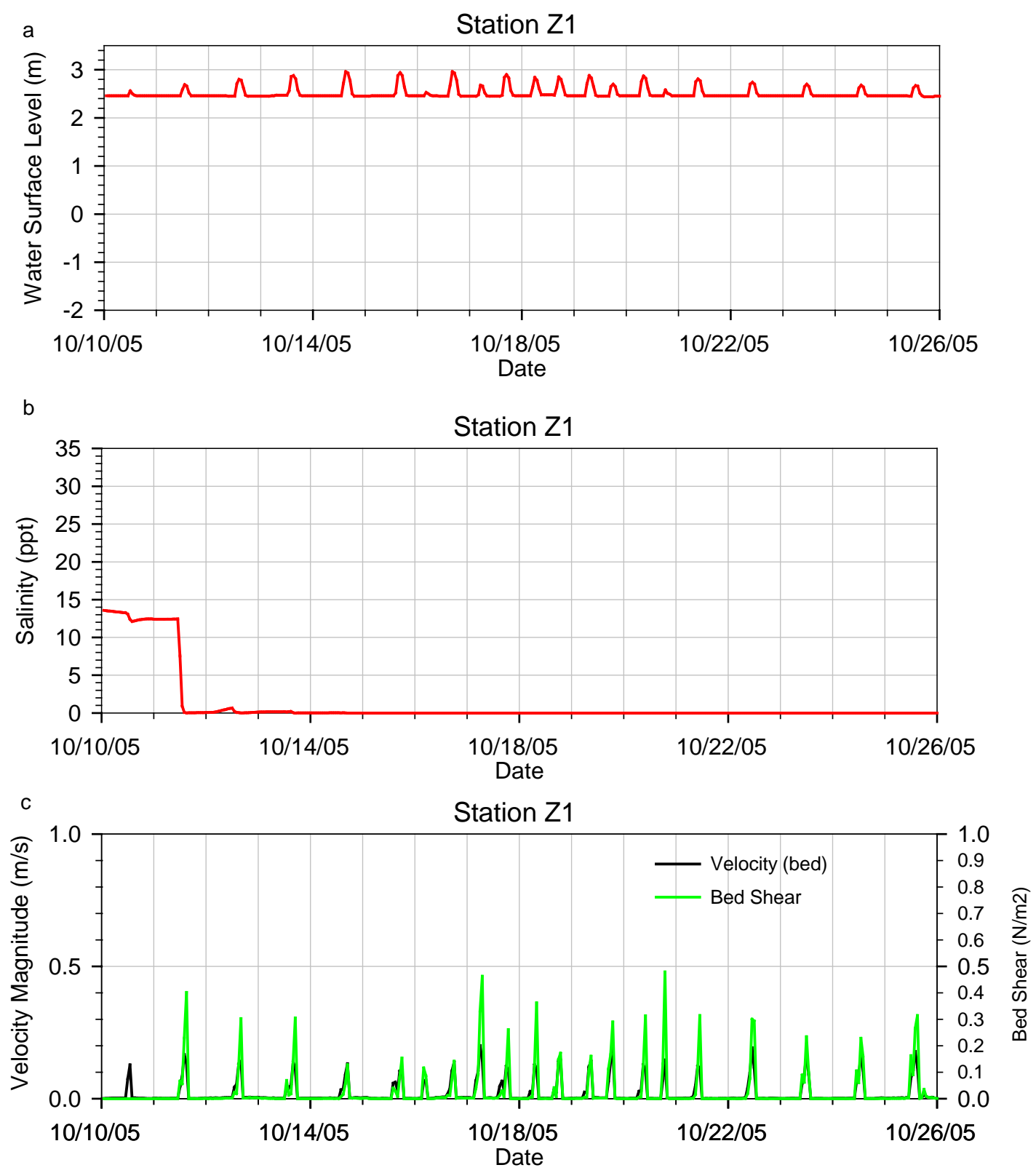

Figure C-26: Scenario 6 (Full Restoration zis a ba + SCN4) - Water-surface elevation, salinity, velocity magnitude, and bed shear stress at zis a ba restoration station Z1, full bank conditions at 26,508 cfs river flow (tides and wind corresponding to October 2005) 

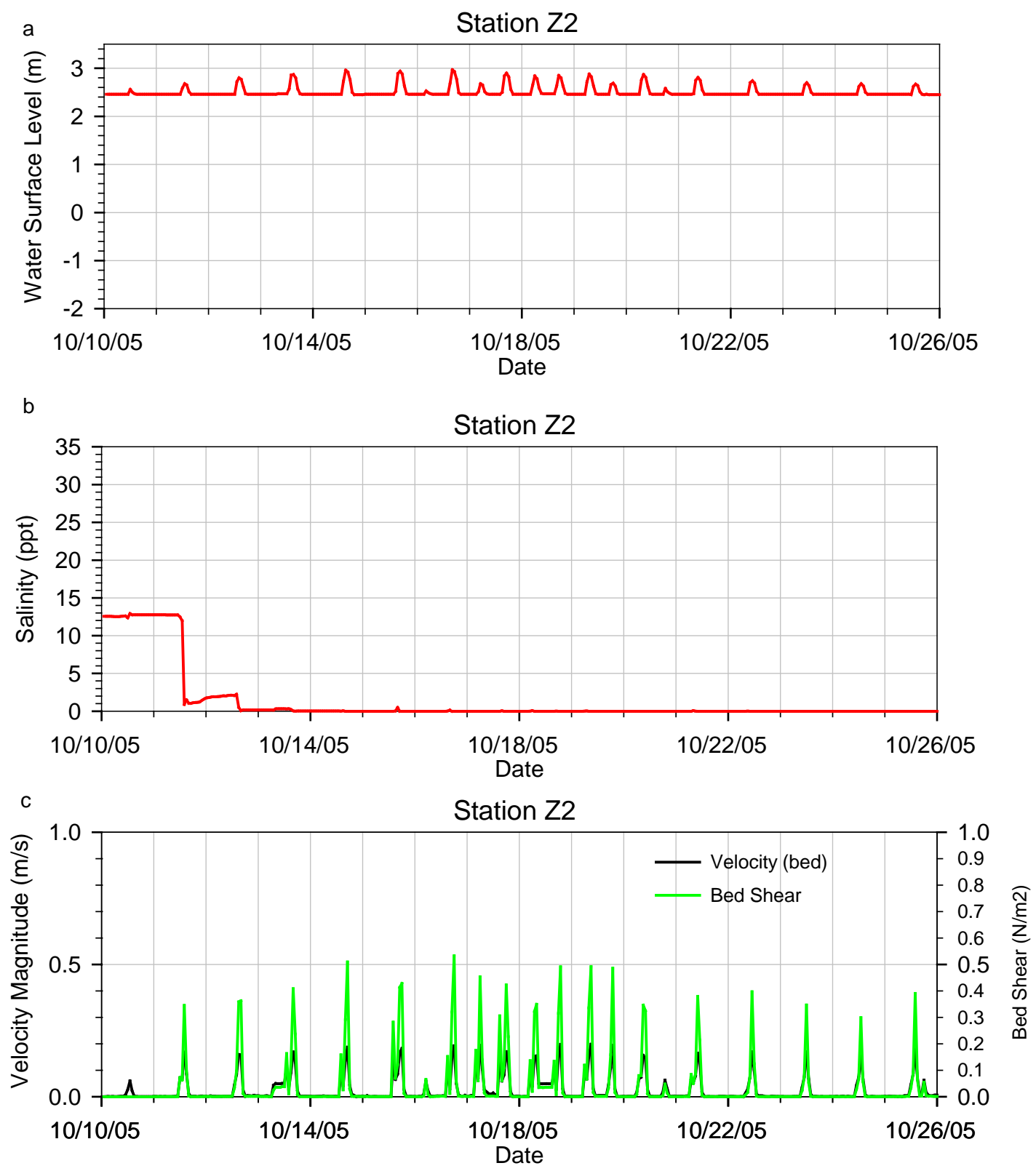

Figure C-27: Scenario 6 (Full Restoration zis a ba + SCN4) - Water-surface elevation, salinity, velocity magnitude, and bed shear stress at zis a ba restoration station Z2, full bank conditions at 26,508 cfs river flow (tides and wind corresponding to October 2005) 

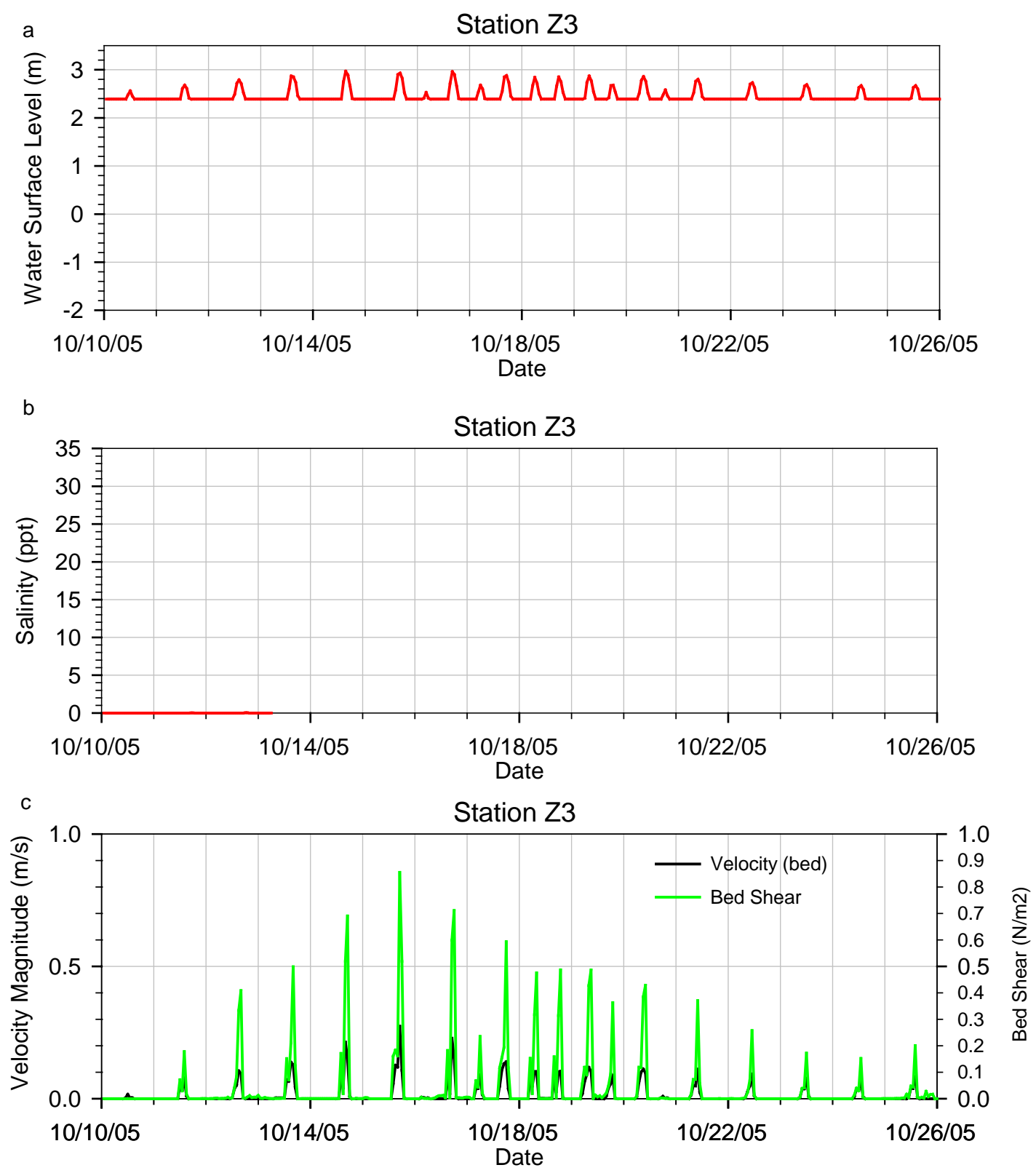

Figure C-28: Scenario 6 (Full Restoration zis a ba + SCN4) - Water-surface elevation, salinity, velocity magnitude, and bed shear stress at zis a ba restoration station Z3, full bank conditions at 26,508 cfs river flow (tides and wind corresponding to October 2005) 

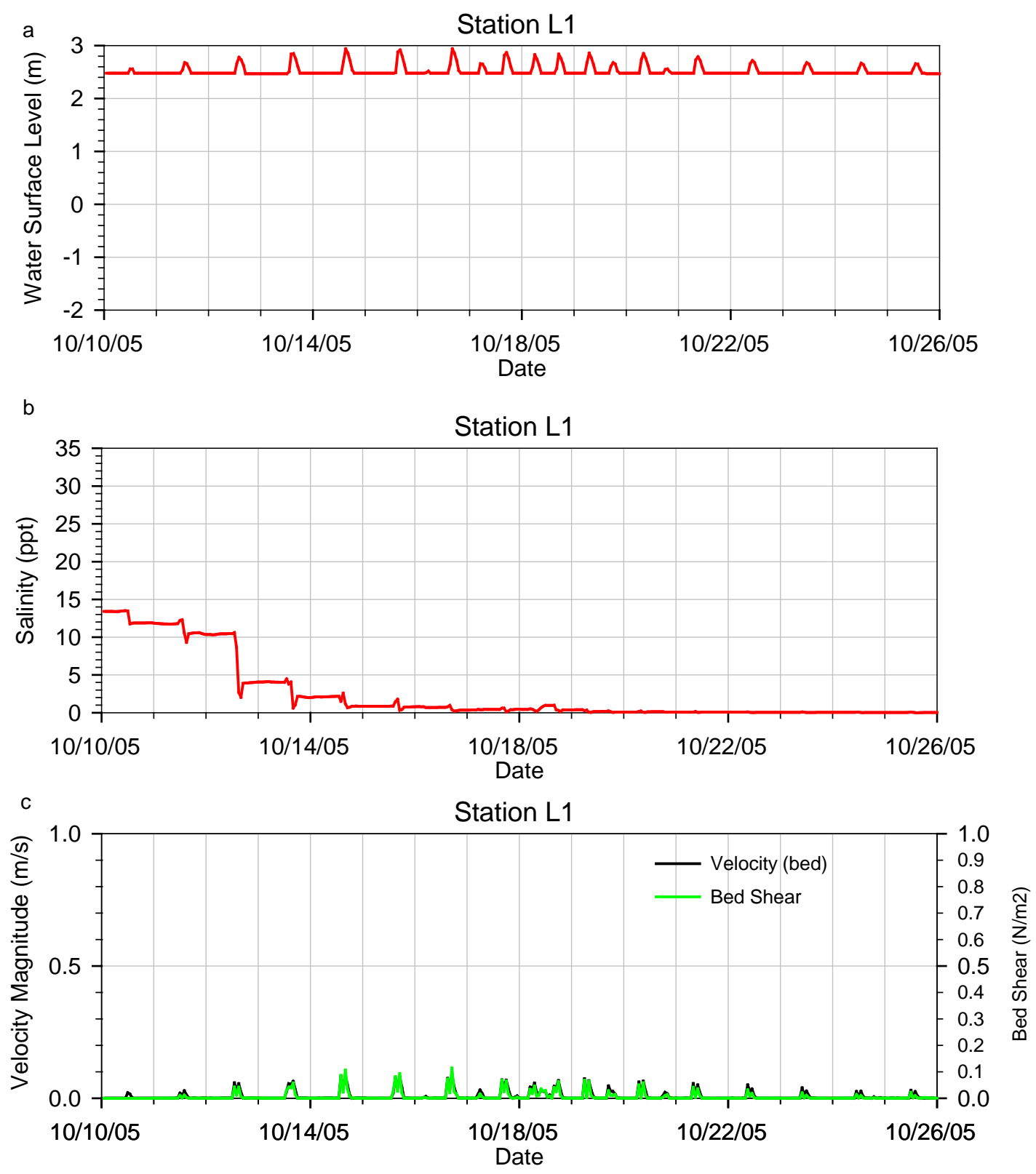

Figure C-29: Scenario 7 (Full Restoration zis a ba + SCN3) - Water-surface elevation, salinity, velocity magnitude, and bed shear stress at Leque Island restoration station L1, full bank conditions at 26,508 cfs river flow (tides and wind corresponding to October 2005) 


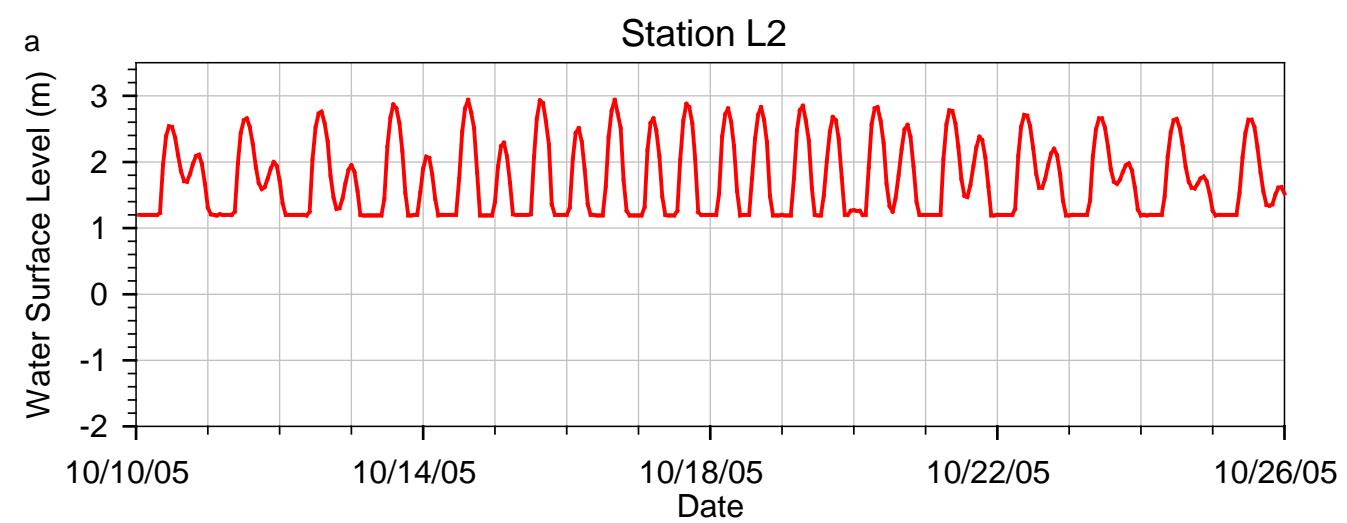

b
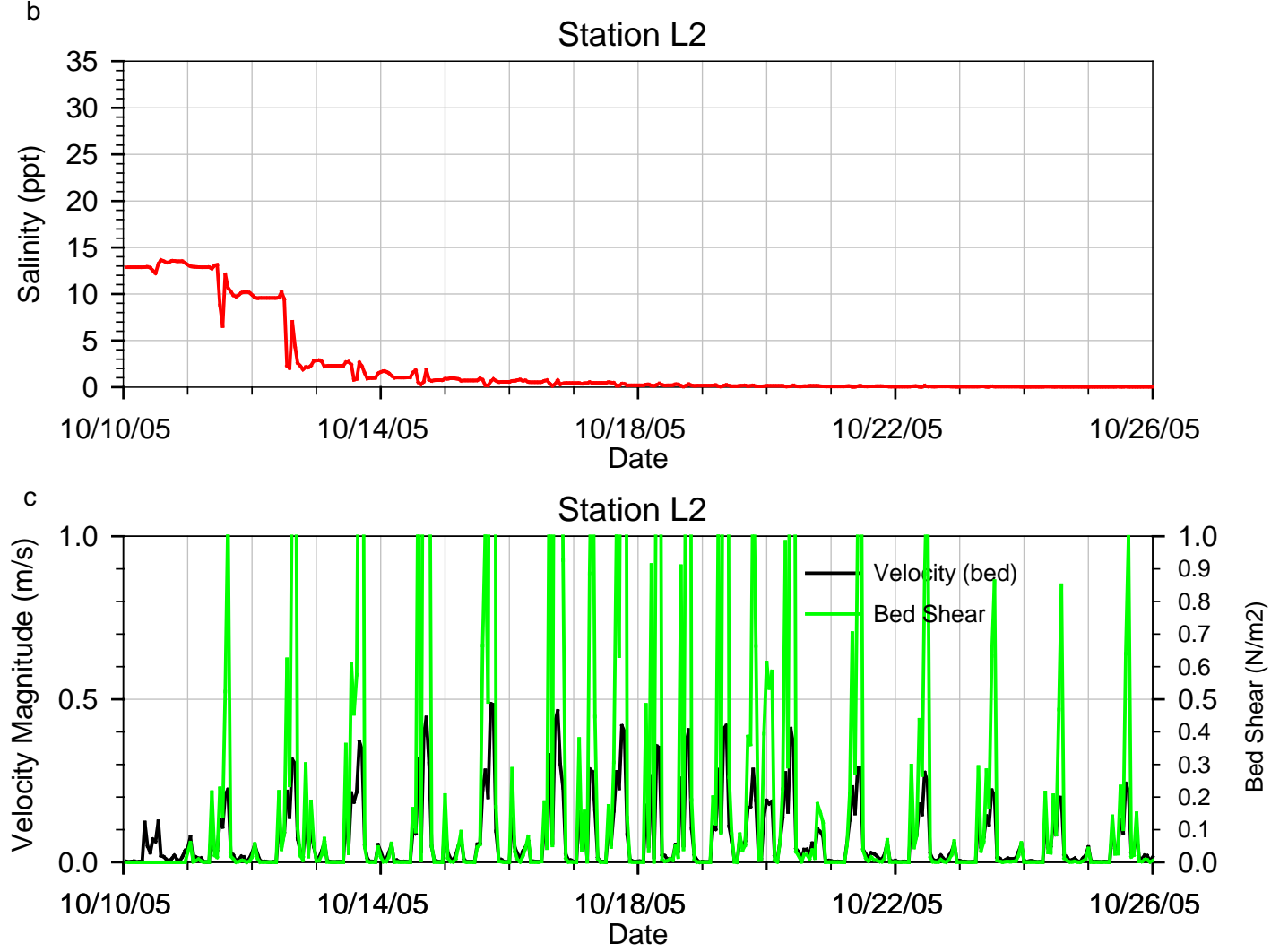

Figure C-30: Scenario 7 (Full Restoration zis a ba + SCN3) - Water-surface elevation, salinity, velocity magnitude, and bed shear stress at Leque Island restoration station L2, full bank conditions at 26,508 cfs river flow (tides and wind corresponding to October 2005) 


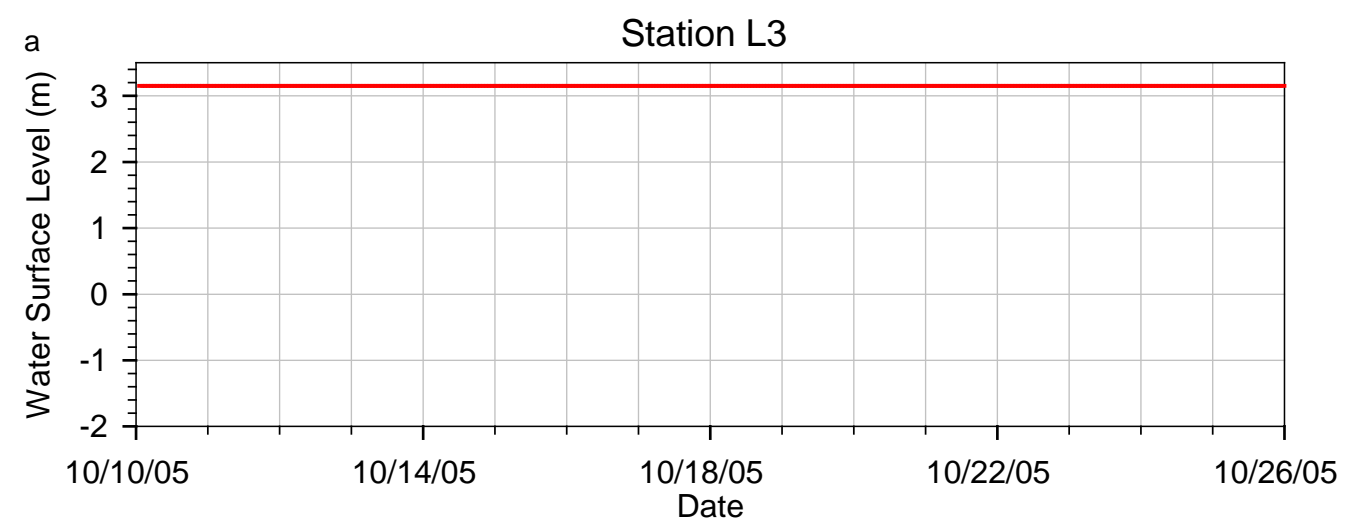

b
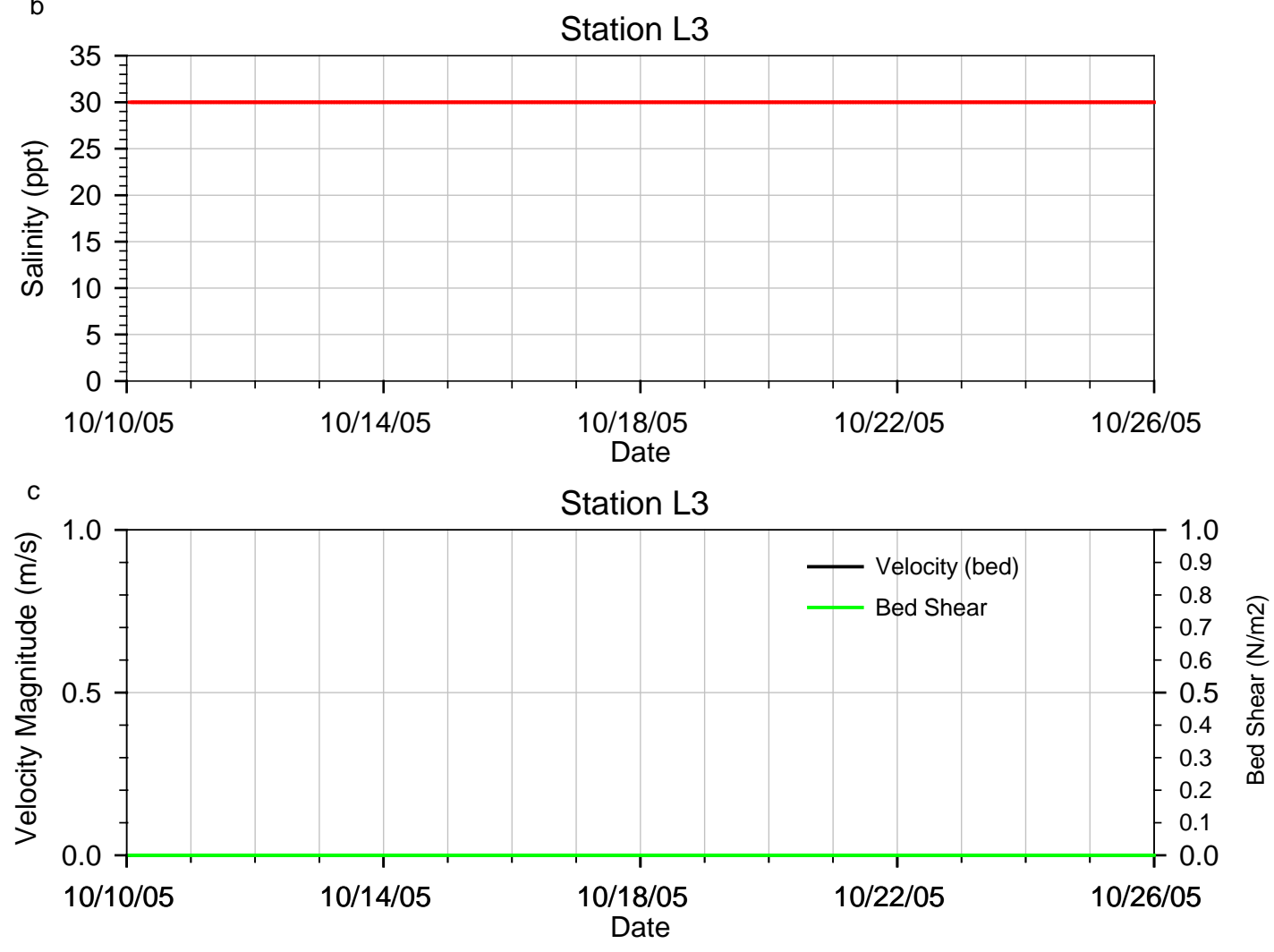

Figure C-31: Scenario 7 (Full Restoration zis a ba + SCN3) - Water-surface elevation, salinity, velocity magnitude, and bed shear stress at Leque Island restoration station L3, full bank conditions at 26,508 cfs river flow (tides and wind corresponding to October 2005) 

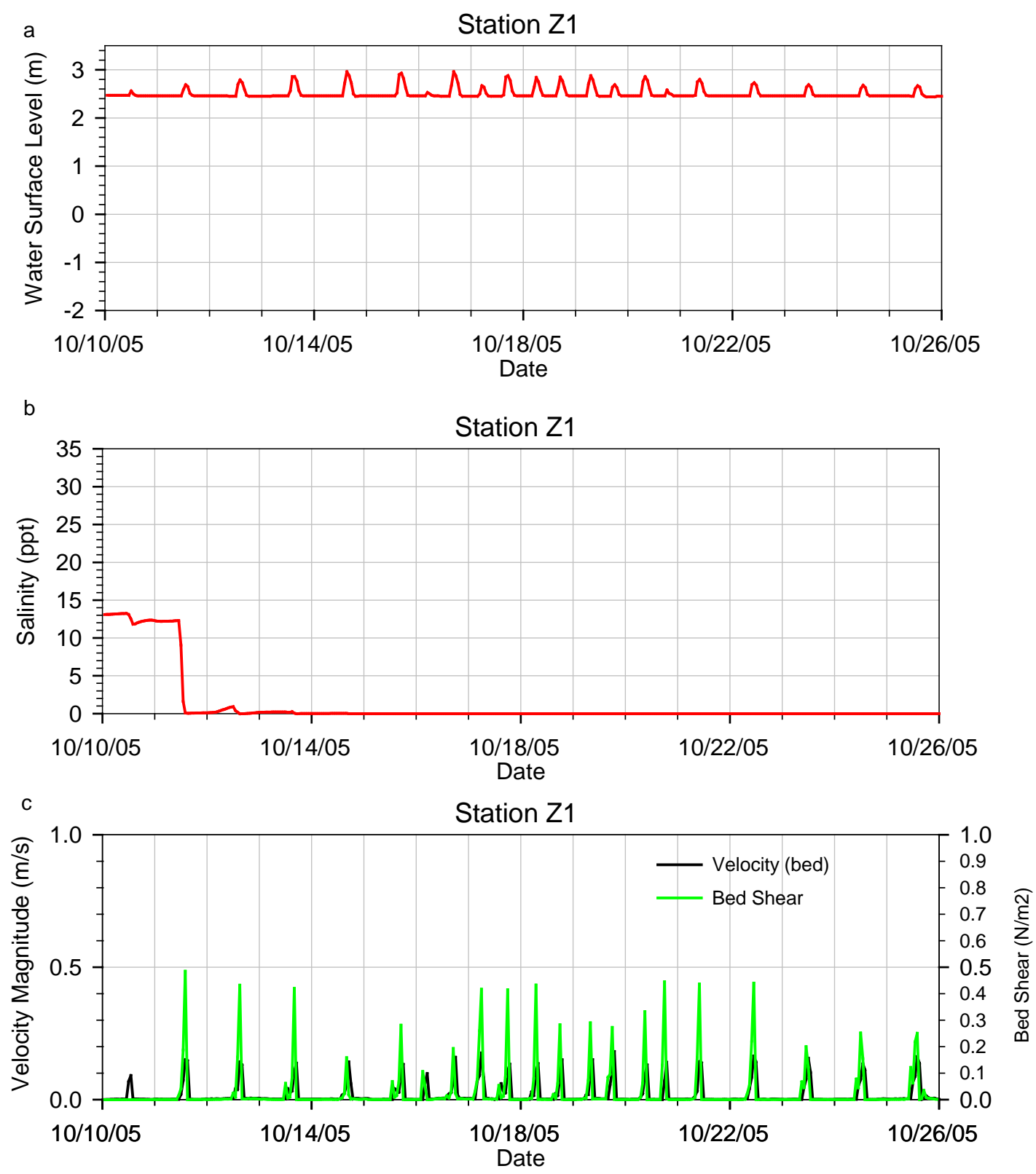

Figure C-32: Scenario 7 (Full Restoration zis a ba + SCN3) - Water-surface elevation, salinity, velocity magnitude, and bed shear stress at zis a ba restoration station Z1, full bank conditions at 26,508 cfs river flow (tides and wind corresponding to October 2005) 

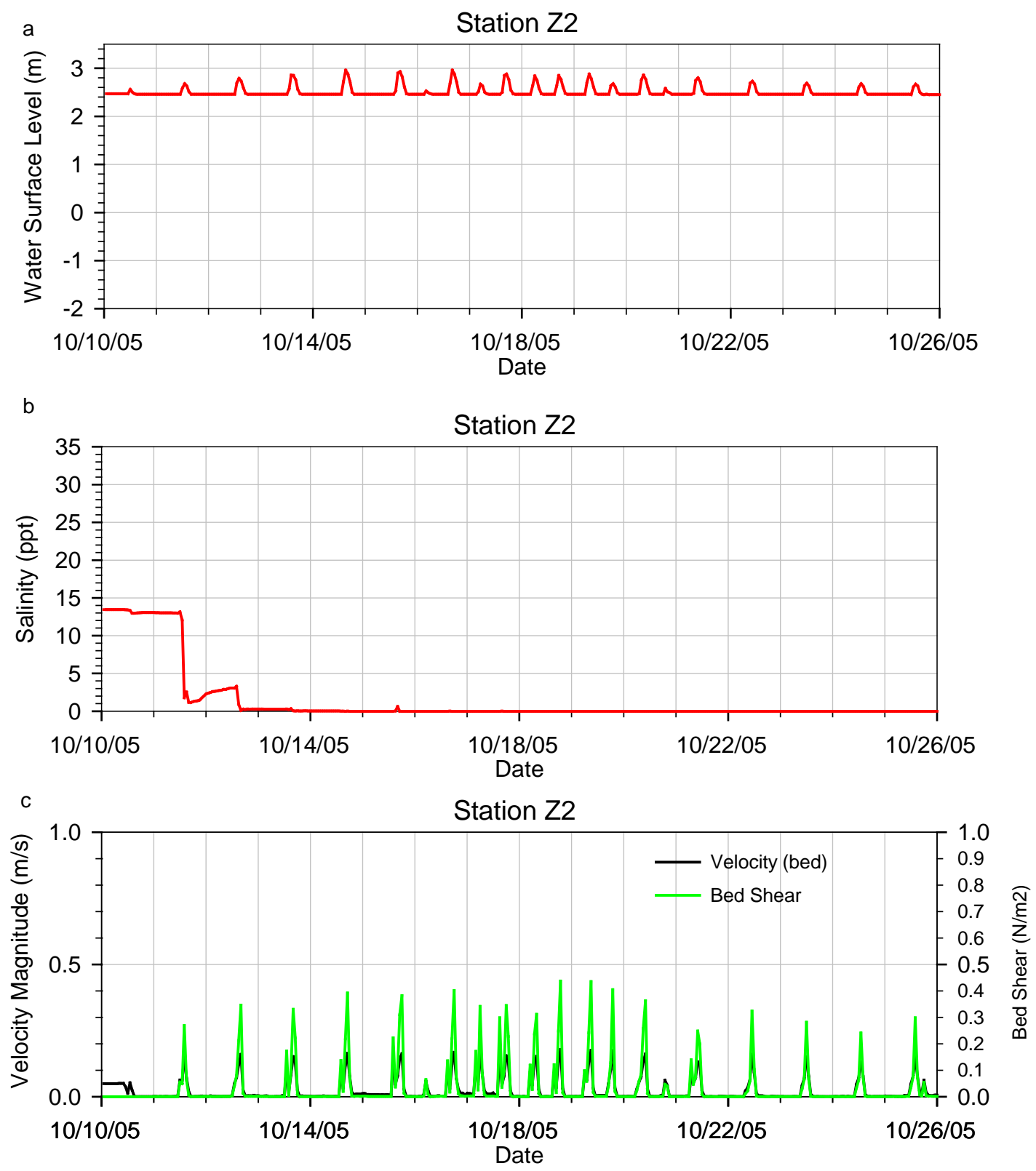

Figure C-33: Scenario 7 (Full Restoration zis a ba + SCN3) - Water-surface elevation, salinity, velocity magnitude, and bed shear stress at zis a ba restoration station Z2, full bank conditions at 26,508 cfs river flow (tides and wind corresponding to October 2005) 

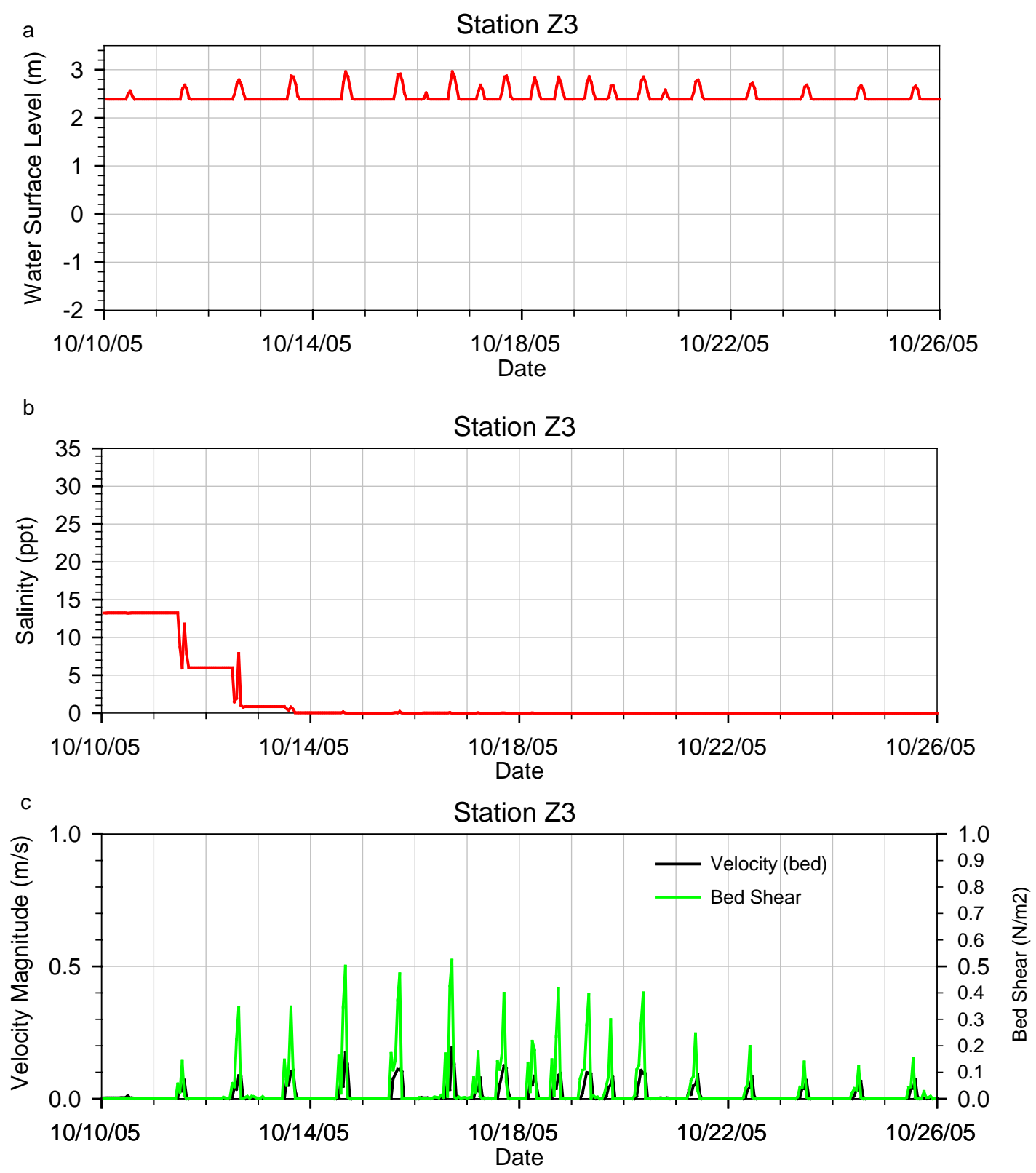

Figure C-34: Scenario 7 (Full Restoration zis a ba + SCN3) - Water-surface elevation, salinity, velocity magnitude, and bed shear stress at zis a ba restoration station Z3, full bank conditions at 26,508 cfs river flow (tides and wind corresponding to October 2005) 


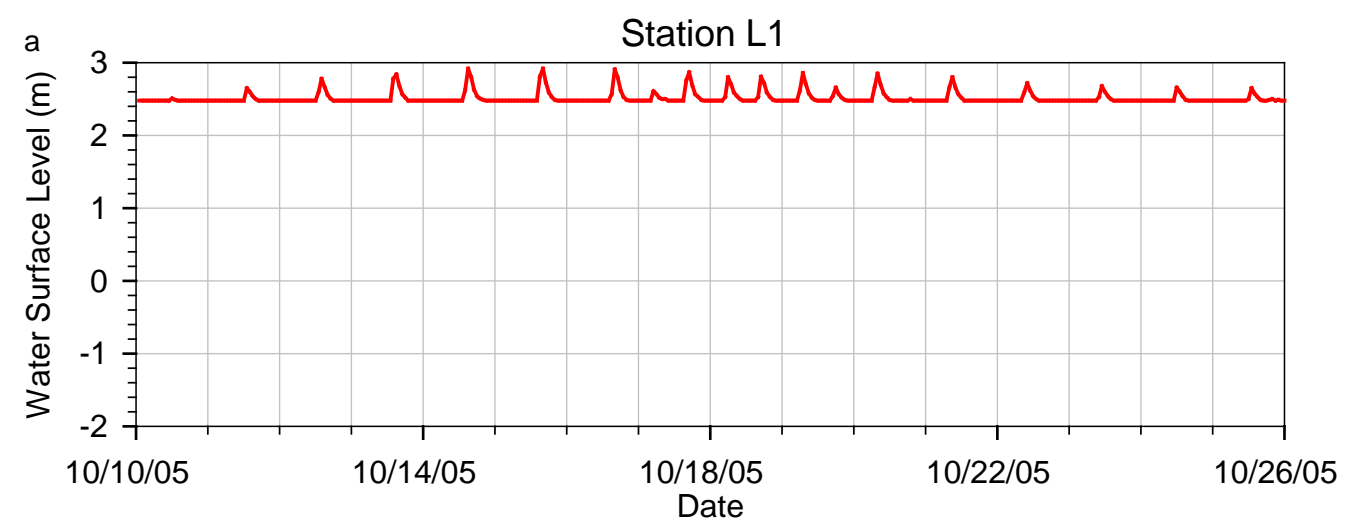

b
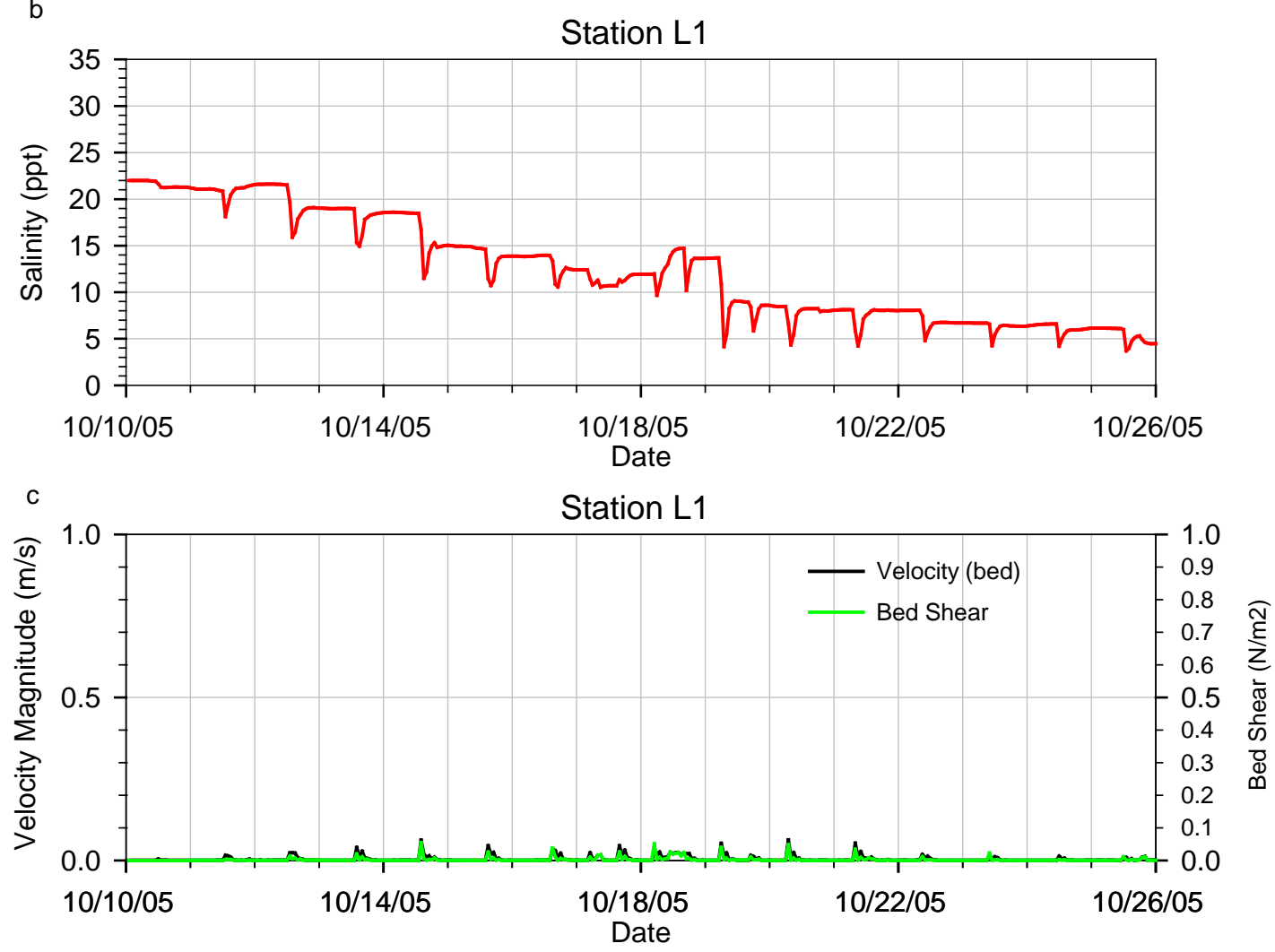

Figure C-35: Scenario 8 (3 Levee Breaches Leque) - Water-surface elevation, salinity, velocity magnitude, and bed shear stress at Leque Island restoration station L1, full bank conditions at 26,508 cfs river flow (tides and wind corresponding to October 2005) 


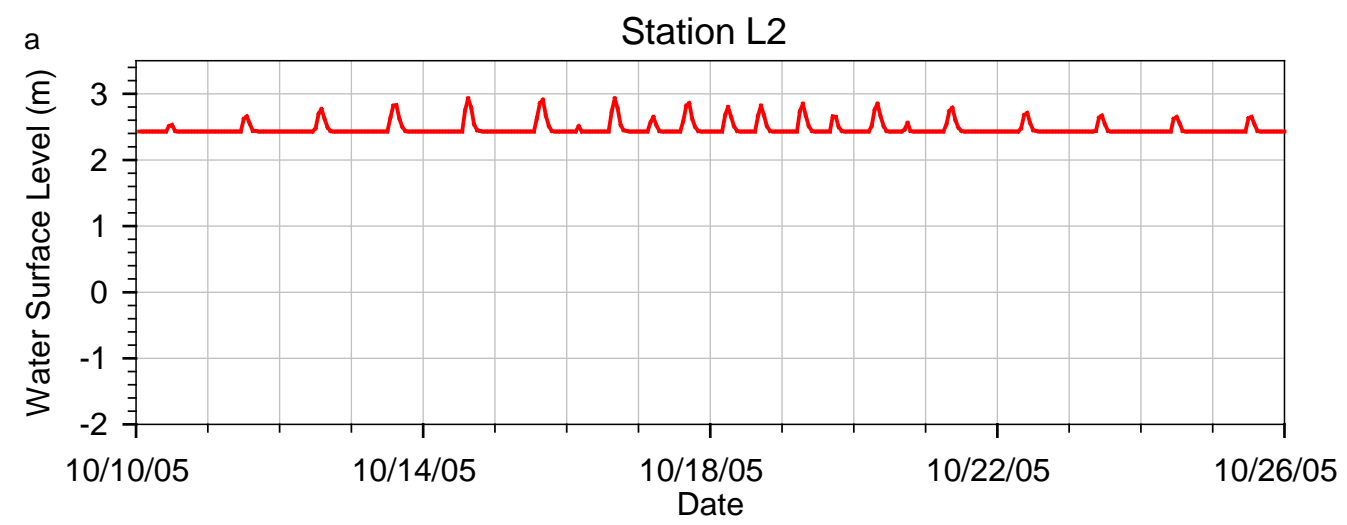

b
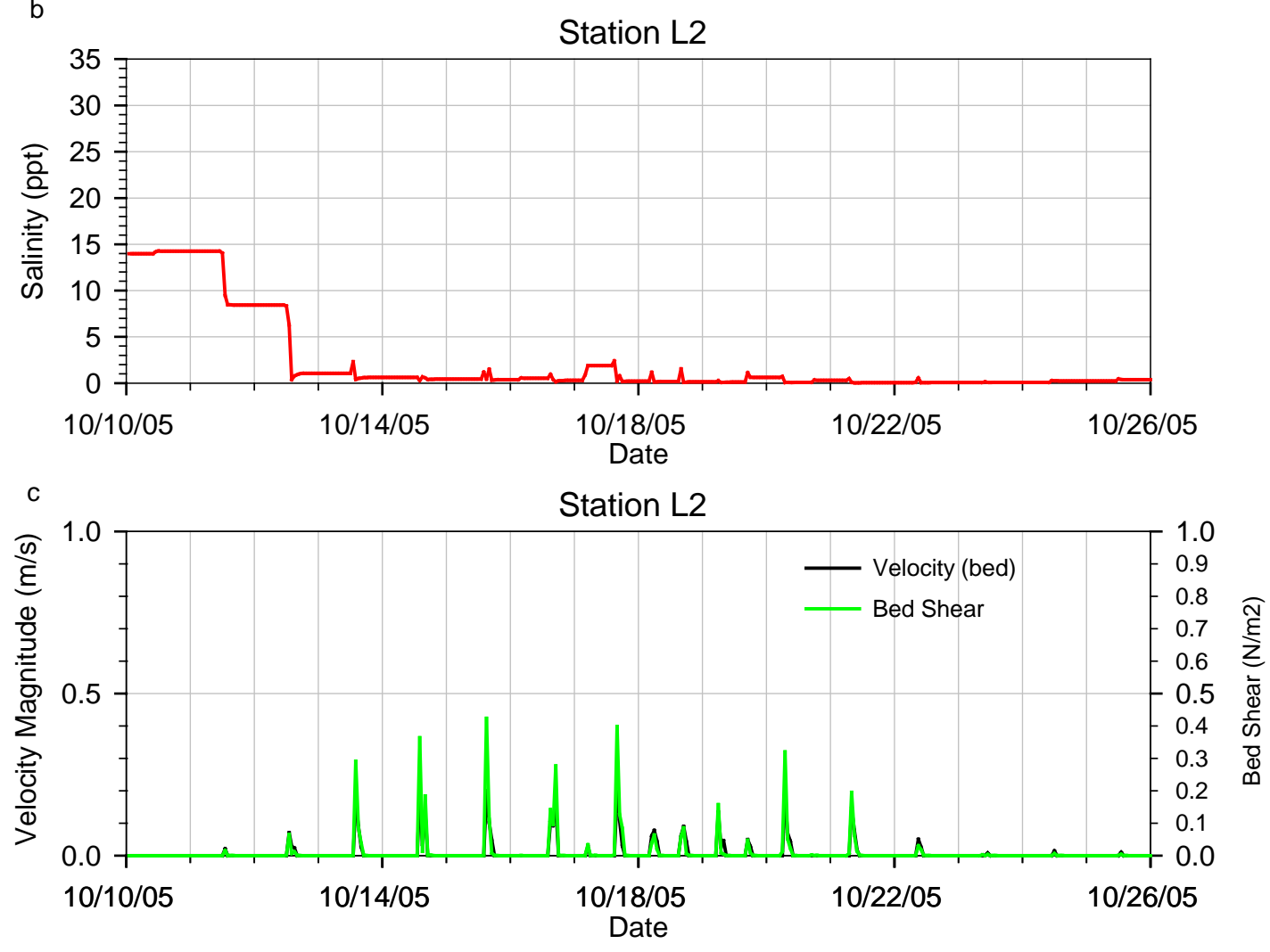

Figure C-36: Scenario 8 (3 Levee Breaches Leque) - Water-surface elevation, salinity, velocity magnitude, and bed shear stress at Leque Island restoration station L2, full bank conditions at 26,508 cfs river flow (tides and wind corresponding to October 2005) 


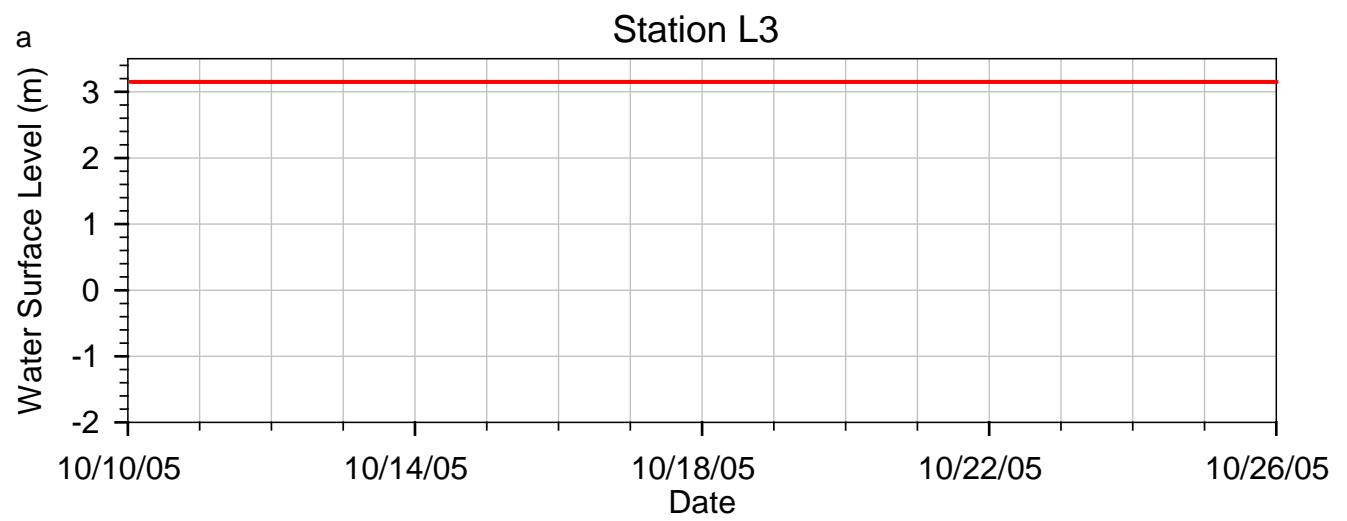

b
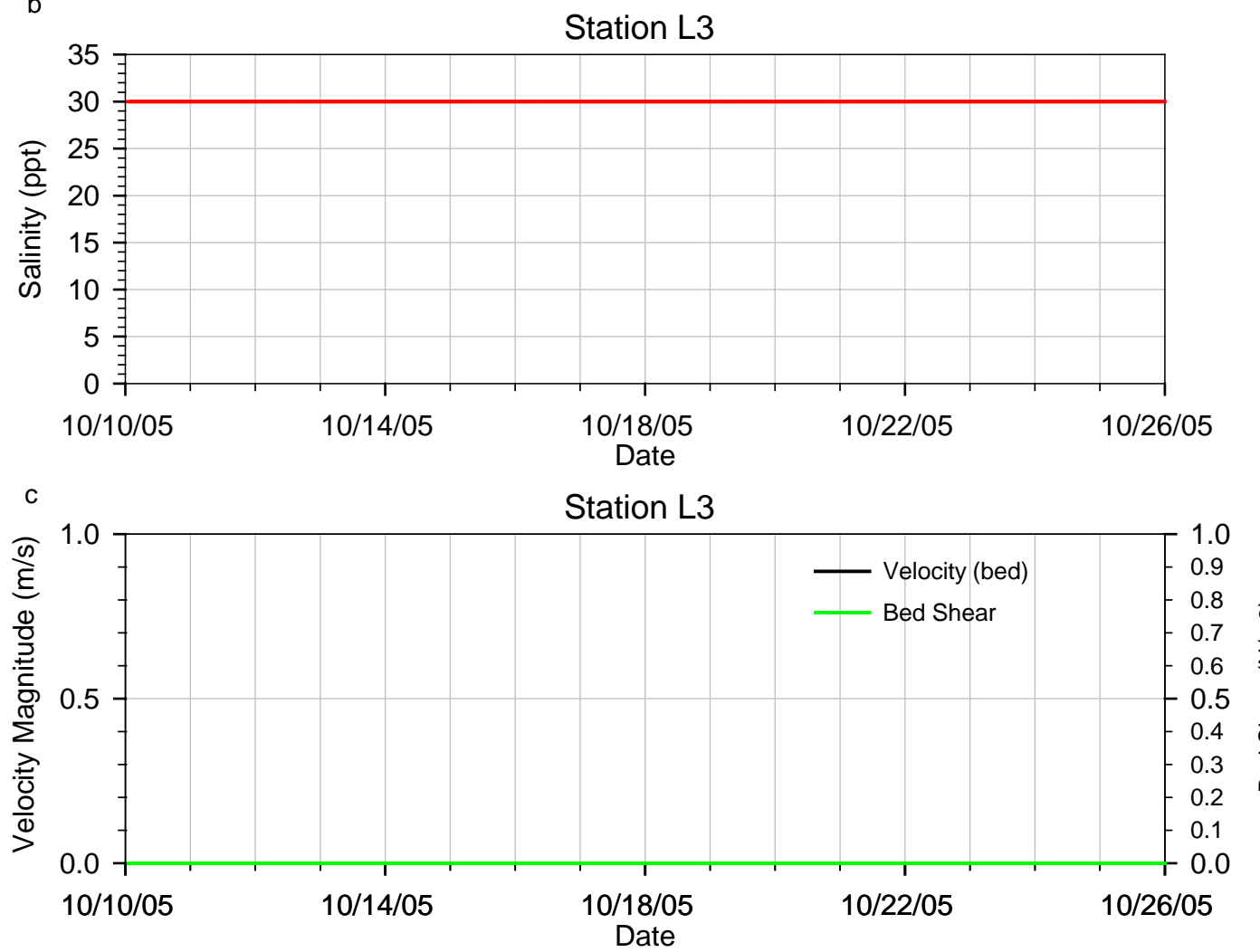

Figure C-37: Scenario 8 (3 Levee Breaches Leque) - Water-surface elevation, salinity, velocity magnitude, and bed shear stress at Leque Island restoration station L3, full bank conditions at 26,508 cfs river flow (tides and wind corresponding to October 2005) 

Appendix D

Plan View Contour Plots - High-Flow (bank-full) Conditions Salinity, Velocity 



\section{Appendix D}

\section{Plan View Contour Plots - High-Flow (bank-full) Conditions - Salinity, Velocity}

Plan view contour plots at high-flow (i.e., bank full) condition for water-surface elevations, salinities, velocities, and bed sheers for Leque Island and zis a ba restoration site stations are provided in this appendix.

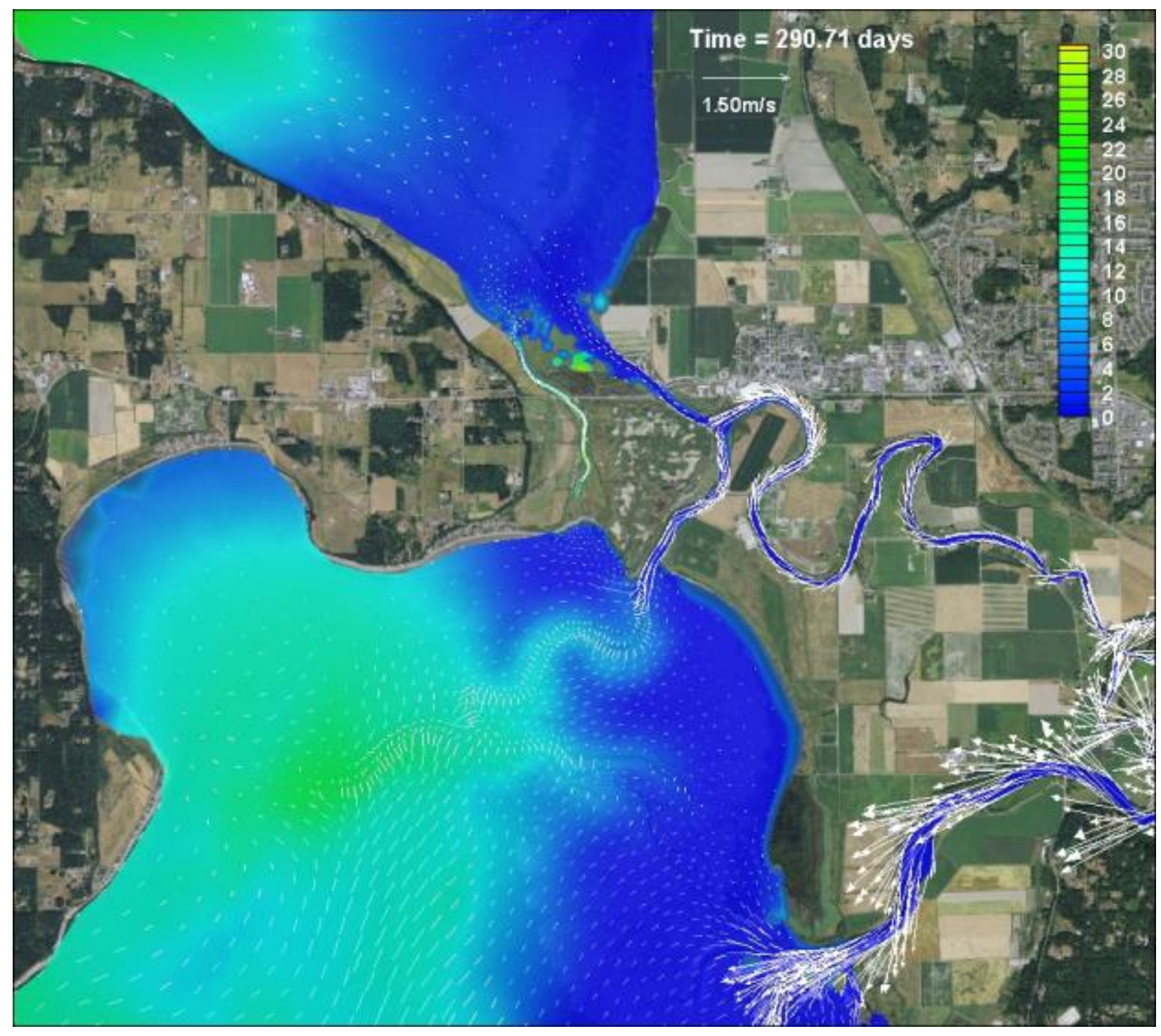

Figure D-1: Scenario 0 (Baseline Condition) - Salinity contours and velocity vectors, high flow (full bank) condition at 26,508 cfs and high tide based on October 17, 2005 


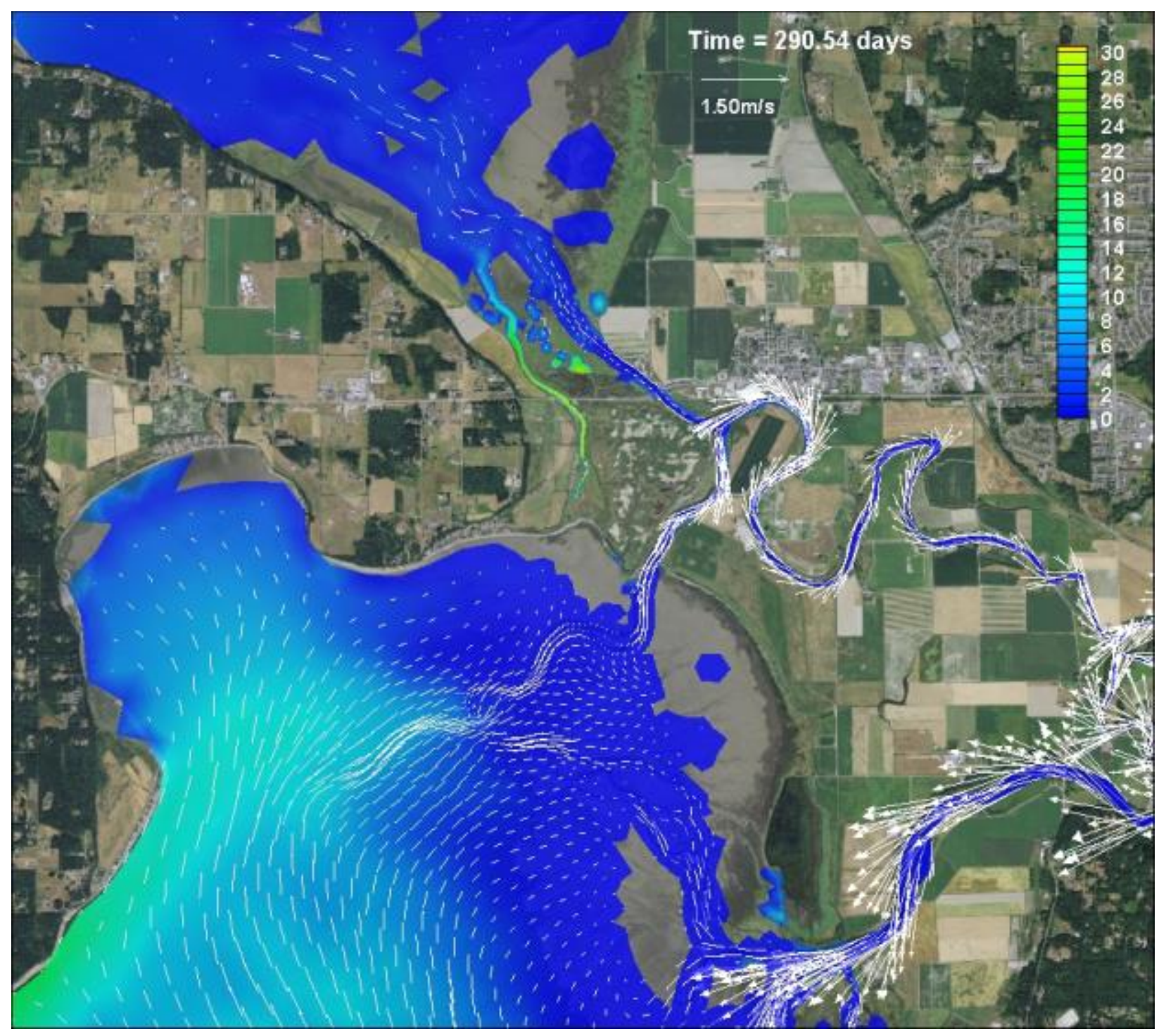

Figure D-2: Scenario 0 (Baseline Condition) - Salinity contours and velocity vectors, high flow (full bank) condition at 26,508 cfs and low tide based on October 17, 2005 


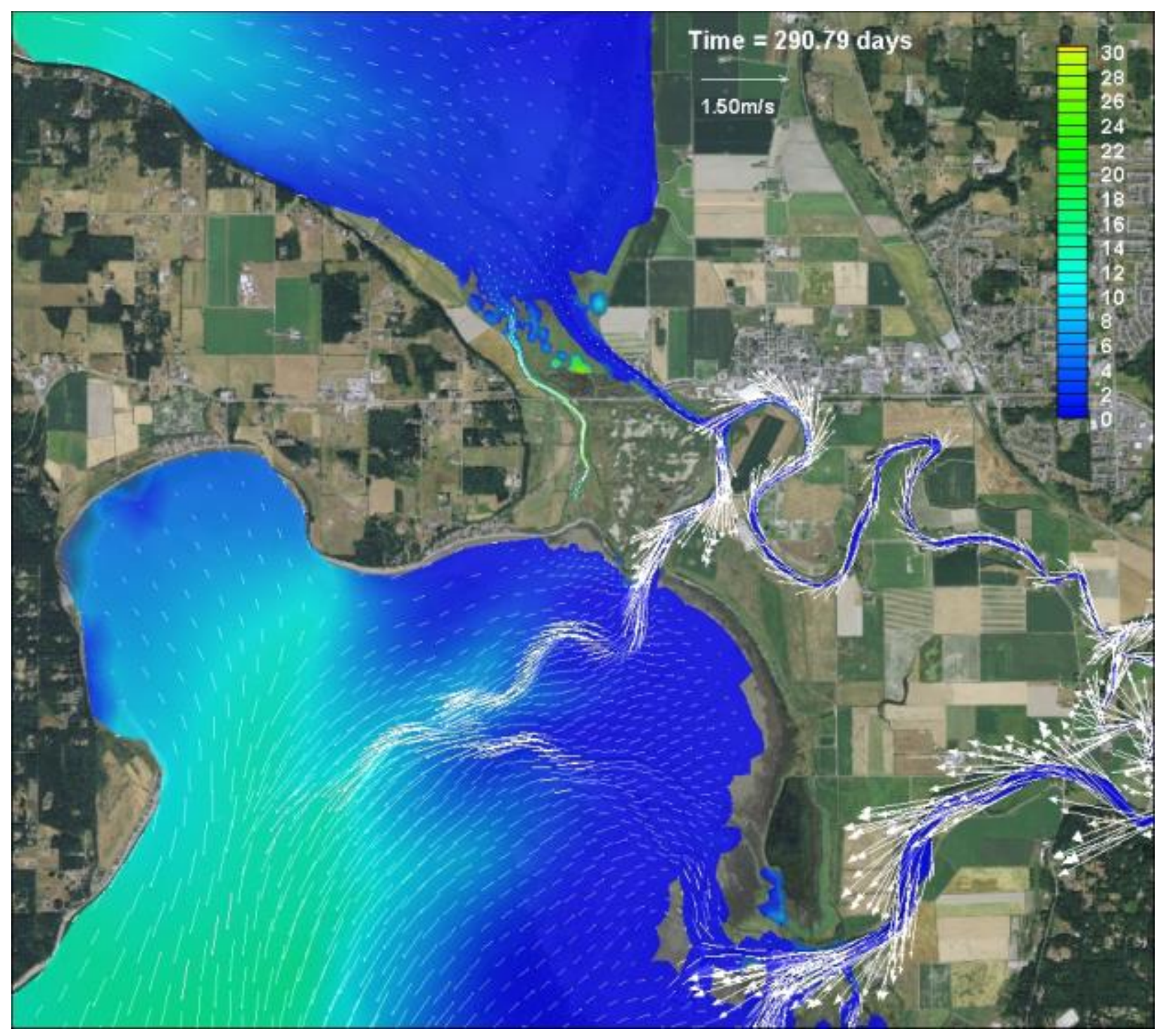

Figure D-3: Scenario 0 (Baseline Condition) - Salinity contours and velocity vectors, high flow (full bank) condition at 26,508 cfs and peak ebb based on October 17, 2005 


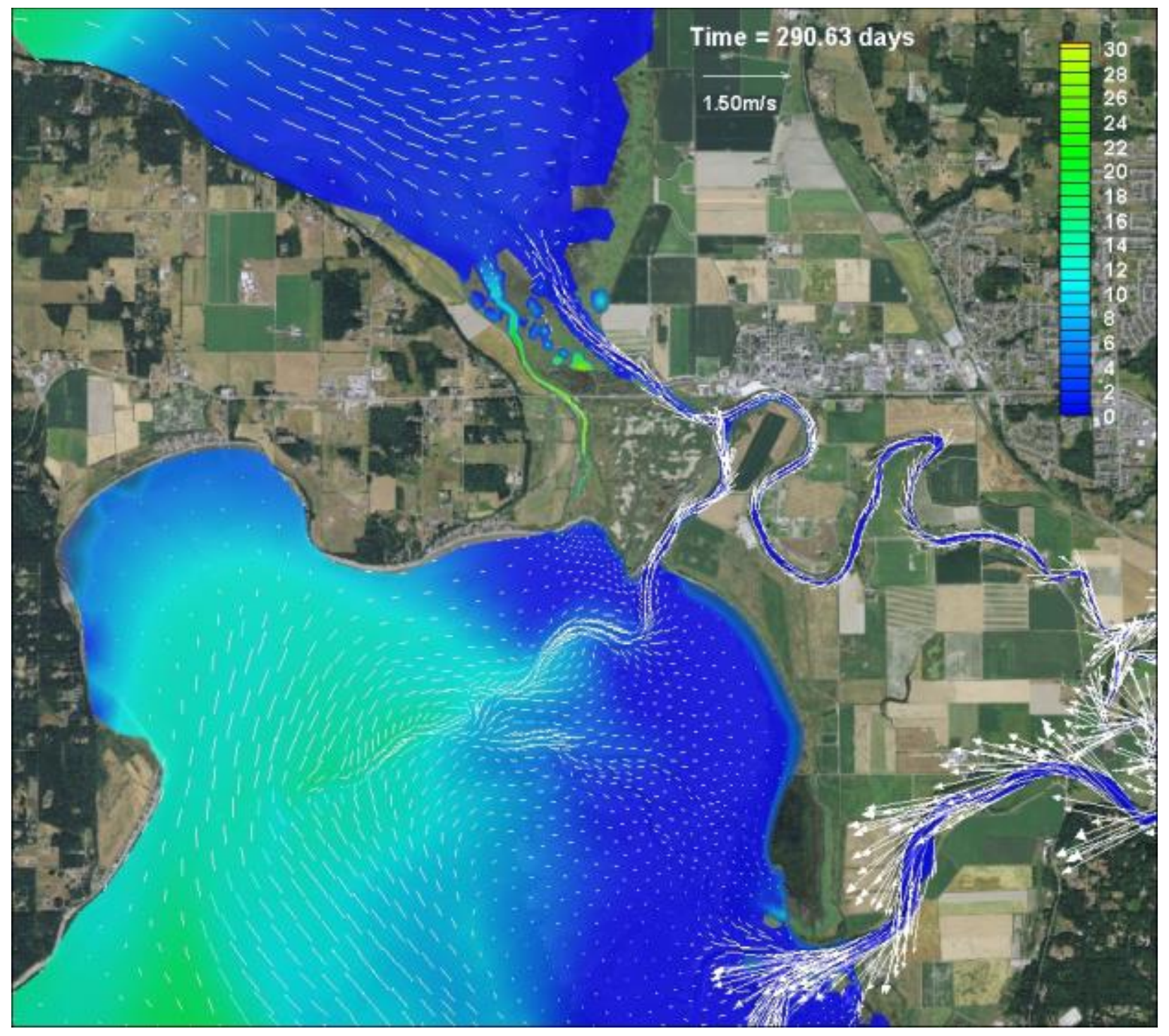

Figure D-4: Scenario 0 (Baseline Condition) - Salinity contours and velocity vectors, high flow (full bank) condition at 26,508 cfs and peak flood based on October 17, 2005 


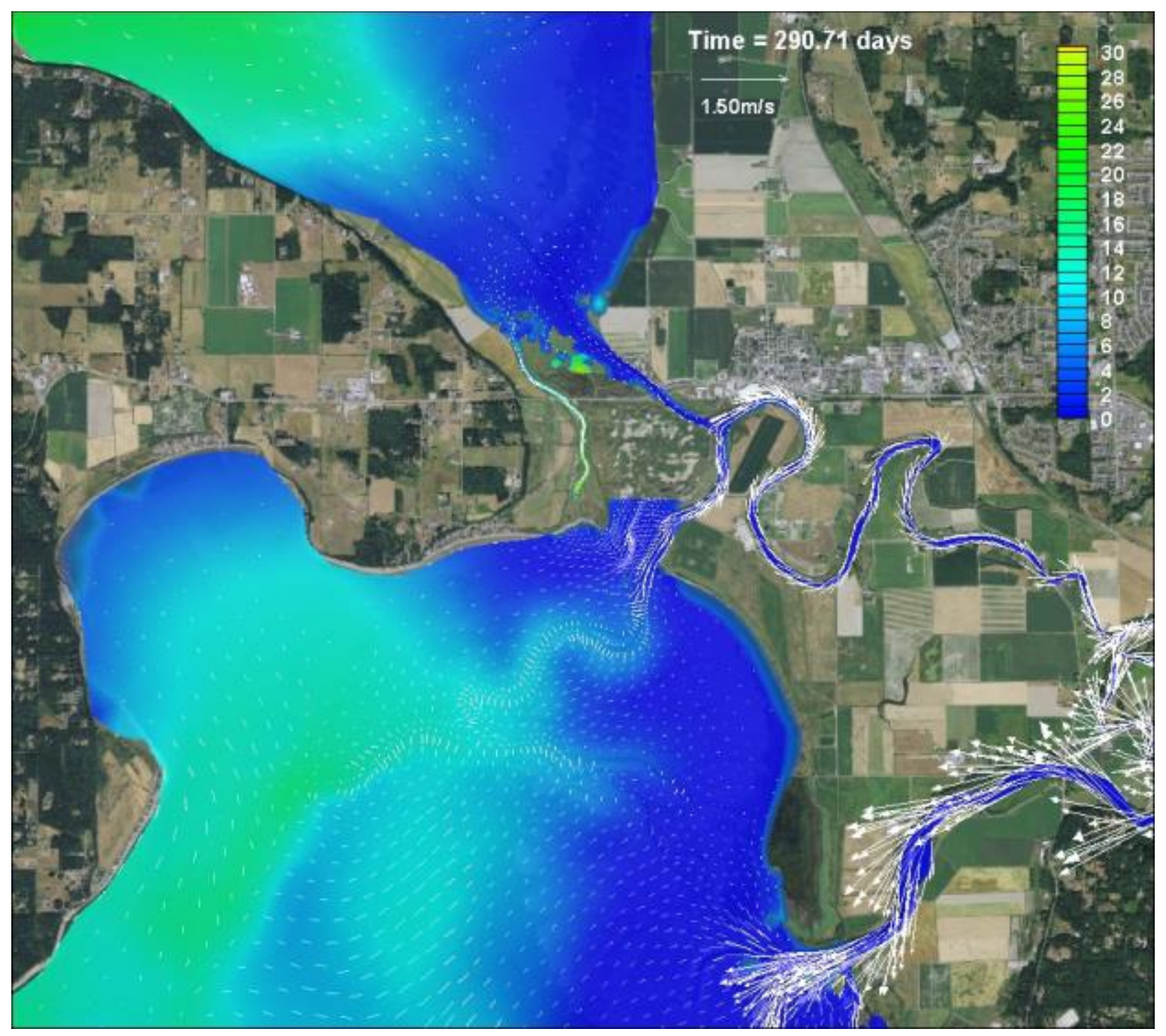

Figure D-5: Scenario 1 (Partial Restoration Leque) - Salinity contours and velocity vectors, high flow (full bank) condition at 26,508 cfs and high tide based on October 17, 2005 


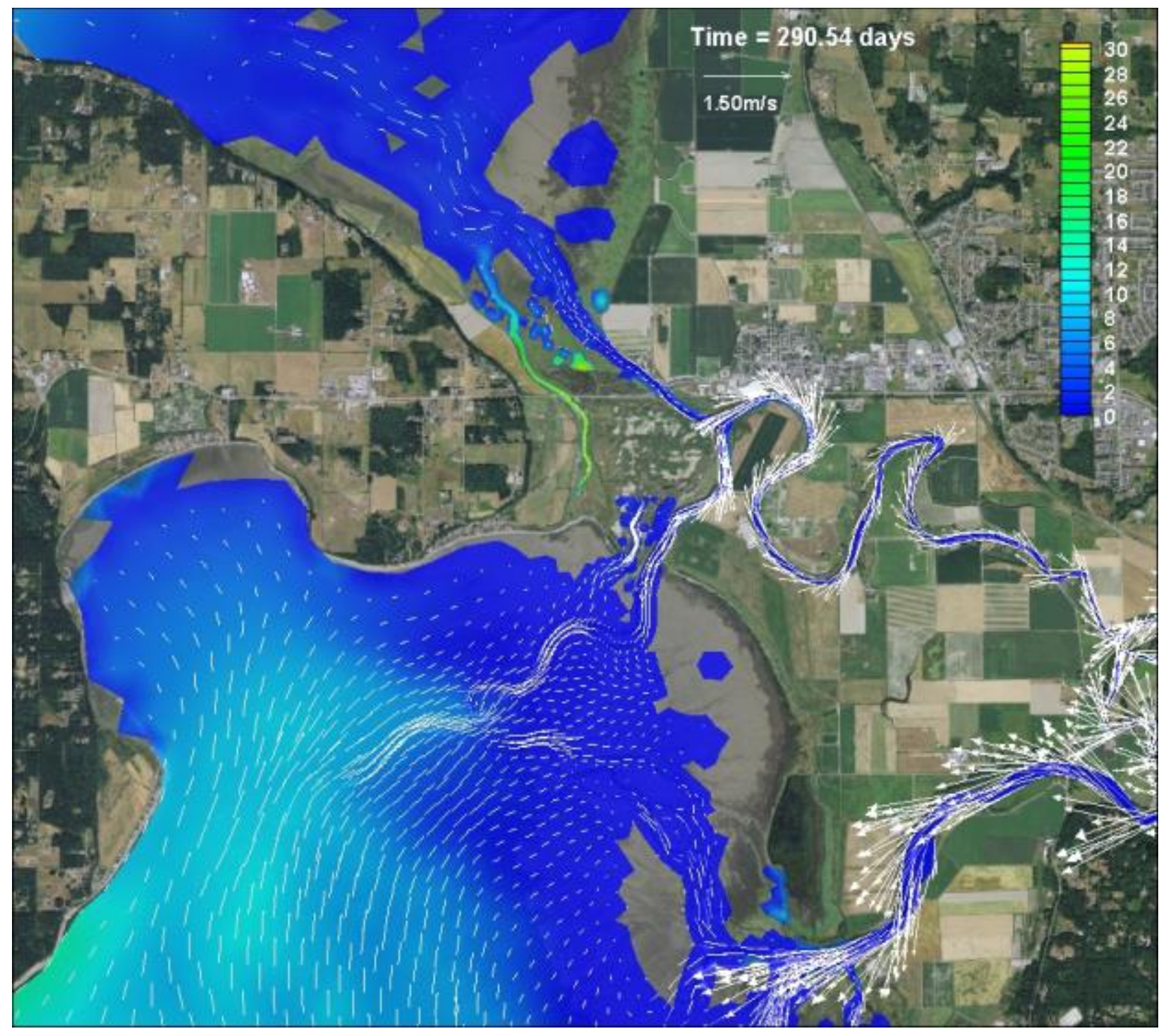

Figure D-6: Scenario 1 (Partial Restoration Leque) - Salinity contours and velocity vectors, high flow (full bank) condition at 26,508 cfs and low tide based on October 17, 2005 


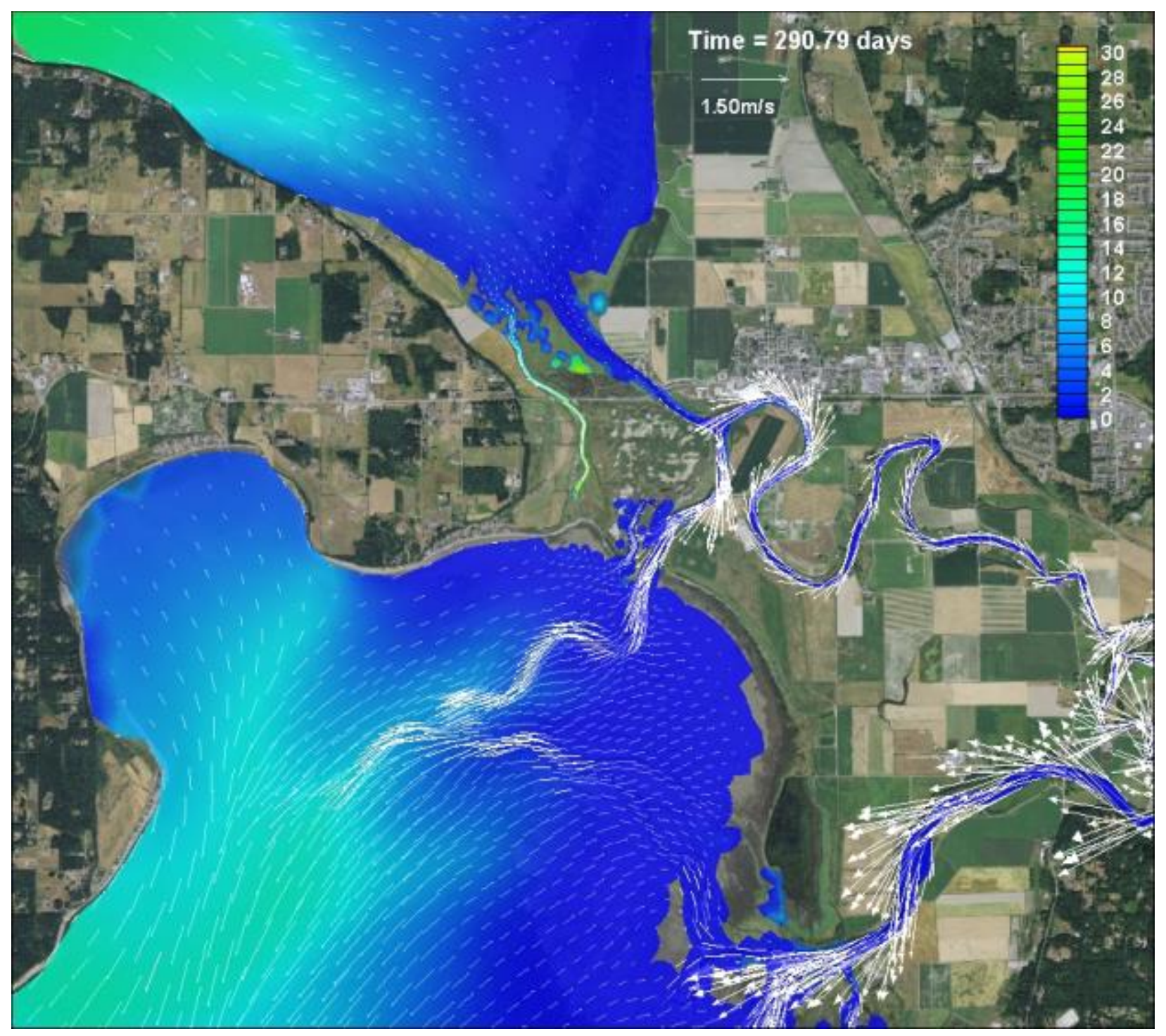

Figure D-7: Scenario 1 (Partial Restoration Leque) - Salinity contours and velocity vectors, high flow (full bank) condition at 26,508 cfs and peak ebb based on October 17, 2005 


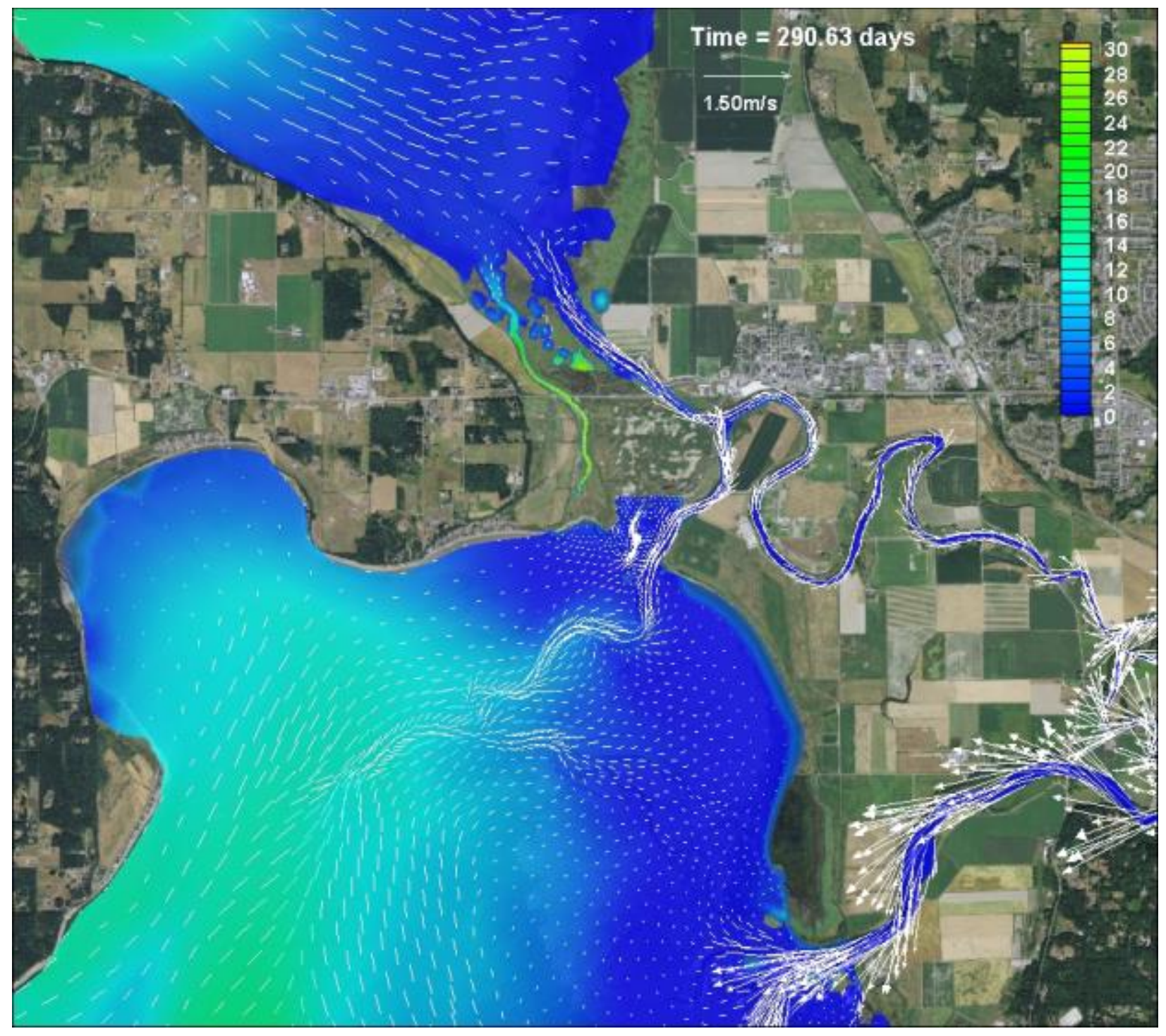

Figure D-8: Scenario 1 (Partial Restoration Leque) - Salinity contours and velocity vectors, high flow (full bank) condition at 26,508 cfs and peak flood based on October 17, 2005 


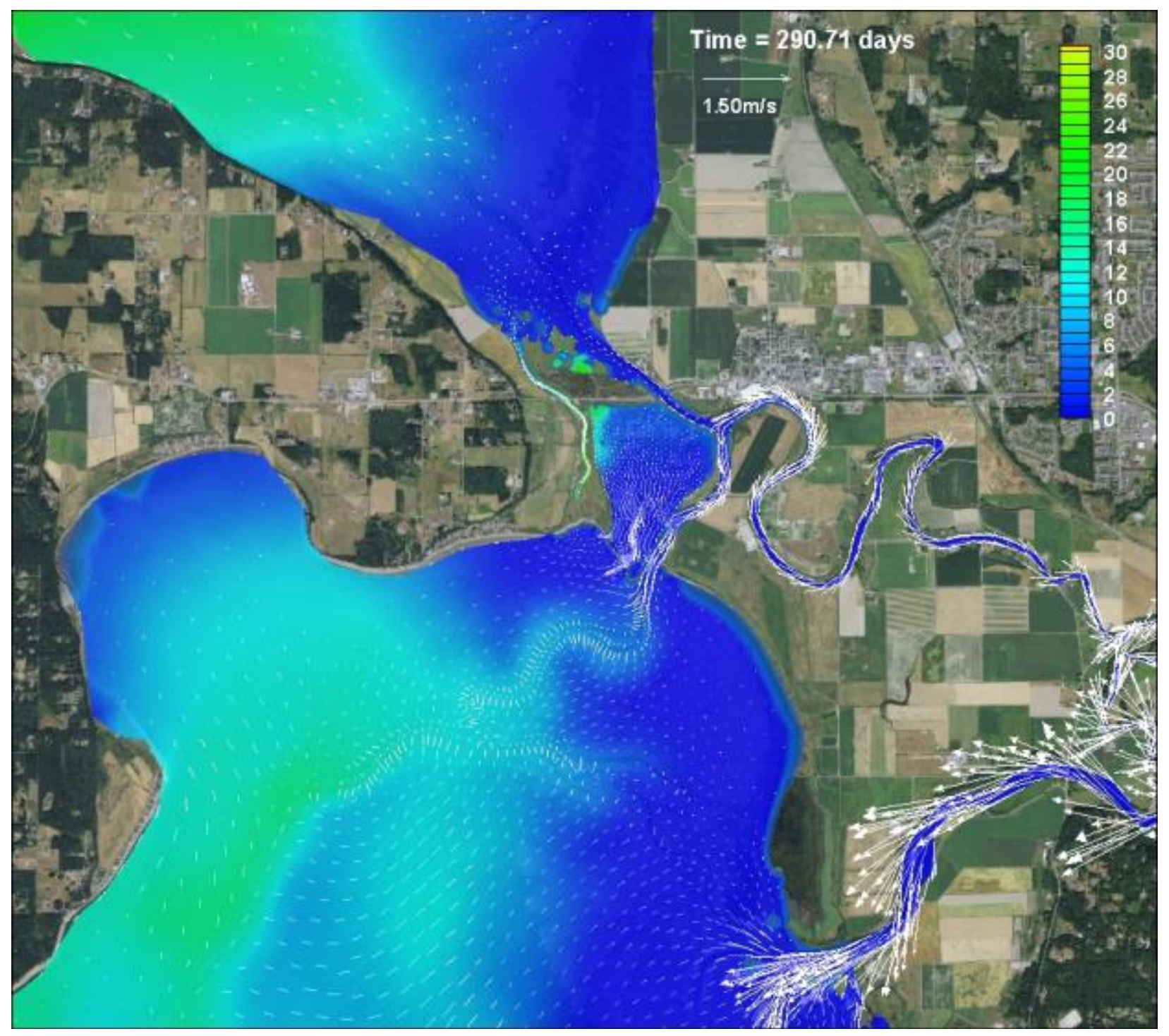

Figure D-9: Scenario 2 (4 Levee Breach Leque) - Salinity contours and velocity vectors, high flow (full bank) condition at 26,508 cfs and high tide based on October 17, 2005 


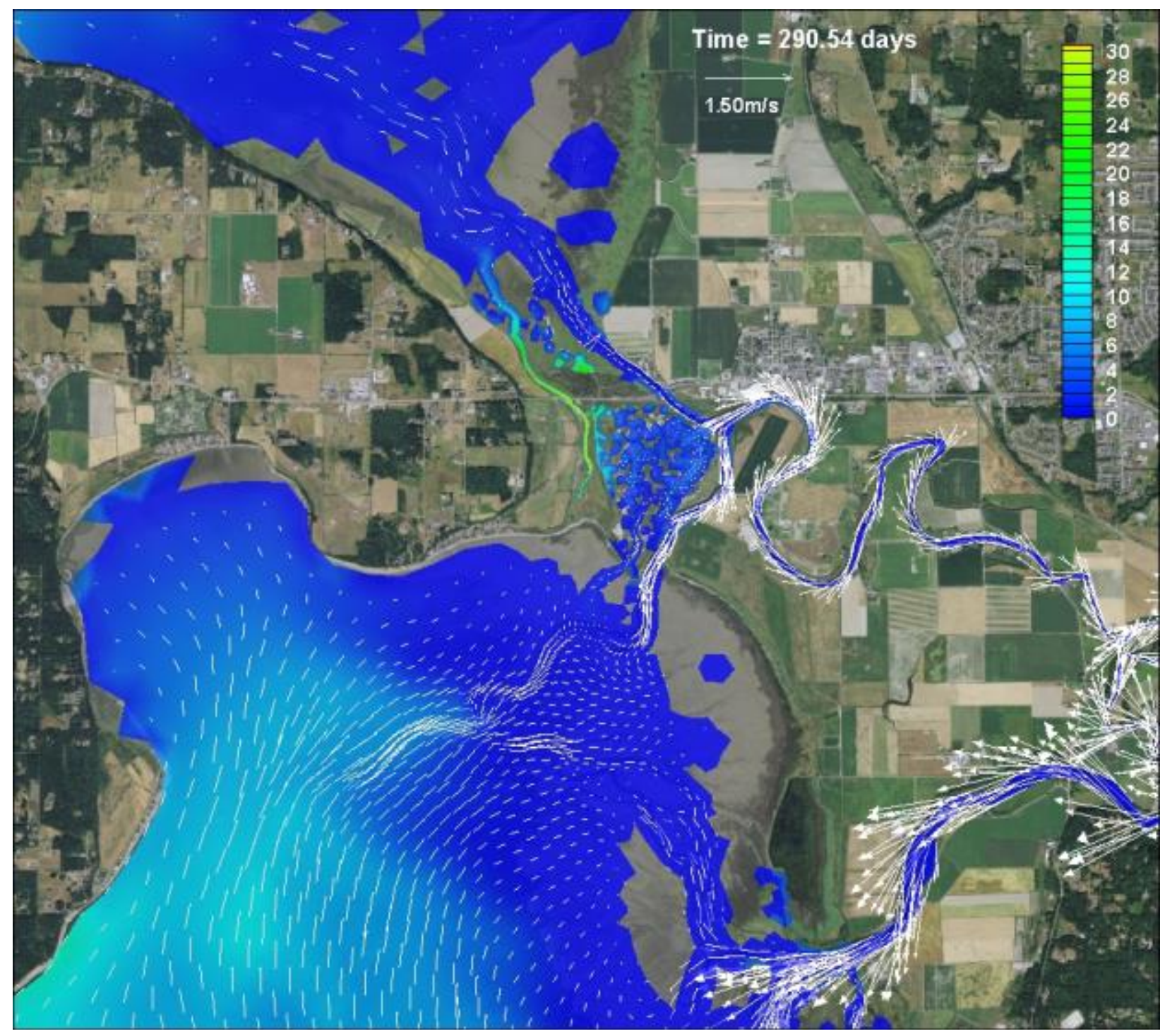

Figure D-10: Scenario 2 (4 Levee Breach Leque) - Salinity contours and velocity vectors, high flow (full bank) condition at 26,508 cfs and low tide based on October 17, 2005 


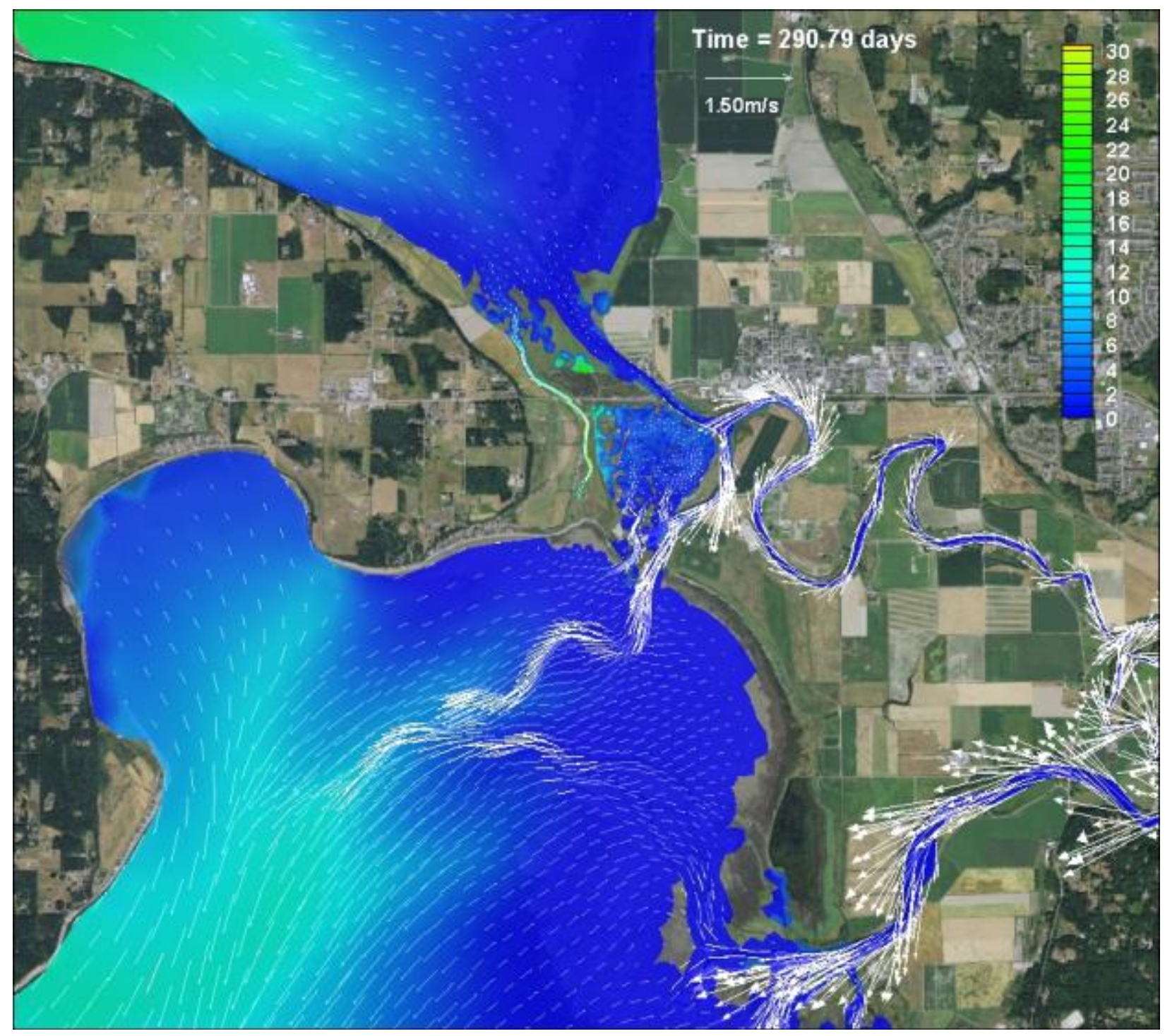

Figure D-11: Scenario 2 (4 Levee Breach Leque) - Salinity contours and velocity vectors, high flow (full bank) condition at 26,508 cfs and peak ebb based on October 17, 2005 


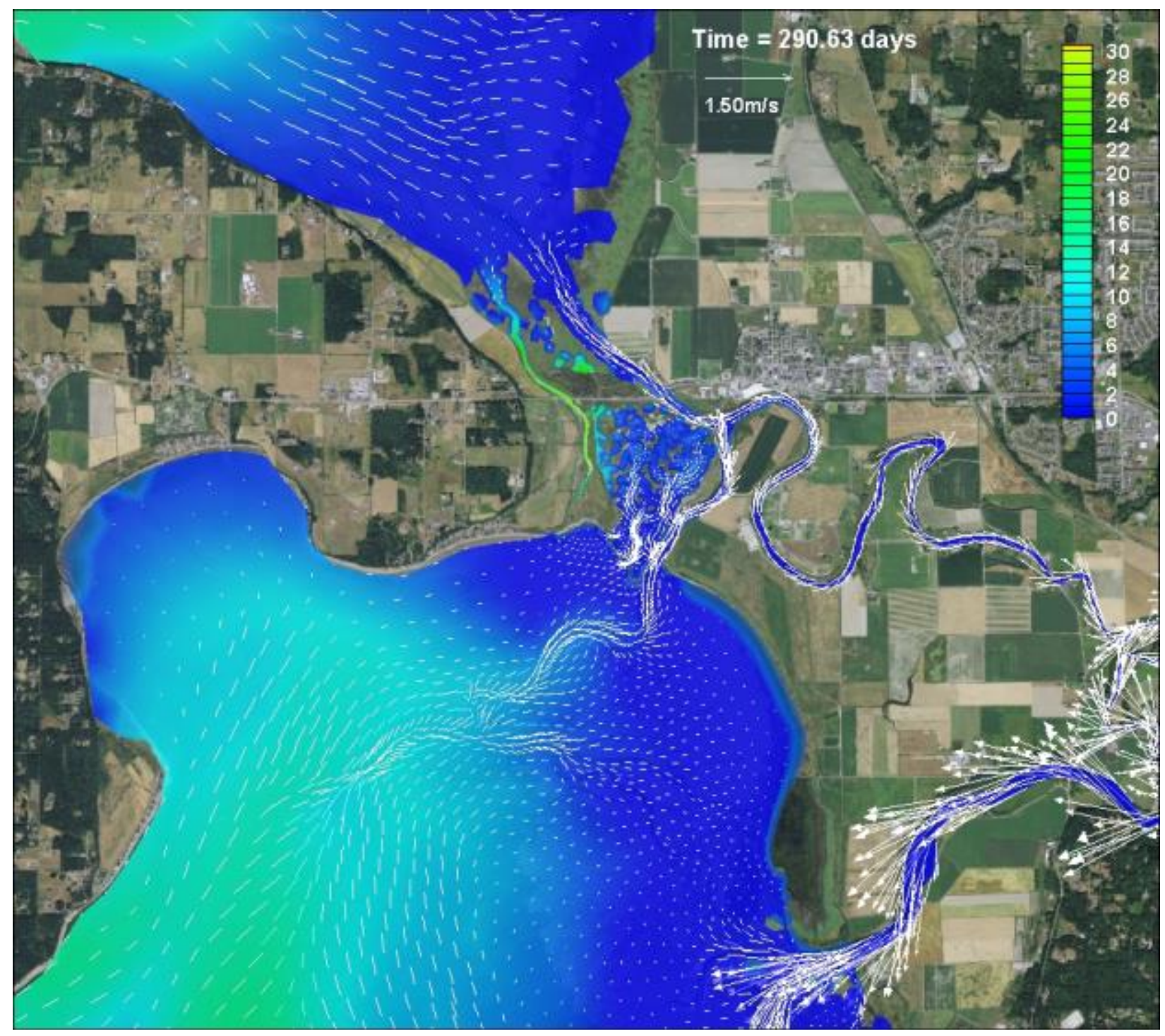

Figure D-12: Scenario 2 (4 Levee Breach Leque) - Salinity contours and velocity vectors, high flow (full bank) condition at 26,508 cfs and peak flood based on October 17, 2005 


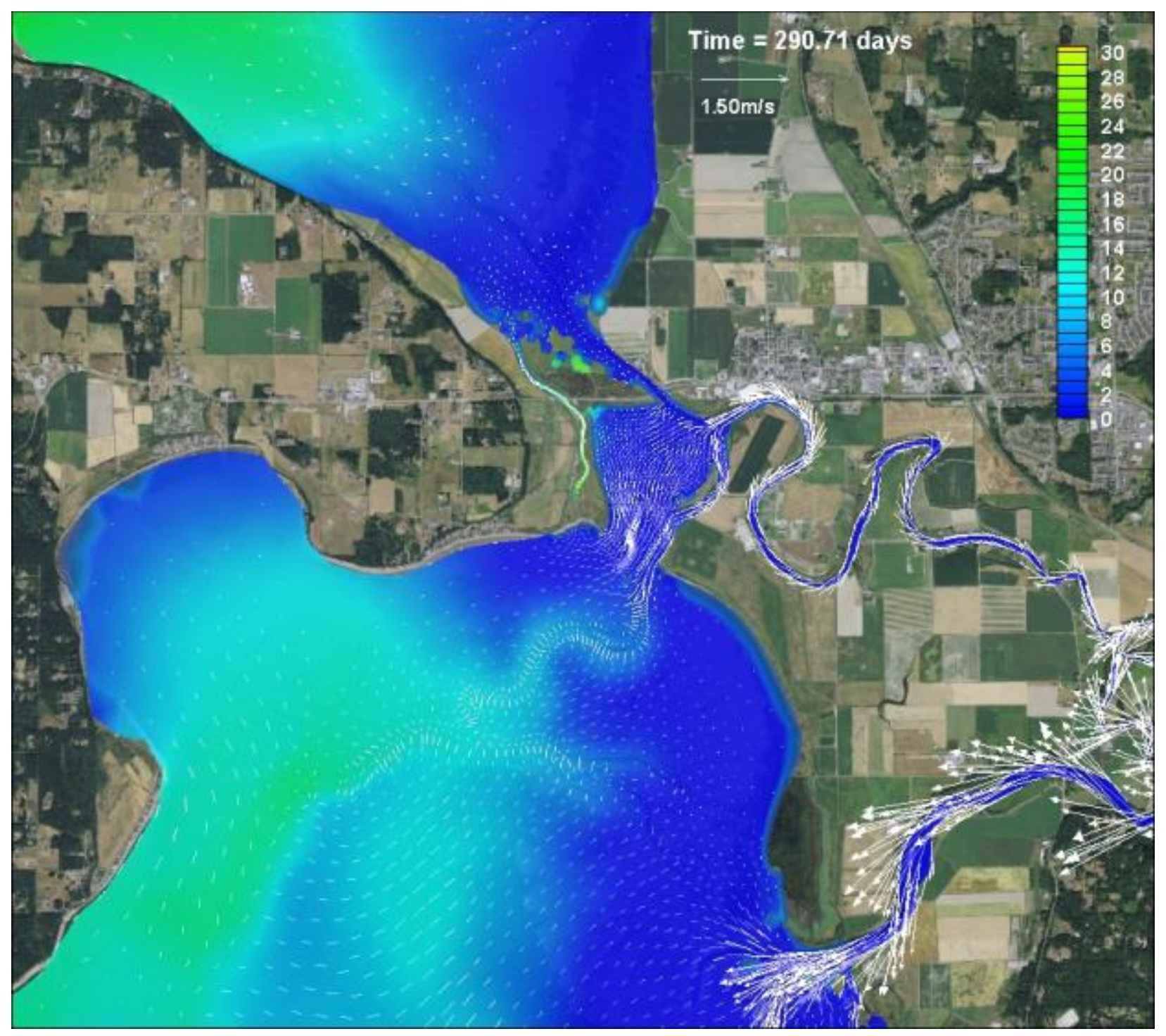

Figure D-13: Scenario 3 (Full Restoration Leque 1) - Salinity contours and velocity vectors, high flow (full bank) condition at 26,508 cfs and high tide based on October 17, 2005 


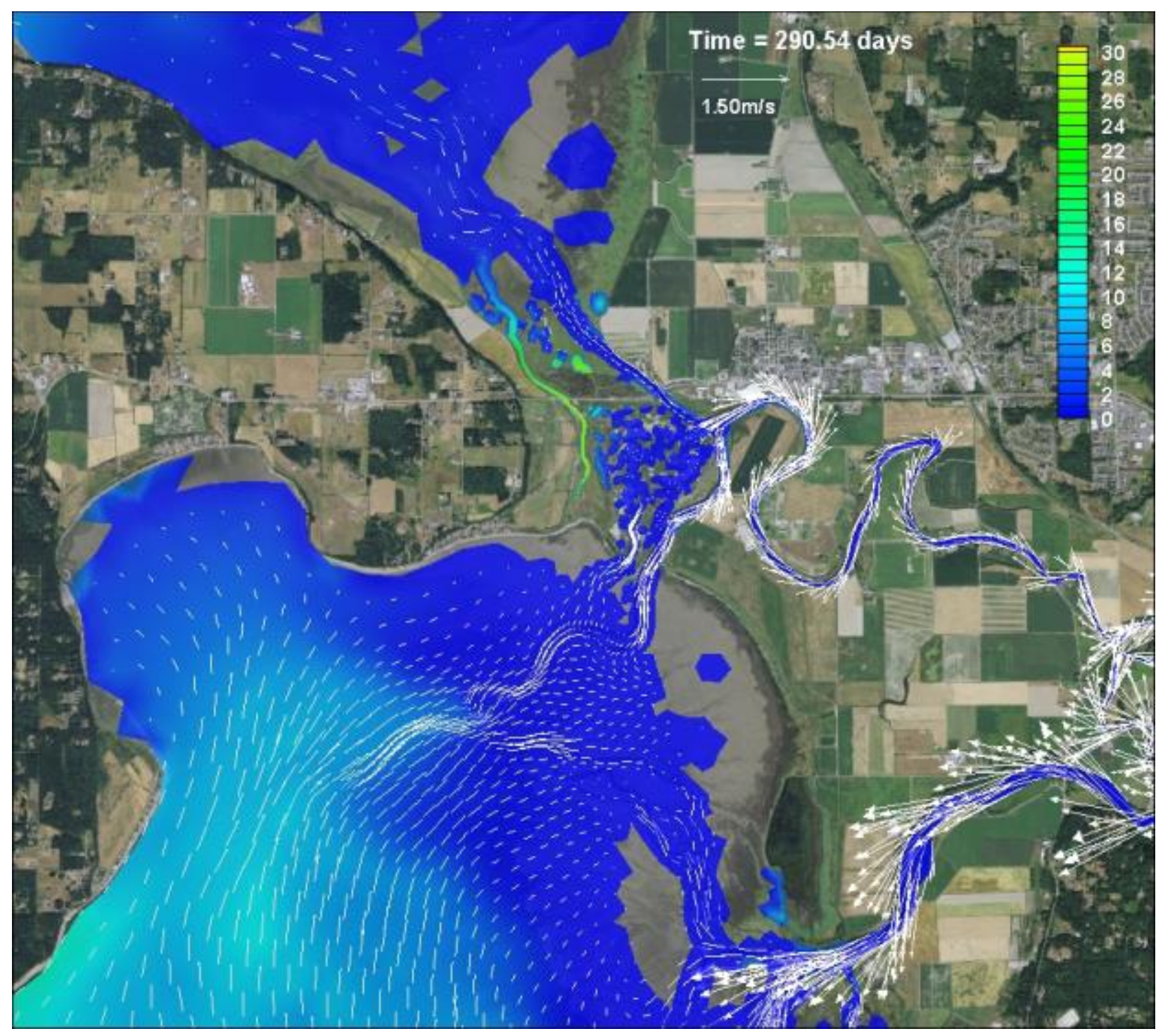

Figure D-14: Scenario 3 (Full Restoration Leque 1) - Salinity contours and velocity vectors, high flow (full bank) condition at 26,508 cfs and low tide based on October 17, 2005 


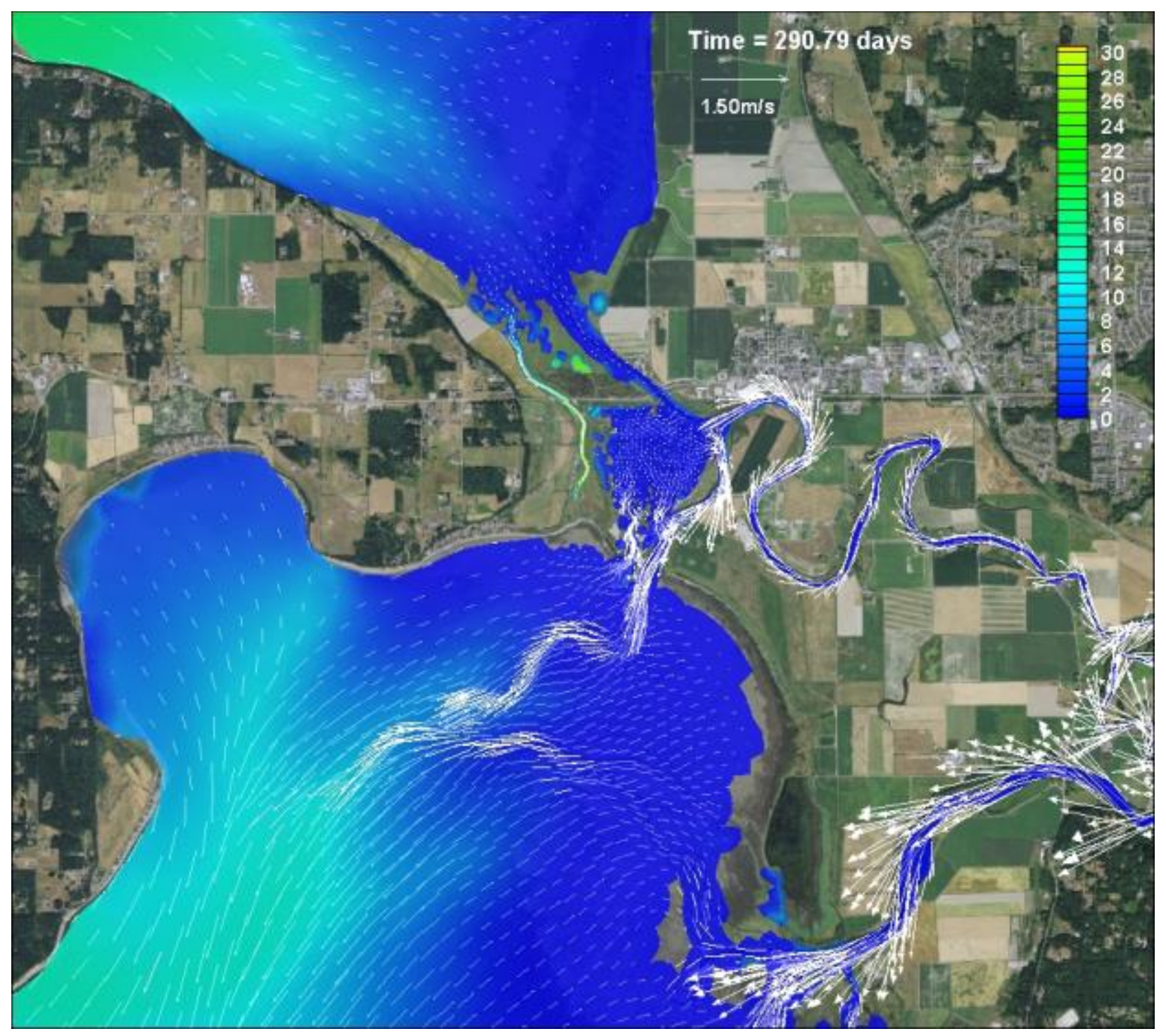

Figure D-15: Scenario 3 (Full Restoration Leque 1) - Salinity contours and velocity vectors, high flow (full bank) condition at 26,508 cfs and peak ebb based on October 17, 2005 


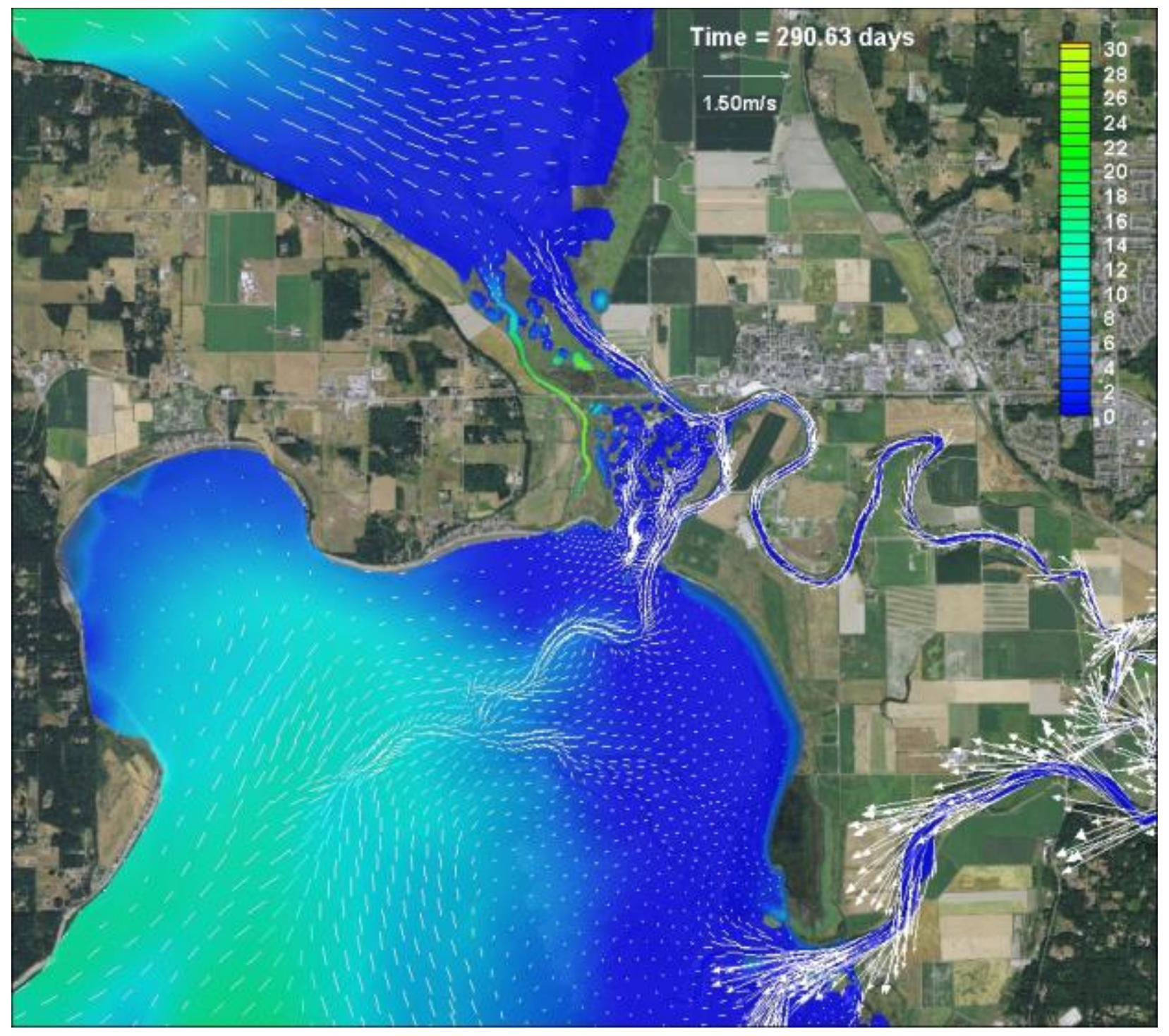

Figure D-16: Scenario 3 (Full Restoration Leque 1) - Salinity contours and velocity vectors, high flow (full bank) condition at 26,508 cfs and peak flood based on October 17, 2005 


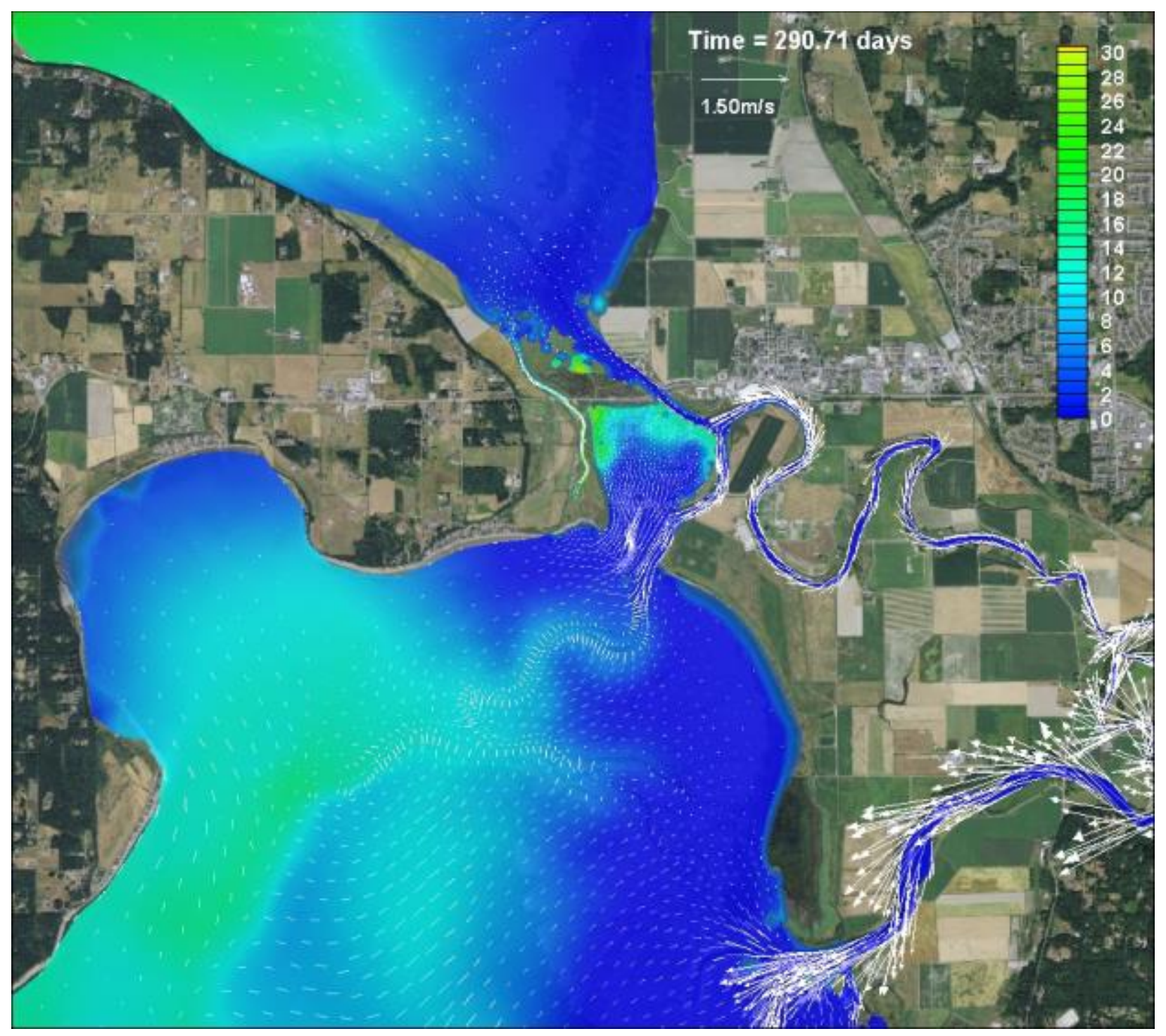

Figure D-17: Scenario 4 (Full Restoration Leque 2) - Salinity contours and velocity vectors, high flow (full bank) condition at 26,508 cfs and high tide based on October 17, 2005 


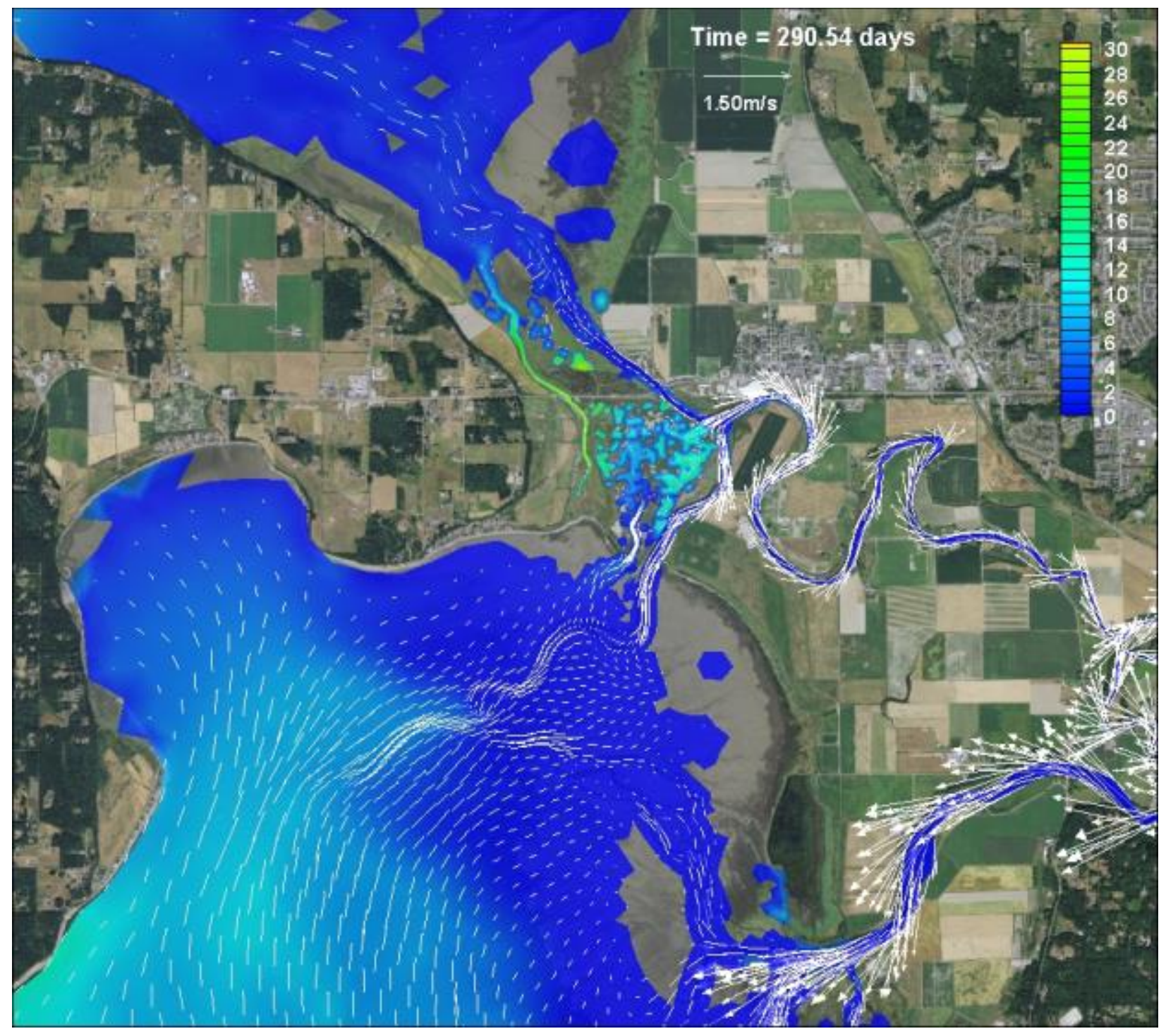

Figure D-18: Scenario 4 (Full Restoration Leque 2) - Salinity contours and velocity vectors, high flow (full bank) condition at 26,508 cfs and low tide based on October 17, 2005 


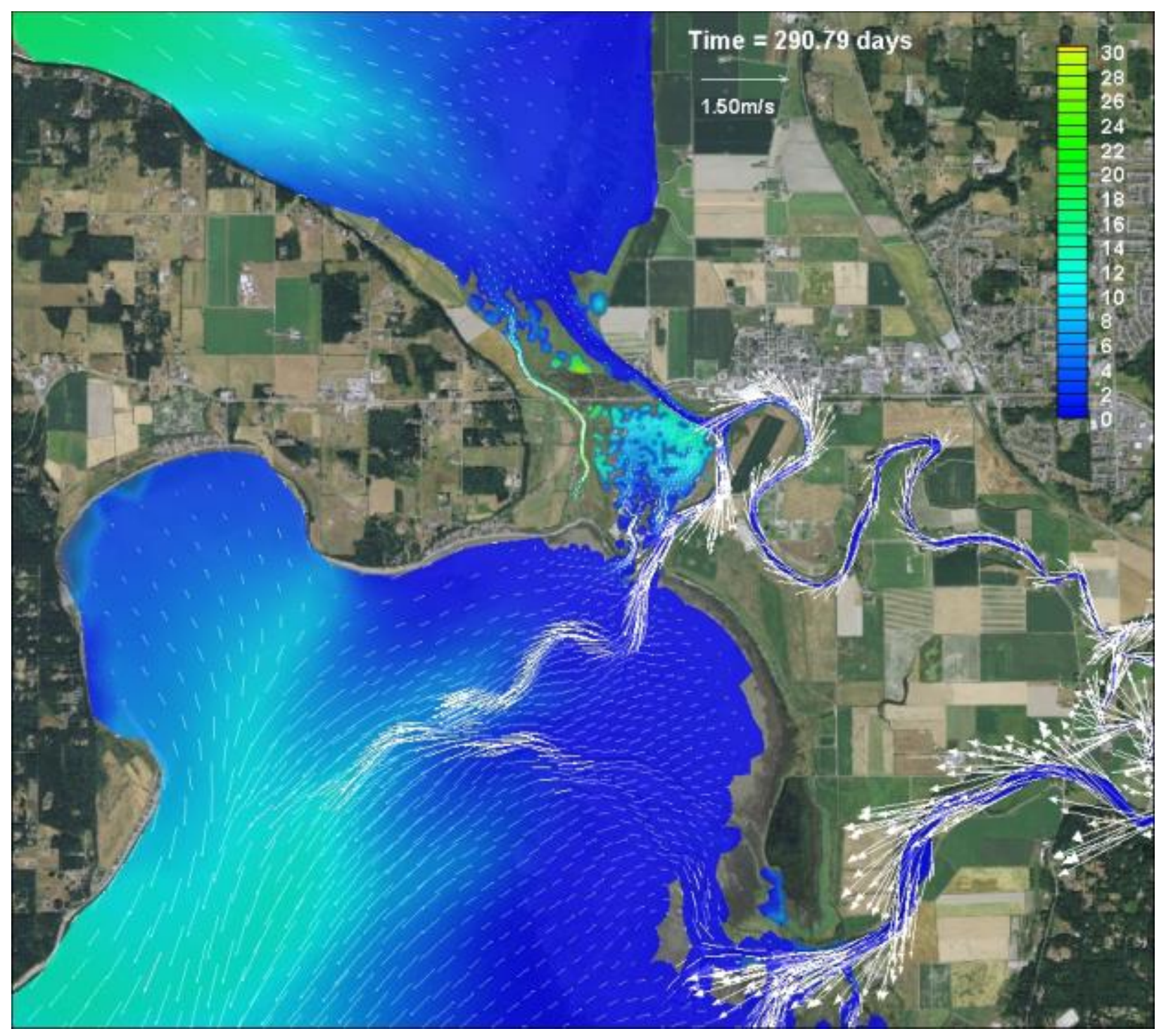

Figure D-19: Scenario 4 (Full Restoration Leque 2) - Salinity contours and velocity vectors, high flow (full bank) condition at 26,508 cfs and peak ebb based on October 17, 2005 


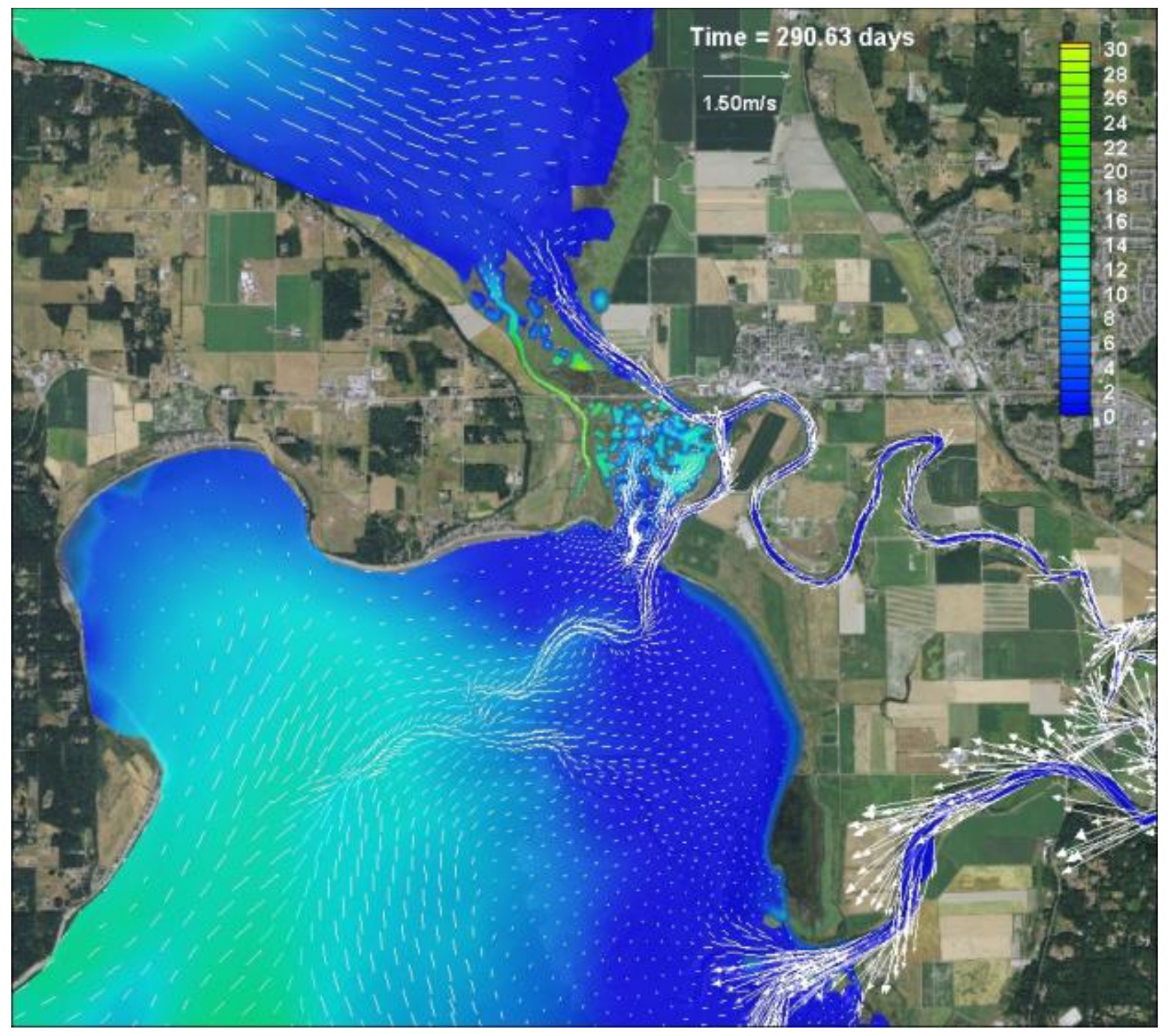

Figure D-20: Scenario 4 (Full Restoration Leque 2) - Salinity contours and velocity vectors, high flow (full bank) condition at 26,508 cfs and peak flood based on October 17, 2005 


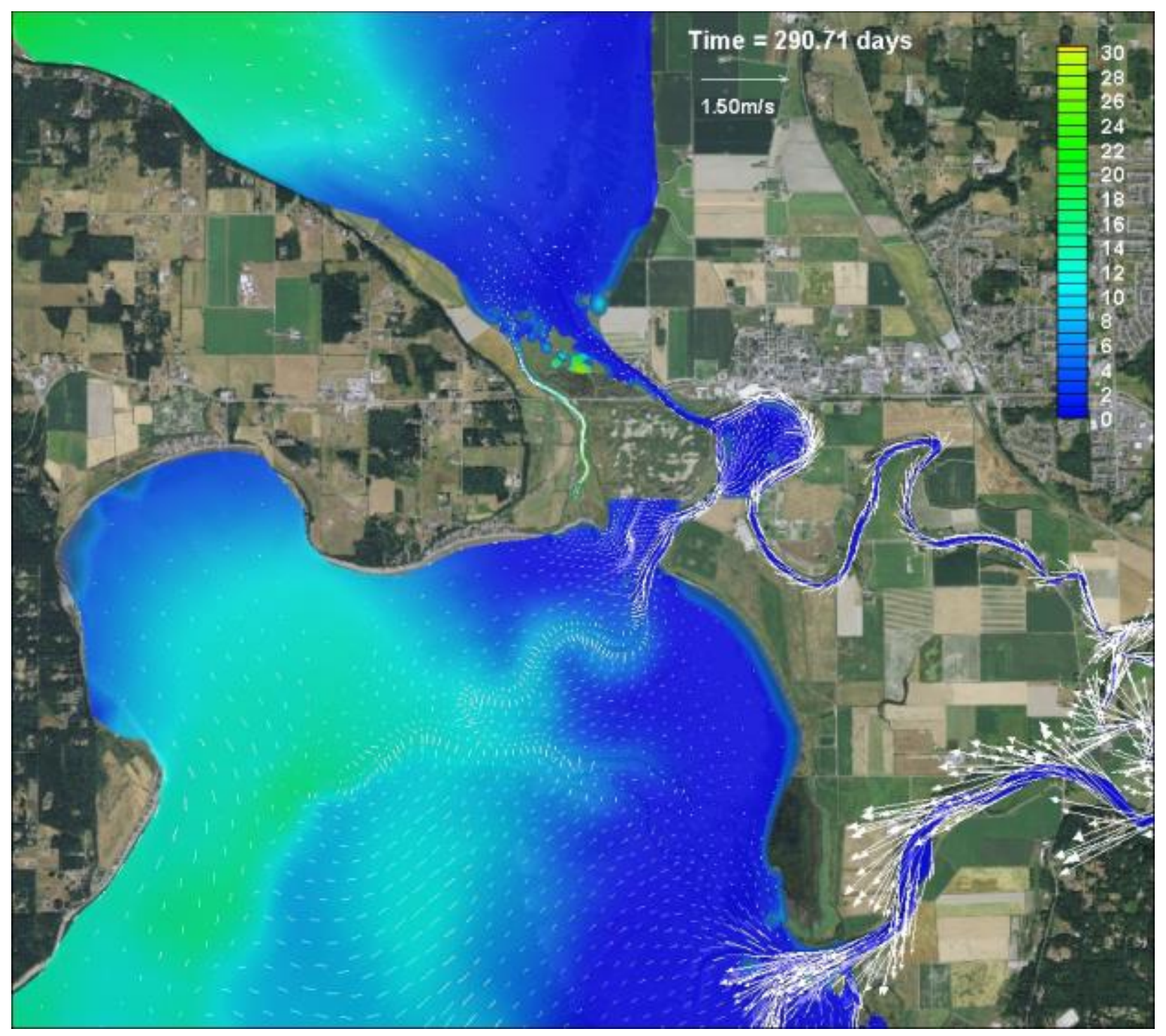

Figure D-21: Scenario 5 (Full Restoration zis a ba + SCN1) - Salinity contours and velocity vectors, high flow (full bank) condition at 26,508 cfs and high tide based on October 17, 2005 


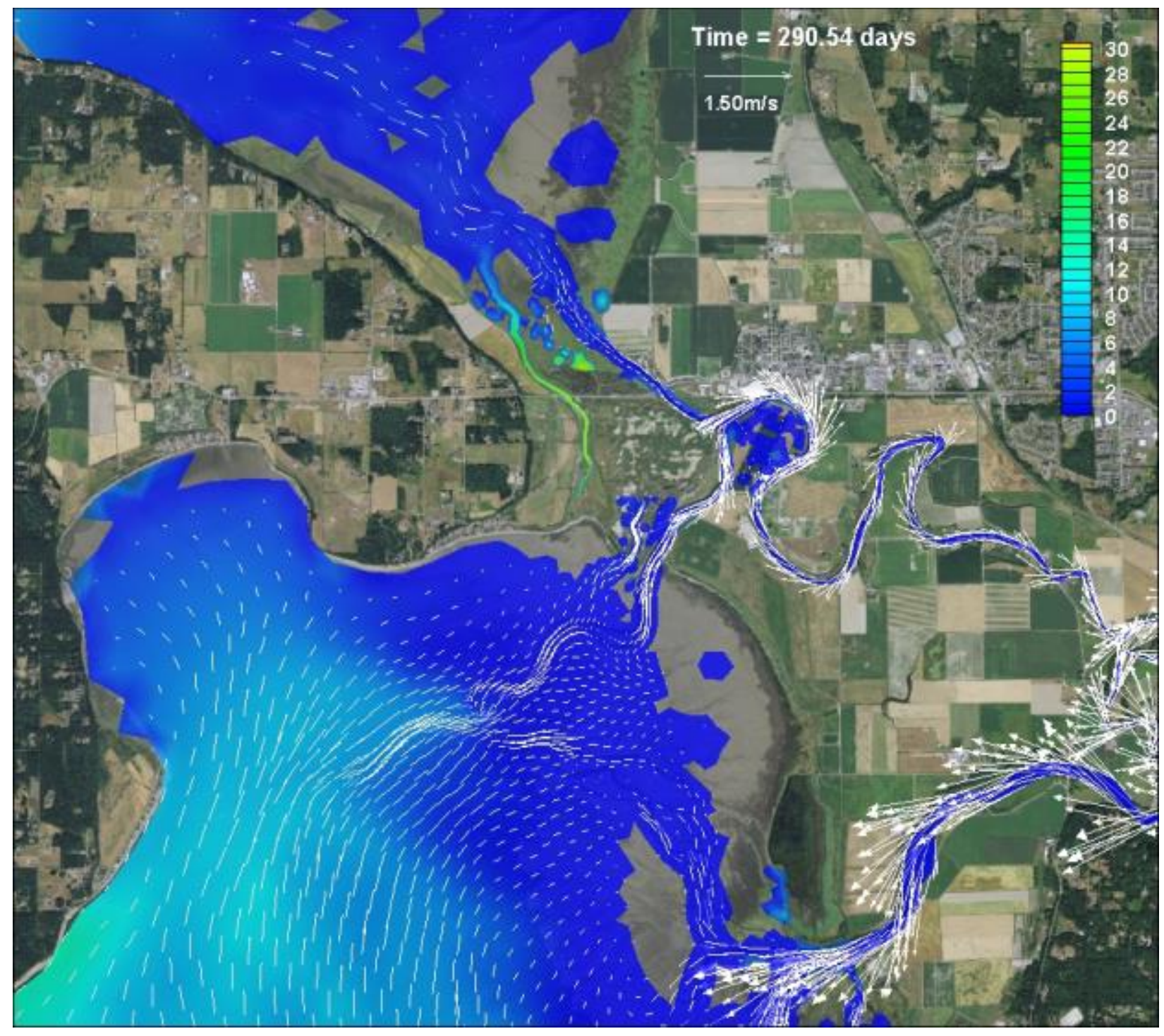

Figure D-22: Scenario 5 (Full Restoration zis a ba + SCN1) - Salinity contours and velocity vectors, high flow (full bank) condition at 26,508 cfs and low tide based on October 17, 2005 


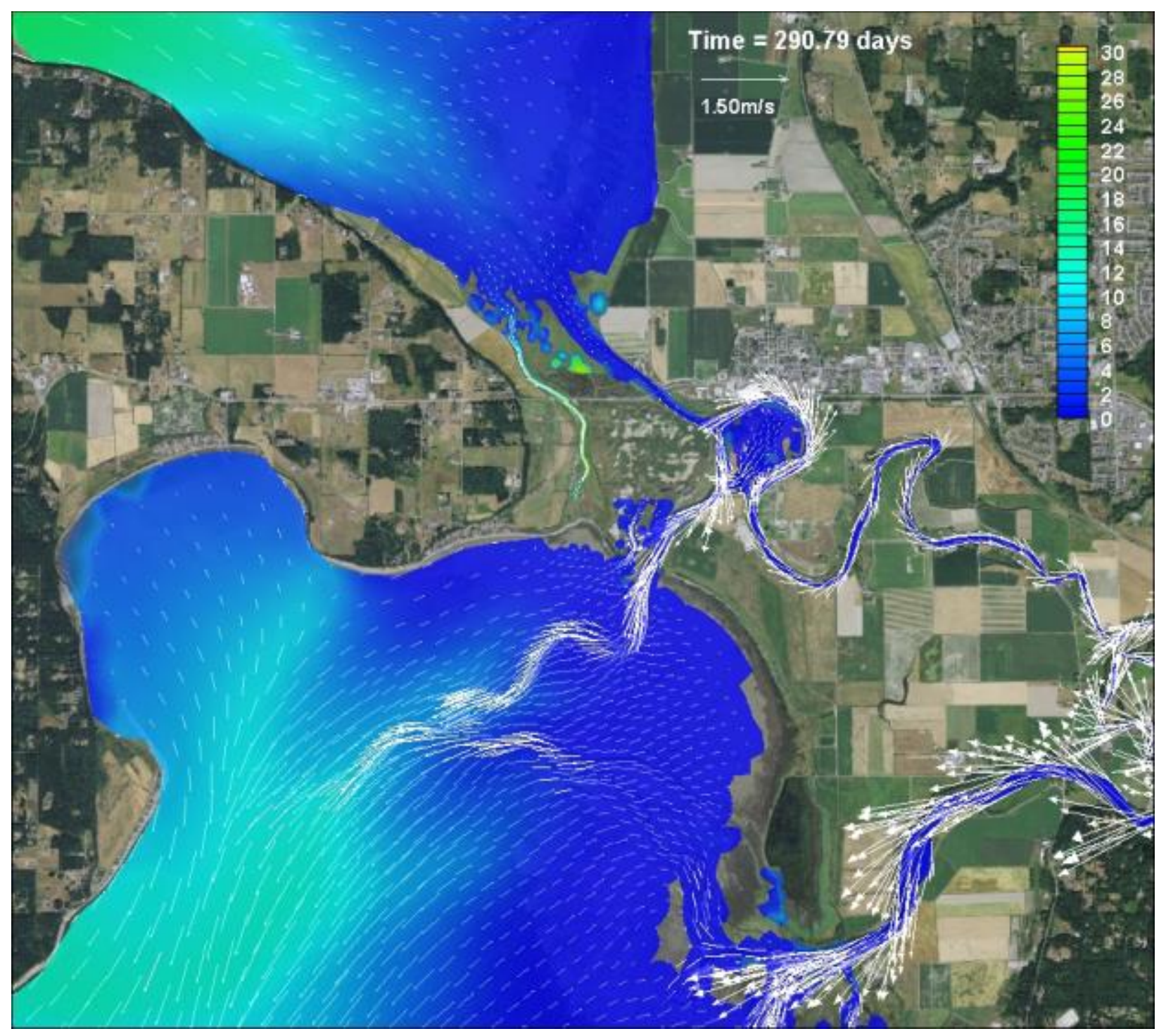

Figure D-23: Scenario 5 (Full Restoration zis a ba + SCN1) - Salinity contours and velocity vectors, high flow (full bank) condition at 26,508 cfs and peak ebb based on October 17, 2005 


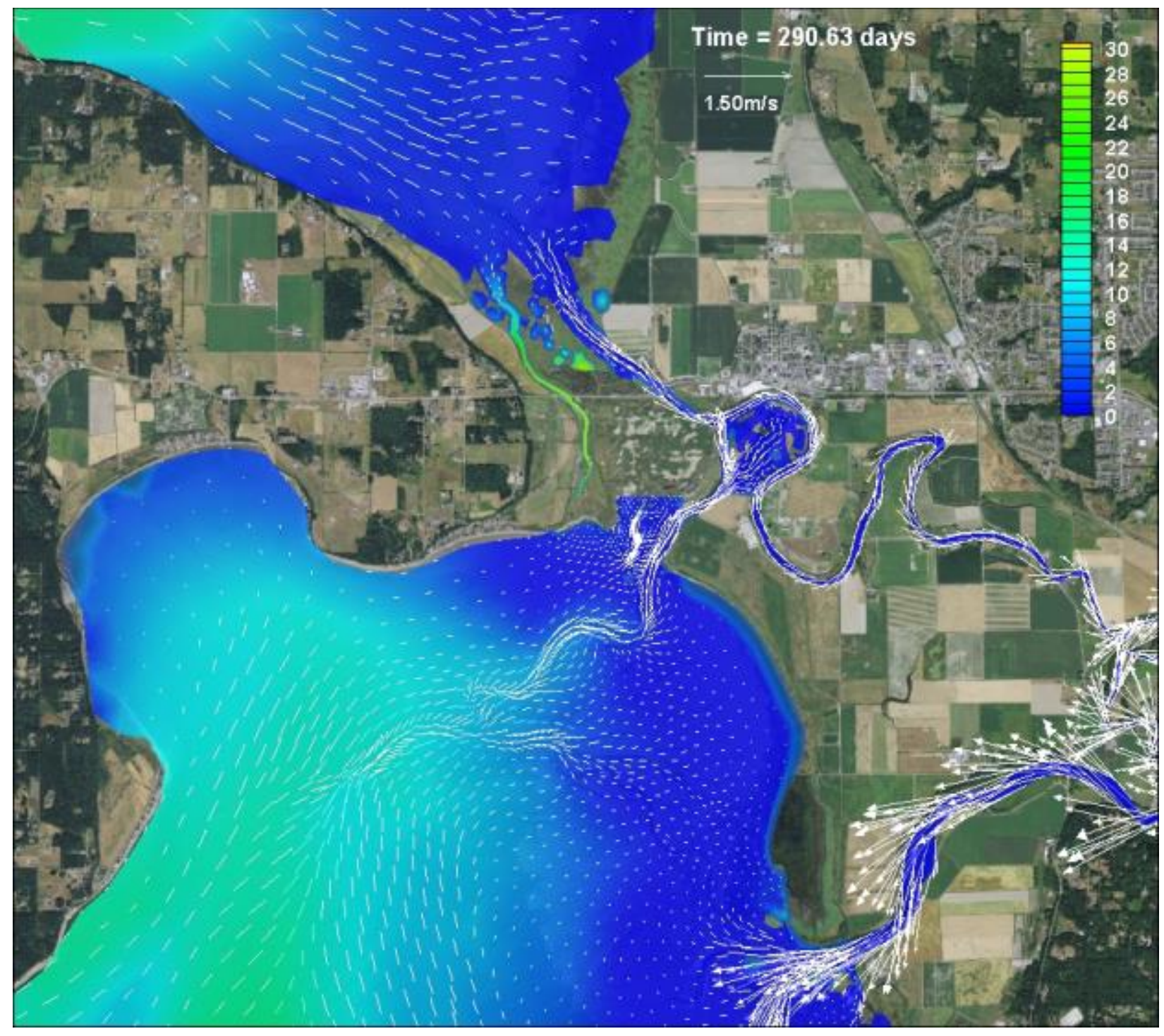

Figure D-24: Scenario 5 (Full Restoration zis a ba + SCN1) - Salinity contours and velocity vectors, high flow (full bank) condition at 26,508 cfs and peak flood based on October 17, 2005 


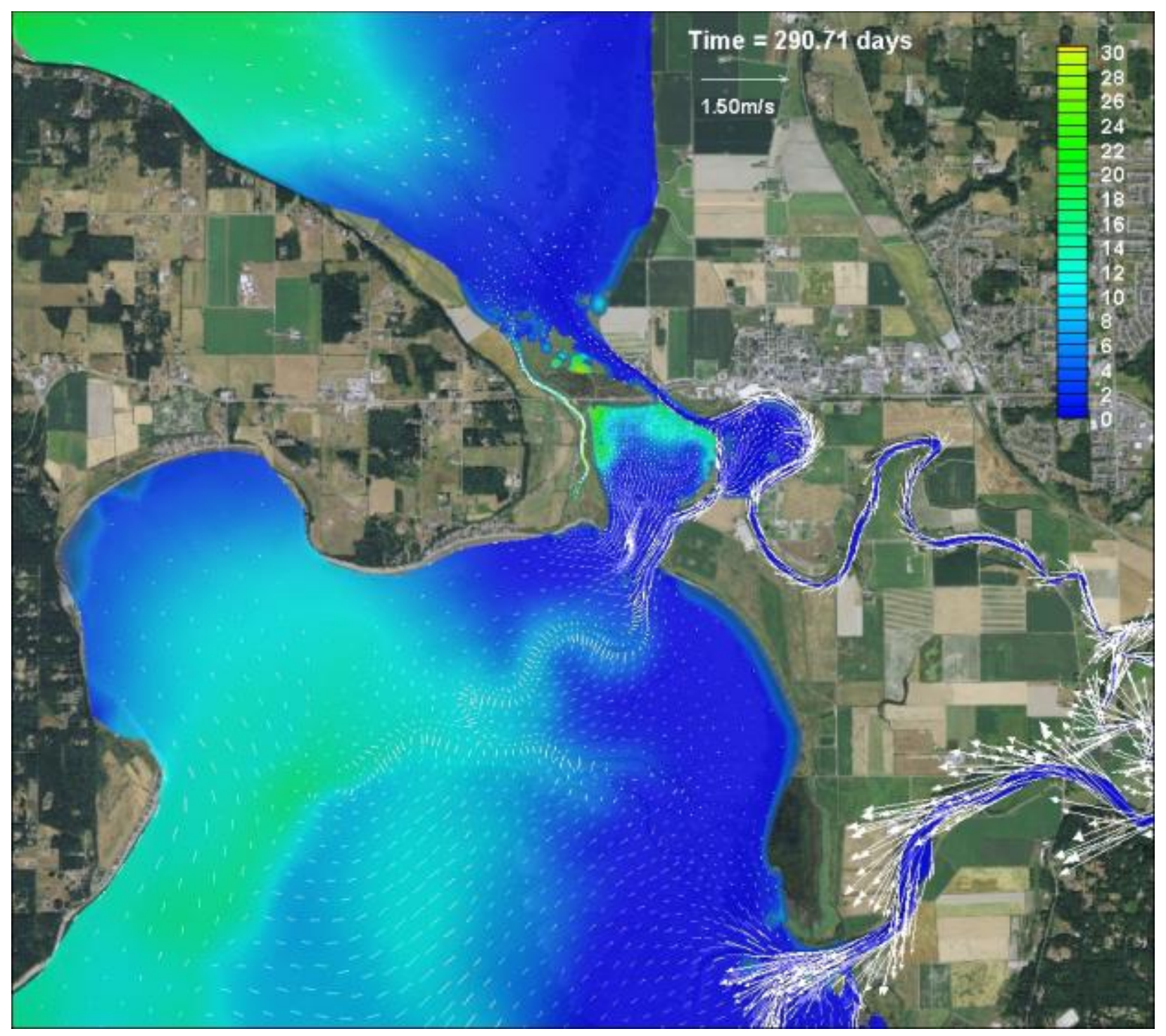

Figure D-25: Scenario 6 (Full Restoration zis a ba + SCN4) - Salinity contours and velocity vectors, high flow (full bank) condition at 26,508 cfs and high tide based on October 17, 2005 


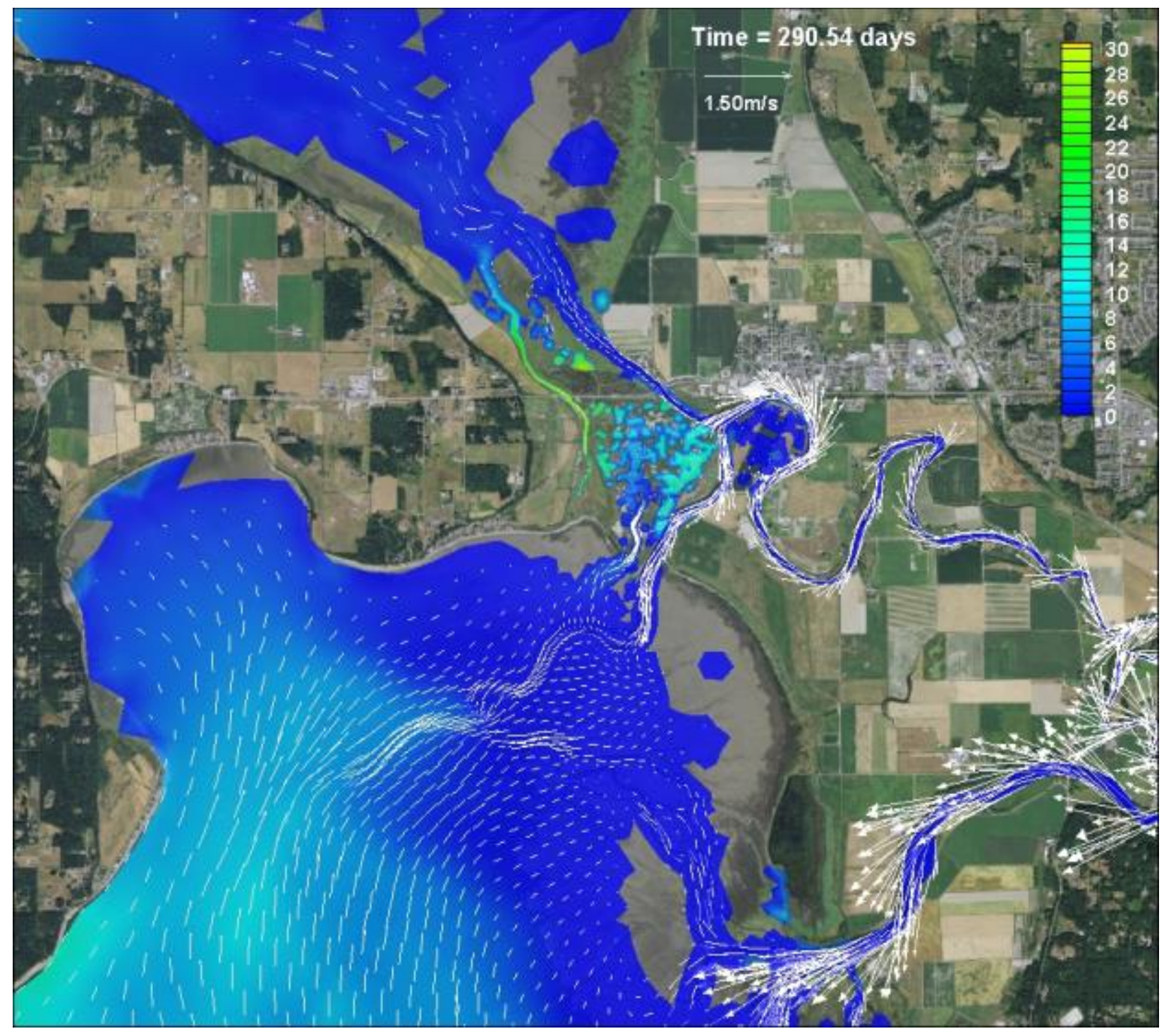

Figure D-26: Scenario 6 (Full Restoration zis a ba + SCN4) - Salinity contours and velocity vectors, high flow (full bank) condition at 26,508 cfs and low tide based on October 17, 2005 


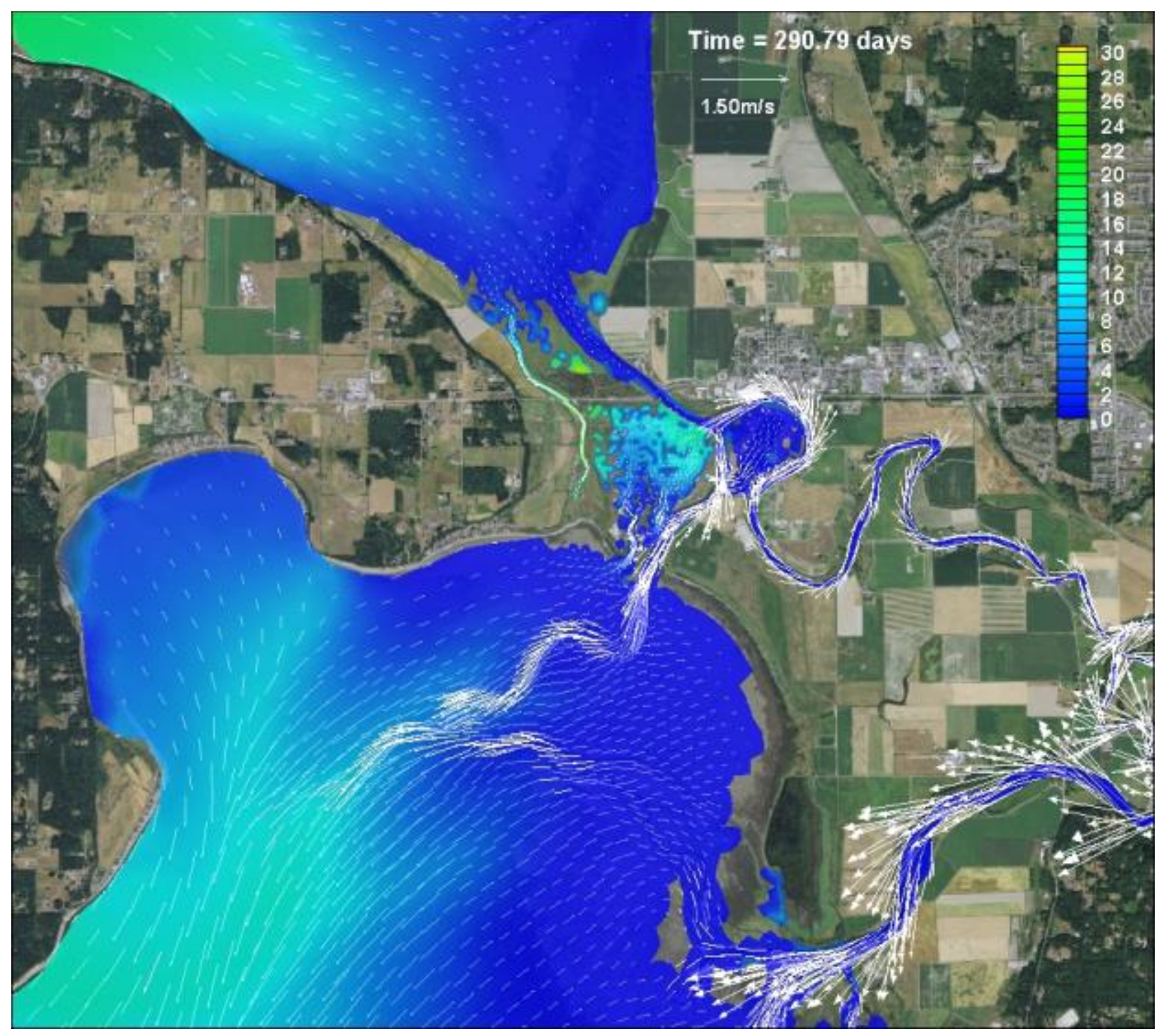

Figure D-27: Scenario 6 (Full Restoration zis a ba + SCN4) - Salinity contours and velocity vectors, high flow (full bank) condition at 26,508 cfs and peak ebb based on October 17, 2005 


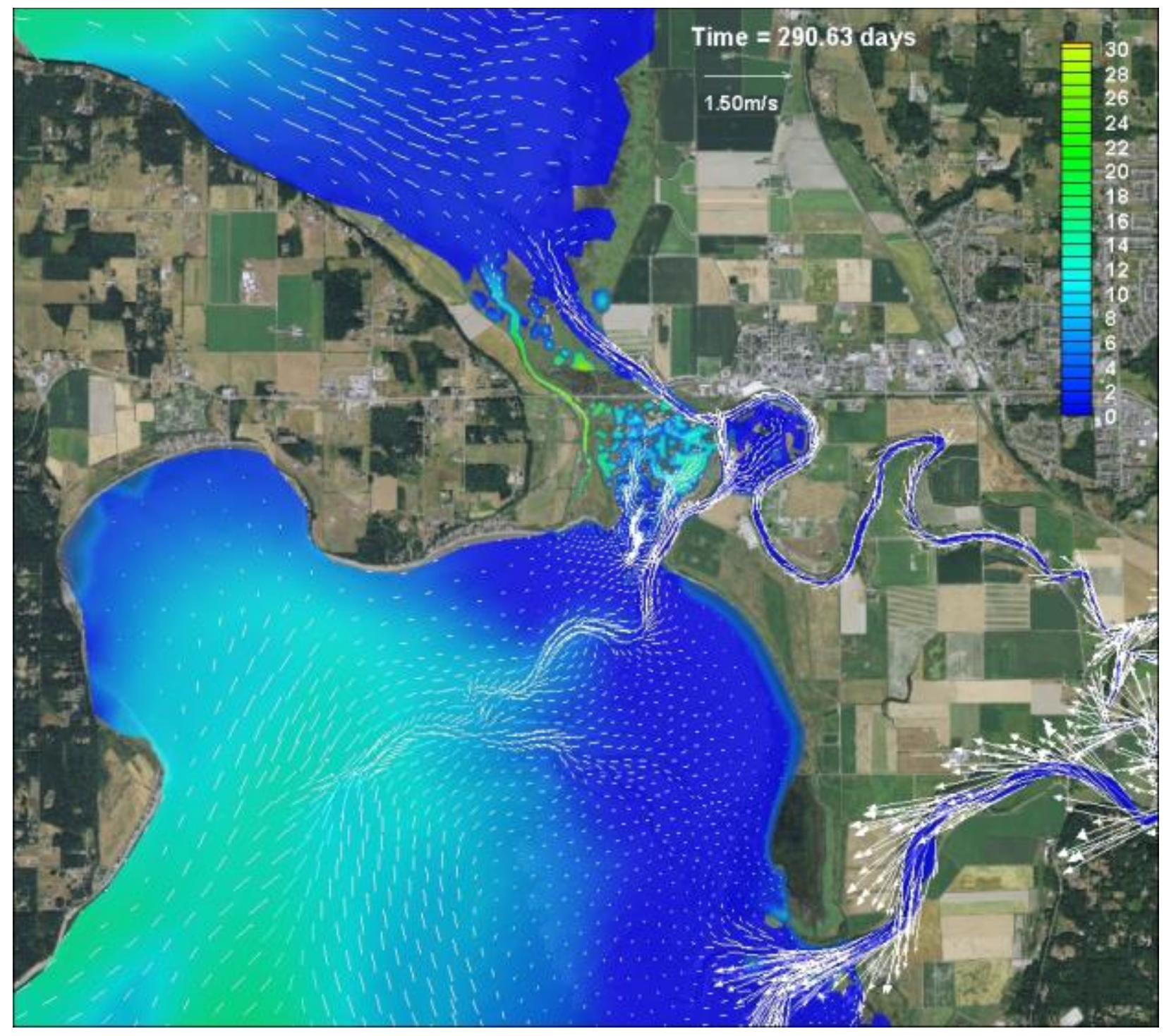

Figure D-28: Scenario 6 (Full Restoration zis a ba + SCN4) - Salinity contours and velocity vectors, high flow (full bank) condition at 26,508 cfs and peak flood based on October 17, 2005 


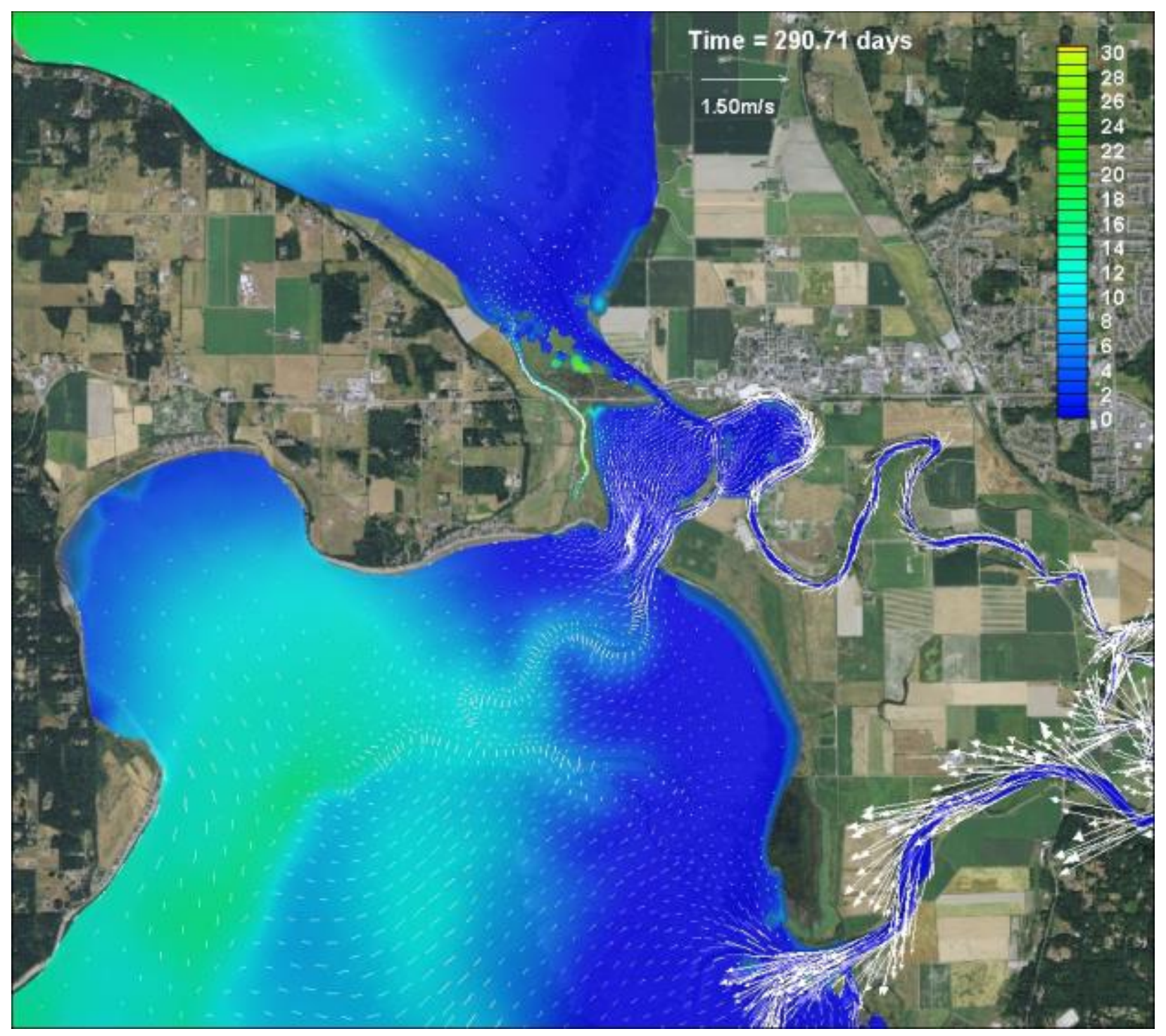

Figure D-29: Scenario 7 (Full Restoration zis a ba + SCN3) - Salinity contours and velocity vectors, high flow (full bank) condition at 26,508 cfs and high tide based on October 17, 2005 


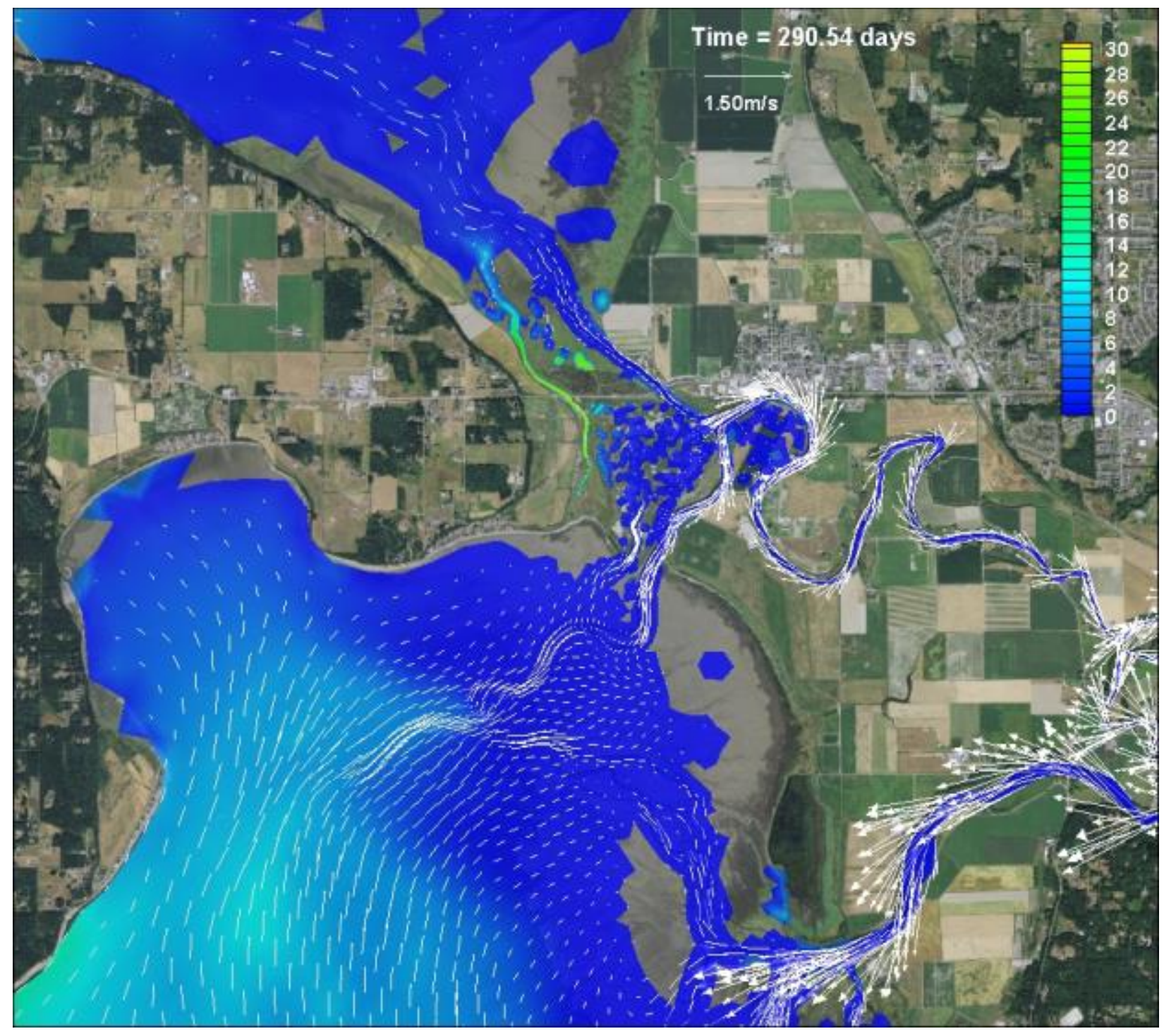

Figure D-30: Scenario 7 (Full Restoration zis a ba + SCN3) - Salinity contours and velocity vectors, high flow (full bank) condition at 26,508 cfs and low tide based on October 17, 2005 


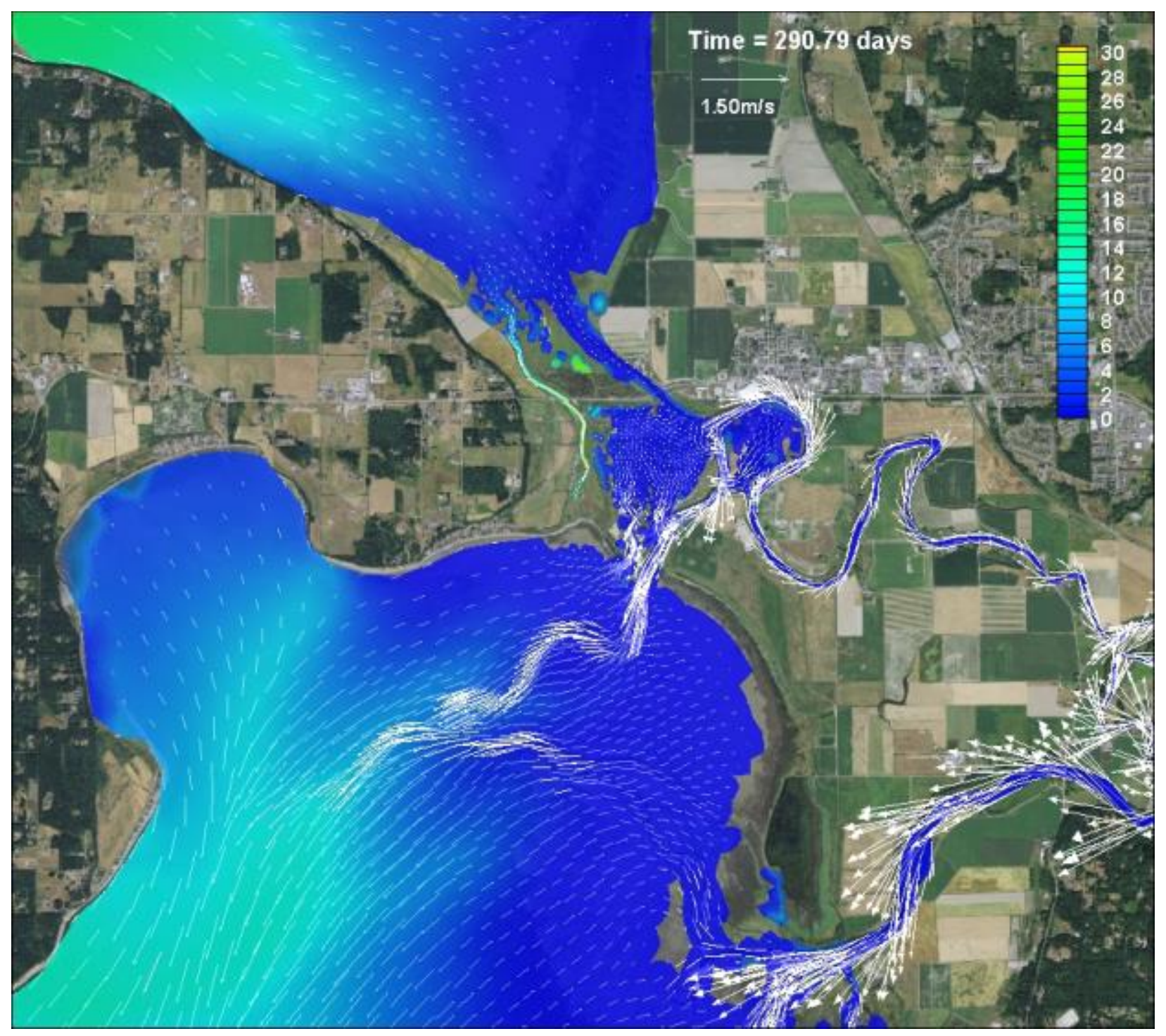

Figure D-31: Scenario 7 (Full Restoration zis a ba + SCN3) - Salinity contours and velocity vectors, high flow (full bank) condition at 26,508 cfs and peak ebb based on October 17, 2005 


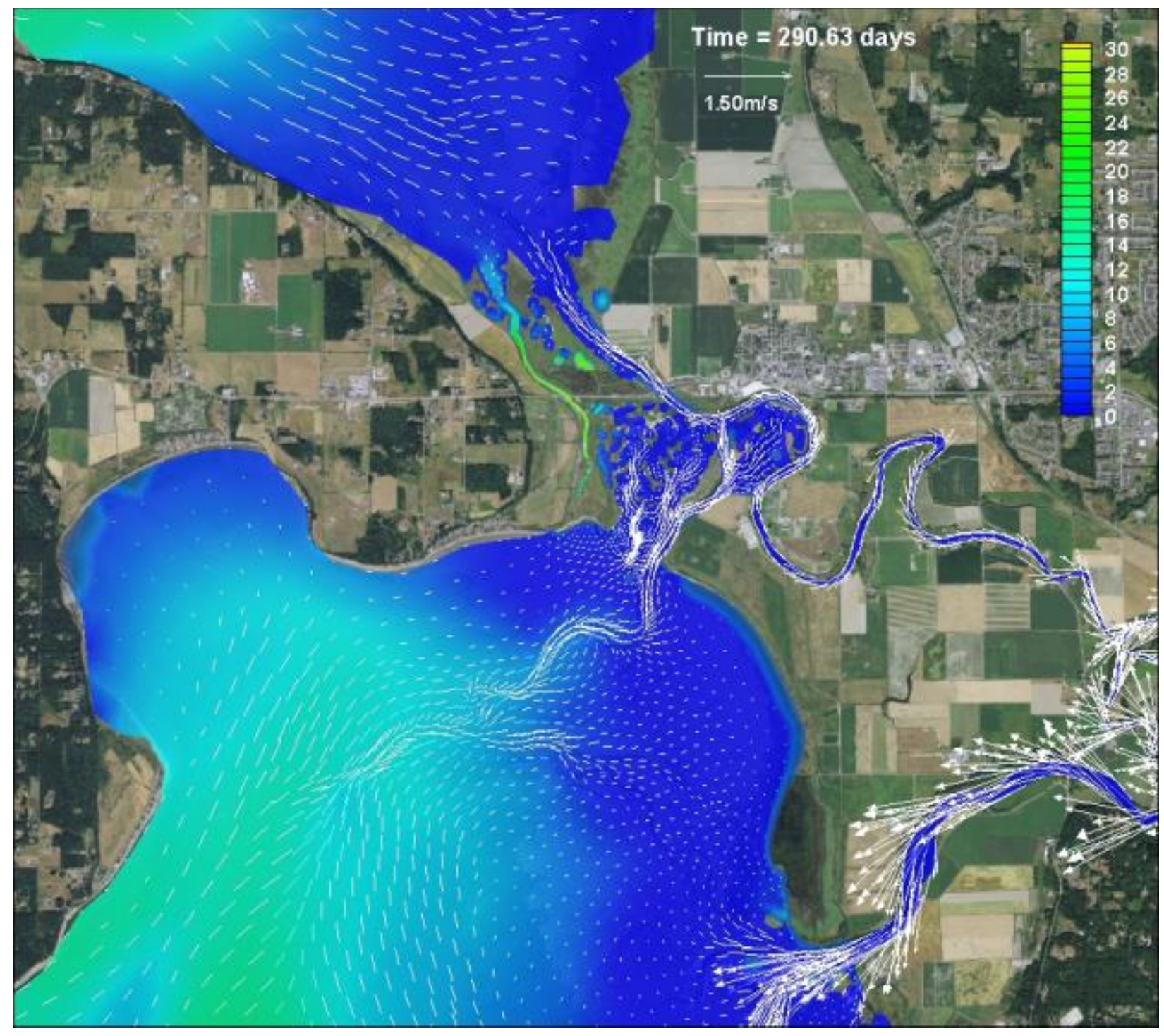

Figure D-32: Scenario 7 (Full Restoration zis a ba + SCN3) - Salinity contours and velocity vectors, high flow (full bank) condition at 26,508 cfs and peak flood based on October 17, 2005 


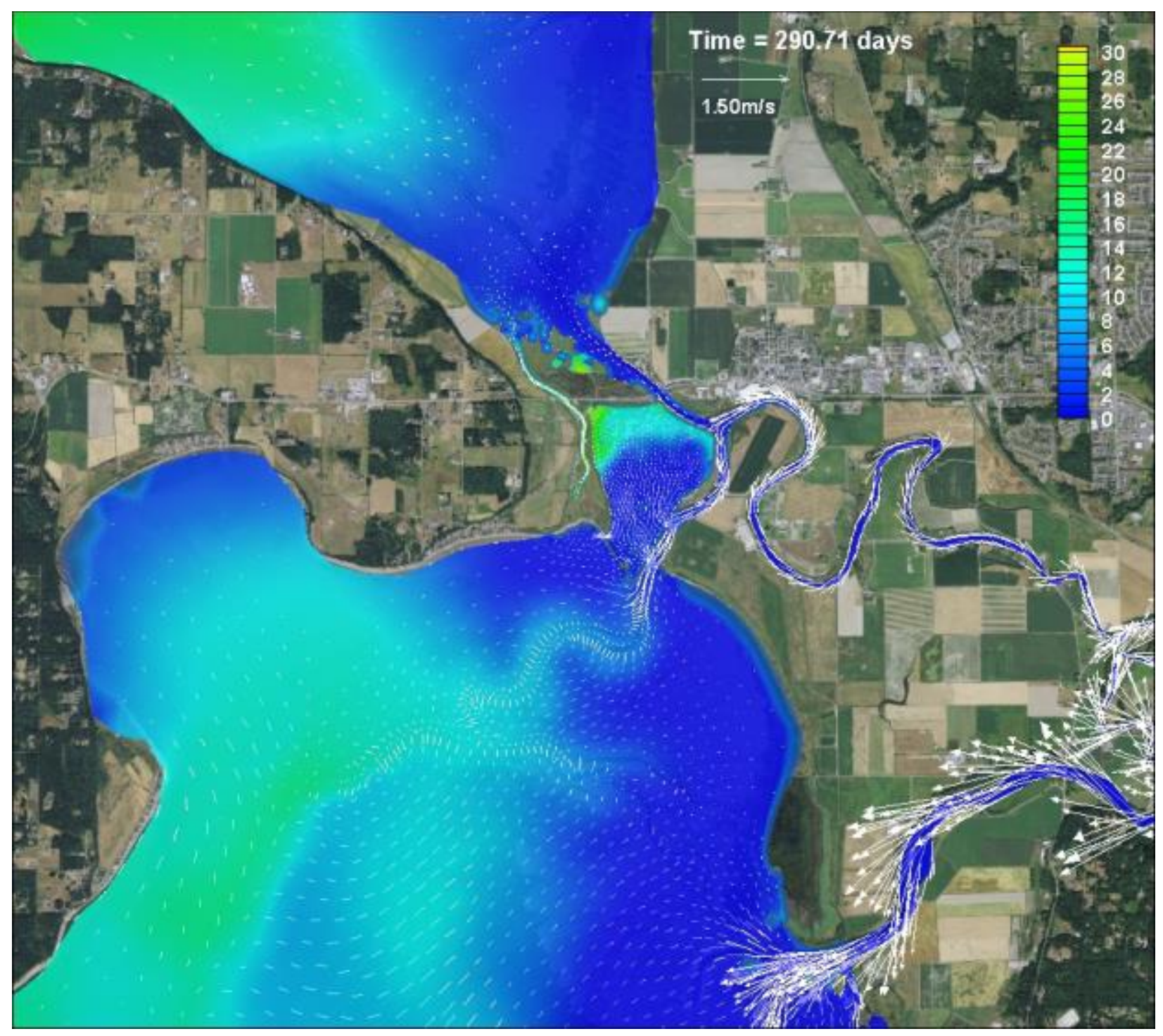

Figure D-33: Scenario 8 (3 Levee Breaches Leque) - Salinity contours and velocity vectors, high flow (full bank) condition at 26,508 cfs and high tide based on October 17, 2005 


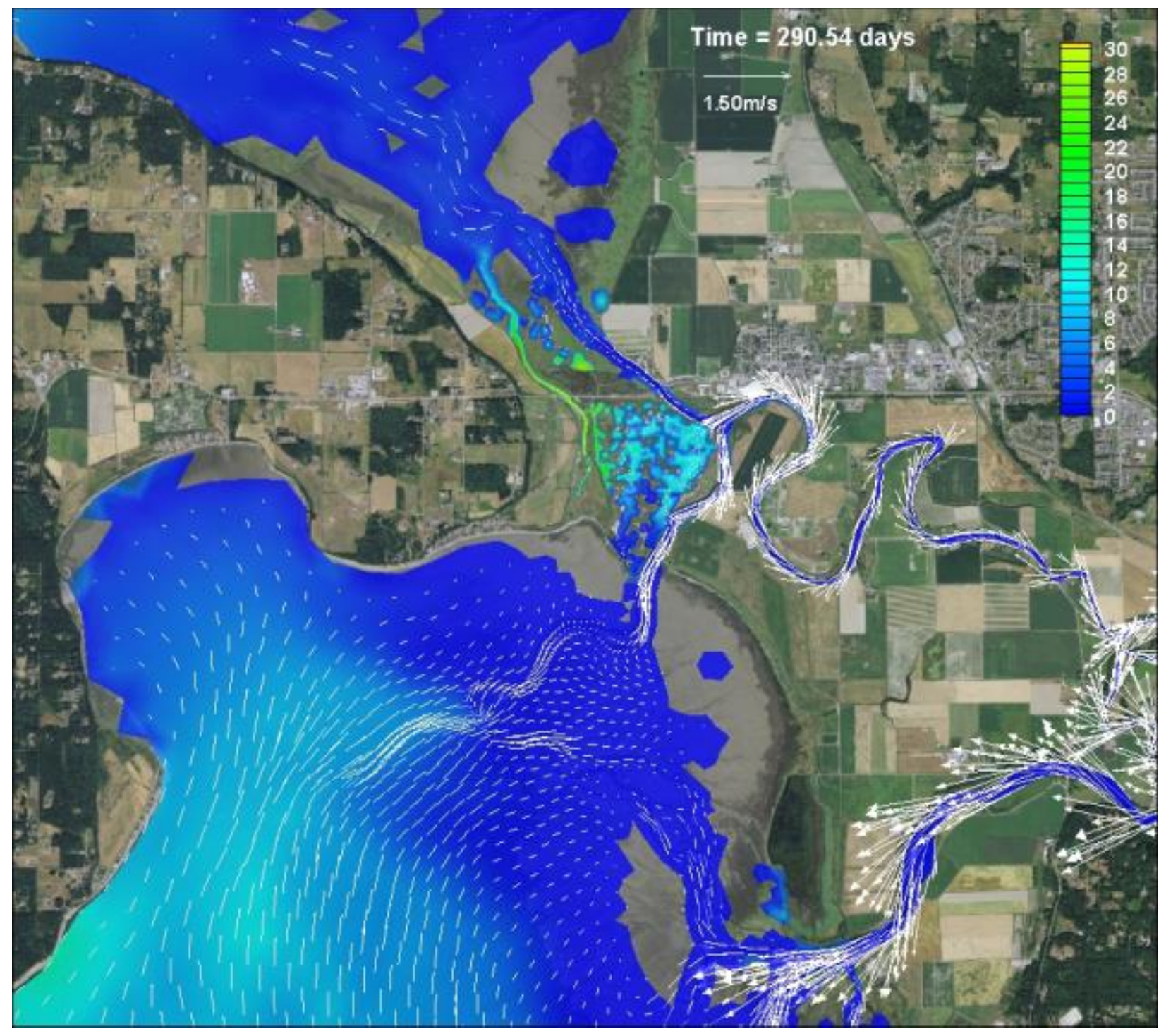

Figure D-34: Scenario 8 (3 Levee Breaches Leque) - Salinity contours and velocity vectors, high flow (full bank) condition at 26,508 cfs and low tide based on October 17, 2005 


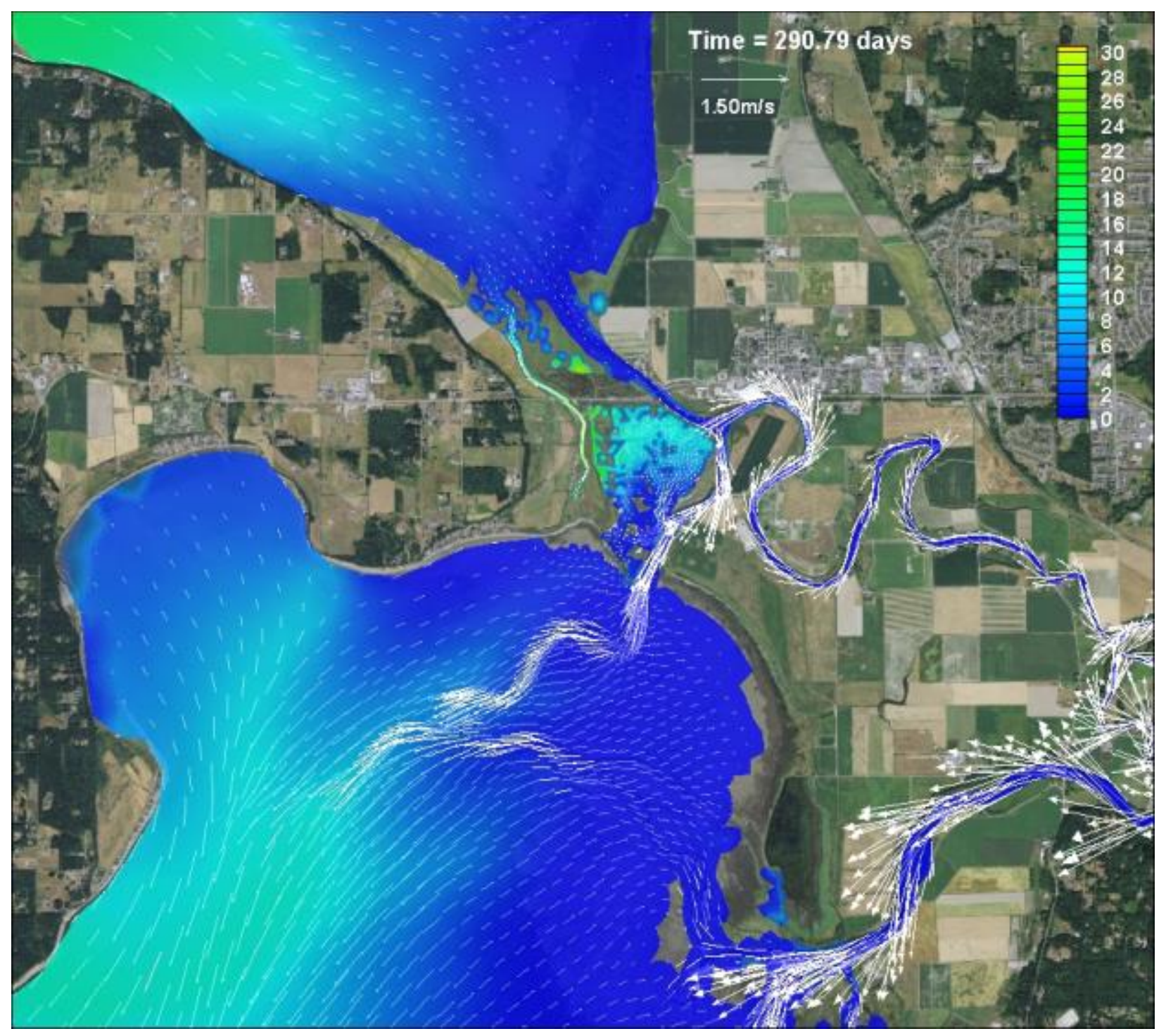

Figure D-35: Scenario 8 (3 Levee Breaches Leque) - Salinity contours and velocity vectors, high flow (full bank) condition at 26,508 cfs and peak ebb based on October 17, 2005 


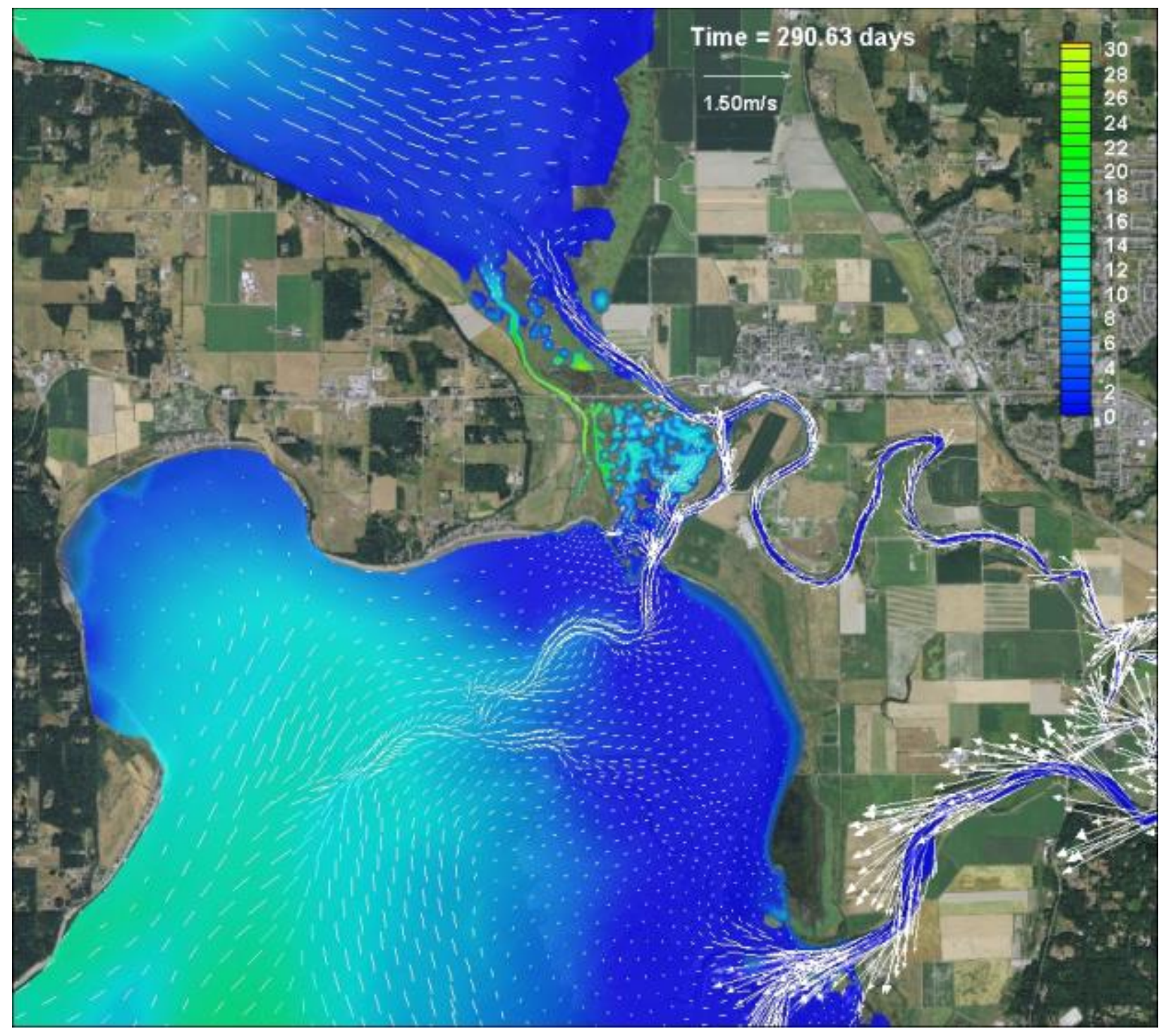

Figure D-36: Scenario 8 (3 Levee Breaches Leque) - Salinity contours and velocity vectors, high flow (full bank) condition at 26,508 cfs and peak flood based on October 17, 2005 


\section{Appendix E}

Plan View Contour Plots - October 2005 Conditions - Bed Shear 



\section{Appendix E}

\section{Plan View Contour Plots - October 2005 Conditions - Bed Shear}

October 2005 plan view contour plots at high-flow (i.e., bank full) condition for bed sheers for Leque Island and zis a ba restoration site stations are provided in this appendix.

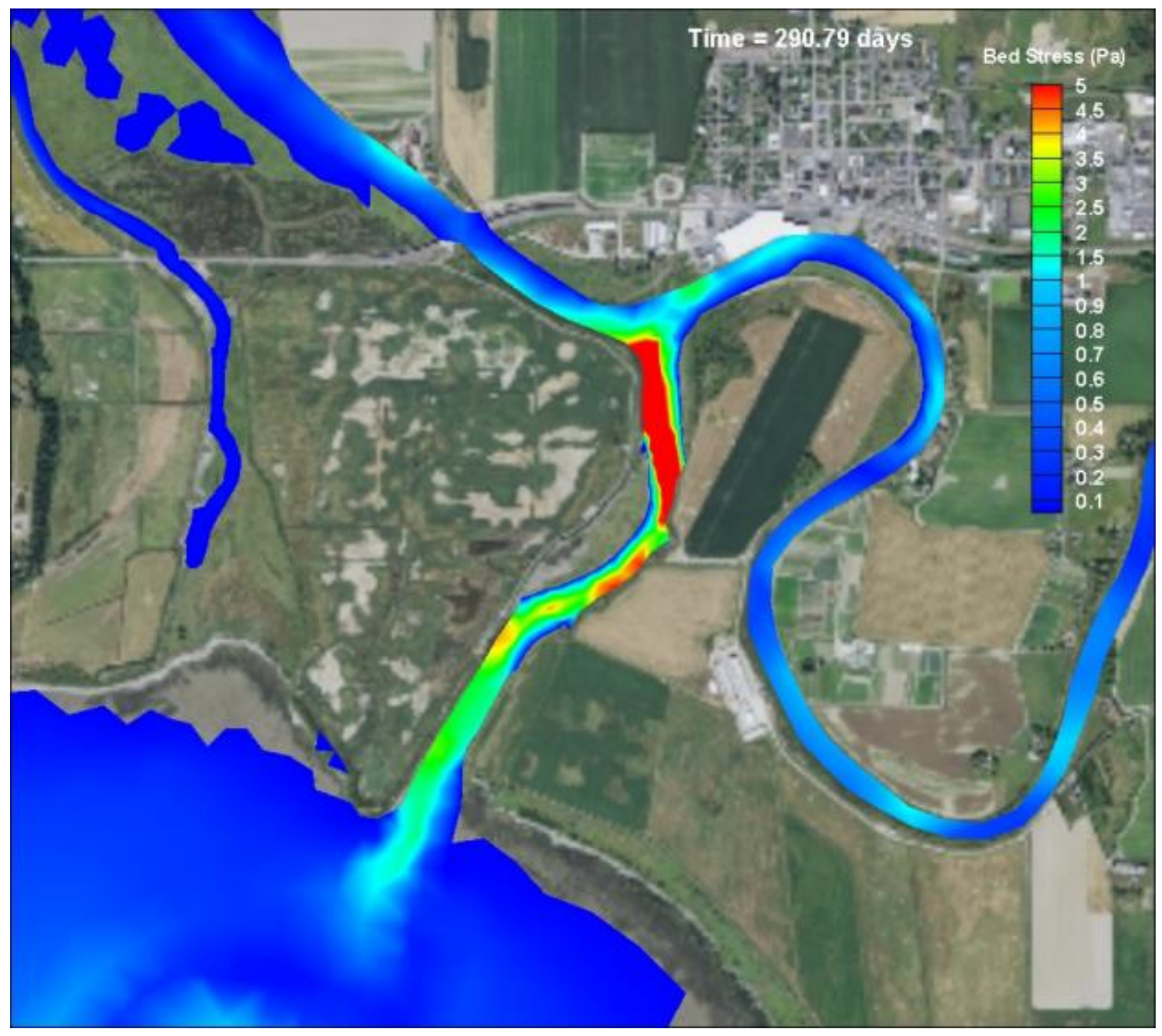

Figure E-1: Scenario 0 (Baseline Condition) - Bed shear stress, October 17, 2005, peak ebb 


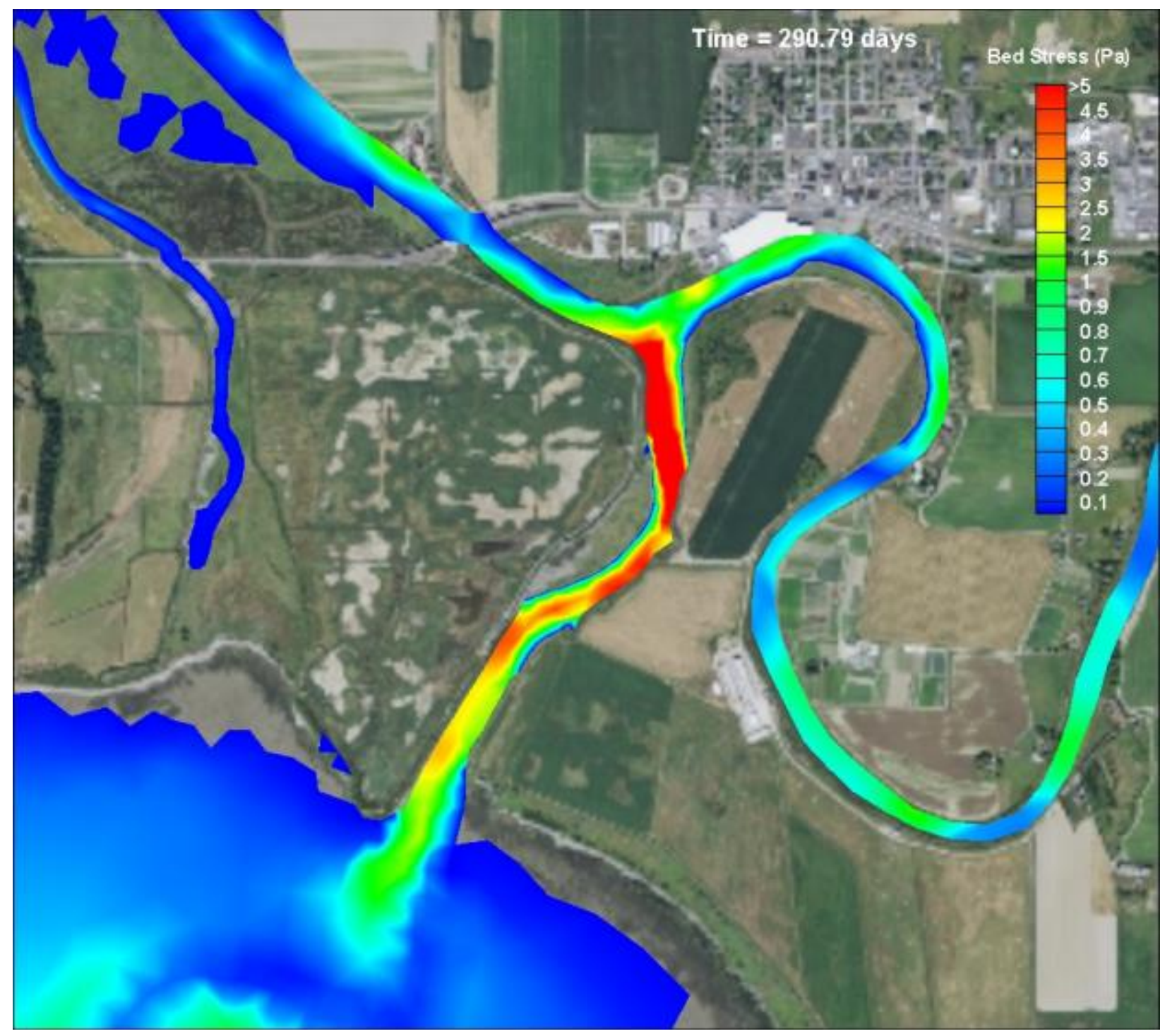

Figure E-2: Scenario 0 (Baseline Condition) - Bed shear stress, October 17, 2005, peak flood 


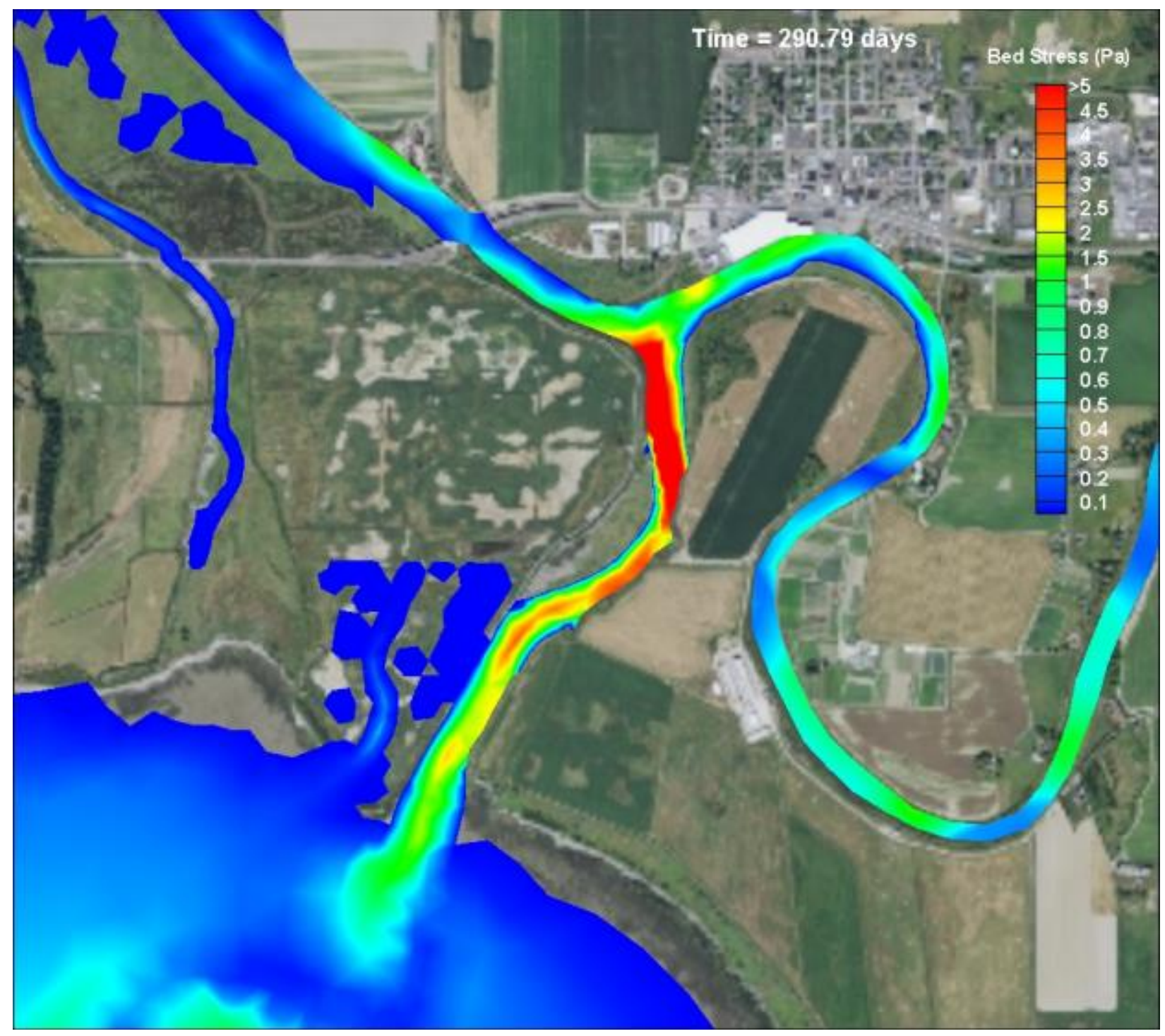

Figure E-3: Scenario 1 (Partial Restoration Leque) - Bed shear stress, October 17, 2005, peak ebb 


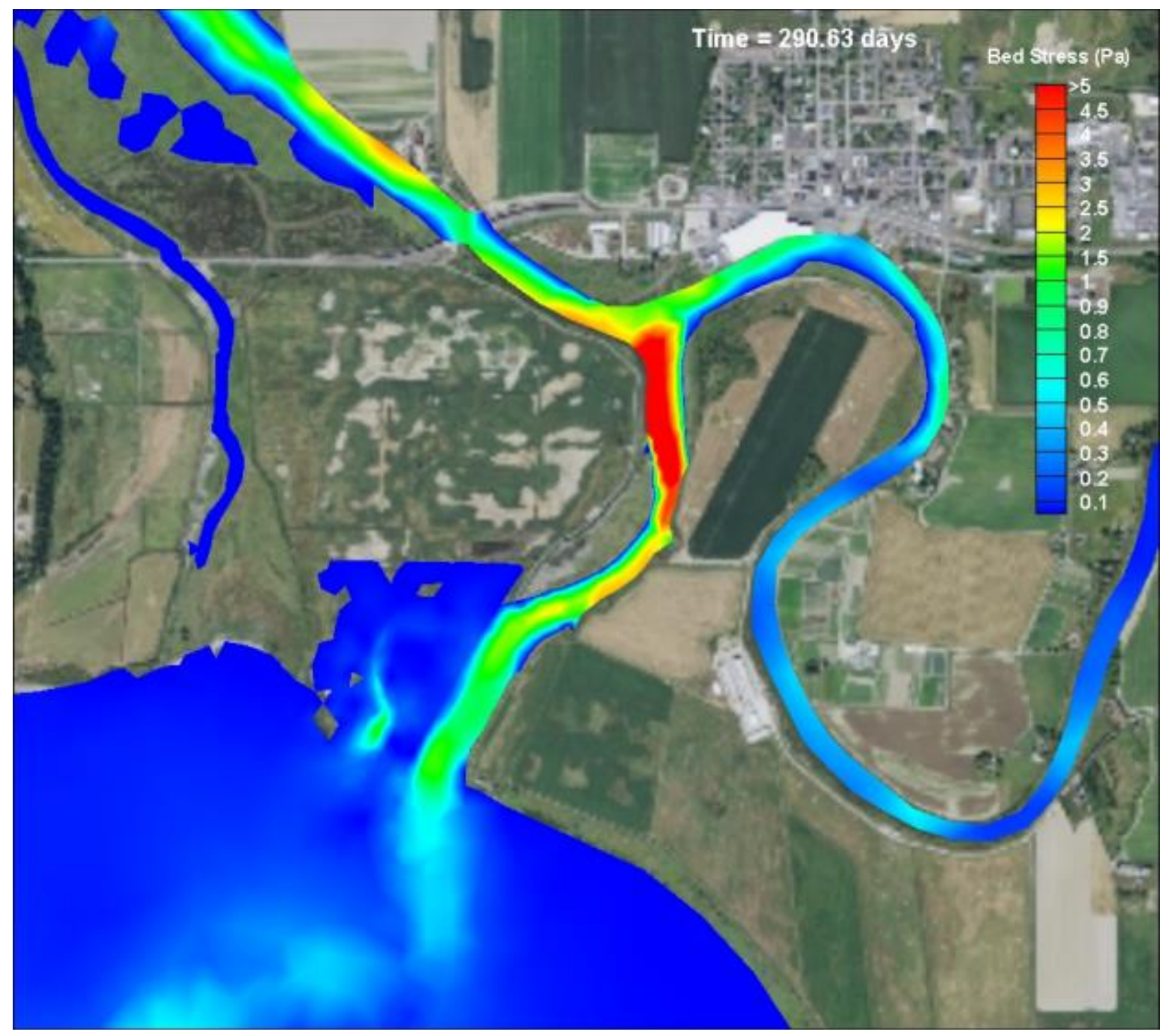

Figure E-4: Scenario 1 (Partial Restoration Leque) - Bed shear stress, October 17, 2005, peak flood 


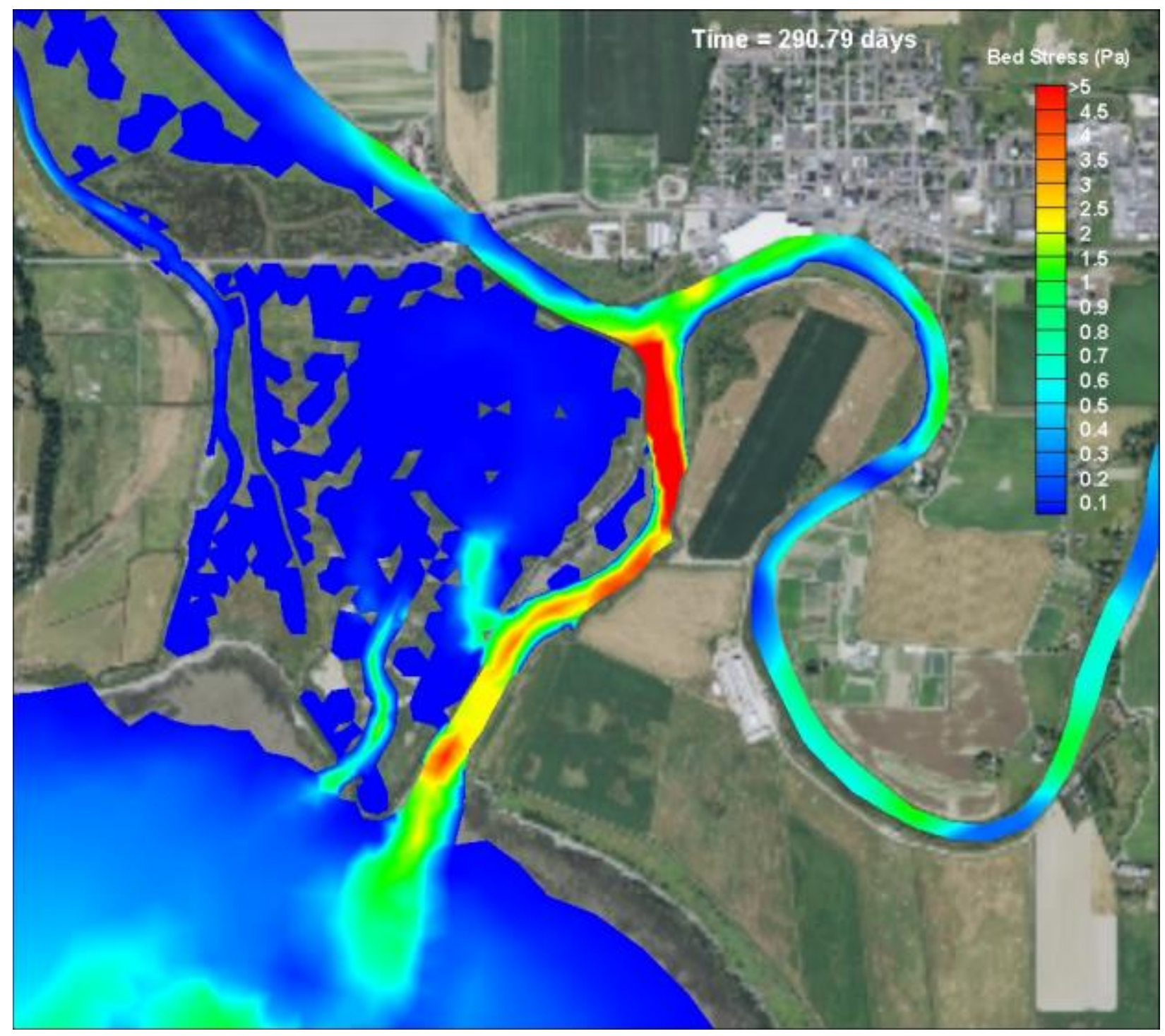

Figure E-5: Scenario 2 (4 Levee Breach Leque) - Bed shear stress, October 17, 2005, peak ebb 


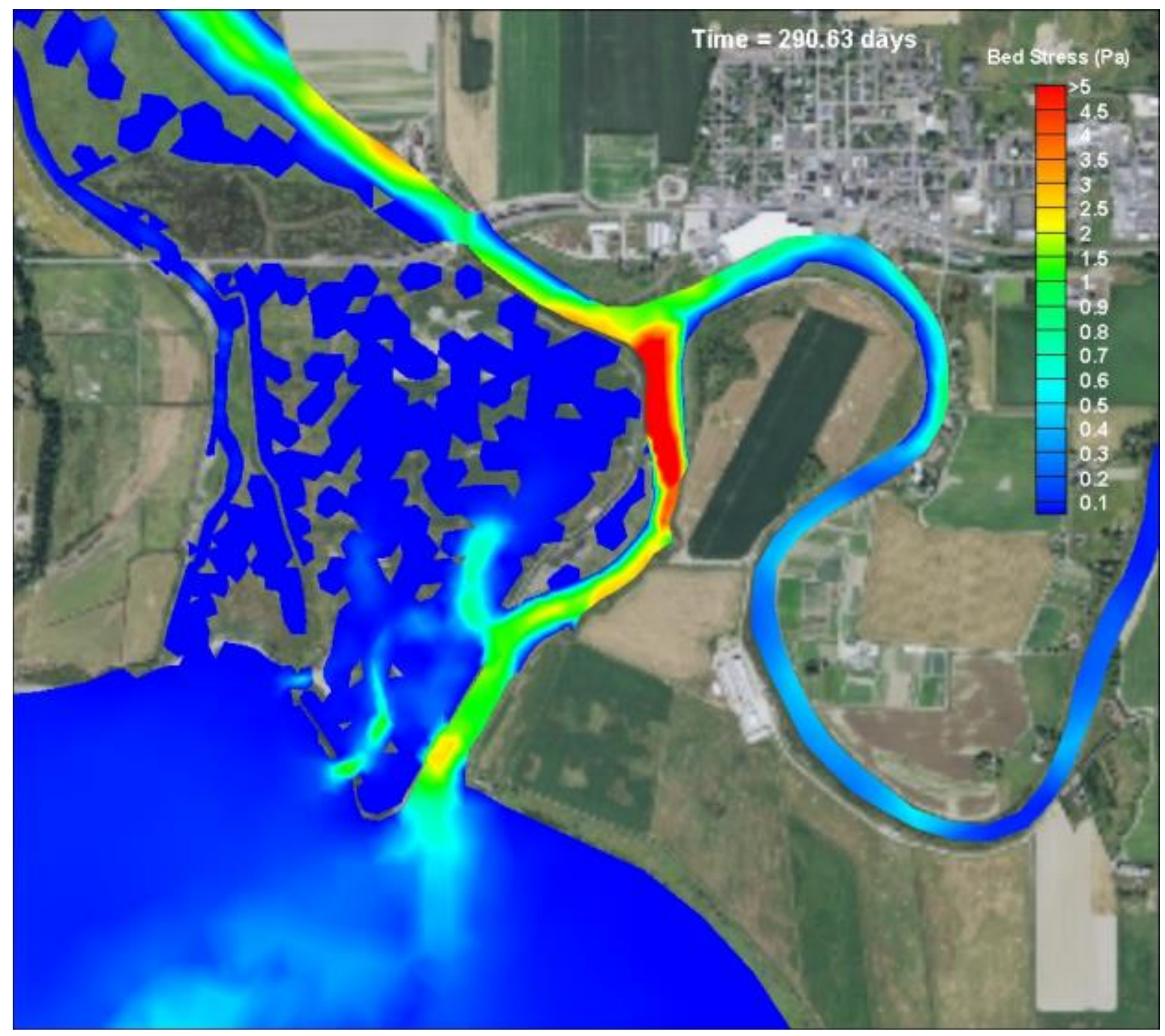

Figure E-6: Scenario 2 (4 Levee Breach Leque) - Bed shear stress, October 17, 2005, peak flood 


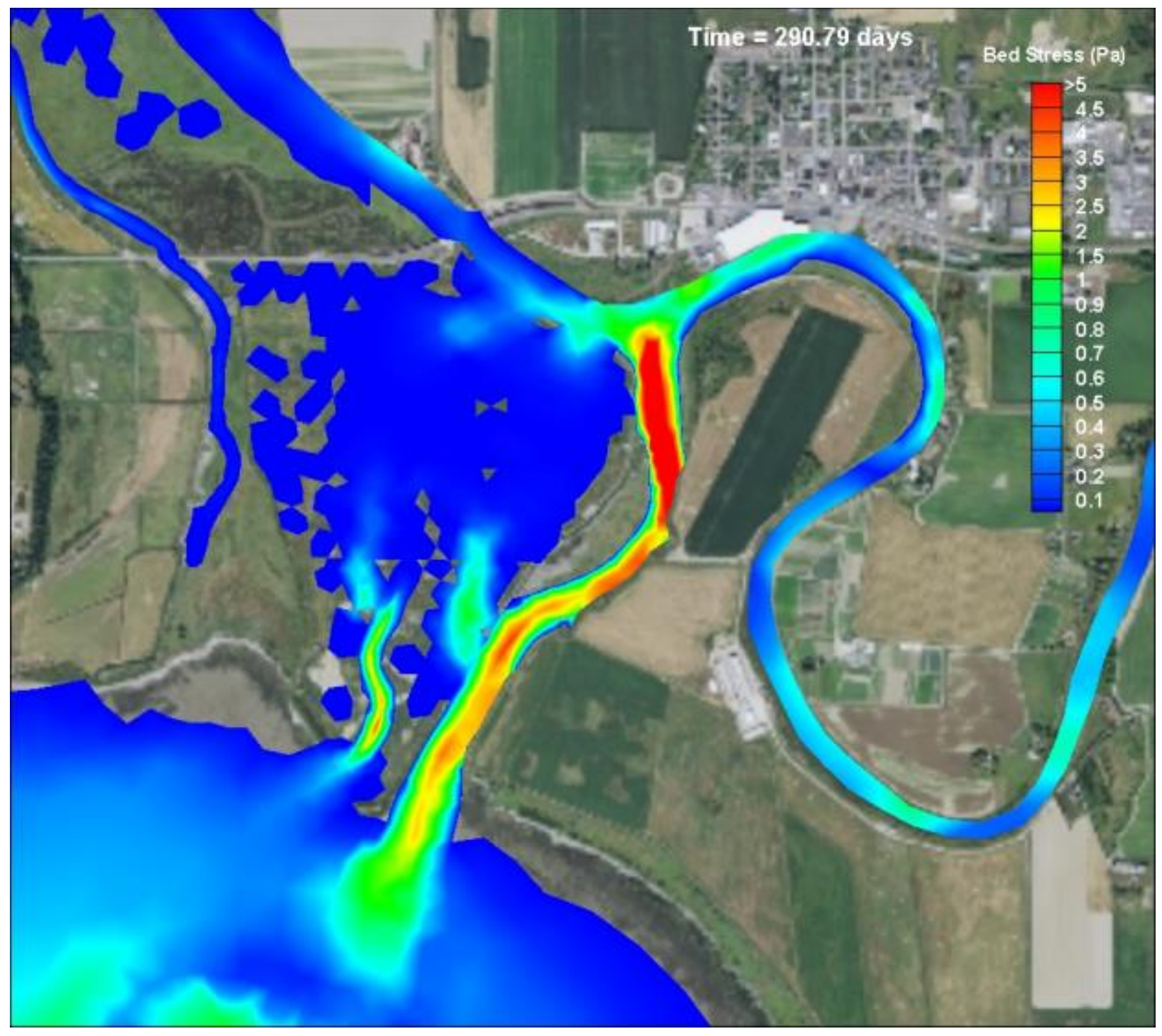

Figure E-7: Scenario 3 (Full Restoration Leque 1) - Bed shear stress, October 17, 2005, peak ebb 


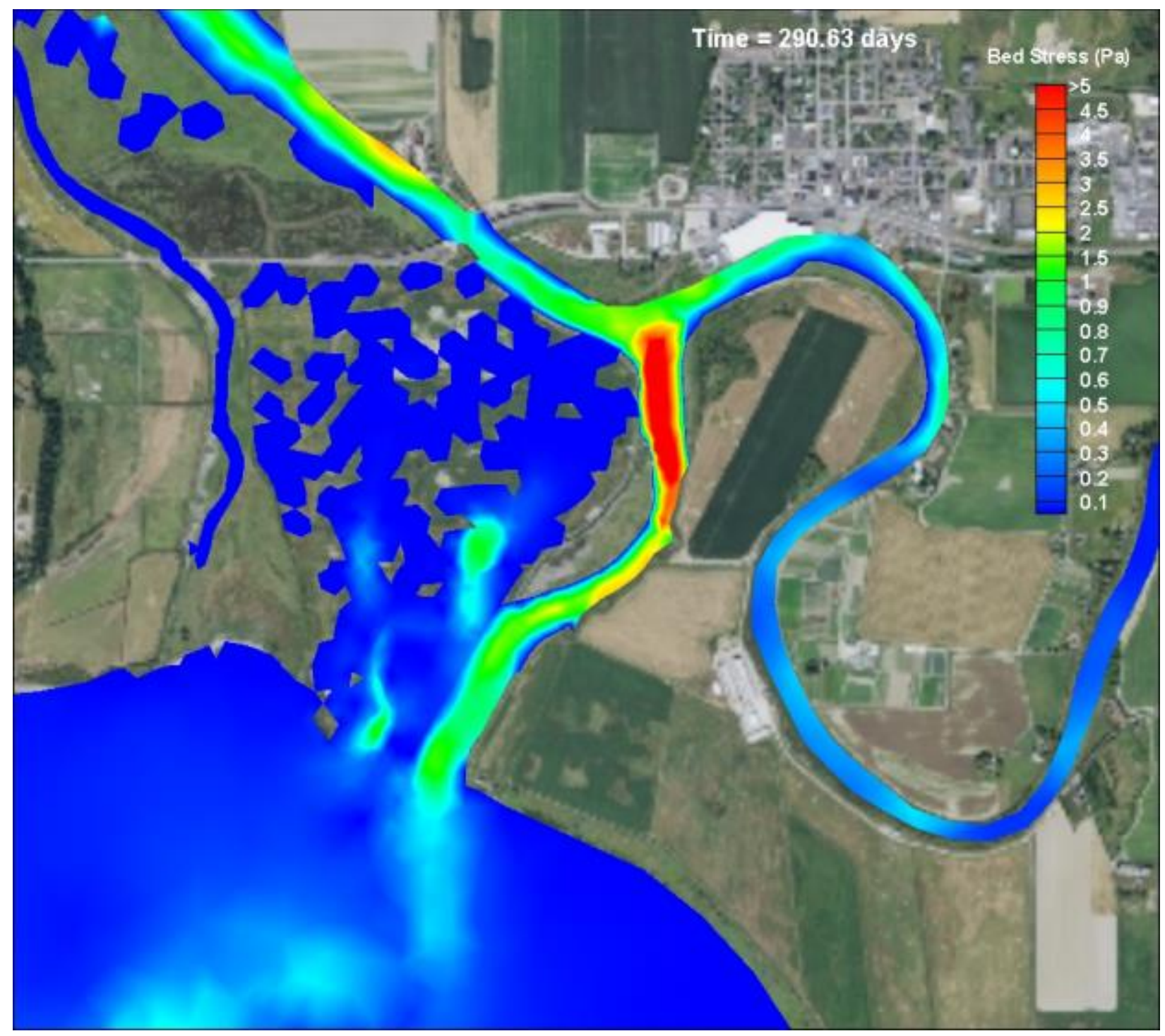

Figure E-8: Scenario 3 (Full Restoration Leque 1) - Bed shear stress, October 17, 2005, peak flood 


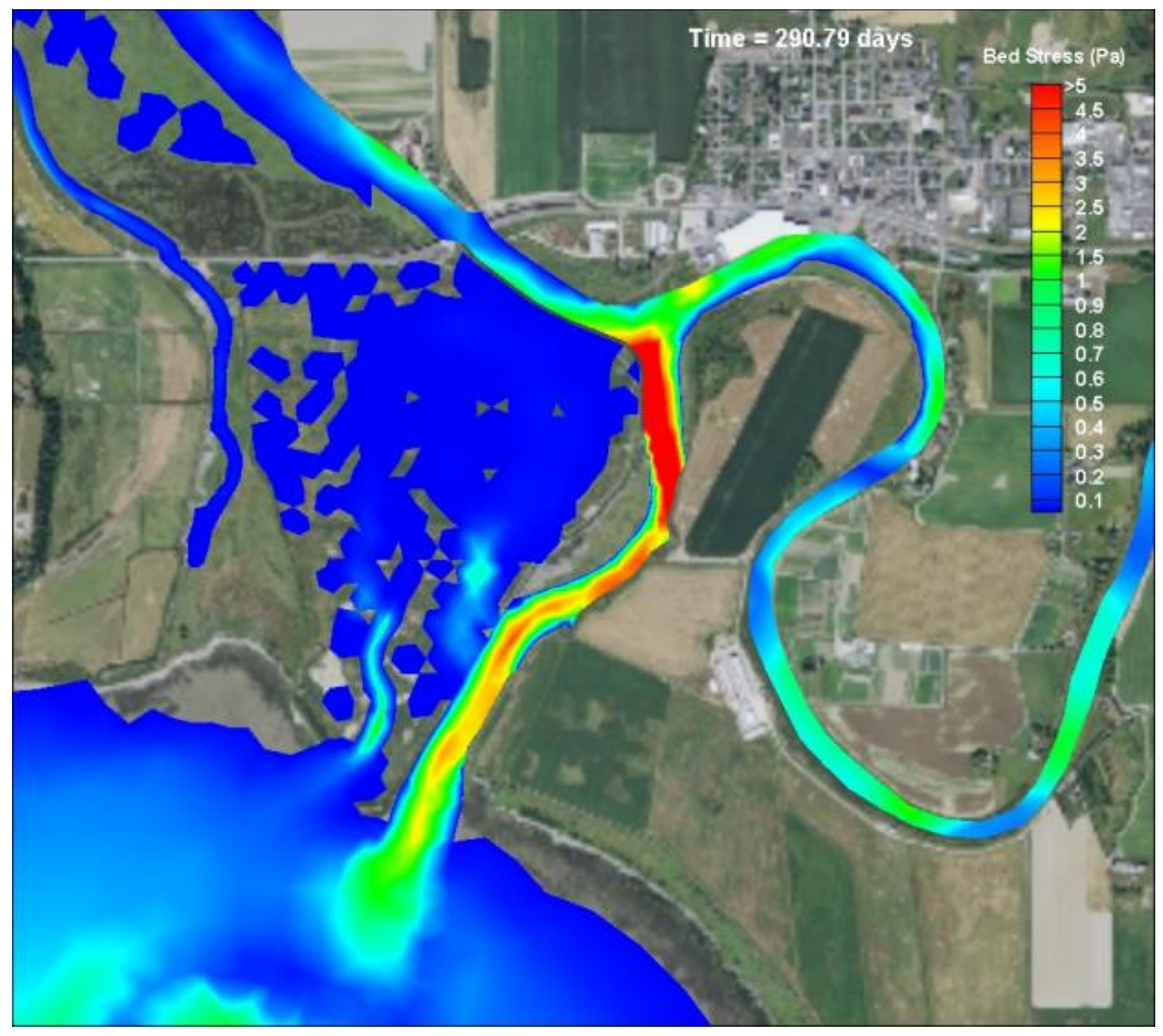

Figure E-9: Scenario 4 (Full Restoration Leque 2) - Bed shear stress, October 17, 2005, peak ebb 


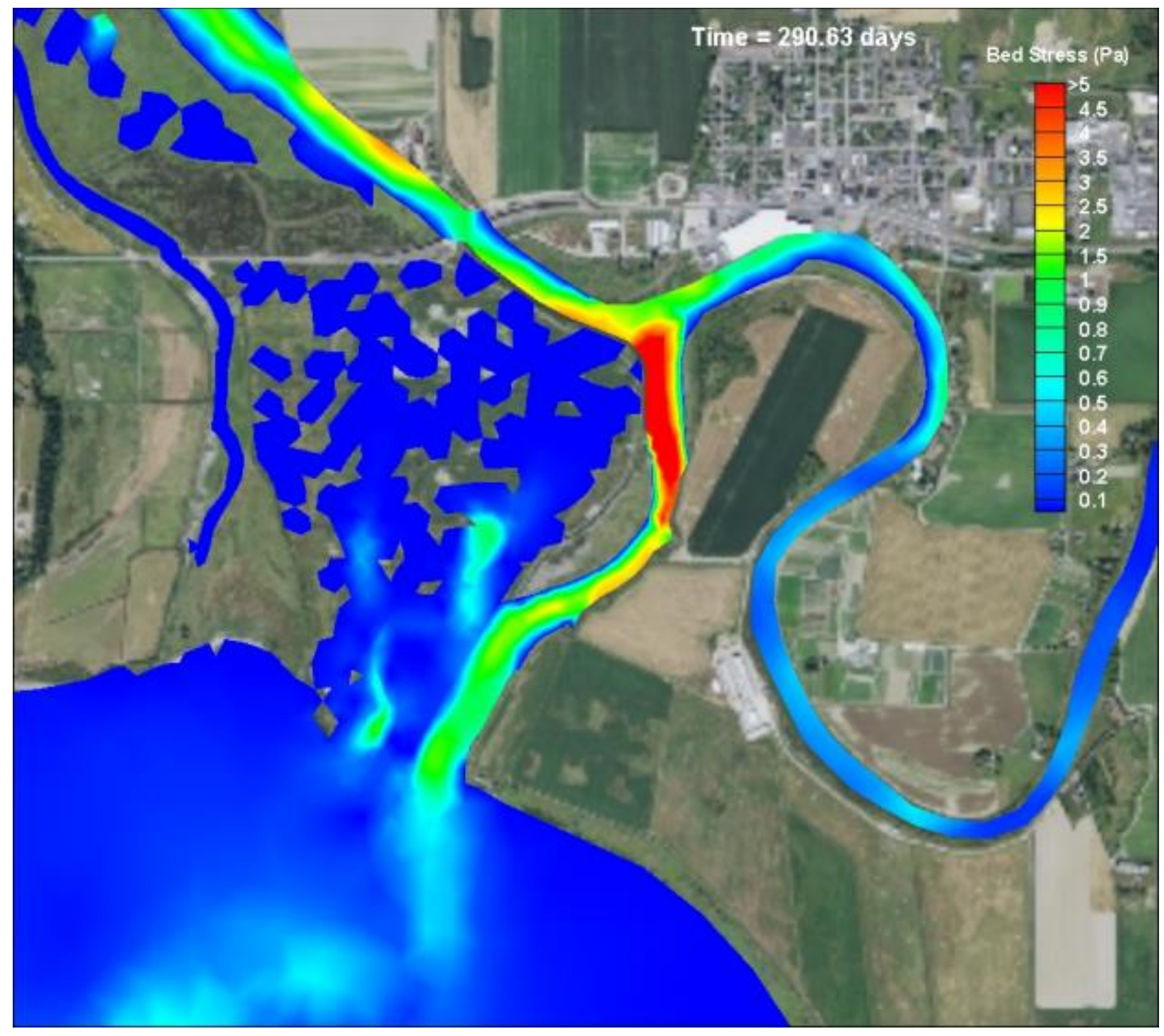

Figure E-10: Scenario 4 (Full Restoration Leque 2) - Bed shear stress, October 17, 2005, peak flood 


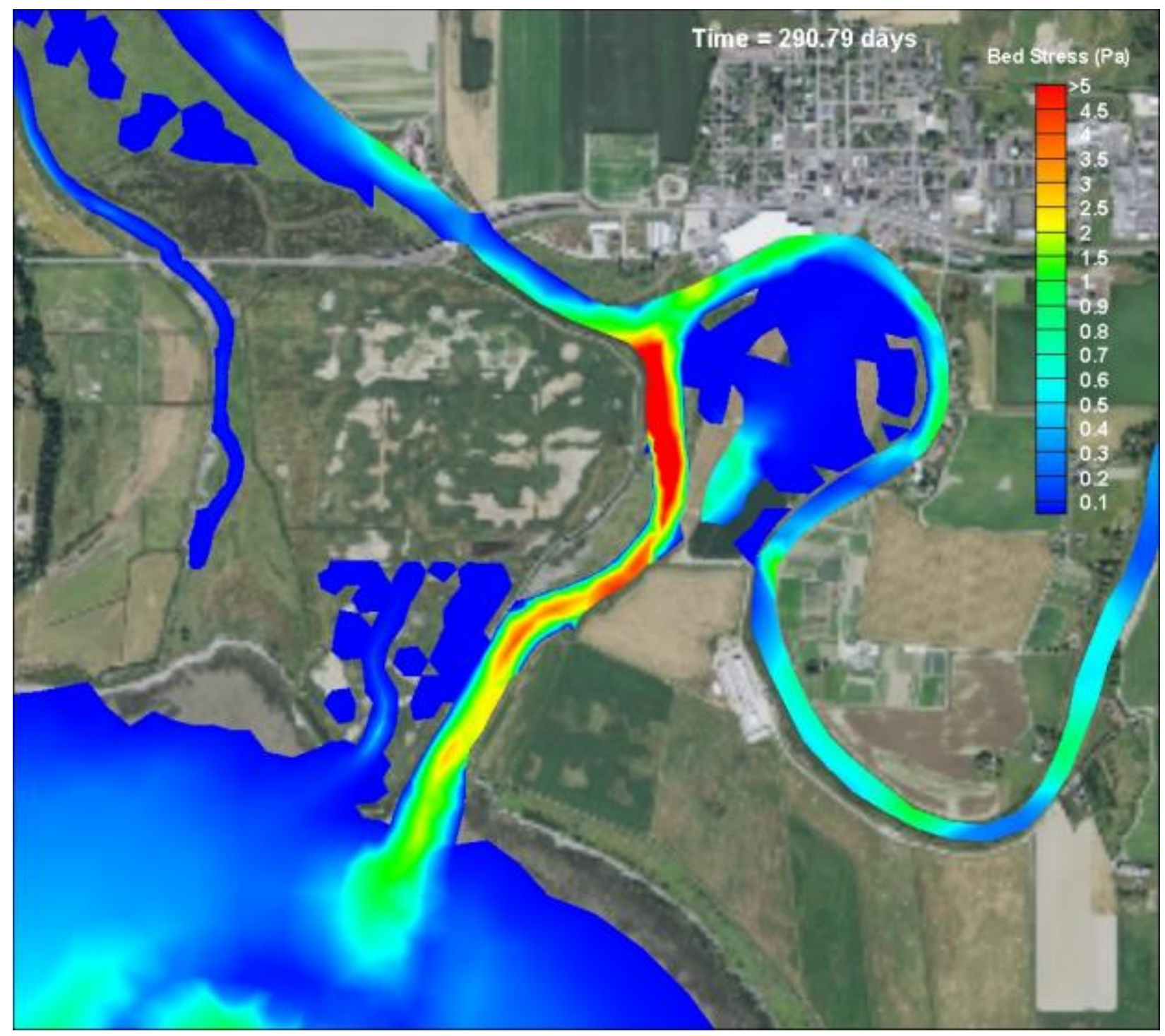

Figure E-11: Scenario 5 (Full Restoration zis a ba + SCN1) - Bed shear stress, October 17, 2005, peak flood 


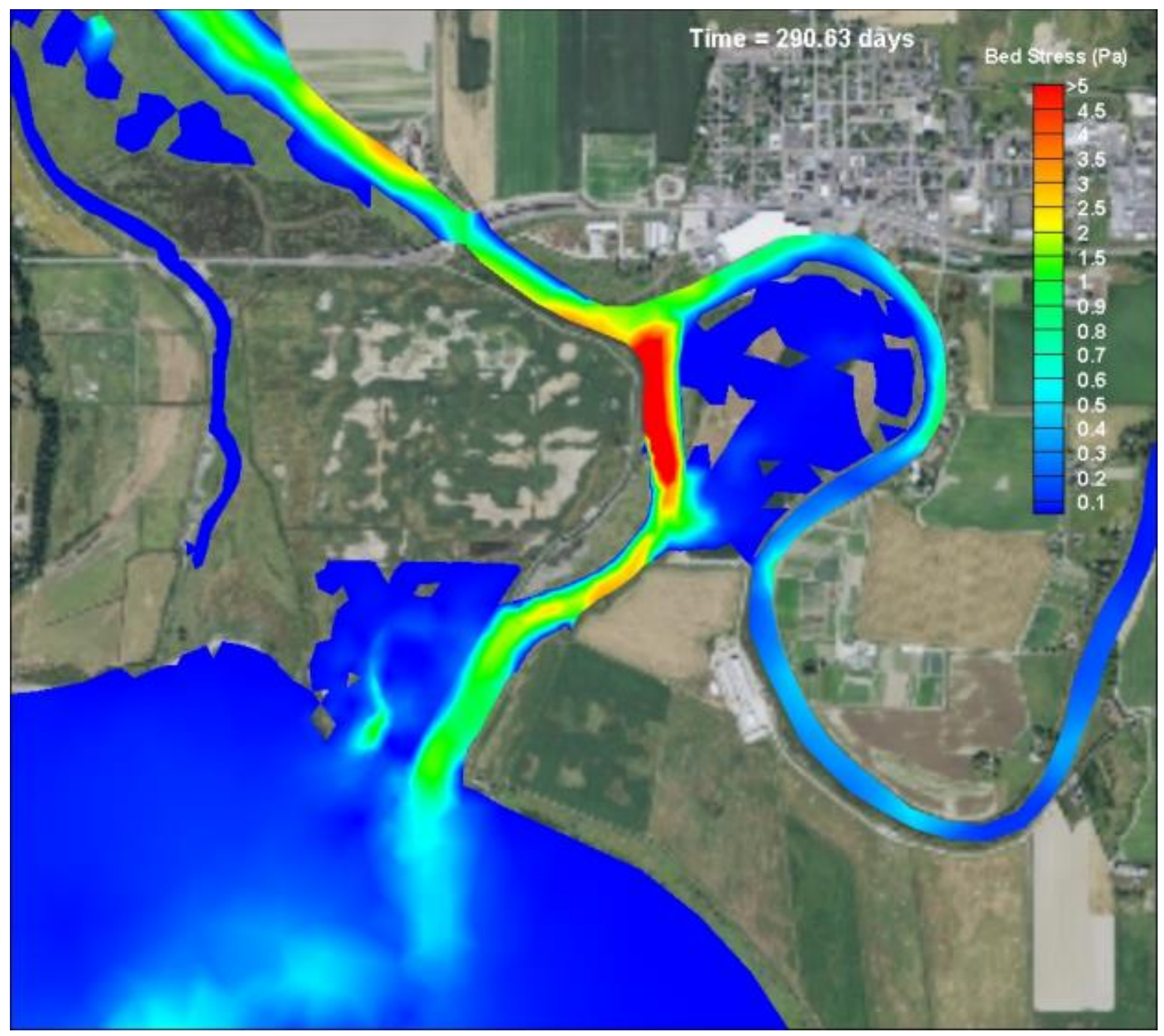

Figure E-12: Scenario 5 (Full Restoration zis a ba + SCN1) - Bed shear stress, October 17, 2005, peak ebb 


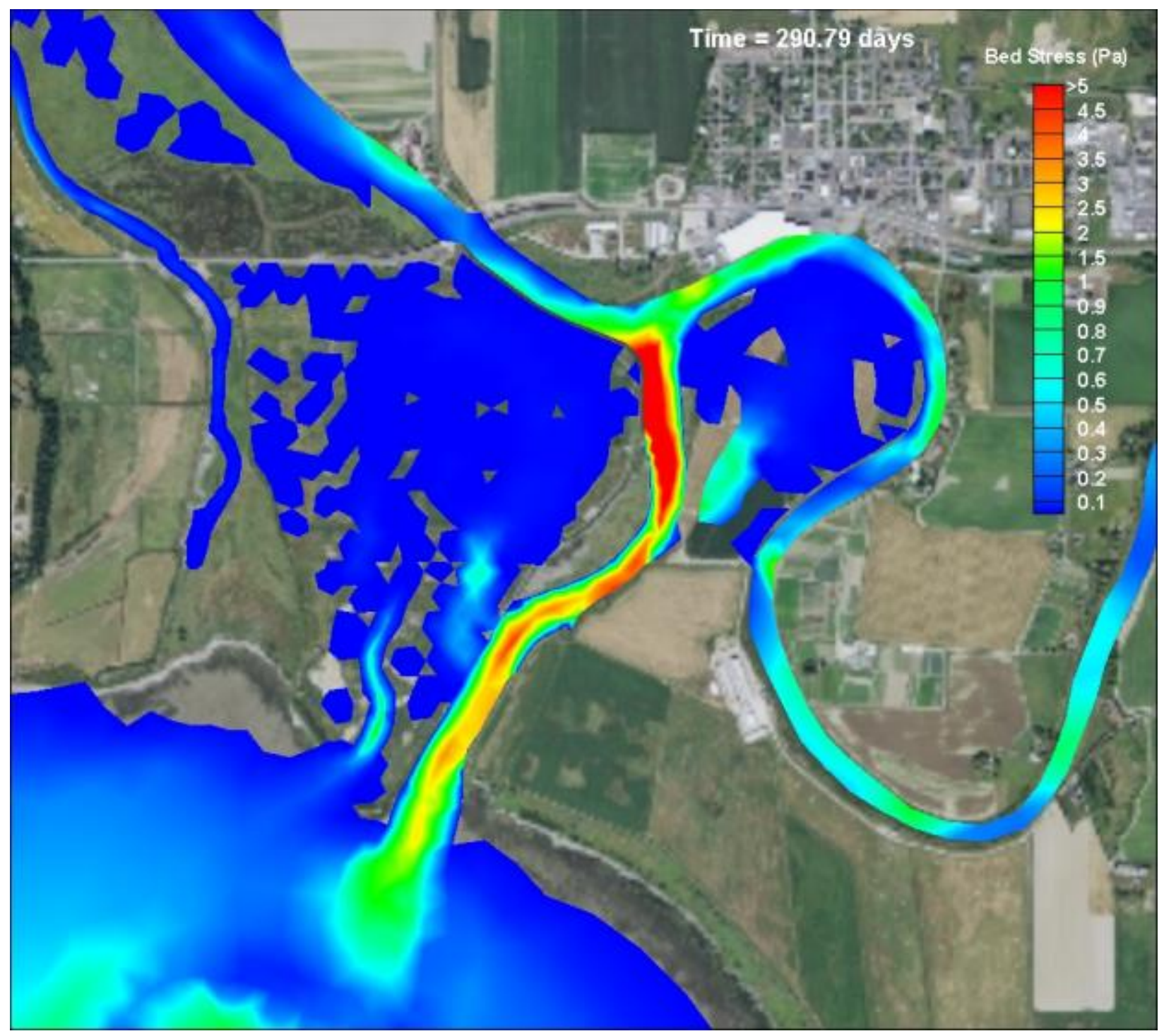

Figure E-13: Scenario 6 (Full Restoration zis a ba + SCN4) - Bed shear stress, October 17, 2005, peak ebb 


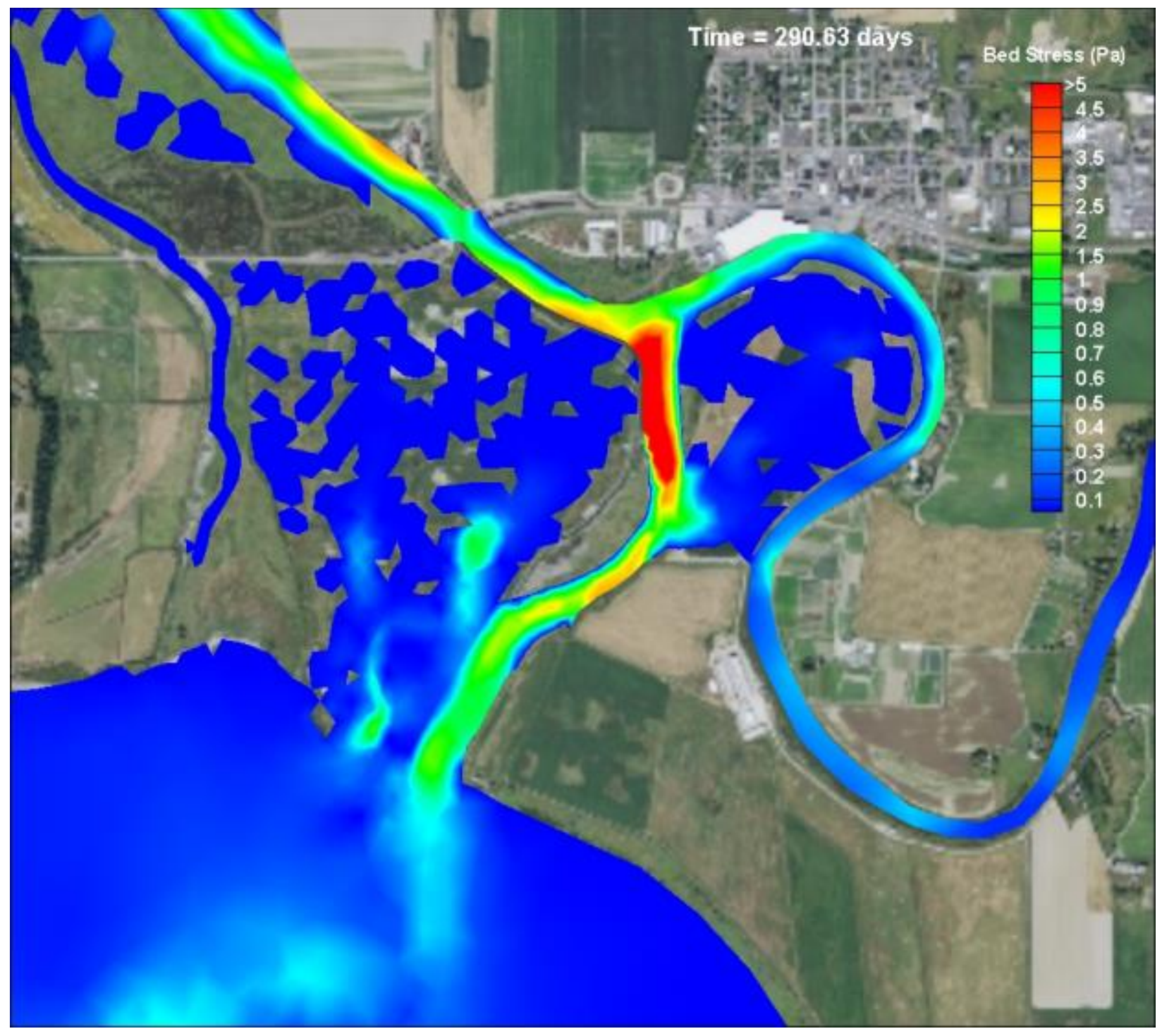

Figure E-14: Scenario 6 (Full Restoration zis a ba + SCN4) - Bed shear stress, October 17, 2005, peak flood 


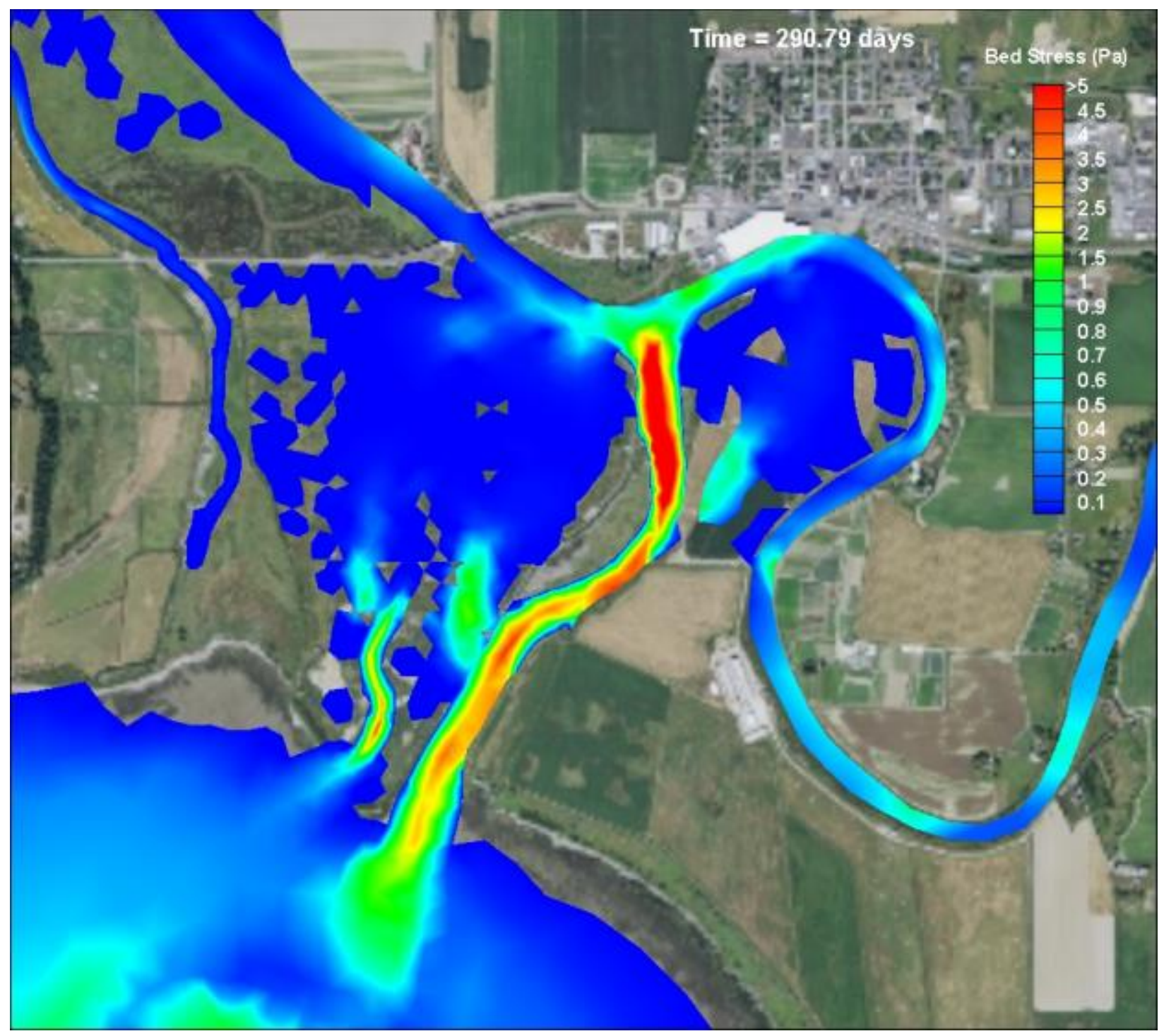

Figure E-15: Scenario 7 (Full Restoration zis a ba + SCN3) - Bed shear stress, October 17, 2005, peak ebb 


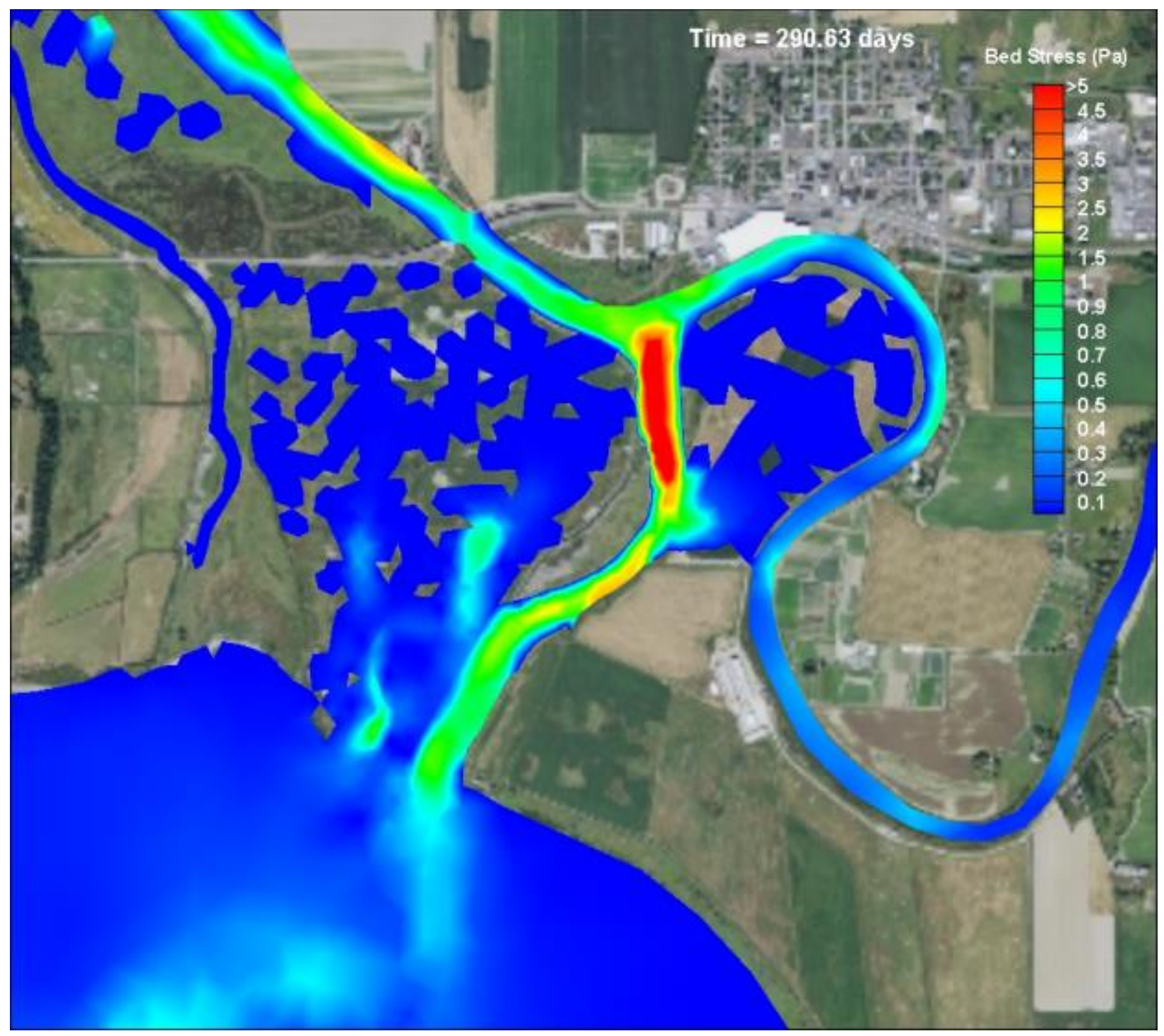

Figure E-16: Scenario 7 (Full Restoration zis a ba + SCN3) - Bed shear stress, October 17, 2005, peak flood 


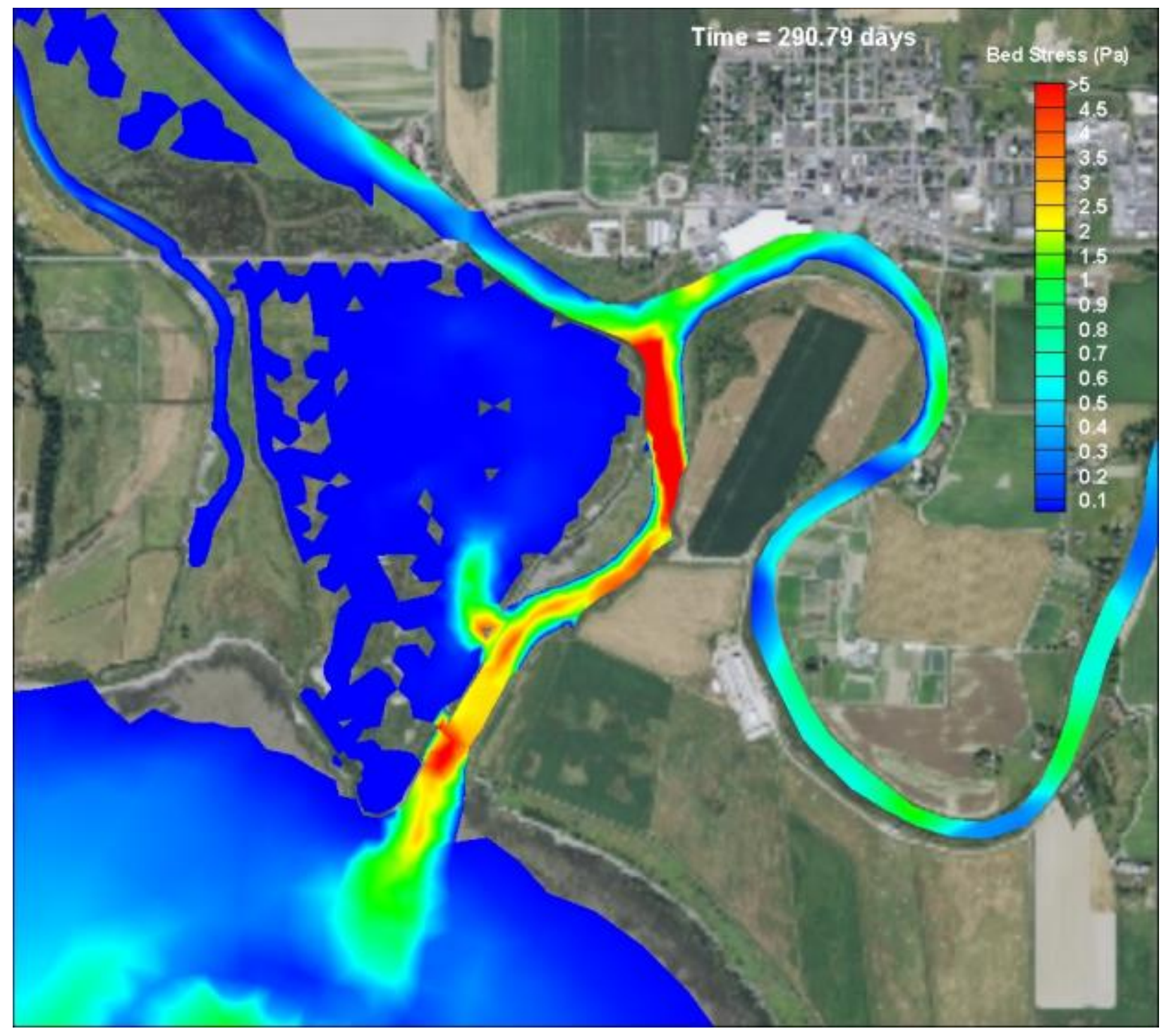

Figure E-17: Scenario 8 (3 Levee Breaches Leque) - Bed shear stress, October 17, 2005, peak ebb 


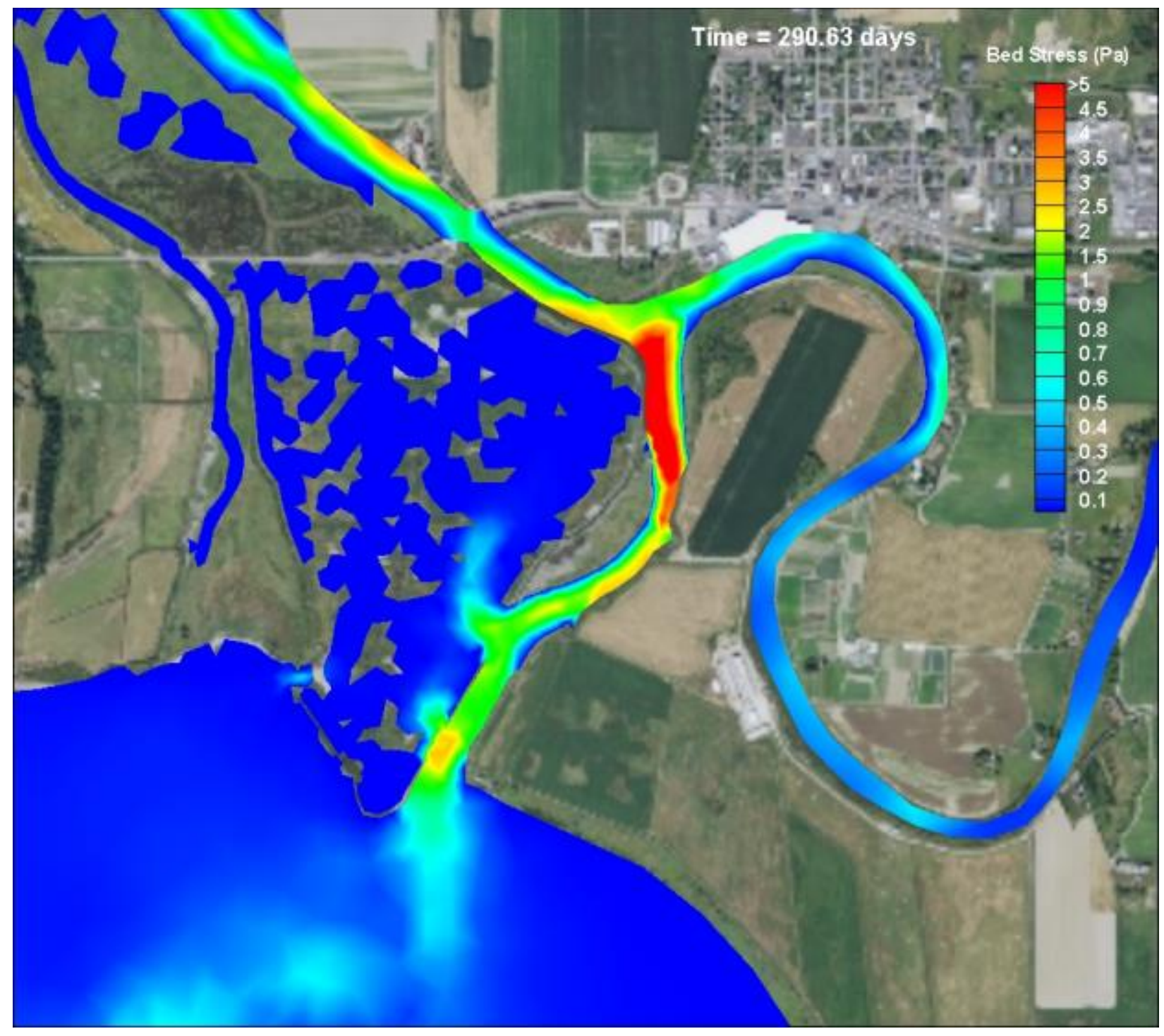

Figure E-18: Scenario 8 (3 Levee Breaches Leque) - Bed shear stress, October 17, 2005, peak flood 


\section{Appendix F \\ Plan View Contour Plots - High-Flow (bank full) Conditions - Bed Shear}





\section{Appendix F}

\section{Plan View Contour Plots - High-Flow (bank-full) Conditions - Bed Shear}

Plan view contour plots at high-flow (i.e., bank full) condition for bed sheers for Leque Island and zis a ba restoration site stations are provided in this appendix.

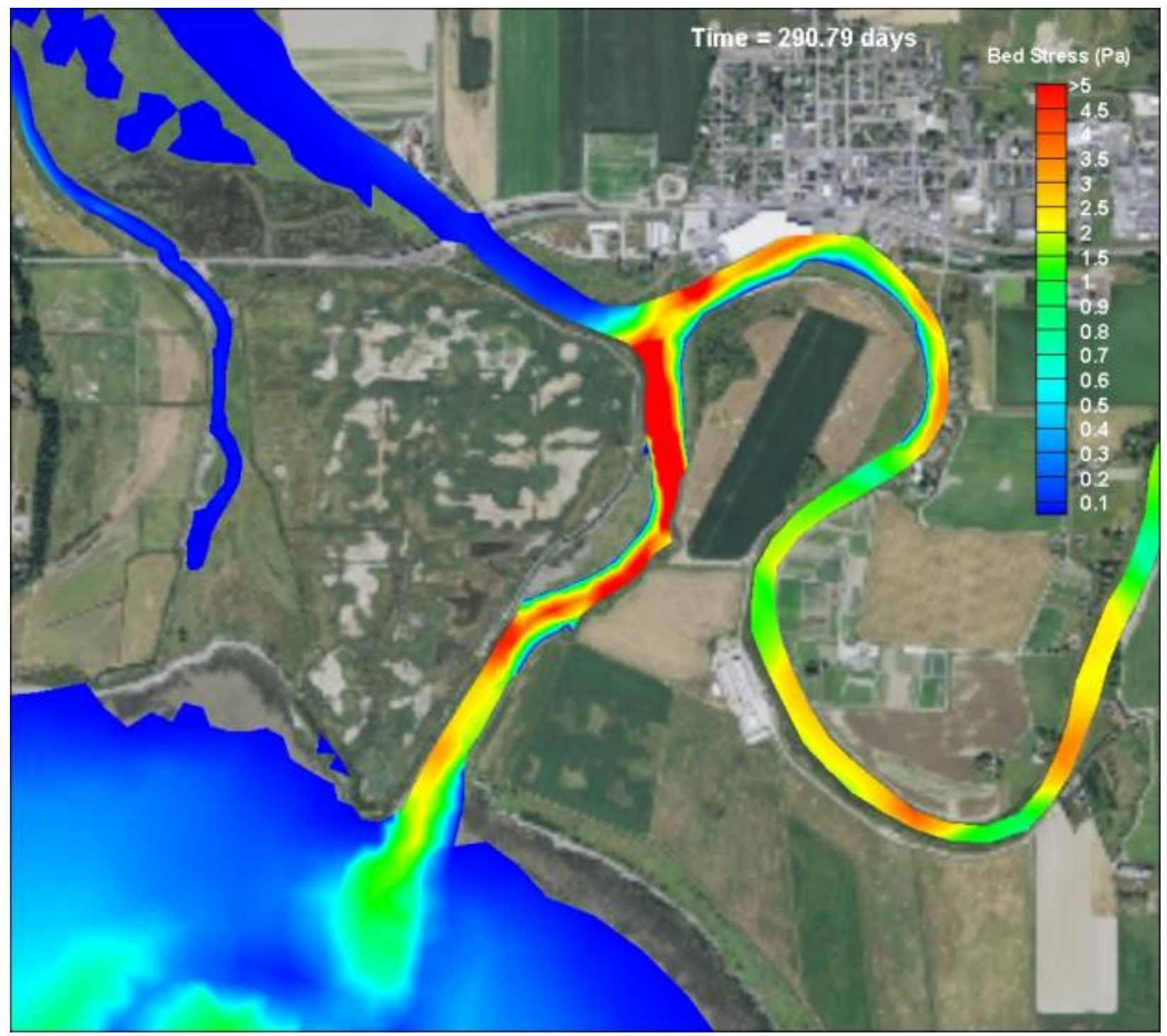

Figure F-1: Scenario 0 (Baseline Condition) - Bed shear stress, high flow (bank full) condition at 26,508 cfs and peak ebb based on October 17, 2005 


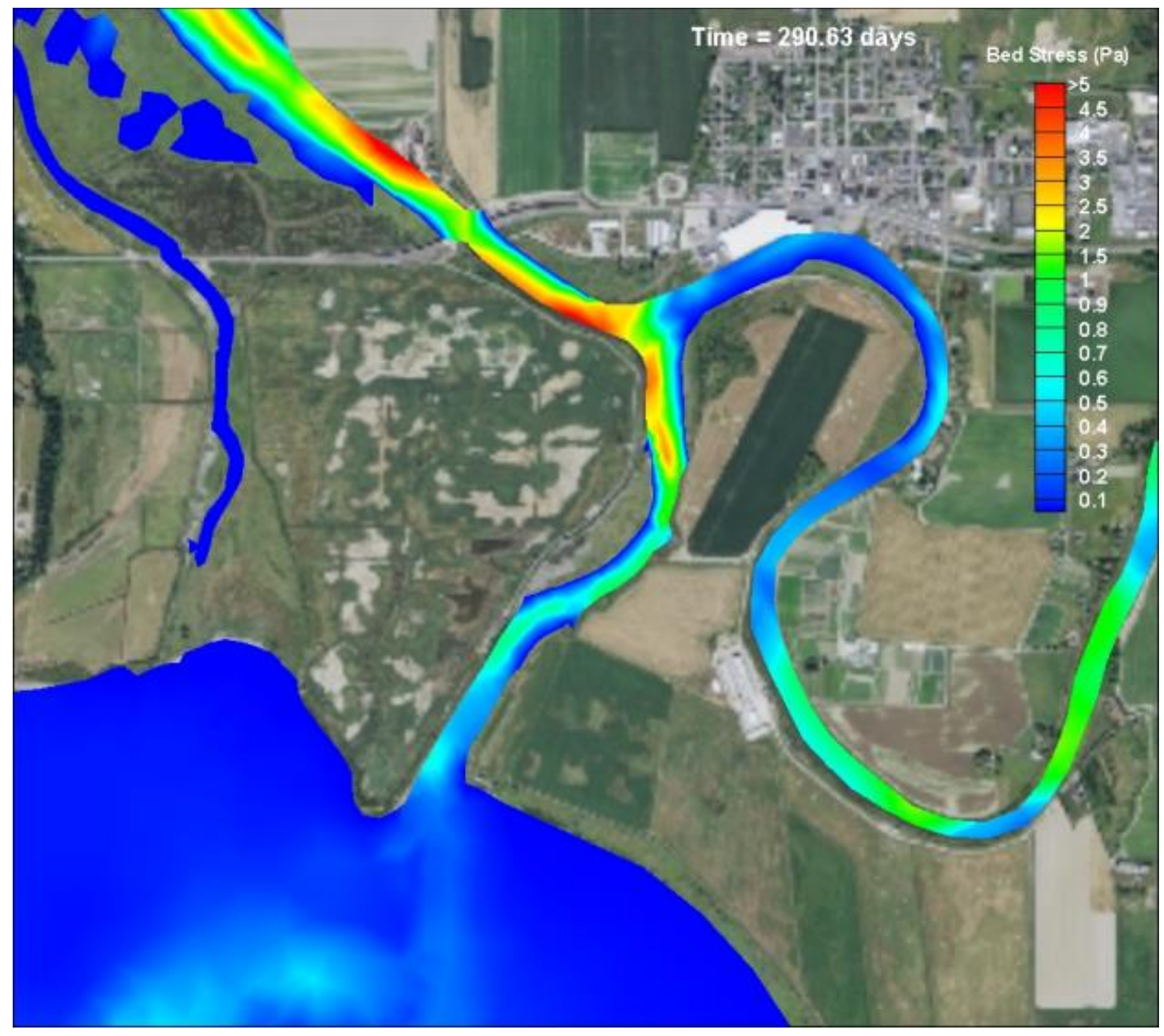

Figure F-2: Scenario 0 (Baseline Condition) - Bed shear stress, high flow (bank full) condition at 26,508 cfs and peak flood based on October 17, 2005 


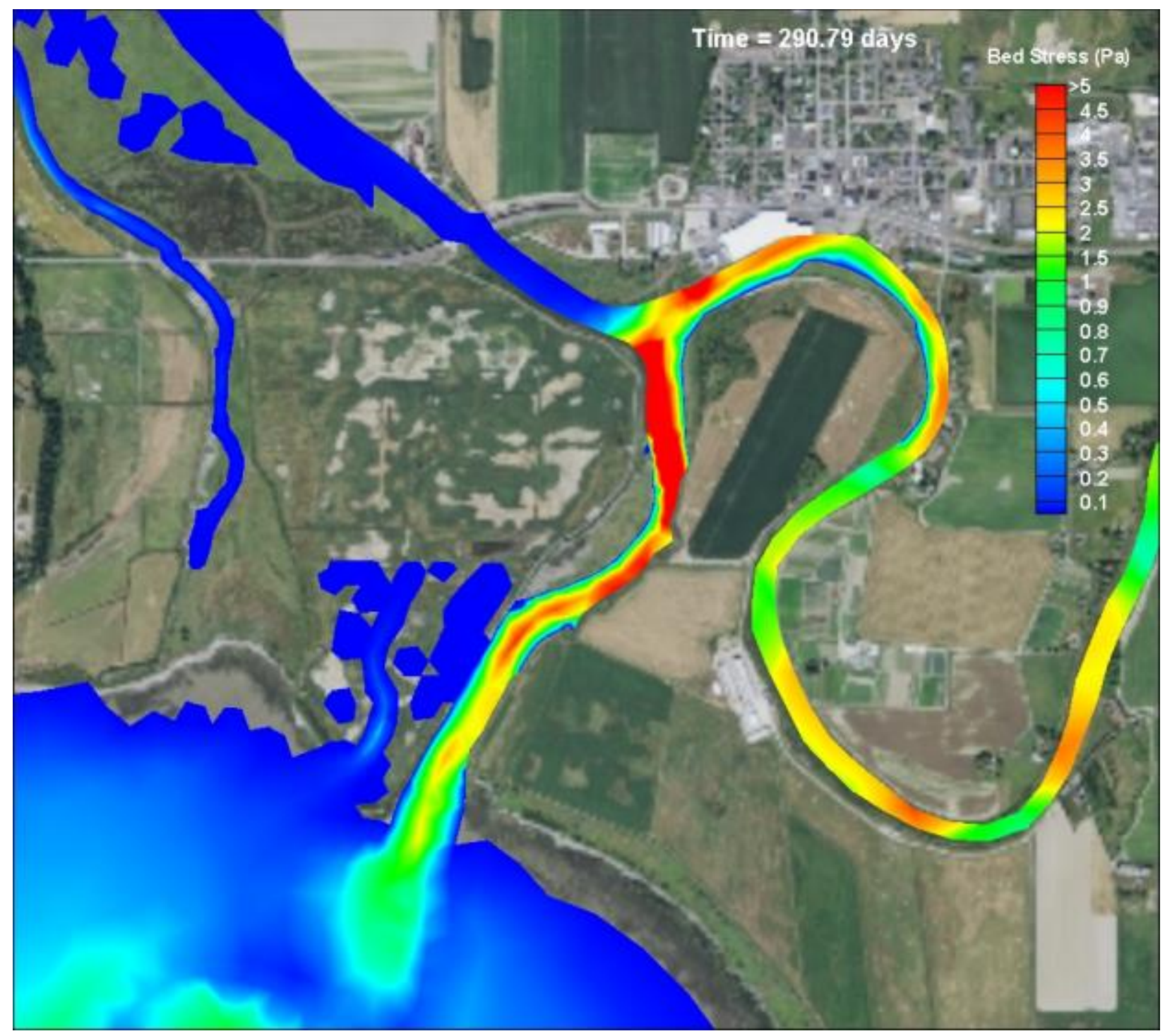

Figure F-3: Scenario 1 (Partial Restoration Leque) - Bed shear stress, high flow (bank full) condition at 26,508 cfs and peak ebb based on October 17, 2005 


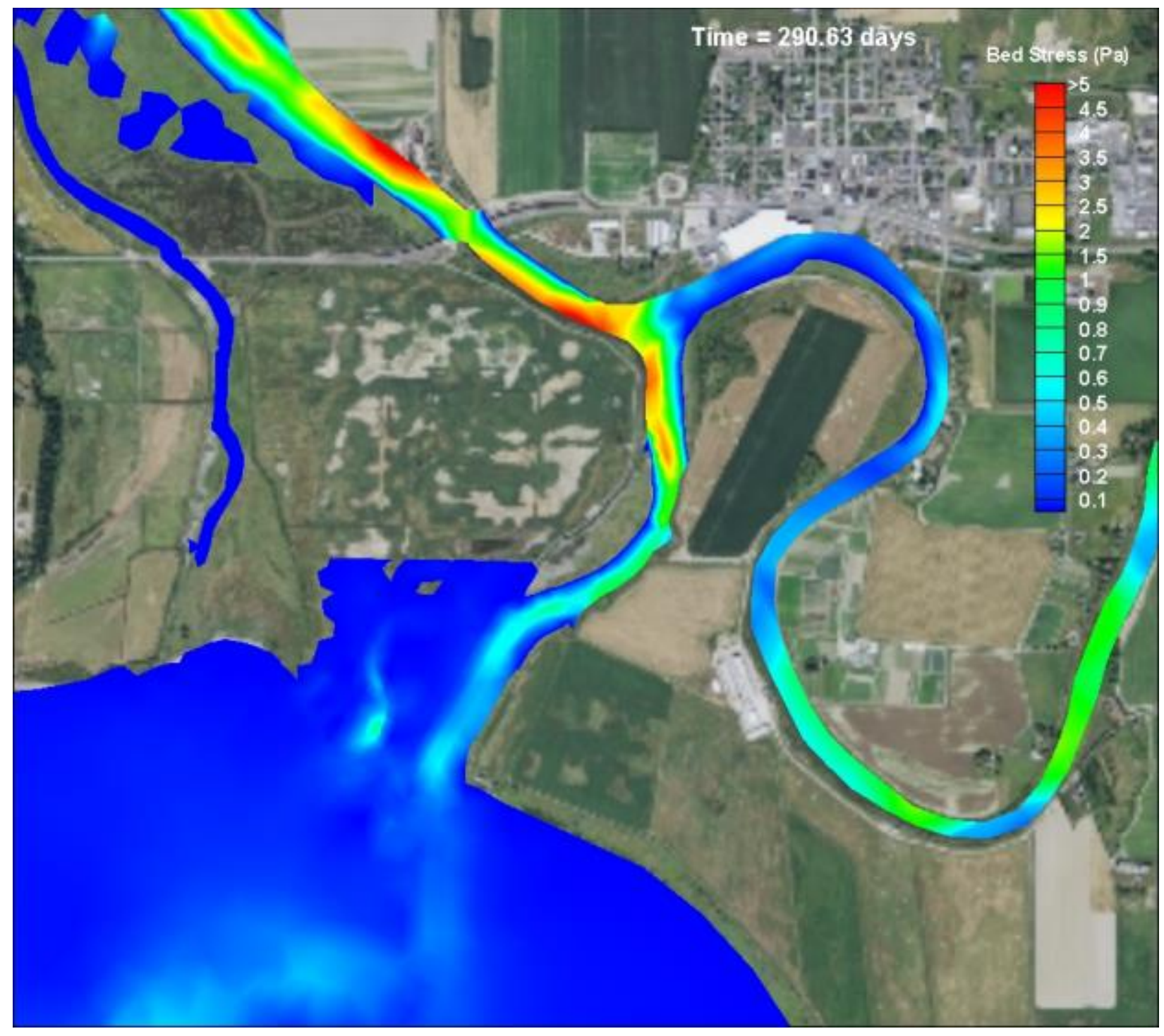

Figure F-4: Scenario 1 (Partial Restoration Leque) - Bed shear stress, high flow (bank full) condition at 26,508 cfs and peak flood based on October 17, 2005 


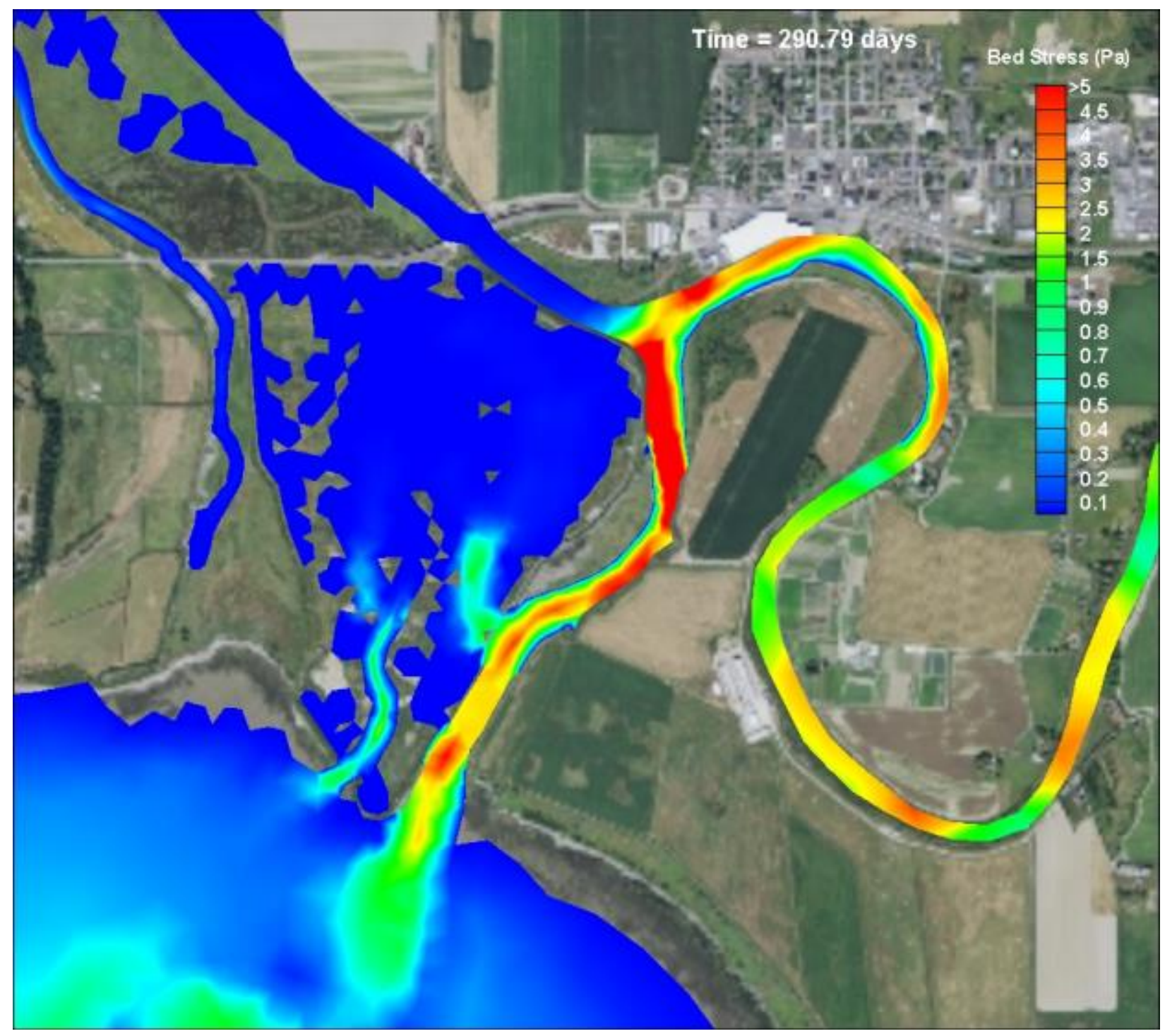

Figure F-5: Scenario 2 (4 Levee Breach Leque) - Bed shear stress, high flow (bank full) condition at 26,508 cfs and peak ebb based on October 17, 2005 


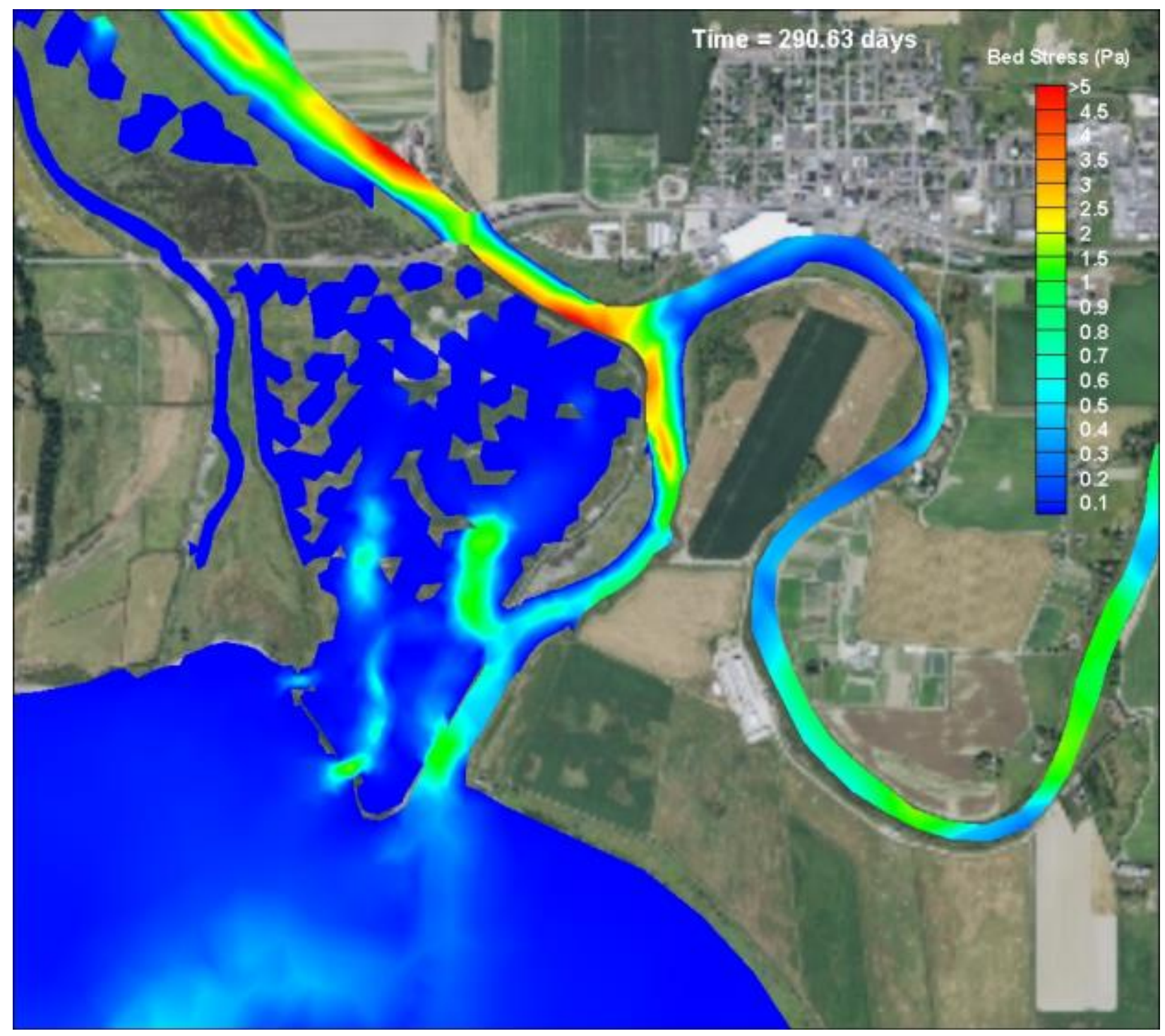

Figure F-6: Scenario 2 (4 Levee Breach Leque) - Bed shear stress, high flow (bank full) condition at 26,508 cfs and peak flood based on October 17, 2005 


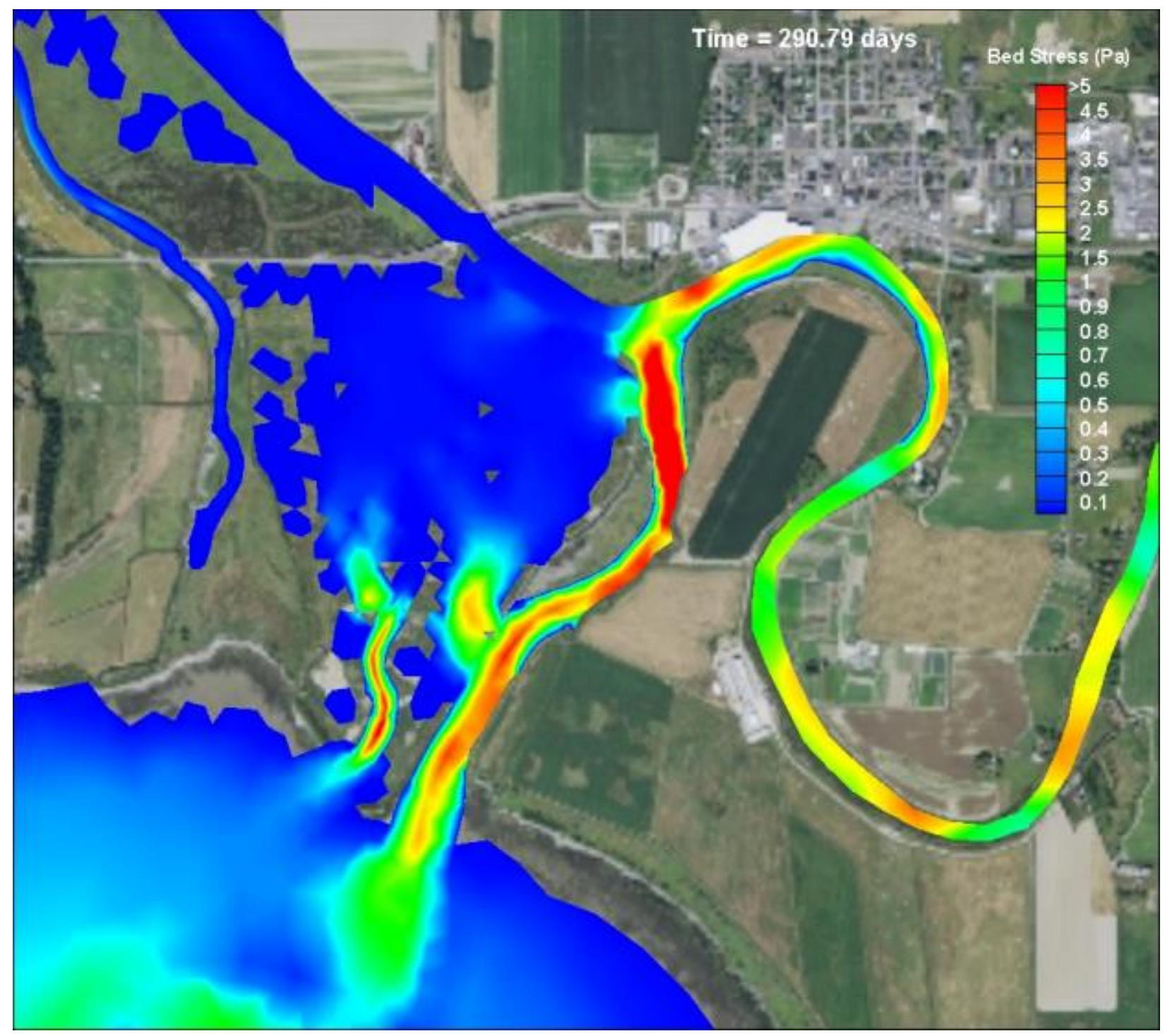

Figure F-7: Scenario 3 (Full Restoration Leque 1) - Bed shear stress, high flow (bank full) condition at 26,508 cfs and peak ebb based on October 17, 2005 


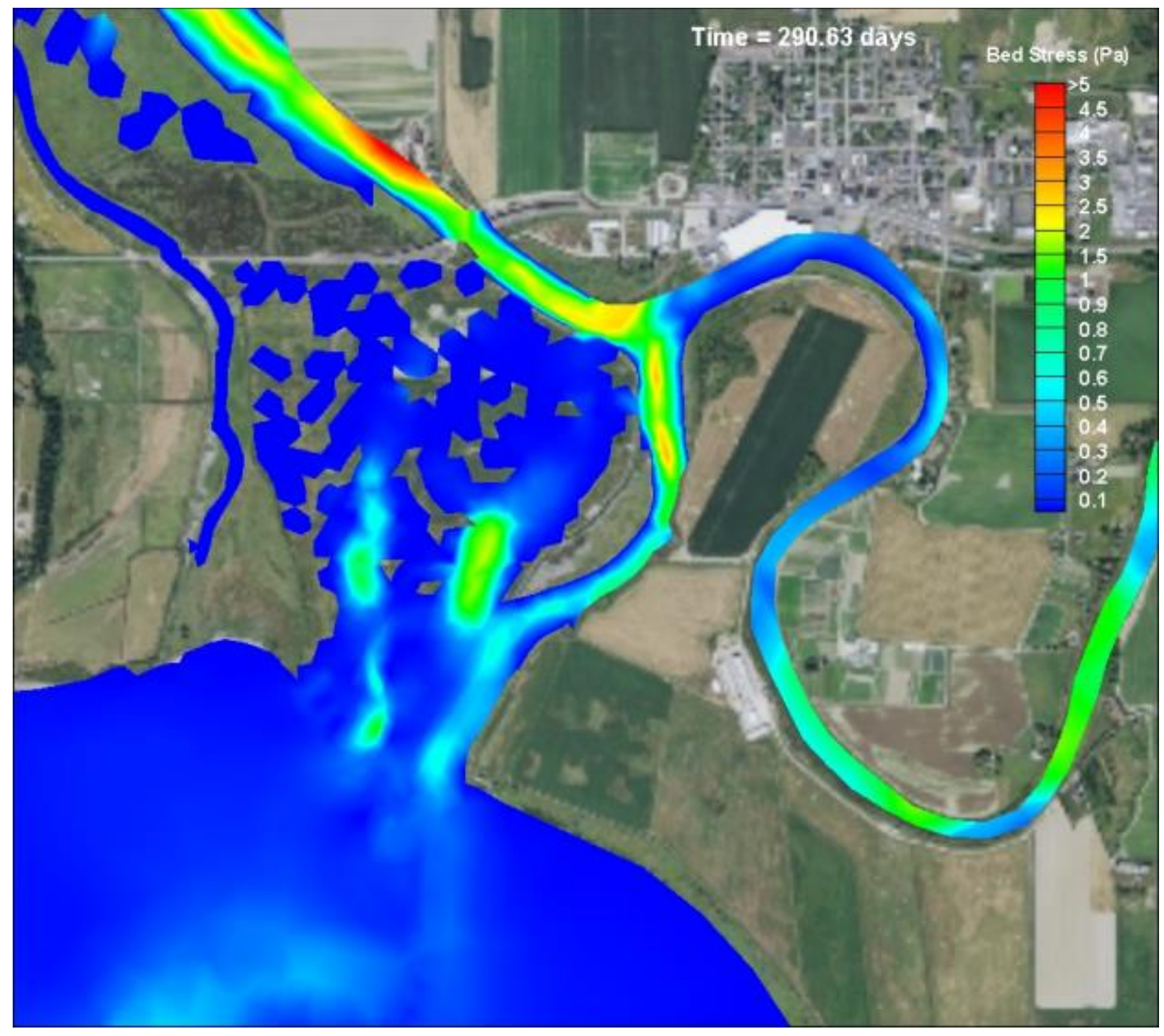

Figure F-8: Scenario 3 (Full Restoration Leque 1) - Bed shear stress, high flow (bank full) condition at 26,508 cfs and peak flood based on October 17, 2005 


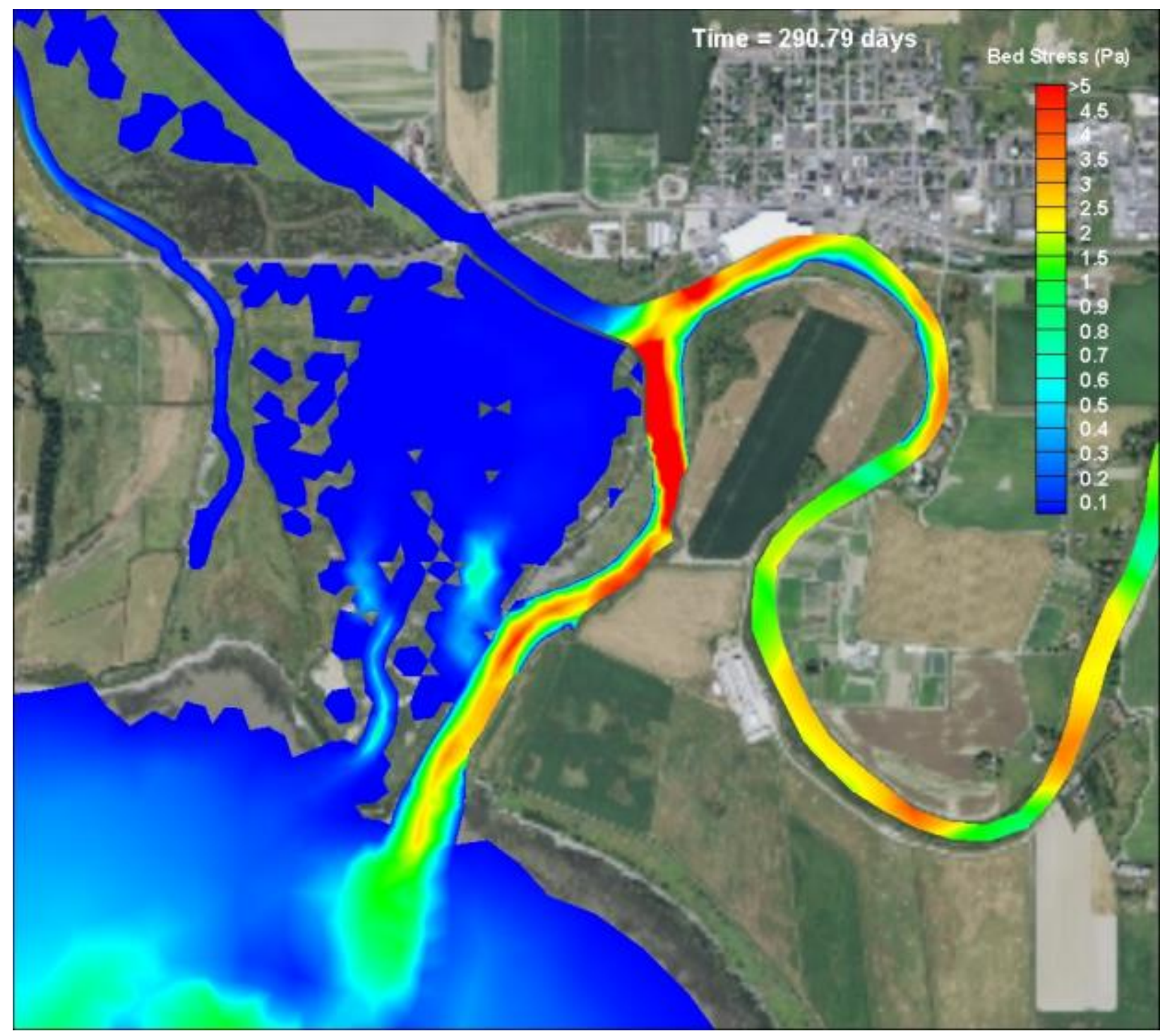

Figure F-9: Scenario 4 (Full Restoration Leque 2) - Bed shear stress, high flow (bank full) condition at 26,508 cfs and peak ebb based on October 17, 2005 


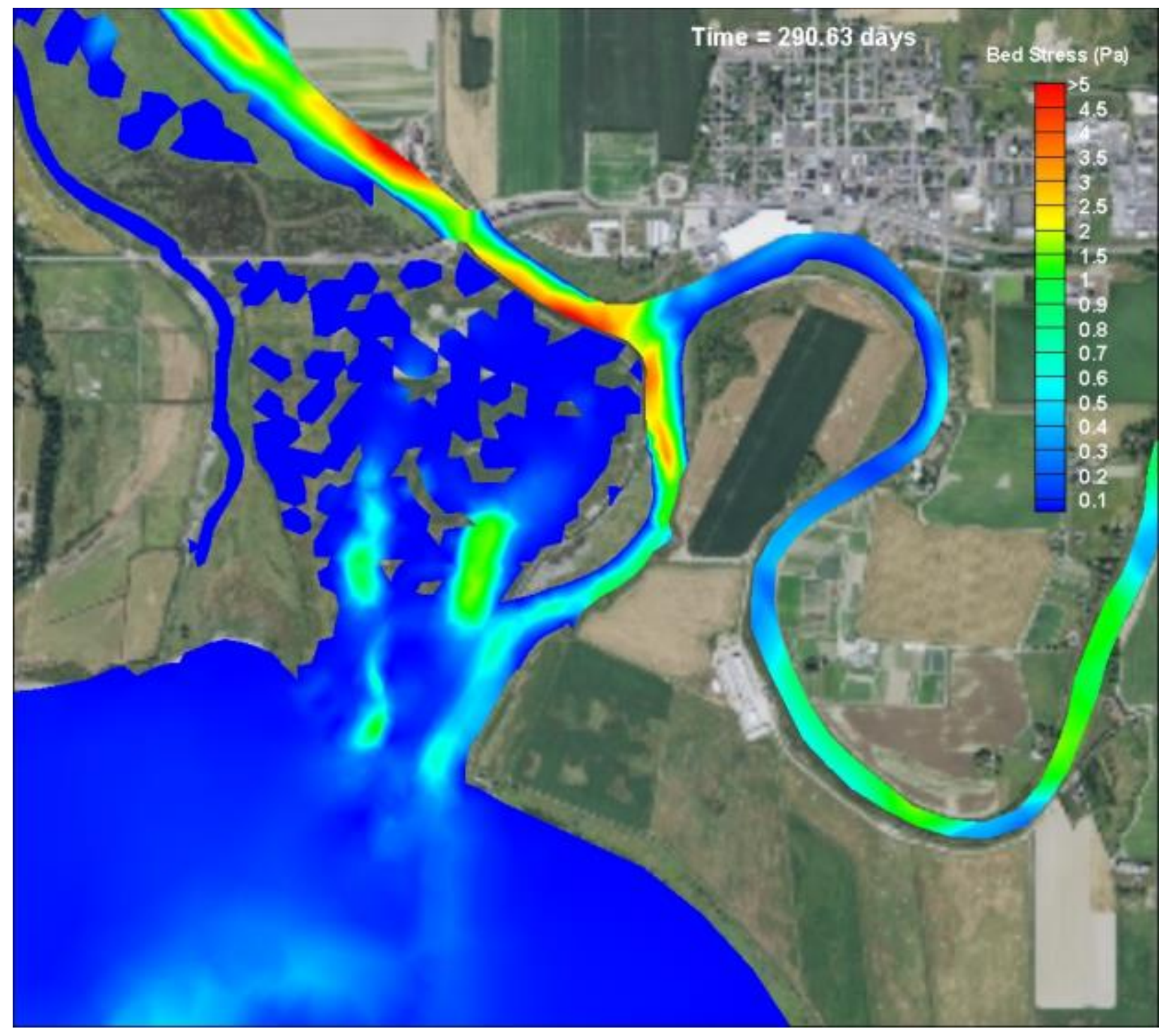

Figure F-10: Scenario 4 (Full Restoration Leque 2) - Bed shear stress, high flow (bank full) condition at 26,508 cfs and peak flood based on October 17, 2005 


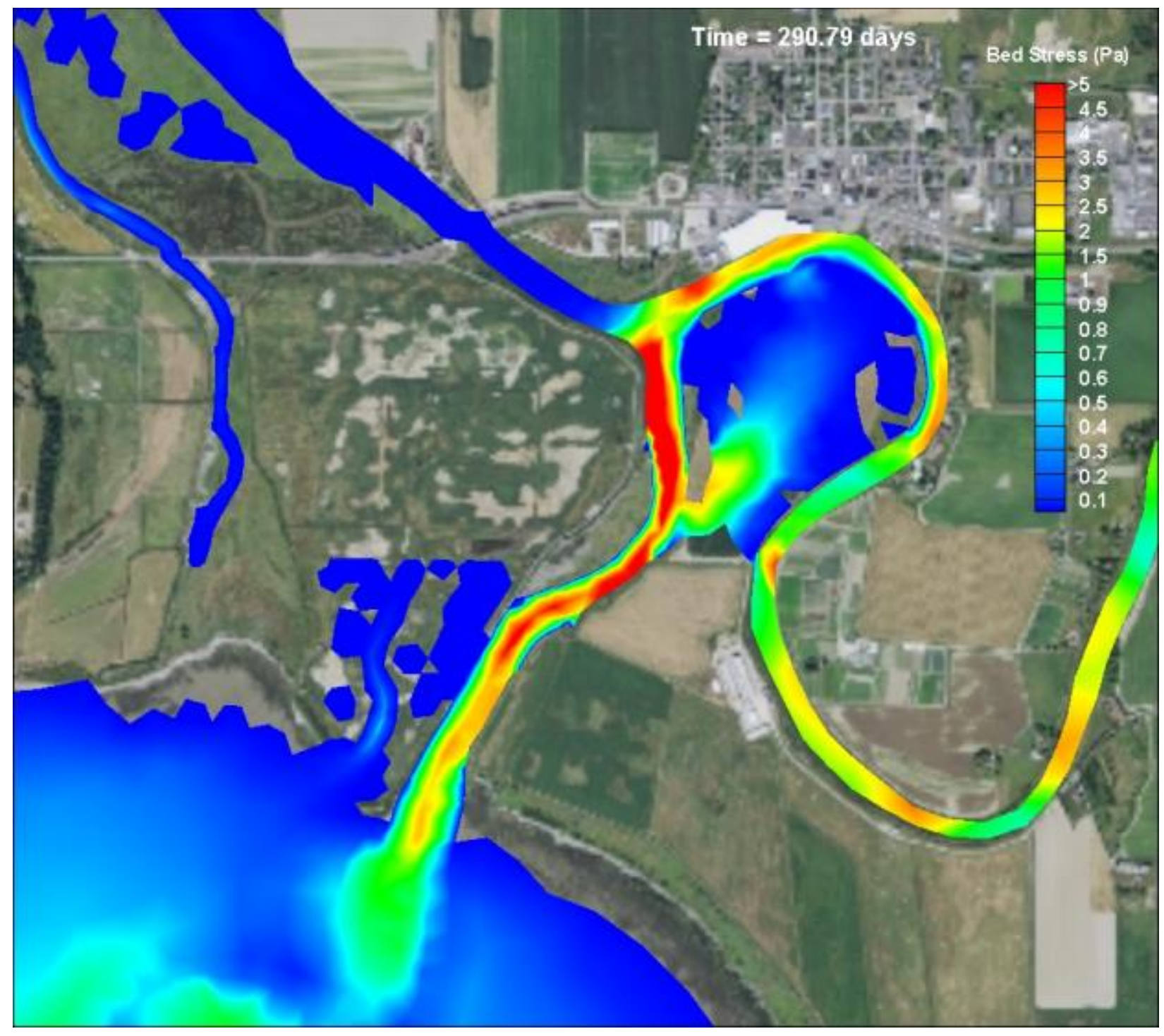

Figure F-11: Scenario 5 (Full Restoration zis a ba + SCN1) - Bed shear stress, high flow (bank full) condition at 26,508 cfs and peak ebb based on October 17, 2005 


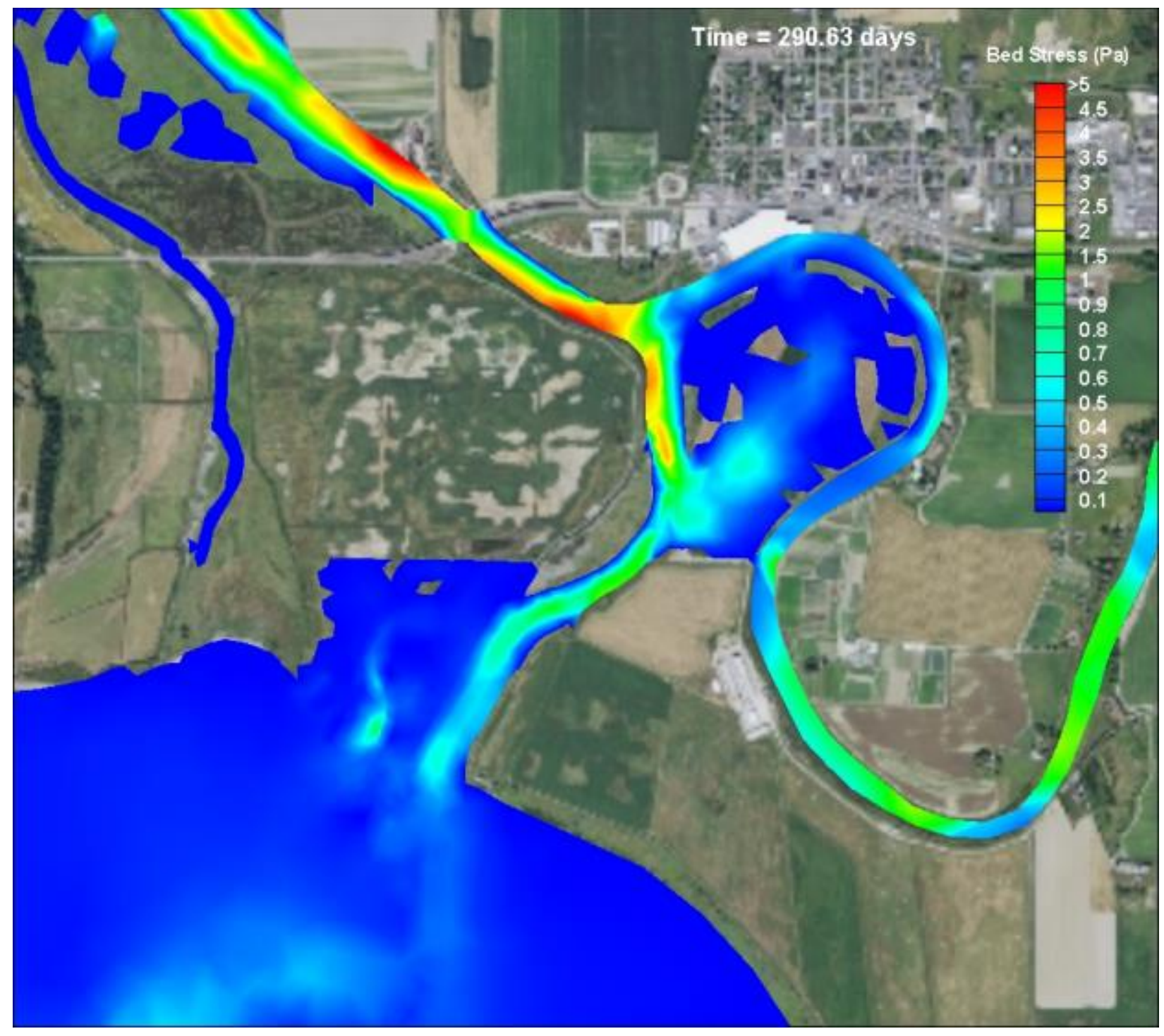

Figure F-12: Scenario 5 (Full Restoration zis a ba + SCN1) - Bed shear stress, high flow (bank full) condition at 26,508 cfs and peak flood based on October 17, 2005 


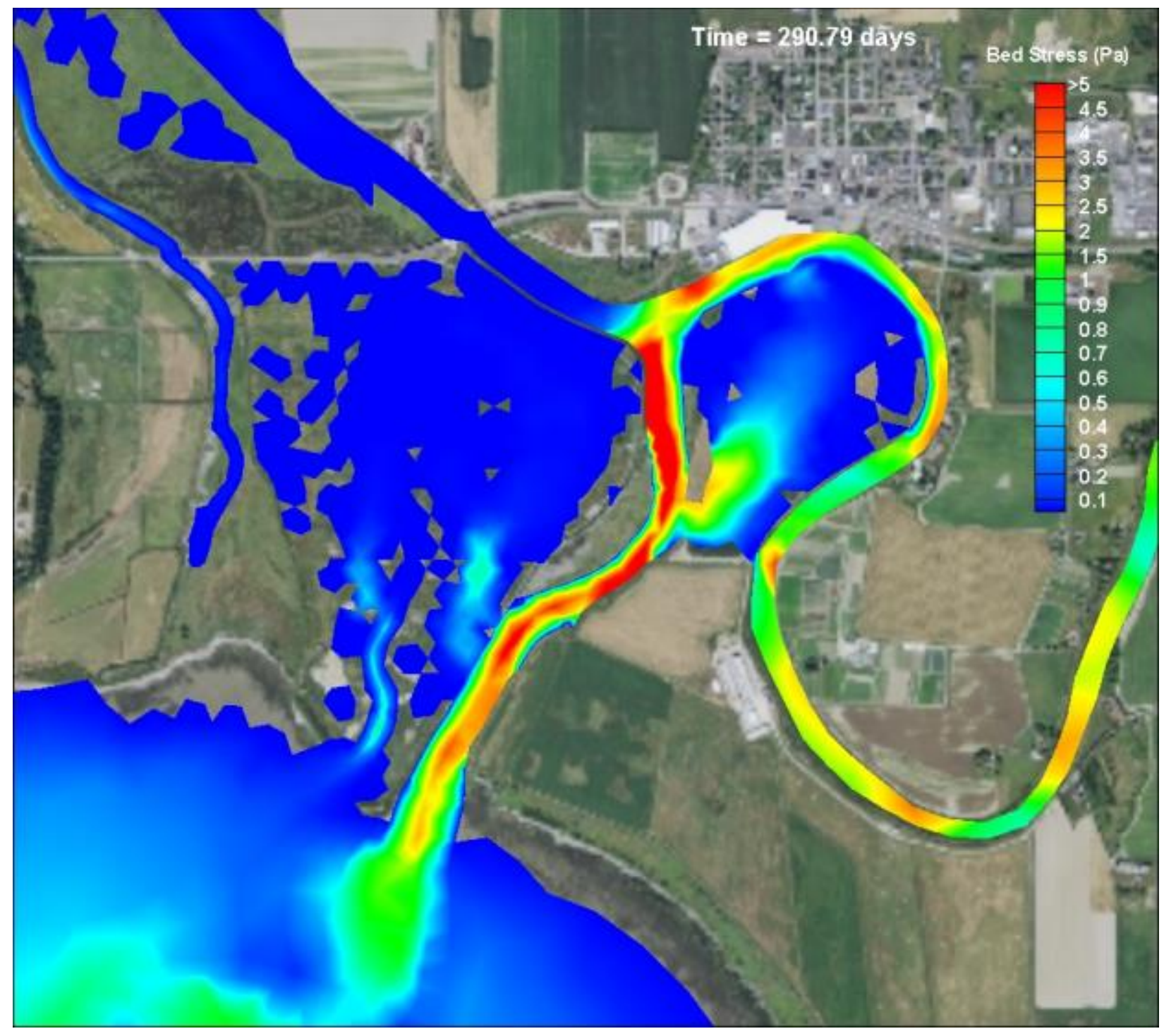

Figure F-13: Scenario 6 (Full Restoration zis a ba + SCN4) - Bed shear stress, high flow (bank full) condition at 26,508 cfs and peak ebb based on October 17, 2005 


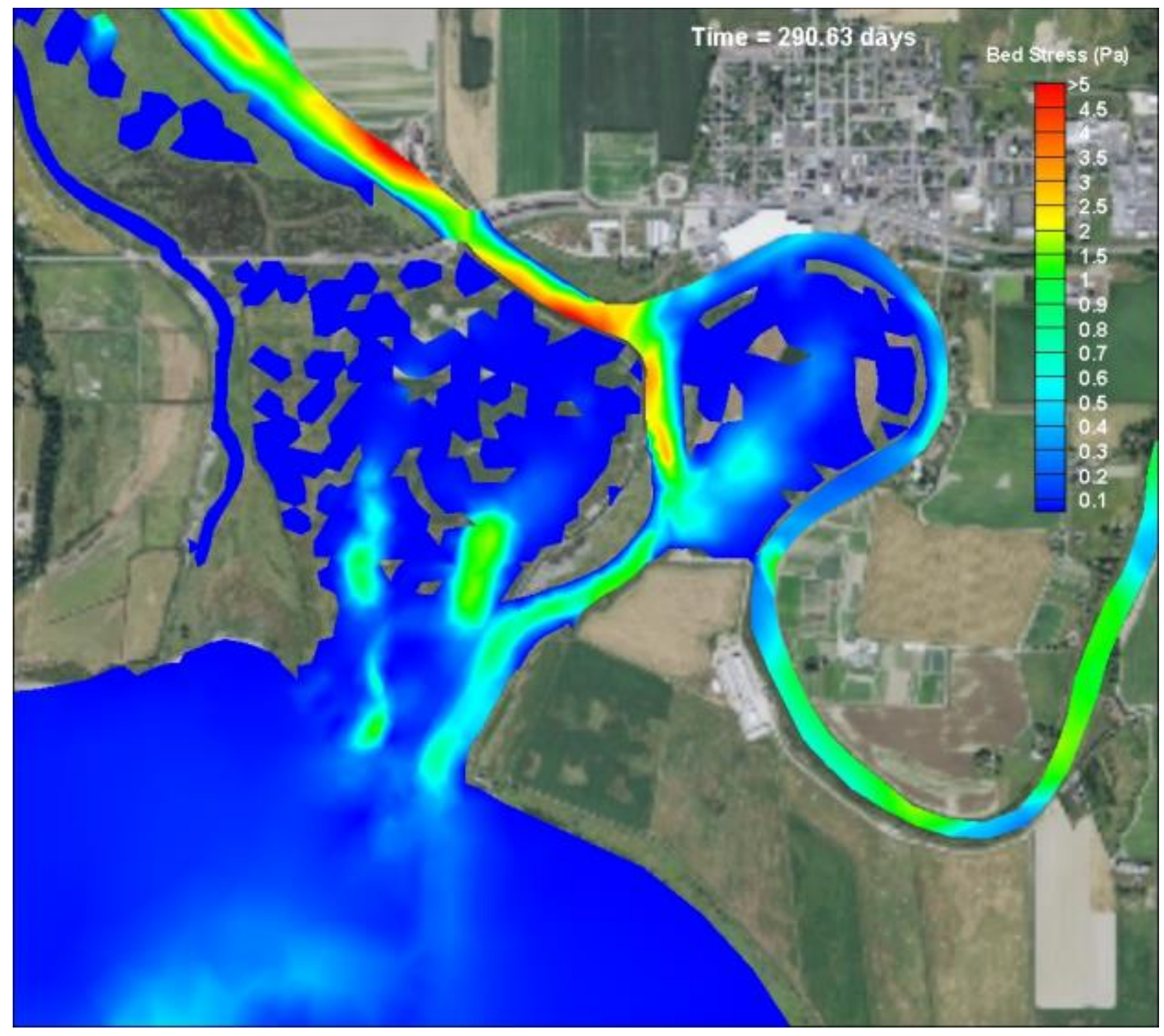

Figure F-14: Scenario 6 (Full Restoration zis a ba + SCN4) - Bed shear stress, high flow (bank full) condition at 26,508 cfs and peak flood based on October 17, 2005 


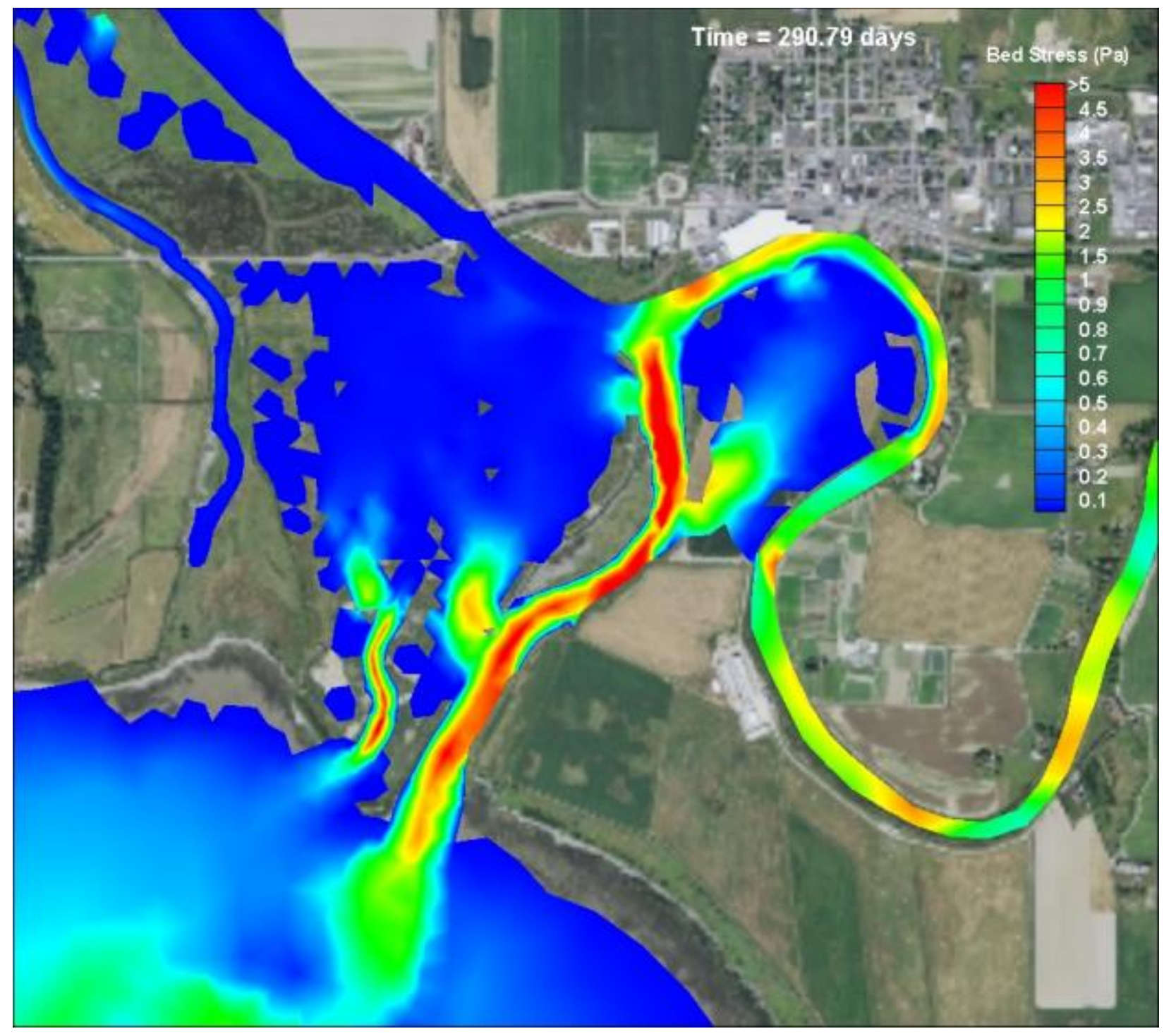

Figure F-15: Scenario 7 (Full Restoration zis a ba + SCN3) - Bed shear stress, high flow (bank full) condition at 26,508 cfs and peak ebb based on October 17, 2005 


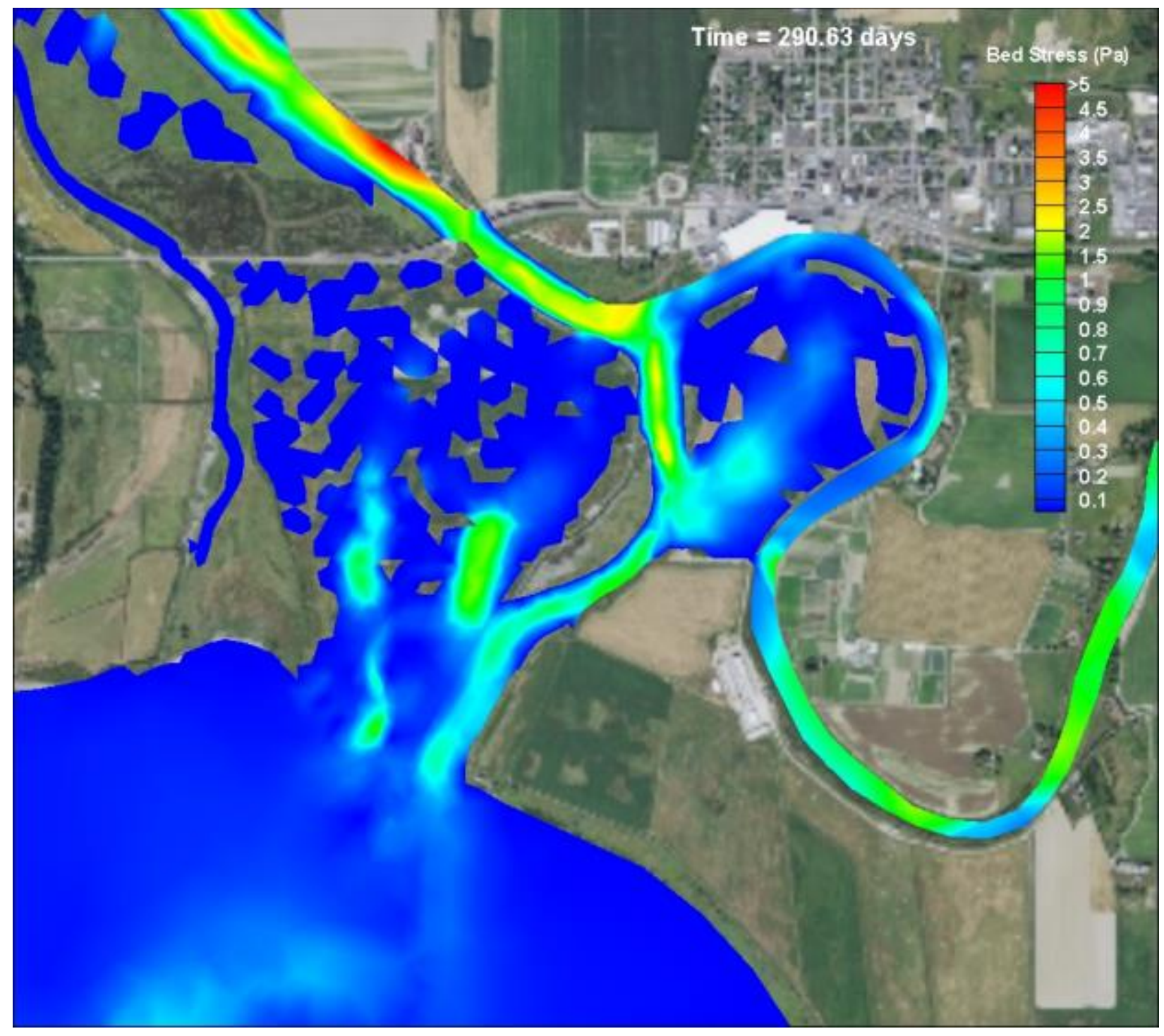

Figure F-16: Scenario 7 (Full Restoration zis a ba + SCN3) - Bed shear stress, high flow (bank full) condition at 26,508 cfs and peak flood based on October 17, 2005 


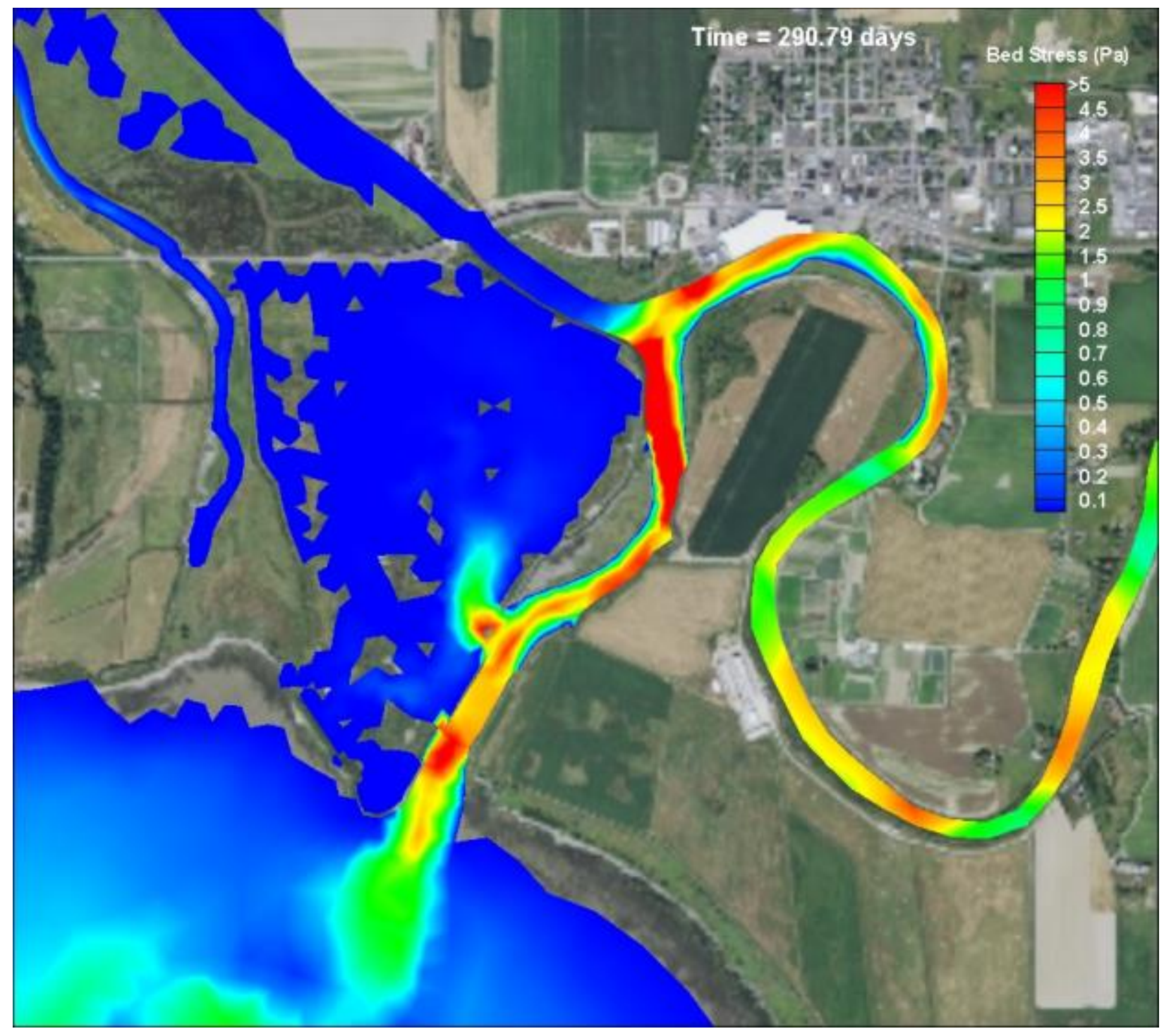

Figure F-17: Scenario 8 (3 Levee Breaches Leque) - Bed shear stress, high flow (bank full) condition at 26,508 cfs and peak ebb based on October 17, 2005 


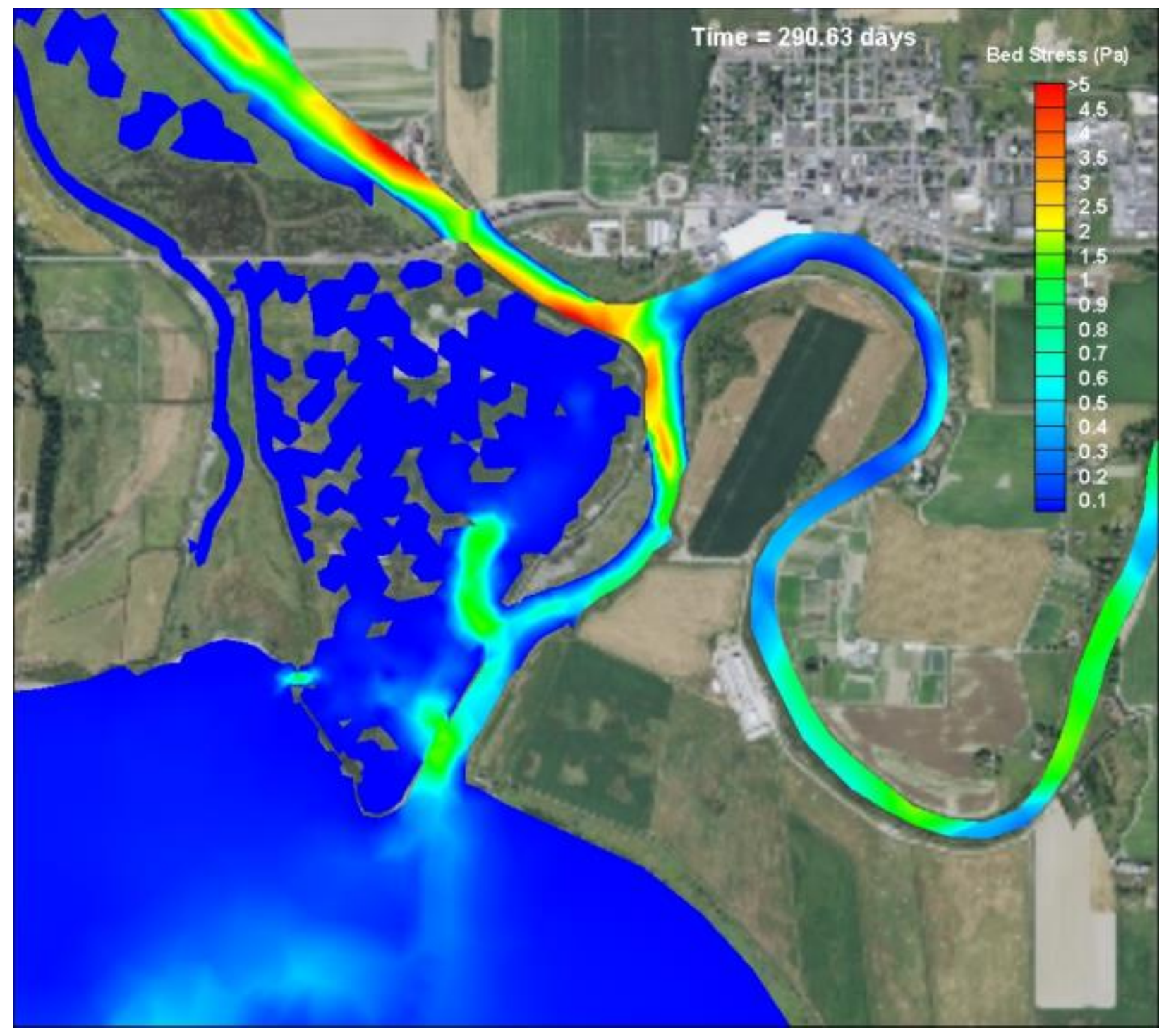

Figure F-18: Scenario 8 (3 Levee Breaches Leque) - Bed shear stress, high flow (bank full) condition at 26,508 cfs and peak flood based on October 17, 2005 
Appendix G

Cumulative Frequency Plots - 2003 Year-Long Simulation WSL, Salinity, Velocity, Bed Shear 



\section{Appendix G}

\section{Cumulative Frequency Plots - 2003 Year-Long Simulation - WSL, Salinity, Velocity, Bed Shear}

Cumulative frequency plots derived from a 2003 year-long simulation, showing surface water elevations, salinities, bottom velocities, and bed sheers for Leque Island and zis a ba restoration site stations are provided in this appendix.

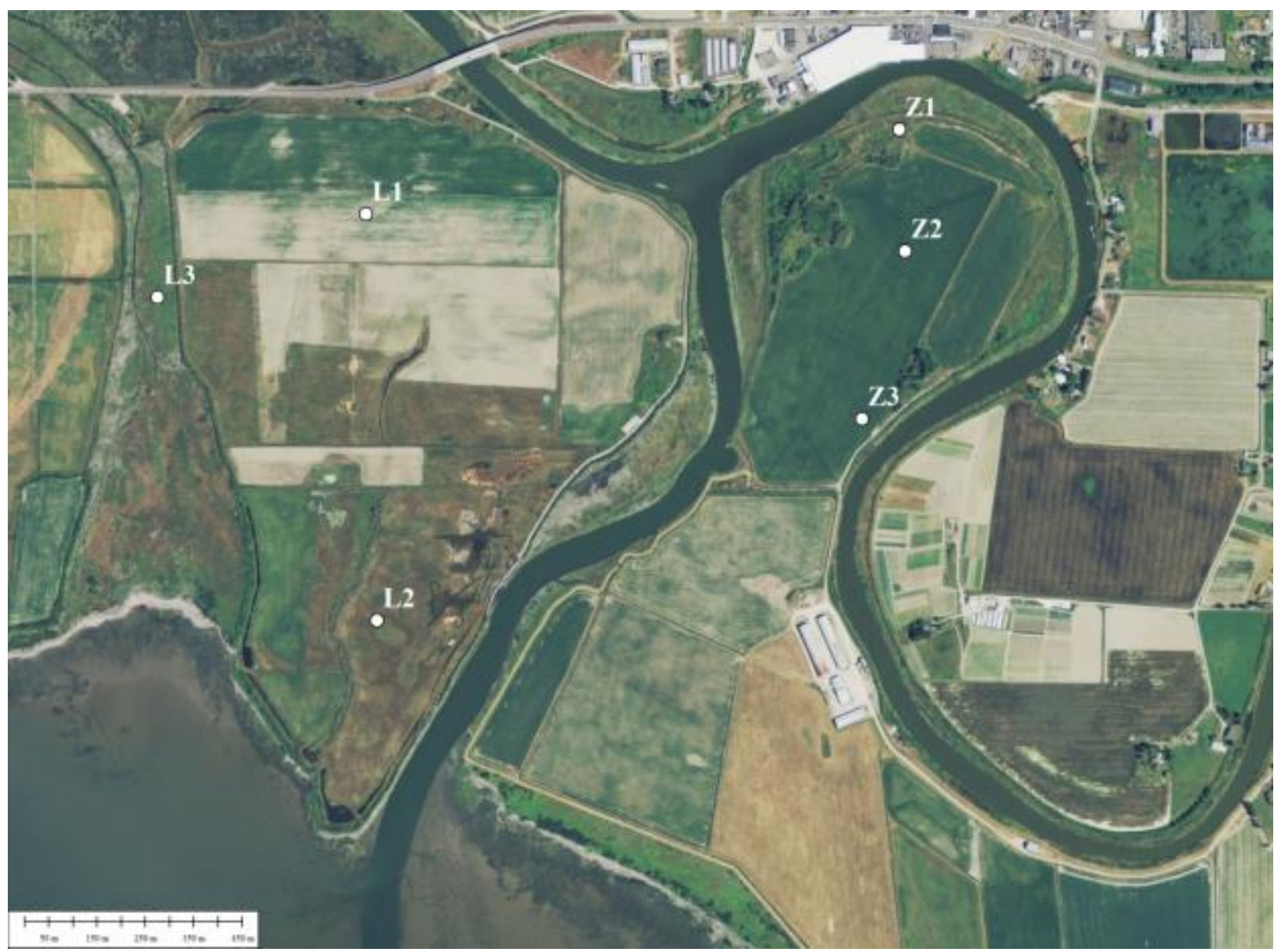

Figure G-1: Leque and zis a ba restoration site plan view and time series station locations 

Water Surface Elevation, $\mathrm{m}$

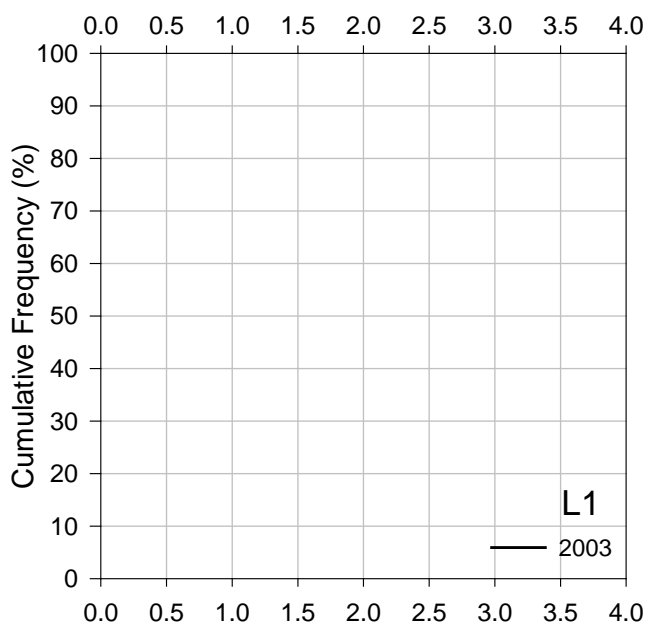

Water Surface Elevation, $\mathrm{m}$

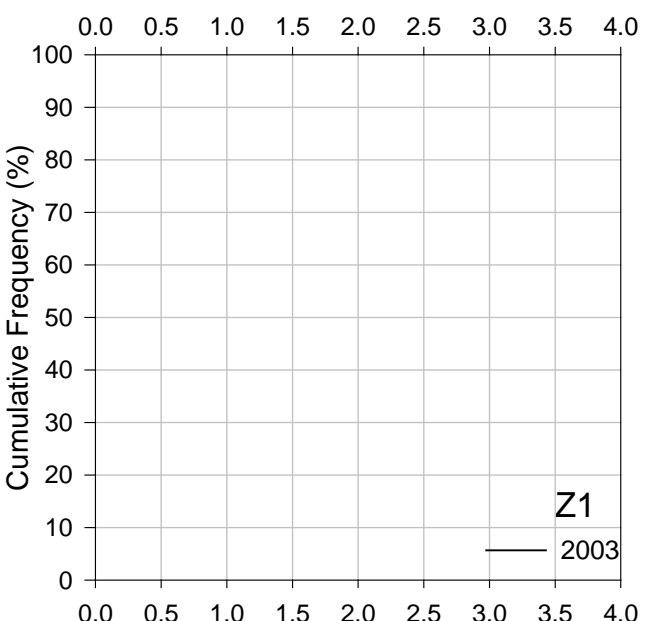

Water Surface Elevation, $\mathrm{m}$

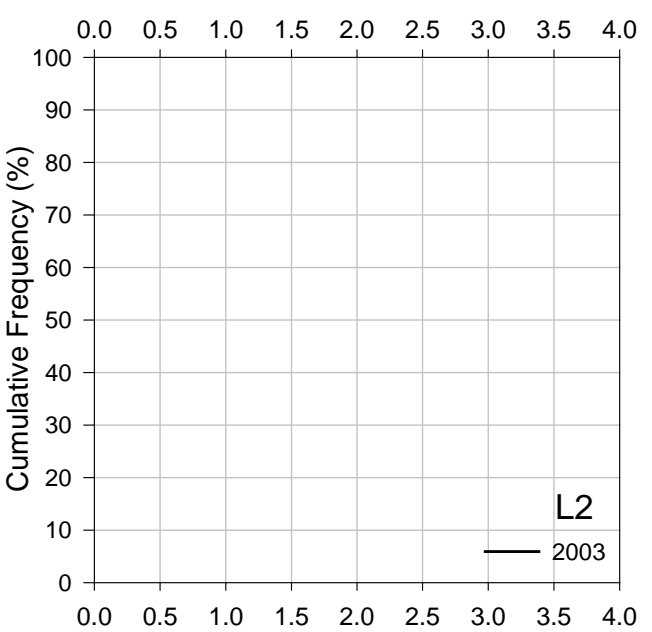

Water Surface Elevation, $\mathrm{m}$

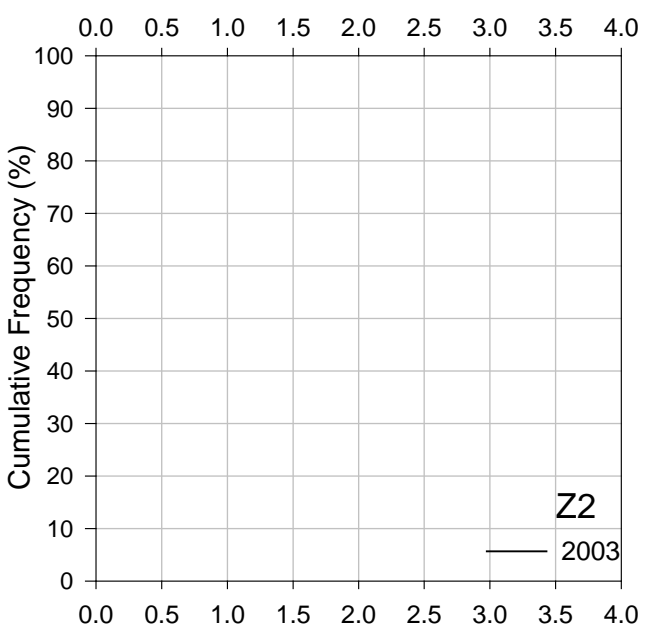

Water Surface Elevation, $\mathrm{m}$

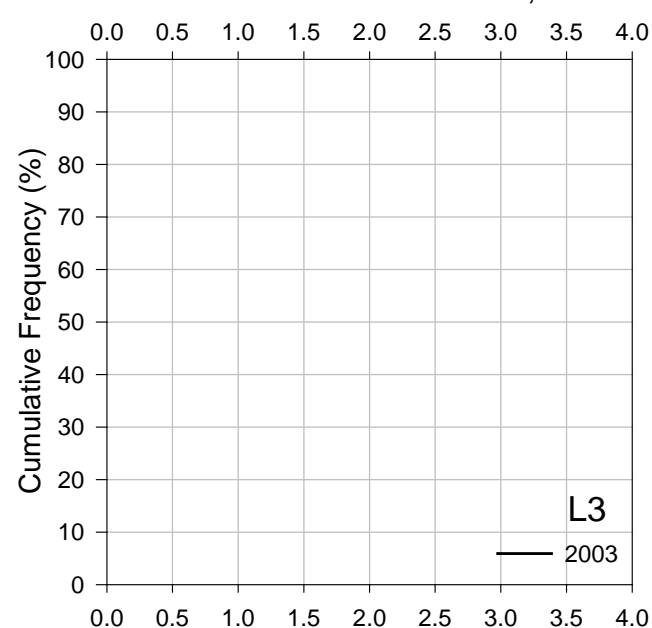

Water Surface Elevation, m

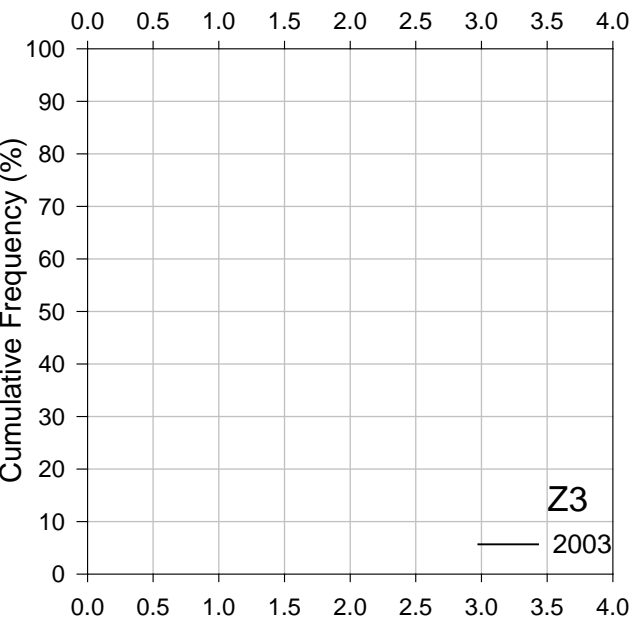

Figure G-2: Scenario 0 (Baseline Condition) - Cumulative Frequency Plot for water-surface elevation at all six locations after a year-long simulation 
Water Surface Elevation, $\mathrm{m}$

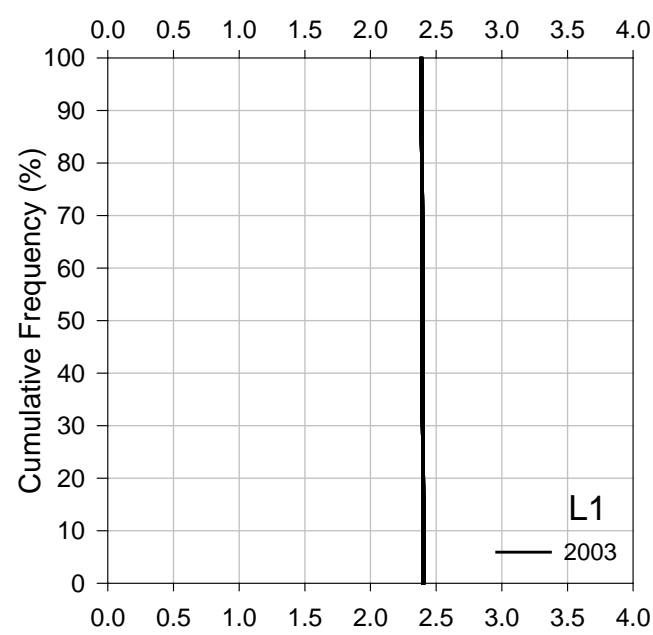

Water Surface Elevation, $\mathrm{m}$

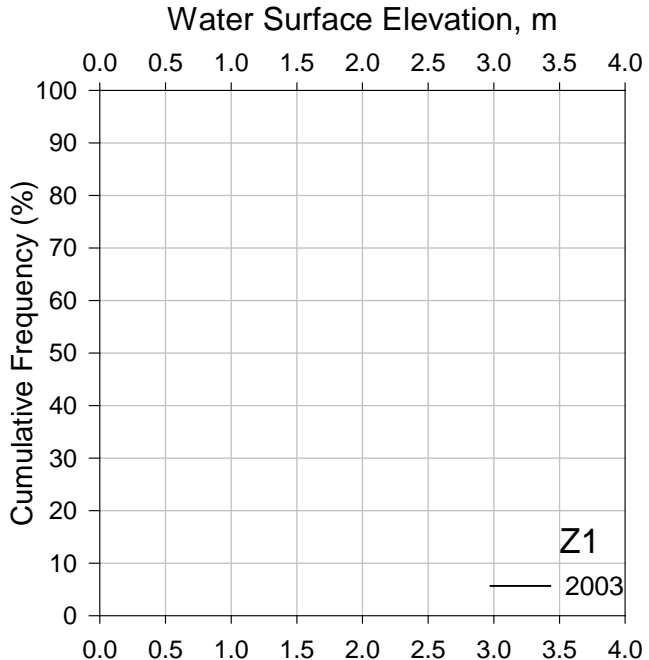

Water Surface Elevation, $\mathrm{m}$

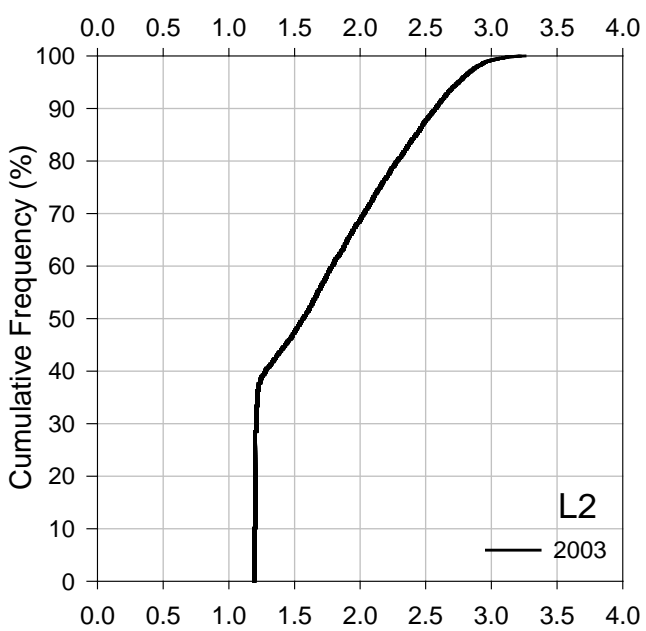

Water Surface Elevation, $\mathrm{m}$

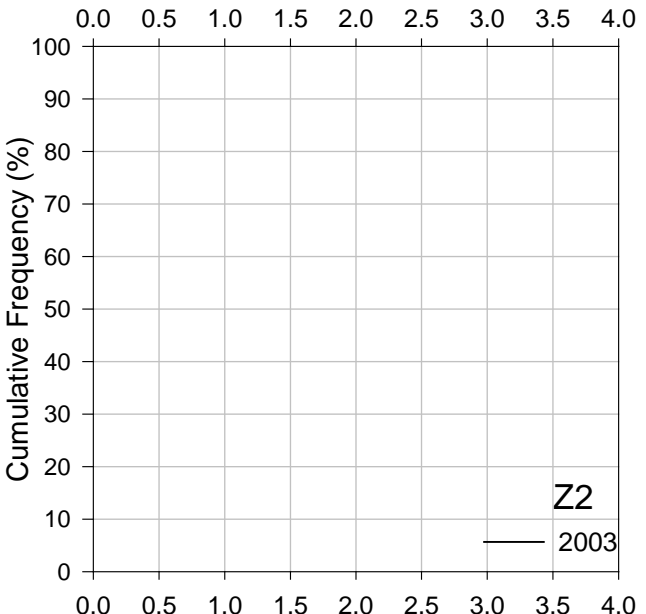

Water Surface Elevation, $\mathrm{m}$

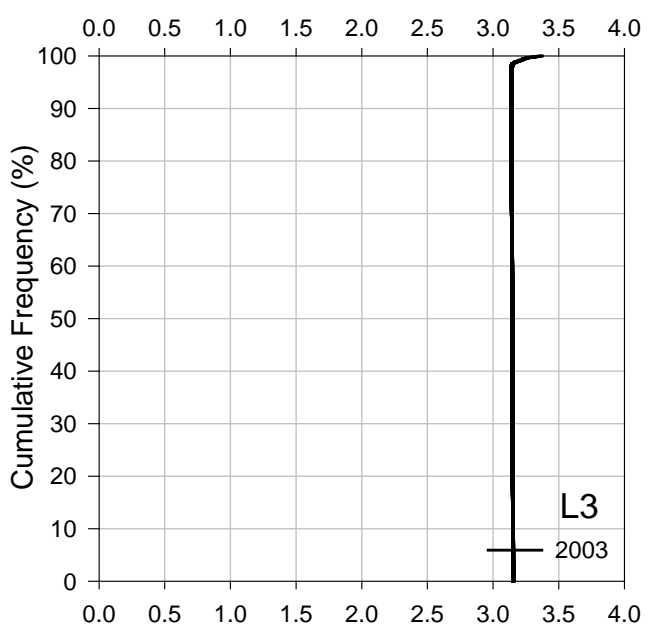

Water Surface Elevation, $\mathrm{m}$

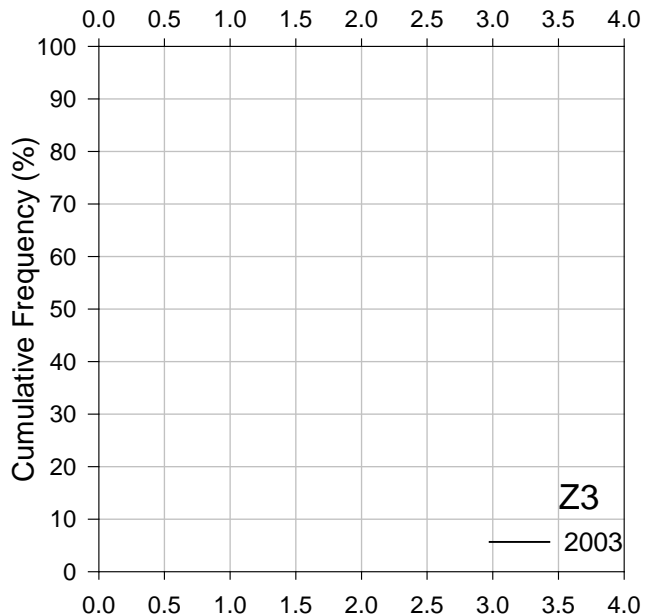

Figure G-3: Scenario 1 (Partial Restoration Leque) - Cumulative Frequency Plot for water-surface elevation at all six locations after a year-long simulation 
Water Surface Elevation, $\mathrm{m}$

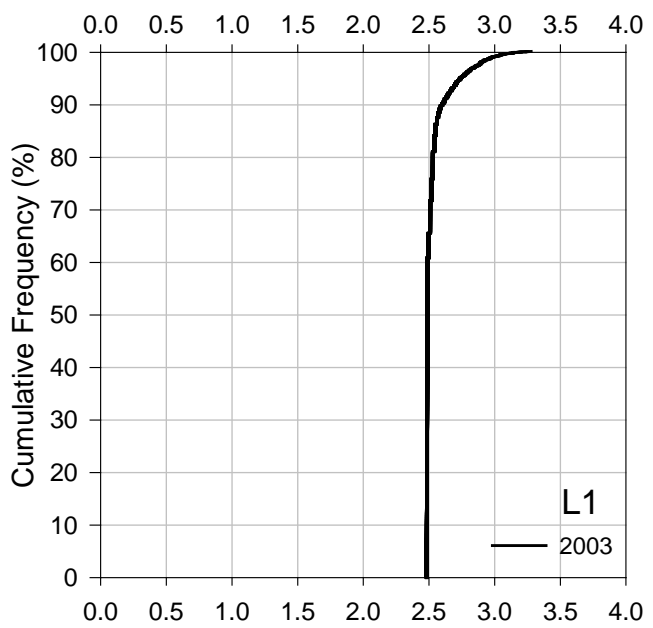

Water Surface Elevation, $\mathrm{m}$

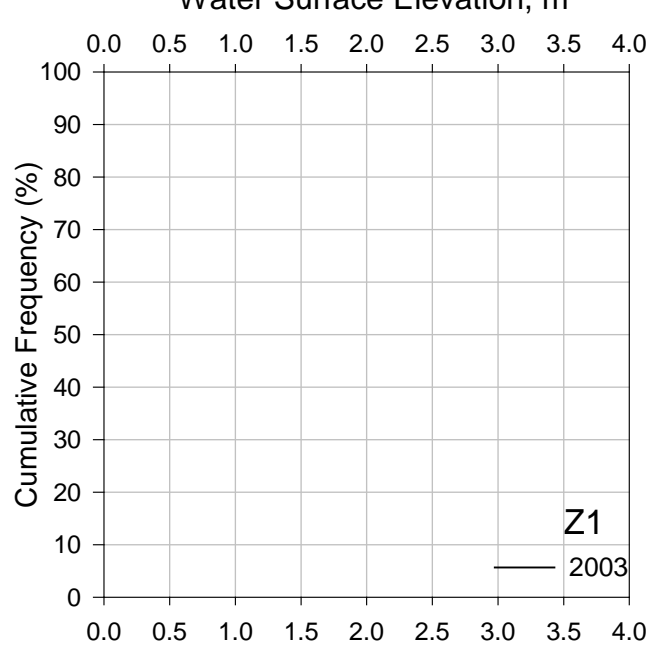

Water Surface Elevation, $\mathrm{m}$

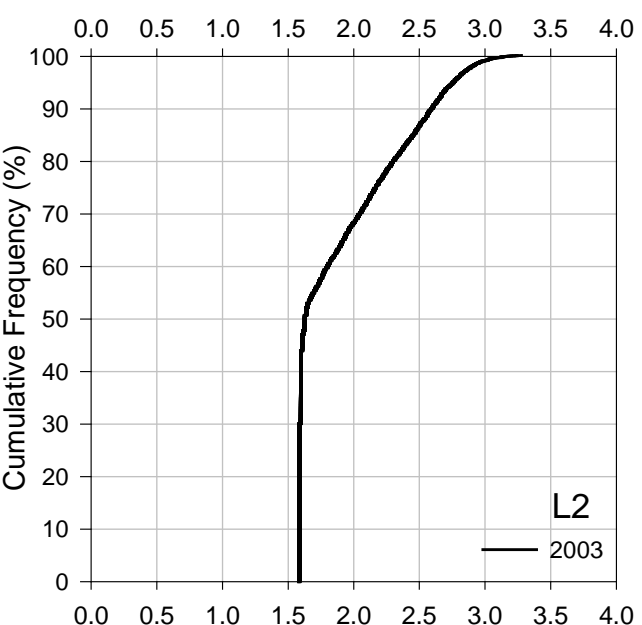

Water Surface Elevation, $\mathrm{m}$

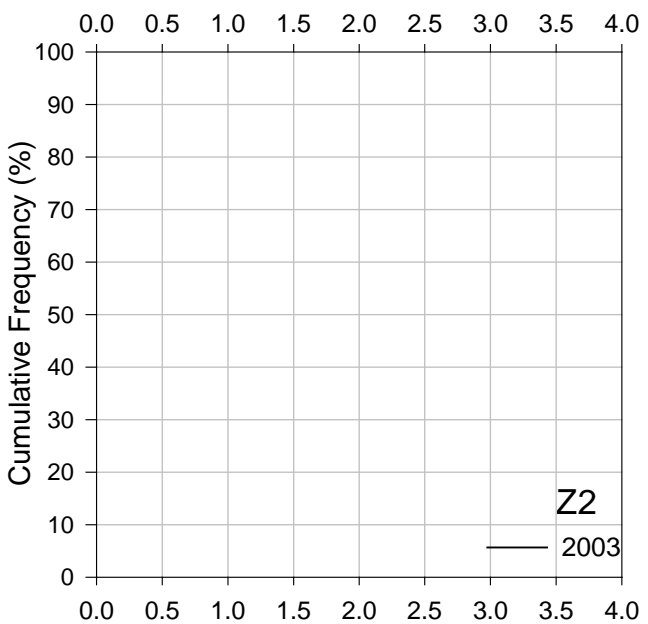

Water Surface Elevation, $\mathrm{m}$

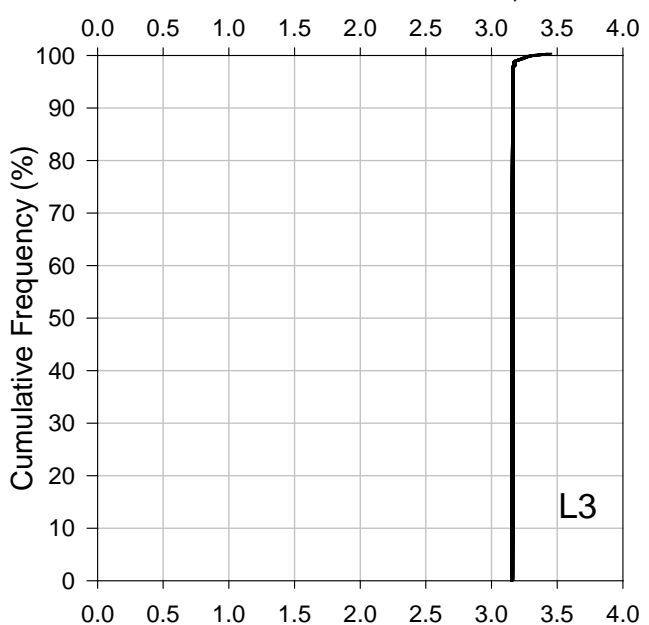

Water Surface Elevation, $\mathrm{m}$

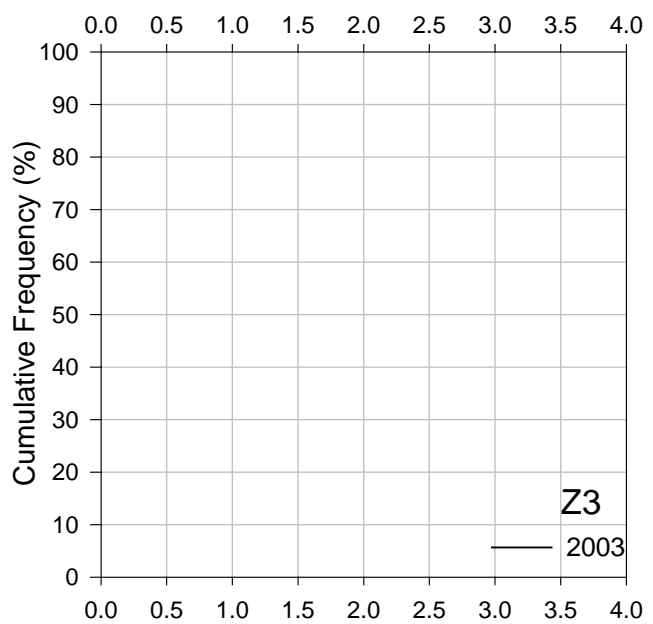

Figure G-4: Scenario 2 (4 Levee Breach Leque) - Cumulative Frequency Plot for water-surface elevation at all six locations after a year-long simulation 
Water Surface Elevation, $\mathrm{m}$

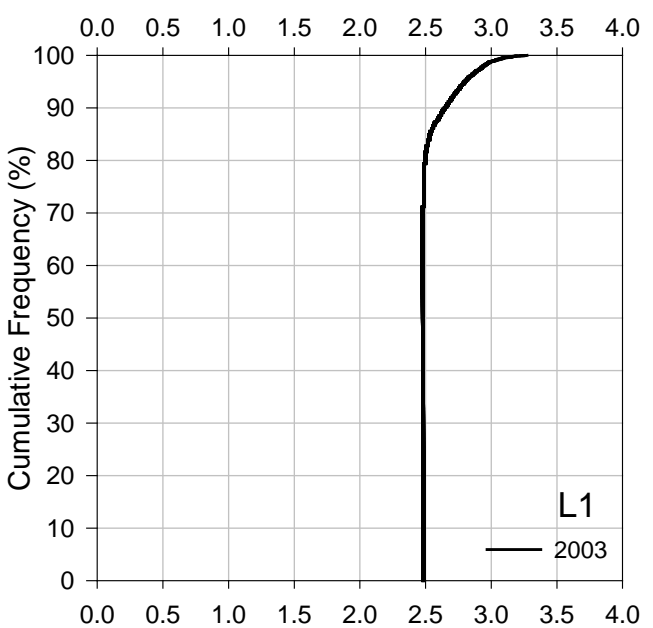

Water Surface Elevation, $\mathrm{m}$

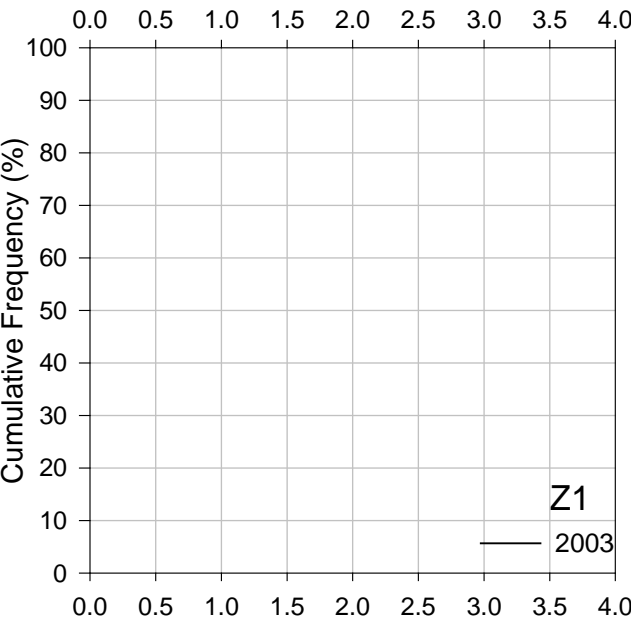

Water Surface Elevation, $\mathrm{m}$

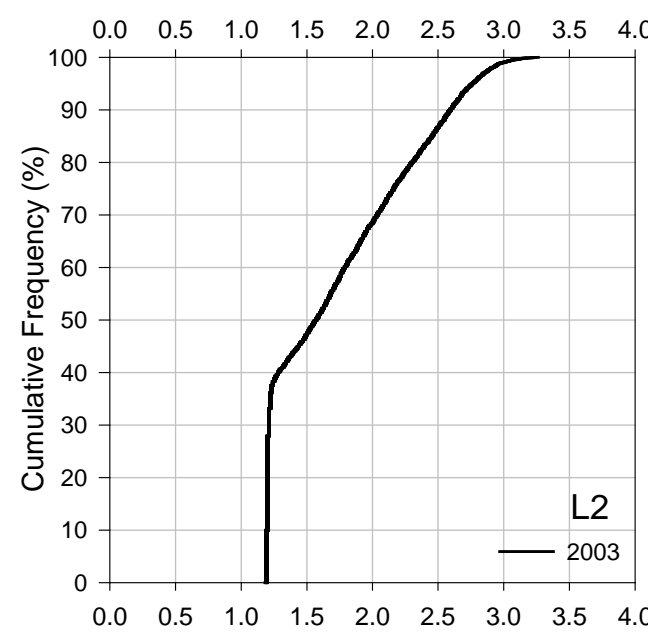

Water Surface Elevation, $\mathrm{m}$

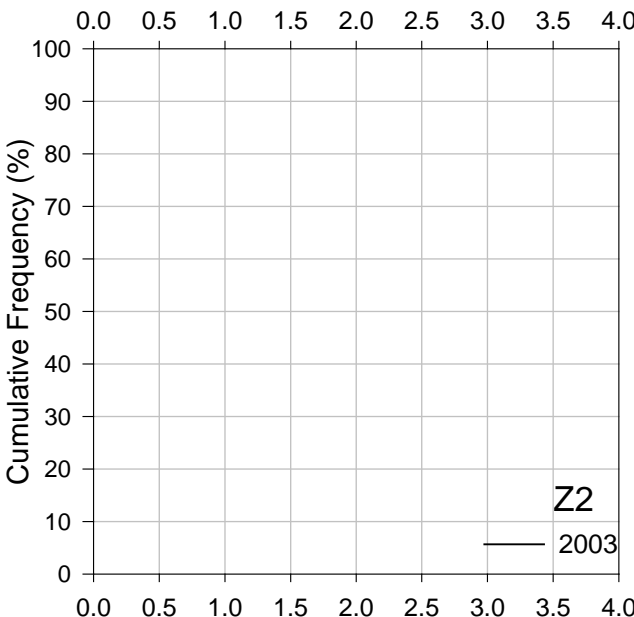

Water Surface Elevation, m

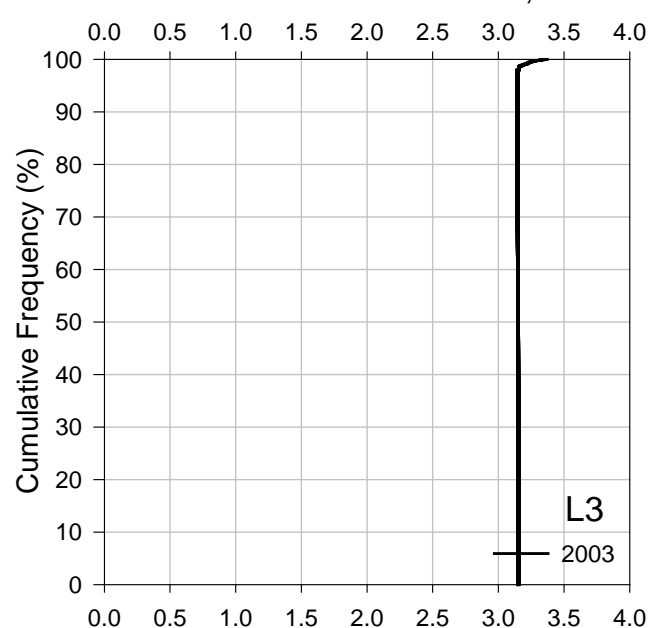

Water Surface Elevation, $\mathrm{m}$

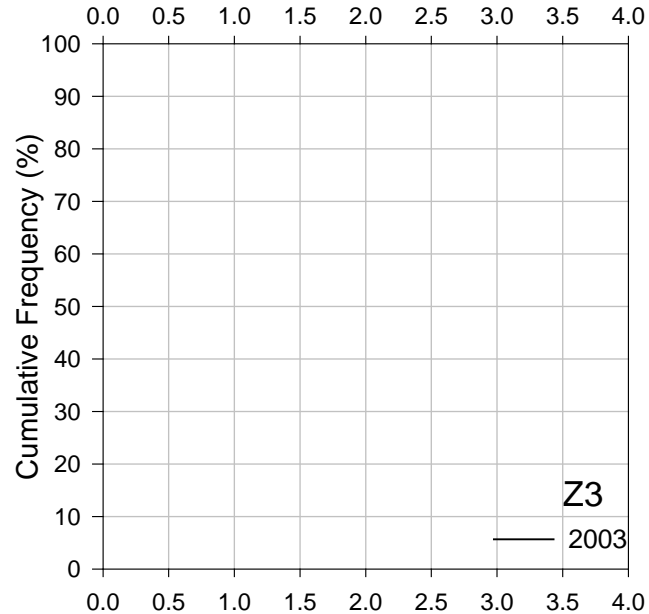

Figure G-5: Scenario 3 (Full Restoration Leque 1) - Cumulative Frequency Plot for water-surface elevation at all six locations after a year-long simulation 
Water Surface Elevation, $\mathrm{m}$

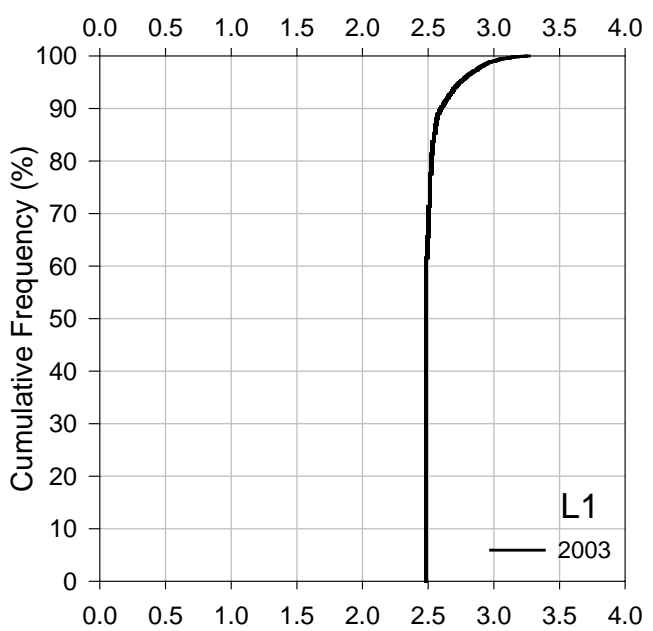

Water Surface Elevation, $\mathrm{m}$

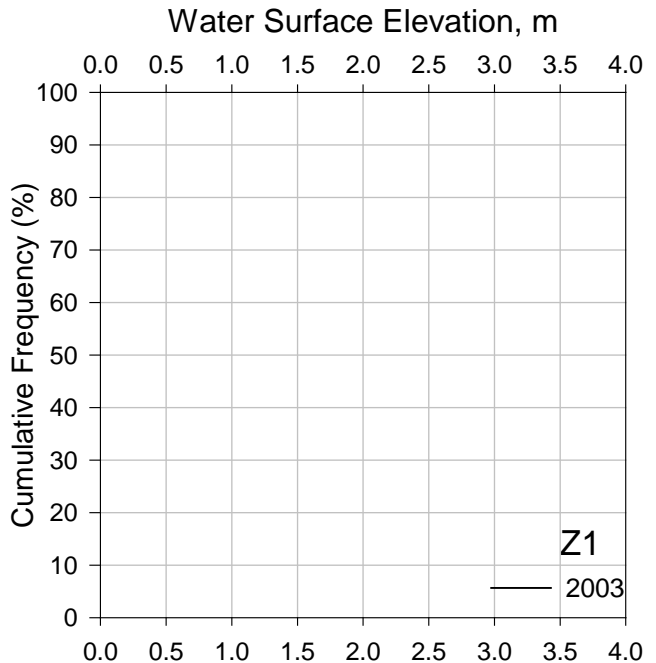

Water Surface Elevation, $\mathrm{m}$

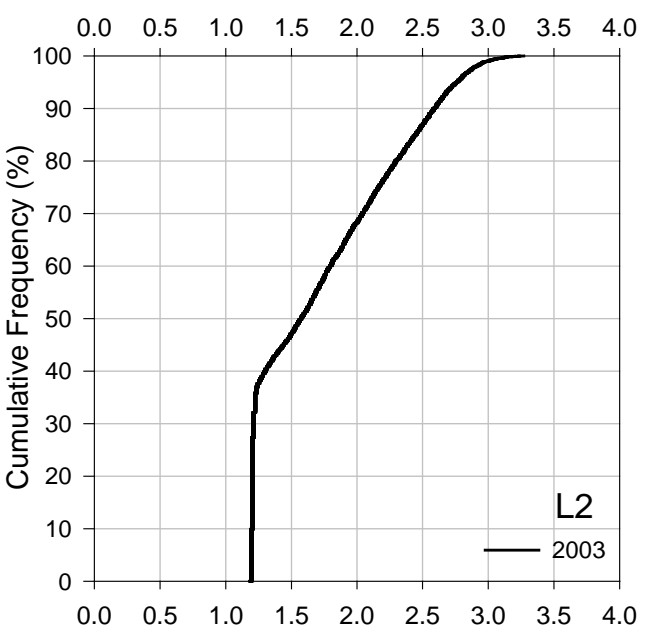

Water Surface Elevation, $\mathrm{m}$

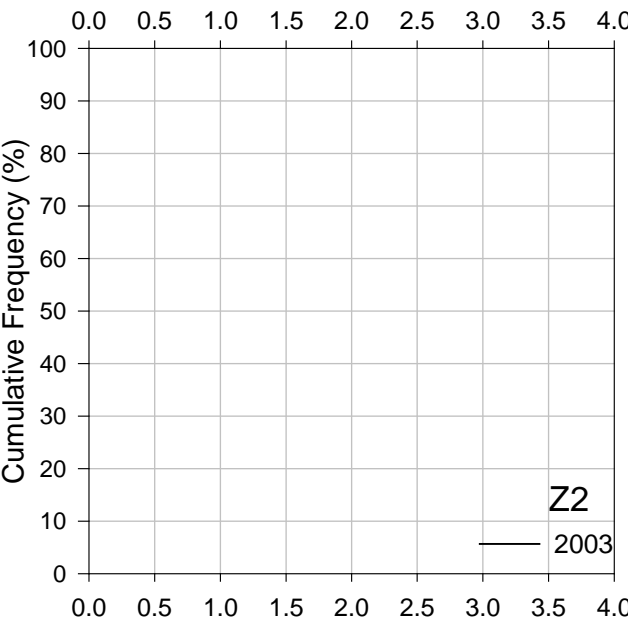

Water Surface Elevation, $\mathrm{m}$

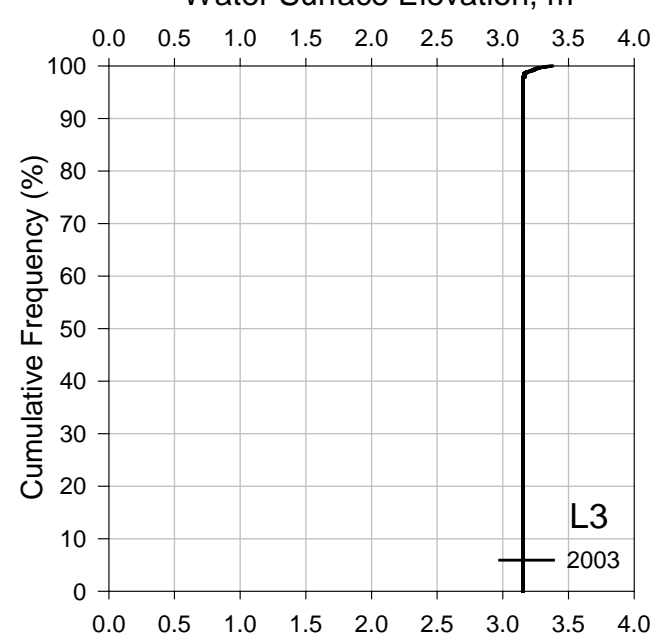

Water Surface Elevation, $\mathrm{m}$

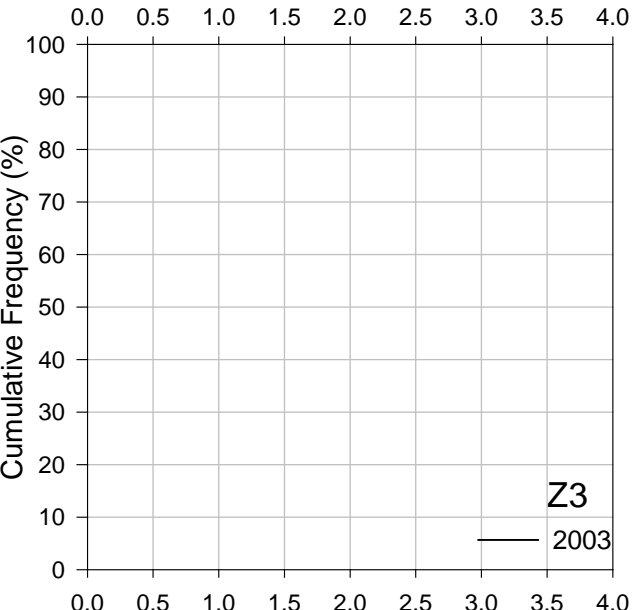

Figure G-6: Scenario 4 (Full Restoration Leque 2) - Cumulative Frequency Plot for water-surface elevation at all six locations after a year-long simulation 

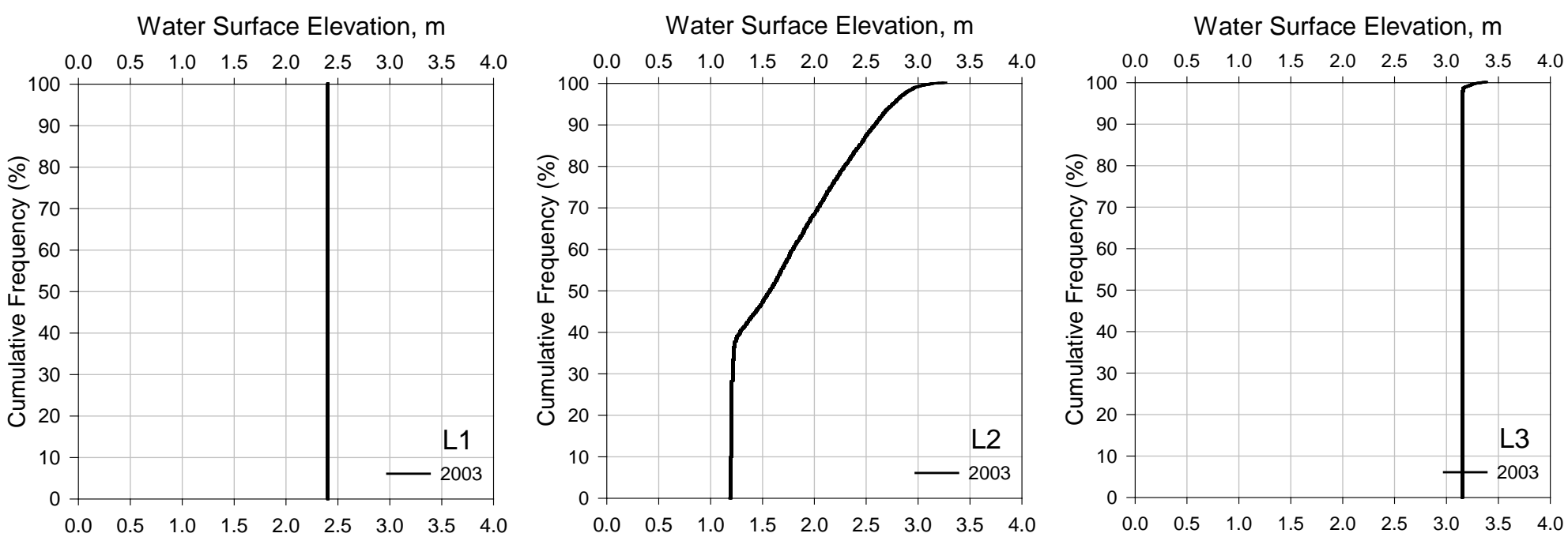

Water Surface Elevation, $\mathrm{m}$

Water Surface Elevation, $\mathrm{m}$

Water Surface Elevation, $\mathrm{m}$
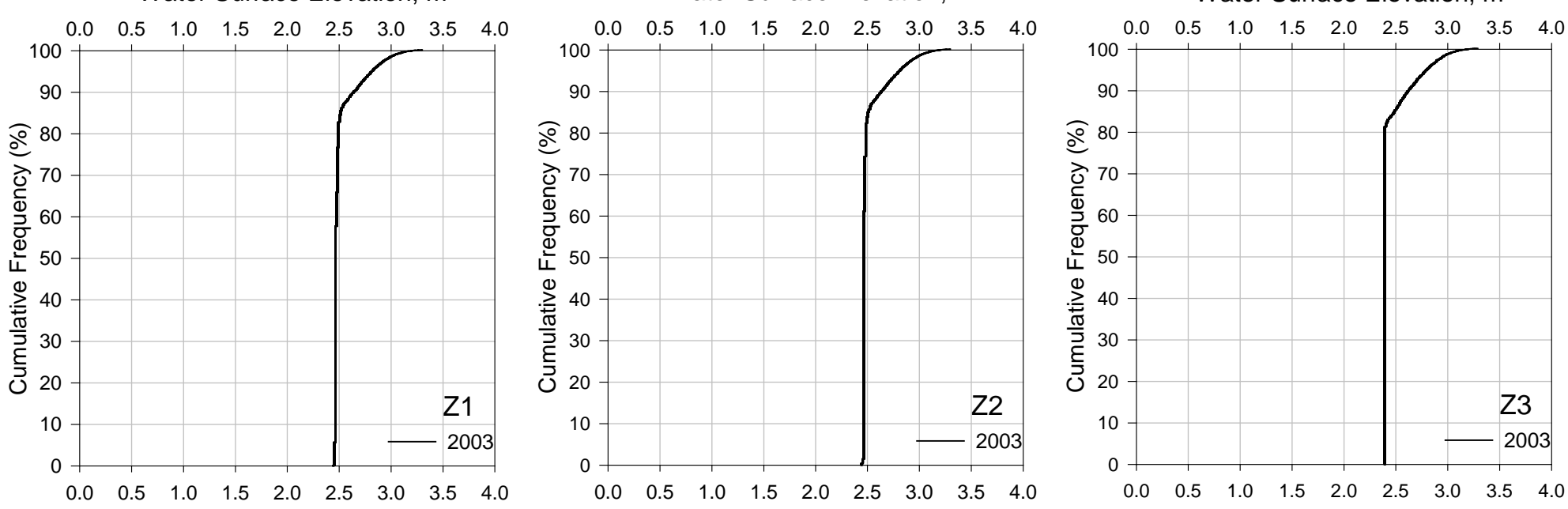

Figure G-7: Scenario 5 (Full Restoration zis a ba + SCN1) - Cumulative Frequency Plot for water-surface elevation at all six locations after a year-long simulation 

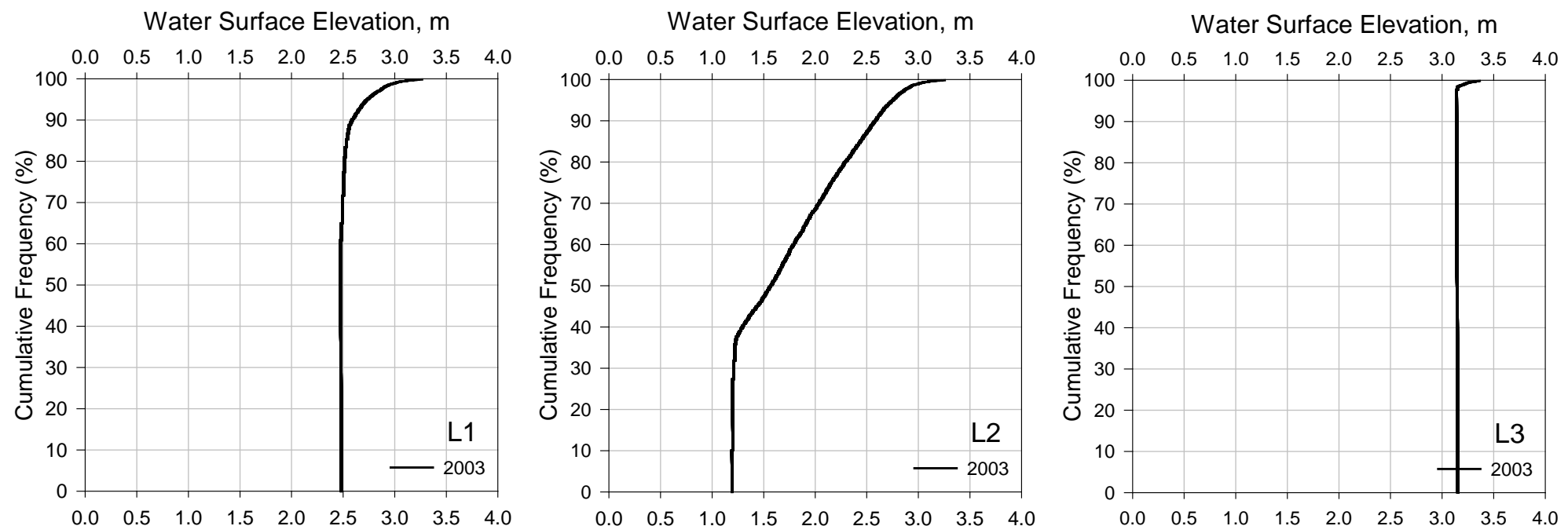

Water Surface Elevation, $\mathrm{m}$

\section{Water Surface Elevation, $\mathrm{m}$}
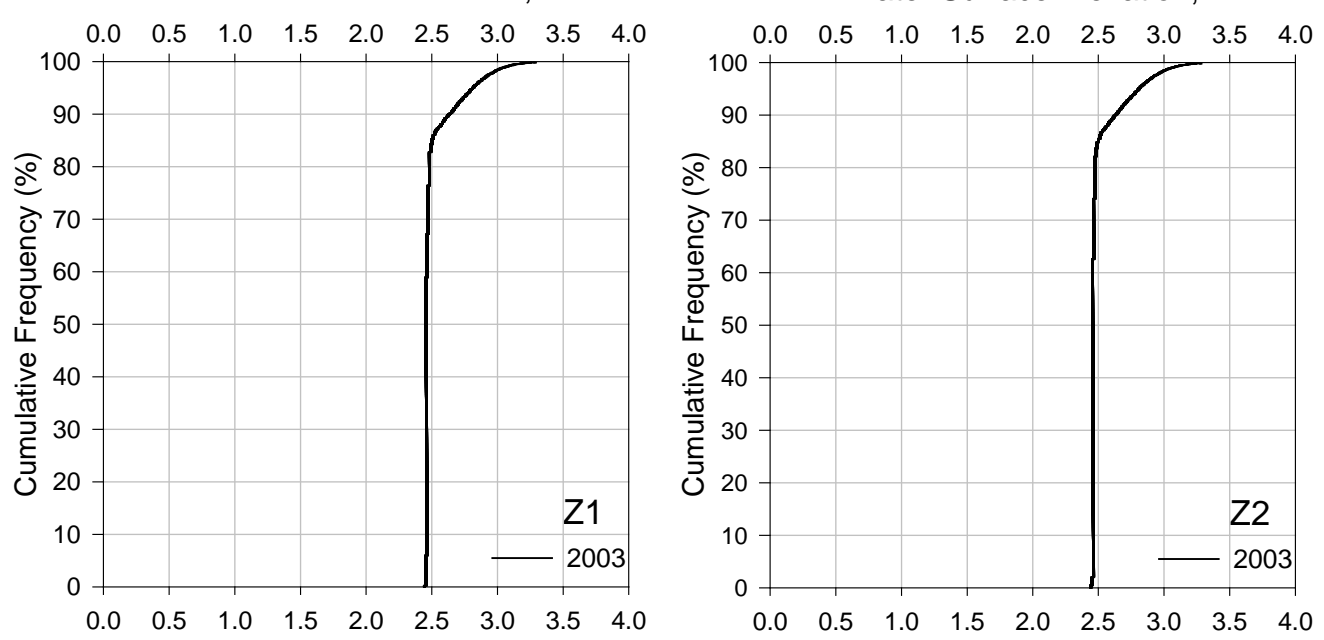

Water Surface Elevation, $\mathrm{m}$

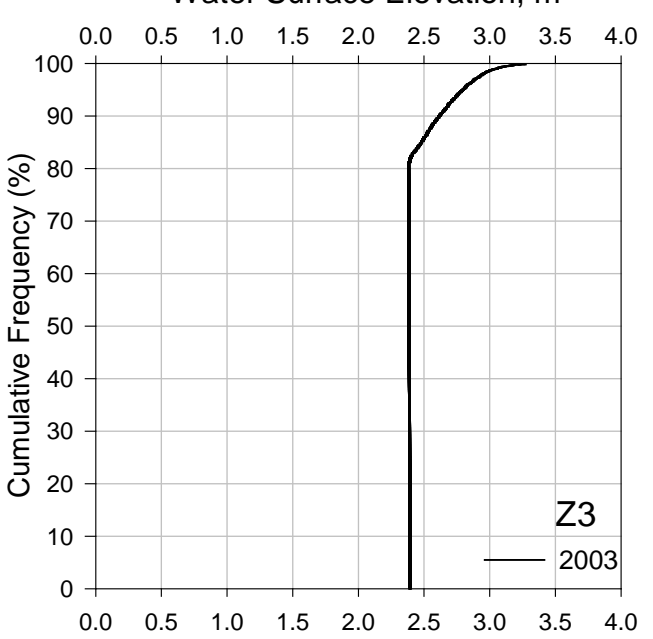

Figure G-8: Scenario 6 (Full Restoration zis a ba + SCN4) - Cumulative Frequency Plot for water-surface elevation at all six locations after a year-long simulation 
Water Surface Elevation, $\mathrm{m}$

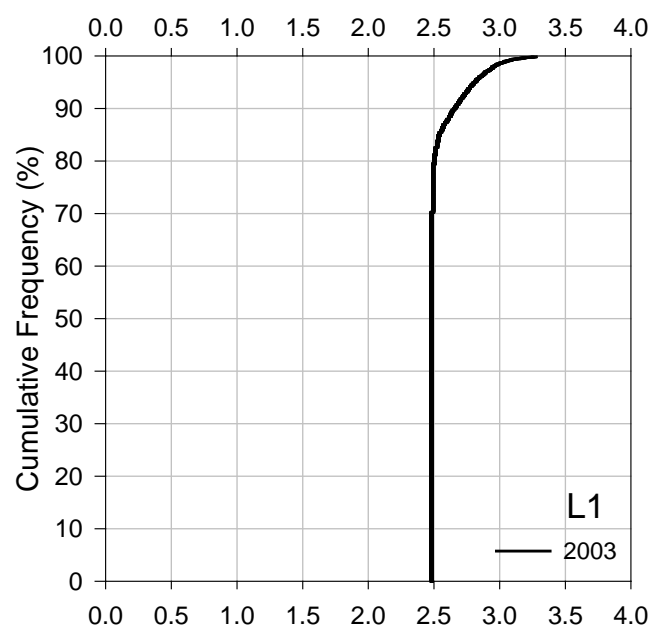

Water Surface Elevation, $\mathrm{m}$

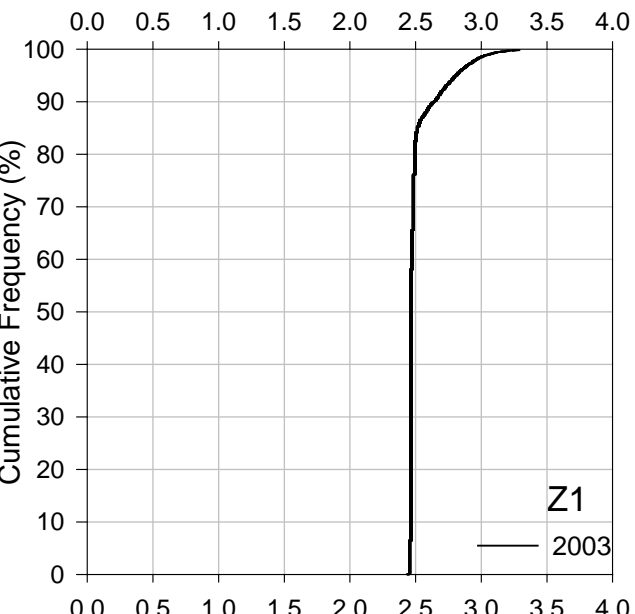

Water Surface Elevation, m

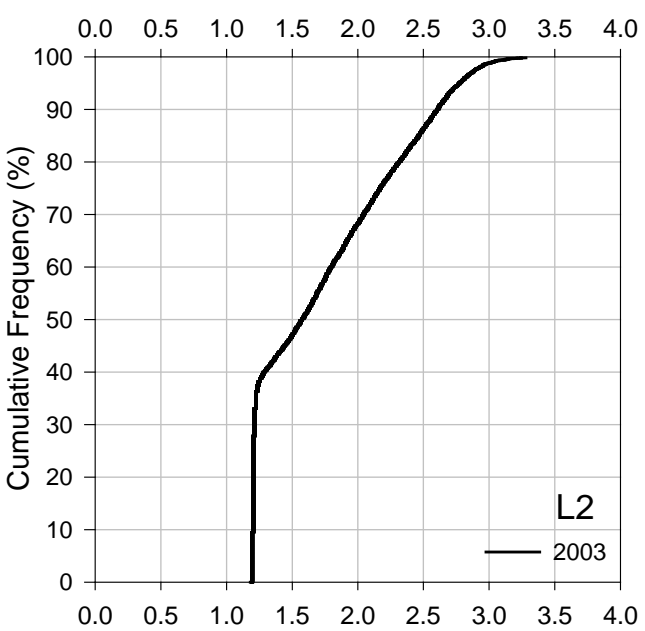

Water Surface Elevation, $\mathrm{m}$

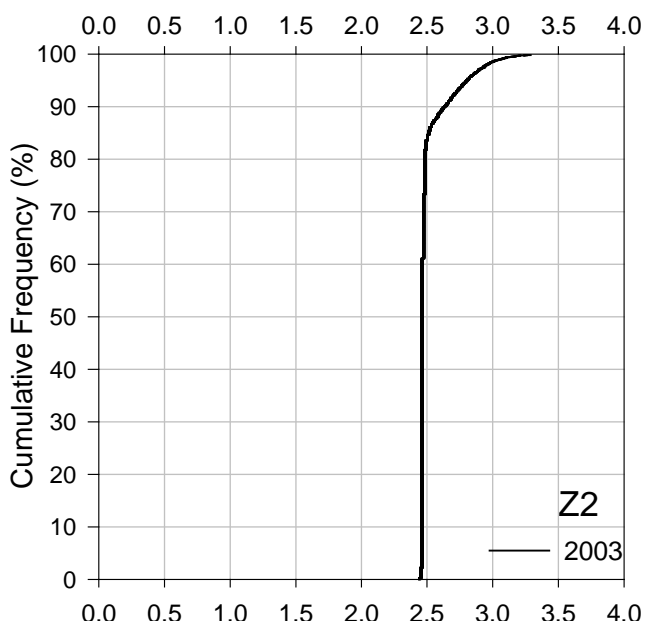

Water Surface Elevation, $\mathrm{m}$

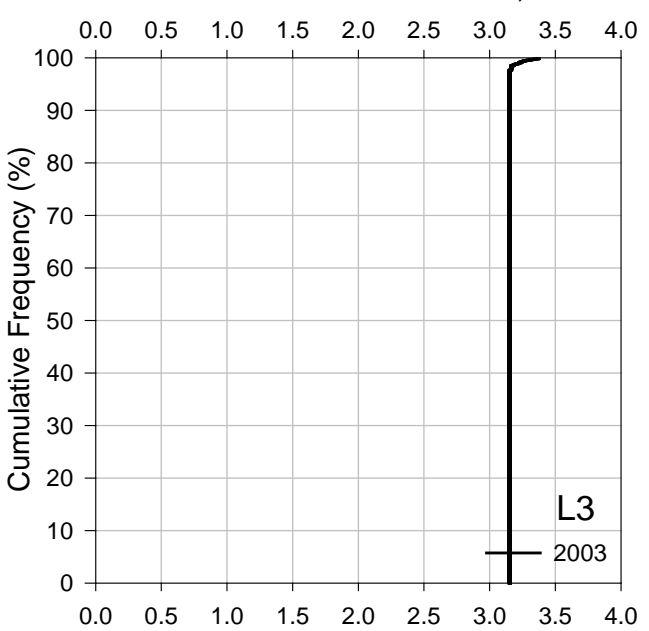

Water Surface Elevation, $\mathrm{m}$

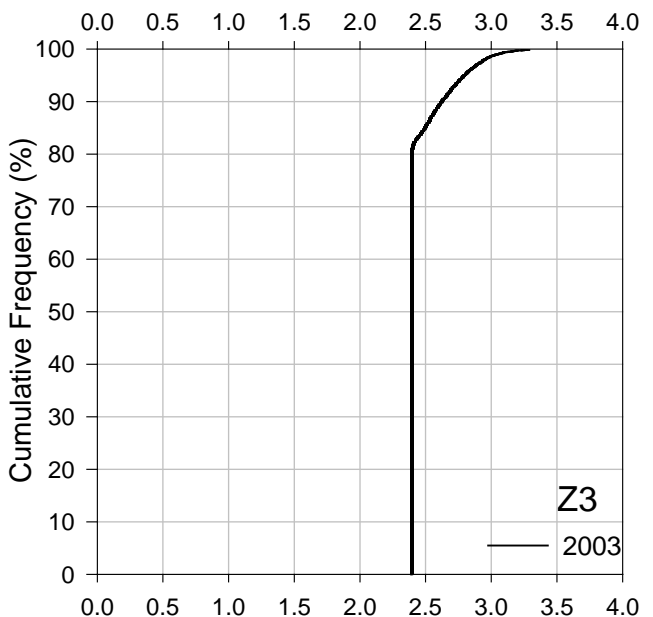

Figure G-9: Scenario 7 (Full Restoration zis a ba + SCN3) - Cumulative Frequency Plot for water-surface elevation at all six locations after a year-long simulation 

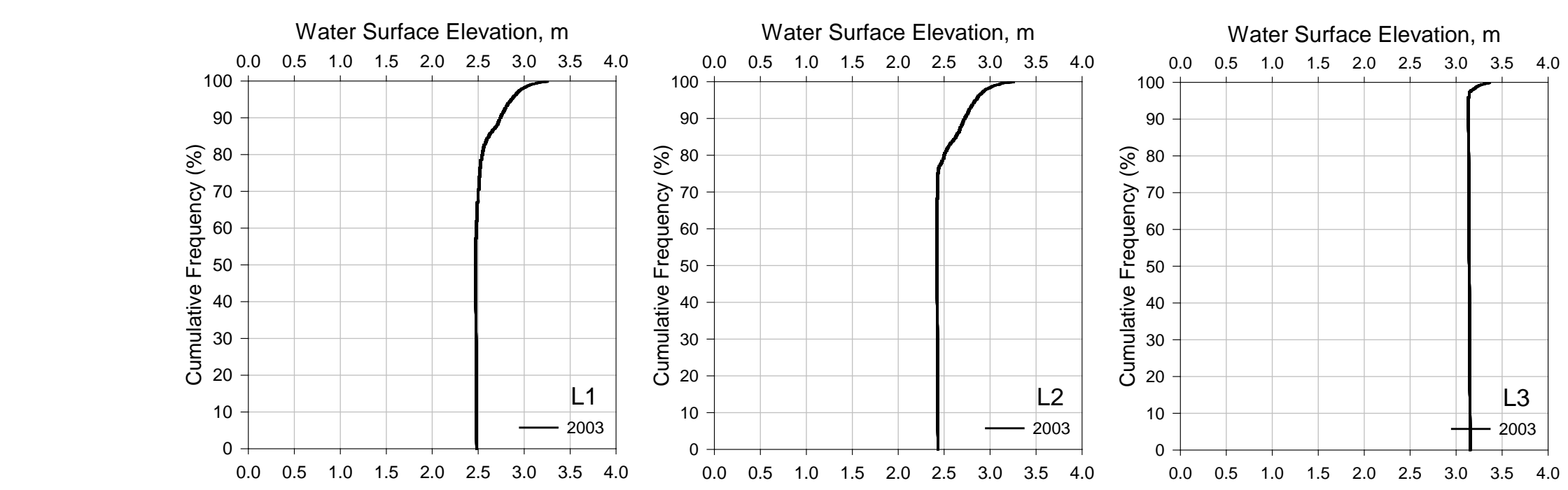

Water Surface Elevation, $\mathrm{m}$

\section{Water Surface Elevation, $\mathrm{m}$}
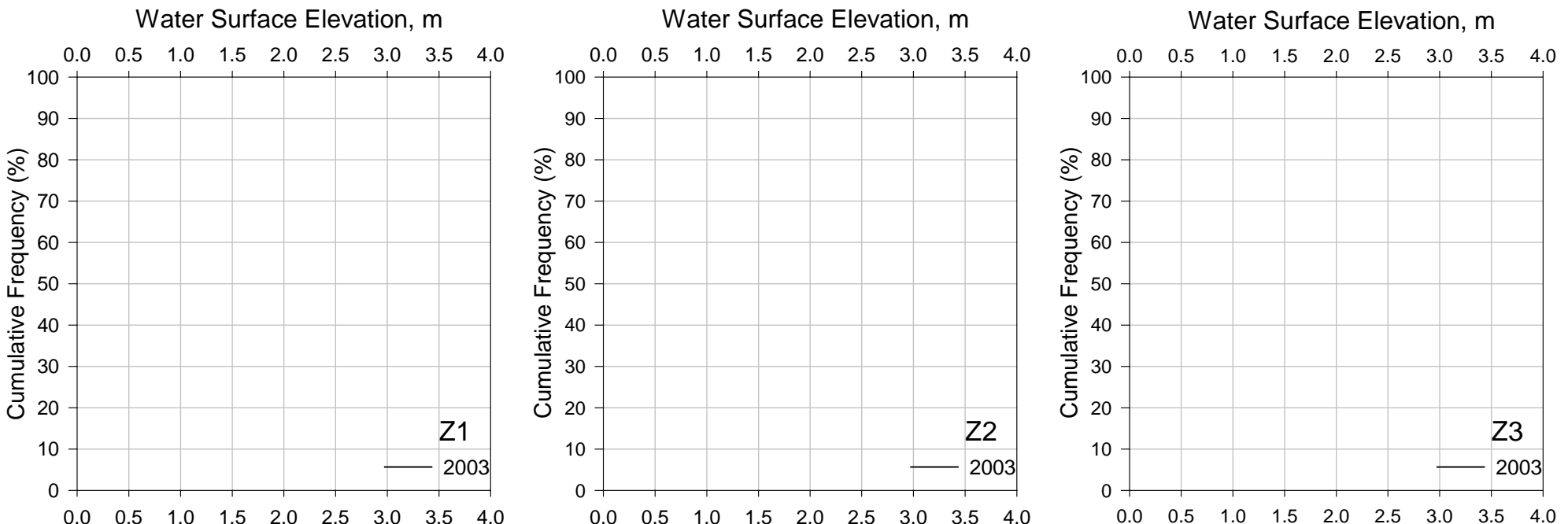

Figure G-10: Scenario 8 (3 Levee Breach Leque) - Cumulative Frequency Plot for water-surface elevation at all six locations after a year-long simulation 

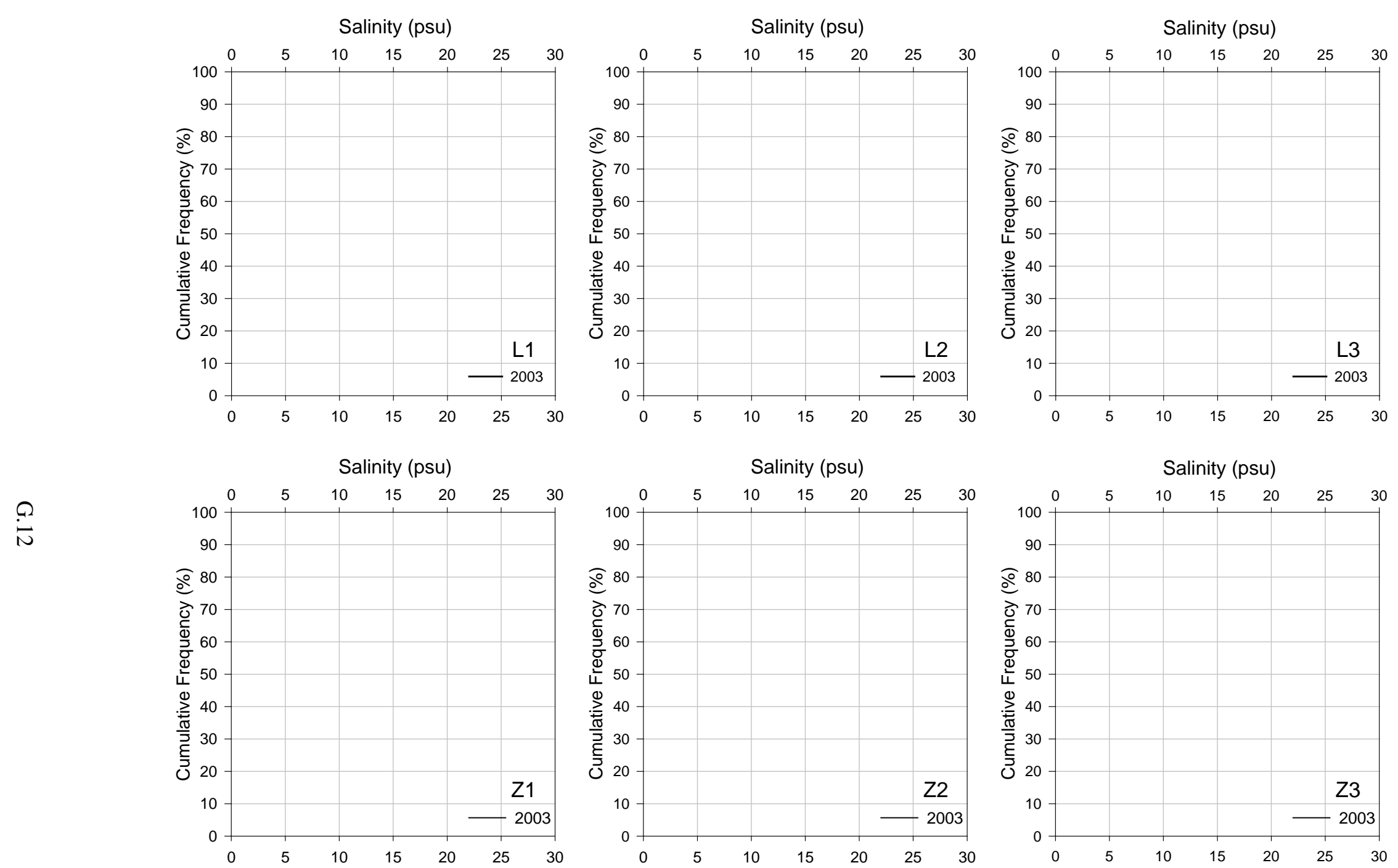

Figure G-11: Scenario 0 (Baseline Condition) - Cumulative Frequency Plot for salinity at all six locations after a year-long simulation 

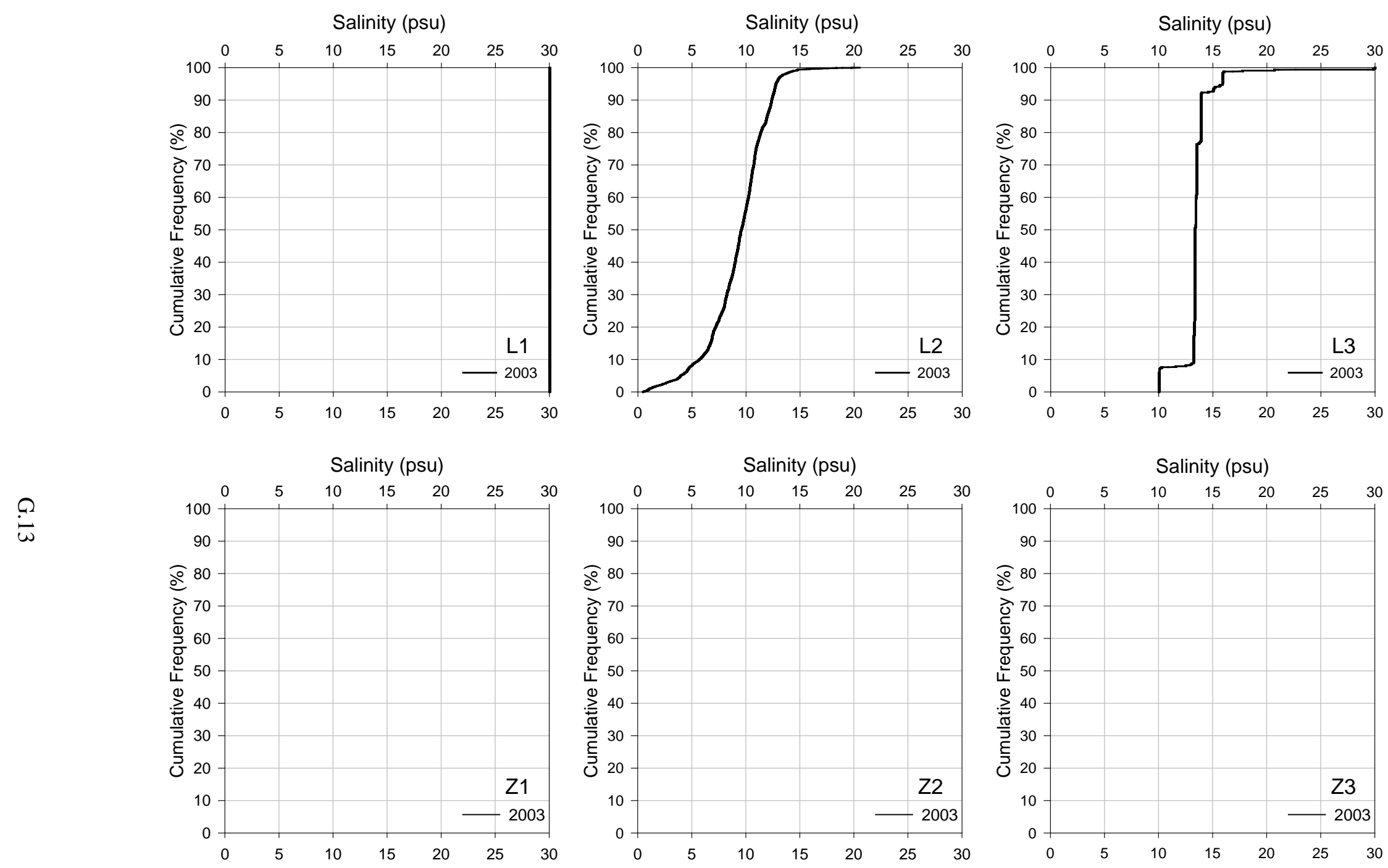

Figure G-12: Scenario 1 (Partial Restoration Leque) - Cumulative Frequency Plot for salinity at all six locations after a year-long simulation 

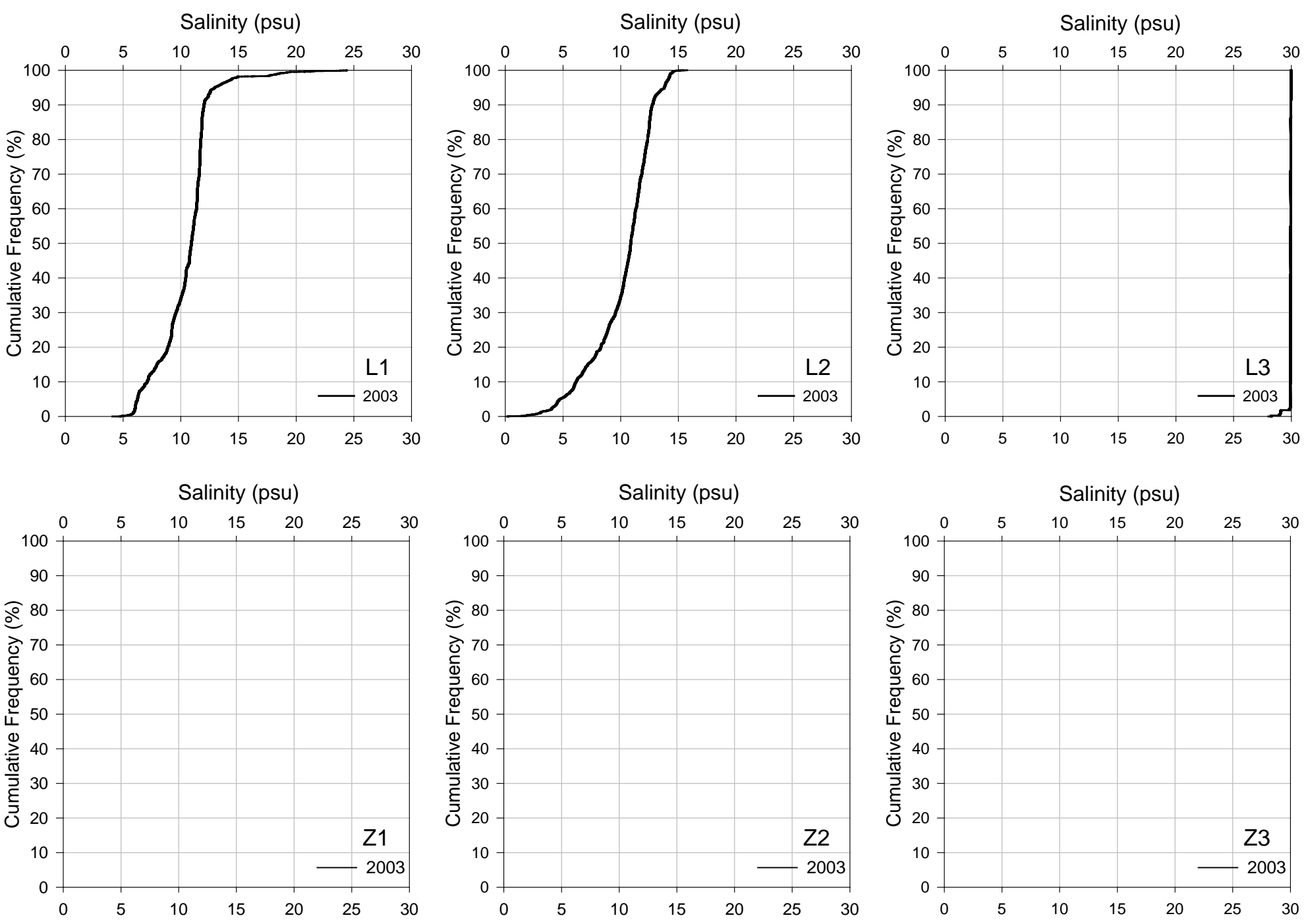

Figure G-13: Scenario 2 (4 Levee Breach Leque) - Cumulative Frequency Plot for salinity at all six locations after a year-long simulation 

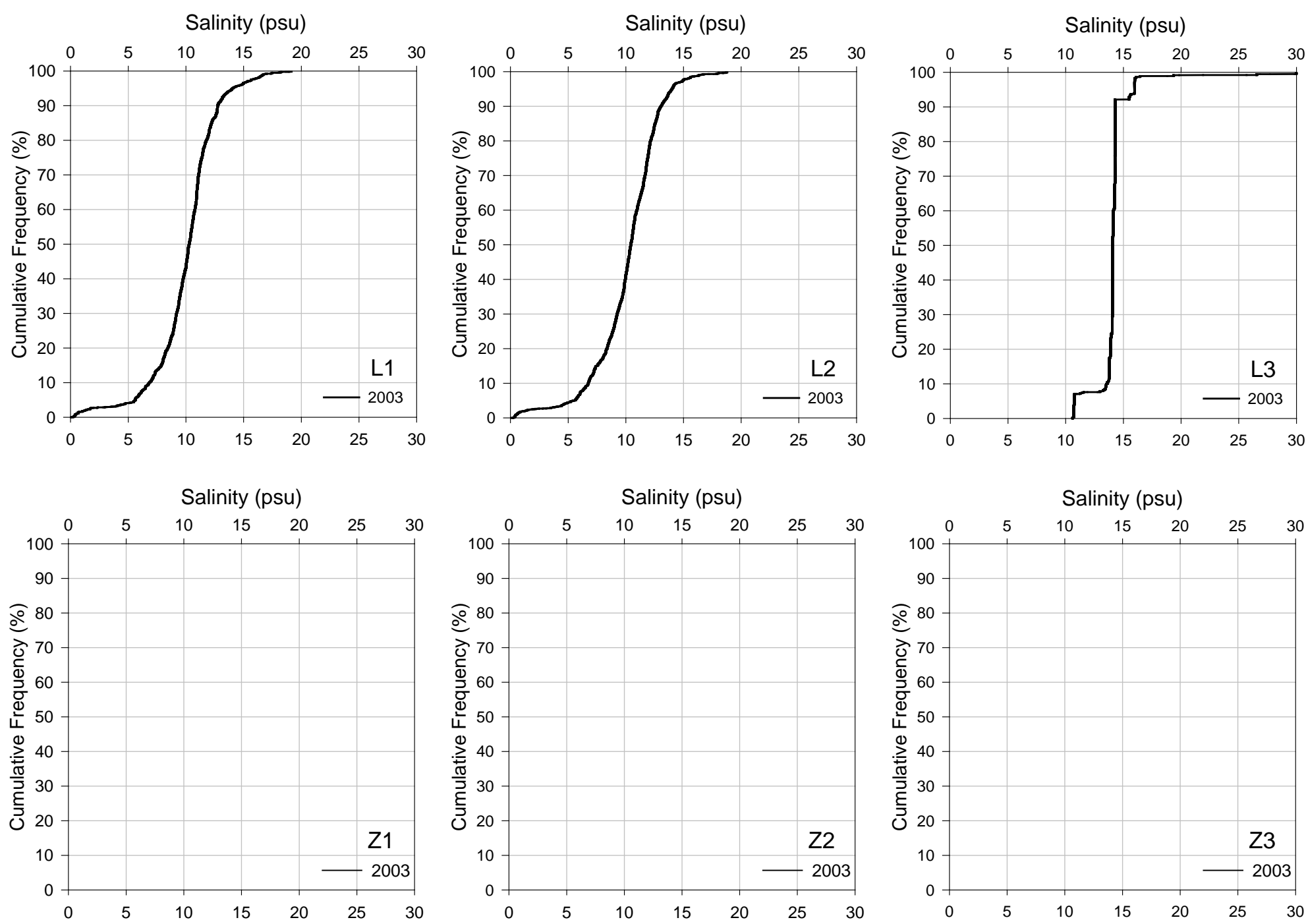

Figure G-14: Scenario 3 (Full Restoration Leque 1) - Cumulative Frequency Plot for salinity at all six locations after a year-long simulation 

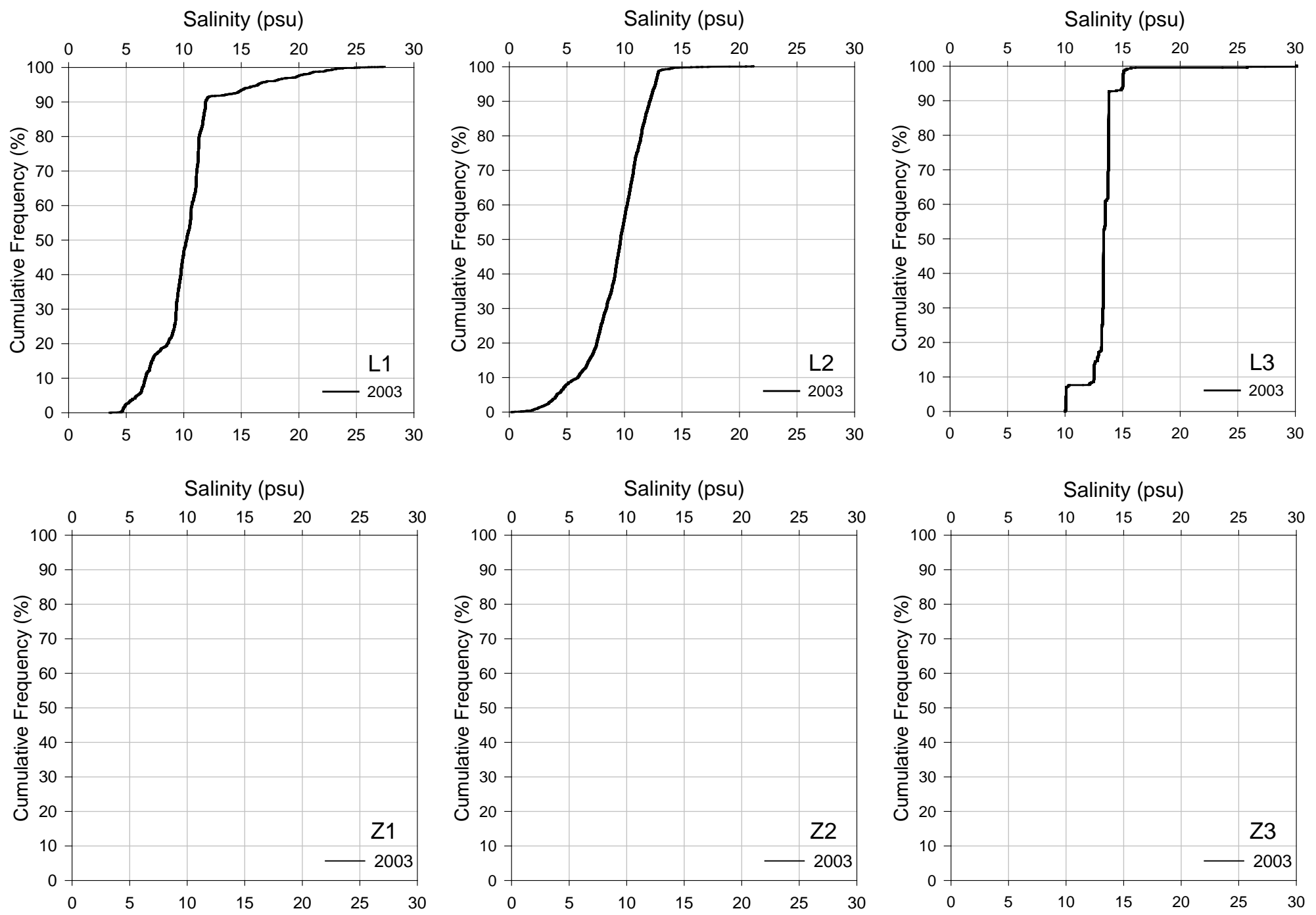

Figure G-15: Scenario 4 (Full Restoration Leque 2) - Cumulative Frequency Plot for salinity at all six locations after a year-long simulation 

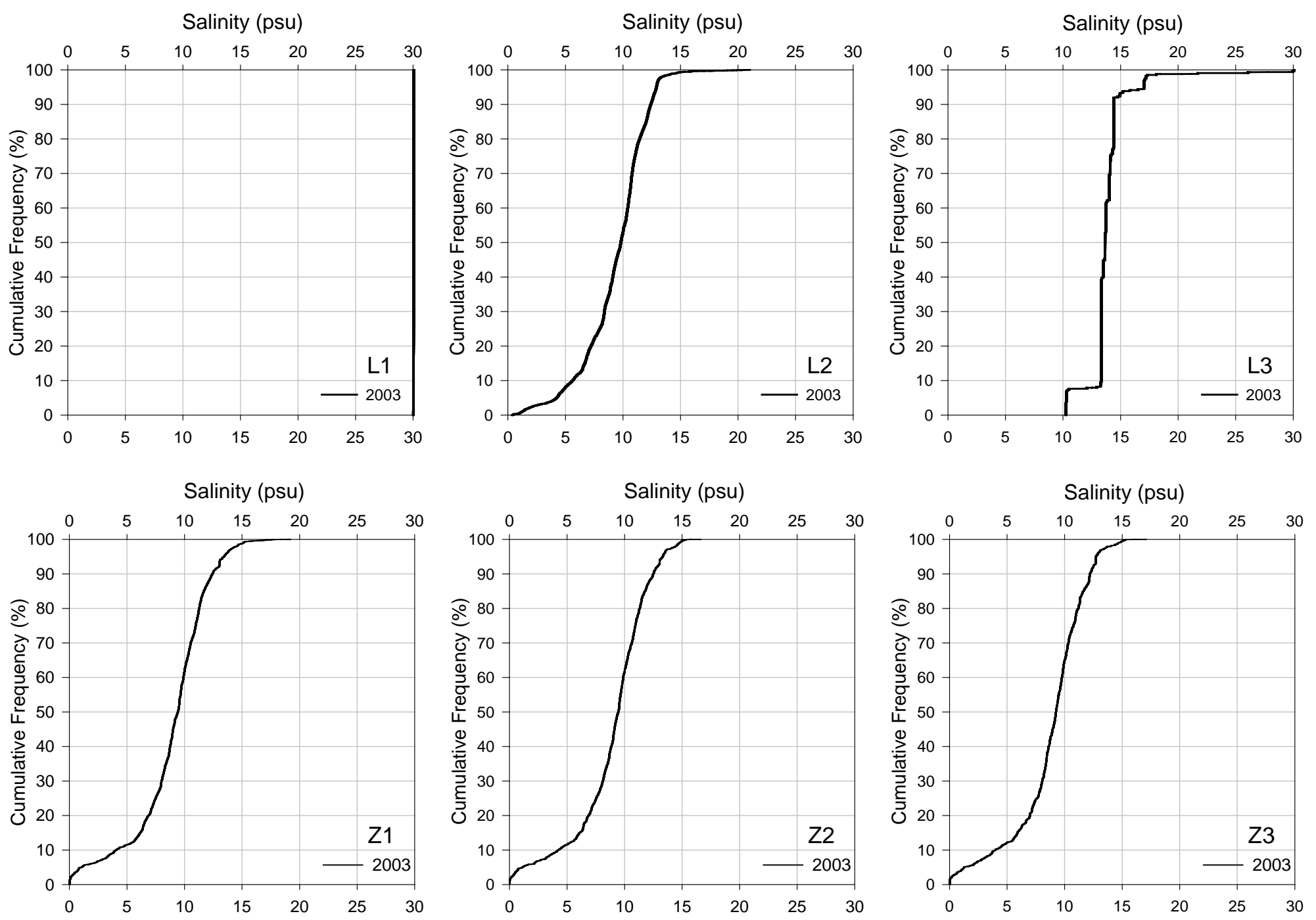

Figure G-16: Scenario 5 (Full Restoration zis a ba + SCN1) - Cumulative Frequency Plot for salinity at all six locations after a year-long simulation. 

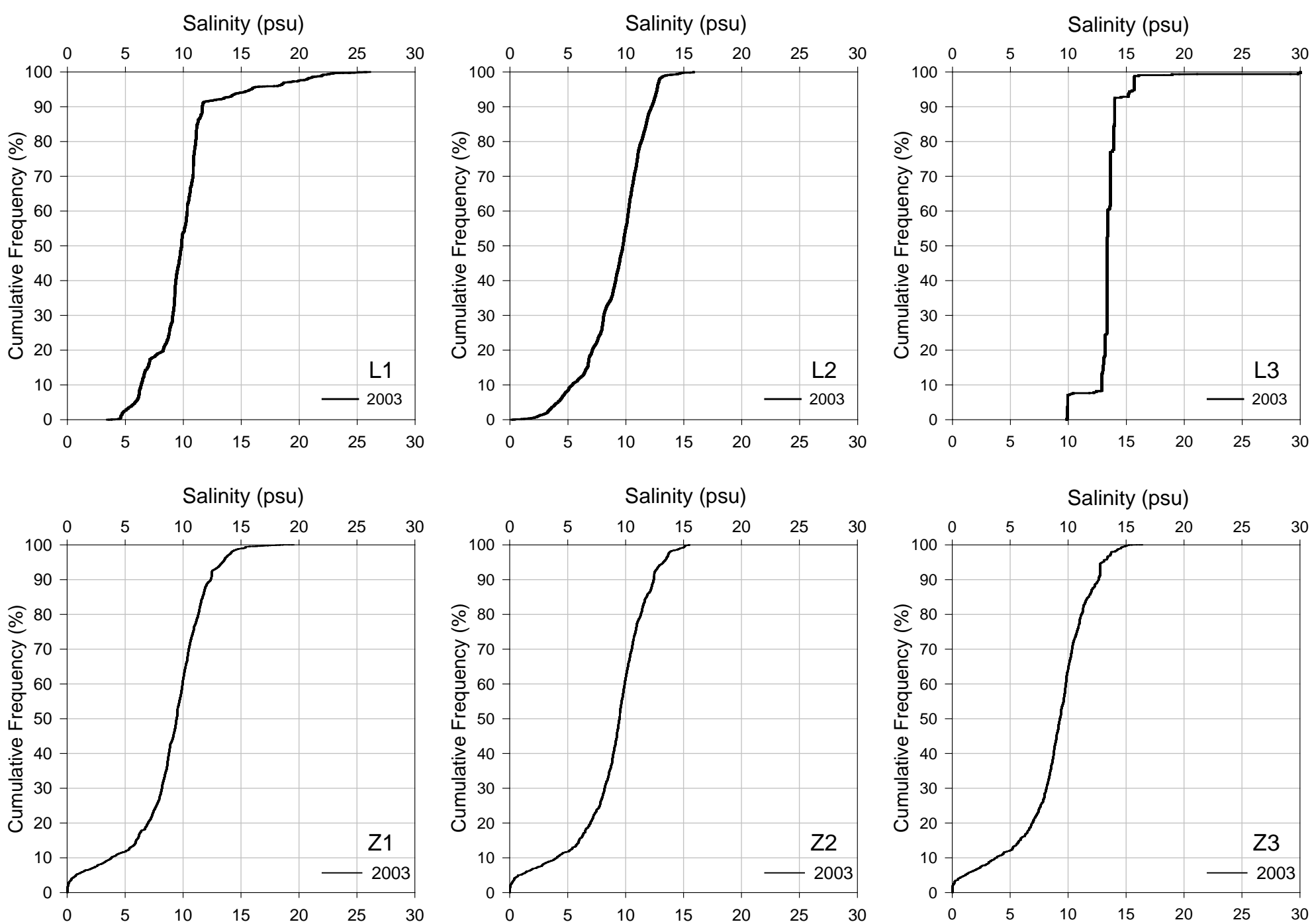

Figure G-17: Scenario 6 (Full Restoration zis a ba + SCN4) - Cumulative Frequency Plot for salinity at all six locations after a year-long simulation 

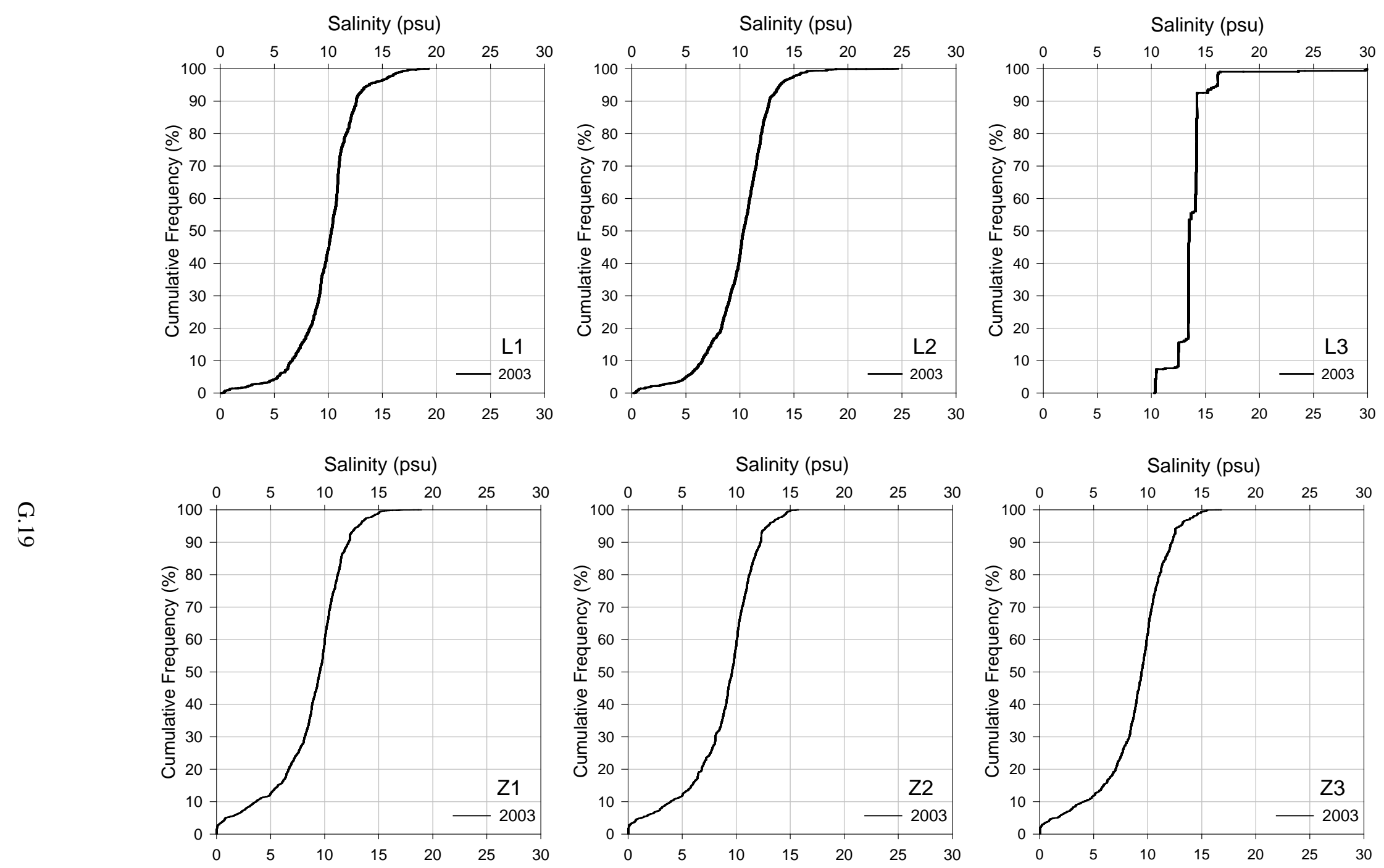

Figure G-18 : Scenario 7 (Full Restoration zis a ba + SCN3) - Cumulative Frequency Plot for salinity at all six locations after a year-long simulation 

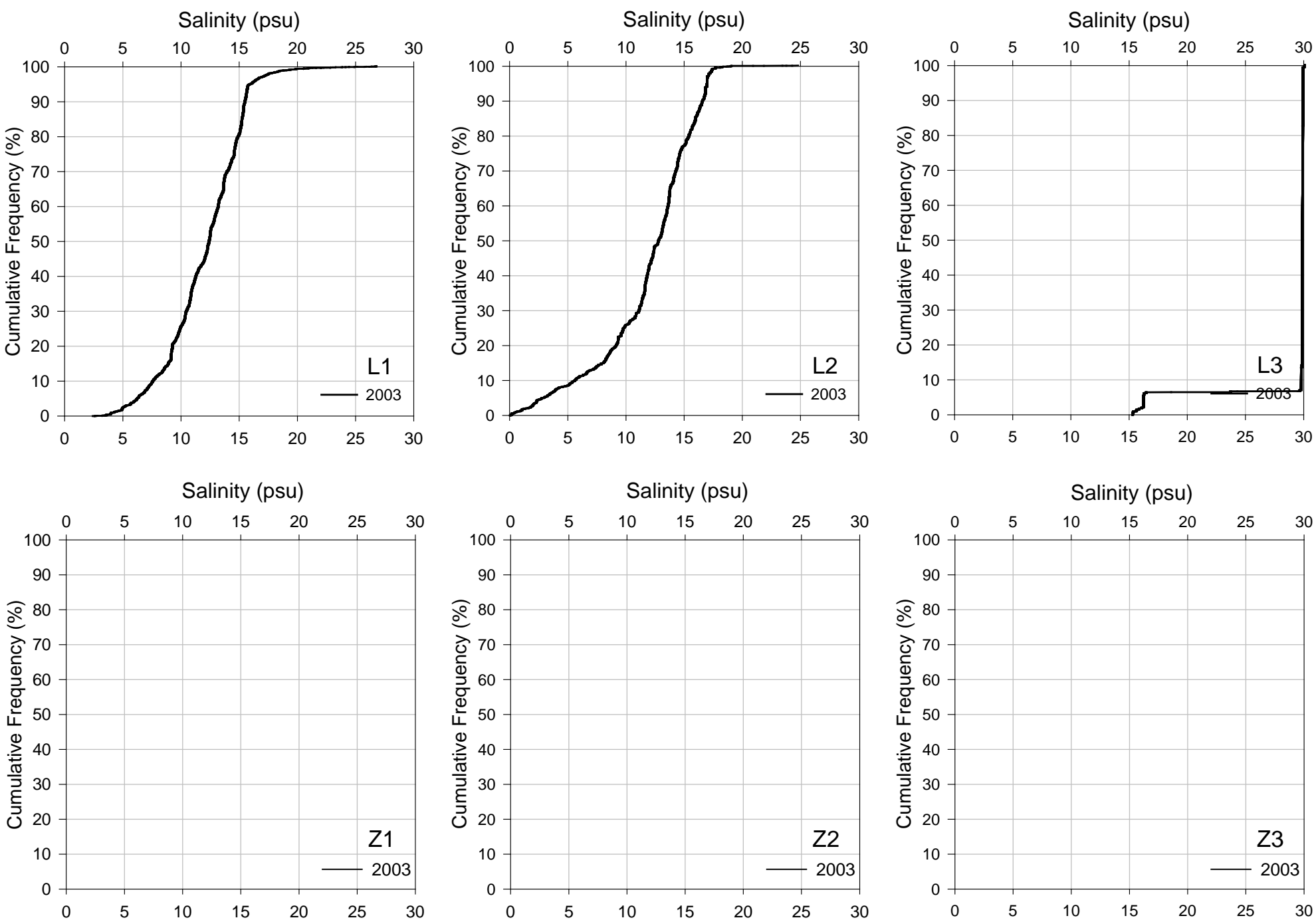

Figure G-19: Scenario 8 (3 Levee Breach Leque) - Cumulative Frequency Plot for salinity at all six locations after a year-long simulation 

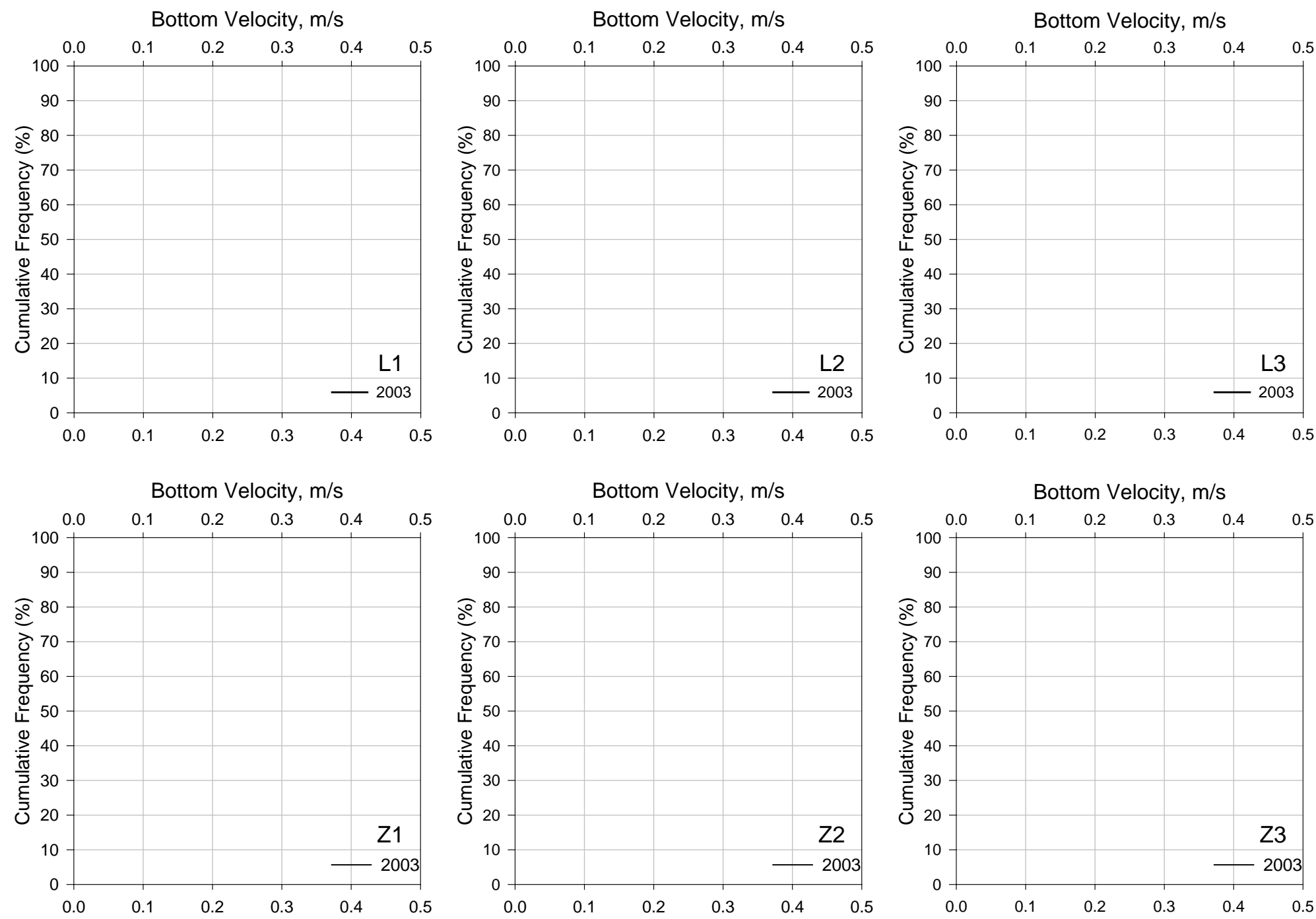

Figure G-20: Scenario 0 (Baseline Condition) - Cumulative Frequency Plot for bottom velocity at all six locations after a year-long simulation 

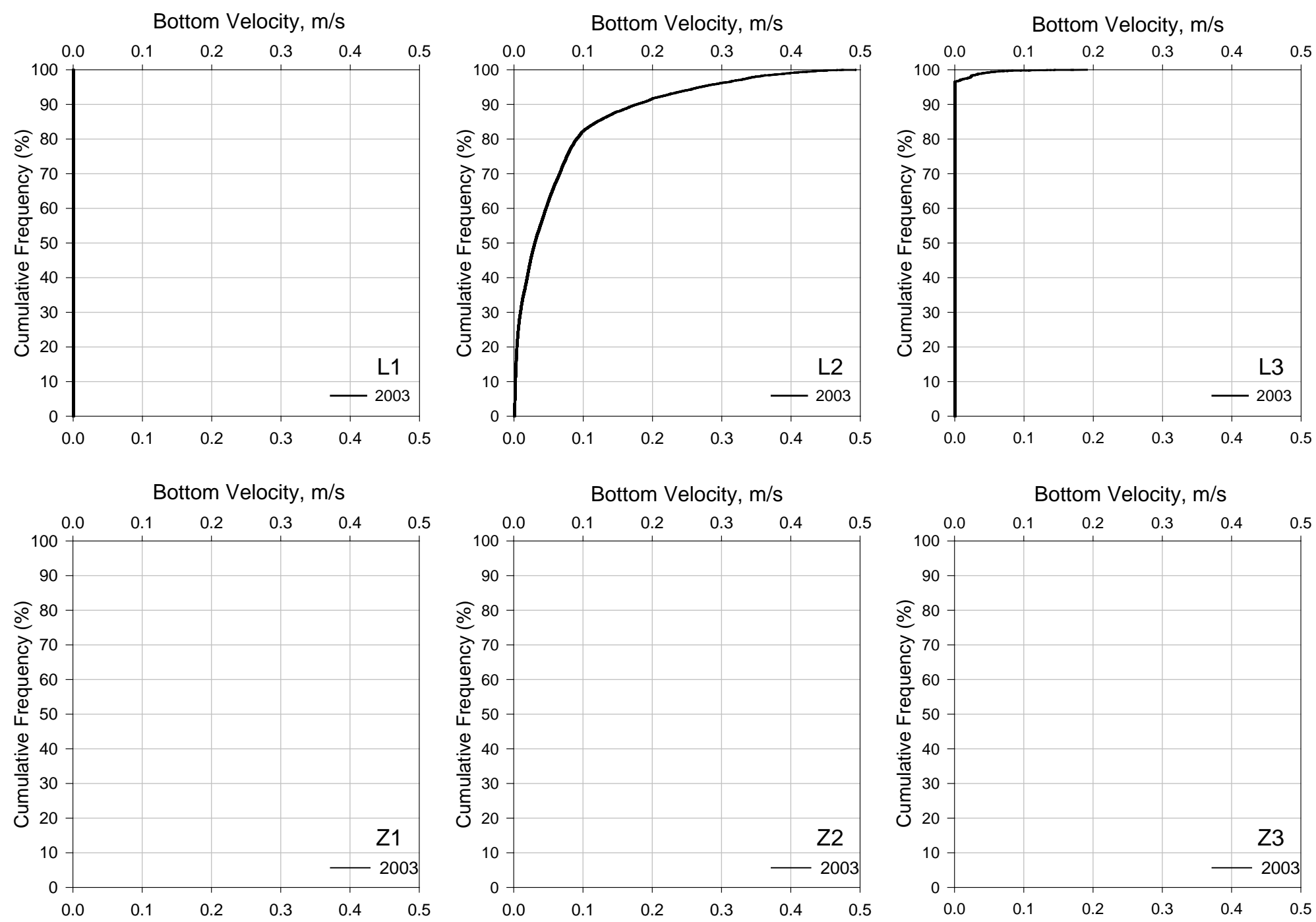

Figure G-21: Scenario 1 (Partial Restoration Leque) - Cumulative Frequency Plot for bottom velocity at all six locations after a year-long simulation 

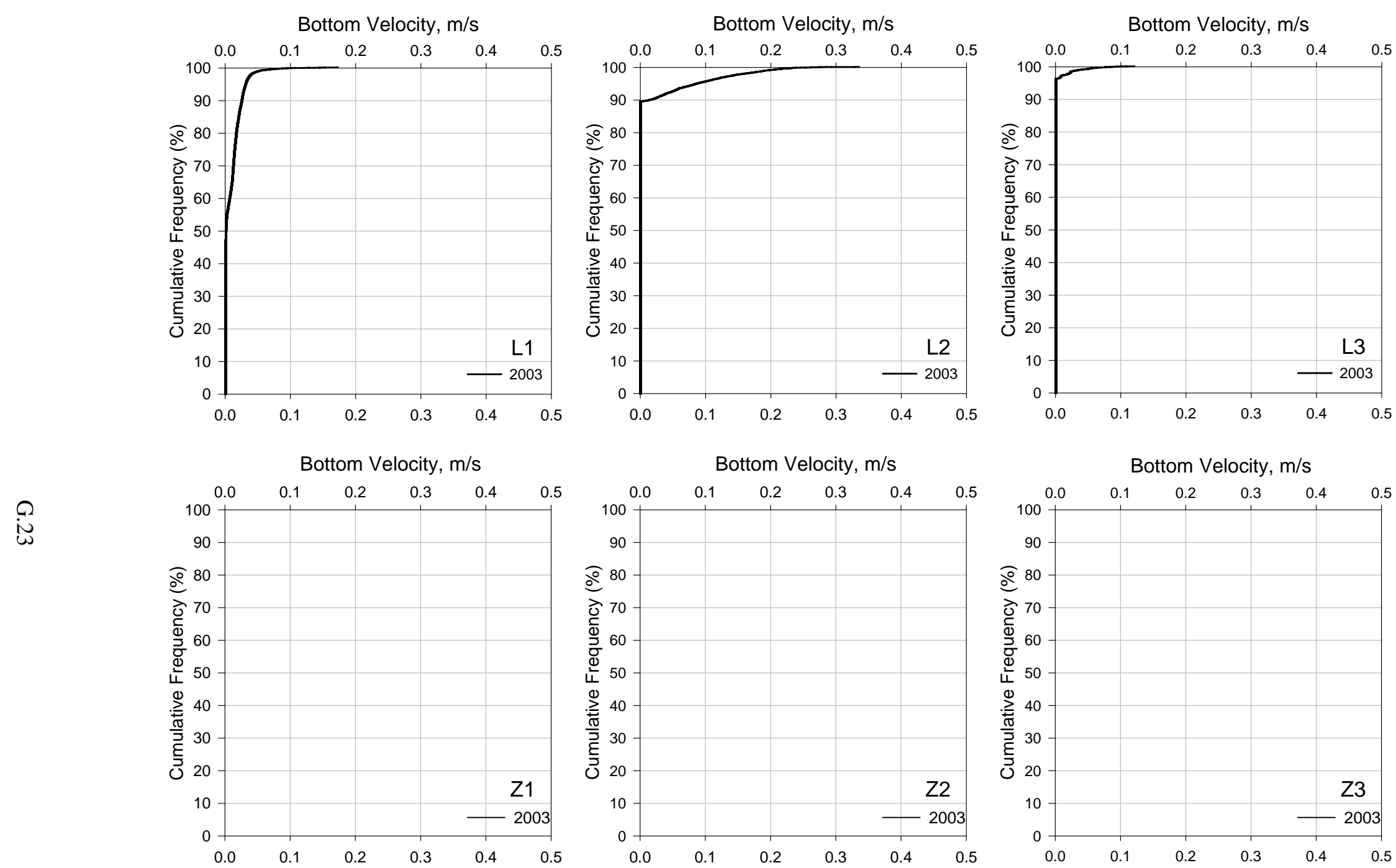

Figure G-22: Scenario 2 (4 Levee Breach Leque) - Cumulative Frequency Plot for bottom velocity at all six locations after a year-long simulation 

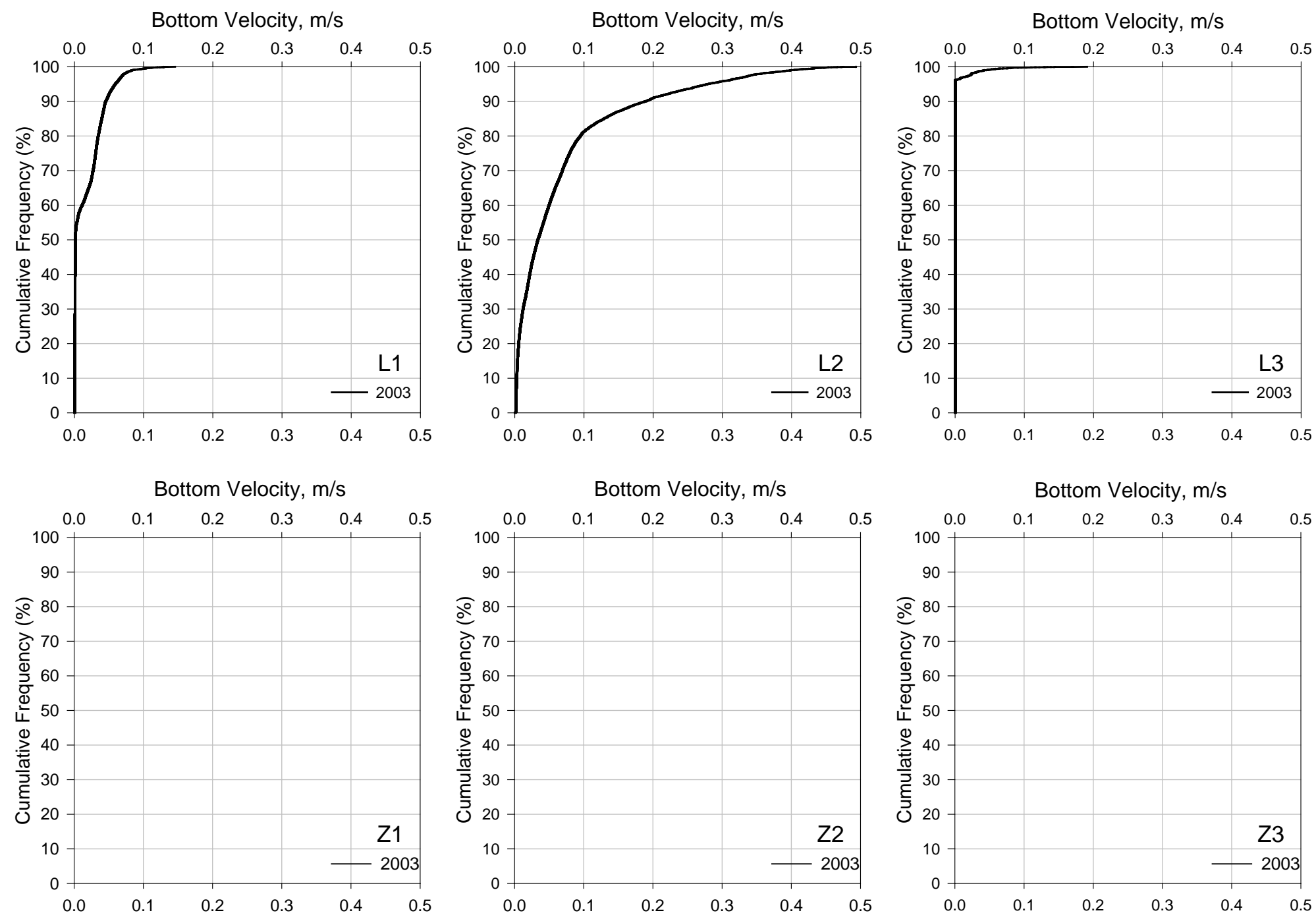

Figure G-23: Scenario 3 (Full Restoration Leque 1) - Cumulative Frequency Plot for bottom velocity at all six locations after a year-long simulation 

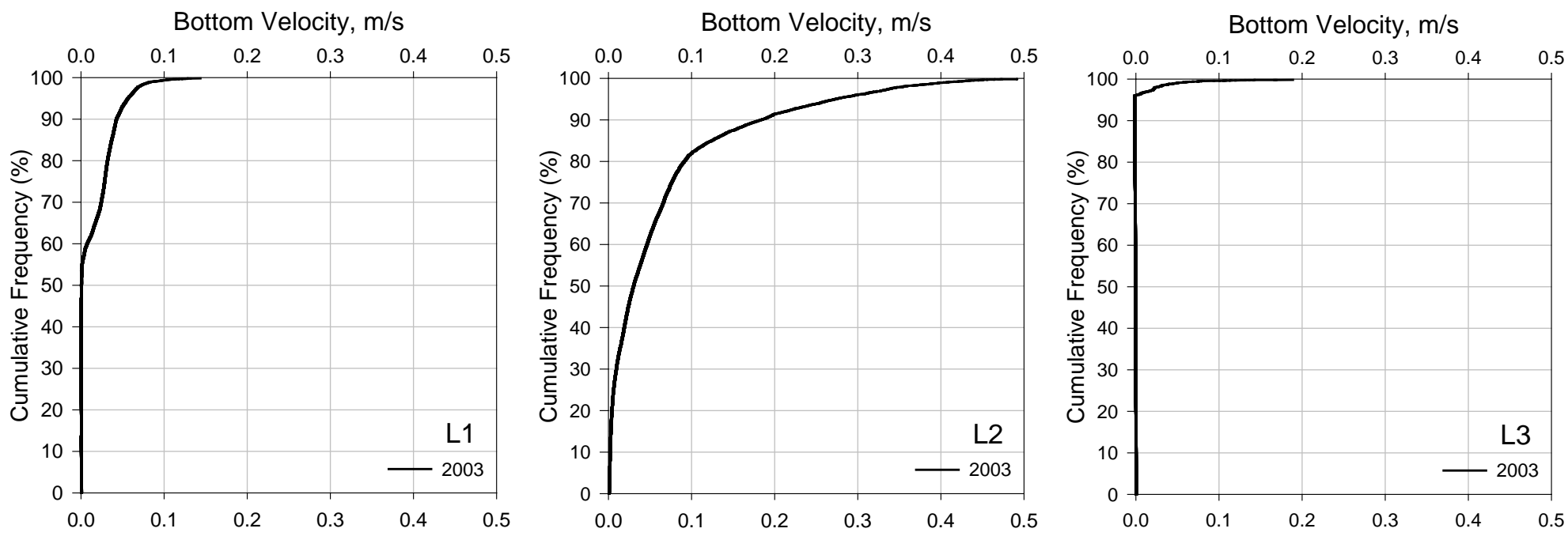

Bottom Velocity, $\mathrm{m} / \mathrm{s}$
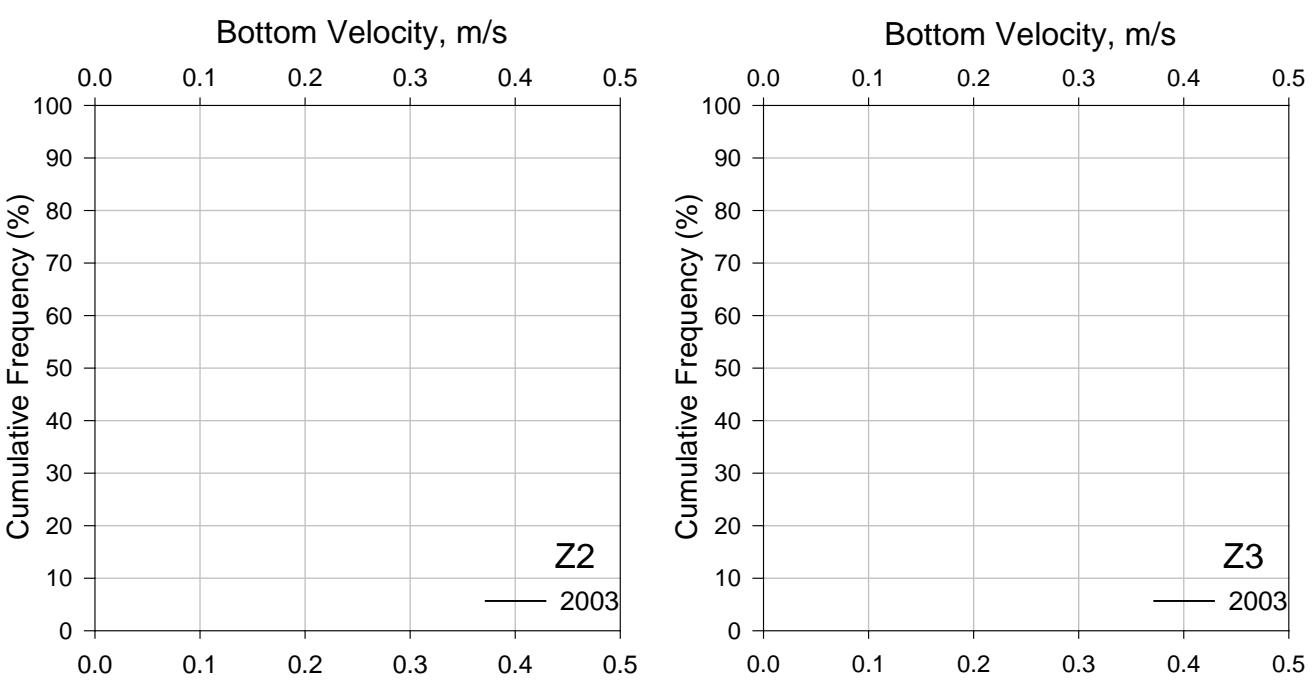

Figure G-24: Scenario 4 (Full Restoration Leque 2) - Cumulative Frequency Plot for bottom velocity at all six locations after a year-long simulation 

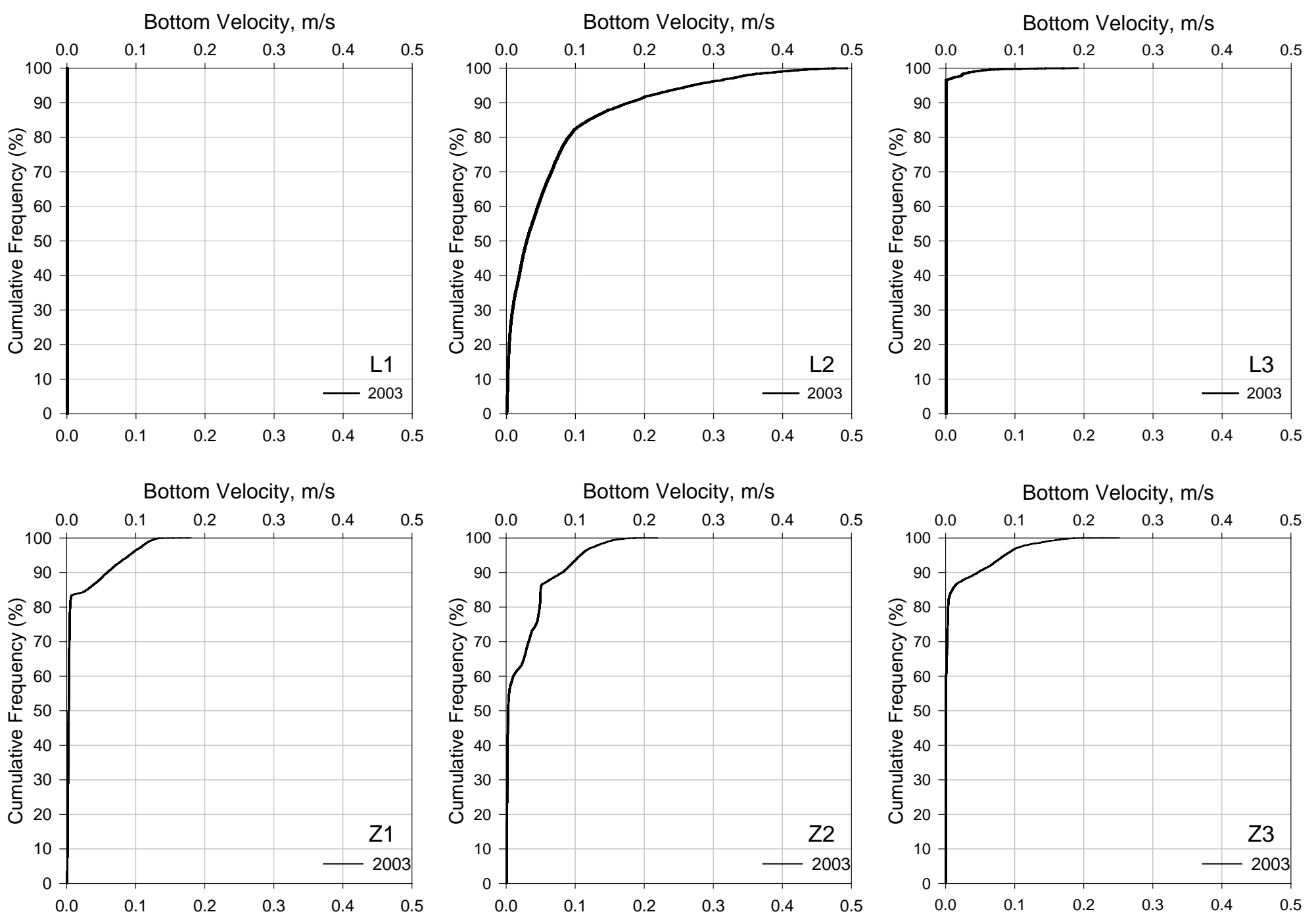

Figure G-25: Scenario 5 (Full Restoration zis a ba + SCN1) - Cumulative Frequency Plot for bottom velocity at all six locations after a year-long simulation 

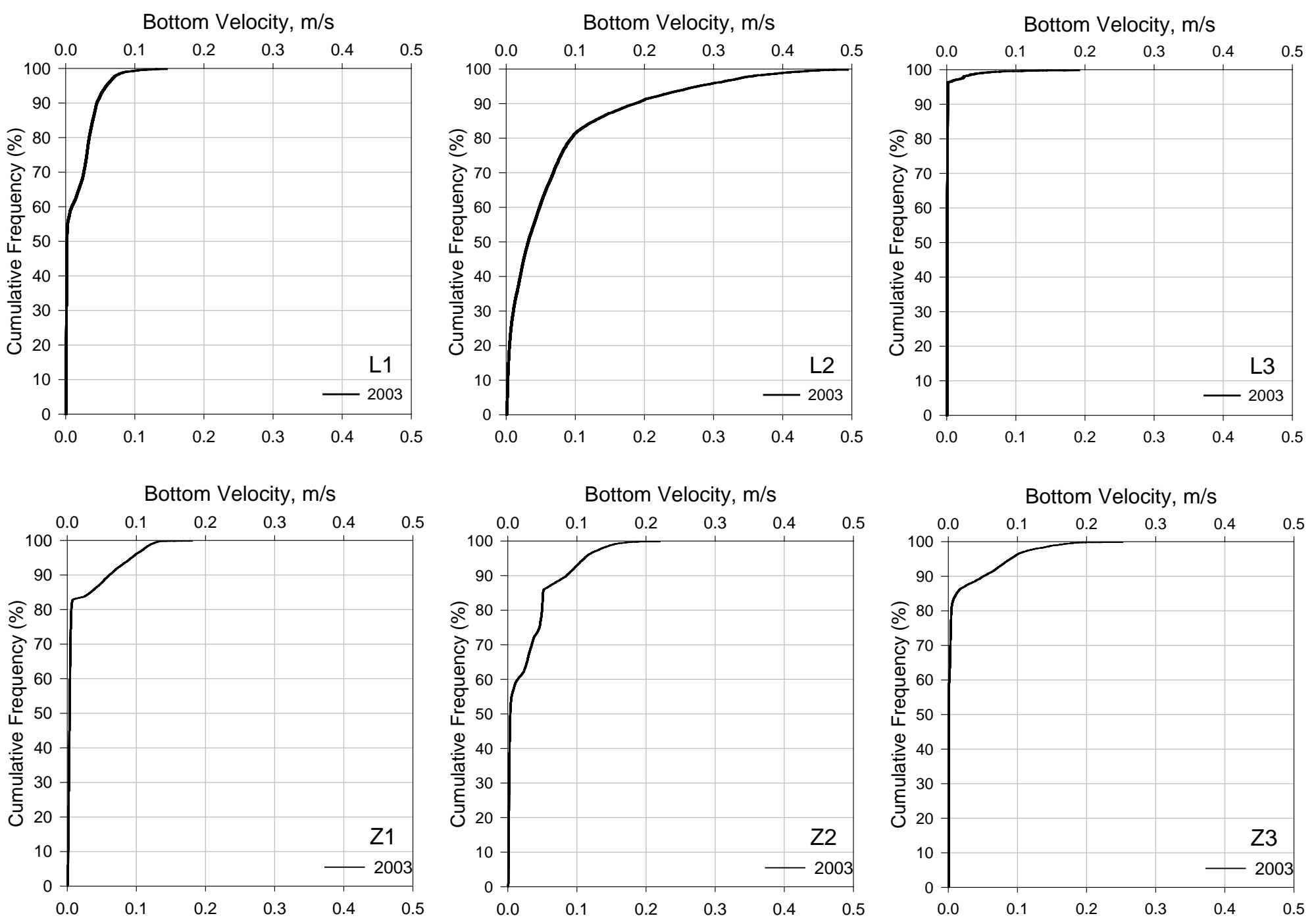

Figure G-26: Scenario 6 (Full Restoration zis a ba + SCN4) - Cumulative Frequency Plot for bottom velocity at all six locations after a year-long simulation 

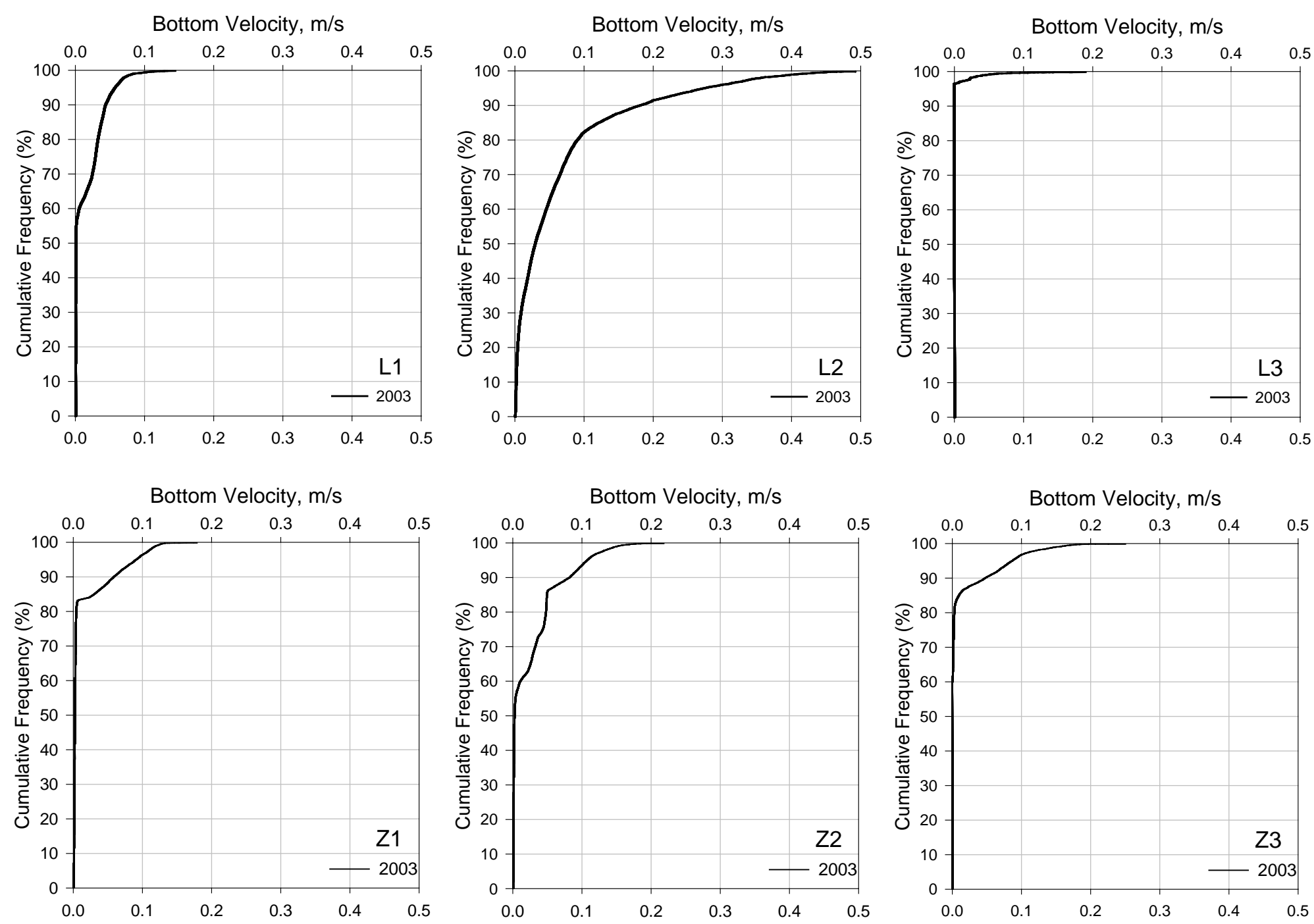

Figure G-27: Scenario 7 (Full Restoration zis a ba + SCN3) - Cumulative Frequency Plot for bottom velocity at all six locations after a year-long simulation 

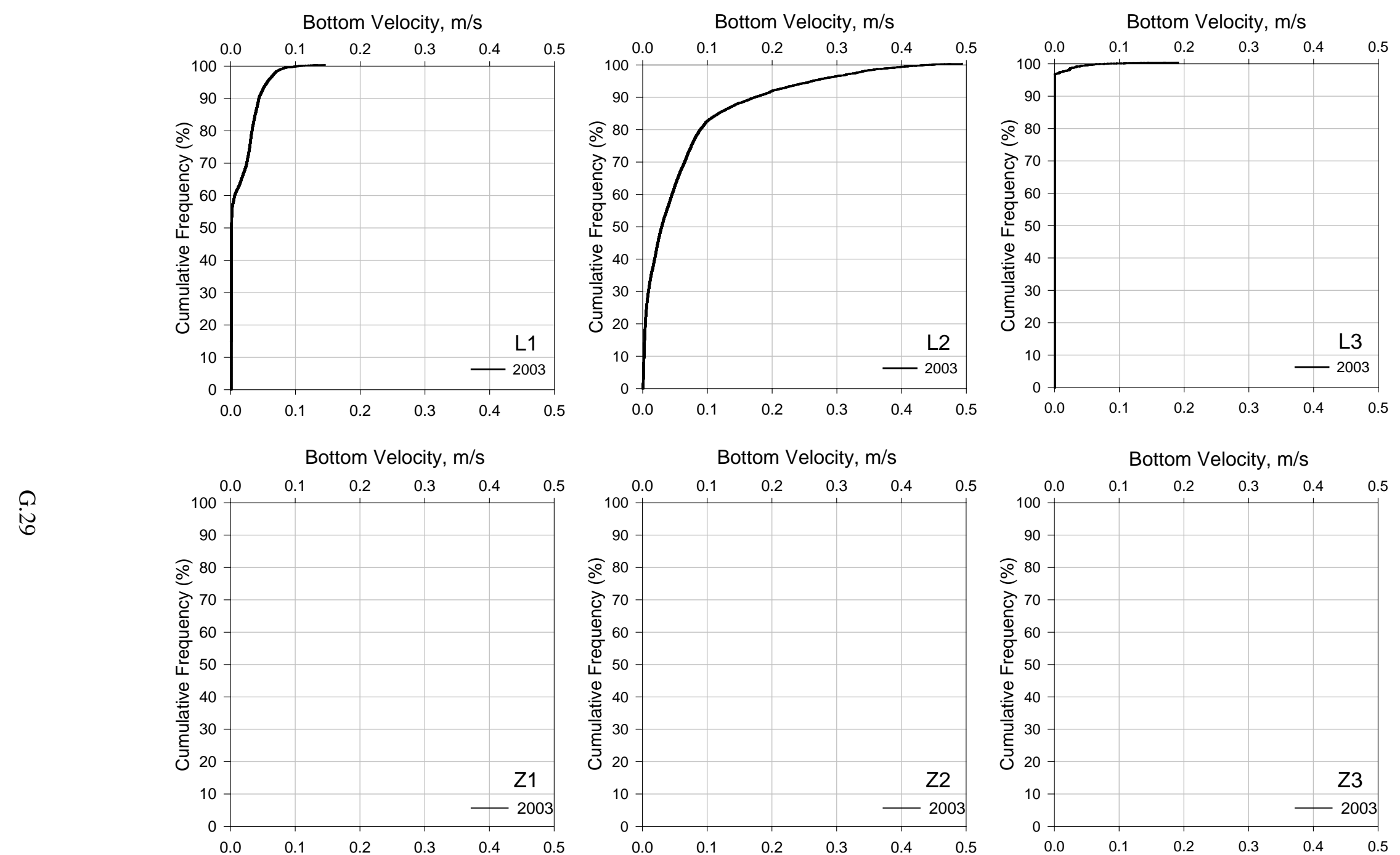

Figure G-28: Scenario 8 (3 Levee Breach Leque) - Cumulative Frequency Plot for bottom velocity at all six locations after a year-long simulation 
Bed Shear, $\mathrm{Pa}$

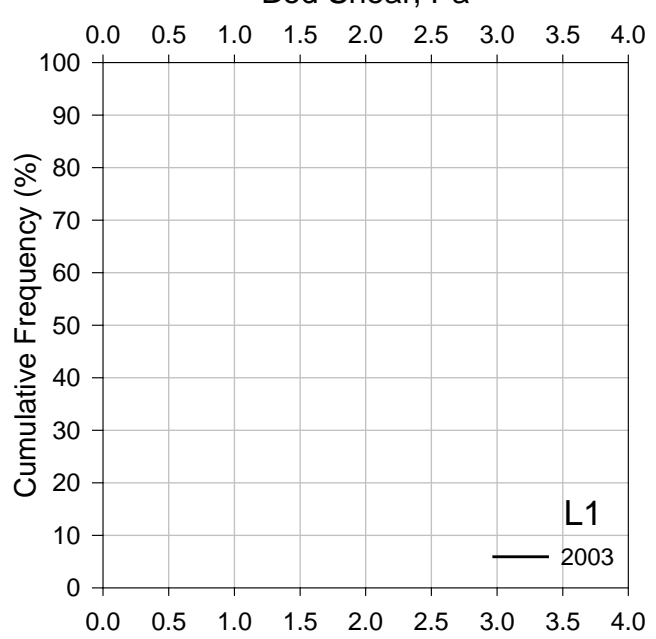

Bed Shear, $\mathrm{Pa}$

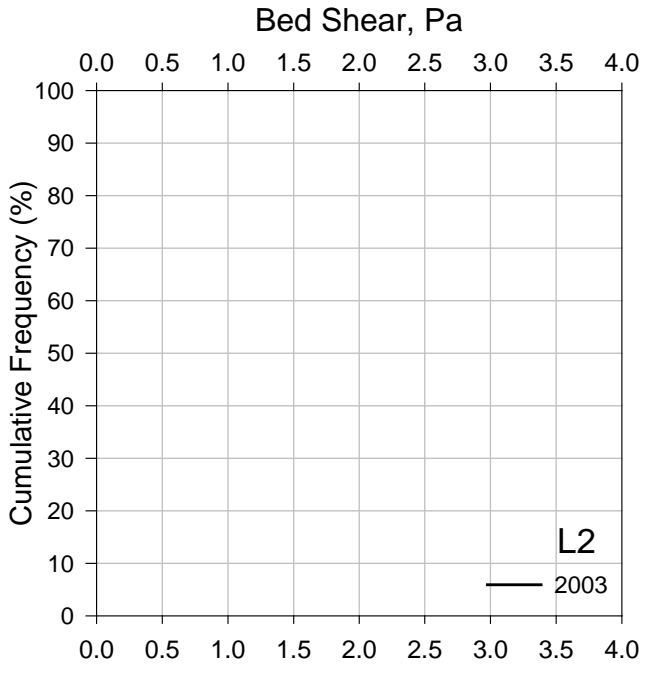

Bed Shear, $\mathrm{Pa}$

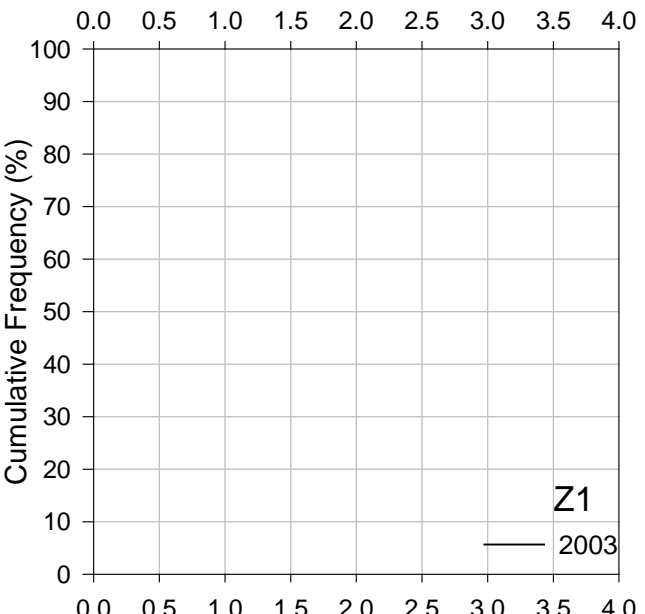

Bed Shear, $\mathrm{Pa}$

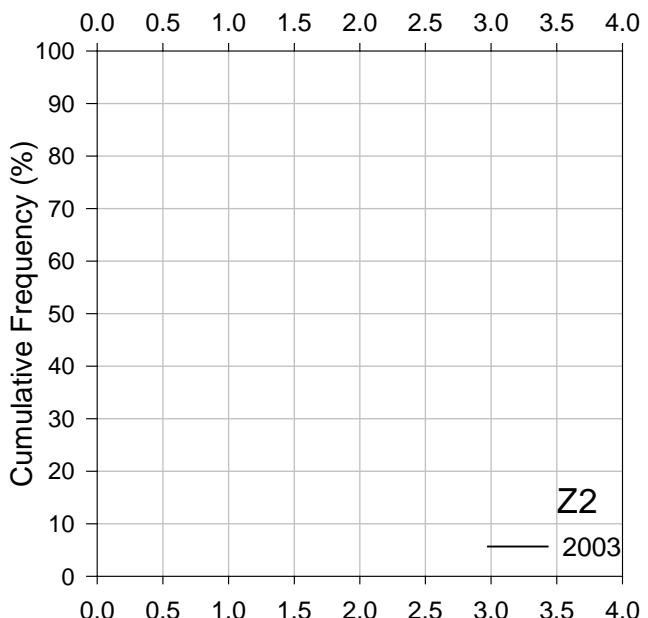

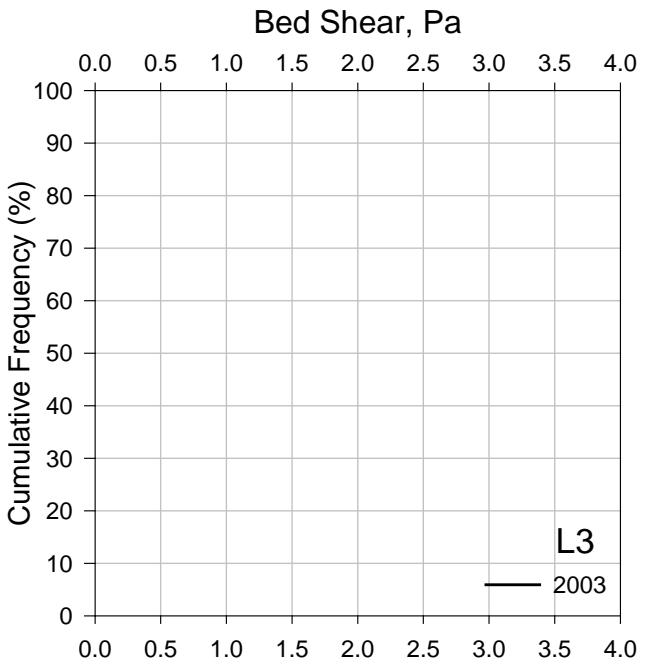

Bed Shear, $\mathrm{Pa}$

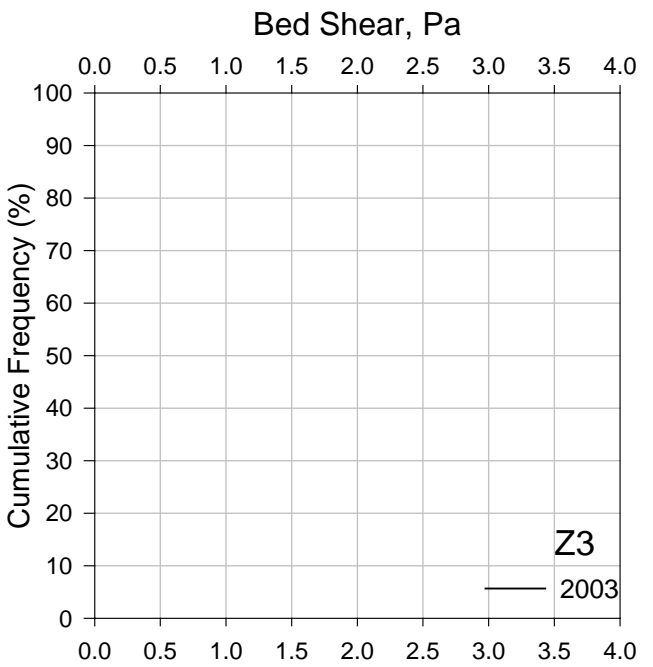

Figure G-29: Scenario 0 (Baseline Condition) - Cumulative Frequency Plot for bed shear at all six locations after a year-long simulation 
Bed Shear, $\mathrm{Pa}$

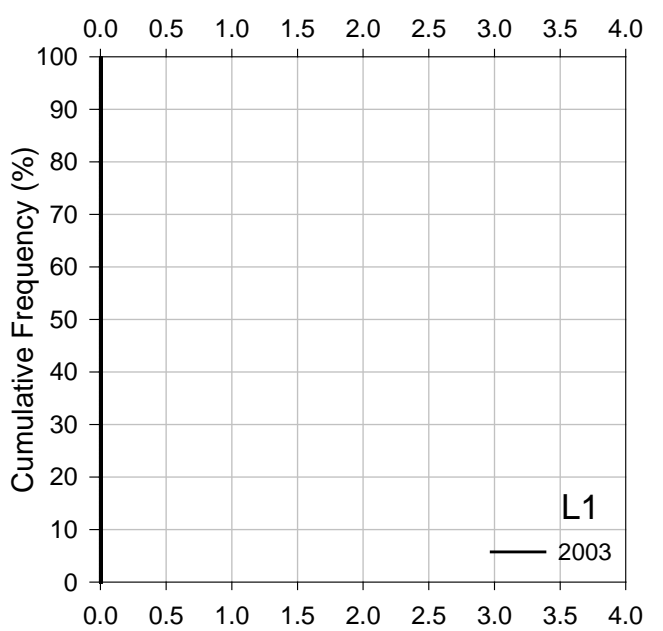

Bed Shear, $\mathrm{Pa}$

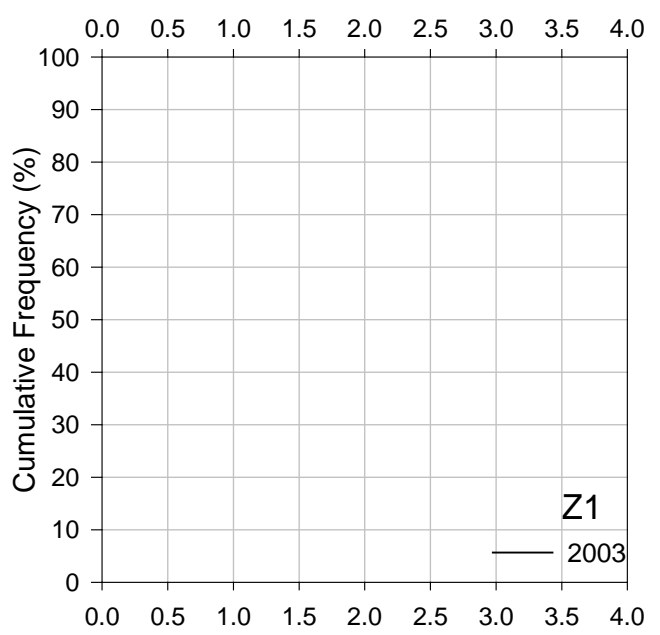

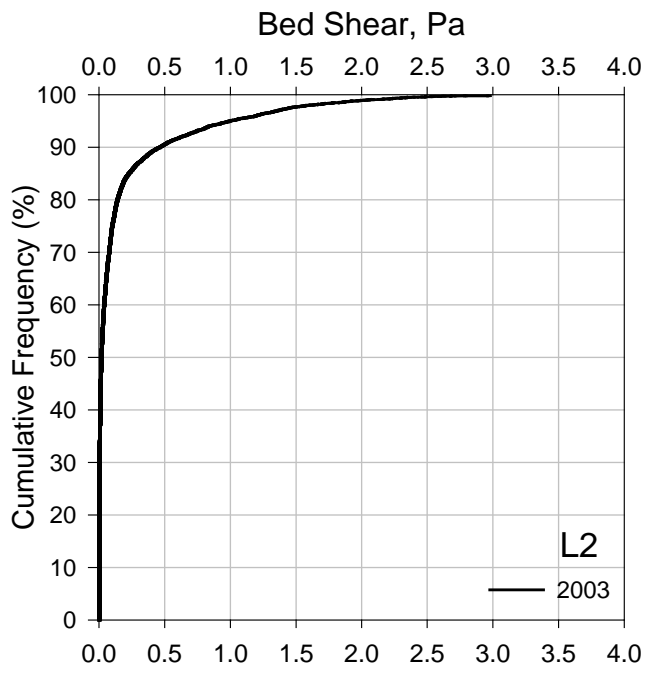

Bed Shear, $\mathrm{Pa}$

Bed Shear, $\mathrm{Pa}$

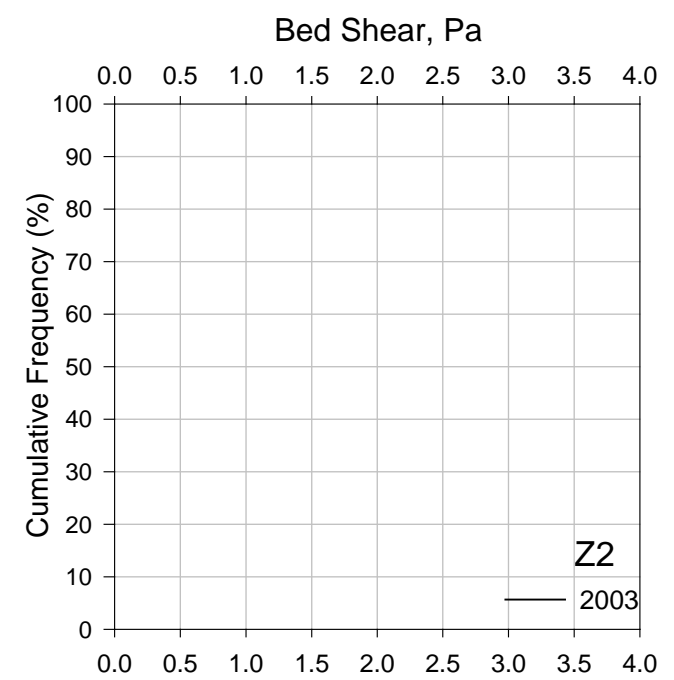

Bed Shear, $\mathrm{Pa}$

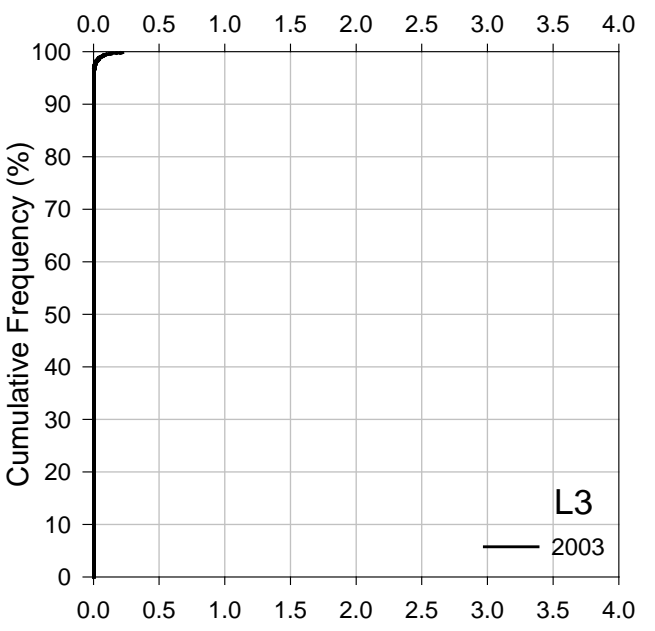

Bed Shear, $\mathrm{Pa}$

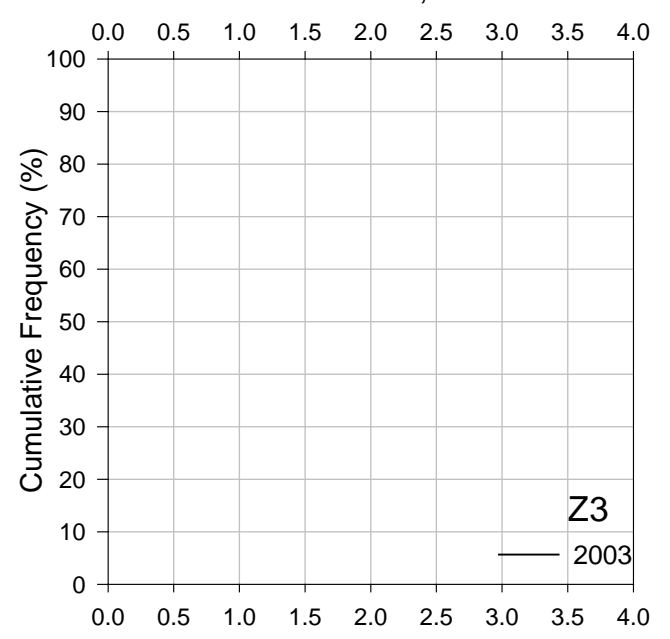

Figure G-30: Scenario 1 (Partial Restoration Leque) - Cumulative Frequency Plot for bed shear at all six locations after a year-long simulation 
Bed Shear, $\mathrm{Pa}$

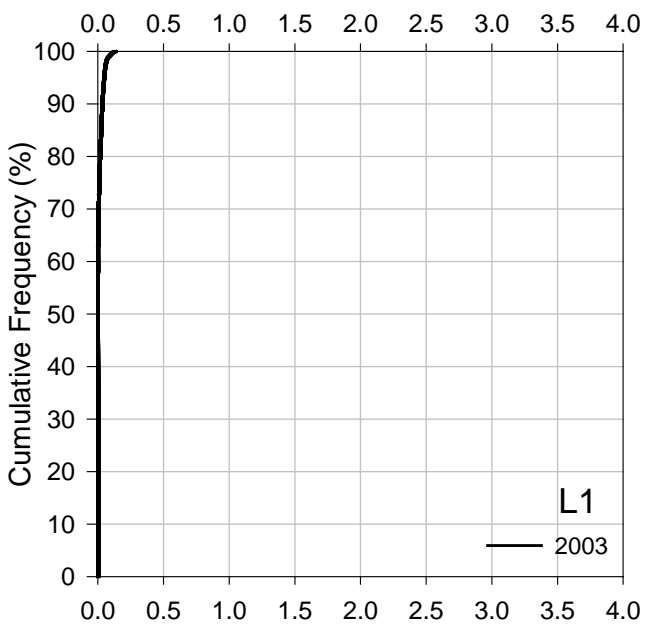

Bed Shear, $\mathrm{Pa}$
Bed Shear, $\mathrm{Pa}$

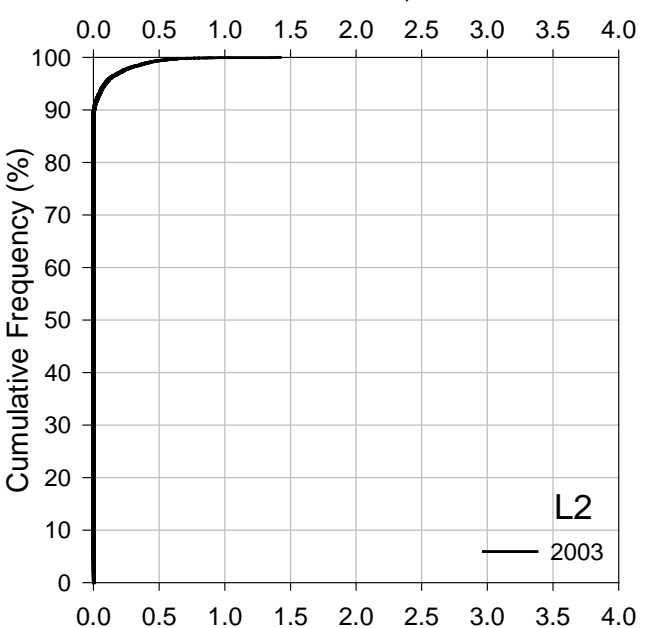

Bed Shear, $\mathrm{Pa}$

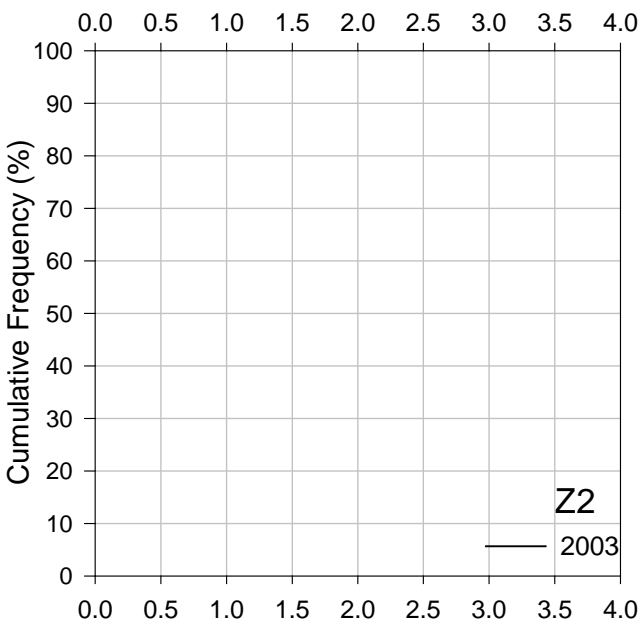

Bed Shear, $\mathrm{Pa}$

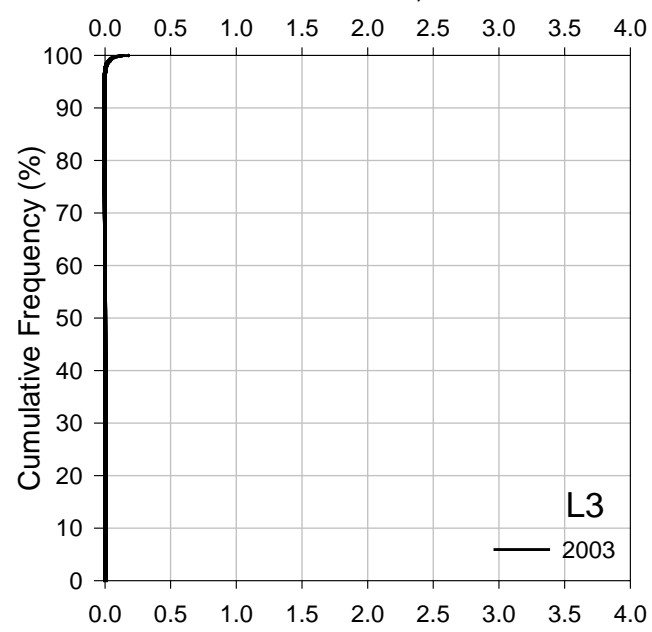

Bed Shear, $\mathrm{Pa}$

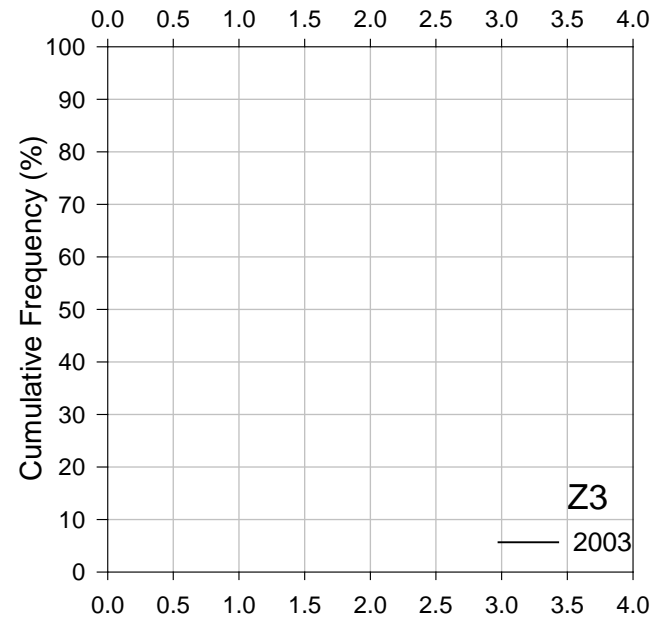

Figure G-31: Scenario 2 (4 Levee Breach Leque) - Cumulative Frequency Plot for bed shear at all six locations after a year-long simulation 

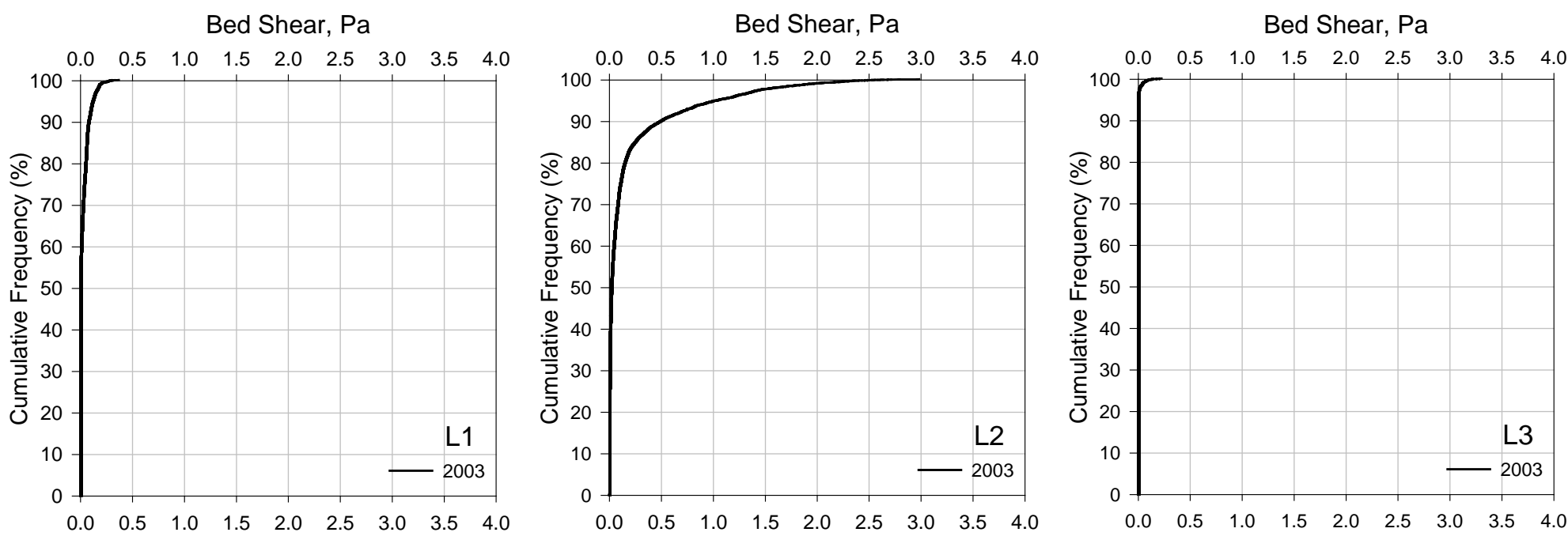

Bed Shear, $\mathrm{Pa}$

Bed Shear, $\mathrm{Pa}$
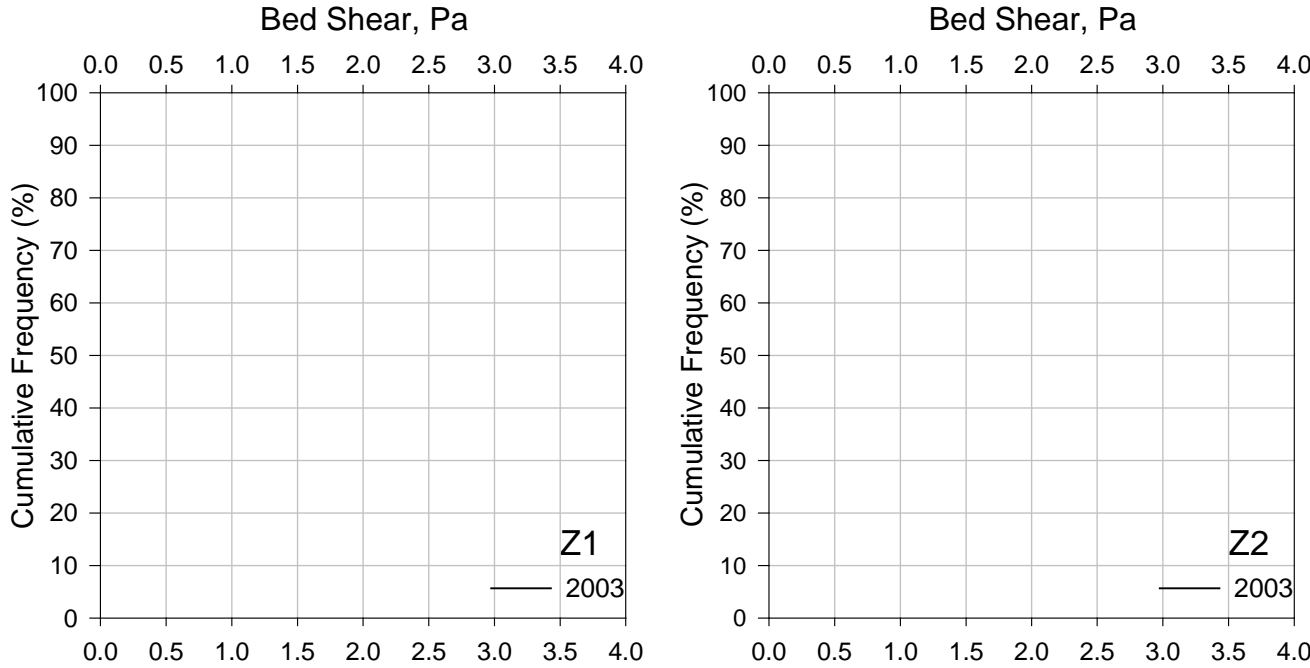

Bed Shear, $\mathrm{Pa}$

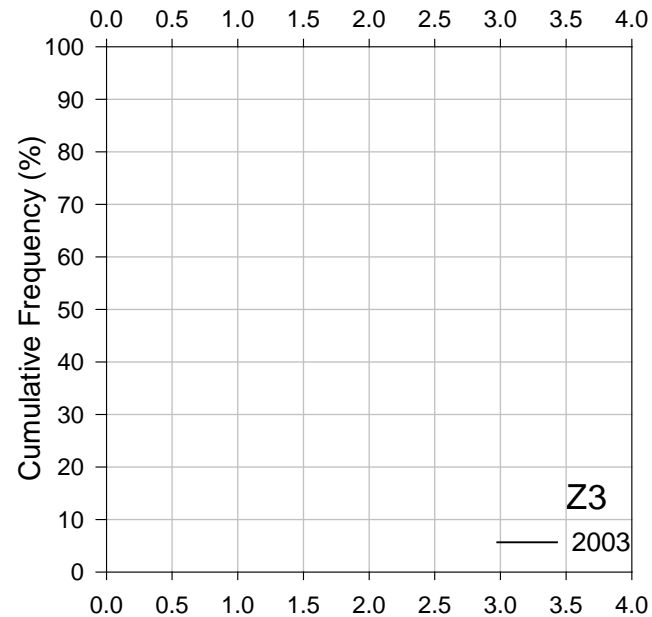

Figure G-32: Scenario 3 (Full Restoration Leque 1) - Cumulative Frequency Plot for bed shear at all six locations after a year-long simulation 
Bed Shear, $\mathrm{Pa}$

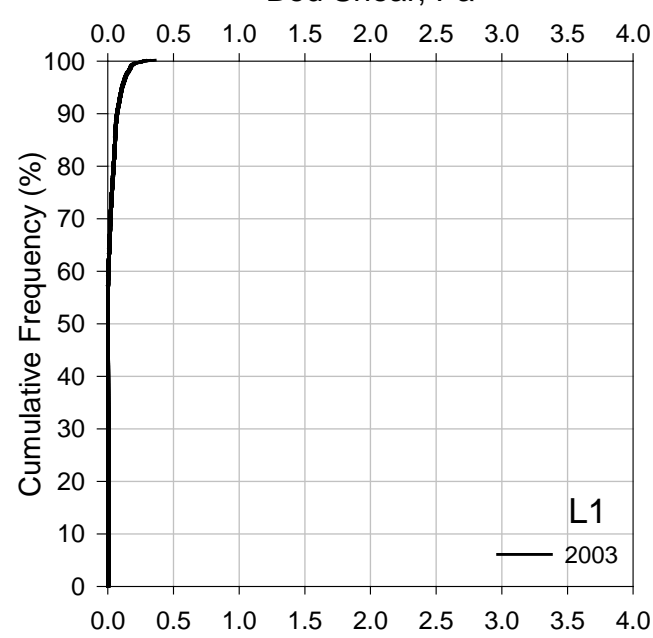

Bed Shear, $\mathrm{Pa}$
Bed Shear, $\mathrm{Pa}$

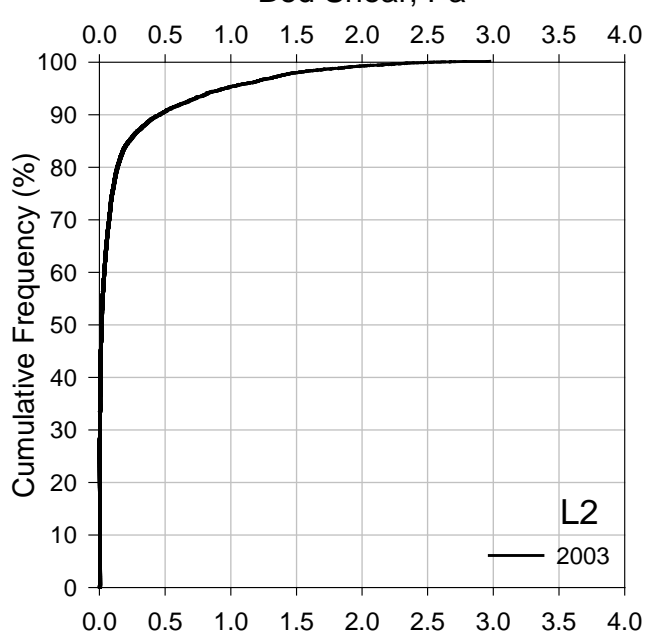

Bed Shear, $\mathrm{Pa}$

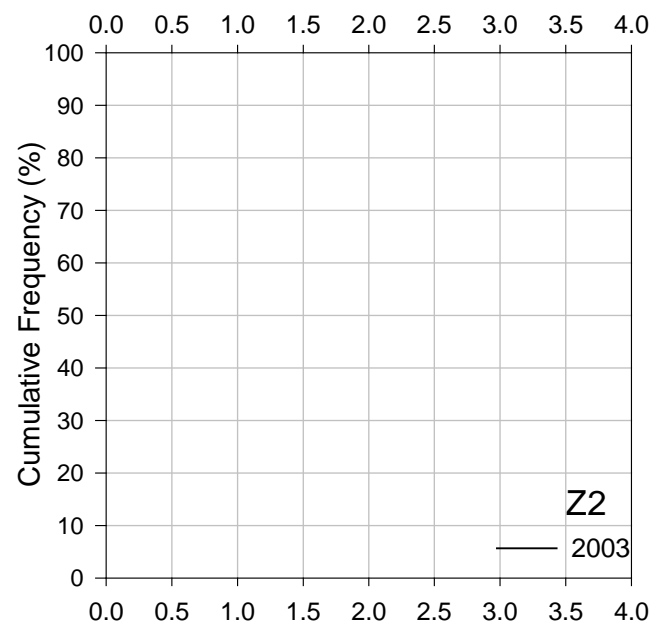

Bed Shear, $\mathrm{Pa}$

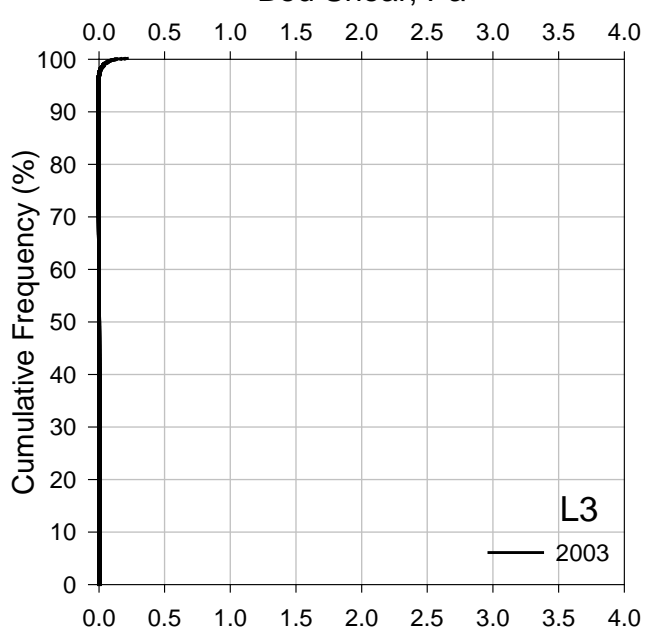

Bed Shear, $\mathrm{Pa}$

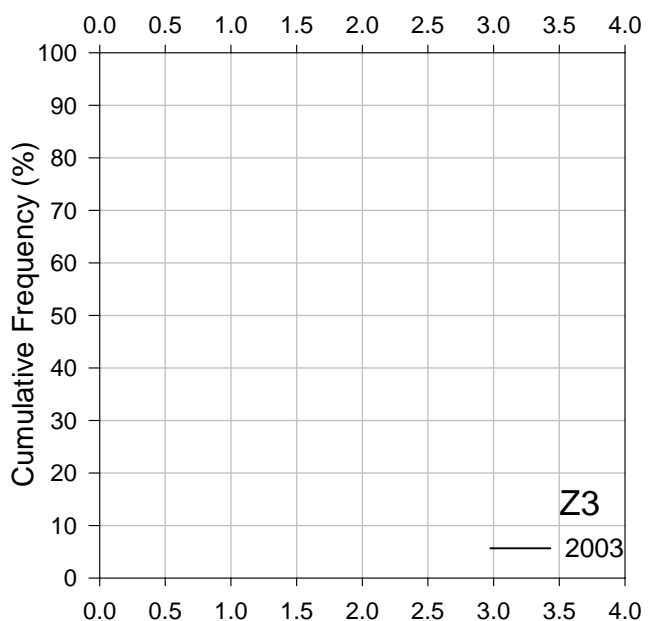

Figure G-33: Scenario 4 (Full Restoration Leque 2) - Cumulative Frequency Plot for bed shear at all six locations after a year-long simulation 
Bed Shear, $\mathrm{Pa}$

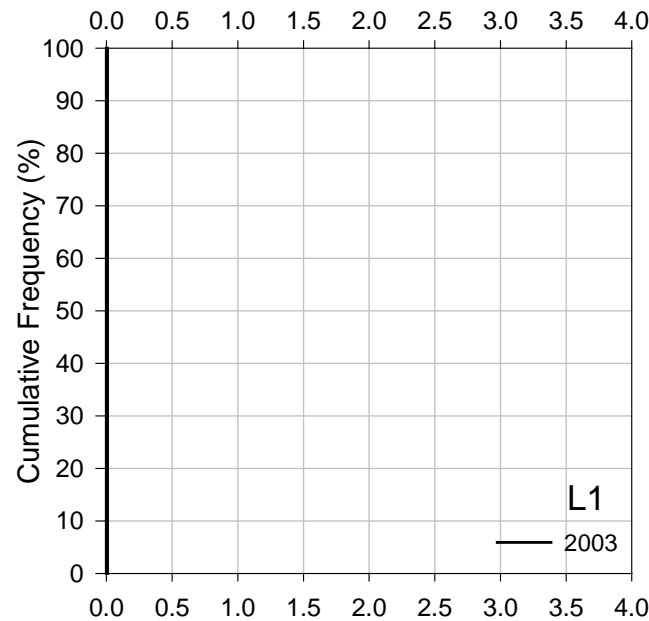

Bed Shear, $\mathrm{Pa}$
Bed Shear, $\mathrm{Pa}$

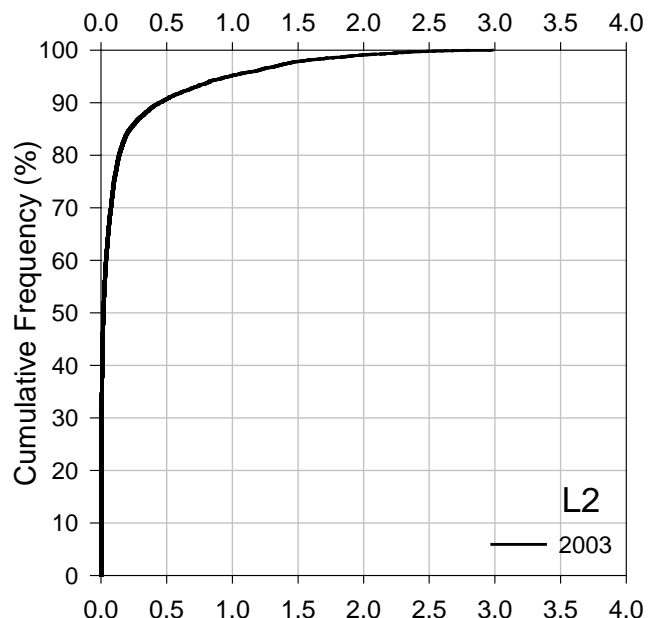

Bed Shear, $\mathrm{Pa}$

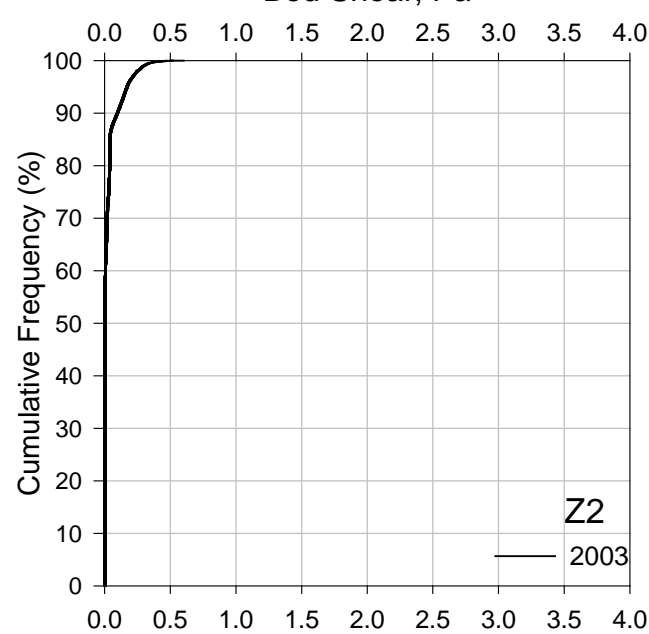

Bed Shear, $\mathrm{Pa}$

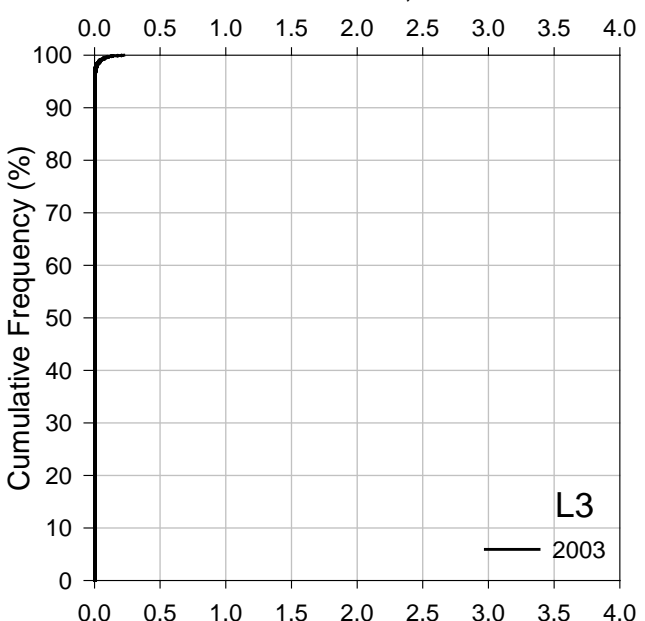

Bed Shear, $\mathrm{Pa}$

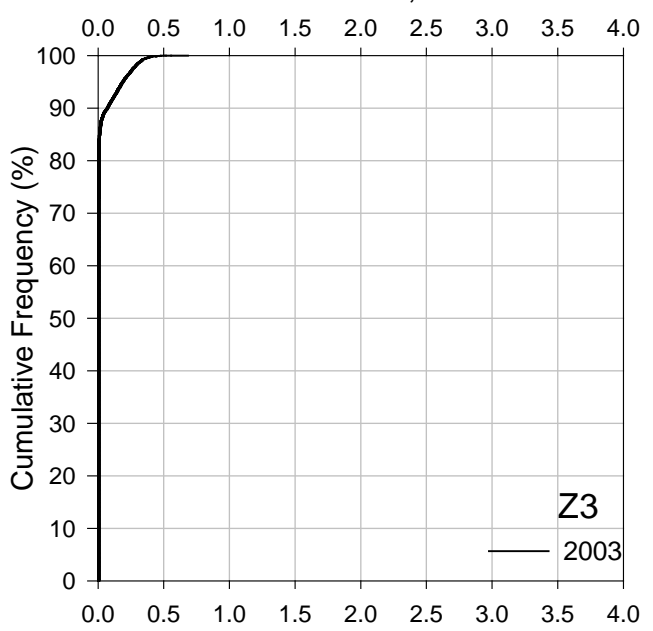

Figure G-34: Scenario 5 (Full Restoration zis a ba + SCN1) - Cumulative Frequency Plot for bed shear at all six locations after a year-long simulation 

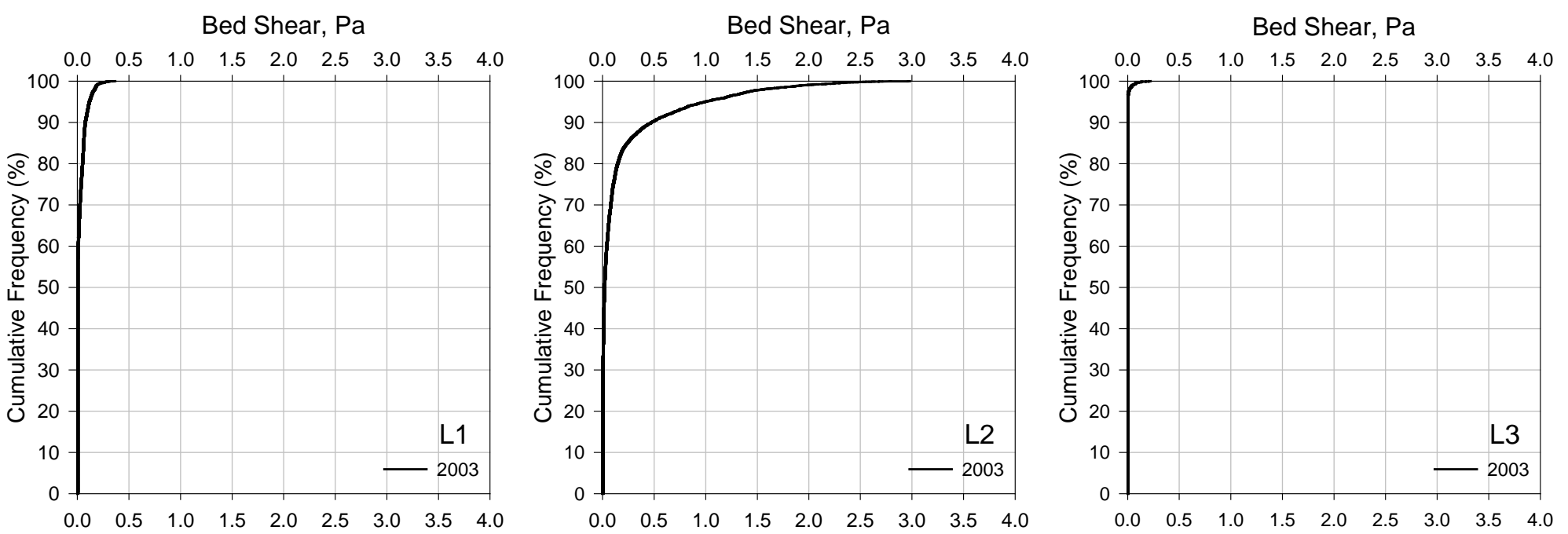

\section{Bed Shear, $\mathrm{Pa}$}

Bed Shear, $\mathrm{Pa}$
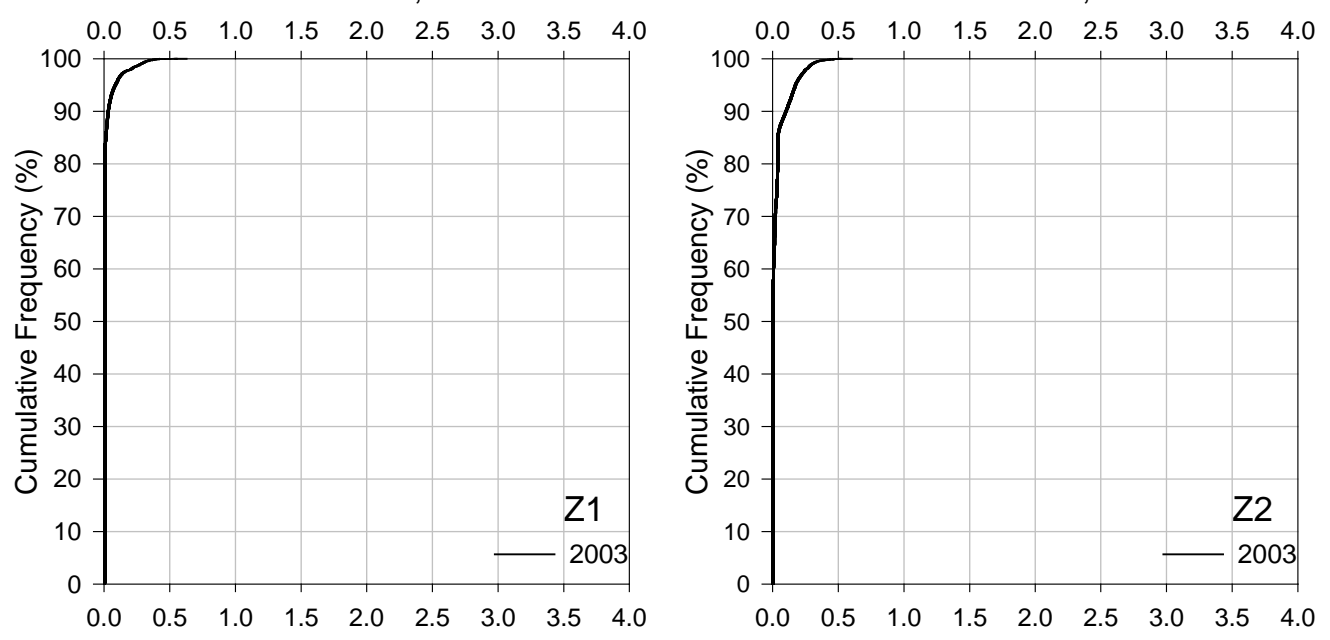

Bed Shear, $\mathrm{Pa}$

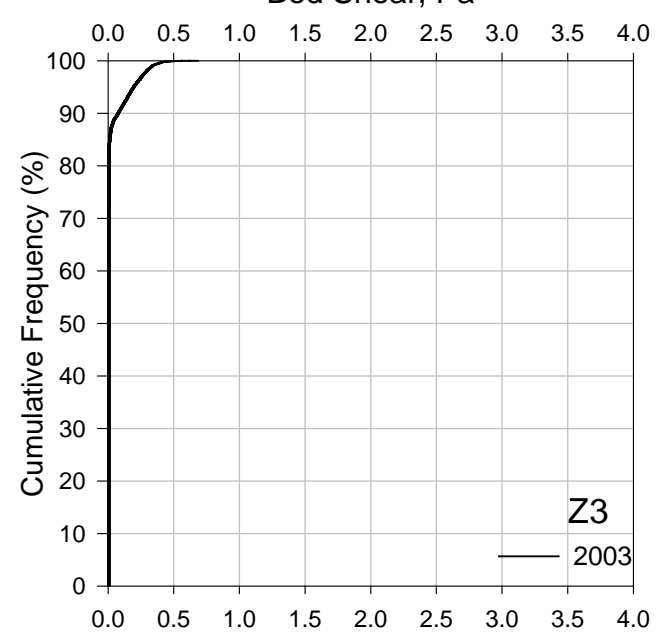

Figure G-35: Scenario 6 (Full Restoration zis a ba + SCN4) - Cumulative Frequency Plot for bed shear at all six locations after a year-long simulation 
Bed Shear, $\mathrm{Pa}$

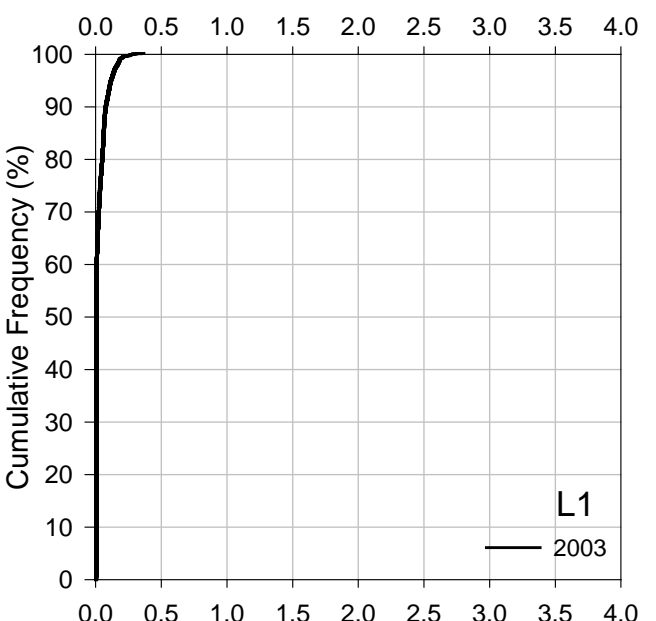

Bed Shear, $\mathrm{Pa}$
Bed Shear, $\mathrm{Pa}$

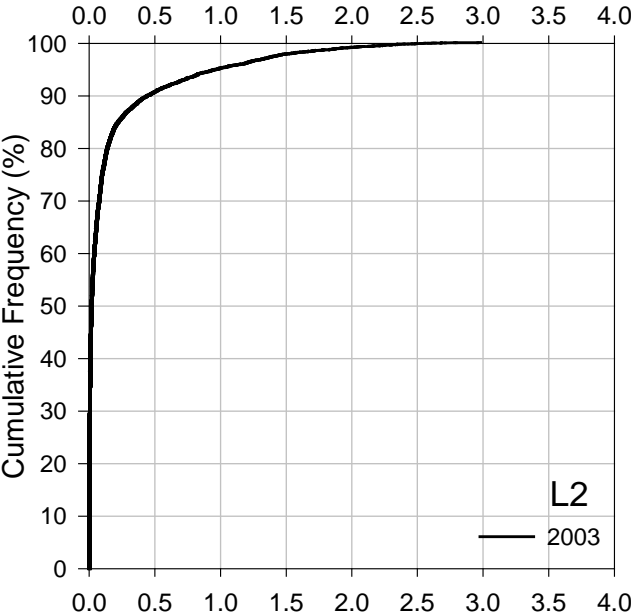

Bed Shear, $\mathrm{Pa}$

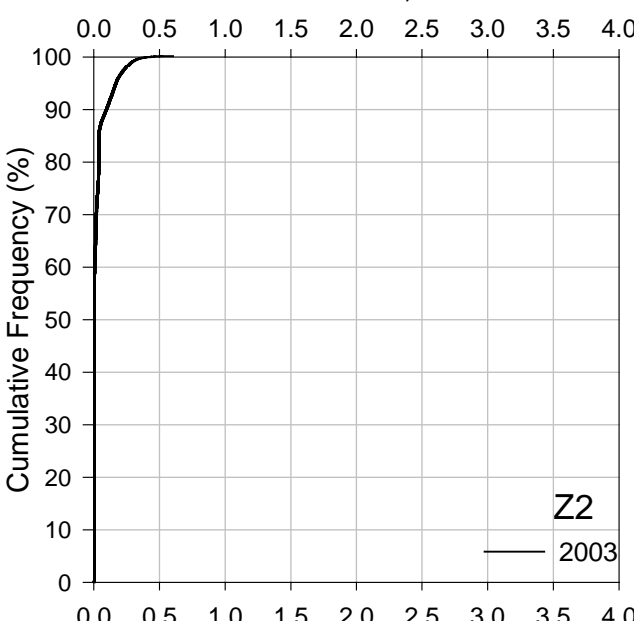

Bed Shear, $\mathrm{Pa}$

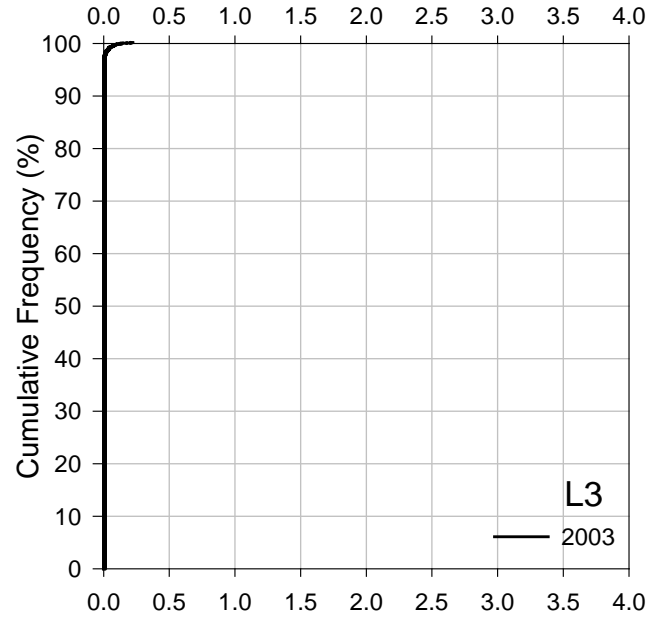

Bed Shear, $\mathrm{Pa}$

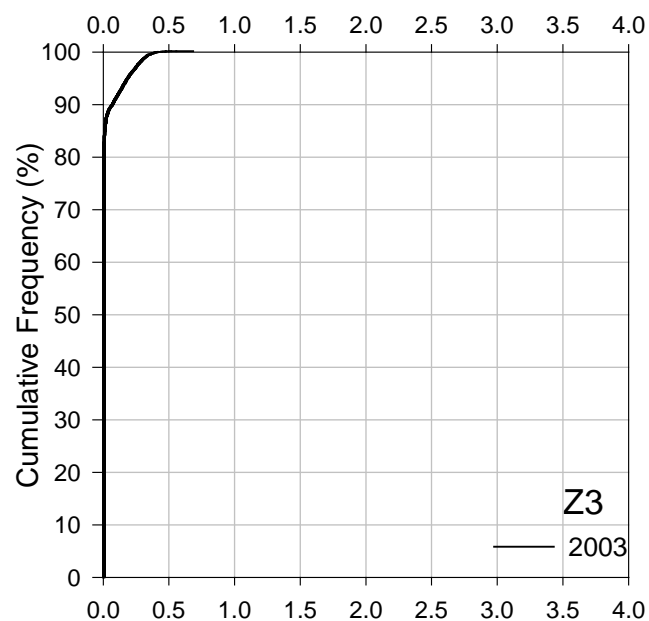

Figure G-36: Scenario 7 (Full Restoration zis a ba + SCN3) - Cumulative Frequency Plot for bed shear at all six locations after a year-long simulation 
Bed Shear, $\mathrm{Pa}$

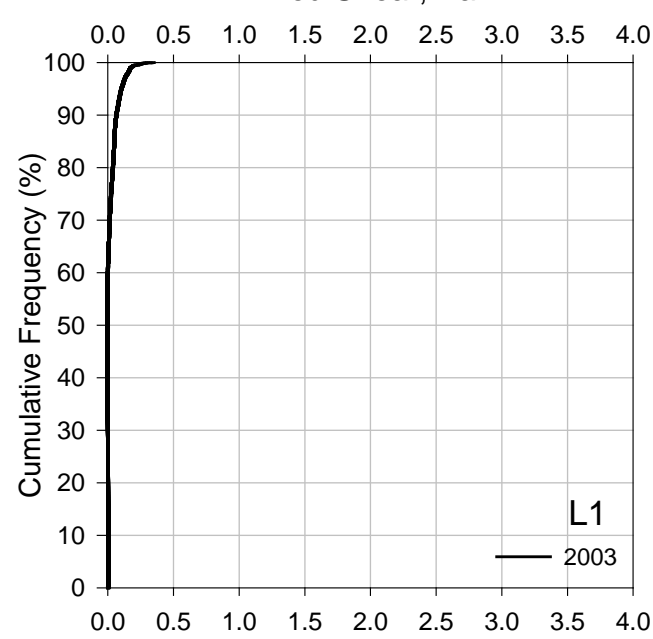

Bed Shear, $\mathrm{Pa}$
Bed Shear, $\mathrm{Pa}$

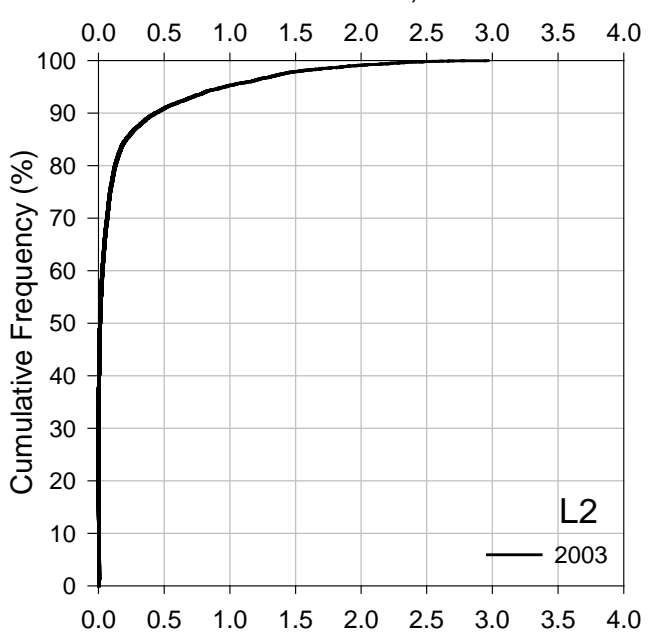

Bed Shear, $\mathrm{Pa}$

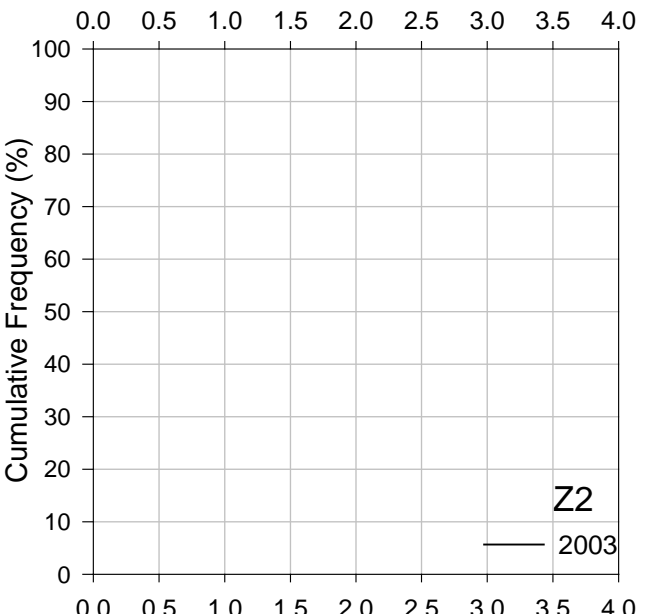

Bed Shear, $\mathrm{Pa}$

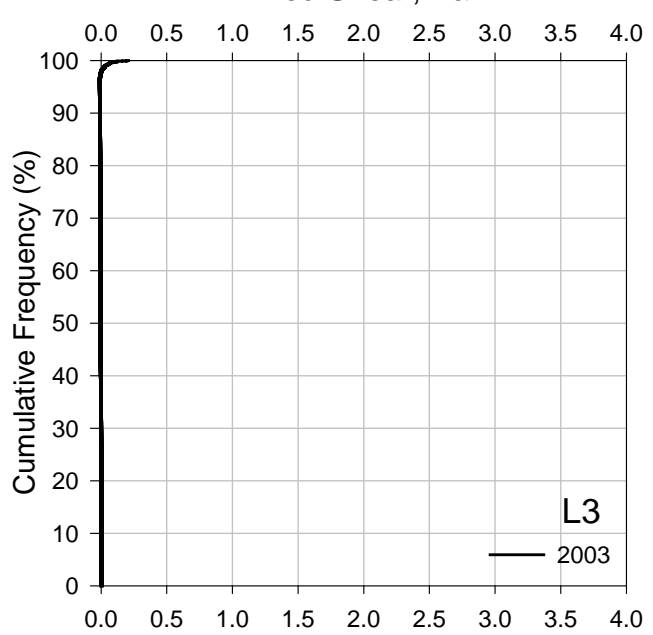

Bed Shear, $\mathrm{Pa}$

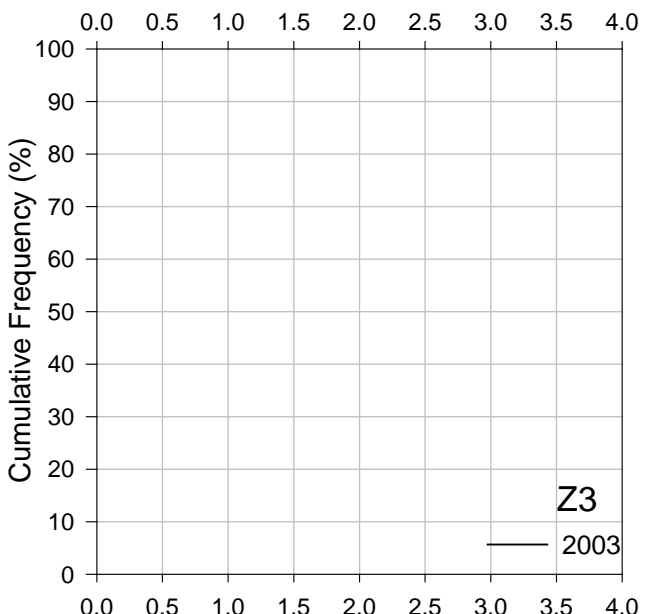

Figure G-37: Scenario 8 (3 Levee Breach Leque) - Cumulative Frequency Plot for bed shear at all six locations after a year-long simulation 


\section{Appendix $\mathrm{H}$}

Plan View Contour Plots - 2003 Year-Long Simulation Depth, Velocity, Bed Shear 



\section{Appendix $\mathrm{H}$}

\section{Plan View Contour Plots - 2003 Year-Long Simulation - Depth, Velocity, Bed Shear}

December 25, 2003, plan view contour plots at maximum tide condition, showing depths, bottom velocities, and bed sheers for Leque Island and zis a ba restoration site stations are provided in this appendix.

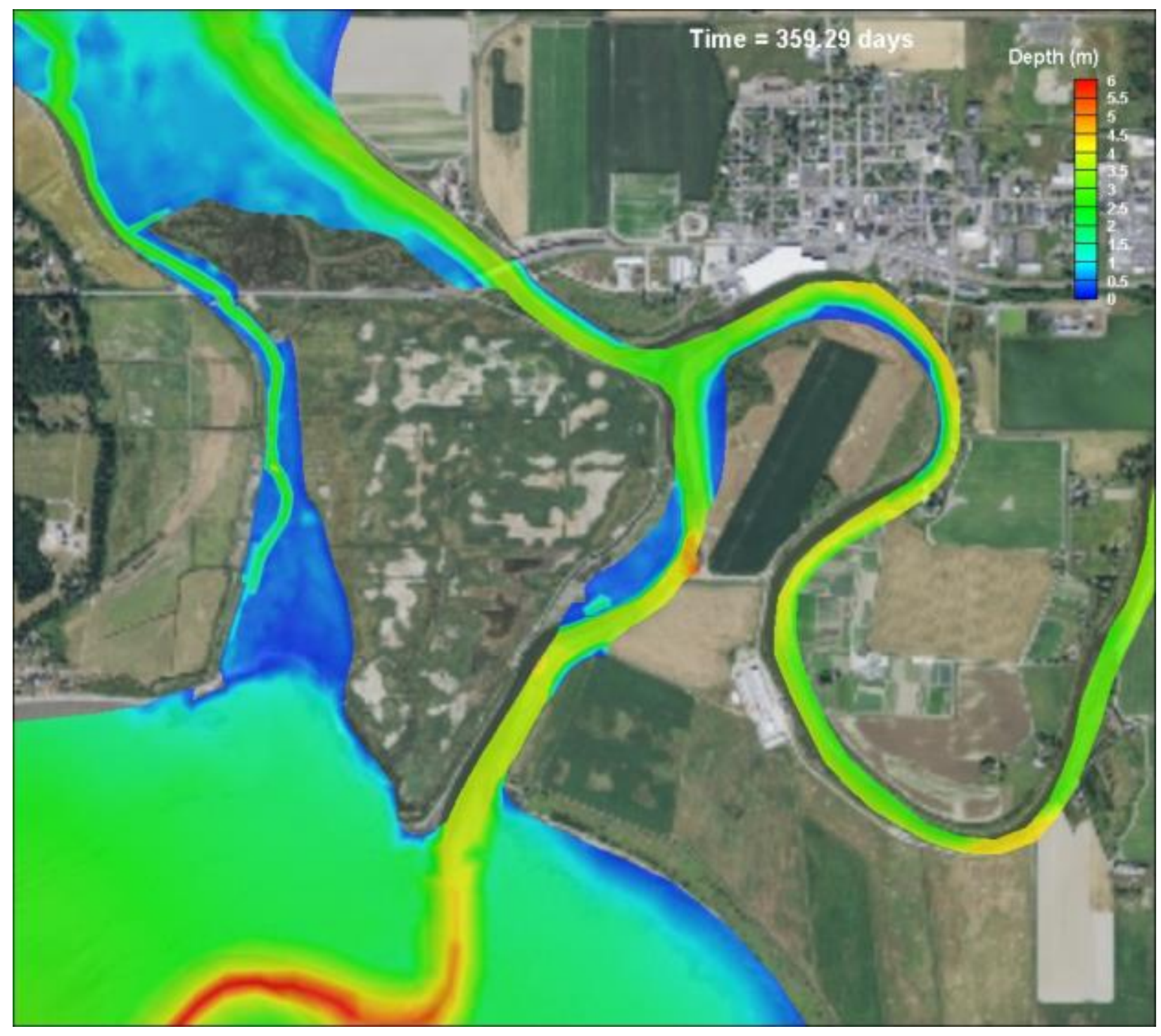

Figure H-1: Scenario 0 (Baseline Condition) - Water depth, maximum tide during year-long simulation based on December 25, 2003 


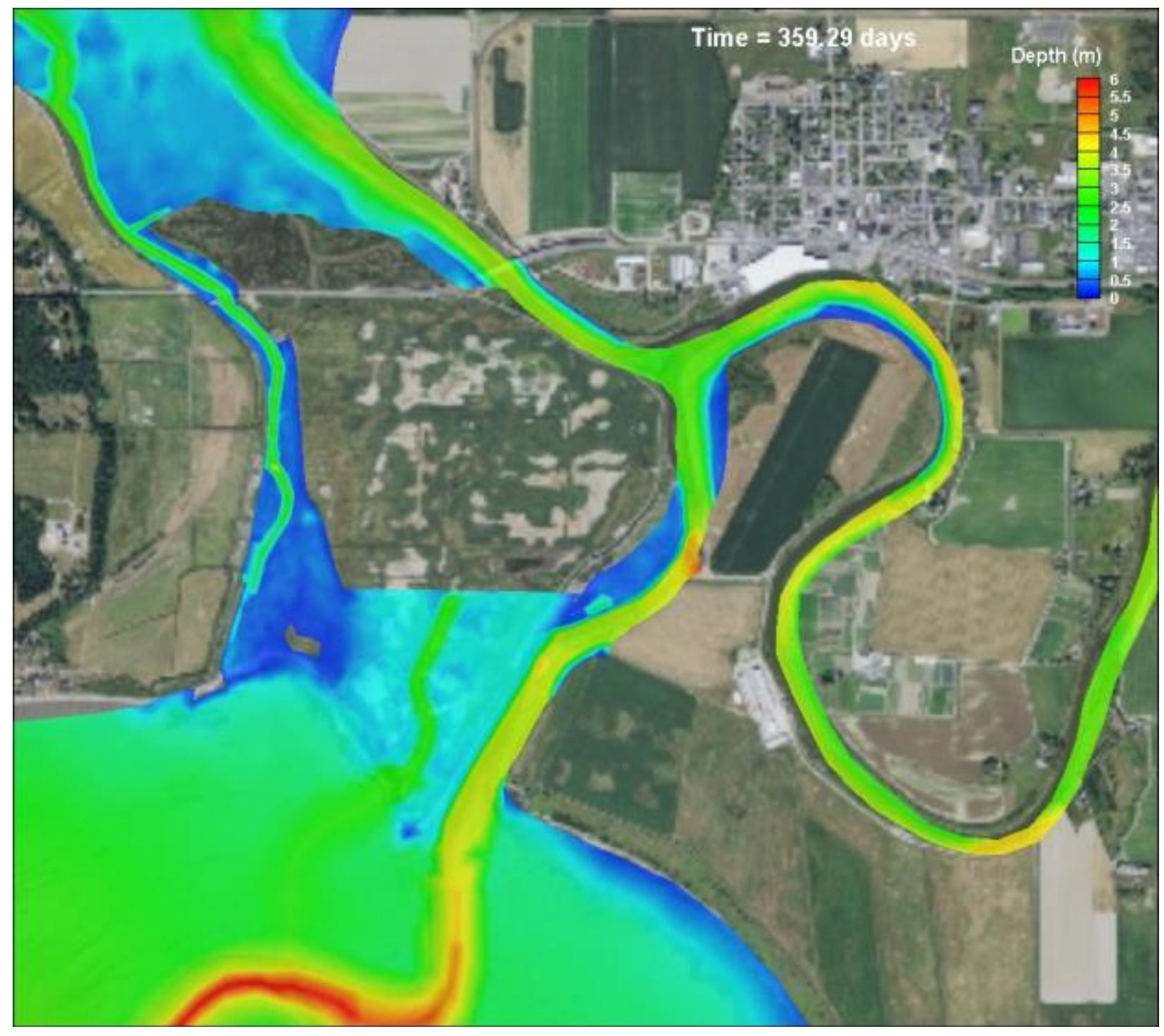

Figure H-2: Scenario 1 (Partial Restoration Leque) - Water depth, maximum tide during year-long simulation based on December 25, 2003 


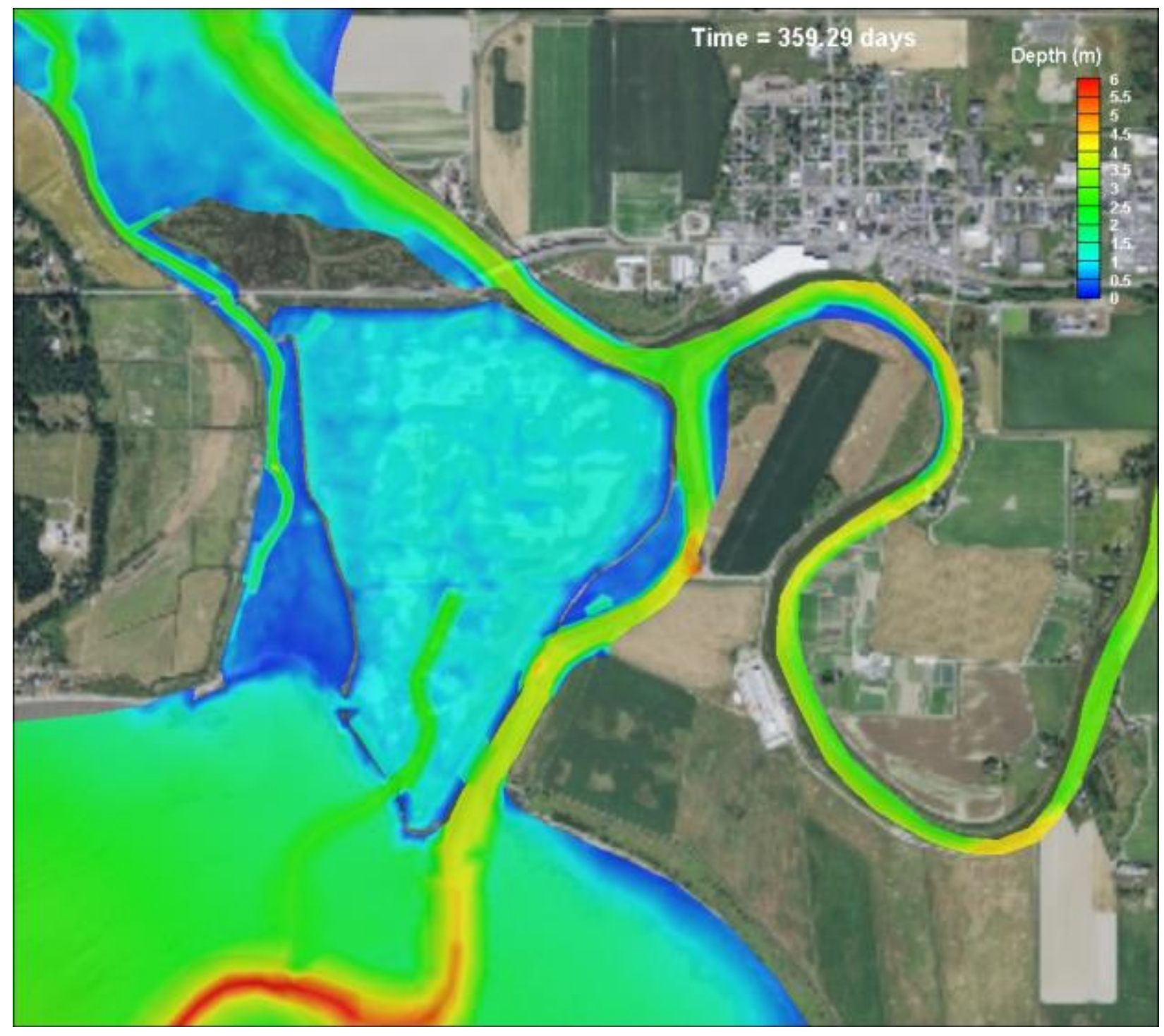

Figure H-3: Scenario 2 (4 Levee Breach Leque) - Water depth, maximum tide during year-long simulation based on December 25, 2003 


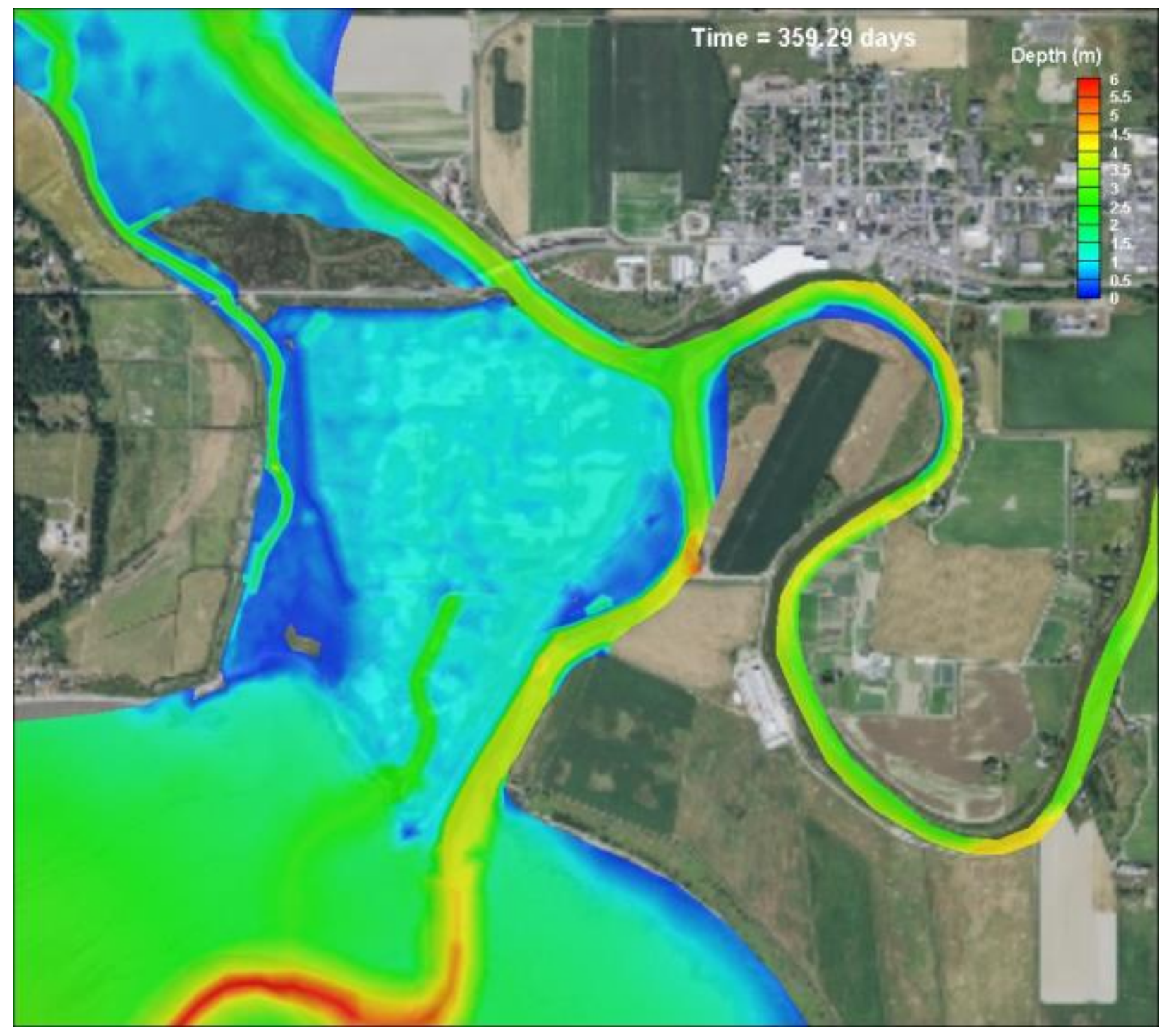

Figure H-4: Scenario 3 (Full Restoration Leque 1) - Water depth, maximum tide during year-long simulation based on December 25, 2003 


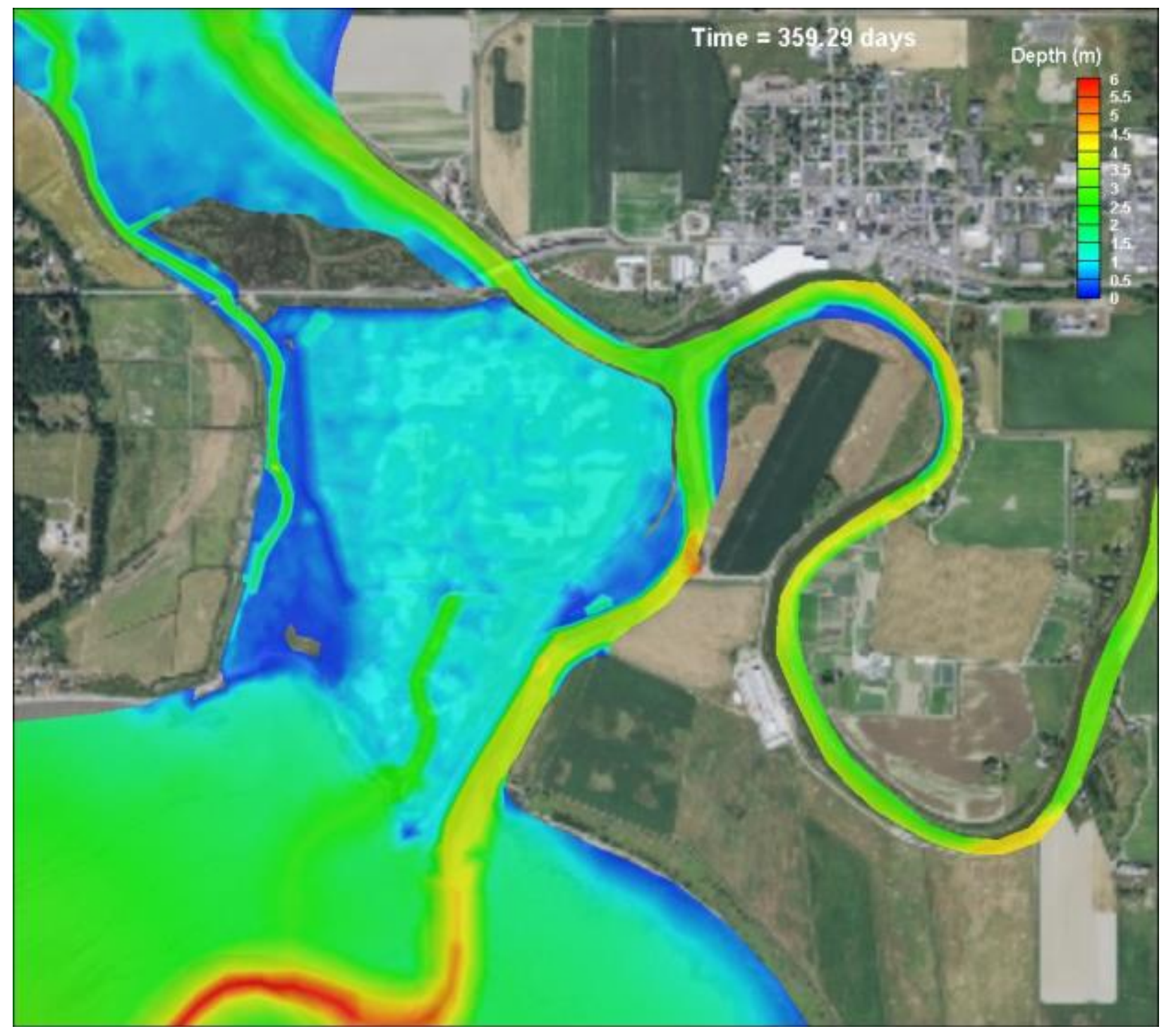

Figure H-5: Scenario 4 (Full Restoration Leque 2) - Water depth, maximum tide during year-long simulation based on December 25, 2003 


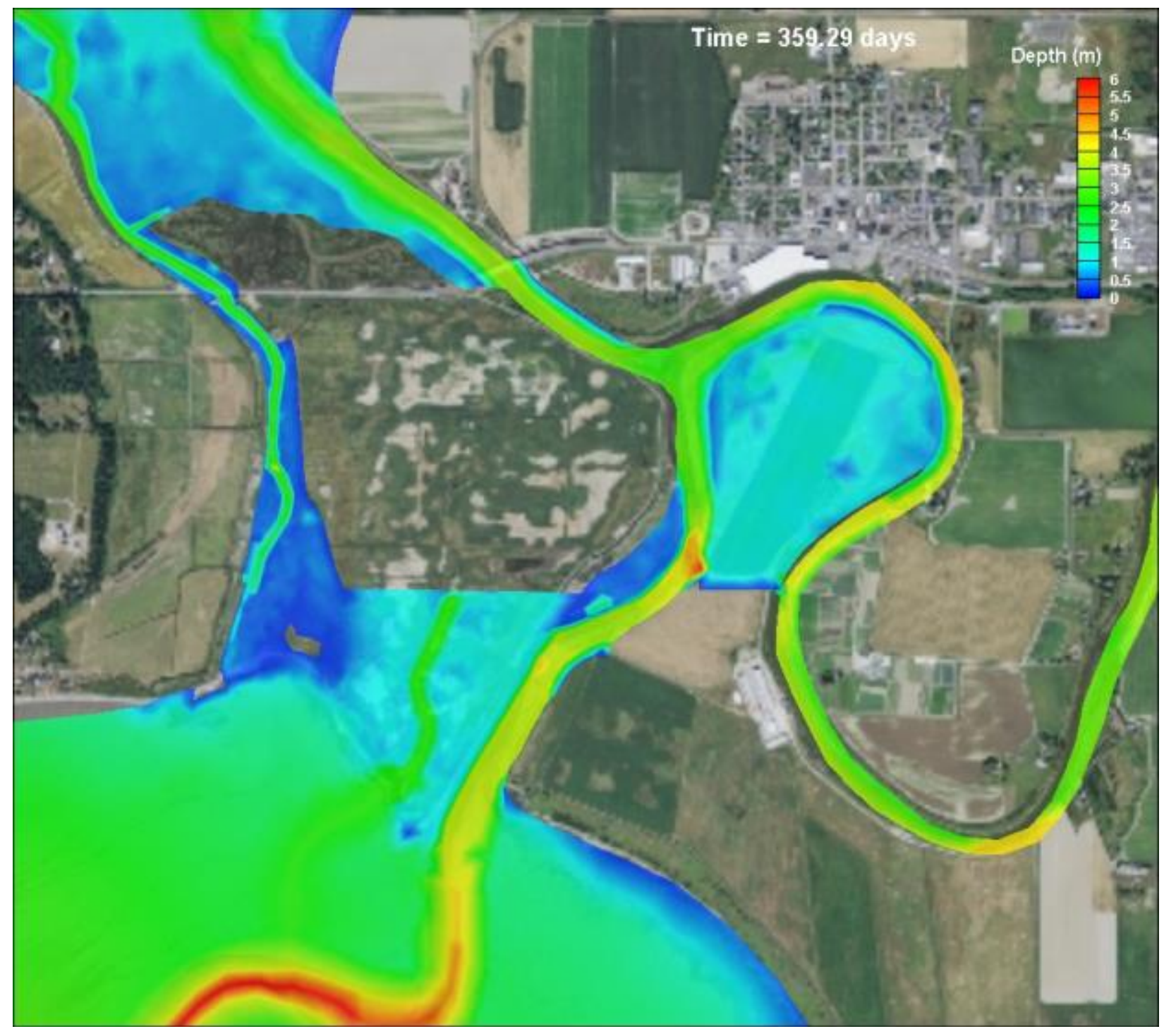

Figure H-6: Scenario 5 (Full Restoration zis a ba + SCN1) - Water depth, maximum tide during yearlong simulation based on December 25, 2003 


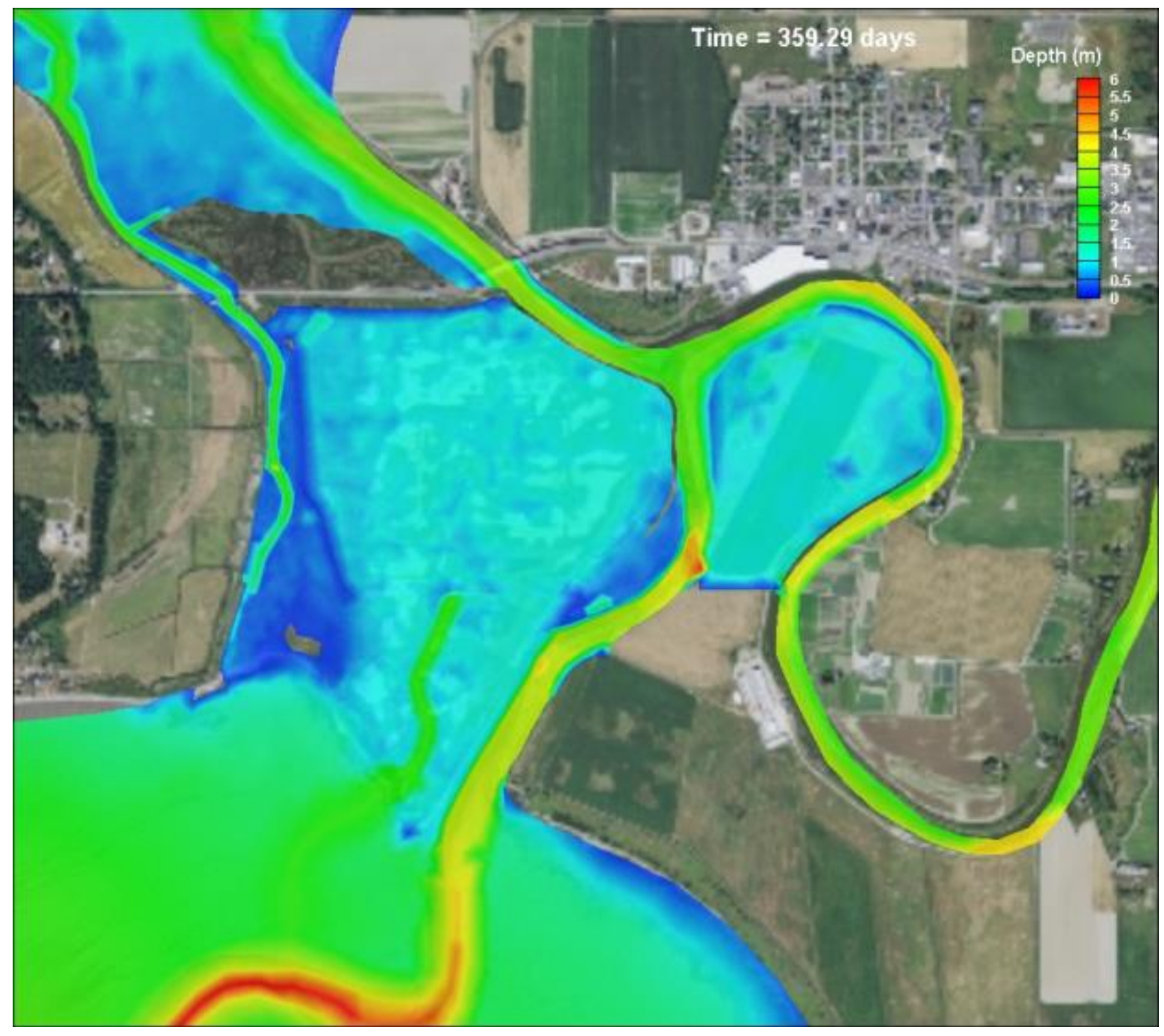

Figure H-7: Scenario 6 (Full Restoration zis a ba + SCN4) - Water depth, maximum tide during yearlong simulation based on December 25, 2003 


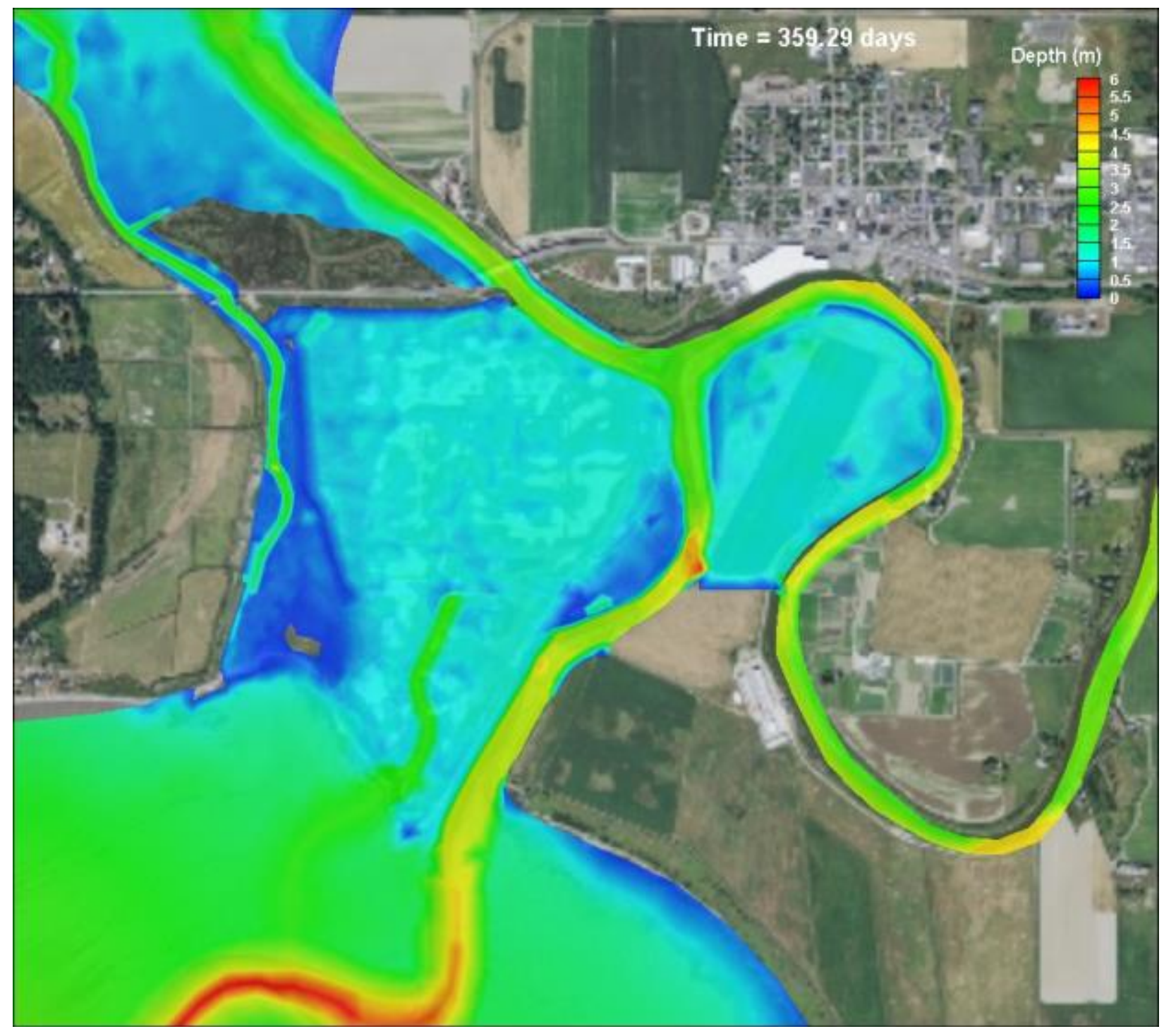

Figure H-8: Scenario 7 (Full Restoration zis a ba + SCN3) - Water depth, maximum tide during yearlong simulation based on December 25, 2003 


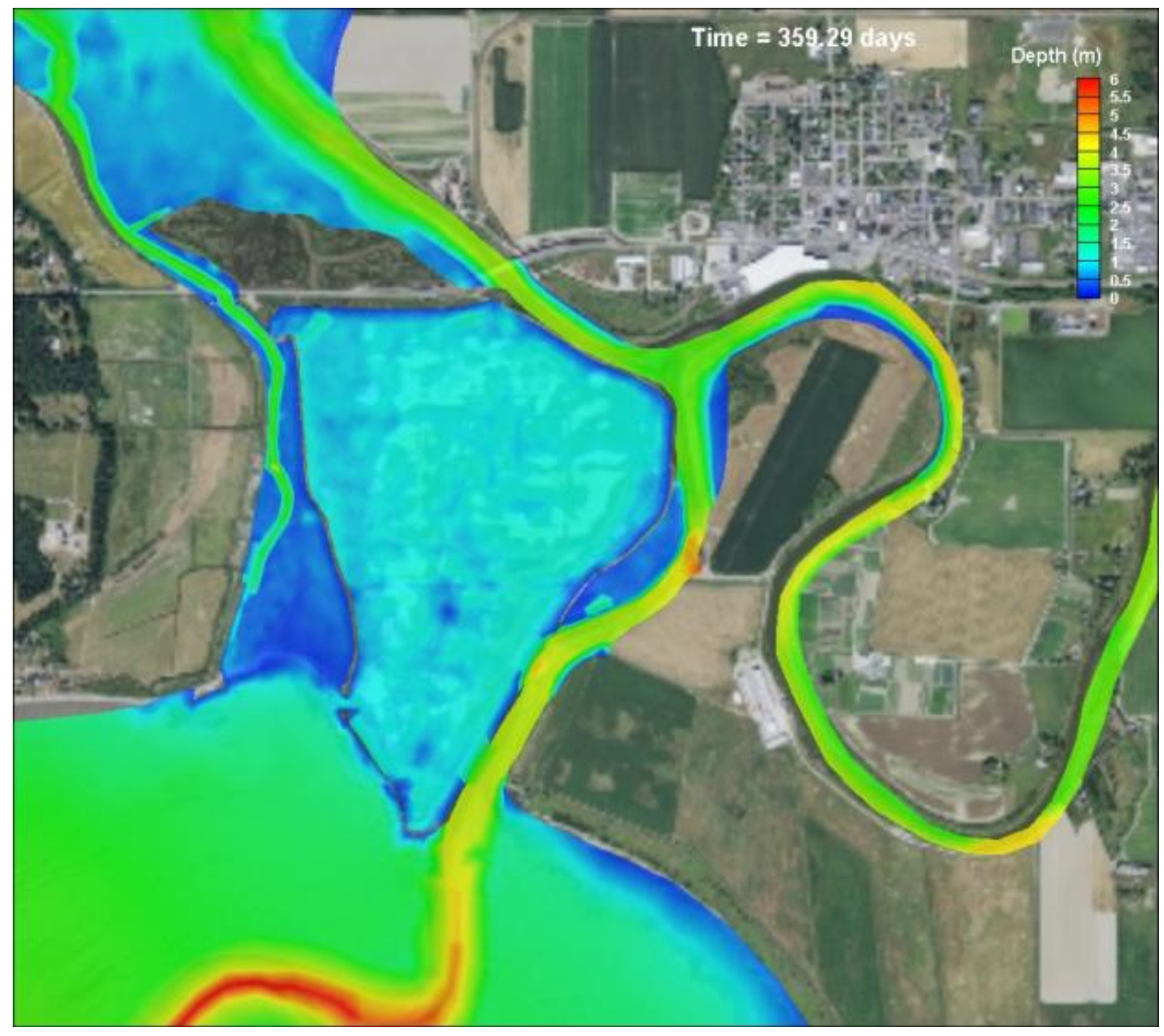

Figure H-9: Scenario 8 (3 Levee Breaches Leque) - Water depth, maximum tide during year-long simulation based on December 25, 2003 


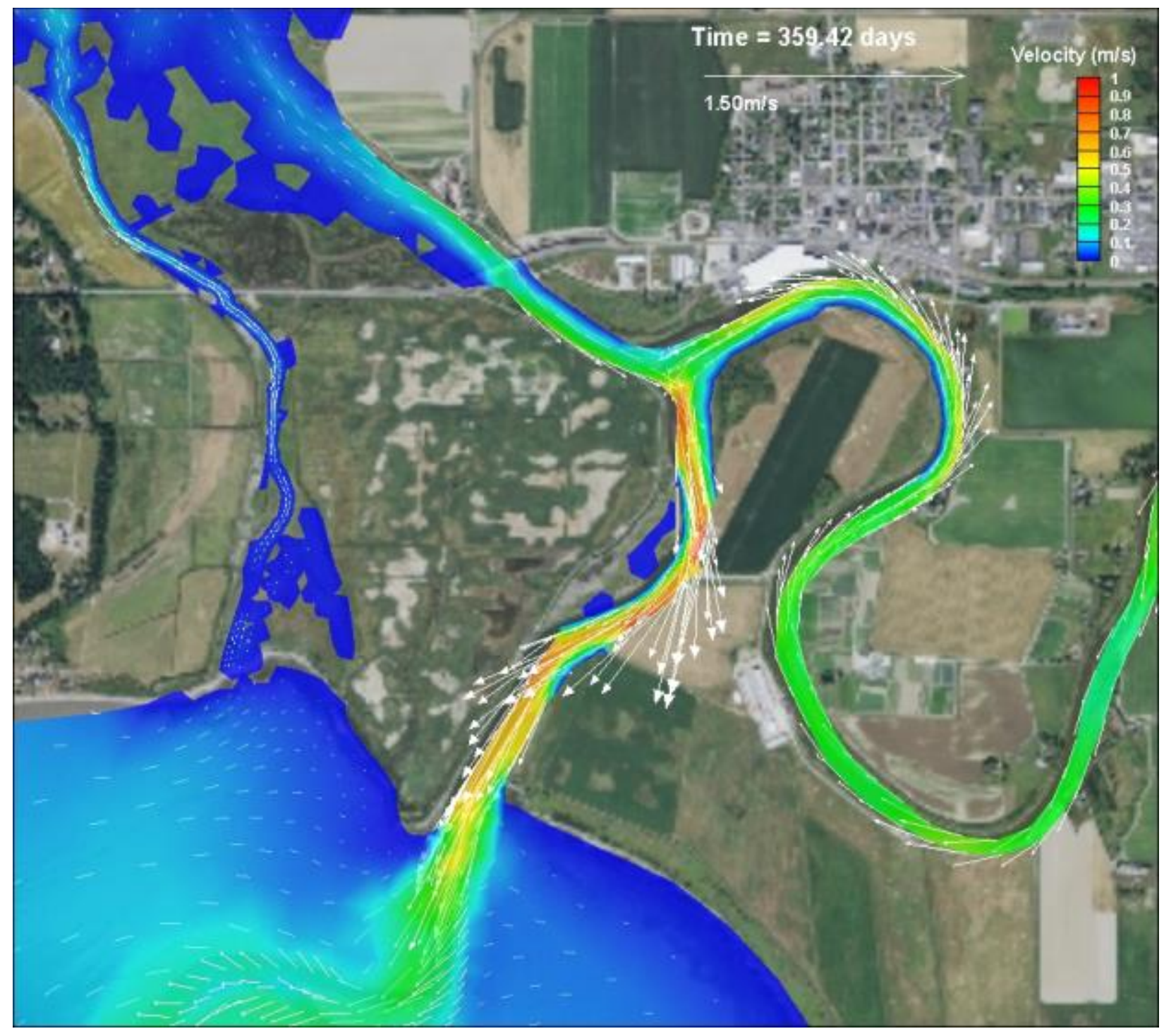

Figure H-10: Scenario 0 (Baseline Condition) - Bottom velocity, maximum tide during year-long simulation based on December 25, 2003 


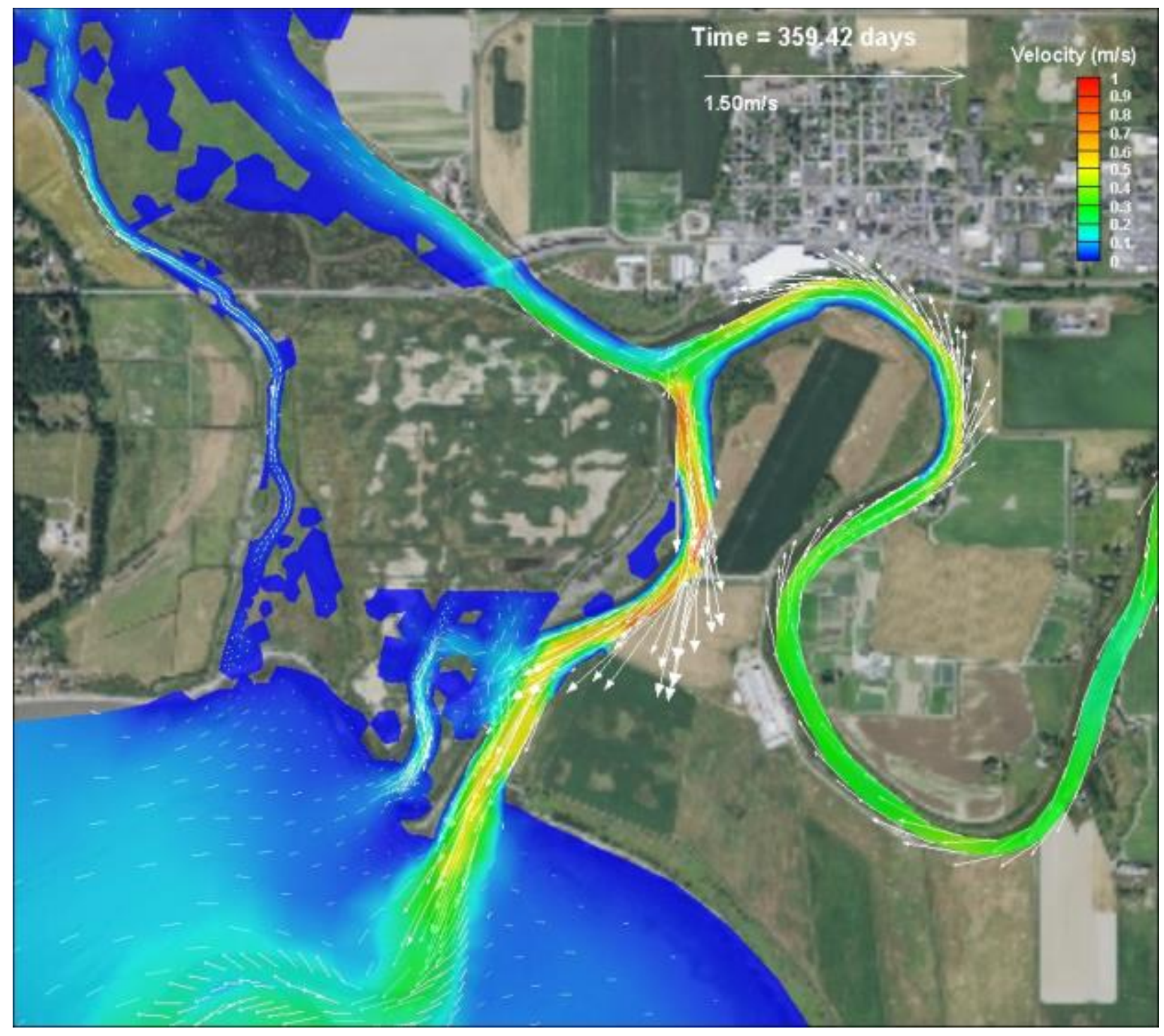

Figure H-11: Scenario 1 (Partial Restoration Leque) - Bottom velocity, maximum tide during year-long simulation based on December 25, 2003 


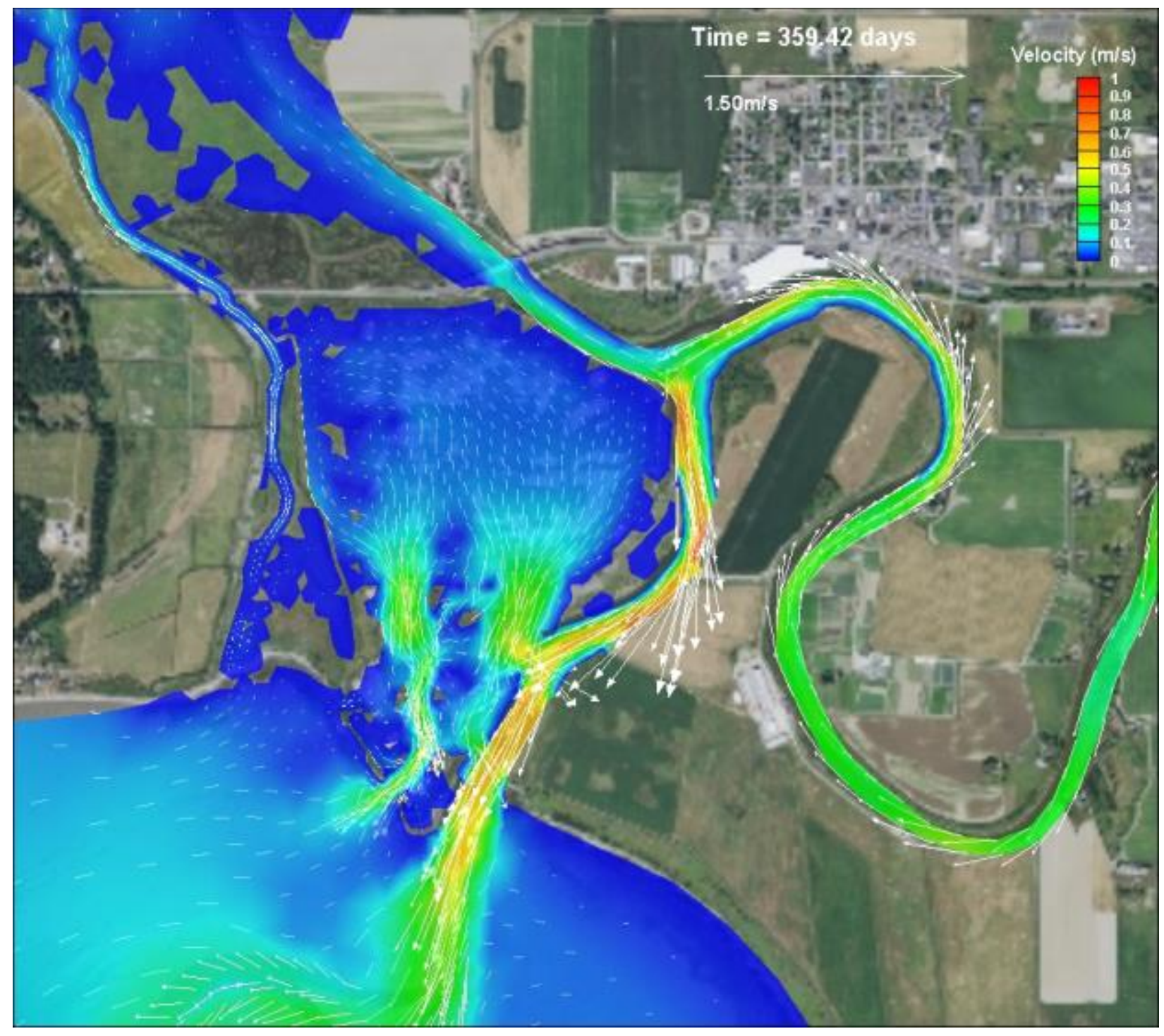

Figure H-12: Scenario 2 (4 Levee Breach Leque) - Bottom velocity, maximum tide during year-long simulation based on December 25, 2003 


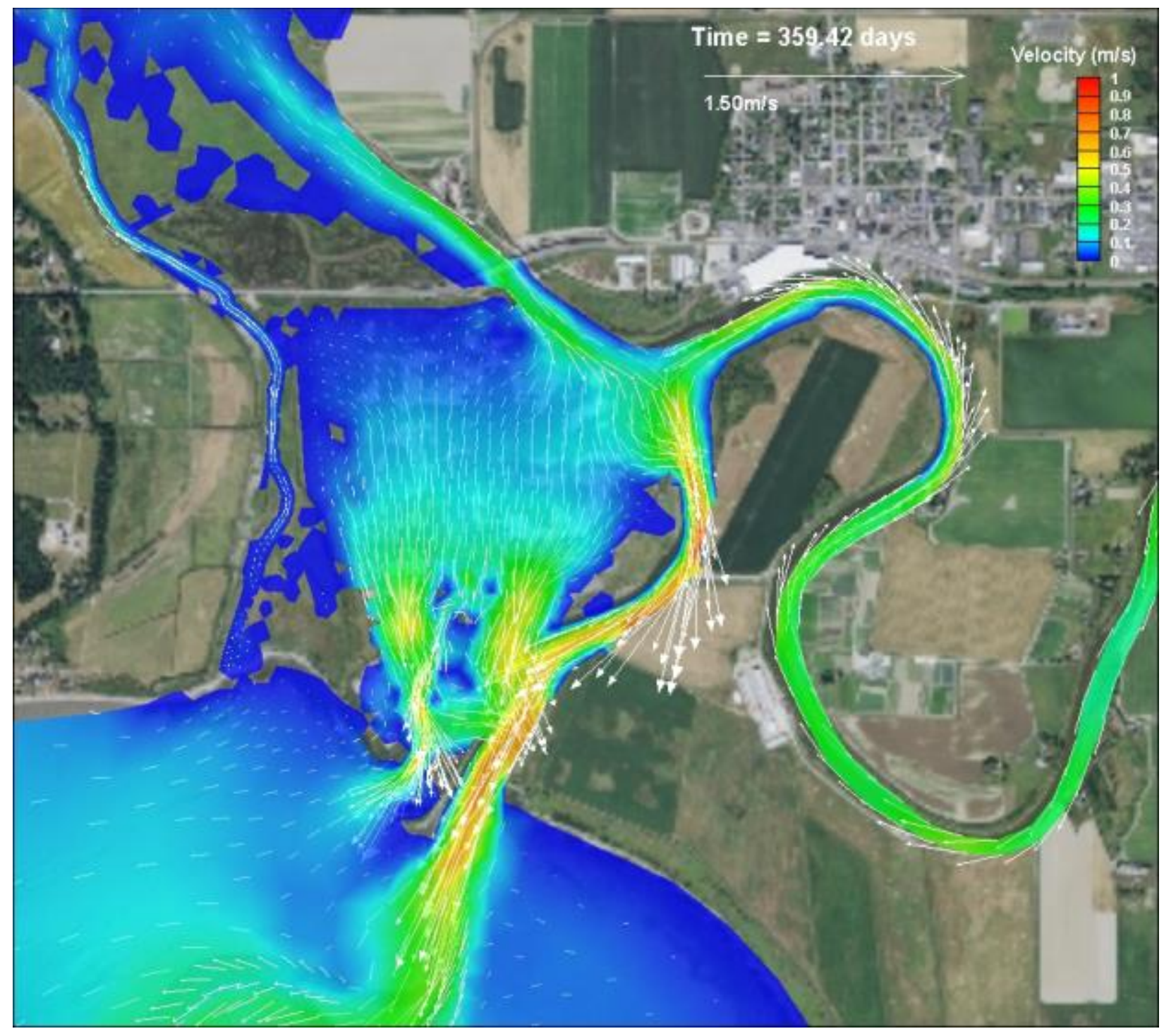

Figure H-13: Scenario 3 (Full Restoration Leque 1) - Bottom velocity, maximum tide during year-long simulation based on December 25, 2003 


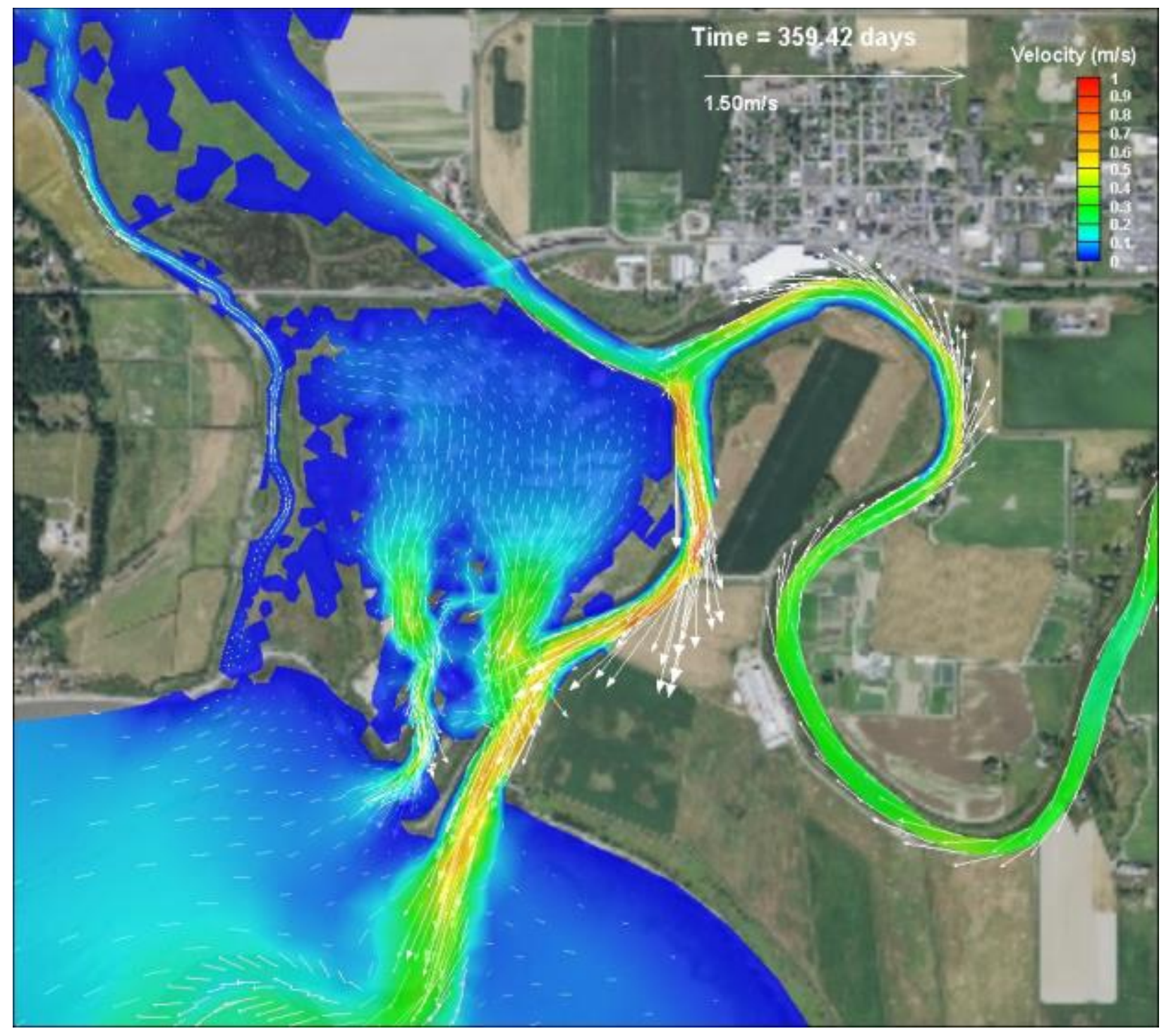

Figure H-14: Scenario 4 (Full Restoration Leque 2) - Bottom velocity, maximum tide during year-long simulation based on December 25, 2003 


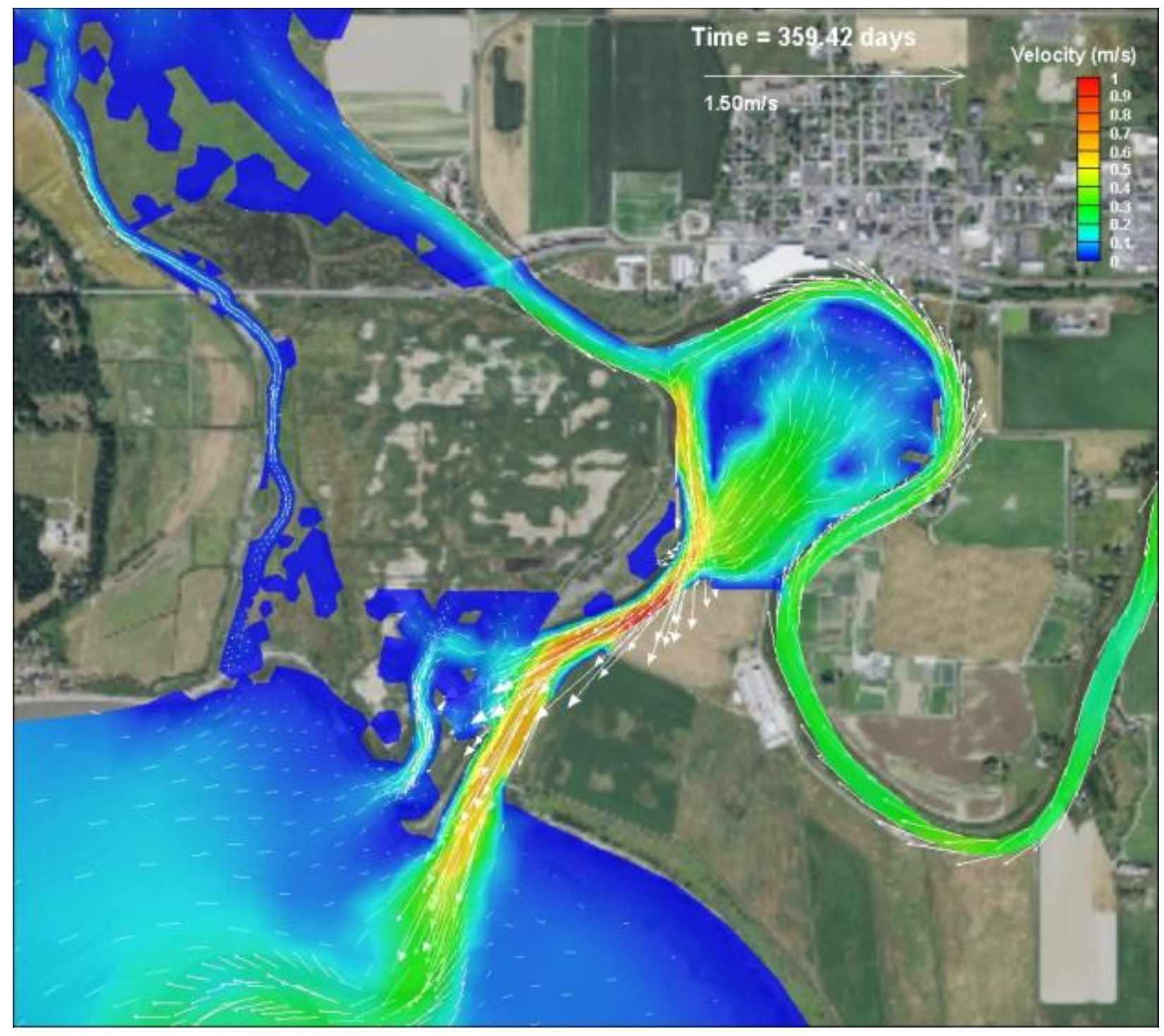

Figure H-15: Scenario 5 (Full Restoration zis a ba + SCN1) - Bottom velocity, maximum tide during year-long simulation based on December 25, 2003 


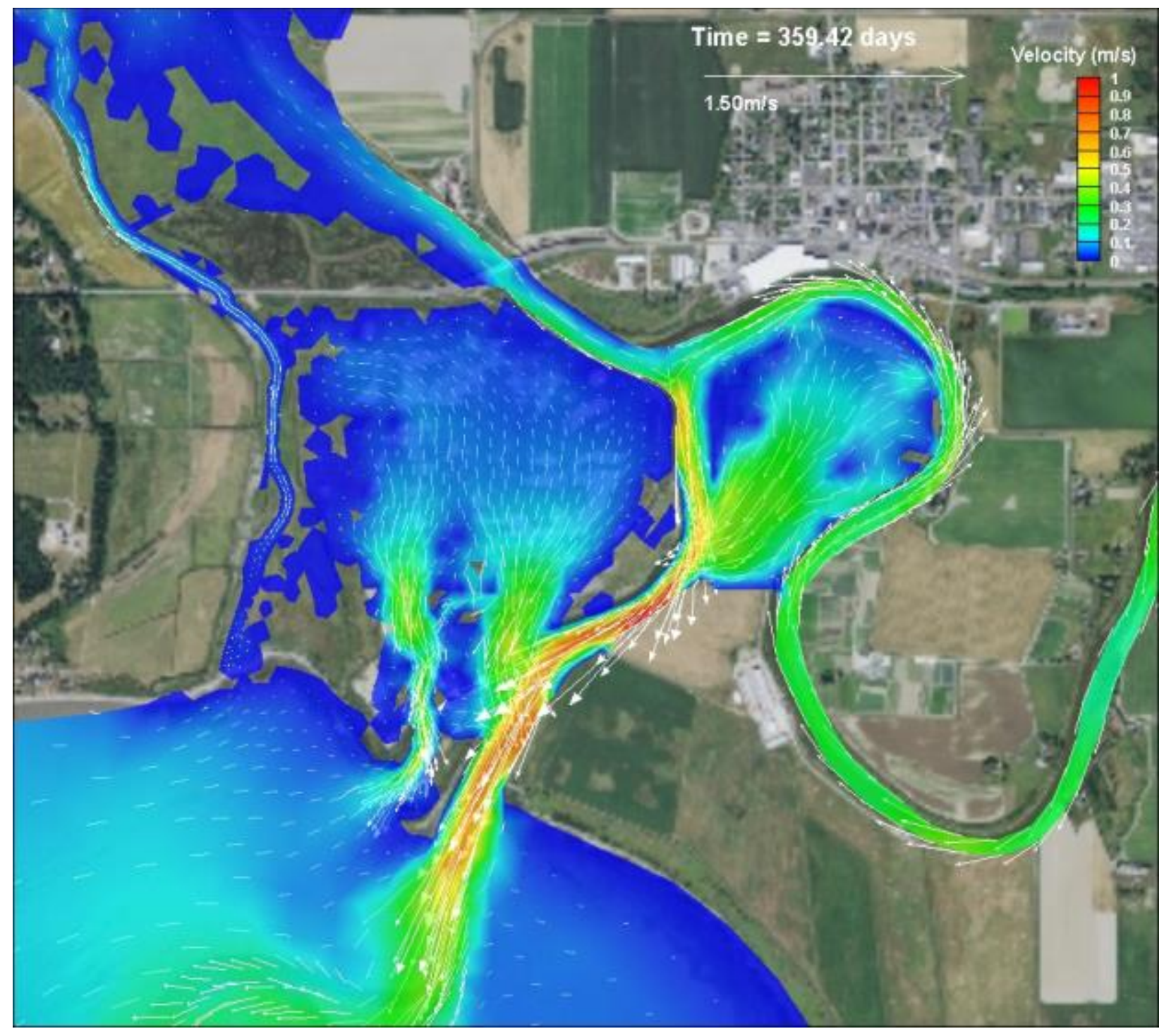

Figure H-16: Scenario 6 (Full Restoration zis a ba + SCN4) - Bottom velocity, maximum tide during year-long simulation based on December 25, 2003 


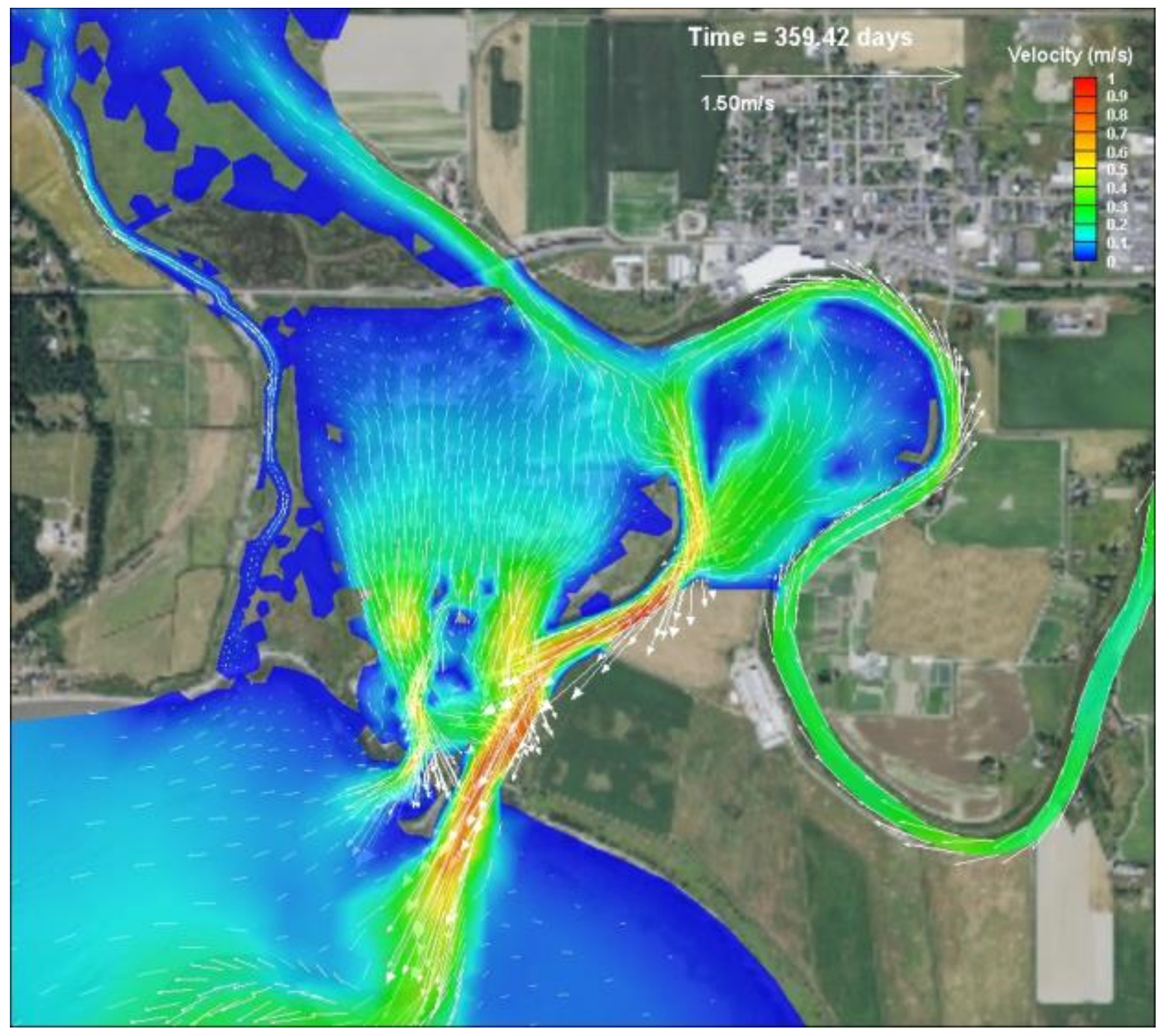

Figure H-17: Scenario 7 (Full Restoration zis a ba + SCN3) - Bottom velocity, maximum tide during year-long simulation based on December 25, 2003 


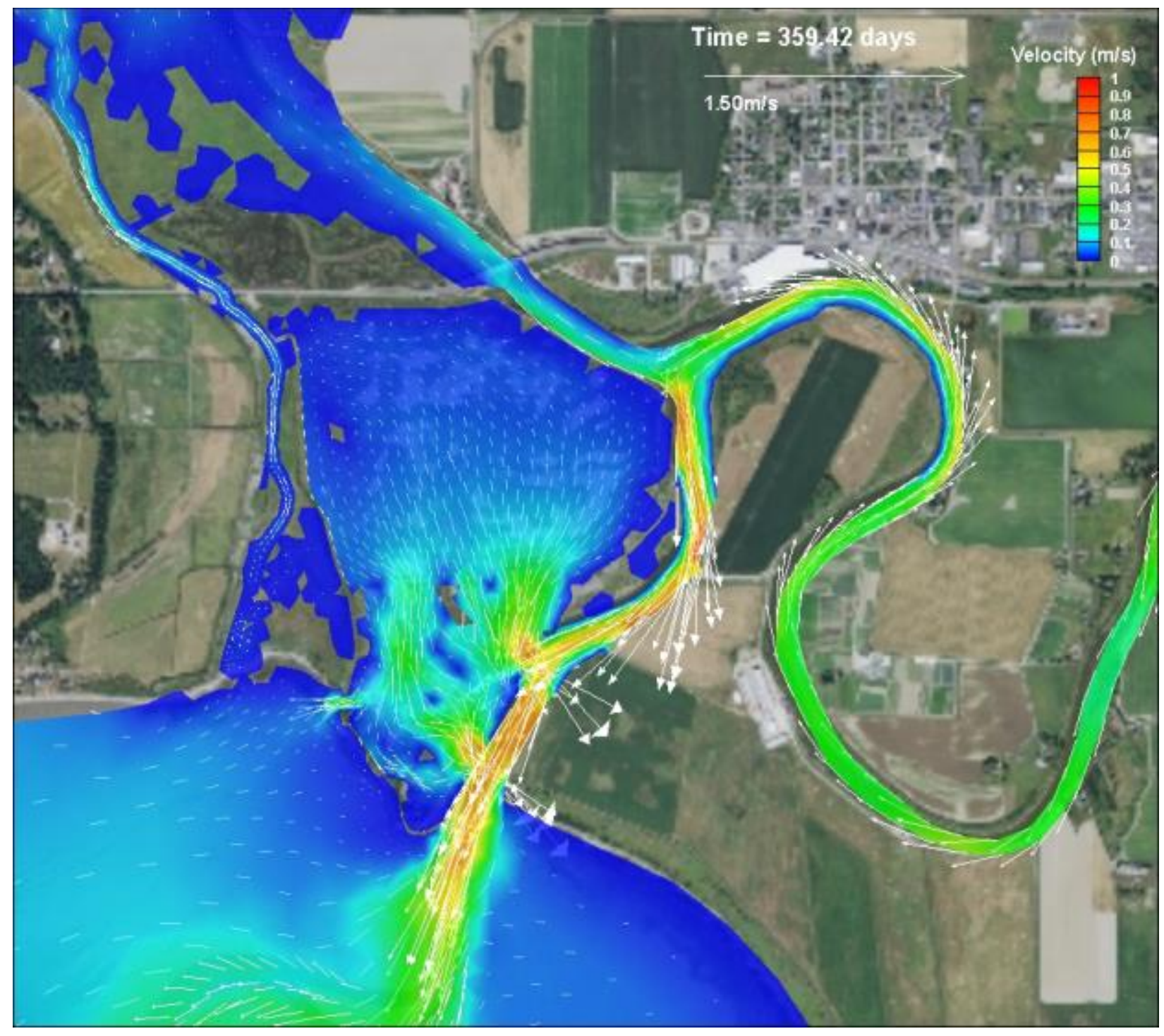

Figure H-18: Scenario 8 (3 Levee Breaches Leque) - Bottom velocity, maximum tide during year-long simulation based on December 25, 2003 


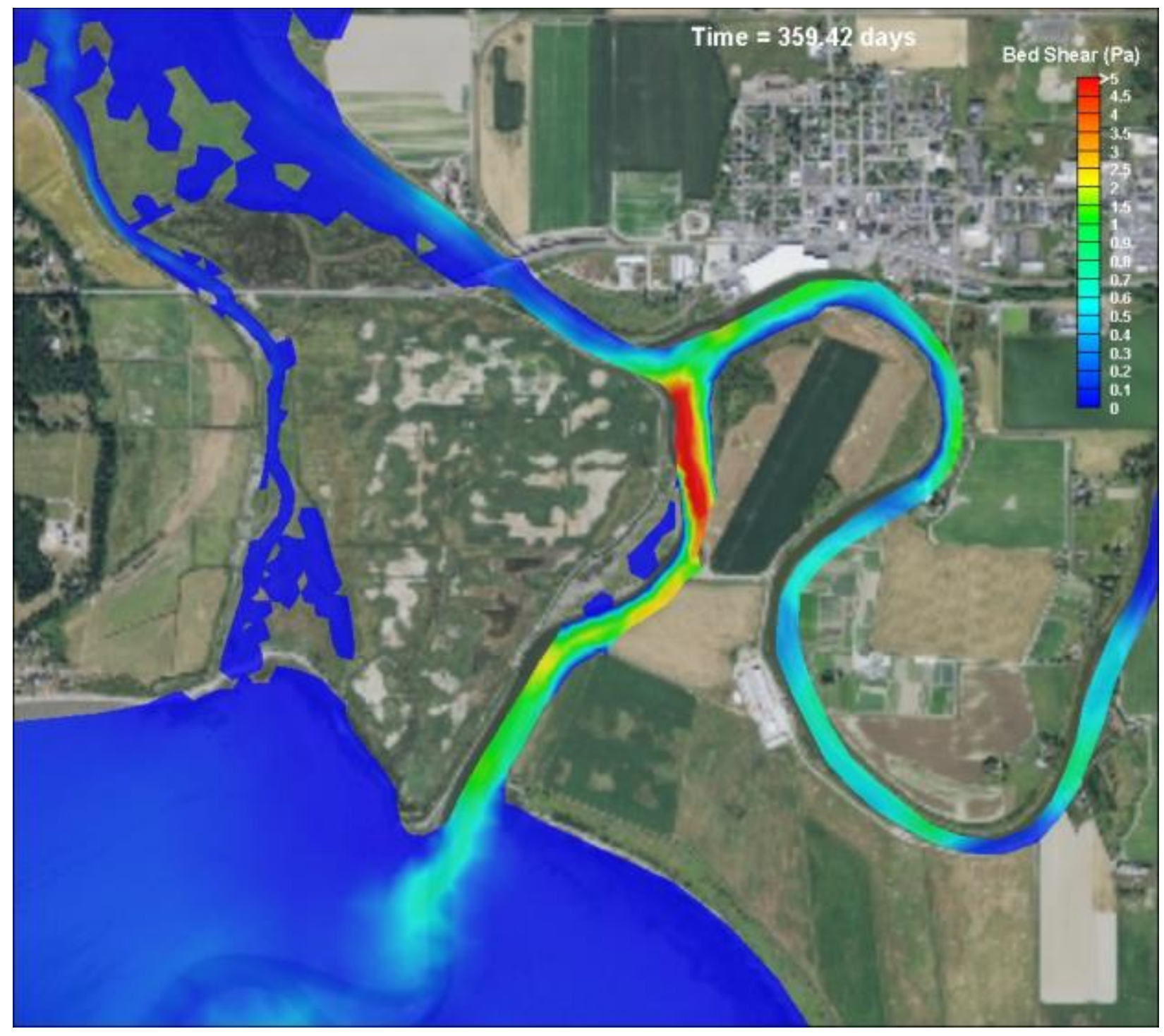

Figure H-19: Scenario 0 (Baseline Condition) - Bed shear, maximum tide during year-long simulation based on December 25, 2003 


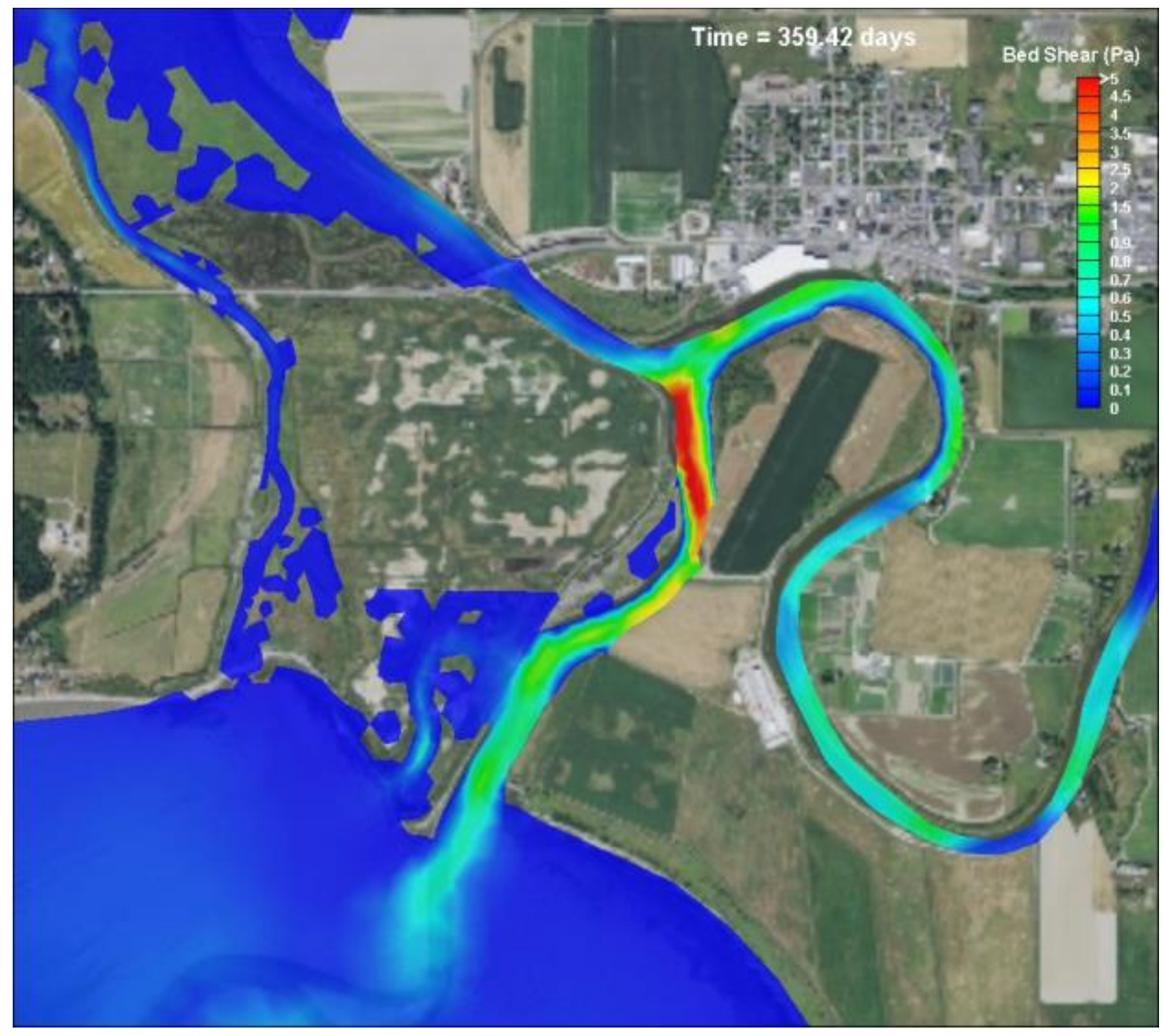

Figure H-20: Scenario 1 (Partial Restoration Leque) - Bed shear, maximum tide during year-long simulation based on December 25, 2003 


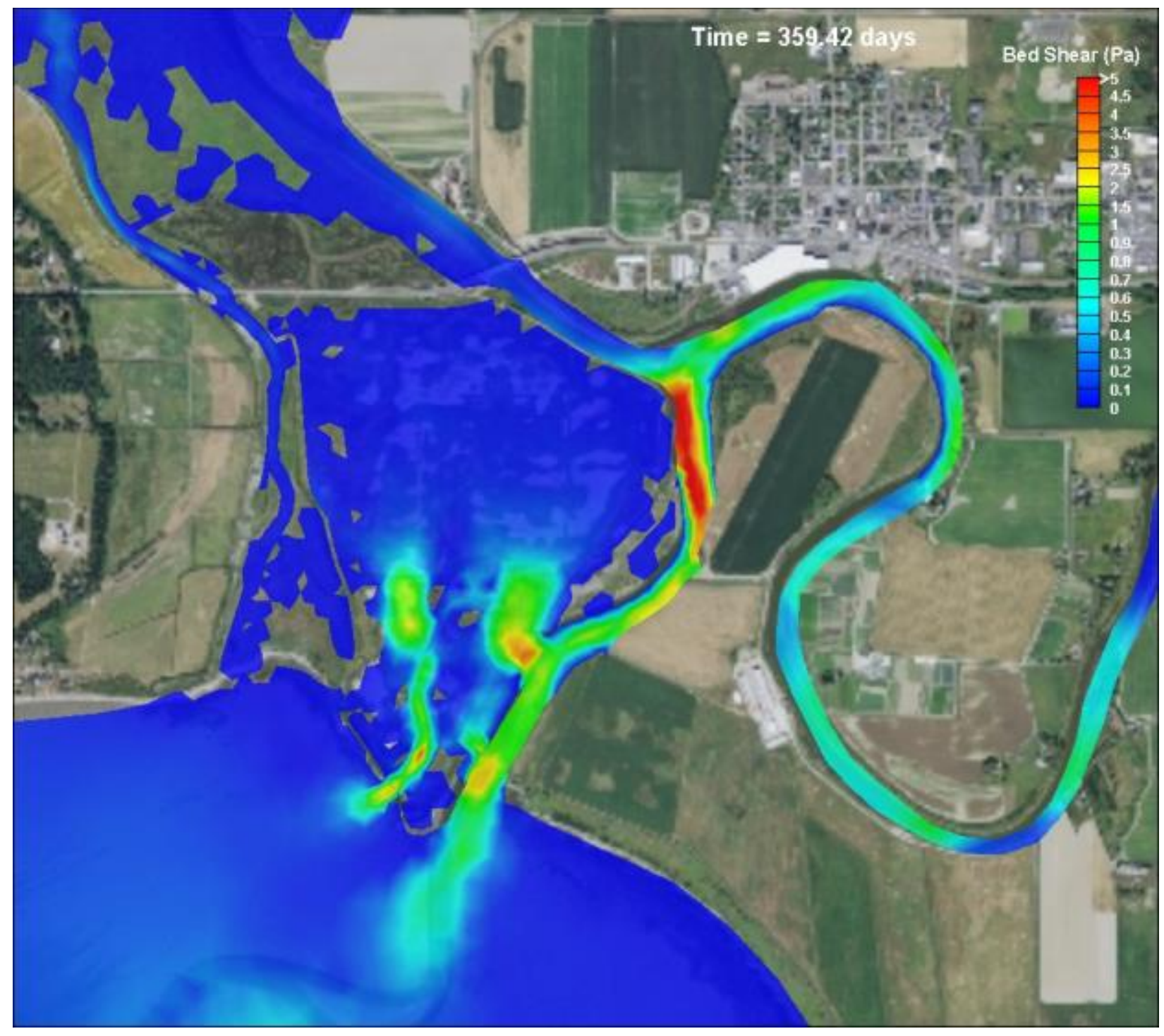

Figure H-21: Scenario 2 (4 Levee Breach Leque) - Bed shear, maximum tide during year-long simulation based on December 25, 2003 


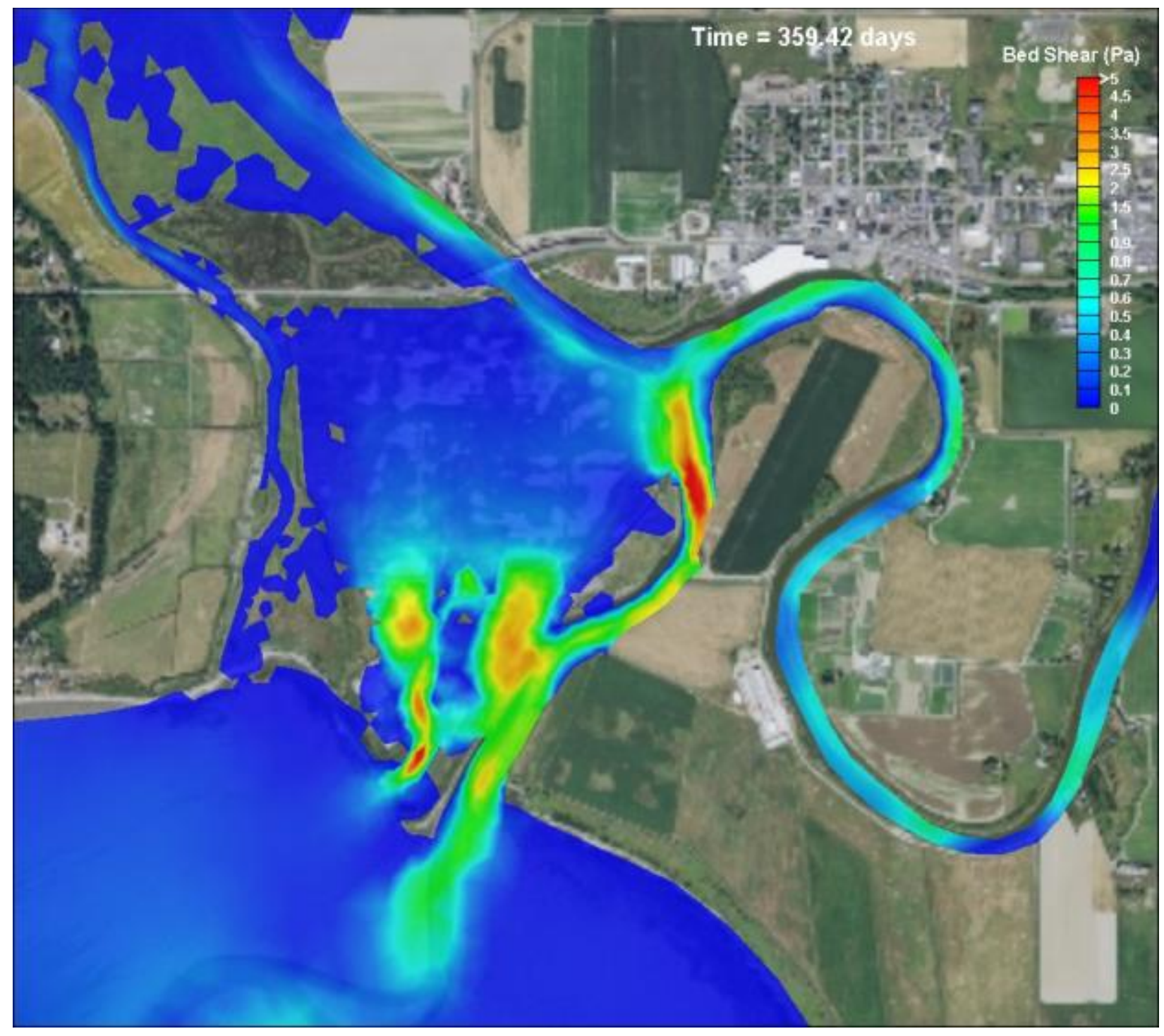

Figure H-22: Scenario 3 (Full Restoration Leque 1) - Bed shear, maximum tide during year-long simulation based on December 25, 2003 


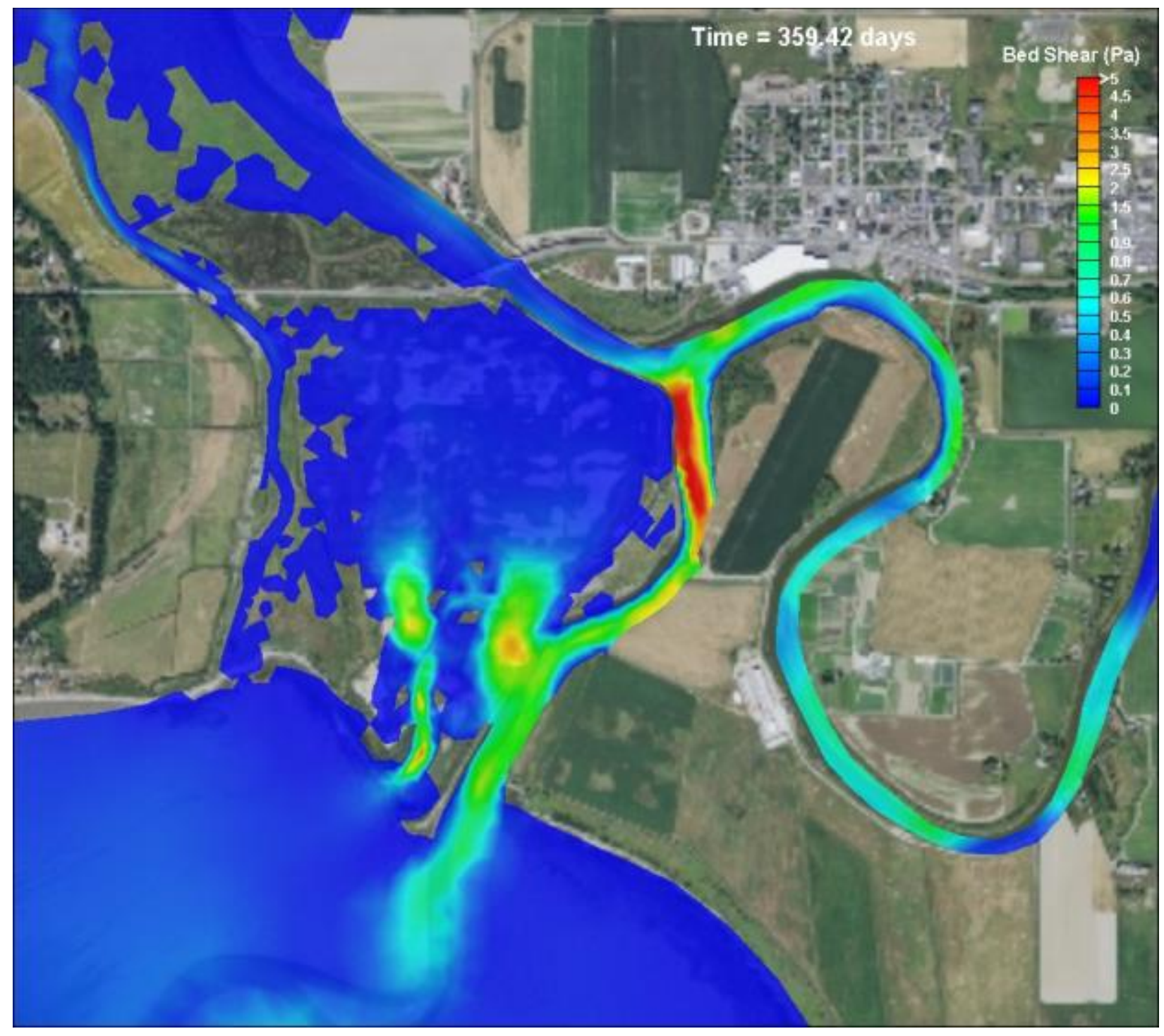

Figure H-23: Scenario 4 (Full Restoration Leque 2) - Bed shear, maximum tide during year-long simulation based on December 25, 2003 


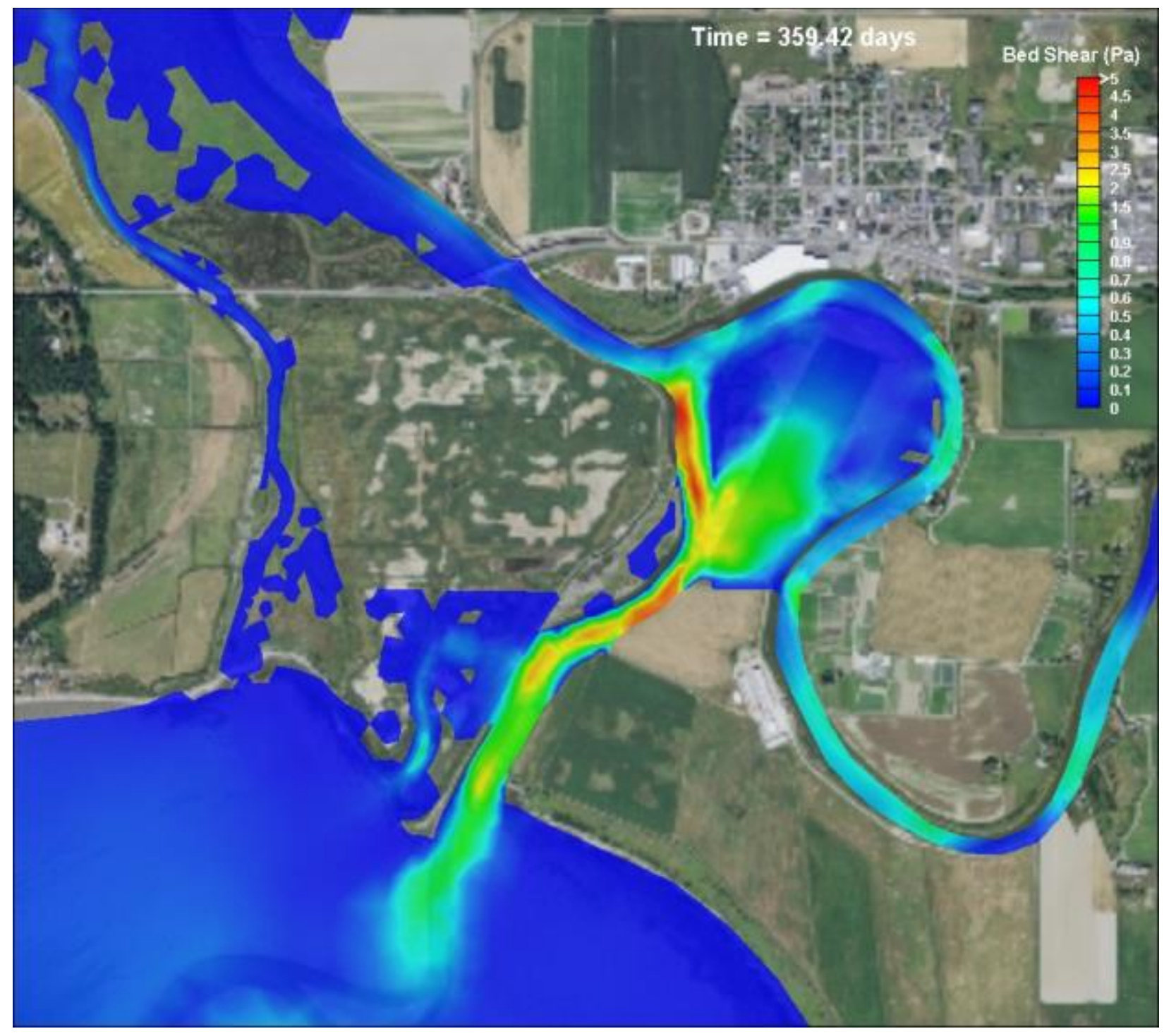

Figure H-24: Scenario 5 (Full Restoration zis a ba + SCN1) - Bed shear, maximum tide during yearlong simulation based on December 25, 2003 


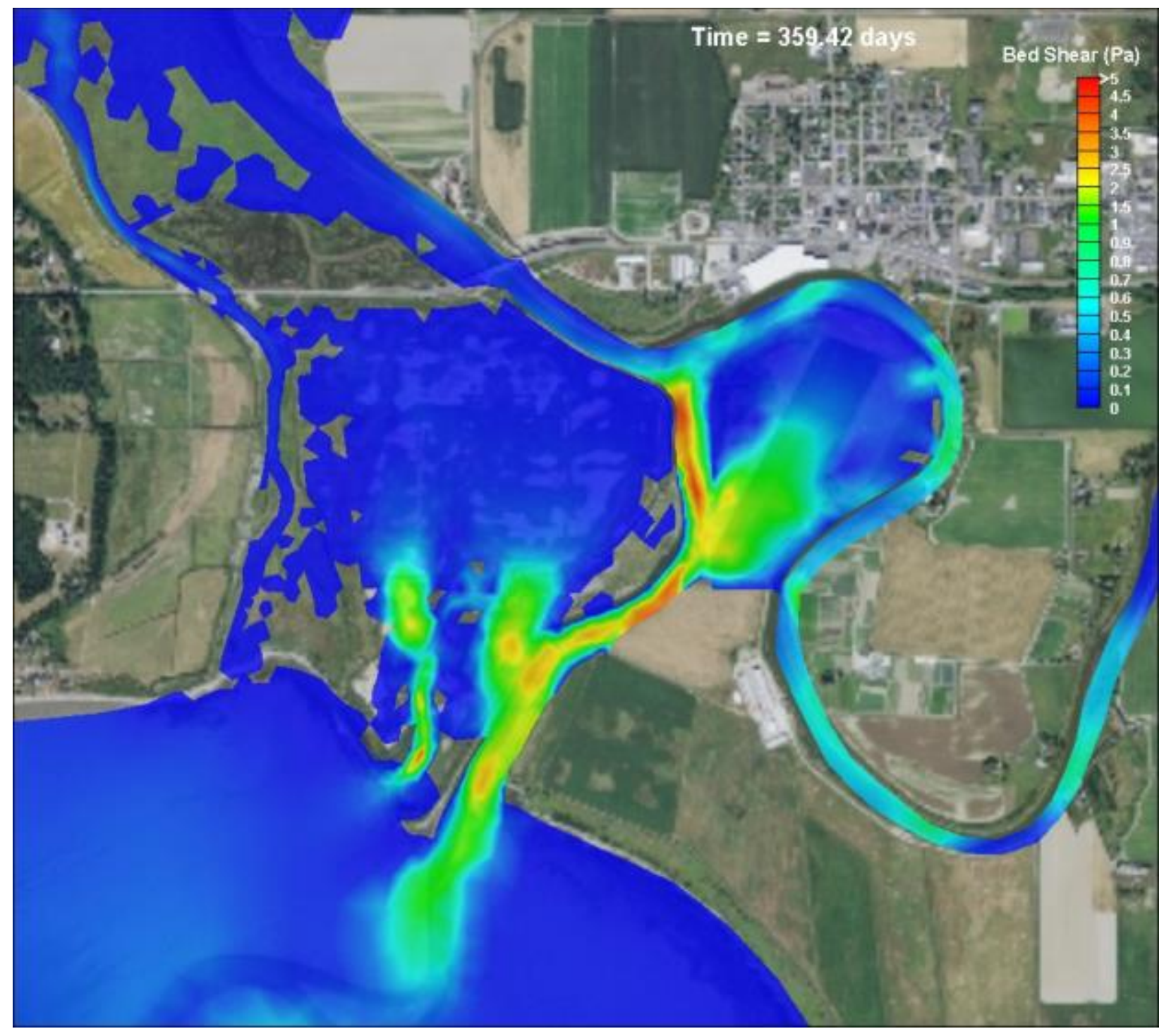

Figure H-25: Scenario 6 (Full Restoration zis a ba + SCN4) - Bed shear, maximum tide during yearlong simulation based on December 25, 2003 


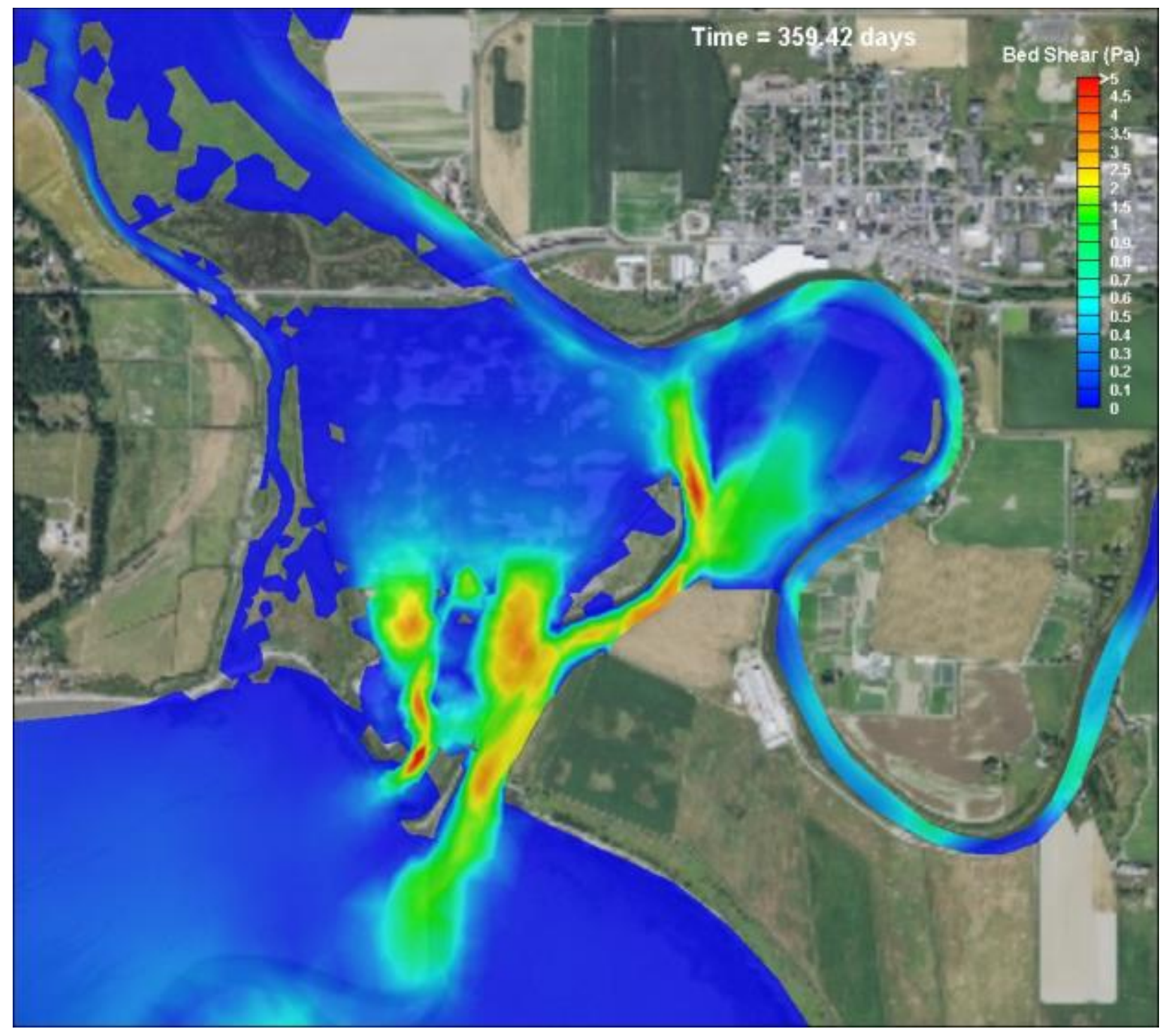

Figure H-26: Scenario 7 (Full Restoration zis a ba + SCN3) - Bed shear, maximum tide during yearlong simulation based on December 25, 2003 


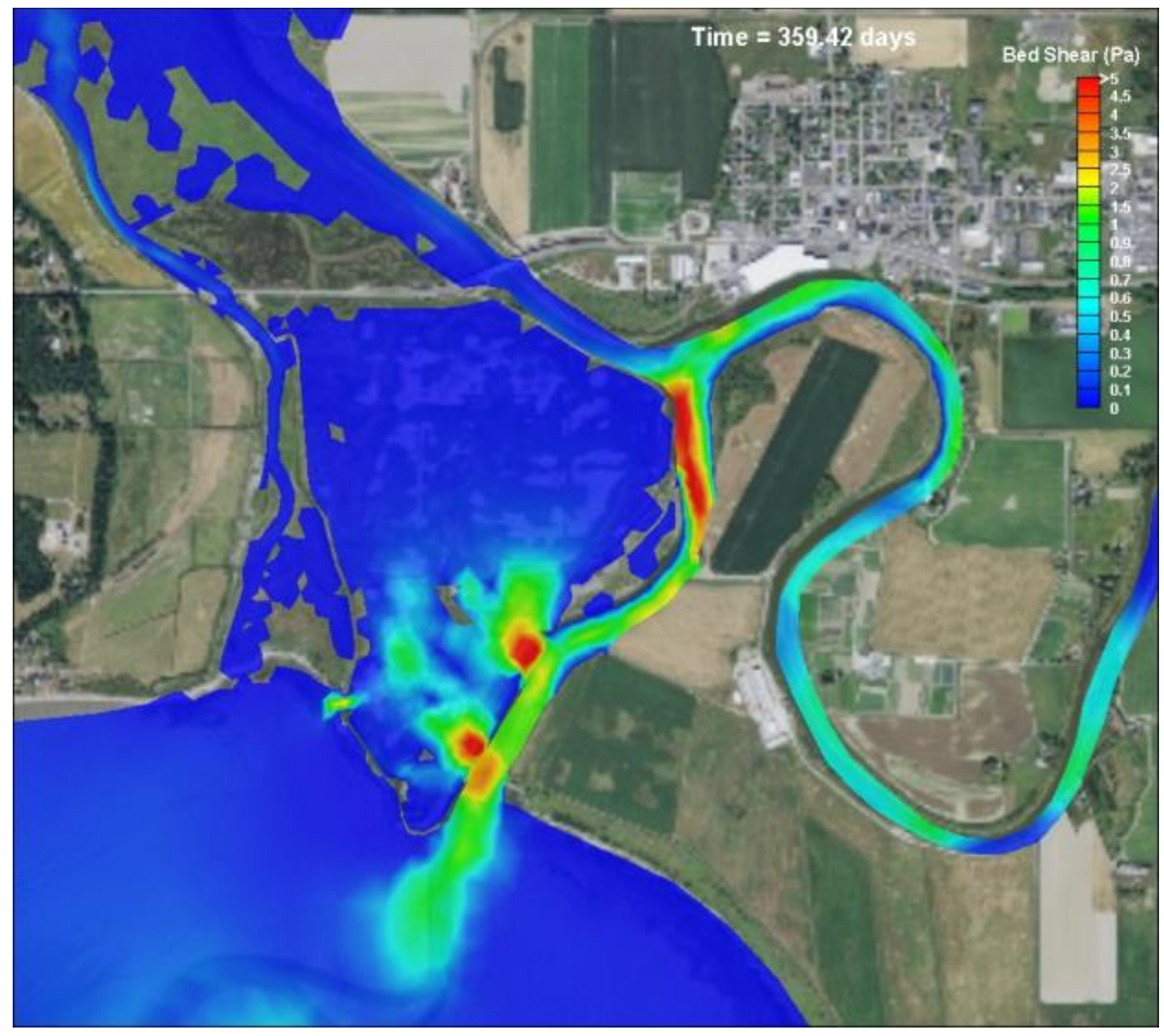

Figure H-27: Scenario 8 (3 Levee Breaches Leque) - Bed shear, maximum tide during year-long simulation based on December 25, 2003 




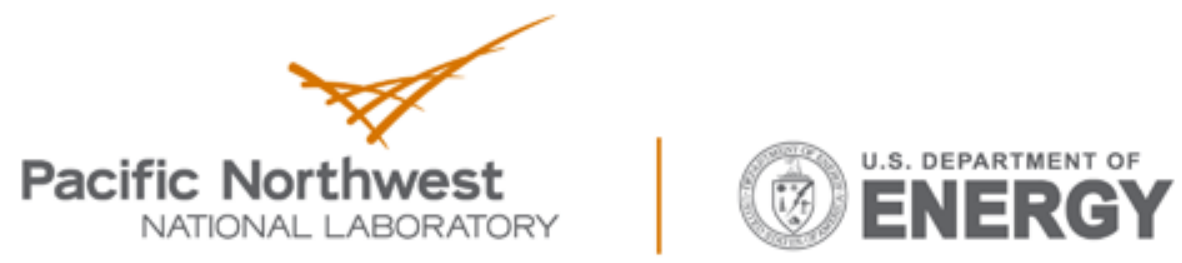

Proudly Operated by Battelle Since 1965

902 Battelle Boulevard

P.O. Box 999

Richland, WA 99352

1-888-375-PNNL (7665)

www.pnnl.gov 